
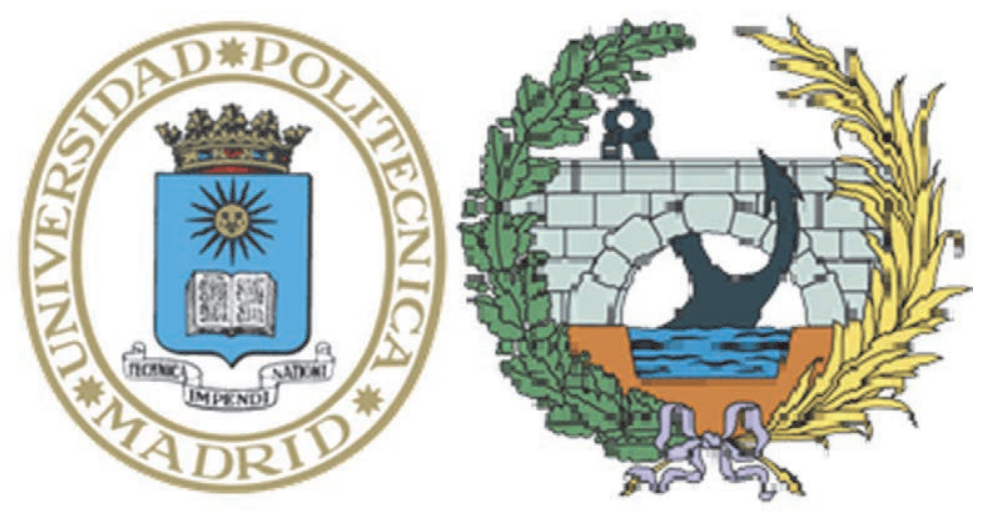

UNIVERSIDAD POLITÉCNICA DE MADRID

ESCUELA TÉCNICA SUPERIOR DE INGENIEROS DE CAMINOS, CANALES $Y$ PUERTOS

\title{
PUENTES CURVOS ATIRANTADOS
}

TESIS DOCTORAL

DARÍOGALANTE BARDÍN

INGENIERO INDUSTRIAL

DIRECTOR: MGUEL ÁNGEI ASTIZ SUÁREZ

DR. INGENIERO DE CAMINOS, CANALES Y PUERTOS. 



\title{
DEPARTAMENTO DE MECÁNICA DE MEDIOS CONTÍNUOS Y TEORÍA DE ESTRUCTURAS
}

ESCUELA TÉCNICA SUPERIOR DE INGENIEROS DE CAMINOS, CANALES Y PUERTOS

\section{PUENTES CURVOS ATIRANTADOS}

\author{
DARÍO GALANIE BARDÍN
}

INGENIERO INDUSTRIAL

DIRECTOR: MGUEL ÁNGEI ASTIZ SUÁREZ

DR. INGENIERO DE CAMINOS, CANALES Y PUERTOS. 



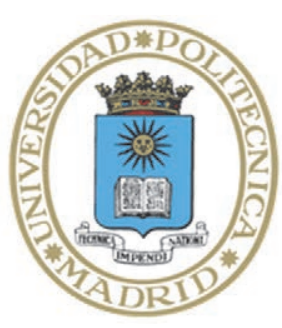

UNIVERSIDAD POLITÉCNICA DE MADRID.

Tribunal nombrado por el Magfco. y Excmo. Sr. Rector de la Universidad Politécnica de Madrid, el día de de 2017.

Presidente D.

Vocal D.

Vocal D.

Vocal D.

Secretario D.

Suplente D.

Suplente D.

Realizado el acto de defensa y lectura de la Tesis el día de de 201 _ en la Escuela Técnica Superior de Ingenieros de Caminos, Canales y Puertos de la Universidad Politécnica de Madrid.

Calificación:

EL PRESIDENTE

LOS VOCALES

EL SECRETARIO 



\section{RESUMEN}

En la actualidad, se está extendiendo el uso del puente con directriz curva en planta como solución, por un lado, a las cada vez más restrictivas condiciones a la hora de desarrollar las directrices de los puentes, y por otro, a las nuevas exigencias arquitectónicas sobre los puentes. Asimismo, el puente atirantado se ha vuelto una opción muy frecuente para luces medias y grandes, donde resulta muy competitivo económicamente frente a otras opciones como la del puente colgante. Estas 2 realidades, han conducido a numerosos ingenieros a diseñar puentes de directriz curva con una configuración atirantada.

En esta tesis se estudia el comportamiento del puente curvo atirantado, analizando la respuesta de los diferentes sistemas estructurales que lo componen. El objetivo esencial, es mostrar los aspectos más relevantes del funcionamiento de estos sistemas estructurales, desde los más simples a los más complejos, mediante análisis teóricos y cálculos parametrizados que permitan llegar a conclusiones que esclarezcan el diseño y cálculo de un puente curvo atirantado.

Para los cálculos estructural realizados en la tesis, se ha desarrollado un paquete de programas de software en el lenguaje de programación Mathematica. Dentro de este paquete, se desarrolla el cálculo completo de la estructura, desde el preproceso, pasando por la resolución numérica de la estructura, hasta la presentación de los resultados gráficos. El método de cálculo implantado ha sido el de los elementos finitos, utilizando elementos de 7 grados de libertad que tienen en cuenta el alabeo de la sección del tablero.

El puente se ha dividido en 2 subsistemas estructurales: el subsistema tablero, que incluye el tablero y los estribos, y el subsistema Pila-Tirantes, que incluye la torre, los tirantes que permiten compensar las cargas horizontales sobre la cabeza de la pila y los tirantes que conectan la cabeza de la pila con el tablero. Los estudios principales realizados sobre estos sistemas estructurales son:

- Análisis de la viga curva cargada fuera de su plano, biapoyada y multiapoyada. Se realiza un estudio detallado del comportamiento de la viga curva bajo diferentes condiciones de contorno, analizando sus mecanismos para resistir las solicitaciones flectoras y torsoras inherentes a su morfología.

- Estudio de la viga curva frente a cargas concéntricas a su plano. Siendo este tipo de carga una de las características fundamentales de este tipo de puentes, se crea una clasificación del tipo de comportamiento mostrado por el tablero a partir de las condiciones de contorno impuestas por el diseño de este y las propiedades mecánicas de la sección. También se investiga diferentes disposiciones de tirantes a lo largo de la cabeza de pila, según razones geométricas y solicitantes sobre el tablero.

- Se examina detalladamente el diseño de la sección del tablero, desde puntos de vista como el geométrico, el mecánico y el funcional. Se hace especial hincapié en la conexión descentrada de la sección del tablero y el tirante de sujeción. 
- Se desarrolla teórica y matemáticamente, la directriz funicular y antifunicular del tablero de los puentes curvos atirantados, para cualquier tipo de disposición de tirantes en la pila.

- Se analiza y se crea un método de diseño y cálculo para el subsistema Pila-Tirantes, que permite identificar desde las fases más tempranas las exigencias sobre este sistema y como se pueden satisfacer de la mejor manera posible. También se desarrollan las formas antifuniculares que eliminan las solicitaciones más perjudiciales para la torre.

- Se unen todas las conclusiones obtenidas, para el desarrollo de diferentes soluciones para hipotéticos puentes, que permiten observar los resultados de los diferentes estudios. 


\section{ABSTRACT}

\section{Curved stayed cable bridges}

Now days, it has become more often to see curved deck bridges as a solution to; on the one hand, increasingly restrictive conditions on developing bridge directrixes, and on the other, new architectural demands for bridges. Likewise, cable-stayed bridges have become a very frequent option for medium and large spans, where they are very financially-competitive compared to other options such as suspension bridges. These two facts have led many engineers to design curved directrix bridges with a cable-stayed configuration.

This thesis studies the behaviour of curved cable-stayed bridges, analysing the response of the different structural systems involved. The core objective is to show the most relevant aspects of the behaviour of these structural systems, from the simplest to the most complex, using theoretical analysis and parametrised calculations which provide conclusions to clarify the design and calculation of curved cable-stayed bridges.

For the structural calculations conducted in the thesis, a software program package was developed in the Mathematica programming language. This package conducts the complete calculation of the structure, from the pre-processing and numerical resolution of the structure to the presentation of results in graph form. The method of calculation used has been that of the finite elements, using elements with seven degrees of freedom that take the warping of deck sections into account.

The bridge was divided into two structural subsystems: the Deck Subsystem, which includes the deck and the abutments; and the Pile-Stay Cables Subsystem, which includes the tower, the stay cables that compensate the horizontal loads on the pile head and the stay cables that connect the pile head to the deck. The main studies carried out on these structural systems are:

- Analysis of the curved beam loaded outside its plane, with 2 or more supports. A detailed study is conducted on the behaviour of the curved beam under different boundary conditions, analysing its mechanisms to resist the bending and twisting stresses inherent to its morphology.

- Study of the curved beam under concentric loads inside its plane. Since this type of load is one of the fundamental characteristics of this kind of bridge, a classification of the type of behaviour shown by the deck is created from the boundary conditions imposed by its design and the mechanical properties of the section. Different stay cable arrangements along the pile head are also studied, according to geometric and stresscausing reasons on the deck.

- The design of the deck section is examined in detail, from points of view such as geometric, mechanical and functional. Emphasis is placed on the offset connection of the deck section and the support stay cable.

- The funicular and anti-funicular directrix of the deck of cable-stayed bridges is developed theoretically and mathematically for any kind of stay cable arrangement on the pile. 
- A design and calculation method is analysed and created for the Pile-Stay Cables Subsystem, allowing from the earliest stages to identify the requirements on this system and how they can be satisfied in the best possible way. Anti-funicular forms are also developed to eliminate the most harmful loads for the tower.

- All the conclusions are combined to develop various solutions for hypothetical bridges, allowing us to observe results from the different studies. 


\section{ÍNDICE}

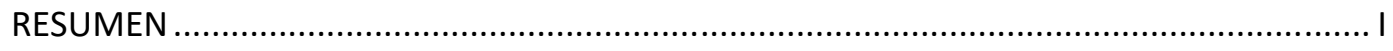

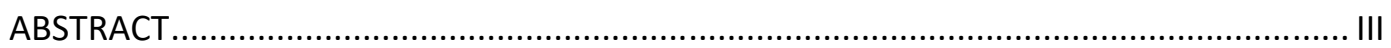

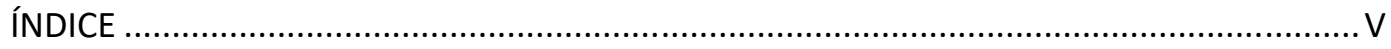

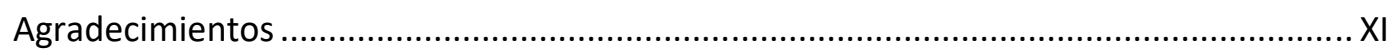

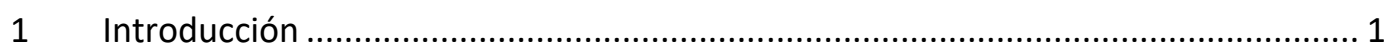

1.1 Motivos para una tesis doctoral sobre puentes curvos atirantados................... 1

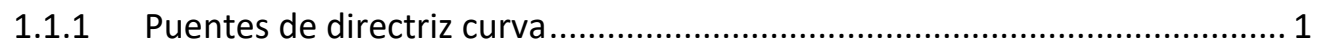

1.1.2 Puentes atirantados ................................................................... 2

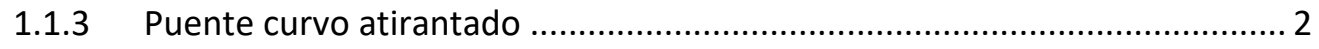

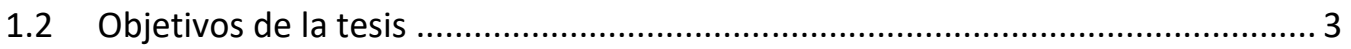

1.3 Contenido de la tesis ....................................................................... 4

1.3.1 Subsistema Tablero: capítulo 2 ................................................. 6

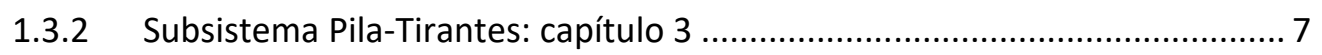

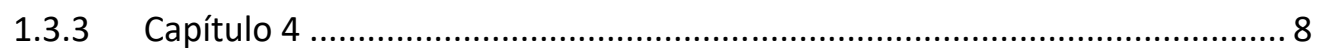

1.3.4 Apéndices: capítulo 5 ............................................................... 8

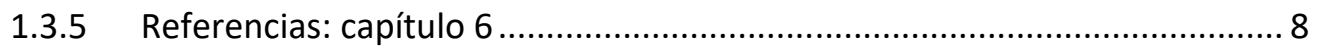

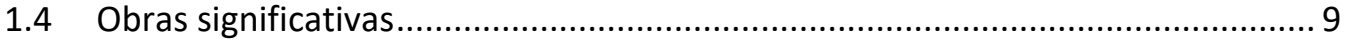

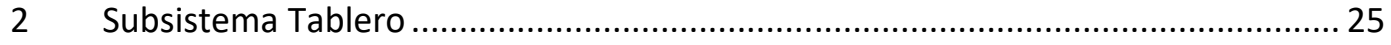

2.1 Viga curva con carga fuera de su plano.................................................... 25

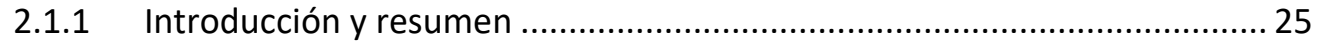

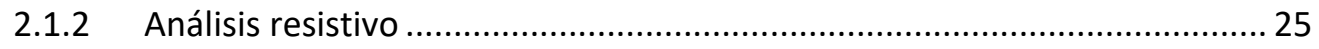

2.1.2.1 Condiciones de contorno ...................................................... 28

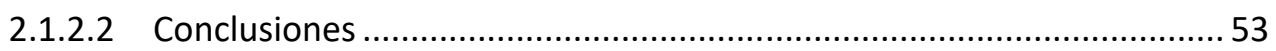

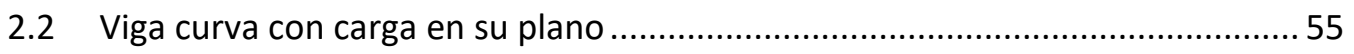

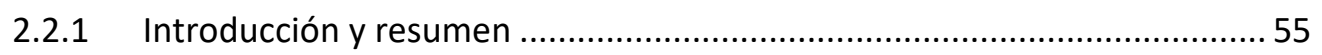

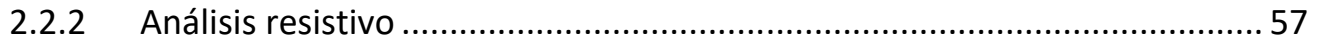

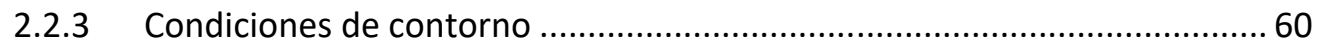

2.2.3.1 Sistema isostático, restringiendo el desplazamiento según la directriz del tablero en los estribos, carga en el plano del tablero, dirección X-X global (Fpx) .... 60

2.2.4 Sistema hiperestático, apoyos intraslacionales en los estribos, carga en el

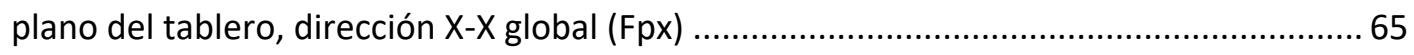

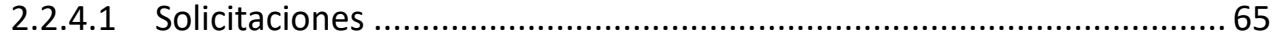


2.2.5 Sistema hiperestático, restringiendo los desplazamientos en los tres ejes en los estribos, carga en el plano del tablero, dirección Y-Y global (Fpy)

2.2.6 Sistema hiperestático, restringiendo el desplazamiento en los 3 ejes de los estribos, carga en el plano del tablero y concéntricas. 84

2.2.6.1 Sistema hiperestático, restringiendo el desplazamiento en los 3 ejes de los estribos, carga en el plano del tablero, concéntrica a la pila situada en el centro del arco del tablero

2.2.6.2 Sistema hiperestático, restringiendo el desplazamiento en los 3 ejes de los estribos, carga en el plano del tablero, concéntrica, pila no situada en el centro de la circunferencia del tablero

2.3 Viga curva sobre apoyos puntuales, con carga perpendicular a su plano ........ 207

2.3.1 Introducción y resumen 207

2.3.2 Viga curva sobre apoyos puntuales inclinados, sometida a una carga distribuida perpendicular a su plano, sobre su centro de cortantes 209

2.3.2.1 Sistemas resistivos 210

2.3.2.2 Trabajo desarrollado por la carga exterior en cada sistema resistivo. 216

2.3.2.3 Conclusiones 220

2.3.3 Viga curva sobre apoyos puntuales inclinados, sometida a un momento torsor distribuido 220

2.3.3.1 Sistemas resistivos 224

2.3.3.2 Trabajo desarrollado por la carga exterior en cada sistema resistivo. 231

2.3.3.3 Análisis y inclusiones. 235

2.3.4 Viga curva sobre apoyos puntuales inclinados, sometida a una carga distribuida perpendicular a su plano, desplazada radialmente respecto de su centro de cortantes 237

2.4 Diseño de la sección del tablero. 243

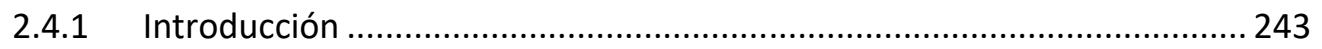

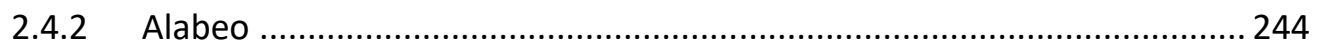

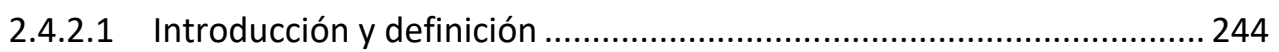

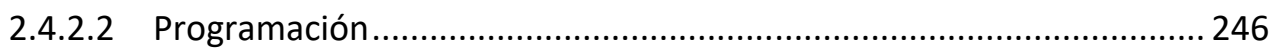

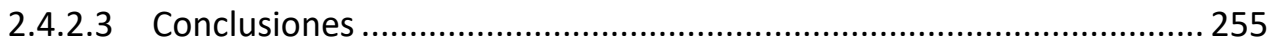

2.4.3 Centro de cortantes, posición del CDC frente al CDG de la sección ..........256

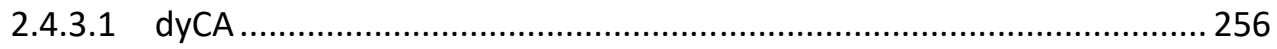

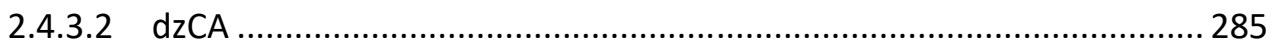

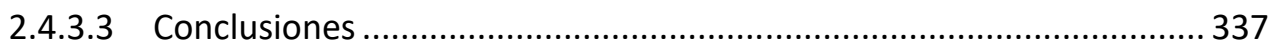


2.4.4.1 Geometría tirantes-sección de tablero.

2.4.4.2 Consecuencias mecánicas de la configuración elegida para la conexión tirante-tablero

2.4.5 Sección de tablero: Inercias y ejes principales de inercia .......................... 358

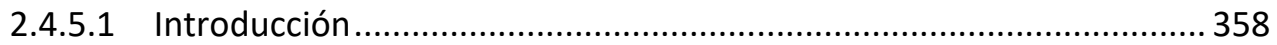

2.4.5.2 Modelo matemático bidimensional simplificado ................................ 358

2.4.5.3 Modelo matemático tridimensional. Viga sobre suelo elástico oblicuo ... 362

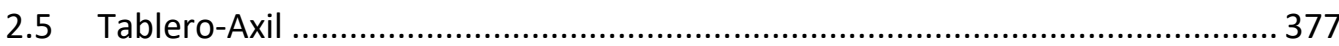

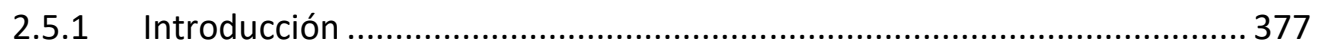

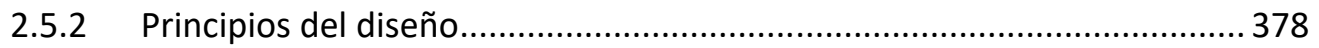

2.5.3 Directriz mediante un cálculo discreto................................................... 379

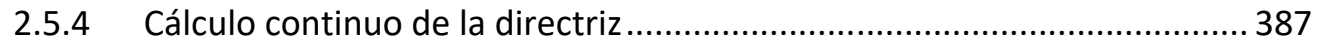

2.5.4.1 Planteamiento del problema …............................................................ 387

2.5.4.2 Solución de la ecuación diferencial....................................................... 390

2.5.5 Conclusión sobre los cálculos realizados................................................. 391

2.5.6 Aproximación por mínimos cuadrados de la directriz de un tablero, con

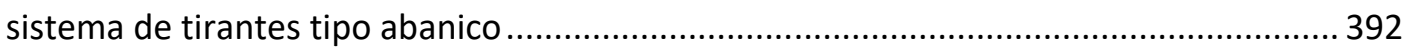

2.5.6.1 Tablero a compresión ....................................................................... 392

2.5.6.2 Tablero a tracción ............................................................................... 394

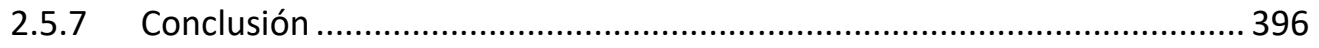

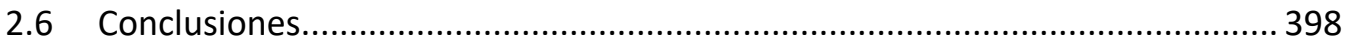

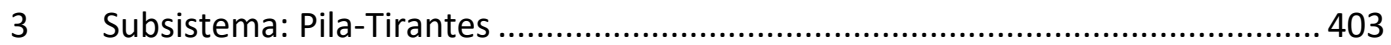

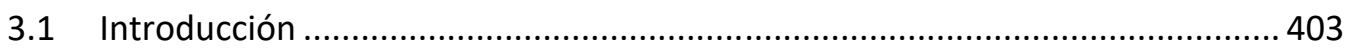

3.2 Análisis de la capacidad resistiva y rigidez del sistema de pila y tirantes de

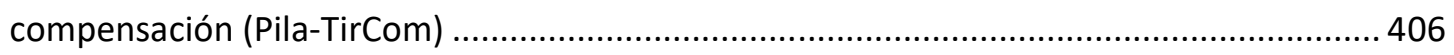

3.2.1 Requerimientos sobre la cabeza de la pila ................................................406

3.2.1.1 Requerimiento de rigidez geométrico sin escalar (cargas puntuales, unitario) . .406

3.2.1.2 Requerimiento de rigidez escalado (cargas uniformes, unitario)........ 412

3.2.2 Comportamiento del sistema............................................................... 420

3.2.2.1 Inclinación de pila ............................................................................. 421

3.2.2.2 Posicionamiento de la pila ................................................................... 424

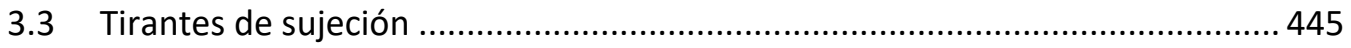


3.4 Sistema completo y ejemplo de aplicación.

3.5 Cabeza de pila, anclaje de tirantes de sujeción en semiarpa

3.5.1 Anclar los tirantes de sujeción (apartado 3.3) en la cabeza de la pila, compensando sus componentes horizontales.

3.5.2 Introduciendo una geometría de cabeza de pila que se adapte lo más posible a la dirección de las cargas que introducen los tirantes de sujeción (antifunicular) 465

3.5.3 Introducir tirantes de compensación a diferentes alturas a lo largo de la

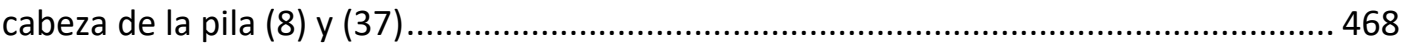

3.5.4 Torre con suficiente rigidez a flexión ........................................... 471

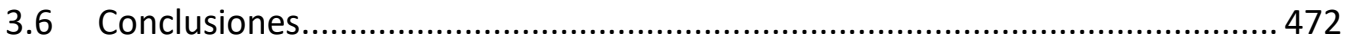

4 Resumen, líneas futuras de estudio, conclusiones y ejemplos ........................... 475

4.1 Resumen, ejemplos y conclusiones detalladas ....................................... 475

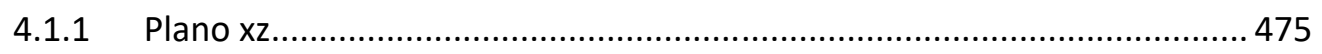

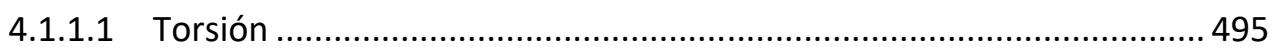

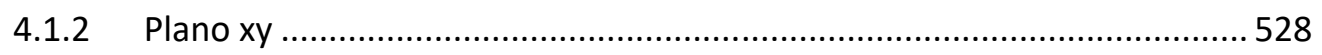

4.1.3 Ejemplo Tablero-Axil para carretera ........................................... 530

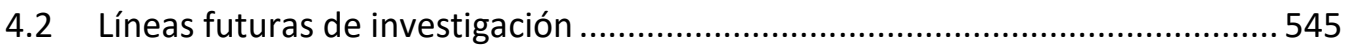

4.2.1 Puentes de uso ferroviario .................................................... 545

4.2.2 Atirantamiento a los 2 extremos del tablero (atirantamiento doble) ...... 546

4.2.3 Atirantamientos alternativos al tablero .......................................... 546

4.2.4 Disposición de tirantes de sujeción en la pila para reducir las solicitaciones transversales en el tablero ......................................................................... 547

4.2.5 Método iterativo que permita la elaboración de curvas antifuniculares tanto para el tablero como para la pila............................................................... 548

4.2.6 Inestabilidad de la pila....................................................... 548

4.2.7 Dinámica en puentes curvos atirantados ......................................... 549

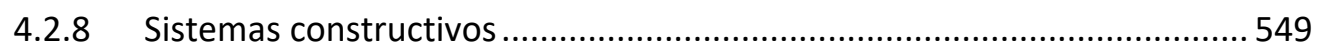

4.2.9 Estados complejos de carga ...................................................... 549

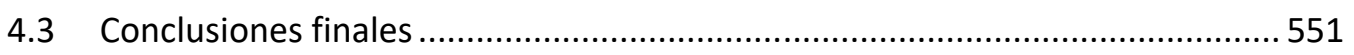

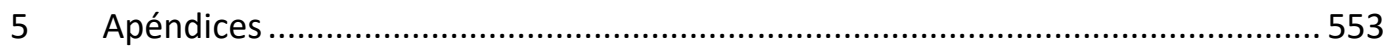

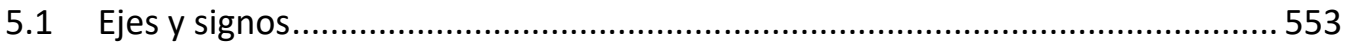

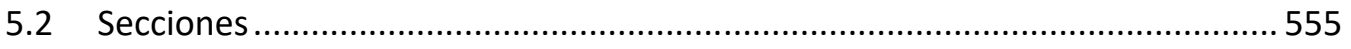

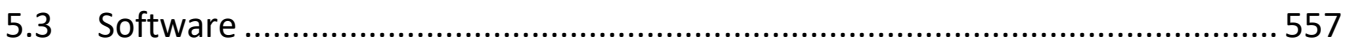

5.3.1 PROGRAMA “MOTOR" ............................................................ 558 
5.3.2 PROGRAMA “ANÁLISIS PILA-TIRCOM"

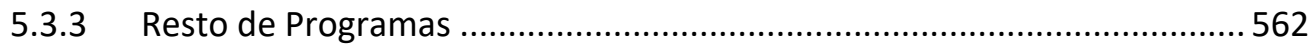

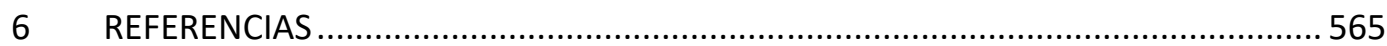





\section{AGRADECIMIENTOS}

A lo largo del laborioso desarrollo de esta tesis he recibido ayuda por parte de multitud de personas, incluso de muchas que no eran conscientes de la asistencia que estaban prestando. Creo que es justo agradecerles su apoyo y comprensión.

En primer lugar, debo agradecer a mi familia el apoyo y la confianza incondicionales que me han prestado. En particular debo hacer una mención a mi mujer, Irene Arnal Rodríguez, sin cuyo constante soporte y ayuda no creo que hubiese sido capaz de sacar adelante todas las obligaciones que he tenido en este periodo. Sin duda gran parte de esta tesis es suya. Nuestros hijos (Gadea y Darío), aún sin ser conscientes del bien que hacían, se han mostrado siempre cariñosos y comprensivos ante mis obligaciones.

Sin duda una de las personas que más ha influido en mi madurez académica y profesional ha sido Miguel Ángel Astiz Suárez. Debo agradecerle el enorme privilegio que supone haber contado con su tutela y dirección para la redacción de esta tesis.

Para que sea viable compatibilizar el trabajo con la redacción de una tesis de estas dimensiones, sin duda alguna, el entorno profesional debe ser el adecuado. Este entorno, está compuesto por personas que deben ser comprensivas con la situación del doctorando y en muchas situaciones, soportar mayores cargas de trabajo de las que les corresponderían. En este apartado debo mencionar en primer lugar a mi socio Alberto López Nafría, el cual me ha apoyado sin fisuras a lo largo de todo el proceso. También creo que es justo nombrar a las personas que trabajan o han trabajado en el estudio y que no han tenido inconveniente en esforzarse más ante mi situación. En este sentido debo nombrar a Daniel Serrano Payo, Jose Luis López, Fernando Calderón y Alberto Palomino. El interés y empuje de este último han sido de gran ayuda.

Sin salirme del ámbito profesional, debo agradecer la enorme comprensión que han mostrado mis clientes. En momentos de gran carga de trabajo y responsabilidad han sido pacientes y benevolentes. Debo hacer mención especial en este aspecto a Álvaro Alday y a José Selgas.

Por último, quiero agradecer el cariño constante que me ha mostrado el resto de mi familia. El soporte que me han brindado mis padres y hermanos ha sido de una enorme ayuda. Mención especial debo hacer a mis abuelos, que hasta el final me apoyaron incondicionalmente. Entre ellos se encontraba grand-père, René-Albert Bardín, que ha sido una inspiración a lo largo de toda mi vida, en lo personal y lo profesional.

Muchas gracias a todos.

Darío Galante Bardín.

Madrid 2017. 

A Irene, Gadea y Darío.

Y a Grand-père. 



\section{INTRODUCCIÓN}

\subsection{Motivos para una tesis doctoral sobre puentes curvos atirantados}

Existen motivos de diversa naturaleza para la realización de esta investigación. Se pueden agrupar en dos grupos fundamentales, de cuya conjugación resulta la razón de ser de la tesis:

- La actual proliferación de puentes de directriz curva, debido fundamentalmente a razones funcionales y estéticas.

- El gran desarrollo de los puentes atirantados como opción apropiada para puentes de luces medias y grandes.

\subsubsection{Puentes de directriz curva}

Desde un punto de vista funcional, el puente curvo permite resolver las cada vez más estrictas y complejas restricciones geométricas que poseen las vías actuales. La naturaleza de estas restricciones es muy diversa, desde una mezcla entre obstáculos naturales y una mayor concienciación medioambiental, pasando por derechos de paso en zonas urbanas hasta el desarrollo de grandes cruces entre viales a diferentes alturas, con enlaces entre ellos. Como claro ejemplo de estas exigencias, está el puente del Complejo Real Park en Sao Paulo, (16).

Desde un punto de vista estético, ha sido notorio el incremento de las exigencias que han surgido sobre los puentes. En este capítulo, se debe hacer especial mención a los puentes peatonales, en los que, en muchos casos el atractivo de su forma resulta ser una de las motivaciones principales en el momento de su diseño. Sin lugar a dudas, la posibilidad de desarrollar directrices curvas en los puentes supone un incremento en la libertad de diseño, que bien utilizada, puede mejorar las propiedades arquitectónicas del puente. Como ejemplos con una clara vocación estética, Ursula Baus y Mike Schlaich realizan una acertada colección de ellos en Footbridges (101), si bien también existen otros ejemplos remarcables, como el puente atirantado sobre el embalse en Granada (42), o la gran mayoría de los puentes desarrollados por Santiago Calatrava (2).

En muchas ocasiones, esta búsqueda estética ha negado principios tan acertados como los que promulgaba Eladio Dieste sobre la belleza de la simplicidad o acerca de lo imprescindible que resulta el profundo conocimiento del entorno, social y tecnológico, de una obra por parte del ingeniero para que esta pueda resultar acertada (102), o los que aborda Carlos Fernández Casado sobre la trascendencia de los ingenieros en la creación de los espacios públicos (13).

Hasta no hace demasiado tiempo, la tipología de puente curvo utilizada era, casi de manera exclusiva, la de tablero sobre apoyos puntuales. Esta tipología es la que más se ha desarrollado por parte de investigadores (11) y de la que más se han ocupado las normativas (3). En el caso de que existan restricciones que impidan esta tipología, lo habitual ha sido la adaptación del entorno para eliminar estas restricciones (21) y (107) para, de ese modo, conseguir la validez de alguna tipología de puente recto. Esto resulta evidente en la mayoría de 
los pasos superiores sobre carretera, donde los cambios de dirección hasta conseguir una directriz perpendicular al trazado de la vía principal se realizan previos a los estribos (23).

La falta de experiencia, de suficiente documentación técnica, de cobertura por parte de las diferentes normativas, de metodologías de diseño claras, sumado a las dudas que ofrecen los complejos métodos constructivos hasta ahora aplicados, han disuadido a los ingenieros de realizar diseños de puentes curvos más complejos. En los últimos años se ha podido ver una cierta evolución en diferentes tipologías de puentes curvos, como puentes atirantados, colgantes o en arco. Se han desarrollado trabajos científicos notables con arcos adaptados a las cargas, como los realizados por Lorenz Lachauer y Toni Kotnik (51), Leonardo Todisco (50) o Juan José Jorquera (46). Este progreso ha sido especialmente fecundo en las pasarelas peatonales (40), donde la libertad de diseño resulta mayor (101), (38) y (59), y para las cuales ingenieros como Schlaich o Javier Manterola han diseñado sistemas muy acertados con puentes colgantes (87) y (88), arco 89), y atirantados (38) y (65), esta última, lamentablemente, desmontada.

\subsubsection{Puentes atirantados}

Los puentes atirantados se han convertido en una opción ampliamente utilizada por los proyectistas para puentes con luces medias y grandes, cuyos valores son parecidos según los diferentes autores (en metros), como Manterola: $100 \rightarrow 900$ (35), Svensson: $100 \rightarrow 1000$ (29), o Gimsing: $200 \rightarrow 2000$ (73) (Gimning incluye los colgantes y, según sus cálculos de coste, cuando se pasa de $1000 \mathrm{~m}$ de luz empieza a resultar más económico el puente mixto, colgado el centro y atirantado el resto).

El puente atirantado resulta mucho más rígido que el colgado para sobrecargas no simétricas, y también mucho más barato, si comparamos el peso del acero de los tirantes. La mayor desventaja es el incremento de carga horizontal sobre el tablero, que en el caso de puentes de luces muy grandes puede llegar a ser determinante para este (35).

La evolución reciente de esta tipología de puentes está siendo bastante notable, con multitud de propuestas morfológicas y resistivas. La tendencia actual es la de sistemas de atirantamiento múltiple con dinteles flexibles, cuyo comportamiento se asimila al de una viga sobre fundación elástica. Como ejemplo de este comportamiento, el puente de Talavera de la Reina (78) resulta muy visible, aunque todavía se pueden encontrar ejemplos en los que se han seguido utilizando tableros con una alta rigidez para compatibilizar el sistema con el uso (106).

\subsubsection{Puente curvo atirantado}

Resulta inevitable llegar a la conclusión, a partir de lo expuesto en los dos puntos anteriores, de que el puente atirantado curvo es una opción cuya aceptación va a ir incrementándose con el tiempo, a medida que vayan apareciendo documentos técnicos y nuevos ejemplos que faciliten el diseño a los ingenieros.

Aprovechando la situación actual de expansión de esta tipología de puentes, previendo un significativo incremento de esta expansión en el futuro y teniendo en cuenta la falta de documentación técnica existente sobre los puentes curvos atirantados, puede ser de gran 
interés un estudio como el que plantea esta tesis, donde se va a clarificar el comportamiento del sistema estructural completo.

Como parte de esta introducción, en el apartado 1.4, se van a mostrar ejemplos significativos de puentes curvos atirantados que permitan establecer una visión de las tendencias actuales en cuanto a su morfología.

\subsection{Objetivos de la tesis}

El objetivo fundamental de la tesis es esclarecer el comportamiento de los puentes curvos atirantados, facilitando la labor de diseño y cálculo a los equipos proyectistas.

La tesis se centra en los puentes curvos atirantados, con una torre posicionada libremente, un solo tirante por sección de apoyo, directrices curvas circulares, funiculares y antifuniculares y sistemas de pila atirantados mediante tirantes de compensación. Sus conclusiones resultan fácilmente extrapolables a sistemas más complejos, como puentes con dos torres o dobles curvas.

Para cumplir con el objetivo fundamental, se han establecido los siguientes objetivos parciales:

- Profundizar en el comportamiento de la viga curva con carga fuera de su plano, centrada y descentrada, biapoyada y multiapoyada, como base del estudio del tablero del puente curvo atirantado. Clarificar los diferentes sistemas resistivos básicos que se dan a medida que se modifican las diferentes variables que definen el problema.

- Estudio pormenorizado del comportamiento de una viga curva bajo cargas en su plano, con especial atención a las cargas concéntricas. Clasificación de los tipos de funcionamiento de los tableros, frente a cargas concéntricas, para diferentes posicionamientos de la pila y obtención de fórmulas que permitan parametrizar el tipo de comportamiento según las variables del problema.

- Estudio de la carga concéntrica, para las diferentes disposiciones de tirantes que se van a dar en la cabeza de la pila. Obtención de las fórmulas que permiten el efecto de "rueda de bicicleta" sobre el tablero a partir de la altura de conexión de los tirantes sobre la pila.

- Esclarecimiento y análisis de los efectos, geométricos y mecánicos, derivados de la posición de la conexión del tirante de sujeción y el tablero y de la diferencia de posición entre el centro de cortantes y el centro de gravedad del tablero.

- Elaboración e implementación de un método gráfico sencillo que permita analizar los conflictos geométricos entre los tirantes de sujeción y el uso del tablero.

- Desarrollo de software que permita la obtención de las propiedades mecánicas frente al alabeo de las secciones y su parametrización frente a las variables geométricas que la definen.

- Solucionar e implementar el problema de las directrices funiculares y antifuniculares del tablero, denominados Tablero-Axil, para pilas rectas e inclinadas con disposiciones de tirantes en arpa, en abanico o en semiarpa. 
- Desarrollo de un software de cálculo estructural parametrizado, que permita el estudio de diferentes configuraciones de forma automática.

- Comparación de los comportamientos de los puentes con directriz curva y directriz Tablero-Axil, frente a diferentes hipótesis de carga.

- Análisis y obtención los requerimientos determinantes para el subsistema Pila-Tirantes. Desarrollo de software parametrizado que permita una sencilla evaluación.

- Elaboración e implementación de un sistema parametrizado que permita el diseño del subsistema Pila-Tirantes al completo a partir de la nivelación de requerimientos y propiedades resistivas del sistema.

- Estudio de las diferentes soluciones a la hora de anclar los tirantes en la cabeza de la pila y elaboración de las morfologías que mejor se comportan.

- Desarrollo de software de análisis del comportamiento de cada uno de los subsistemas que permita identificar de forma clara y rápida los problemas de comportamiento del puente curvo atirantado.

- Desarrollar un documento técnico que incluya una traza analítica, desde los elementos básicos de comportamiento más sencillo (tirantes, viga curva...) hasta los sistemas más complejos que los agrupan (Pila-Tirantes, viga curva sobre apoyos elásticos, puente curvo atirantado).

\subsection{Contenido de la tesis}

El sistema estructural que forma un puente curvo atirantado es tremendamente complejo. A su alto grado de hiperestaticidad, su no-linealidad y su enorme flexibilidad, características que comparte con los puentes rectos atirantados (35), (80), (29) y (73) se le suma su espacialidad (79). Esta espacialidad, además de sumar complejidad a la hora de estudiar el comportamiento y solicitaciones de cada elemento del sistema, multiplica las posibilidades morfológicas posibles (101), (38) y (59). Solo reduciendo el problema hasta sus esencias, a sus elementos más básicos, se podrá tener una clara visión del comportamiento del conjunto.

Dentro de este complejo funcionamiento del sistema está su diferente comportamiento frente a las cargas que se pueden dar sobre el tablero. Un ejemplo de ello es el modo en el que se pone en carga el puente para soportar la acción de peso propio, mediante el pretensado de los tirantes que unen la cabeza de la pila con el tablero. Las referencias a sistemas estructurales conocidos (26), (82), (80), (20) y (98), como pueden ser los puentes curvos, los arcos o las "ruedas de bicicleta" van a ser frecuentes a lo largo del análisis del sistema (sobre todo en el estudio de subsistemas más sencillos), con la intención de hacer lo más intuitivo posible el análisis.

Para el análisis de todos los sistemas resistivos se han utilizado programas desarrollados específicamente para este fin en Mathematica, Apéndice 5.3.

La no linealidad en la relación entre tensión y deformación de los tirantes, debido a su gran flexibilidad (no linealidad geométrica) y el comportamiento de los materiales (relajación, fluencia y retracción) (27) se van a dejar fuera en la mayoría de los análisis. Si bien son efectos importantes a tener en cuenta en el análisis resistivo del puente, en muchos casos no van a 
ayudar a clarificar, sino más bien todo lo contrario, la respuesta resistente del sistema, y su estudio puede realizarse a posteriori sin que esto modifique ninguno de los conceptos que se buscan.

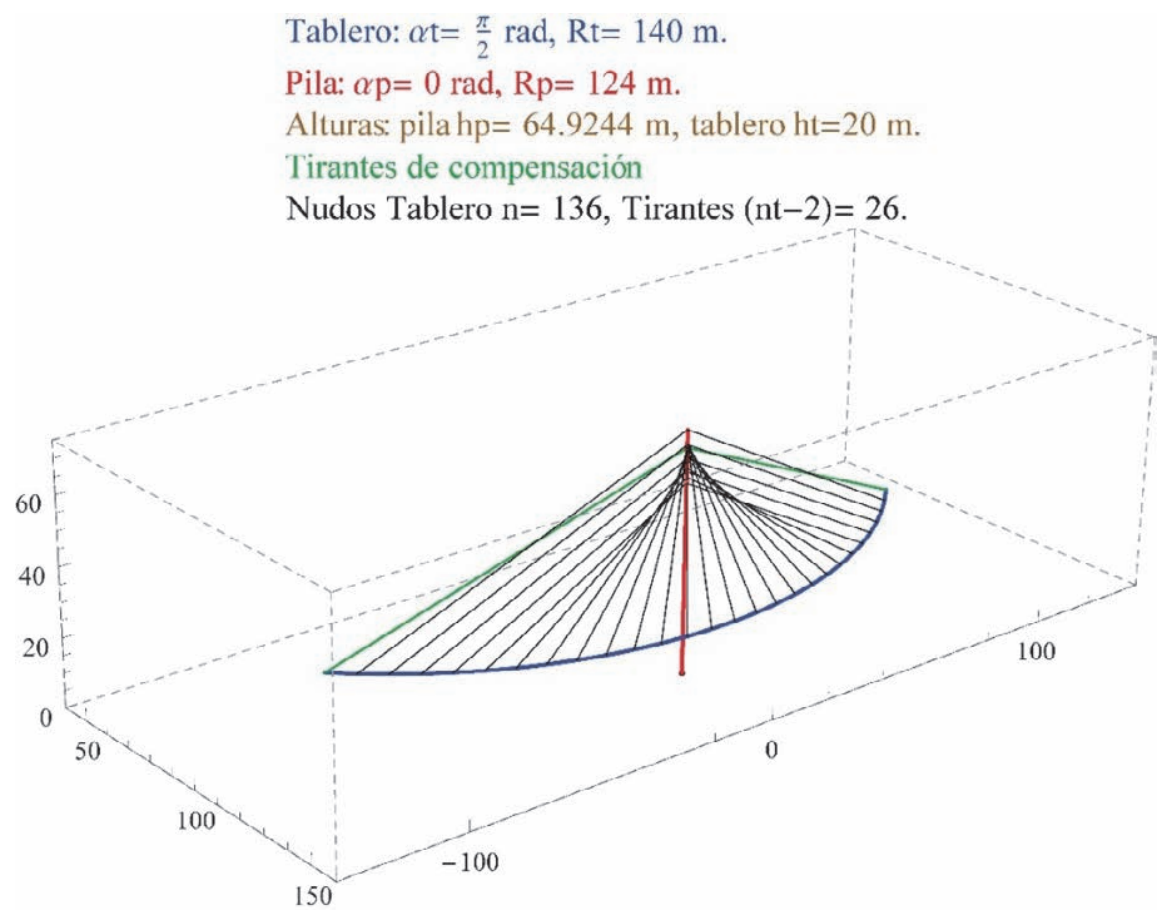

Ilustración 1.1. Modelo de cálculo de un puente atirantado curvo, con la directriz circular, con pila autocompensada y disposición de tirantes de sujeción según relación dX-altura. Imagen del progrma de cálculo: PROGRAMA MOTOR.

Tablero: $\mathrm{FHT} 0=20 \mathrm{KN}, \mathrm{xo}=10 \mathrm{~m}$.

Alturas: pila $h p=71.9177 \mathrm{~m}$, tablero $\mathrm{ht}=20 \mathrm{~m}$.

StTOTAL $=180 \mathrm{~m}$.

Tirantes de compensación

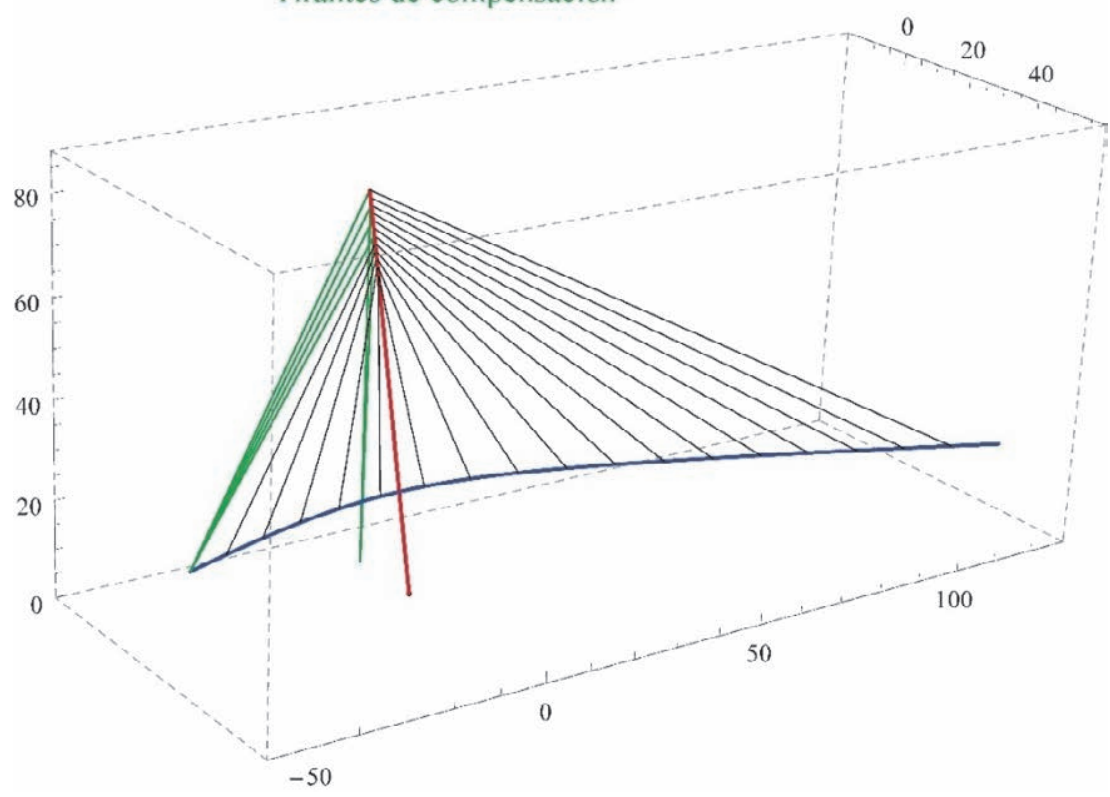

Ilustración 1.2 Modelo de cálculo de un puente atirantado curvo asimétrico, con la directriz Tablero-Axil, con pila fuera del eje de simetría del tablero y disposición de tirantes de sujeción según relación distancia-altura. Imagen del progrma de cálculo: PROGRAMA MOTOR. 
La tipología de curvatura que se va a analizar, va a ser circular (Ilustración 1.1), menos en el caso del Tablero-Axil (Ilustración 1.2), cuya curvatura viene dada por las formas funiculares y antifuniculares de las componentes horizontales de la carga de los tirantes de sujeción.

Con el declarado fin de simplificar el sistema completo y hacerlo lo más comprensible posible, se ha optado por dividir el sistema estructural completo en dos subsistemas principales cuyo comportamiento, por separado, va a resultar más intuitivo: subsistema Tablero (capítulo 2). y subsistema Pila-Tirantes (capítulo 3). A su vez estos subsistemas serán analizados y discretizados hasta sus componentes más sencillos. La separación que se ha planteado, tiene en cuenta el comportamiento del sistema estructural. De esta manera, lo que se busca es separar el sistema completo en subsistemas cuyo comportamiento sea fácilmente diferenciable.

\subsubsection{Subsistema Tablero: capítulo 2}

En este capítulo se va a desgranar el comportamiento del tablero de un puente curvo atirantado, desde sus sistemas resistivos más básicos hasta el sistema resistivo completo:

- Apartado 2.1. En este apartado se analiza el comportamiento de una viga curva biapoyada con diferentes tipos de empotramiento en los estribos y con diferentes tipos de cargas. El objetivo es profundizar y comparar los dos sistemas resistivos principales que permiten la estabilidad de una viga curva con carga fuera de su plano: el empotramiento a flexión y el empotramiento a torsión, a medida que se varían las condiciones de contorno. A lo largo de todo el apartado, se muestra la formulación matemática de la que se obtienen los resultados, con la intención de que el proceso sea lo más claro y comprensible.

- Apartado 2.2. Este apartado aborda uno de los asuntos más determinantes en el diseño y cálculo de los puentes curvos atirantados: el comportamiento de una viga curva en su plano bajo cargas concéntricas. Se estudia este comportamiento bajo diferentes configuraciones de puente, cubriendo la mayor parte de los casos posibles para clasificar los tipos de comportamientos que se pueden dar y, finalmente, parametrizarlos frente a las variables del problema. De nuevo, se muestra la formulación de todo el proceso, con la intención de que la comprensión del proceso sea completa. También se analiza el comportamiento de cargas según los ejes globales.

- Apartado 2.3. Este apartado resulta la evolución lógica respecto de los anteriores, en particular del apartado 2.1, introduciendo en el sistema de viga curva cargada fuera de su plano un nuevo elemento: los apoyos intermedios entre los estribos. De nuevo se centra el análisis en los sistemas resistivos que garantizan la estabilidad del sistema, y en este caso se introducen dos sistemas nuevos, que serán los más determinantes a partir de este apartado: el empotramiento elástico en los apoyos sucesivos, "ee", y el empotramiento a torsión en el estribo, "eTxD". Para comparar entre la eficacia de estos sistemas resistivos, se utilizan los teoremas energéticos de Menabrea (66) y (47). Para mayor claridad, las formulaciones se desarrollan para cada análisis. 
- Apartado 2.4. En esta parte nos centraremos en el diseño de la sección del tablero, tanto desde el punto de vista resistivo como desde el punto de vista geométrico. Se hace especial hincapié en el comportamiento de la sección frente al alabeo, lo que va a permitir utilizar secciones abiertas como opción realista en ciertas configuraciones de puentes. También se profundiza en el comportamiento de los tableros cuando el centro de cortantes no es coincidente con el centro de gravedad, y como fenómeno semejante, cuando el apoyo en los tirantes de sujeción se realiza excéntrico respecto del centro de gravedad. Por último, se estudian los ejes principales, sus direcciones y las propiedades mecánicas del tablero sobre modelos matemáticos simplificados - de los que se aportan todas las formulaciones-, en los que se conjugan los dos planos de trabajo.

- Apartado 2.5. Como se ha comentado anteriormente, las cargas horizontales introducidas por los tirantes en el tablero resultan determinantes para el tablero en este tipo de puentes. En este apartado se estudian las curvas funiculares y antifuniculares de estas componentes horizontales, con diferentes configuraciones de pila y tirantes. Se plantea la solución según dos tipos de formulación: discreta y continua. Finalmente se deducen, mediante mínimos cuadrados, las ecuaciones que parametrizan estas curvas para la disposición de tirantes en abanico.

\subsubsection{Subsistema Pila-Tirantes: capítulo 3}

En este capítulo se desglosa el subsistema Pila-Tirantes, que se compone de la pila, los tirantes de compensación (aquellos que sirven para compensar las acciones que producen momentos flectores sobre la pila) y los tirantes de sujeción (aquellos que unen la cabeza de la pila y el tablero). En este caso, lo que se hace es separar el estudio de las exigencias que le traslada el tablero (denominadas en la tesis como requerimientos) y el comportamiento del subsistema, con el objetivo de que se equilibren.

- Apartado 3.2. En este apartado se analiza el conjunto más complejo del subsistema, compuesto por la pila y los tirantes de compensación (denominado PilaTirCom). El apartado se divide en requerimientos y comportamiento:

o Subapartado 3.2.1: esta parte se centra en los requerimientos que va a tener el sistema PilaTirCom parametrizados por las variables que definen el problema. A su vez, se consideran por separado las cargas puntuales, que afectan a los tirantes de forma individual, y las cargas distribuidas, cuyo centro de gravedad no se sitúa sobre el tablero.

o Subapartado 3.2.2: en este bloque estudiaremos cómo repercute en el comportamiento del sistema PilaTircom la inclinación de la pila, su posición y su altura. El estudio se realiza desde el punto de vista del equilibrio y desde el punto de vista de la rigidez que ofrece el sistema en las diferentes direcciones.

- Apartado 3.3. Se dedica al estudio de los tirantes de sujeción, mostrando cómo cambia su comportamiento a lo largo del tablero, a medida que se varía la configuración de la pila. 
- Apartado 3.4. En este apartado se le añaden los tirantes de sujeción al sistema PilaTirCom para definir el comportamiento del subsistema completo. Para que las conclusiones sean claras, se desarrolla un ejemplo, en el que se van siguiendo los pasos que se han expuesto a lo largo de los apartados anteriores.

- Apartado 3.5. A lo largo de la cabeza de pila se van a anclar los tirantes de sujeción, según la disposición elegida: arpa, semiarpa y abanico. En este apartado se estudian las disposiciones más recomendables desde el punto de vista teórico, según la configuración del puente. A su vez, se plantean 4 soluciones que permiten disminuir las solicitaciones más perjudiciales para la torre, las transversales.

- Apartado 3.6. Se termina recopilando las conclusiones sobre el subsistema Pila-Tirantes.

\subsubsection{Capítulo 4}

En este capítulo se agrupan las conclusiones sobre de la tesis. Para poder articular todos los capítulos de una forma clara, a medida que se van desarrollando las conclusiones se plantean varios ejemplos similares de una pasarela peatonal de $110 \mathrm{~m}$ de longitud y un viaducto de $340 \mathrm{~m}$ de longitud. A partir de estos ejemplos se toman diferentes decisiones, siguiendo las deducciones de los diferentes capítulos, y de este modo se concretan las conclusiones y los resultados.

\subsubsection{Apéndices: capítulo 5}

Se utiliza este capítulo para introducir toda la información que resulta útil a lo largo de la tesis, sin estar directamente relacionada con el comportamiento del puente:

- Apartado 5.1. Se explican gráficamente los ejes de coordenadas locales y globales que se utilizan a lo largo de la tesis.

- Apartado 5.2. Se muestra toda la información sobre las secciones de tablero que se han utilizado en la tesis.

- Apartado 5.3. Se muestra un diagrama de flujo en el que se puede ver la cadena de programas que se han utilizado en los diferentes análisis y dónde se sitúan en el curso del estudio del puente curvo atirantado. También se detallan las propiedades de cada programa y sus utilidades.

\subsubsection{Referencias: capítulo 6}

Se utiliza este capítulo para introducir las referencias que se han utilizado a lo largo de la tesis por orden alfabético. 


\subsection{Obras significativas}

Con la intención de presentar la situación actual de los puentes curvos atirantados, se van a presentar las obras ejecutadas que nos resultaron más significativas y ordenadas de acuerdo con las cualidades más interesantes para la presente tesis.

Probablemente lo que más influye sobre la morfología del puente es el uso para el que ha sido diseñado: peatonal, tráfico de vehículos o ferroviario.

Los puentes atirantados para uso ferroviario han sido los menos frecuentes. Esto se debe principalmente a las enormes exigencias dinámicas y de rigidez que este tipo de uso requiere, sobre todo en ferrocarriles de alta velocidad. Debido a estos requerimientos y aprovechando el doble uso que suelen tener este tipo de puentes (ferroviario y automovilístico), el tipo de sección más frecuente son cerchas de gran canto que unen las dos alturas que separan los diferentes usos. El tipo de pila más utilizado es el de "Y" invertida, "V" invertida o " $\mathrm{H}$ " centrada respecto del eje del tablero, con una disposición de tirantes tipo semiarpa en la pila y doble atirantamientos a los bordes del tablero. En China están proliferando este tipo de puentes de forma bastante llamativa (30). Como ejemplos significativos, tenemos el puente Tianxingzhou (91), con $504 \mathrm{~m}$ de vano principal y $17 \mathrm{~m}$ entre cordones de cerchas (Ilustración 1.3), el Yujiang (106), de 228 m y 15,2 m entre cordones de cercha, o el ambicioso puente Hutong (30), en construcción, con 1092 m de vano principal y 16 $\mathrm{m}$ entre cordones de cerchas.

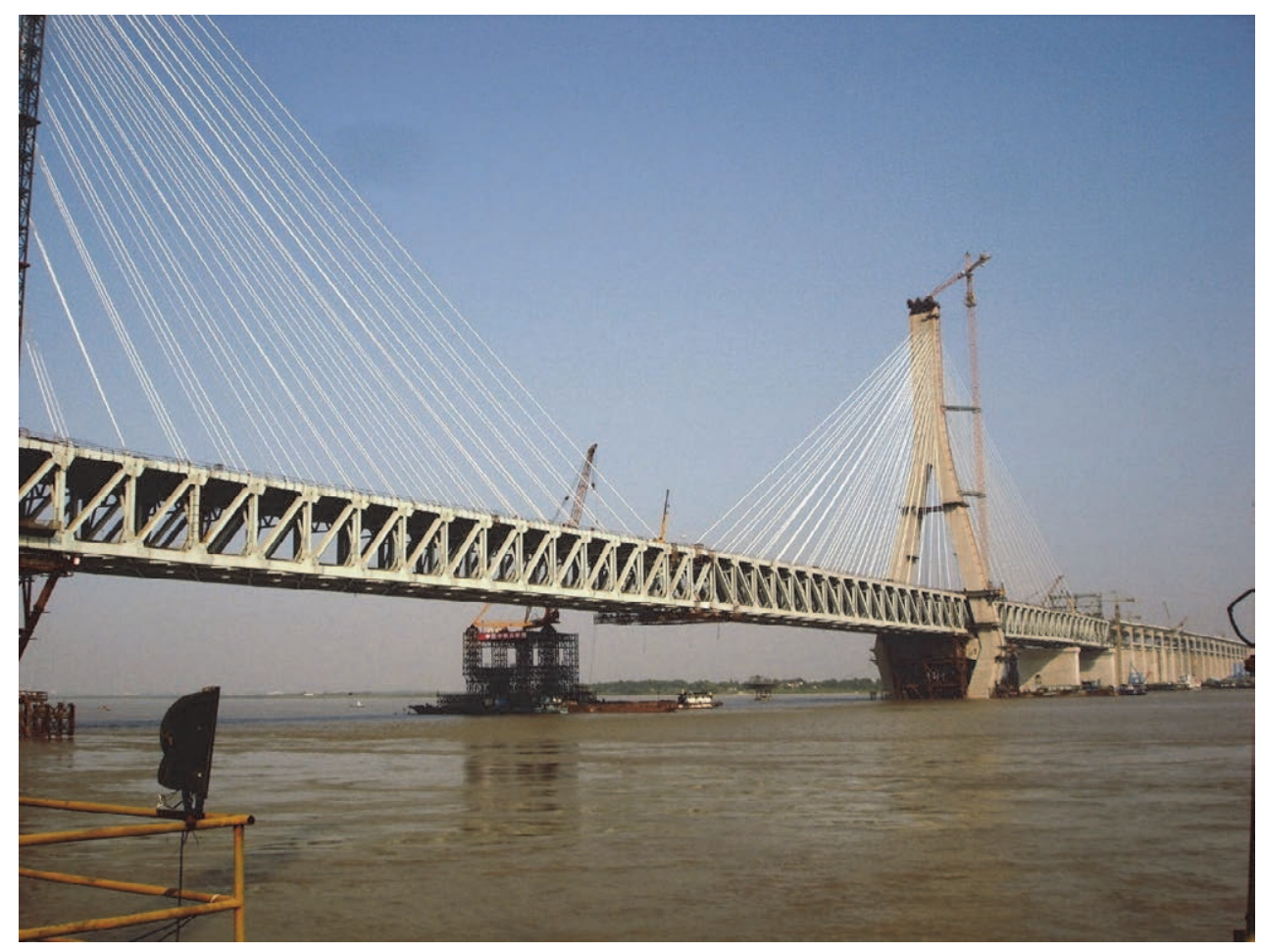

Ilustración 1.3. Tianxingzhou stayed-cable bridge, (91).

Como ejemplo de puente curvo atirantado de uso ferroviario, nos encontramos con el Bridge of Strings (61) en Jerusalén, obra de Santiago Calatrava, (llustración 1.4), con un uso mixto ferroviario-peatonal, y (61), con un vano principal de 143 metros, así como y con el 
reciente puente tranviario de Plaszow (II). Este último tiene una configuración de pila y tirantes muy similar a la de los puentes atirantados rectos para uso ferroviario (Ilustración 1.5).

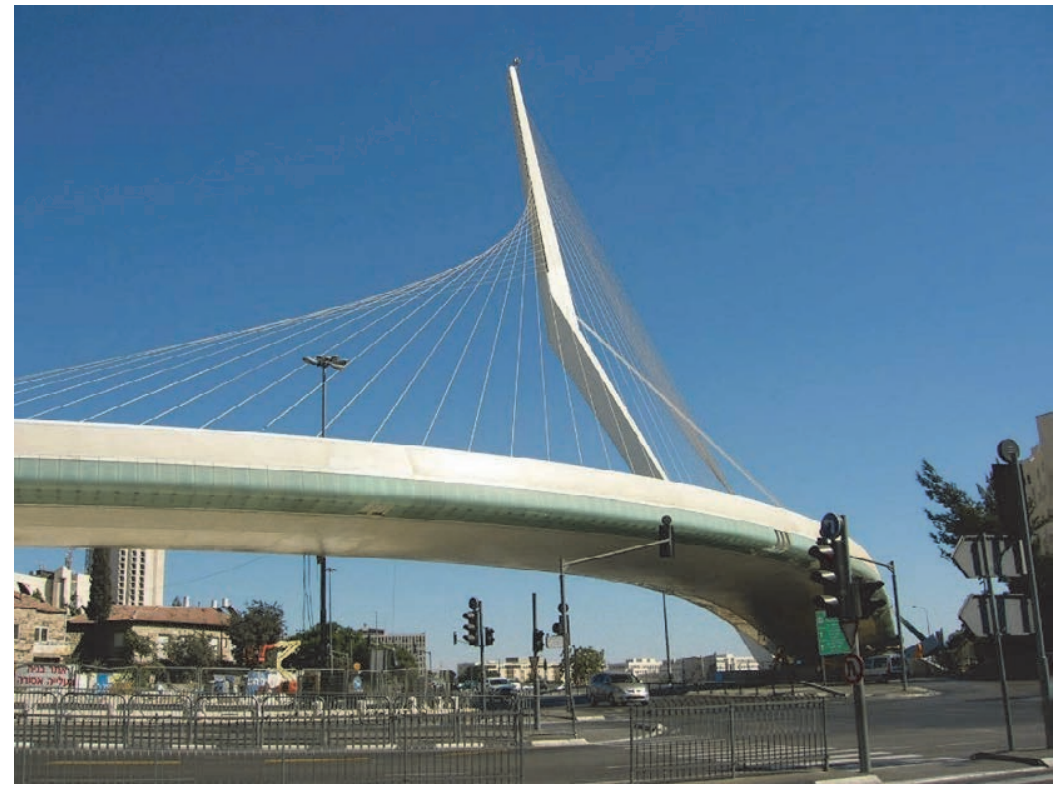

Ilustración 1.4. Bridge of strings, (61).

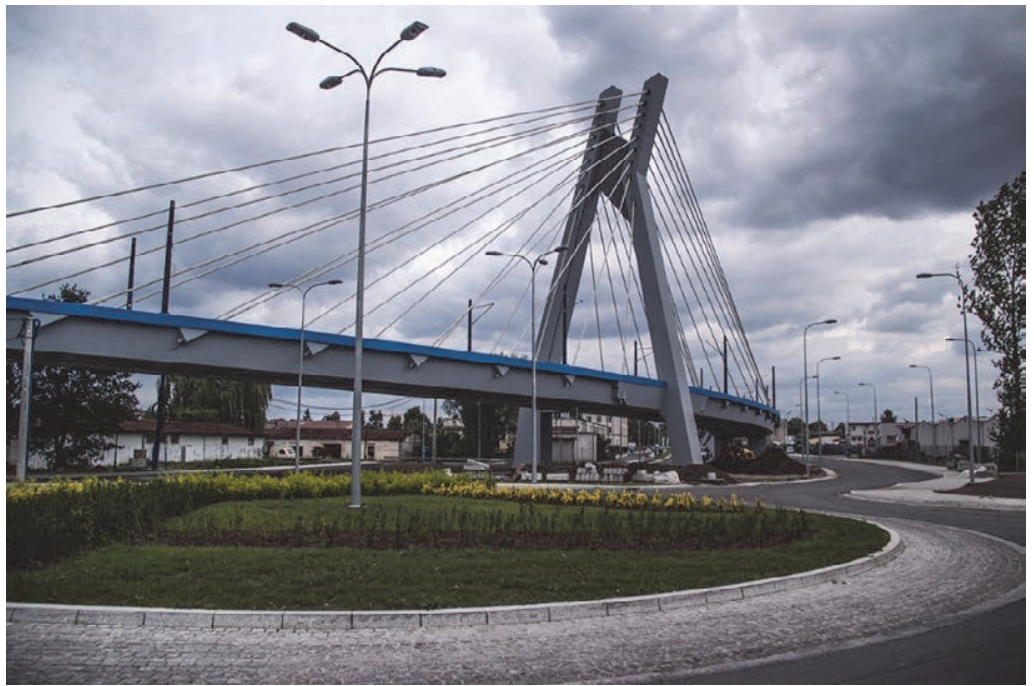

Ilustración 1.5. Plaszow Tramway Bridge (II). (Fuente: Mota-Engil Central Europe Newsletter)

Los puentes atirantados de carretera, por el contrario, son muy frecuentes. En la actualidad, las secciones de tablero que se utilizan con mayor frecuencia son el cajón y la doble jácena, con cantos mucho menores que en el caso ferroviario, buscando el comportamiento de viga sobre fundación elástica. El cajón es lo más característico en puentes con atirantamiento simple en sección de apoyo, como ocurre en el impresionante viaducto de Millau de Virlogeux, que es ligeramente curvo (63), mientras que la bijácena es más frecuente en puentes con atirantamiento doble en sección de apoyo, como el Quincy Bayview (74), y encontramos algunos ejemplos de secciones dobles de cajón, como el puente del Centenario en Sevilla (35), y la propuesta desarrollada para la bahía de San Francisco (21). 


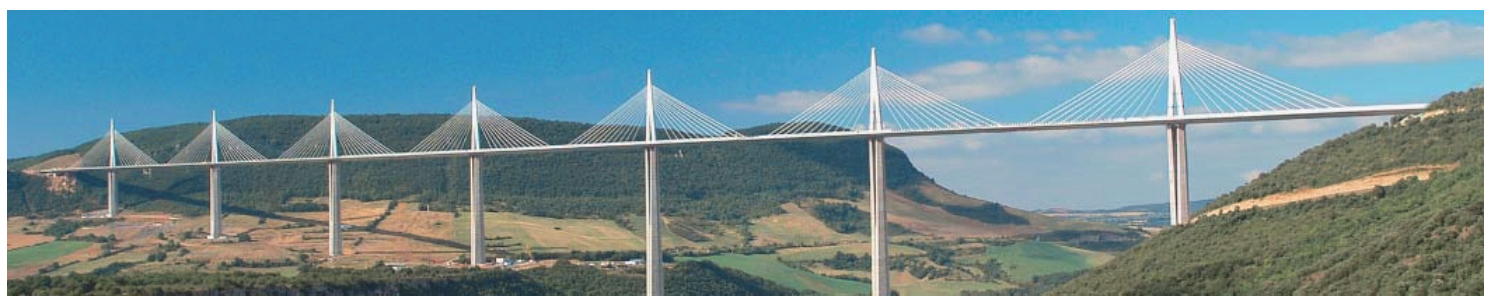

Ilustración 1.6. Millau Viaduct, (63).

La torre de un puente atirantado resulta el elemento más prominente de este tipo de obras (97). Esto ha llevado en numerosas ocasiones a cargar de contenido arquitectónico a este elemento con diferente fortuna (90), como el viaducto de Millau (Ilustración 1.6), el puente del Alamillo (2), el puente Grand Wisata (24) y el Zwolle Cable (83).

El tipo de de pila que se utiliza en puentes de carretera atirantados resulta más variado que en el caso del uso ferroviario, resultando muy dependiente del tipo de atirantamiento que se realice, que por otro lado también resulta más variado que en el caso de puentes de uso ferroviario. Como división principal, para puentes rectos, se puede separar el tipo de pila en aquellas de atirantamiento central y aquellas de atirantamiento a bordes (45) y (17).

Para el atirantamiento centrado en el eje del tablero, se utiliza preferentemente la pila centrada en el eje del puente o pila centrada, en la que se minimiza su anchura con el propósito de reducir el área ocupada sobre el tablero (35). A favor de esta necesidad de minimizar la anchura de la pila centrada, en los puentes rectos, está que en la dirección transversal del puente solo debe soportar el viento que incide sobre ella misma, que se puede reducir mediante un correcto diseño (31). En el caso de puentes curvos, no se puede eximir a la pila de las cargas transversales a menos que se compensen las curvas con una contracurva, como realiza el viaducto japonés de Katsushika (48) (Ilustración 1.7). Estas cargas transversales sobre la pila requieren una rigidez transversal que se puede conferir mediante el correcto diseño y dimensionamiento de la sección de la pila. Así ocurre en el viaducto de Millau (63), en el puente del puerto comercial de Venecia (60) (Ilustración 1.9), en el viaducto de Yabegawa y también en el puente Prospekt Aleksandrovskoy Fermy, donde se desdobla la pila en una " $\mathrm{Y}$ " invertida (108) (Ilustración 1.8). Otra opción es hacerlo mediante atirantamientos que compensen esta carga transversal (48) y (35), como se realiza en el puente Safti de Singapur, (33). En todos ellos se requiere de una rigidez a torsión aportada por el tablero, que se debe realizar en una sección cerrada empotrada en los estribos y pila. La curvatura no resulta suficiente para producir un empotramiento elástico ("ee", apartado 2.3 ) suficientemente rígido para las exigencias de este tipo de puentes. 


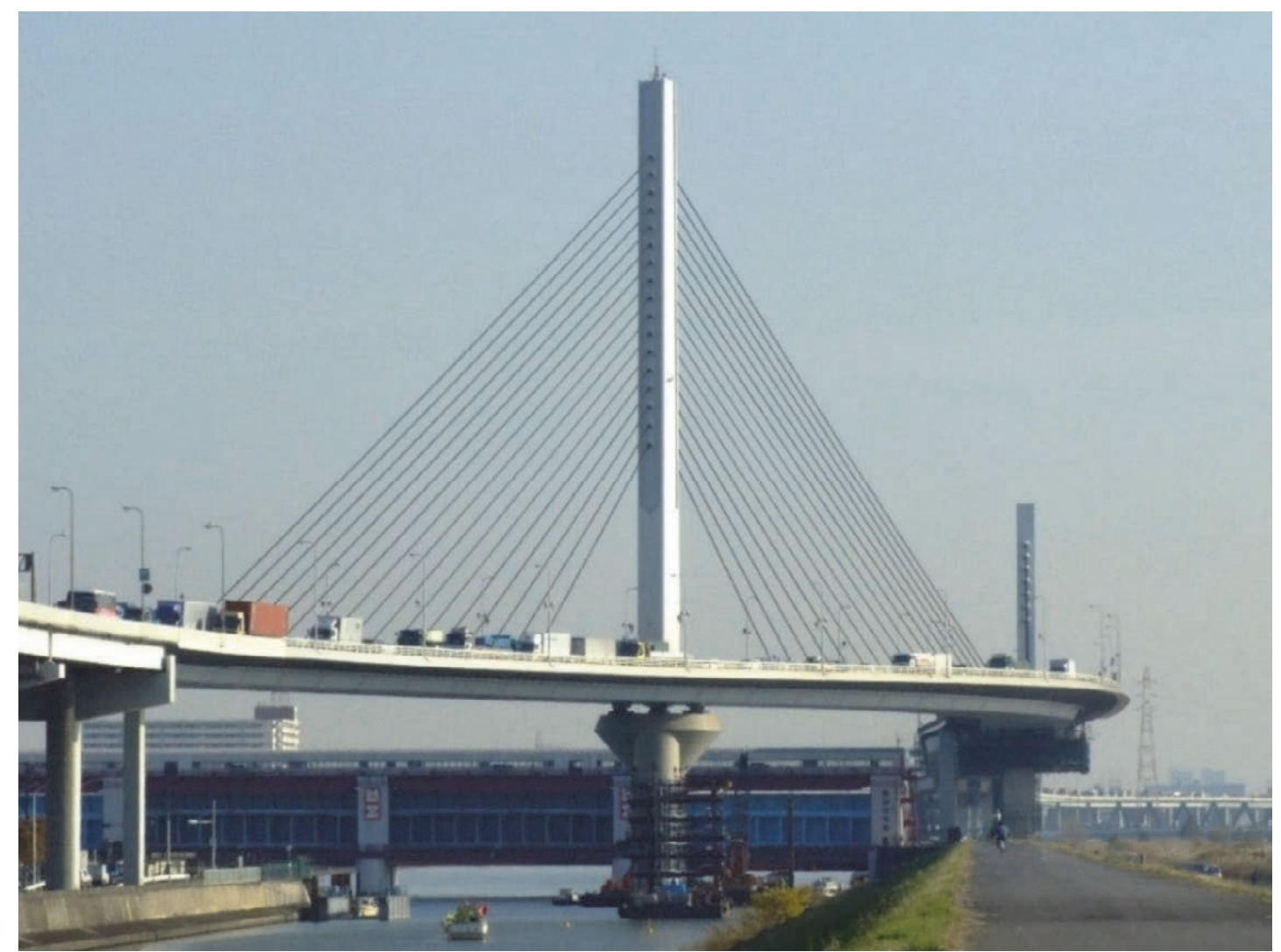

Ilustración 1.7. Katsushika harp bridge (Autor: LERK, Licencia: https://creativecommons.org/licenses/by/2.5/deed.es).

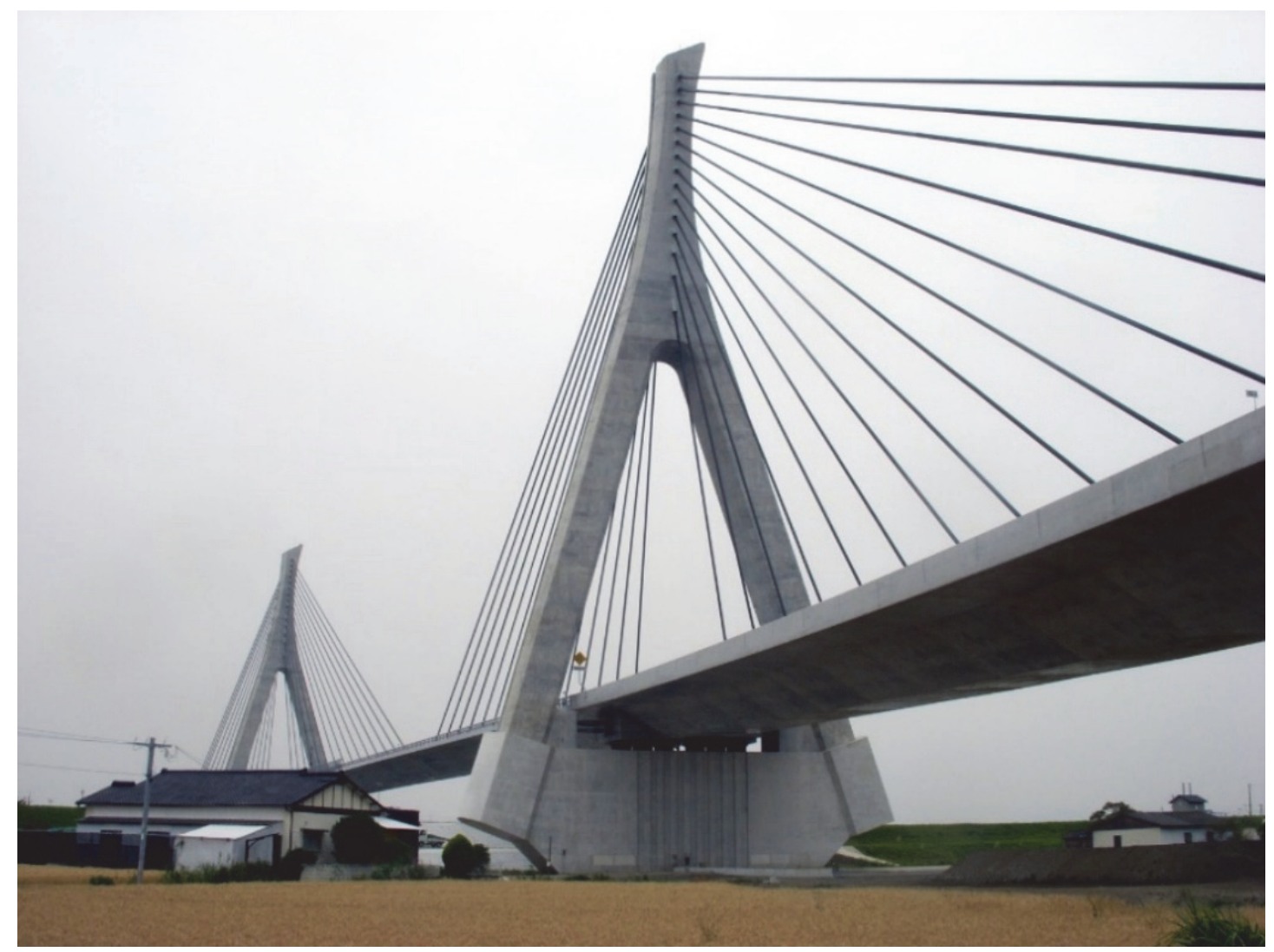

Ilustración 1.8. Yabegawa bridge. 


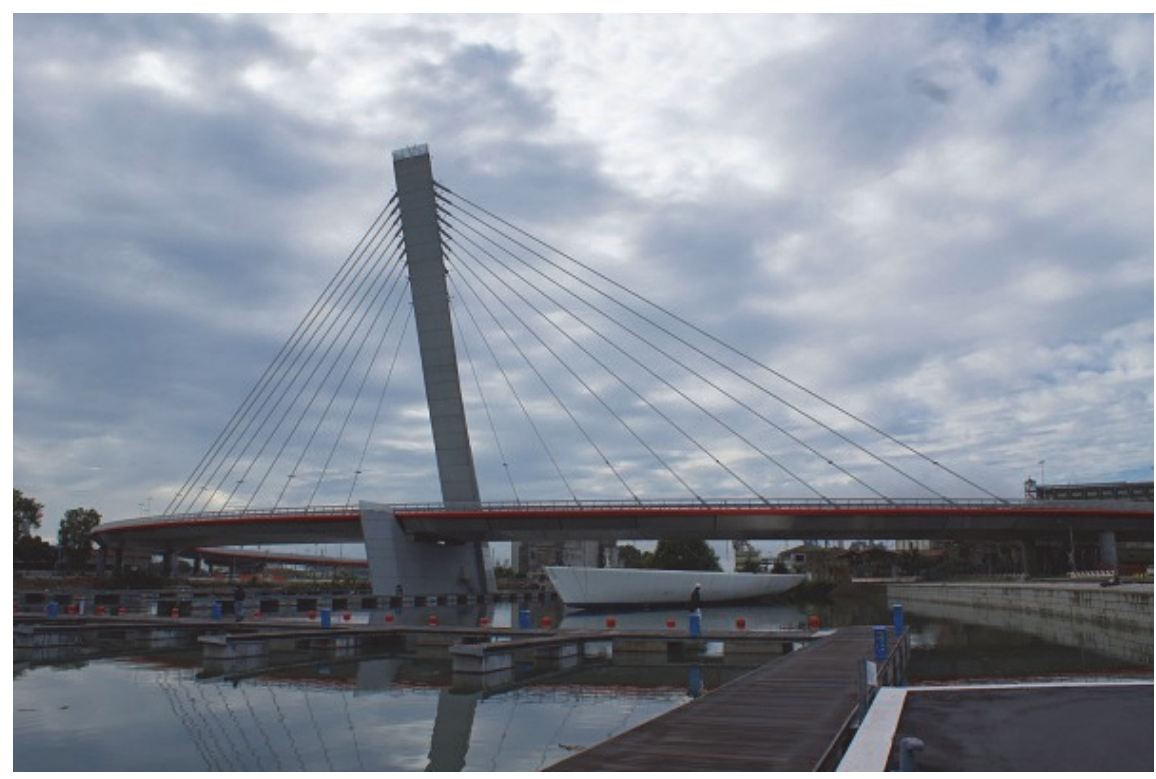

Ilustración 1.9. Venice port bridge. (Autor: Nicolas Janberg, Fuente: Structurae)

Cuando el atirantamiento es doble y se lleva a los bordes del tablero, la morfología de pilas en puentes rectos resulta mucho más variada. Desde pilas simples centradas, normalmente para puentes de pequeñas o medianas luces, y en los bordes, hasta morfologías más complejas como " $\mathrm{H}$ ", en diamante, " $\mathrm{Y}$ " invertida o " $\mathrm{A}$ ". Estas 3 últimas tipologías, que en la realidad son de similar funcionamiento, pero resuelven diferentes problemas geométricos, están teniendo una gran difusión en la actualidad por su excelente comportamiento, tanto en atirantamiento a bordes como en atirantamiento centrado (Ilustración 1.8). Un ejemplo que refleja con claridad las virtudes de estas nuevas configuraciones es el puente sobre el río Suir en Waterford (Irlanda) (64). Estas configuraciones tienen un excelente comportamiento transversal, esto las ha hecho muy atractivas para los puentes de trazado curvo, como ya se ha comentado para puentes de atirantamiento único, como el de Yabegawa o el del puerto de Venecia, (60) (Ilustración 1.9), y también en los de atirantamiento doble, como el puente de Térénez (104) (Ilustración 1.11), el puente Octavio Frias de Oliveira (16) o el Berliner Brücke, (Ilustración 1.12). El puente de Ténérez, como el de Sao Paulo y el de Berlín, se resuelven con un doble atirantamiento, y esto obliga a posicionar la pila muy cerca del tablero, en una posición centrada respecto del eje de simetría del arco y con una altura determinada, para no tener problemas geométricos con los tirantes de sujeción y el uso del puente (cf. subapartado 2.4.4.1). En puentes de menores luces, se han desarrollado pilas dobles en pórtico, pilas en " $\mathrm{H}$ ", como se observa en el puente de entrada al aeropuerto de Malpensa (15). Con doble atirantamiento, como ocurre en puentes de directriz recta, el tablero queda casi exento de sus solicitaciones torsoras, lo cual permite que el tipo de la sección del tablero pueda ser en losa, como el Octavio Frias de Oliveira, doble cajón, como el viaducto de Térénez o multijácena, como es el caso del Berliner Brücke. 


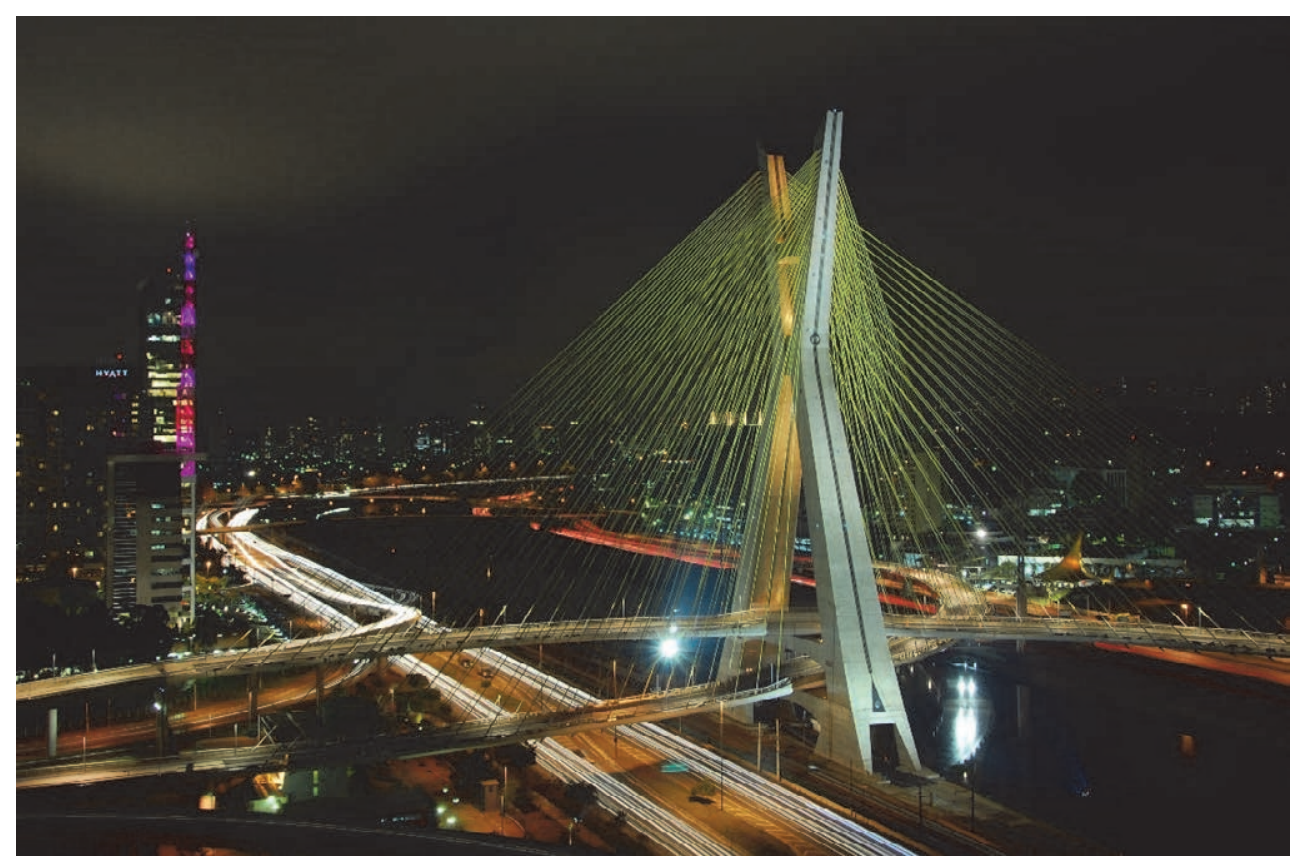

Ilustración 1.10. Puente Octavio Frias de Oliveira. (Autor: Marcosleal, Licencia: https://creativecommons.org/licenses/by-sa/3.0/deed.en)

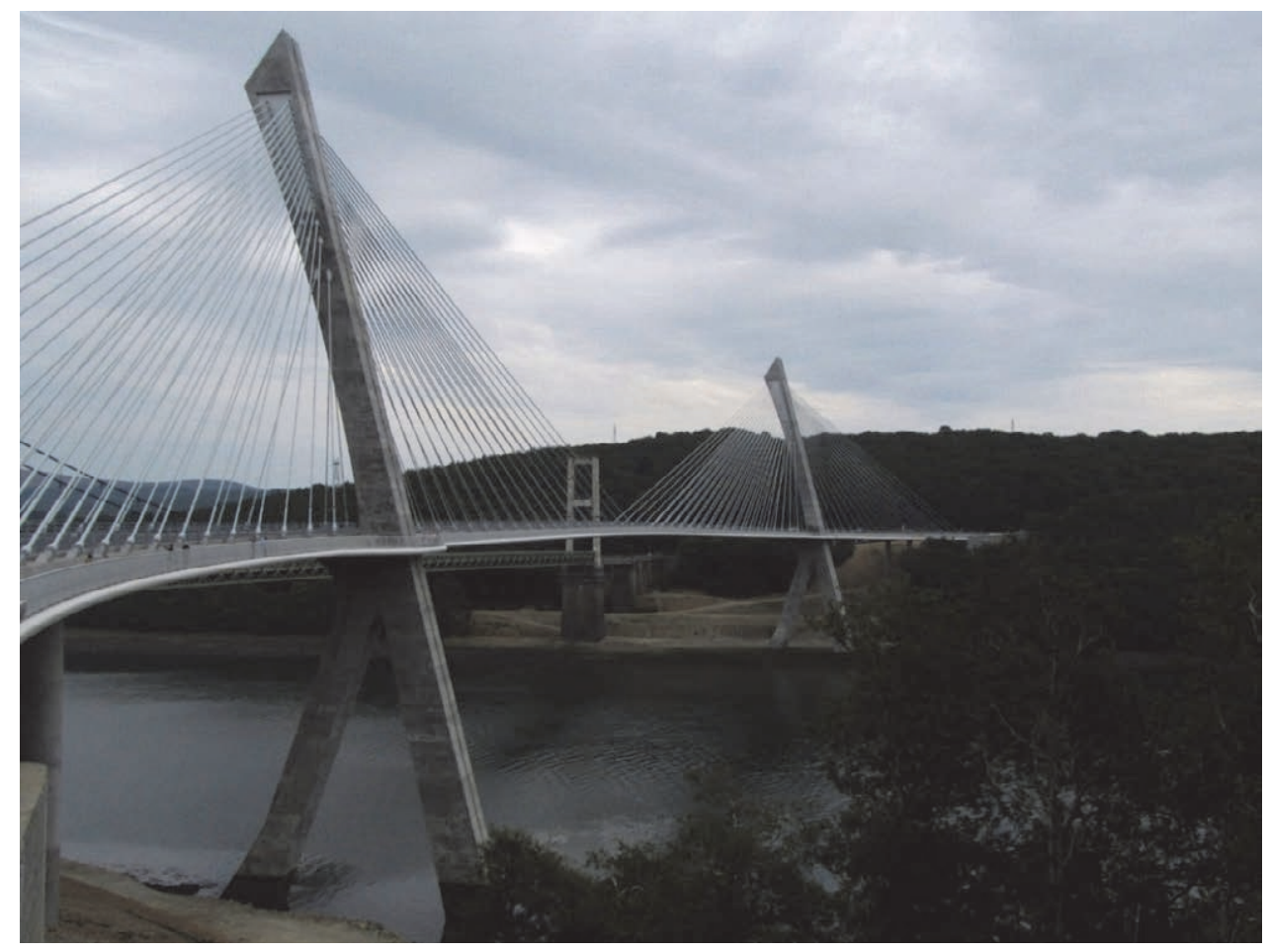

Ilustración 1.11. Térénez Viaduct (Autor: Donar Reiskoffer, Licencia: https://creativecommons.org/licenses/by/3.0/deed.en) 


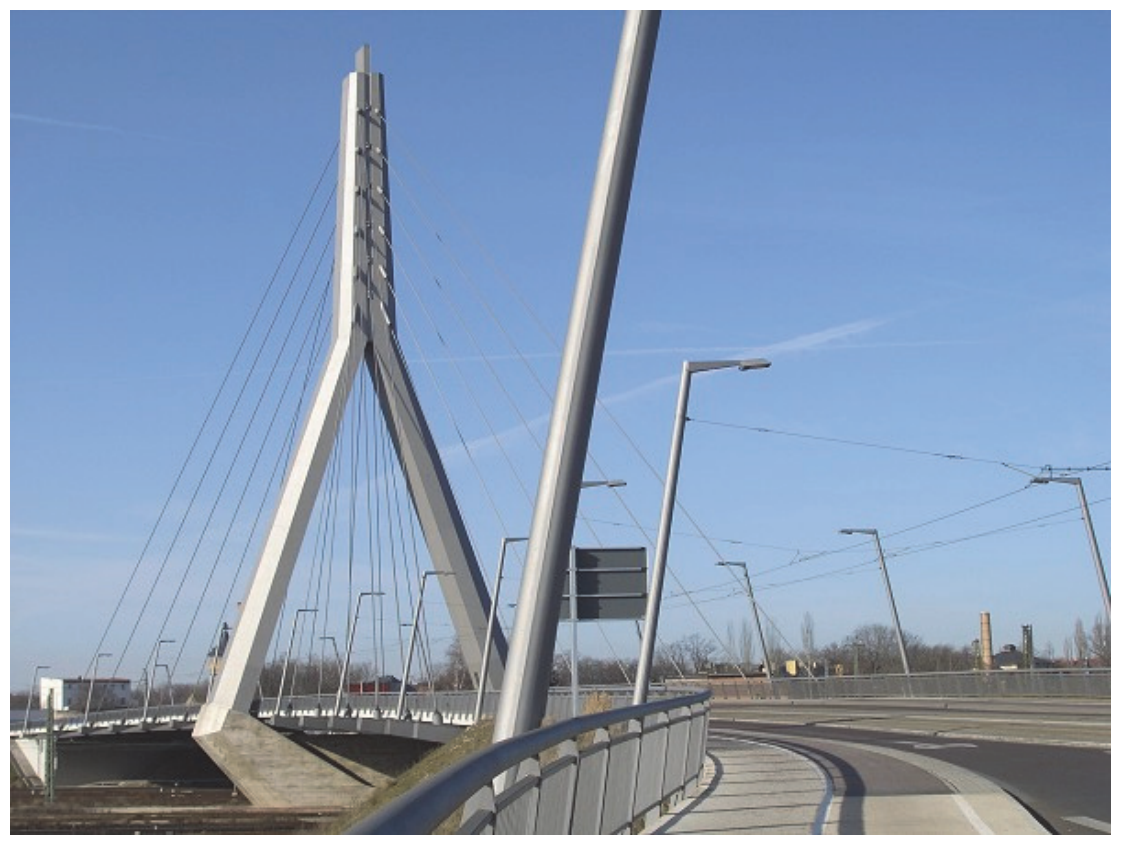

Ilustración 1.12. Berliner Brücke (Autor: Inge Kanakaris-Wirtl, Fuente: Structurae)

Sin duda es en el uso peatonal donde más se ha centrado la creciente producción de puentes curvos atirantados. La libertad formal y las inferiores exigencias de comportamiento, han dado rienda suelta a los ingenieros para desarrollar diseños de un gran valor estético y técnico. En pasarelas curvas atirantadas de uso peatonal se utiliza casi de forma exclusiva el atirantamiento simple por sección de apoyo, aunque existen excepciones remarcables, con atirantamiento en los bordes, como el puente peatonal Bob Kerrey (103) (Ilustración 1.13), donde el problema geométrico de los cables se soluciona pegando la pila al tablero, dándole una altura suficiente a la torre y haciendo la zona útil de la pasarela de menor anchura que el tablero estructura. Con una técnica similar para salvar los problemas geométricos del doble atirantamiento, nos encontramos también con el Langkawi Sky, un puente en el que se da rigidez a la pila mediante tirantes de compensación a los estribos (llustración 1.14).

Como se expone en el subapartado 2.2.6, la carga horizontal concéntrica introducida por los tirantes de sujeción resulta determinante. Si a esta carga concéntrica se le suma la escasa anchura de las pasarelas peatonales y que las exigencias de rigidez vertical del tablero son menores que en los otros usos, se ha llegado a una gran difusión de las pasarelas colgantes con atirantamiento simple a borde en la sección de apoyo, con Schlaich como estandarte de esta tipología. Las dos propiedades que hacen atractiva esta configuración son la asimilación de las péndolas a tirantes radiales, con los beneficios que esto conlleva en las solicitaciones en el plano XY (subapartado 2.2.6.2), y la simplicidad de conexión en la cabeza de la pila. Como punto negativo está la falta de rigidez frente a cargas puntuales. Como ejemplo de todas las virtudes de esta configuración, está el puente sobre Gahlensche Strasse (87) (Ilustración 1.15), con el anillo a compresión, sin necesidad de tirantes de compensación (zona autocompensada, véase subapartado3.2.2.2) y sección abierta, utilizando el acoplamiento del momento torsor y el momento flector de eje radial para soportar las cargas excéntricas (apartado 2.1). Otros ejemplos relevantes de puentes colgantes curvos son el Liberty, en Greenville, con la pila en zona exterior, sección abierta y tirantes de compensación, el de Gimberg Harbour (88), de 
tracción (pila en zona exterior), sección cerrada y tirantes de compensación, el puente Peace, en Irlanda, de compresión, sección cerrada y sin tirantes de compensación (de AECOM) o la pasarela en Sasnitz, con sección de tablero cerrada y anclaje de tirantes de sujeción sobre el tablero, para que la carga de este pase por encima del centro de cortantes.

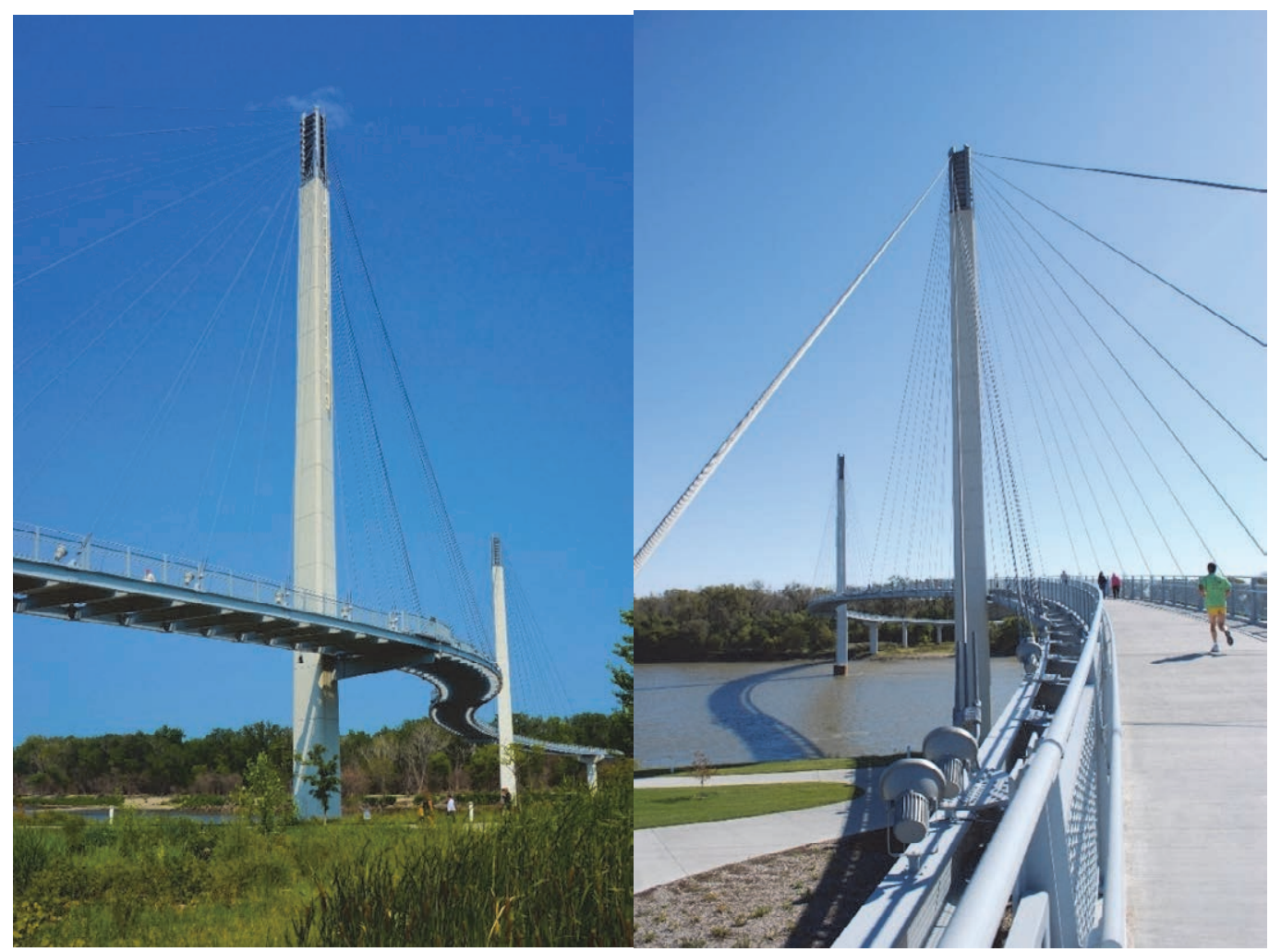

Ilustración 1.13. Bob Kerrey pedestrian bridge. (Foto izquierda, Autor: Collinulness. Foto derecha, Autor: Masrur Odinaev. Licencia de ambas: https://creativecommons.org/licenses/by-sa/3.0/deed.es)

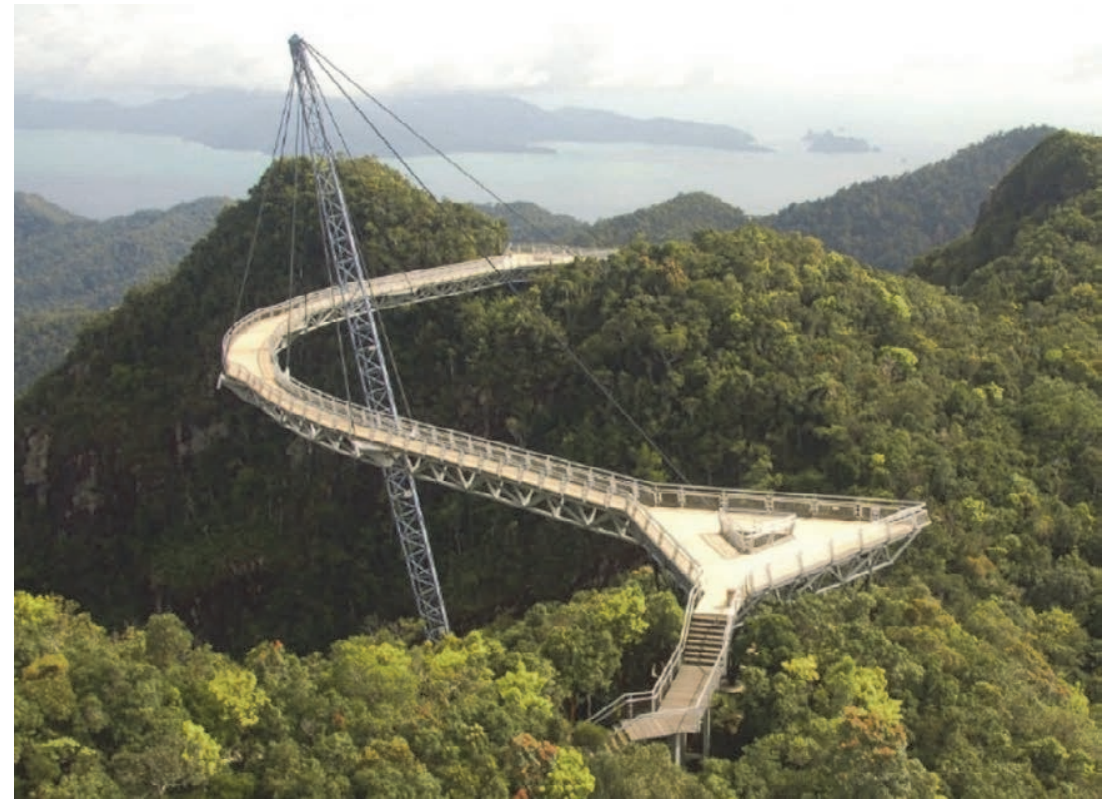

Ilustración 1.14. Langkawi Sky Bridge (Autor: Flickr user "The Dilly Lama", Licencia:

https://creativecommons.org/licenses/by/2.0/deed.es) 


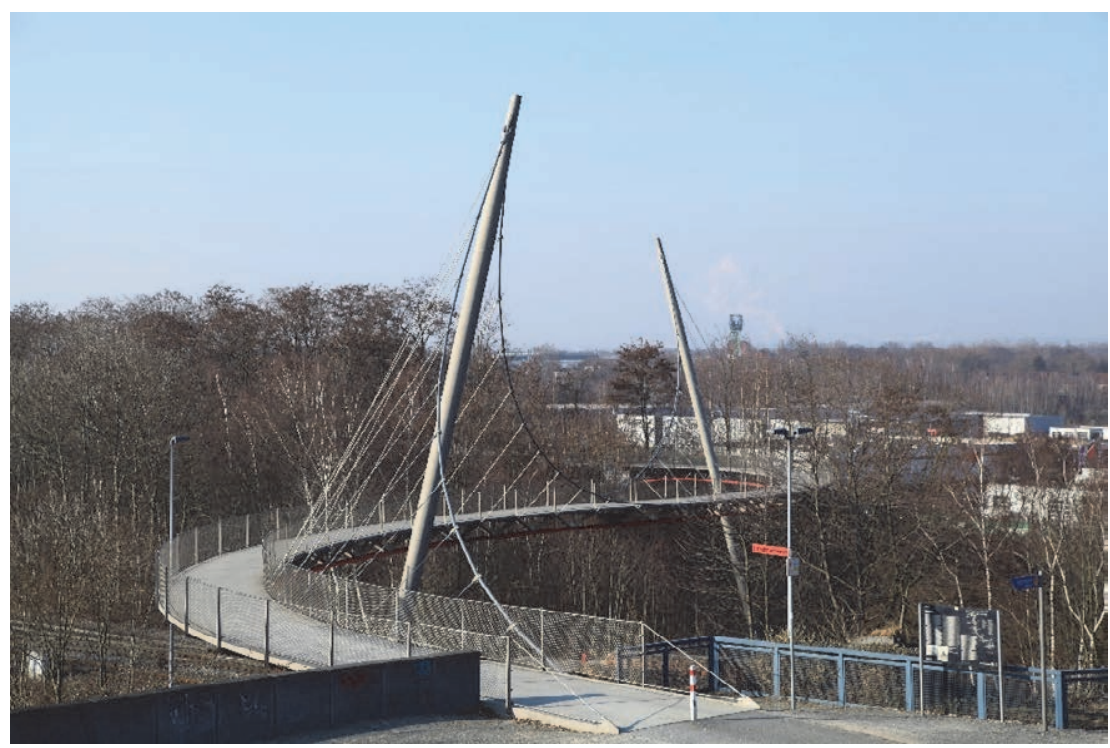

Ilustración 1.15. Bridge across Gahlensche Strasse (Autor: Frank Vincentz, Licencia:

https://creativecommons.org/licenses/by-sa/3.0/deed.es)

Si centramos ahora nuestra atención en las pasarelas con atirantamiento simple en cada apoyo, se puede hacer una primera separación: las de directriz curva circular y las de otro tipo de curva. Uno de los problemas principales que debe resolverse, en lo referente al tablero, en las pasarelas de directriz circular, es la carga concéntrica que transmiten los tirantes (subapartado 2.2.6.2) en el plano XY.

Este problema se ha afrontando de diferente manera en los diferentes proyectos desarrollados. En primer lugar, tenemos la pasarela del malecón en Murcia (101) y (37), de Manterola, donde se ha aproximado la pila hacia el centro del arco, punto que transforma al arco en antifunicular de las cargas concéntricas horizontales, y se utiliza una disposición de tirantes en semiarpa, asimilando el módulo de la carga concéntrica a lo largo del tablero (subapartado 2.2.6.2.3.2 e llustración 1.16). La pila queda en la zona interior, lo que lleva a la necesidad de tirantes de compensación no anclados en los estribos y los tirantes de sujeción se anclan en el borde interior de la pasarela. El problema de situar la pila en esa zona son las altas cargas que recibe el sistema PilaTirCom. Una solución parecida se da para la pasarela de La Rosa (8), si bien en este caso la figura es un óvalo, para la pasarela de Haro, en la Rioja, para la pasarela de Santa María de Benquerencia en Toledo, para el Hovenring en Eindhoven (Países Bajos), que cierra completamente el círculo (Ilustración 1.17), y para la pasarela sobre el canal Maas-Schelde, para el que se consigue una disposición de tirantes en abanico, en una pasarela con curva y contracurva. La sección de tablero predominante es el cajón, aunque existen casos en los que se aprovecha el empotramiento elástico "ee" (apartado 2.3) para introducir secciones abiertas sin capacidad a torsión uniforme (a la cabeza de este tipo de tableros está Schlaich). 


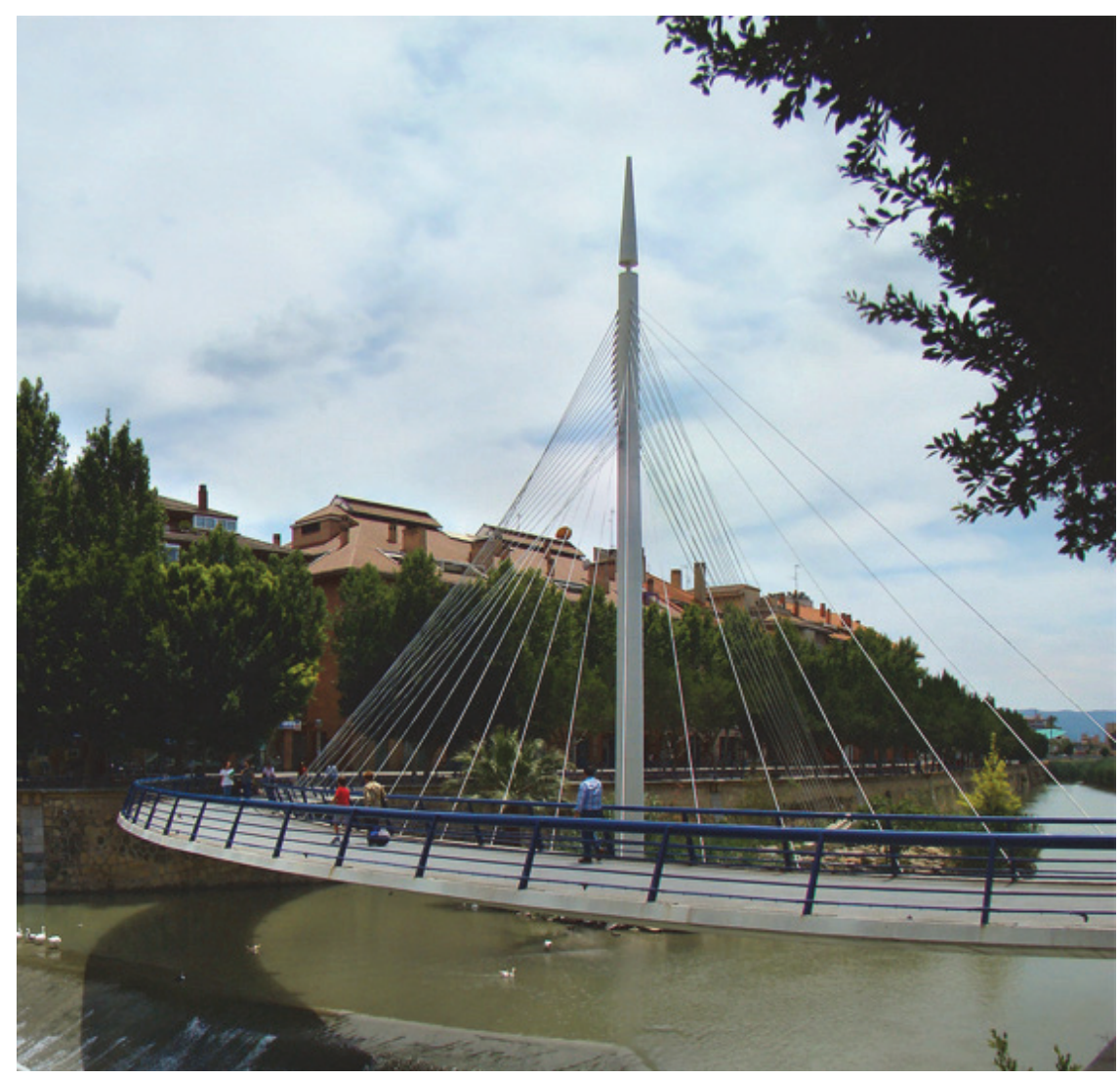

Ilustración 1.16. Pasarela Malecón Murcia. (Autor: Tango7174, Licencia: https://commons.wikimedia.org/wiki/File:Murcia4_tango7174.jpg?uselang=es)

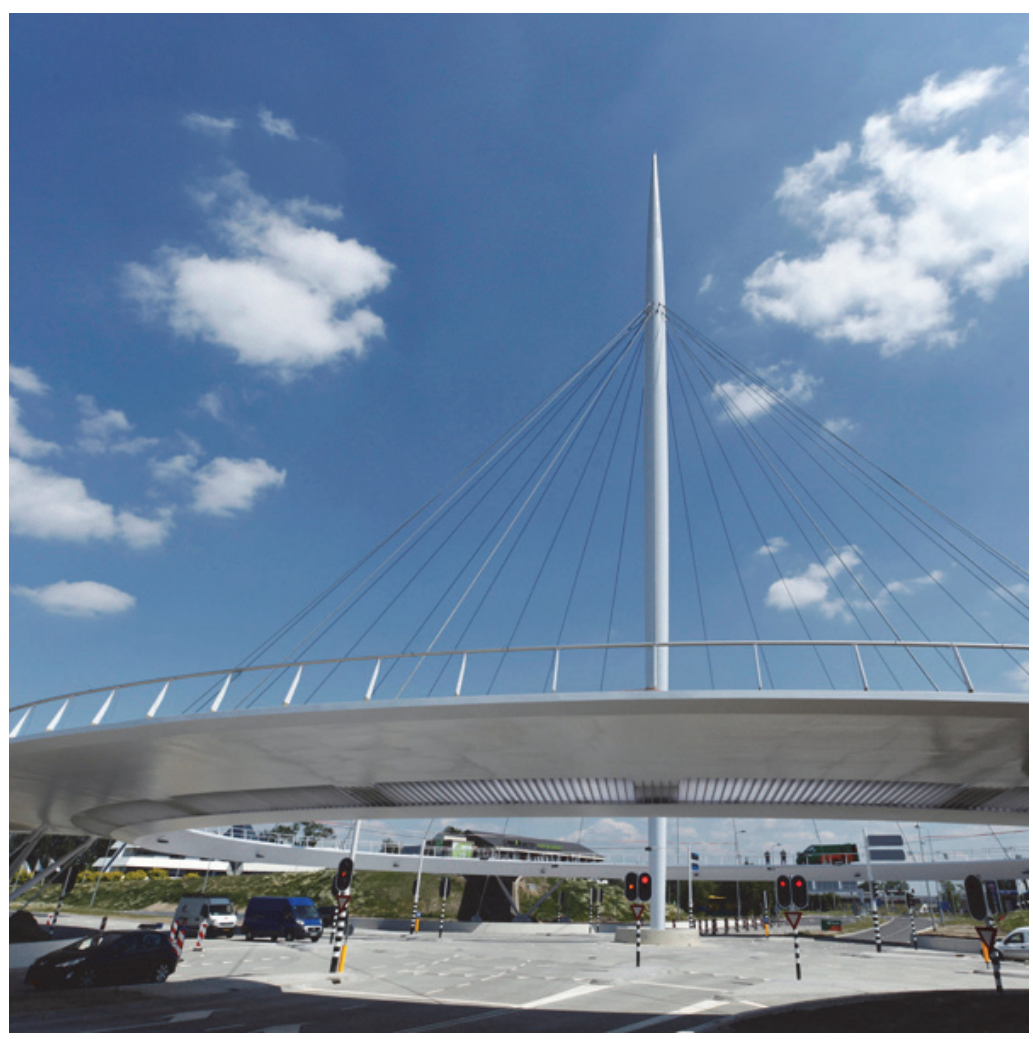

Ilustración 1.17. Hovenring en Eindhoven. (Autor: Bruggenbouwer, Licencia: https://creativecommons.org/licenses/by-sa/3.0/deed.es) 
Otra forma de disminuir las cargas concéntricas transversales sobre el tablero y a su vez disminuir las solicitaciones sobre el sistema PilaTirCom pasa por disponer la pila cerca del tablero; esto es efectivo cuando la curvatura de la directriz no es excesiva. Habitualmente el tablero se empotra en la pila, ayudando al sistema de empotramiento elástico "ee", cuya efectividad depende, entre otras variables, de la curvatura de la directriz. En la pasarela de Oira, con atirantamiento de sujeción en semiarpa y tirantes de compensación a los estribos, se empotra la sección cajón del tablero en las pilas, como vemos en la llustración 1.18. En las pasarelas de South Quay, en Londres (una de ellas es móvil, rotando respecto de la pila), se realiza un sistema resistivo parecido al de la pasarela de Oira, si bien se intentan homogeneizar las cargas horizontales sobre el tablero mediante una disposición tipo arpa de los tirantes de sujeción sobre la pila, buscando adaptar las cargas a la forma disminuyendo las solicitaciones sobre el tablero, la pila no dispone de tirantes de compensación, lo que provoca una sección de torre más voluminosa (llustración 1.19).

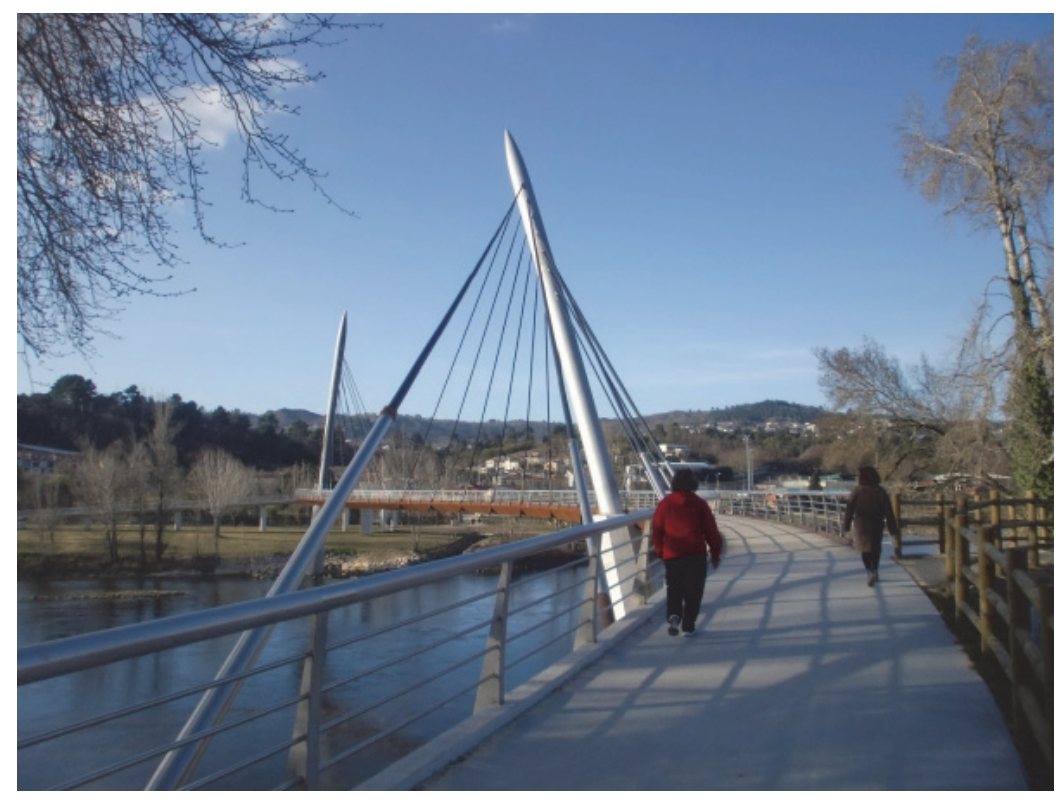

Ilustración 1.18. Pasarela Oira. (Autor: Tfeliz, Licencia: https://creativecommons.org/licenses/by-sa/3.0/deed.es)

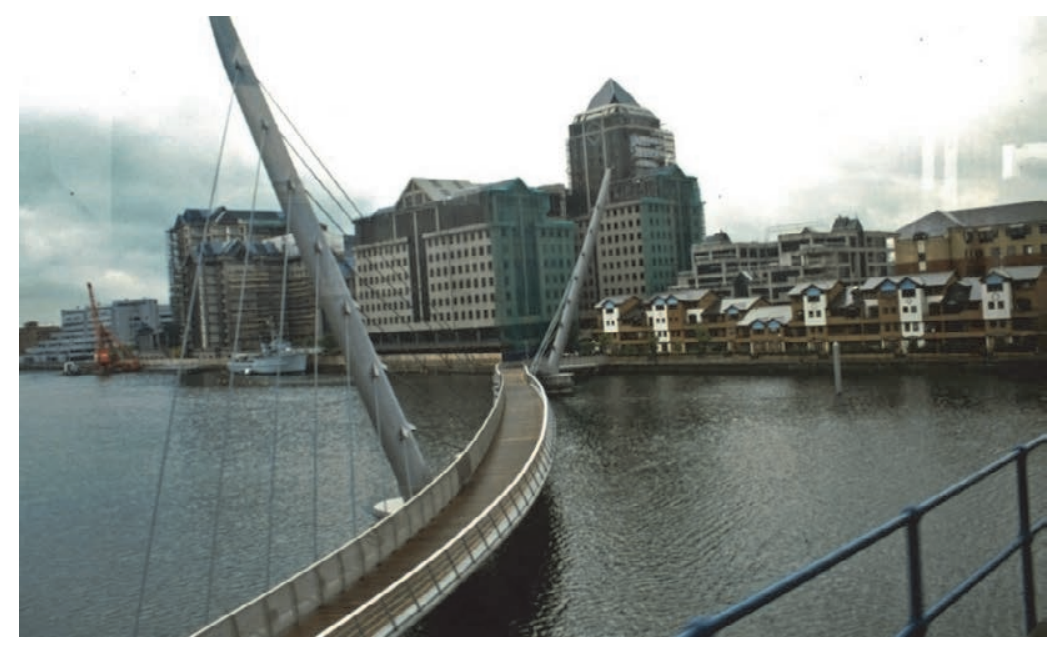

Ilustración 1.19. South Quay Footbridge. (Autor: qwesy qwesy, Licencia: https://creativecommons.org/licenses/bysa/3.0/deed.es) 
También existen ejemplos con similar sistema estructural, aunque en este caso con la pila dispuesta fuera del arco que forma el tablero. Con un tablero similar al utilizado en el South Quay, con un potente tubo de sección circular situado en el borde sustentado por los tirantes y empotrado en la pila, están las pasarelas de Agro y As, en la provincia de La Coruña (Arteixo y Ferrol). Ambas disponen de tirantes de compensación que no se anclan en los estribos (necesarios fuera de la zona autocompensada) y mientras que la de Agro lleva una disposición de tirantes tipo arpa, la de As los lleva en semiarpa. Sin empotrar el tablero con la pila están, por un lado, la pasarela San Juan de la Cruz en Palencia (44), con la pila compensada con dos tirantes, y la pasarela CHIO, en Aachen (71), en la que la pila se sitúa también en el exterior del arco que desarrolla el tablero, pero en este caso no lleva tirantes de compensación, lo cual supone una sección de pila más potente.

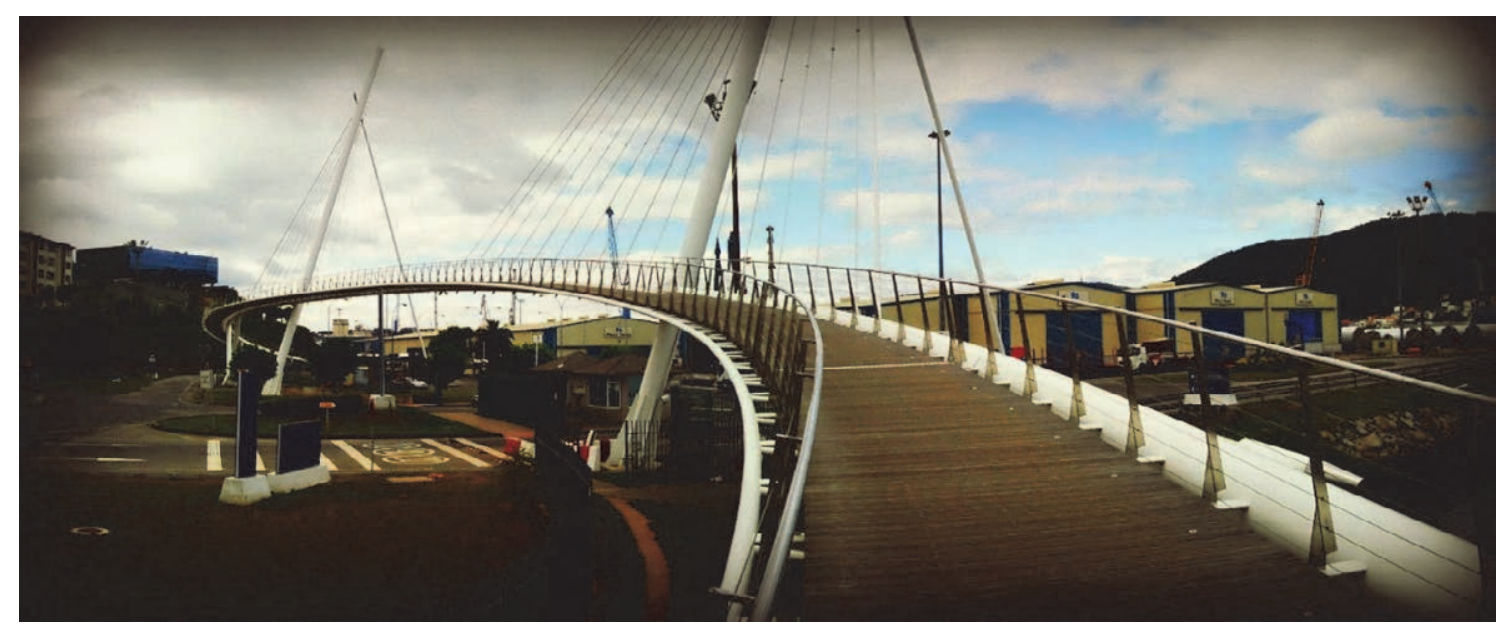

Ilustración 1.20. Pasarela As (Autor: carrodeguas, Licencia: https://creativecommons.org/licenses/bysa/3.0/deed.es)

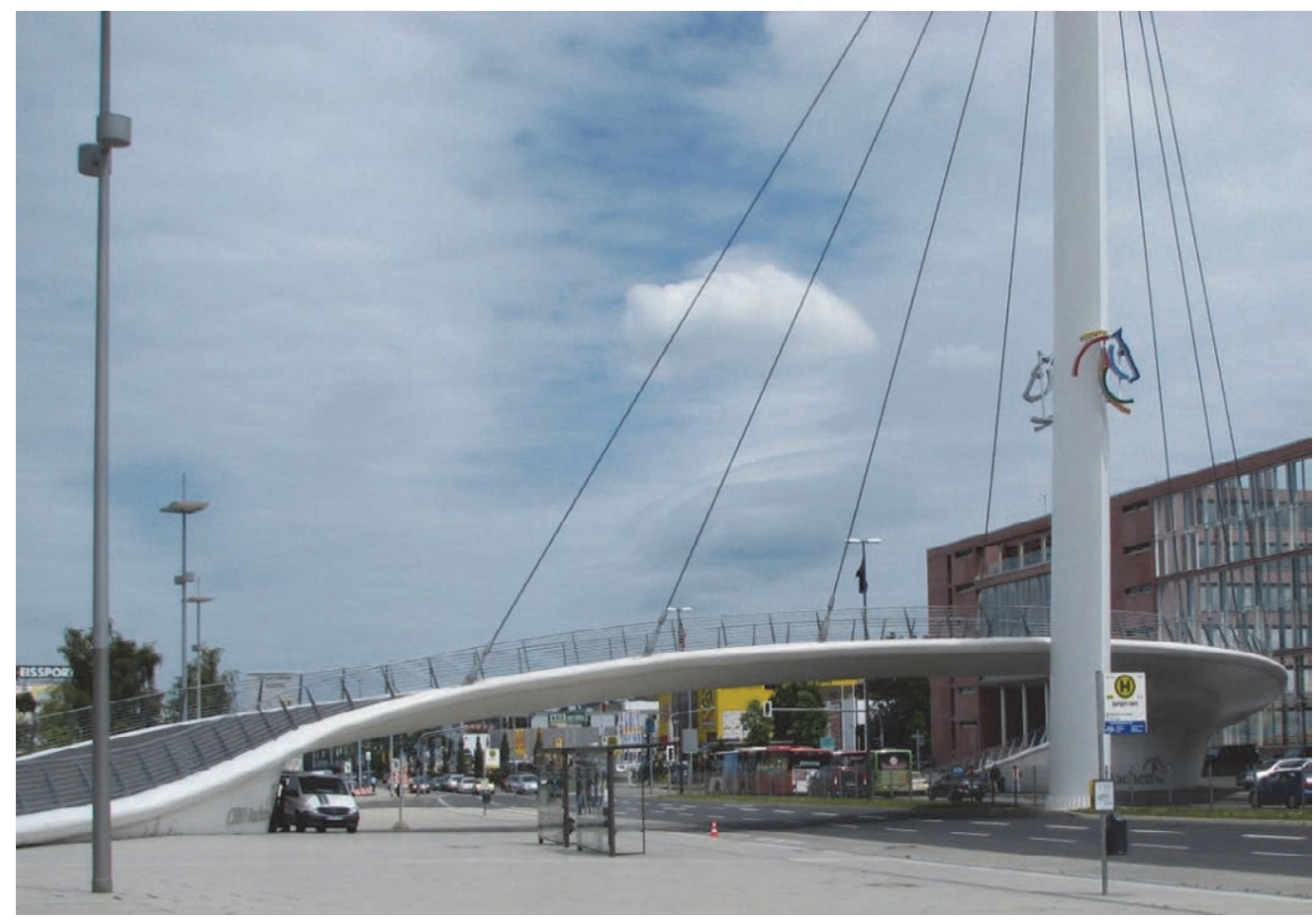

Ilustración 1.21. CHIO-Brücke. (Autor: ACBahn, Licencia: https://creativecommons.org/licenses/by/3.0/) 
Hasta ahora, las pasarelas curvas atirantadas presentadas tienen una directriz curva circular (doble circular mediante óvalos en La Rosa). La carga concéntrica introducida por la pila no ha influido en el trazado del tablero, si bien se ha visto cómo en muchos de ellos se presenta una disposición de tirantes en arpa sobre una pila inclinada, que puede mejorar las solicitaciones en el tablero, hasta el punto de conseguir que la directriz circular sea la forma funicular o antifunicular de las cargas horizontales que introducen los tirantes de sujeción, como se presenta en el subapartado 2.2.6.2.3.2.

Pero sí que se han desarrollado pasarelas en las que las directrices del tablero mejoran las solicitaciones transversales debidas a las cargas horizontales que los tirantes de sujeción le transmiten. Como ejemplo claro de esta, tenemos la pasarela del Voluntariado realizada para la Expo de Zaragoza por Manterola (38), con un tablero en cajón a tracción, un anclaje de los tirantes de sujeción sobre el borde exterior del tablero y una pila con tirantes de compensación a uno de los estribos y al eje de simetría de la curva (que no de la pasarela, que se realiza asimétrica).

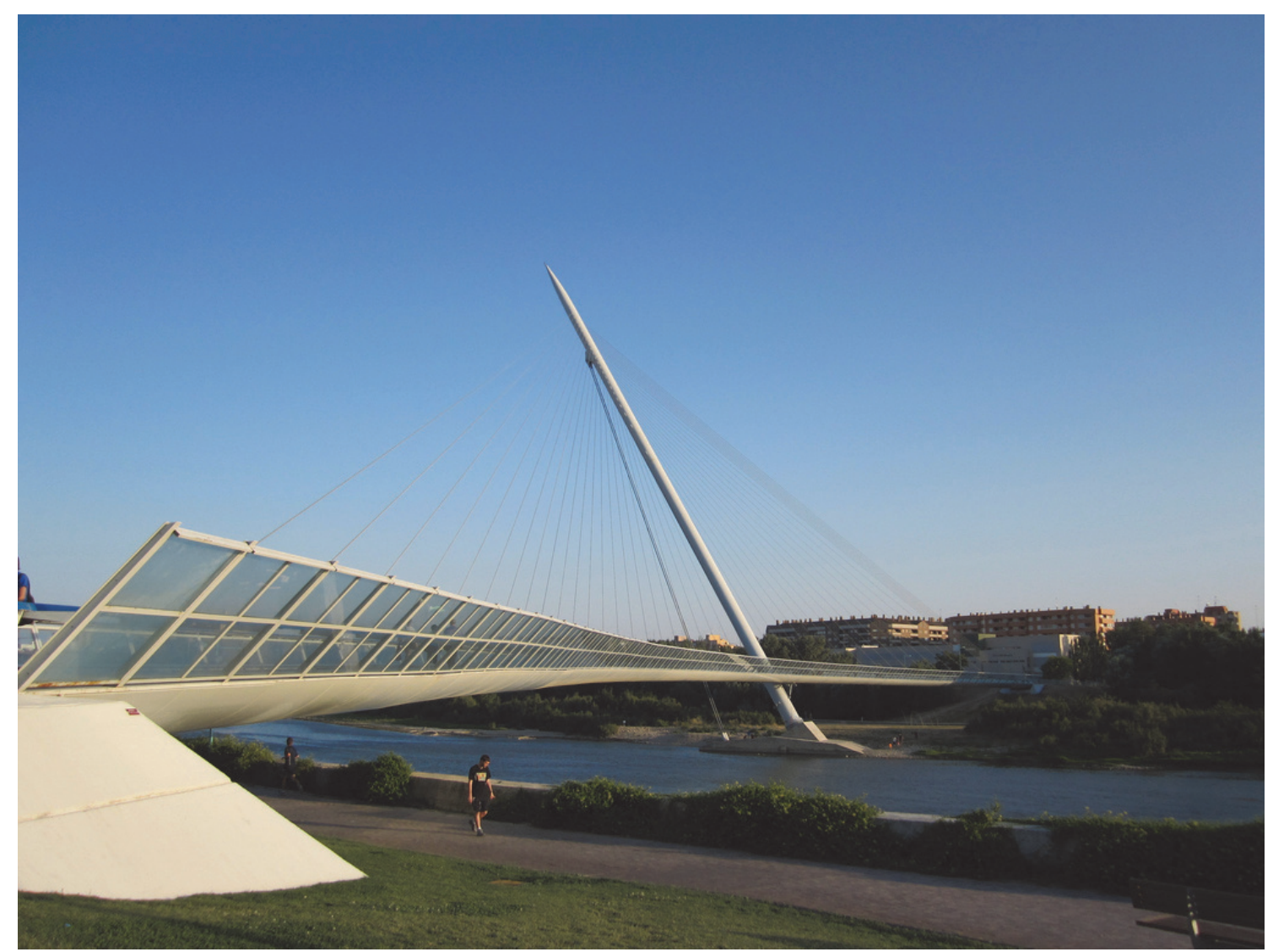

Ilustración 1.22. Pasarela del voluntariado. (Autor: Patricia Salgado, Licencia: https://creativecommons.org/licenses/by/2.0/deed.es)

Por último, no se quiere dejar de mencionar aquellas pasarelas que utilizan dobles tableros como método de compensación de fuerzas para la pila. En Madrid se desmontó, debido a la operación Madrid Río, un ejemplo destacado de esta tipología desarrollado por Manterola, la pasarela atirantada sobre el Manzanares (65). Se situaban dos tableros, de 
sección en cajón y atirantados a un borde, simétricos respecto de un eje en el que se posicionaba la pila. Los tirantes de sujeción se anclan en semiarpa a la cabeza de la pila.

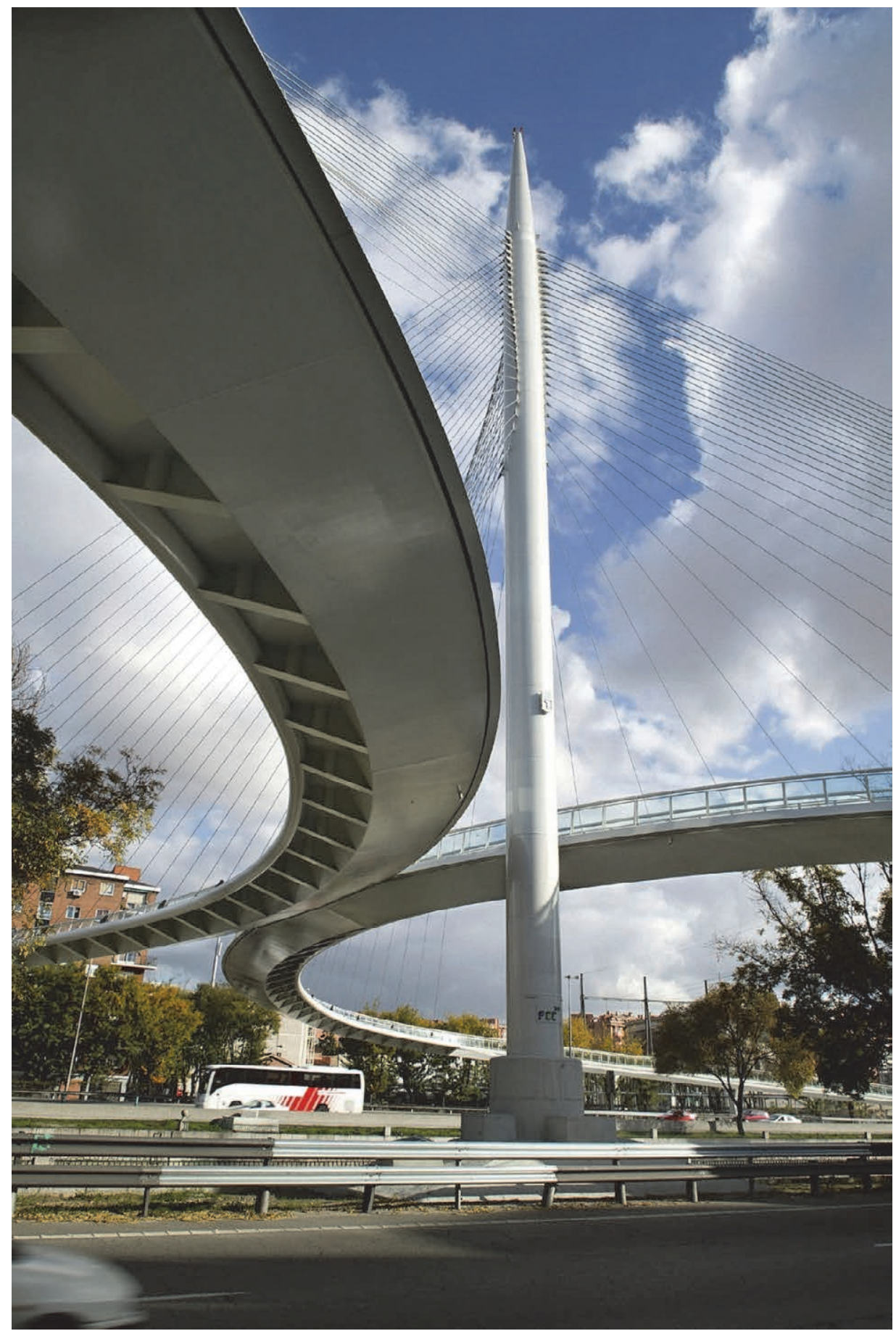

Ilustración 1.23. Pasarela sobre el Manzanares.

Otra pasarela con este tipo de solución es la Ponte del Mare, en Pescara (59), en la que se plantean dos tableros curvos de sección cerrada (mediante cerchas tridimensionales) con radios diferentes, separando así a peatonaes y ciclistas, que parten y llegan a los mismos puntos. El anclaje de los tirantes de sujeción se realiza en un borde del tablero y en semiarpa en la pila. La pila lleva dos tirantes de compensación (Ilustración 1.24). 

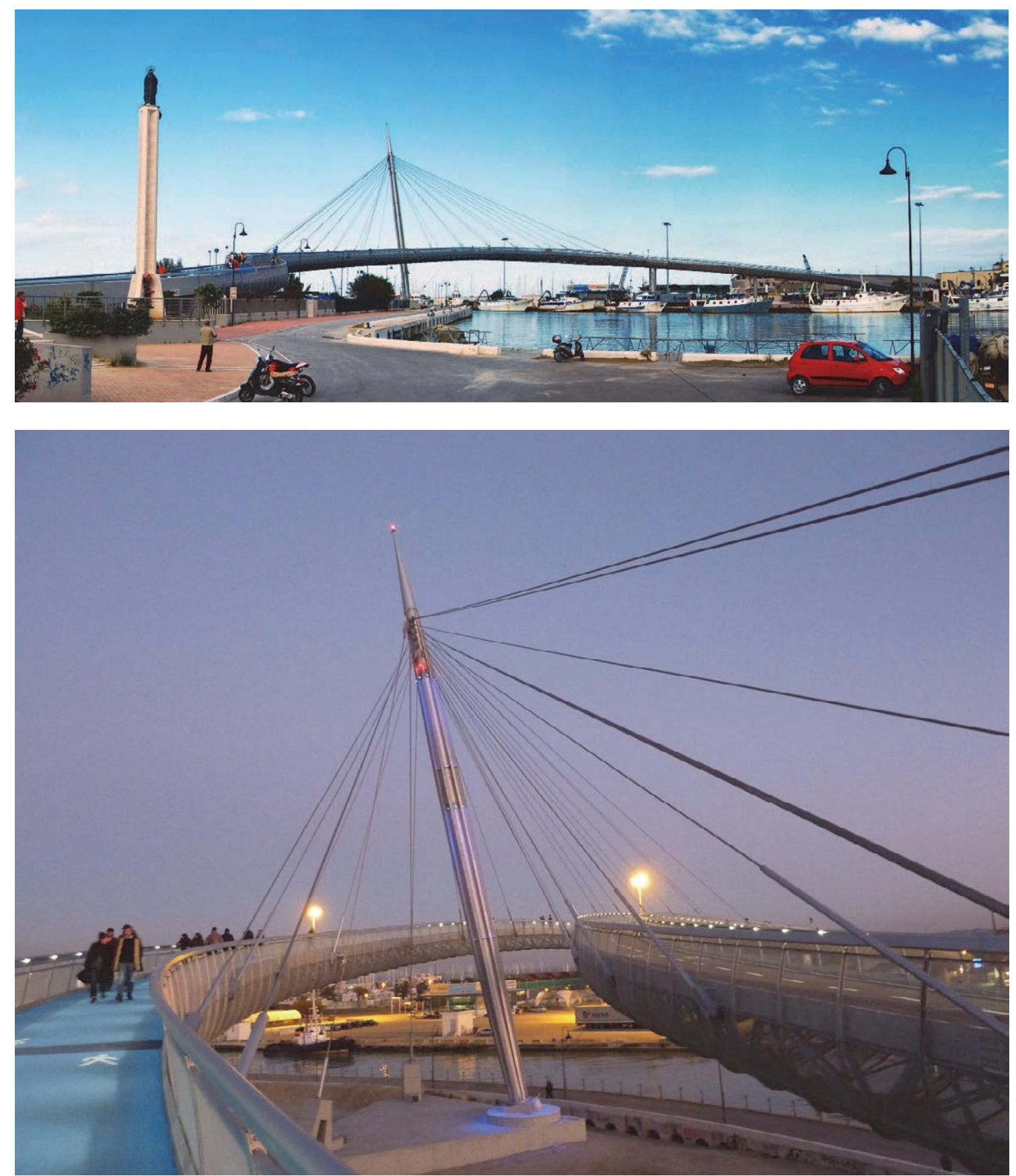

Ilustración 1.24. Ponte del Mare. (Fotografía superior: Autor: Exephyo, Licencia:

https://creativecommons.org/licenses/by-sa/3.0/deed.es. Fotografía inferior: Autor: Gianni o, Licencia: https://creativecommons.org/licenses/by-sa/4.0/deed.en) 


\section{SUBSISTEMA TABLERO}

\subsection{Viga curva con carga fuera de su plano}

\subsubsection{Introducción y resumen}

El objetivo de este capítulo es profundizar en el comportamiento de una viga curva biapoyada, como elemento esencial del puente curva atirantado. Este análisis, como el resto de la tesis, va encaminado a la mejor comprensión del sistema completo que supone el puente curvo atirantado. Con esta intención, se separan desde este inicio los dos mecanismos que va a tener el tablero para soportar las solicitaciones torsoras intrínsecas a su morfología: el empotramiento a torsión y el empotramiento a flexión.

Se realizan dos modelos isostáticos, uno empotrado a flexión y otro a torsión, en los apoyos, de los que se obtienen las ecuaciones. Estos modelos se comparan bajo dos tipos de carga diferente, una centrada (subapartado 2.1.2.1.1) y otra descentrada (subapartado 2.1.2.1.2). Para cada una de la hipótesis de carga, se varían las condiciones geométricas de la viga biapoyada y las propiedades mecánicas de la sección, analizando detalladamente el comportamiento de cada uno sistemas, tanto desde el punto de vista de las solicitaciones como de las deformaciones. De la comparación del comportamiento y efectividad de los dos sistemas se extraen conclusiones, con el fin de ser verificadas en el sistema hiperestático que que se analiza en los siguientes apartados.

Se finaliza el capítulo con el análisis del sistema hiperestático de una viga biempotrada en los dos extremos, tanto a flexión como a torsión. De nuevo se introducen dos hipótesis de carga: centrada (subapartado 2.1.2.1.3) y descentrada (subapartado 2.1.2.1.4), y se varía la geometría de la curva y las propiedades mecánicas de la sección. Finalmente, se comentan los resultados, frente a los obtenidos en los sistemas isostáticos, confirmando la efectividad de cada sistema según las condiciones geométricas y las propiedades mecánicas de la sección.

\subsubsection{Análisis resistivo}

La viga curva, es una estructura cuya mayor particularidad resistiva está en el acoplamiento de los momentos torsor y flector debido a la curvatura de la viga, (34), (57) y (41). En el caso particular de que esté cargada perpendicularmente a su plano, se anularán los siguientes grados de libertad:

a) Son despreciables, tanto las elongaciones de la pieza según el eje $\mathrm{x}$ local de la pieza (coincidente con el centro de gravedad de la pieza), como las solicitaciones axiles, $N x \approx 0$.

b) También resultan despreciables las deformaciones radiales y las rotaciones según el eje vertical, lo que supone que tanto el cortante radial como el momento según el eje vertical van a ser nulos: $Q y=0$ y $M z=0$.

En la llustración 2.1, se puede apreciar un tramo diferencial de una viga curva, de radio $\mathrm{R}$ y ángulo d $\alpha$, cargada perpendicular a su plano mediante una carga vertical y a lo largo de su eje mediante un momento torsor. Las simplificaciones adoptadas son, que el centro de 
cortantes, (93), coincide con el de gravedad, entorno al que se concentran todas las propiedades elásticas y la pieza no alabea ni distorsiona (no se va a tener en cuenta la torsión no uniforme).

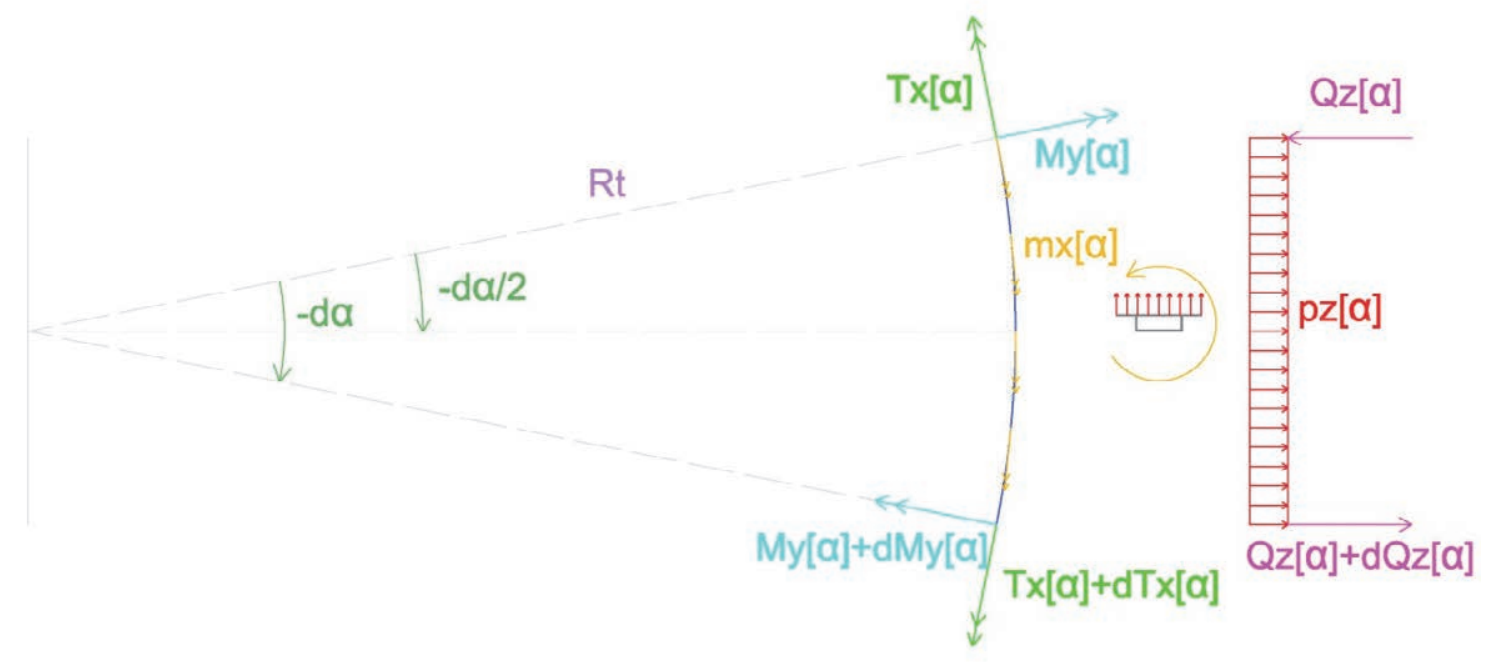

Ilustración 2.1. Modelo de cálculo para un tablero curvo. Cargado fuera de su plano.

$(\operatorname{My}[\alpha]+d M y[\alpha])-\operatorname{My}[\alpha] \operatorname{Cos}[d \alpha]-\operatorname{Tx}[\alpha] \operatorname{Sin}[d \alpha]-$

$\mathrm{pz}[\alpha] \operatorname{Rt} d \alpha \operatorname{Rt} \operatorname{Sin}[\mathrm{d} \alpha / 2]-\mathrm{Qz}[\alpha] \operatorname{Rt} \operatorname{Sin}[\mathrm{d} \alpha]==0$

Equilibrio de Momentos Torsores respecto de $\operatorname{Tx}[\alpha]+\mathrm{d} \mathbf{T x}[\alpha]$

$(\operatorname{Tx}[\alpha]+\mathrm{dTx}[\alpha])-\operatorname{Tx}[\alpha] \operatorname{Cos}[d \alpha]+\operatorname{My}[\alpha] \operatorname{Sin}[d \alpha]+$ $\mathrm{pz}[\alpha] \mathrm{Rt} d \alpha(\mathrm{Rt}-\mathrm{Rt} \operatorname{Cos}[\mathrm{d} \alpha / 2])+\mathrm{Qz}[\alpha] \mathrm{Rt}(1-\operatorname{Cos}[\mathrm{d} \alpha])-\mathrm{mx}[\alpha] \mathrm{Rt} \mathrm{d} \alpha==0$

Equilibrio de Cargas Verticales

$\mathrm{Qz}[\alpha]+\mathrm{dQz}[\alpha]-\mathrm{Qz}[\alpha]-\mathrm{pz}[\alpha] \mathrm{Rt} \mathrm{d} \alpha==0$

Si se simplifican las ecuaciones, asumiendo lo siguiente:

$\operatorname{Sin}[d \alpha / 2] \rightarrow d \alpha / 2$

$\operatorname{Sin}[\mathrm{d} \alpha]->d \alpha$

$\operatorname{Cos}[d \alpha] \rightarrow 1$

$\operatorname{Cos}\left[\frac{d \alpha}{2}\right] \rightarrow 1$

$\mathrm{d} \alpha^{2} \rightarrow 0$

$\mathrm{d} \alpha \mathrm{dTx}[\alpha] \rightarrow 0$

d $\alpha$ Rt dQz $[\alpha] \rightarrow 0$

$\mathrm{d} \alpha \mathrm{dMy}[\alpha] \rightarrow 0$ 


$$
\begin{aligned}
& \mathrm{dMy}[\alpha]-\mathrm{d} \alpha \operatorname{Rt} \mathrm{Qz}[\alpha]-\mathrm{d} \alpha \operatorname{Tx}[\alpha]==0 \rightarrow \operatorname{Rt} \mathrm{d} \alpha==\mathrm{ds} \rightarrow \frac{\mathrm{dMy}[\mathbf{s}]}{\mathrm{ds}}=\frac{\mathrm{Tx}[\mathbf{s}]}{\mathrm{Rt}}+\mathrm{Qz}[\mathbf{s}] \\
& -\mathrm{d} \alpha \mathrm{mx}[\alpha] \mathrm{Rt}+\mathrm{dTx}[\alpha]+\mathrm{d} \alpha \mathrm{My}[\alpha]==0 \rightarrow \operatorname{Rt} d \alpha==\mathrm{ds} \rightarrow \frac{\mathrm{dTx}[\mathbf{s}]}{\mathrm{ds}}==\mathrm{mx}[\mathbf{s}]-\frac{\mathrm{My}[\mathbf{s}]}{\mathrm{Rt}} \\
& -\mathrm{d} \alpha \mathrm{pz}[\alpha] \mathrm{Rt}+\mathrm{dQz}[\alpha]==0 \rightarrow \mathrm{Rt} \mathrm{d} \alpha=\mathrm{ds} \rightarrow \frac{\mathrm{dQz}[\mathrm{s}]}{\mathrm{ds}}==\mathrm{pz}[\mathrm{s}]
\end{aligned}
$$

El acoplamiento entre flector y torsor, se produce de forma que el torsor por la curvatura se transforma en una acción equivalente a un cortante, mientras que el momento flector por la curvatura se transforma en una acción equivalente a un par torsor por unidad de longitud.

Este acoplamiento, que se va a mostrar determinante a lo largo de casi todos los análisis que vamos a realizar, en los que intervenga el tablero, muestra dos principios que se deben conservar a lo largo de toda la tesis:

- El acoplamiento es directamente proporcional a la curvatura (este principio, aunque obvio por las ecuaciones vistas, se debe tener muy presente cuando se estén analizando los TABLEROS AXILES).

- Al estar acoplados torsor y flector, van a estar en el mismo orden (global o local), de forma que cualquier medida que palie o incremente una va a afectar de forma inmediata a la otra (siendo obvio de nuevo, se debe tener siempre presente cuando se estén analizando sistemas más complejos, para que el análisis sea completo). Un ejemplo claro y sencillo de este principio es el efecto sobre el torsor que tiene un empotramiento a flexión en los extremos o como se verá en los sistemas multiapoyados, el efecto que tiene un torsor sobre el flector cuando los apoyos interiores no impiden el giro a torsión del tablero.

Las ecuaciones diferenciales resultantes, son (con funciones en s y $\alpha$ ):

$$
\begin{aligned}
& \operatorname{Tx}[s] \prime^{\prime}+\frac{\operatorname{Tx}[s]}{R t^{2}}=m x[s] '-\frac{Q z[s]}{R t} \\
& M y[s])^{\prime}+\frac{M y[s]}{R t^{2}}==\frac{m x[s]}{R t}+Q z[s] \text { ' } \\
& Q z[s]^{\prime}==p z[s] \\
& \operatorname{Tx}[\alpha] \text { ' ' }^{-\operatorname{Tx}}[\alpha]==\operatorname{Rt} \operatorname{mx}[\alpha] \text { ' }-\operatorname{Rt} Q z[\alpha] \\
& \operatorname{My}[\alpha] \text { ' ' }+\operatorname{My}[\alpha]==\operatorname{Rt} \operatorname{mx}[\alpha]+\operatorname{Rt} Q z[\alpha] \text { ' } \\
& Q z[\alpha]^{\prime}==\operatorname{Rt} p z[\alpha]
\end{aligned}
$$


Si se solucionan estas ecuaciones diferenciales para una viga curva empotrando a

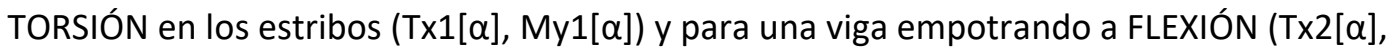
My2 $[\alpha])$, ambas con una carga vertical según el eje del tablero, se obtendrá para la siguiente geometría:

$$
\begin{aligned}
& \alpha_{t}=\frac{\pi}{2} \\
& R t=280 \\
& p z[s]=-1
\end{aligned}
$$

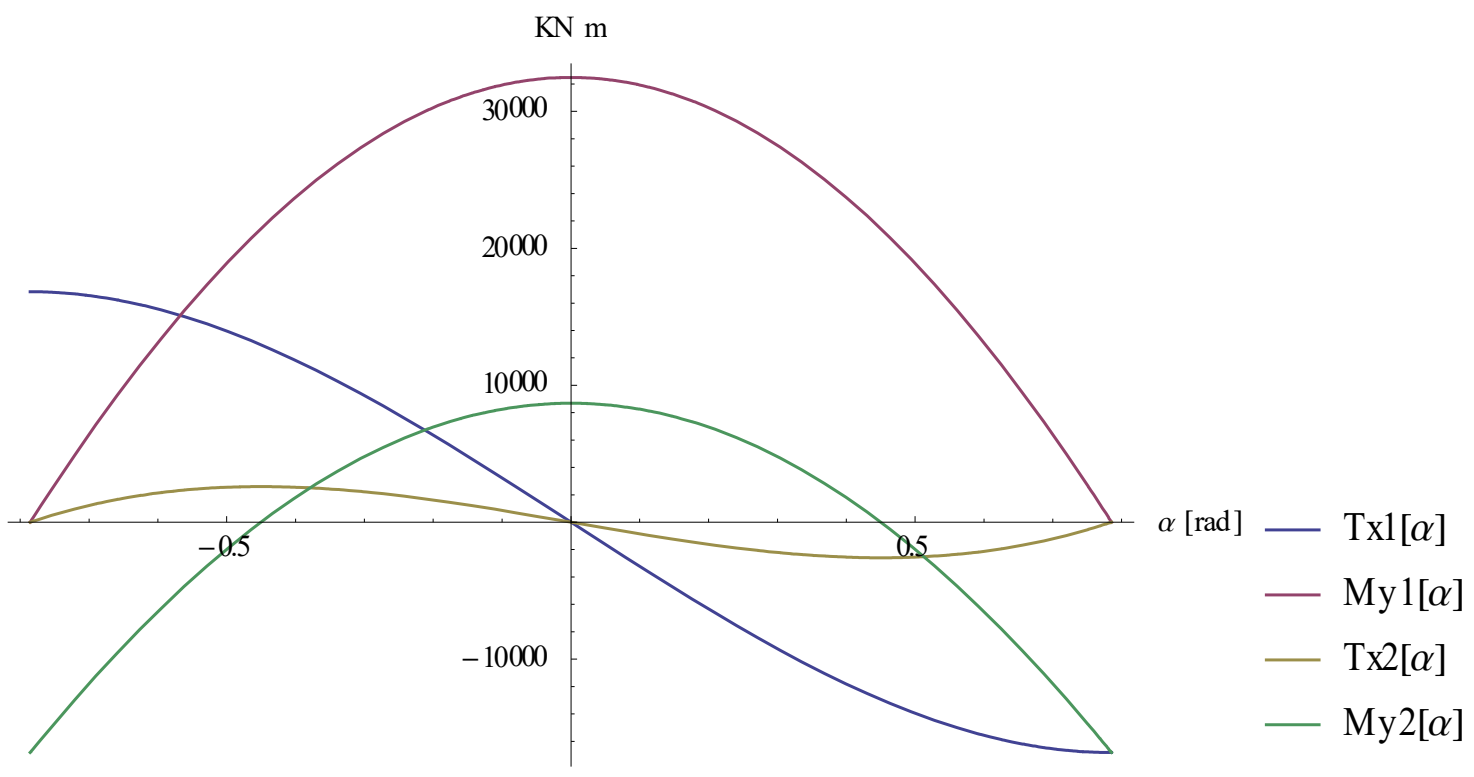

Diagrama 2.1. Solicitaciones sobre una viga curva, con diferentes condiciones de contorno.

Aunque se estudiará más adelante, ya se puede observar un efecto muy interesante, que es el hecho de que, sumando el momento negativo y positivo, con valor absoluto, en el caso en el que se ha empotrado el momento flector en los estribos, se obtiene un resultado menor que el máximo momento obtenido en el caso en el que empotramos el torsor.

\subsubsection{Condiciones de contorno}

\subsection{Sistema isostático, carga vertical, repartida y centrada respecto al eje del tablero}

\subsection{Solicitaciones}

Para analizar el comportamiento del sistema según diferentes condiciones de contorno, es importante entender la naturaleza del efecto que produce que este sistema, con una carga centrada, incorpore un nuevo grado de libertad (torsión), frente a una viga biapoyada recta. Una vez analizada la naturaleza del efecto torsor de la viga, se van a analizar las condiciones de contorno que permiten restringirlo y el mecanismo mediante el cual lo hace, analizando los efectos que estos mecanismos tienen sobre la viga.

Si se comienza por la naturaleza del efecto, analizando la viga curva, respecto de la línea que formando una cuerda une los 2 estribos, se puede entender con facilidad el momento 
estabilizador que deben introducir los estribos para que el sistema sea estable, contrarrestando el momento desestabilizador Hest:

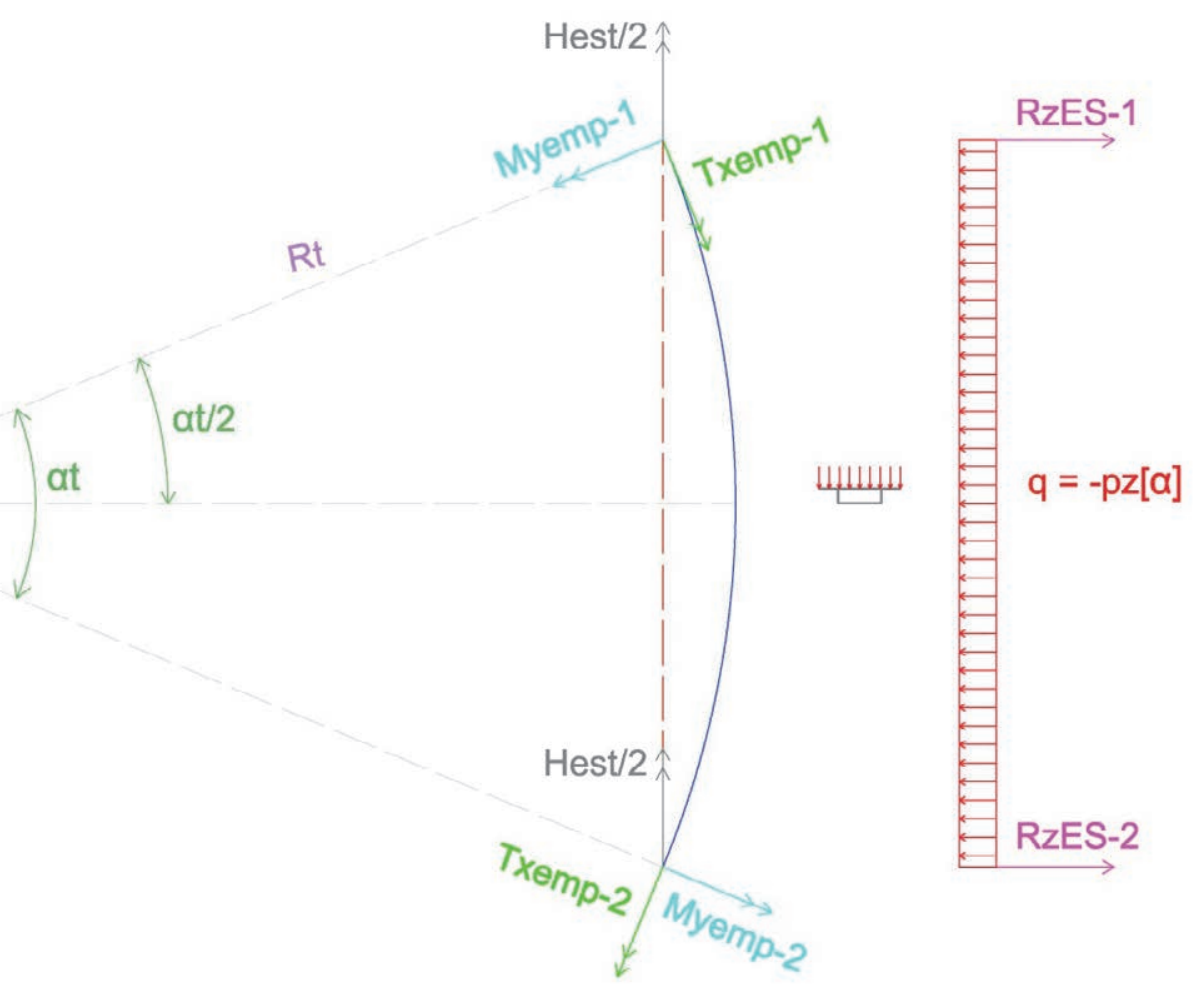

Ilustración 2.2. Modelo de cálculo para un tablero curvo bajo carga gravitatoria distribuida en su eje longitudinal.

El momento desestabilizador respecto de la cuerda que une los estribos, Hest, se puede obtener de la siguiente ecuación:

$$
\text { Hest }==q t^{2} \alpha t\left(\frac{2}{\alpha t} \operatorname{Sin}[\alpha t / 2]-\operatorname{Cos}[\alpha t / 2]\right)
$$

$\mathrm{Y}$ a partir de este momento (Hest), al que se debe dar respuesta en los estribos, existen 2 opciones a la hora de restringirlo, empotrar el tablero a torsión o hacerlo a flexión. Los momentos de empotramiento que obtendríamos en los estribos según la decisión escogida, serán (con las direcciones que aparecen en la llustración 2.2, es importante notar que según las direcciones presentadas el momento flector de empotramiento va a salir positivo, esto va a ser muy útil para la comprensión de las gráficas y diagramas):

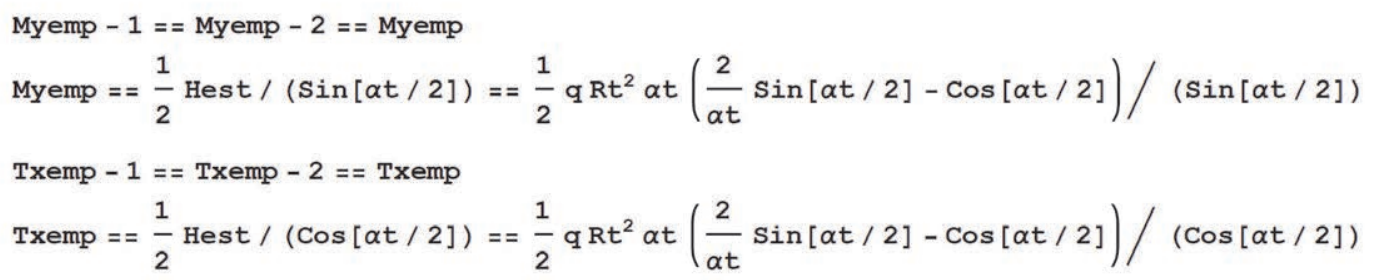


El momento positivo que se produce en el centro del vano, tiene un eje perpendicular a la cuerda que une los 2 estribos. Para una comprensión más clara de los efectos que van a tener las condiciones de contorno de los estribos sobre este momento positivo, se van a separar sus fuentes en 2. Por un lado, las acciones exteriores (tanto la carga como las reacciones de los estribos) perpendiculares al plano en el que se encuentra el tablero, que van a producir un momento denominado $\mathrm{My}^{+}{ }_{\text {S/emp }} \mathrm{y}$, por otro lado, los momentos de empotramiento que se producen en los estribos debidos a las condiciones de contorno impuestas en estos, que van a producir un momento positivo en el centro del vano denominado $\mathrm{My}_{\text {emp }}^{+}$. La primera fuente va a ser invariable para las diferentes opciones que se van a considerar, mientras que es la segunda la que muestra los efectos de las condiciones de contorno sobre el momento positivo en el centro de la viga (con las direcciones que aparecen en la llustración 2.2).

$$
\begin{aligned}
& \mathrm{My}_{\text {S/emp }}^{+}==0.5 q \mathrm{Rt}^{2} \alpha \mathrm{t}\left(\operatorname{Sin}[\alpha \mathrm{t} / 2]-\frac{2}{\alpha \mathrm{t}}(1-\operatorname{Cos}[\alpha \mathrm{t} / 2])\right) \\
& \text { Momento positivo en el centro de vano, debido al momento FLECTOR empotrado en los estribos : } \\
& \mathrm{My}^{+}{ }_{\text {emp }}==-\operatorname{Cos}[\alpha t / 2] \mathrm{Mycmp}==-\operatorname{Cos}[\alpha t / 2]\left(0.5 \mathrm{qRt}{ }^{2} \alpha t\left(\frac{2}{\alpha t} \operatorname{Sin}[\alpha t / 2]-\operatorname{Cos}[\alpha t / 2]\right) /(\operatorname{Sin}[\alpha t / 2])\right) \\
& \text { Momento positivo en el centro de vano, debido al momento TORSOR empotrado en los estribos : } \\
& \mathrm{My}_{\text {emp }}^{+}==\operatorname{Sin}[\alpha \mathrm{t} / 2] \mathrm{Txemp}==\operatorname{Sin}[\alpha \mathrm{t} / 2]\left(0.5 \mathrm{qRt} \mathrm{Rt}^{2}\left(\frac{2}{\alpha t} \operatorname{Sin}[\alpha \mathrm{t} / 2]-\operatorname{Cos}[\alpha \mathrm{t} / 2]\right) /(\operatorname{Cos}[\alpha \mathrm{t} / 2])\right) \\
& \text { Momento Positivo TOTAL (con el momento FLECTOR empotrado en los estribos) : } \\
& M_{Y}^{+}==0.5 q \operatorname{Rt}^{2} \alpha t\left(\operatorname{Sin}[\alpha t / 2]-\frac{2}{\alpha t}(1-\operatorname{Cos}[\alpha t / 2])\right) \\
& -\operatorname{Cos}[\alpha t / 2]\left(0.5 q R t^{2} \alpha t\left(\frac{2}{\alpha t} \operatorname{Sin}[\alpha t / 2]-\operatorname{Cos}[\alpha t / 2]\right) /(\operatorname{Sin}[\alpha t / 2])\right) \\
& \text { Momento Positivo TOTAL (con el momento TORSOR empotrado en los estribos) : } \\
& \mathrm{MY}^{+}==0.5 \mathrm{qRt} \mathrm{t}^{2} \alpha \mathrm{t}\left(\operatorname{Sin}[\alpha t / 2]-\frac{2}{\alpha t}(1-\operatorname{Cos}[\alpha t / 2])\right) \\
& +\operatorname{Sin}[\alpha t / 2]\left(0.5 q R t^{2} \alpha t\left(\frac{2}{\alpha t} \operatorname{Sin}[\alpha t / 2]-\operatorname{Cos}[\alpha t / 2]\right) /(\operatorname{Cos}[\alpha t / 2])\right)
\end{aligned}
$$

De las ecuaciones obtenidas se extrae (ya apreciable en los diagramas de momentos obtenidos en el punto anterior, Diagrama 2.1), que el empotramiento a TORSIÓN en los estribos es menos efectivo cuanto mayor sea el ángulo desarrollado por el tablero $(\alpha t)$, que por otro lado es cuando mayor es el momento que se debe estabilizar en los estribos. Además, a esta ineficiencia a medida que incrementa el ángulo desarrollado por el tablero, se suma otro inconveniente, el incremento que este empotramiento produce en el momento positivo del centro del vano (este aumento, llega a ser muy significativo, con ángulos superiores a $\frac{\pi}{3}$ ). En cambio, el empotramiento a flexión convierte todos estos inconvenientes en virtudes, así se hace más eficiente cuanto mayor resulta el momento a estabilizar, reduce el momento flector positivo y anula el momento torsor en el centro del vano, esto último, además de pura geometría, se puede entender volviendo a las ecuaciones que relacionan los 2 momento (EI torsor y el flector):

$$
\frac{d T x[s]}{d s}=m x[s]-\frac{M y[s]}{R t}
$$


Todos estos efectos, se pueden apreciar en las siguientes gráficas, donde se muestra el momento desestabilizador (Hest), el momento flector de empotramiento (Memp), el momento torsor de empotramiento (Temp), el momento positivo en el centro de vano sin tener en cuenta empotramientos en los estribos $\left(\mathrm{M}^{+}{ }_{S / \text { emp }}\right)$ y el momento positivo en el centro del vano $\left(M^{+}\right)$, en función del ángulo desarrollado por el tablero:

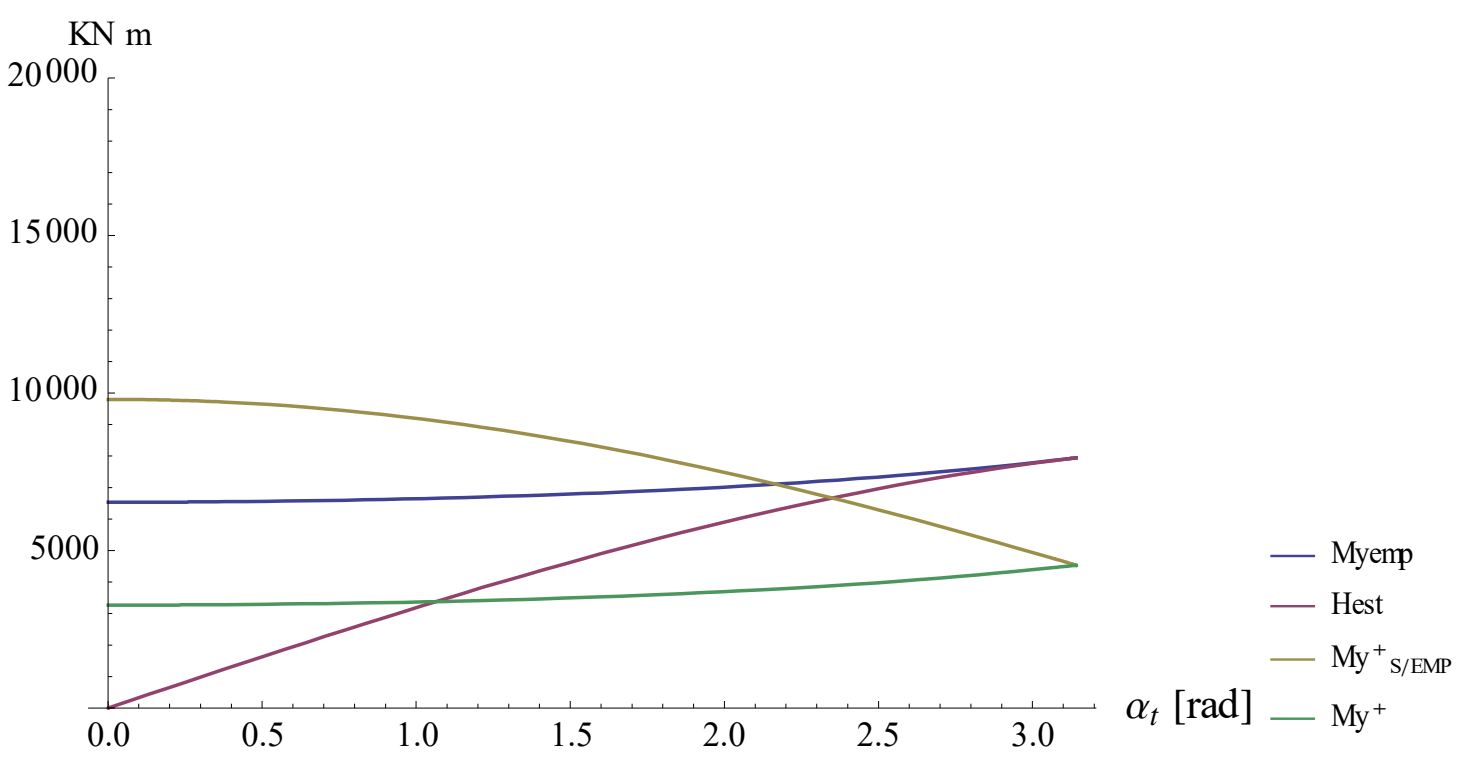

Diagrama 2.2. Solicitaciones de un tablero curvo, empotrado a flexión en los estribos. $L t=280 \mathrm{~m}, q=$ $1 \mathrm{KN} / \mathrm{ml}(\mathrm{pz}[\mathrm{s}]=-1 \mathrm{KN} / \mathrm{ml}), \mathrm{Rt}=\mathrm{Lt} / \alpha \mathrm{t}$.

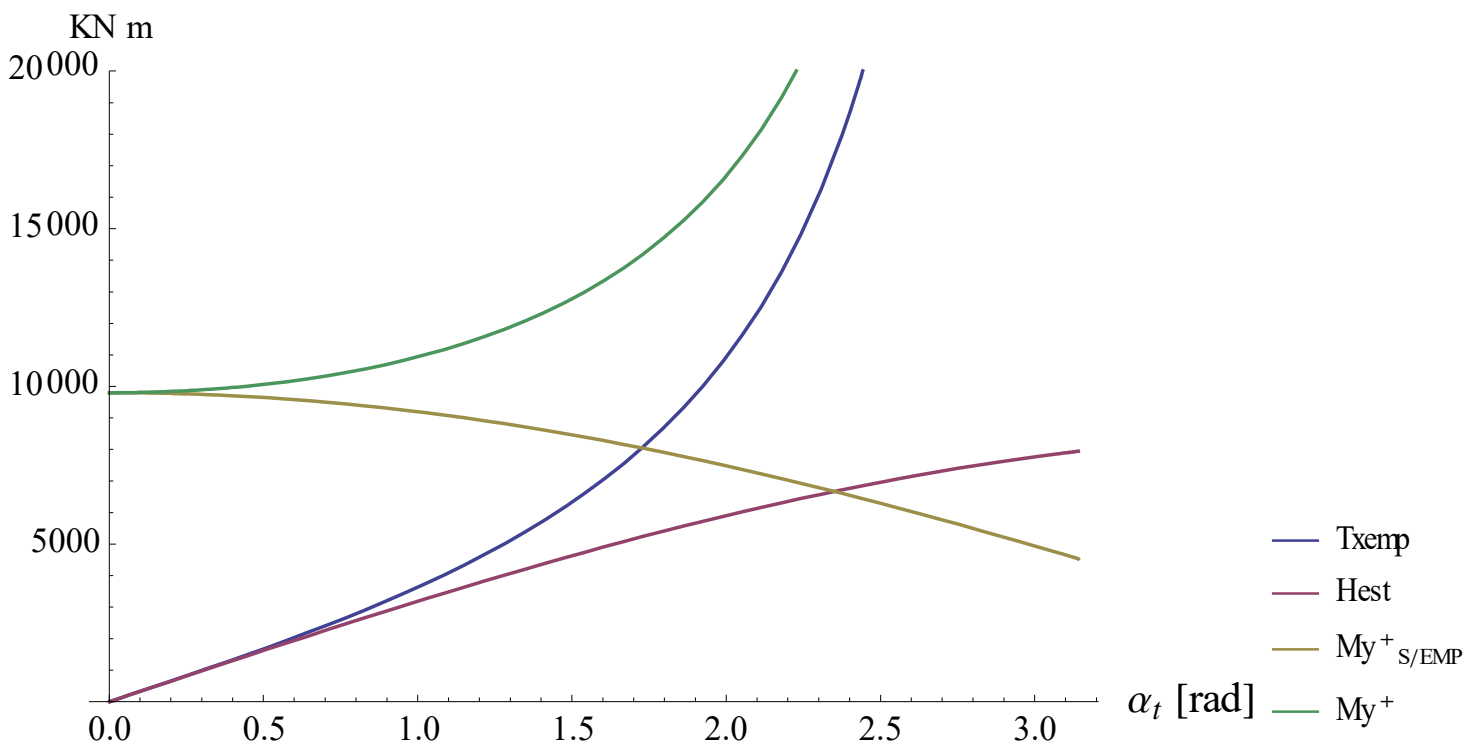

Diagrama 2.3. Solicitaciones de un tablero curvo, empotrado a torsión en los estribos. . $L t=280 \mathrm{~m}, q=$ $1 \mathrm{KN} / \mathrm{ml}(\mathrm{pz}[\mathrm{s}]=-1 \mathrm{KN} / \mathrm{ml}), \mathrm{Rt}=\mathrm{Lt} / \alpha \mathrm{t}$.

\subsection{Conclusiones}

Las conclusiones que se sacan de los diagramas anteriores (Diagrama 2.2 y Diagrama 2.3) y que van a ser de una gran importancia a medida que avancemos en la compresión del puente curvo atirantado, son las siguientes: 
1. El empotramiento a torsión solo es efectivo para pequeños ángulos, donde se muestra efectivo en el empotramiento en el estribo y a su vez no incrementa demasiado el momento positivo en el centro del vano.

2. Para ángulos mayores de $\frac{\pi}{3}$ la eficiencia del empotramiento a torsión se reduce drásticamente, y con la misma intensidad (como ya se ha explicado anteriormente) incrementa el momento positivo que se produce en el centro del vano.

3. El empotramiento a flexión es preferible en todos los casos. Si bien es verdad que su eficiencia frente al momento desestabilizador mejora a medida que el ángulo desarrollado por el tablero $(\alpha t)$ aumenta. Es importante entender que este momento negativo de empotramiento siempre es beneficioso para el momento positivo del centro del vano (todos estos beneficios aparecerán en el estudio de tableros curvos sobre apoyos puntuales, donde los giros de flexión quedan restringidos por la propia naturaleza del tablero sobre múltiples apoyos). Aunque siempre se debe tener muy presente, que la capacidad de este empotramiento va a estar vinculada a la capacidad a torsión de la sección, debido a su acoplamiento.

\subsection{Deformaciones}

Solo viendo el diagrama de esfuerzos del tablero (Diagrama 2.1), es fácil entender que el empotramiento a flexión hace siempre más rígido el sistema que el empotramiento a torsión, frente a una carga vertical uniforme centrada respecto al eje del tablero. Esta diferencia está directamente relacionada con la eficiencia de cada uno de los empotramientos, que como ya se ha comentado, dependen del ángulo desarrollado (dz: Desplazamiento vertical):

\begin{tabular}{|l|l|l|}
\hline & $\alpha_{t}=\frac{\pi}{2}$ & $\alpha_{t}=\frac{\pi}{12}$ \\
\hline$d_{\mathrm{z}}\left(\varphi_{\text {KMyT }}=1\right)_{\text {Flexión }}$ & $12,41 \%$ & $67,6 \%$ \\
\hline$d_{\mathrm{z}}\left(\varphi_{\text {KMYT }}=1\right)_{\text {Torsión }}$ & & \\
\hline
\end{tabular}

Tabla 2.1. Comparación deformaciones vertical máxima según las condiciones de contorno. Flexión: Empotramiento del tablero a flexión en los estribos. Torsión: Empotramiento del tablero a torsión en los estribos.

Por otro lado, para analizar la rigidez del sistema (sus deformaciones), se va a introducir el concepto de la relación que existe entre la rigidez al giro a flexión y la rigidez al giro a torsión del tablero $\left(\varphi_{K M y T}=\frac{E I y y}{G J}\right)$. Esta relación va a estar en torno a la unidad para secciones tipo cajón mientras que puede llegar a valores muy grandes, en el caso de que la sección no tenga demasiada rigidez a torsión, como las secciones abiertas.

Como los sistemas que se están analizando en este subapartado son isostáticos, la variación del coeficiente $\varphi_{K M Y T}$ no tiene influencia sobre las solicitaciones de la pieza. Esto hace, que la disminución de la rigidez a torsión de la pieza tenga una relación inversa sobre los giros y finalmente sobre las deformaciones, con unas solicitaciones invariables. De esta manera, es sencillo entender que cuanto mayor sean las solicitaciones torsoras que debe resistir el sistema, más determinante es la rigidez a torsión de la pieza y a partir de ahí se 
puede utilizar todo lo analizado referente a cómo influye el ángulo desarrollado sobre las solicitaciones, que recordándolo de nuevo, no van a cambiar por ser un sistema isostático, y sus condiciones de contorno. En la Tabla 2.2 se muestran el desplazamiento vertical ( $\mathrm{dz}$ ) y el giro de torsión (gx), para el centro del vano del puente.

\begin{tabular}{|c|c|c|}
\hline & $\alpha_{t}=\frac{\pi}{2}($ emp TORSIÓN $)$ & $\alpha_{t}=\frac{\pi}{2}($ emp FLEXIÓN $)$ \\
\hline$\frac{d_{\mathrm{z}}\left(\varphi_{K M y T}=40\right)-d_{\mathrm{z}}\left(\varphi_{K M y T}=1\right)}{d_{\mathrm{z}}\left(\varphi_{K M y T}=1\right)}$ & $769 \%$ & $194 \%$ \\
\hline$\frac{g_{\mathrm{x}}\left(\varphi_{K M y T}=40\right)-g_{\mathrm{x}}\left(\varphi_{K M y T}=1\right)}{g_{\mathrm{x}}\left(\varphi_{K M y T}=1\right)}$ & $1946 \%$ & - \\
\hline
\end{tabular}

Tabla 2.2. $\alpha_{t}=\frac{\pi}{2}$. Comparación deformaciones verticales máximas y giros de torsión máximos, según las condiciones de contorno y características de la sección del tablero (dz: Desplazamiento vertical, gx: Giro según eje de torsión).

De este mismo modo, cuando el ángulo desarrollado es menor también habrá menores solicitaciones torsoras y estas van a tener menos influencia sobre las deformaciones y giros en el centro del vano. Esto hace que la relación de rigideces pierda importancia:

\begin{tabular}{|c|c|c|}
\hline$\frac{d_{\mathrm{z}}\left(\varphi_{K M y T}=40\right)-d_{\mathrm{z}}\left(\varphi_{K M y T}=1\right)}{d_{\mathrm{z}}\left(\varphi_{K M y T}=1\right)}$ & $\alpha_{t}=\frac{\pi}{12}($ emp TORSIÓN $)$ & $\alpha_{t}=\frac{\pi}{12}($ emp FLEXIÓN $)$ \\
\hline$\frac{g_{\mathrm{x}}\left(\varphi_{K M y T}=40\right)-g_{\mathrm{x}}\left(\varphi_{K M y T}=1\right)}{g_{\mathrm{x}}\left(\varphi_{K M y T}=1\right)}$ & $11 \%$ & $1 \%$ \\
\hline
\end{tabular}

Tabla 2.3. $\alpha_{t}=\frac{\pi}{12}$. Comparación deformaciones verticales máximas y giros de torsión máximos, según las condiciones de contorno y características de la sección del tablero (dz: Desplazamiento vertical, gx: Giro según eje de torsión).

En el caso de los empotramientos a flexión, se ha decidido no mostrar los cambios en el giro de torsión gx, porque al haber cambio de signo entre el giro en el estribo y el del centro del vano, el valor en el centro del vano pierde su significado analítico (varía el comportamiento a medida que cambiamos la relación de rigideces $\left.\varphi_{K M y T}=\frac{E I y y}{G J}\right)$. En cambio, en el empotramiento a Torsión, donde el giro a torsión parte desde un valor nulo hasta su mayor valor en el centro del vano, se puede apreciar como el incremento de giro deja de depender del ángulo desarrollado, siendo el incremento igual para las diferentes curvaturas.

\subsection{Sistema isostático, carga vertical, repartida y descentrada respecto al eje del tablero}

\subsection{Solicitaciones}

Como introducción al problema y para una clara comprensión del efecto que tiene descentrar la carga, se va a separar la carga en dos: por un lado, una carga centrada respecto al centro del vano y por otro lado un momento torsor, aplicado a lo largo de todo el tablero (esto es solo posible si se puede considerar la sección transversal del tablero indeformable y con ello la distorsión despreciable). El primero se ha estudiado en profundidad en el punto 
anterior, y los 2 en conjunto se van a estudiar posteriormente. Luego este punto se va a centrar en el efecto que tiene sobre el sistema estructural un momento torsor aplicado de forma distribuida a lo largo de todo el tablero:

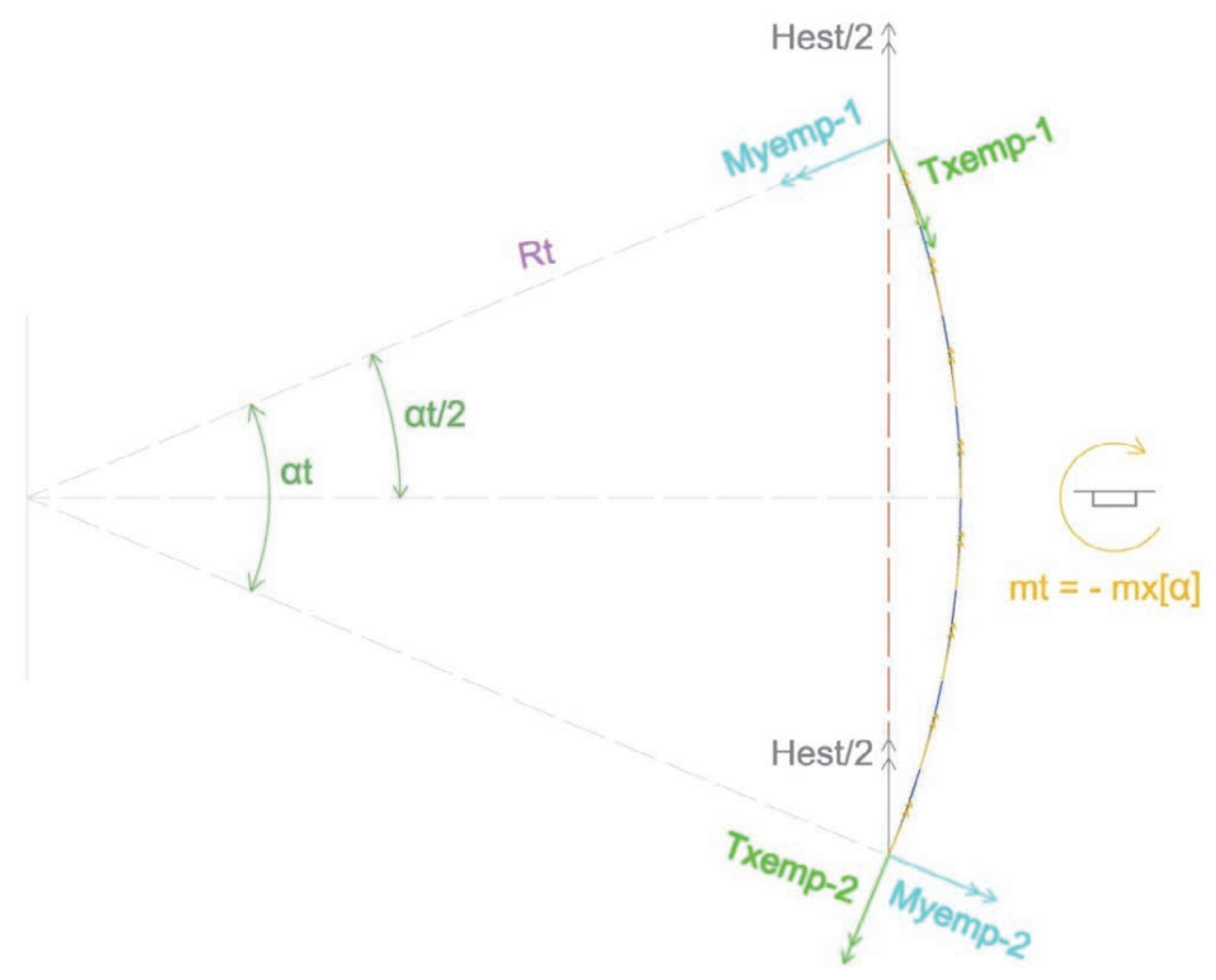

Ilustración 2.3. Modelo de cálculo para un tablero curvo cargado con un momento torsor distribuido.

Si se vuelven a sacar las ecuaciones para obtener tanto el momento desestabilizador como los momentos de empotramiento y el momento positivo en el centro del vano, obtenemos (con las direcciones que aparecen en la llustración 2.3, de nuevo se remarca el hecho de que, en favor de un diagrama más claro, el momento de empotramiento se ha dibujado en su dirección positiva):

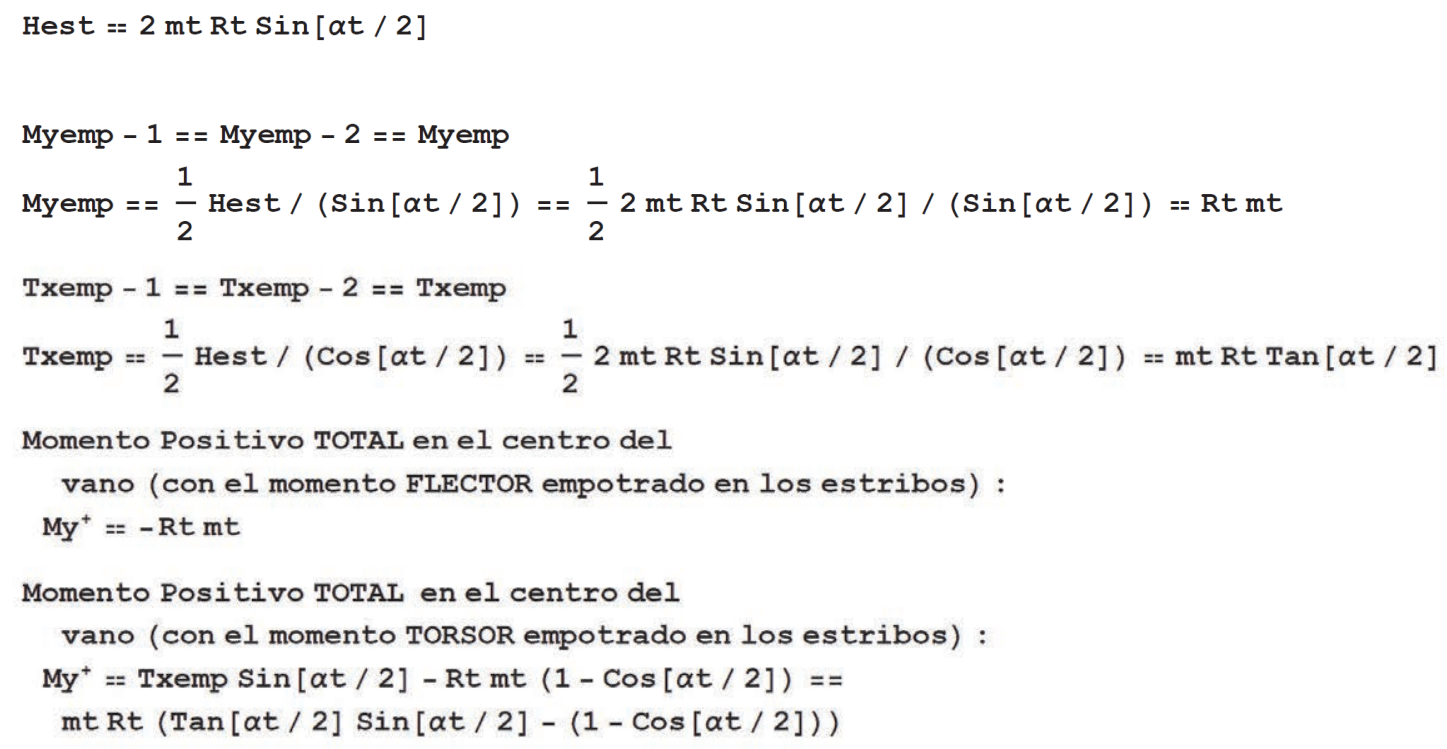


Se puede observar, como el momento flector de empotramiento no depende del ángulo recorrido, sino solamente del radio y del momento torsor solicitante. De esta manera, cuando el radio tiende a infinito (una curvatura pequeña o nula), el empotramiento a flexión, para hacer el sistema estable, se dispara de la misma manera. Este momento flector negativo solicita a todo el tablero de forma constante entre los estribos. El torsor, como se puede deducir sencillamente a partir de las ecuaciones que muestran el comportamiento del sistema, tiene pendiente nula, luego sabiendo que en los estribos es " 0 ", no queda otra opción que sea nulo a lo largo de todo el tablero. Mientras que el empotramiento a torsión, se muestra muy eficiente con radio infinito (puente recto) y va perdiendo eficiencia a medida que se va introduciendo una mayor curvatura. En lo que al momento positivo en el centro del vano se refiere, apenas se ve afectado con ángulos pequeños, mientras que a medida que va creciendo el ángulo, se va acentuando el efecto pernicioso del empotramiento a torsión (se han omitido los diagramas cambiando la carga de torsión aplicada de signo, por su total simetría respecto al eje de abscisas):
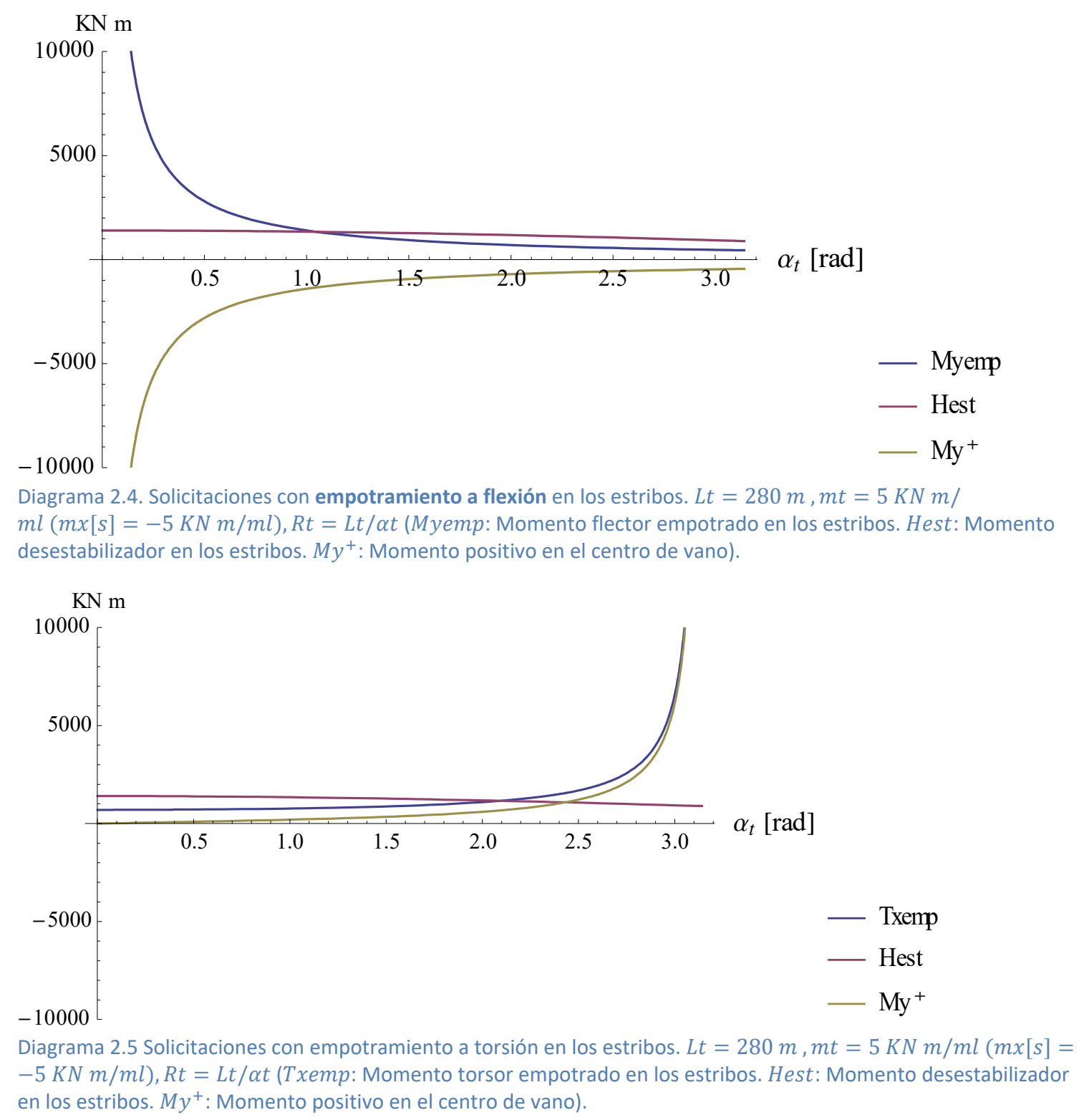
Para analizar el efecto conjunto que supone descentrar la carga distribuida a lo largo del tablero, suponiendo la sección transversal del tablero indeformable (despreciando la distorsión), solo hay que sumar los efectos del momento torsor a los que ya vimos en el subapartado 2.1.2.1.1, con carga distribuida centrada respecto del eje longitudinal del tablero.

Si se analiza el efecto que tiene sobre el sistema descentrar la carga, se evidencia que, partiendo del problema planteado el problema en el subapartado 2.1.2.1.1, la única diferencia sería incrementar el radio correspondiente a la aplicación de la carga, sumando la distancia de descentrado de la carga (con las direcciones que aparecen en la llustración 2.4):

$$
\begin{gathered}
m t=q d e s q \\
R t^{\prime}=R t+d e s q
\end{gathered}
$$

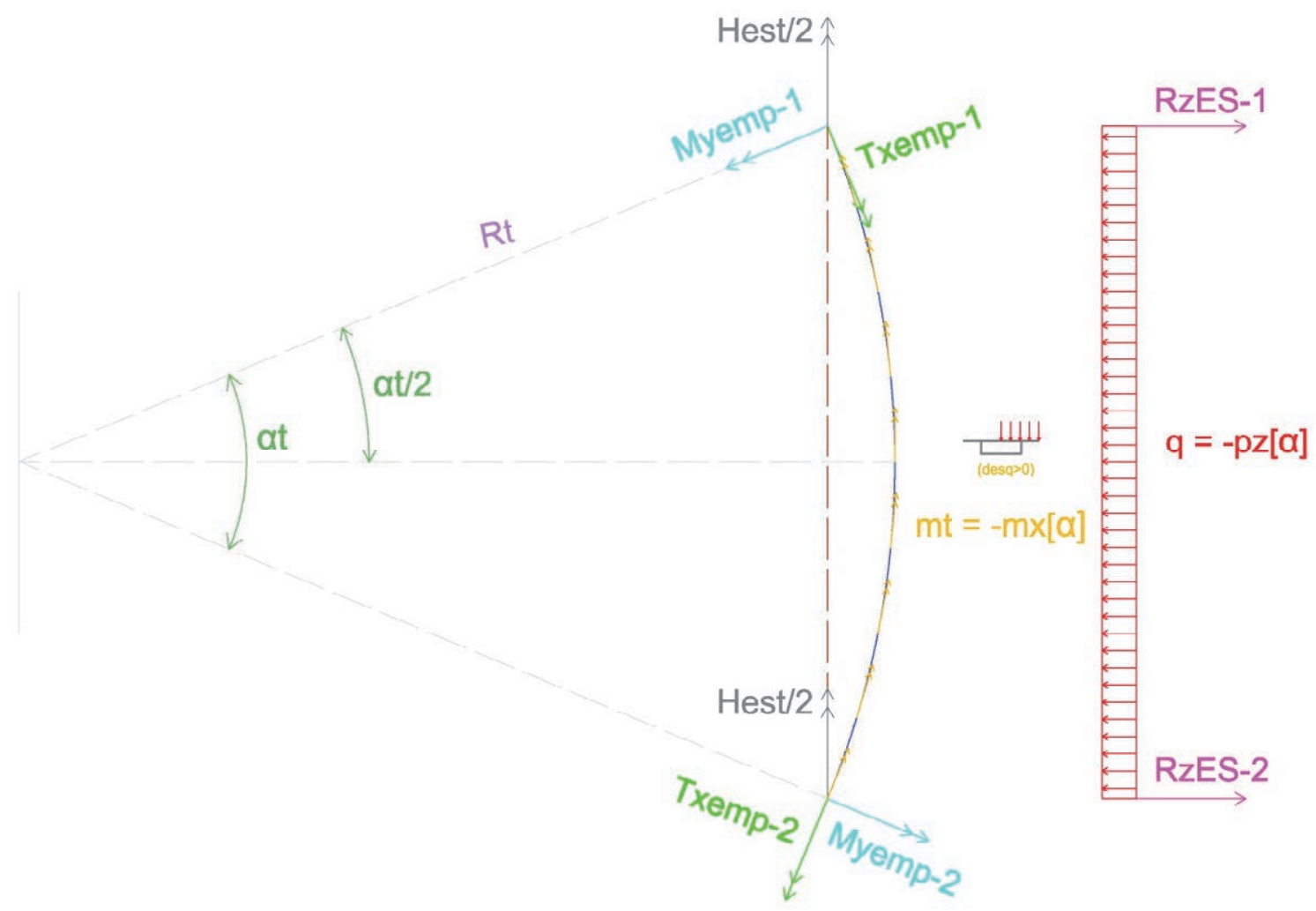

Ilustración 2.4. Modelo de cálculo para un tablero curvo bajo carga gravitatoria distribuida, desplazada respecto del eje longitudinal del tablero.

Hest $=$ q Rt ' $\alpha t\left(\frac{2}{\alpha t} R t^{\prime} \cdot \operatorname{Sin}[\alpha t / 2]-R t \operatorname{Cos}[\alpha t / 2]\right)$

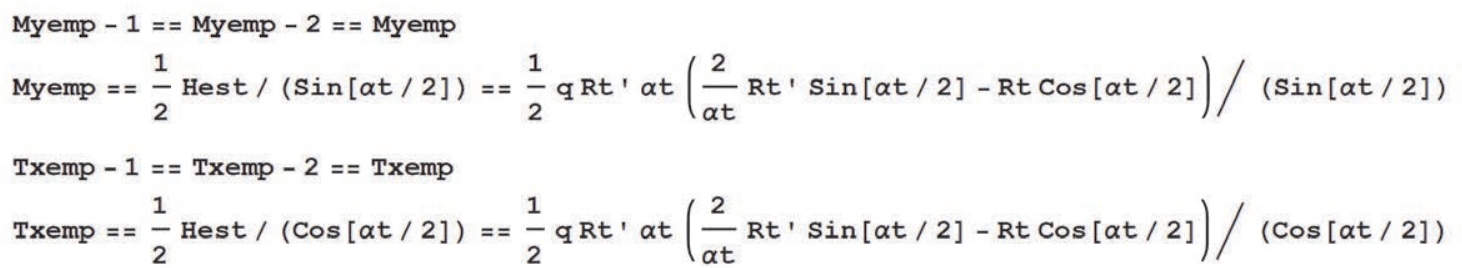


Una vez cambiadas las ecuaciones, con el consiguiente incremento en el momento a estabilizar, todos los análisis realizados para la carga centrada son completamente válidos. Si bien el hecho de que tengamos torsión incluso con pequeños ángulos hace que, para este tipo de carga, el empotramiento a flexión con ángulos pequeños $\left(\leq \approx \frac{\pi}{9}\right)$ sea poco efectivo. Por otro lado, esta torsión con pequeños ángulos también agudiza o minora, según el signo del descentramiento de la carga, el efecto pernicioso que tiene el empotramiento a torsión sobre el momento positivo a mitad de vano:

$$
\mathrm{MY}^{+}{ }_{\mathrm{S} / \mathrm{emp}}=0.5 \mathrm{qRt} \cdot \alpha \mathrm{t}\left(\mathrm{Rt} \cdot \operatorname{Sin}[\alpha t / 2]-\frac{2}{\alpha t} \mathrm{Rt}(1-\operatorname{Cos}[\alpha t / 2])\right)
$$

Momento positivo en el centro de vano,

debido al momento FLECTOR empotrado en los estribos :

$\mathrm{My}_{\text {emp }}^{+}==-\operatorname{Cos}[\alpha \mathrm{t} / 2] \mathrm{Myemp}==$

$$
-\operatorname{Cos}[\alpha t / 2]\left(\frac{1}{2} q R t ' \alpha t\left(\frac{2}{\alpha t} \operatorname{Rt} \cdot \operatorname{Sin}[\alpha t / 2]-\operatorname{Rt} \operatorname{Cos}[\alpha t / 2]\right) /(\operatorname{Sin}[\alpha t / 2])\right)
$$

Momento positivo en el centro de vano, debido al momento TORSOR empotrado en los estribos :

$$
\begin{aligned}
& \mathrm{MY}_{\text {emp }}^{+}==\operatorname{Sin}[\alpha t / 2] \text { Txemp }== \\
& \operatorname{Sin}[\alpha t / 2]\left(\frac{1}{2} \text { q Rt ' } \alpha t\left(\frac{2}{\alpha t} \operatorname{Rt} \cdot \operatorname{Sin}[\alpha t / 2]-\operatorname{Rt} \operatorname{Cos}[\alpha t / 2]\right) /(\operatorname{Cos}[\alpha t / 2])\right)
\end{aligned}
$$

Momento Positivo TOTAL en el centro del

vano (con el momento FLECTOR empotrado en los estribos) :

$$
\begin{aligned}
& \mathrm{My}^{+}=0.5 \mathrm{qRt} \text { ' } \alpha t\left(R t ' \operatorname{Sin}[\alpha t / 2]-\frac{2}{\alpha t} \operatorname{Rt}(1-\operatorname{Cos}[\alpha t / 2])\right)- \\
& \operatorname{Cos}[\alpha t / 2]\left(\frac{1}{2} q \operatorname{Rt} ' \alpha t\left(\frac{2}{\alpha t} \operatorname{Rt} \cdot \operatorname{Sin}[\alpha t / 2]-\operatorname{Rt} \operatorname{Cos}[\alpha t / 2]\right) /(\operatorname{Sin}[\alpha t / 2])\right)
\end{aligned}
$$

Momento Positivo TOTAL en el centro del vano

(con el momento TORSOR empotrado en los estribos) :

$$
\begin{aligned}
& \mathrm{MY}^{+}=0.5 \mathrm{qRt} \mathrm{R}^{\prime} \alpha \mathrm{t}\left(\mathrm{Rt} \cdot \operatorname{Sin}[\alpha t / 2]-\frac{2}{\alpha t} \operatorname{Rt}(1-\operatorname{Cos}[\alpha t / 2])\right)+ \\
& \operatorname{Sin}[\alpha t / 2]\left(\frac{1}{2} q \operatorname{Rt} \operatorname{l}^{\prime} \alpha t\left(\frac{2}{\alpha t} \operatorname{Rt} \cdot \operatorname{Sin}[\alpha t / 2]-\operatorname{Rt} \operatorname{Cos}[\alpha t / 2]\right) /(\operatorname{Cos}[\alpha t / 2])\right)
\end{aligned}
$$




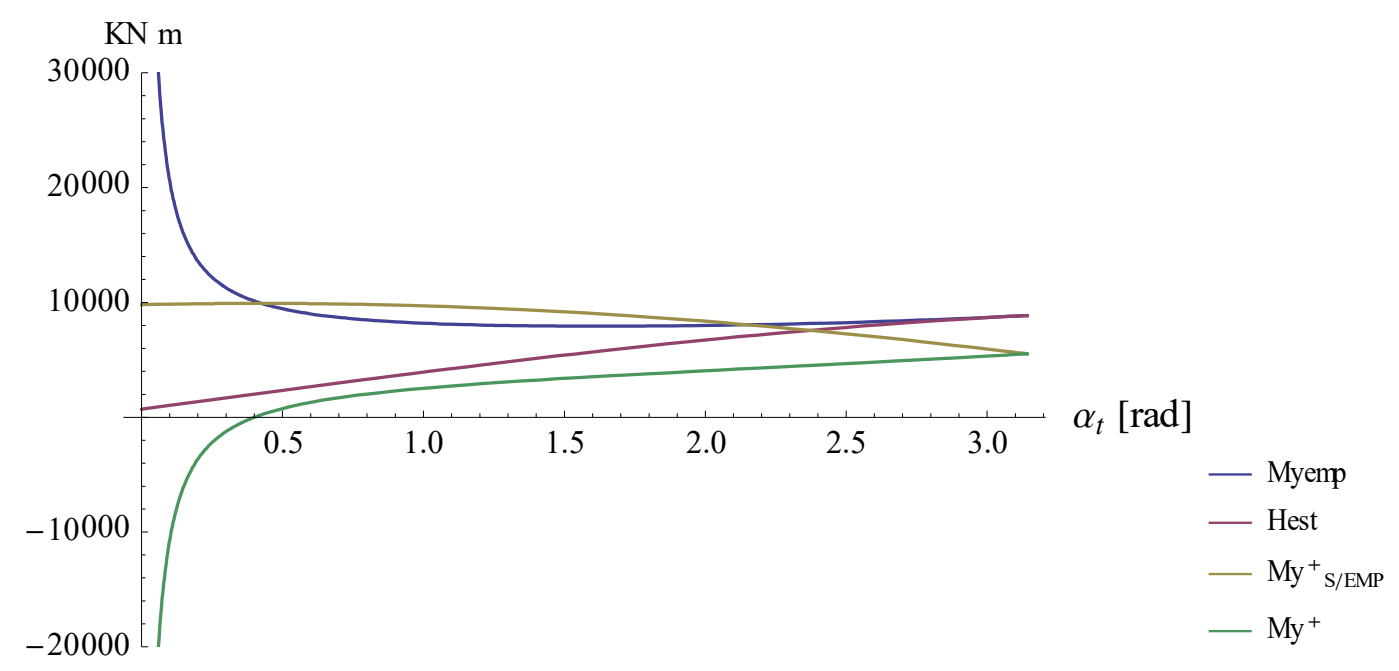

Diagrama 2.6. Solicitaciones con empotramiento a flexión en los estribos. $L t=280 \mathrm{~m}$, desq $=5 \mathrm{~m}, R t=$ $\frac{L t}{\alpha t}, R t^{\prime}=\frac{L t}{\alpha t}+$ desq, $q=1 \frac{K N}{m l}\left(p z[s]=-1 \frac{K N}{m l}\right)$. (Myemp: Momento flector empotrado en los estribos. Hest:

Momento desestabilizador en los estribos. $\mathrm{My}_{S / E M P}^{+}$: Momento positivo en el centro de vano, Sin tener en cuenta el efecto del empotramiento. $\mathrm{My}^{+}$: Momento positivo en el centro de vano).

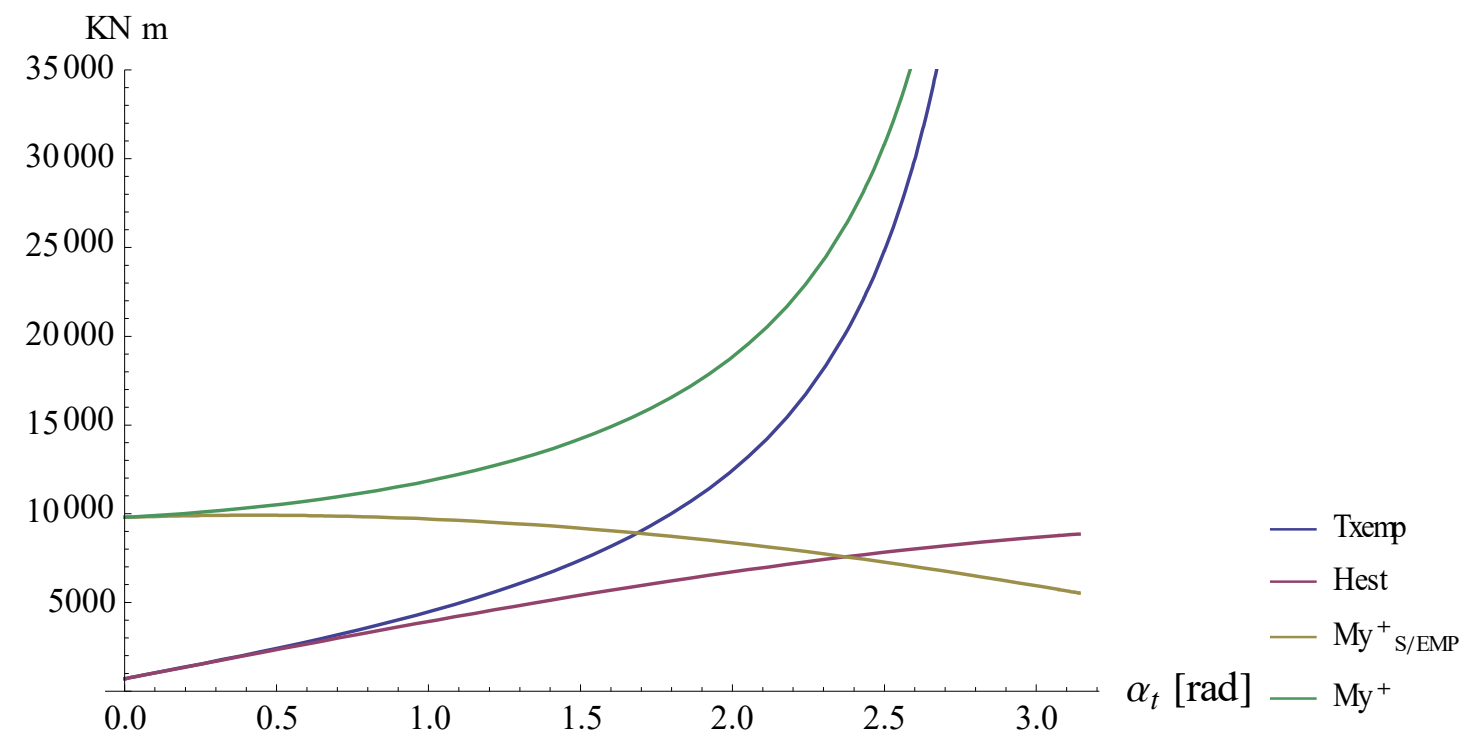

Diagrama 2.7. Solicitaciones con empotramiento a torsión en los estribos. . $L t=280 \mathrm{~m}$, desq $=5 \mathrm{~m}, \mathrm{Rt}=$ $\frac{L t}{\alpha t}, R t^{\prime}=\frac{L t}{\alpha t}+$ desq, $q=1 \frac{K N}{m l}\left(p z[s]=-1 \frac{K N}{m l}\right)$. (Myemp: Momento flector empotrado en los estribos. Hest: Momento desestabilizador en los estribos. $\mathrm{My}_{S / E M P}^{+}$: Momento positivo en el centro de vano, Sin tener en cuenta el efecto del empotramiento. $\mathrm{My}^{+}$: Momento positivo en el centro de vano). 


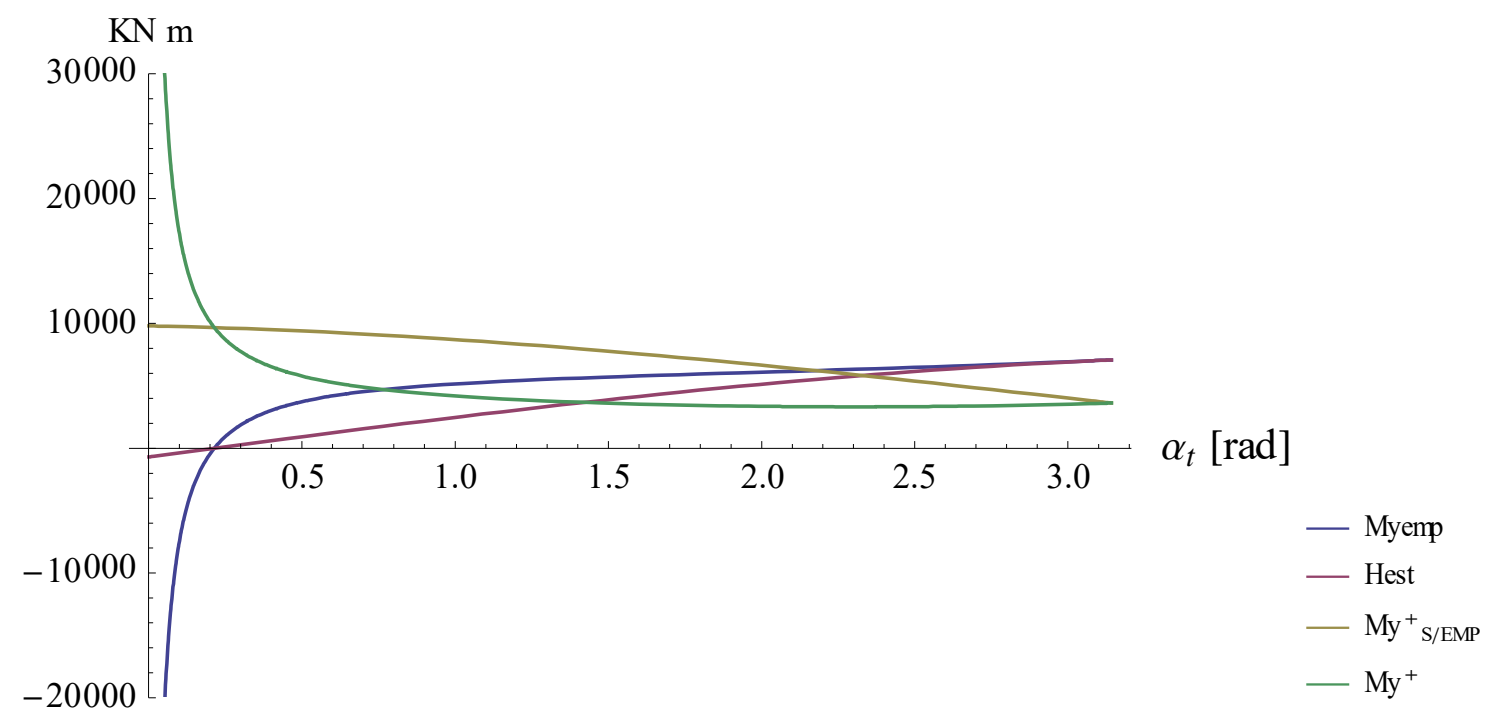

Diagrama 2.8. Solicitaciones con empotramiento a flexión en los estribos. $L t=280 \mathrm{~m}$, desq $=-5 \mathrm{~m}, R t=$ $\frac{L t}{\alpha t}, R t^{\prime}=\frac{L t}{\alpha t}+$ desq, $q=1 \frac{K N}{m l}\left(p z[s]=-1 \frac{K N}{m l}\right)$. (Myemp: Momento flector empotrado en los estribos. Hest: Momento desestabilizador en los estribos. $\mathrm{My}_{S / E M P}^{+}$: Momento positivo en el centro de vano, Sin tener en cuenta el efecto del empotramiento. $M y^{+}$: Momento positivo en el centro de vano).

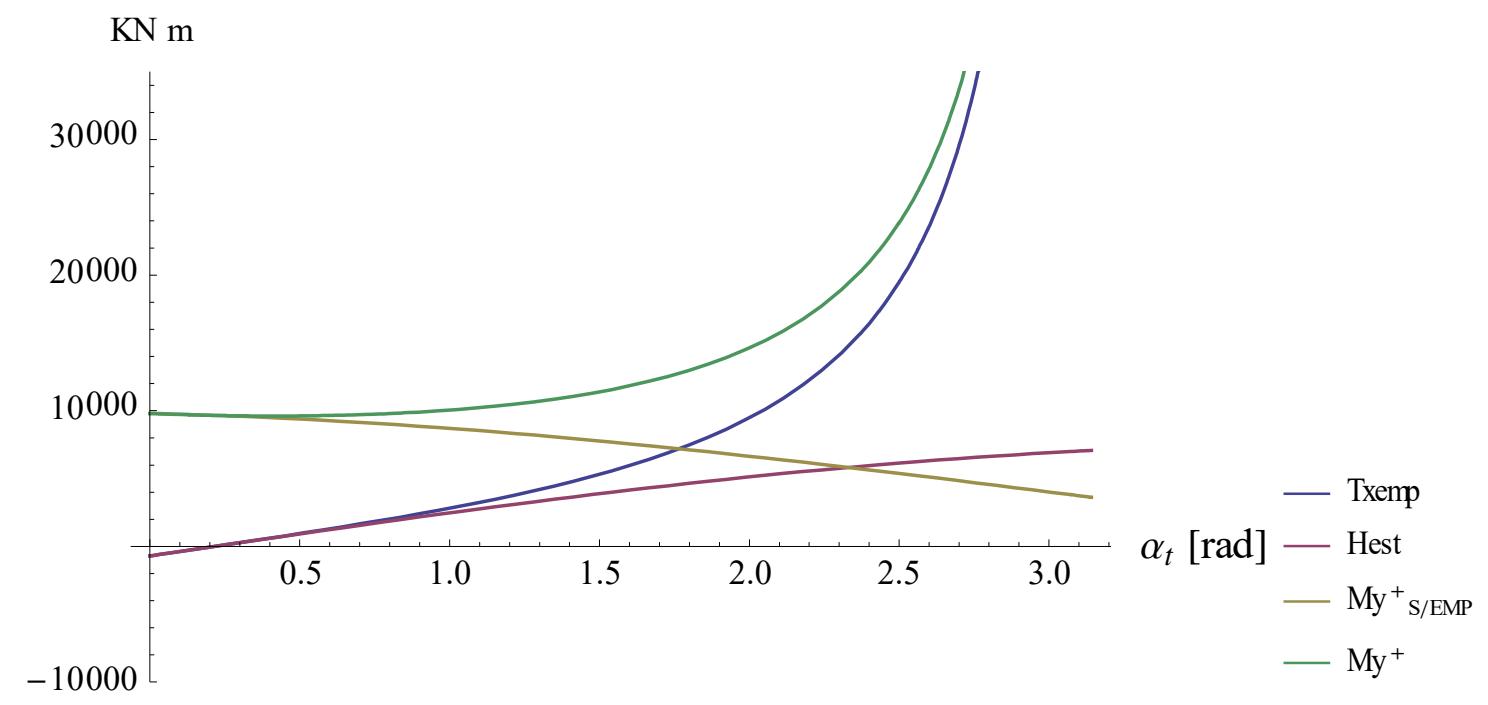

Diagrama 2.9. Solicitaciones con empotramiento a torsión en los estribos. . $L t=280 \mathrm{~m}$, desq $=-5 \mathrm{~m}, \mathrm{Rt}=$ $\frac{L t}{\alpha t}, R t^{\prime}=\frac{L t}{\alpha t}+$ desq, $q=1 \frac{K N}{m l}\left(p z[s]=-1 \frac{K N}{m l}\right)$. (Myemp: Momento flector empotrado en los estribos. Hest: Momento desestabilizador en los estribos. $\mathrm{My}^{+}{ }_{S / E M P}$ : Momento positivo en el centro de vano, Sin tener en cuenta el efecto del empotramiento. $M y^{+}$: Momento positivo en el centro de vano).

\subsection{1 Conclusiones}

Como conclusión a este análisis, es útil todo lo que se concluyó en el punto anterior (subapartado 2.1.2.1.1).

1. En el sistema con empotramiento a flexión, se observa que sea cual sea el tipo de descentramiento, se vuelve muy poco eficiente para ángulos pequeños $(\alpha t \lesssim$ $\frac{\pi}{9}$ para desq $>0$ y $\alpha t \lesssim \frac{\pi}{8}$ para des $q<0$ ), donde llega a ser pernicioso 
incluso para el momento positivo a mitad de vano. Esto va a cobrar mucha importancia en puentes curvos sobre múltiples apoyos (apartado 2.3).

2. En el caso de empotramiento a torsión, si el descentramiento es negativo, se reducen los efectos negativos que este tipo de empotramiento tiene sobre el momento positivo en el centro de vano, aumentando sensiblemente los ángulos para los cuales sigue siendo efectivo. Si el descentramiento es positivo, sus efectos perniciosos sobre el momento positivo en el centro del vano aumentan ligeramente.

\subsection{Deformaciones}

Para poder hacer un análisis más claro de lo que supone el descentramiento de la carga sobre el tablero, se ha decidido separar la carga de nuevo para visualizar correctamente lo que lo diferencia de la carga centrada: la torsión. En las siguientes tablas se muestra en deformaciones y giros en el centro de del vano, el torsor que debe soportar el tablero al descentrar la carga (de forma aislada, sin introducir la carga), frente al mismo tablero con la carga centrada respecto al eje del tablero. De nuevo se estudia el cambio de comportamiento debido a la variación en la relación de rigideces $\left(\varphi_{K M y T}=\frac{E I}{G J}\right)$. En la siguiente tabla (Tabla 1) se muestran, dz: Desplazamiento vertical, gx: Giro según eje de torsión, para el centro del vano del puente:

\begin{tabular}{|c|c|c|}
\hline & $\alpha_{t}=\frac{\pi}{2}($ emp TORSIÓN $)$ & $\alpha_{t}=\frac{\pi}{2}($ emp FLEXIÓN $)$ \\
\hline$\frac{d_{\mathrm{z}}\left(\varphi_{K M y T}=1\right)_{\text {Torsión }}}{d_{\mathrm{z}}\left(\varphi_{K M y T}=1\right)_{\text {Carga centrada }}}$ & $4 \%$ & $0 \%$ \\
\hline$\frac{g_{\mathrm{x}}\left(\varphi_{K M y T}=1\right)_{\text {Torsión }}}{g_{\mathrm{x}}\left(\varphi_{K M y T}=1\right)_{\text {Carga centrada }}}$ & $6 \%$ & - \\
\hline
\end{tabular}

Tabla 2.4. Comparación deformaciones. $L t=280 \mathrm{~m}, m t=5 \mathrm{KN} \mathrm{m} / \mathrm{ml}(m x[\mathrm{~s}]=-5 \mathrm{KN} \mathrm{m} / \mathrm{ml}), R t=L t / \alpha t . \mathrm{dz}$ : Desplazamiento vertical en el centro del vano, gx: Giro según eje de torsión en el centro del vano.

\begin{tabular}{|c|c|c|}
\hline & $\alpha_{t}=\frac{\pi}{2}($ emp TORSIÓN $)$ & $\alpha_{t}=\frac{\pi}{2}($ emp FLEXIÓN $)$ \\
\hline$\frac{d_{\mathrm{z}}\left(\varphi_{K M y T}=40\right)_{\text {Torsión }}}{d_{z}\left(\varphi_{K M y T}=40\right)_{\text {Carga centrada }}}$ & $9 \%$ & $0 \%$ \\
\hline$\frac{g_{\mathrm{x}}\left(\varphi_{K M y T}=40\right)_{\text {Torsión }}}{g_{\mathrm{x}}\left(\varphi_{K M Y T}=40\right)_{\text {Carga centrada }}}$ & $9,5 \%$ & - \\
\hline
\end{tabular}

Tabla 2.5. Comparación deformaciones. $L t=280 \mathrm{~m}, m t=5 \mathrm{KN} \mathrm{m} / \mathrm{ml}(m x[\mathrm{~s}]=-5 \mathrm{KN} \mathrm{m} / \mathrm{ml}), R t=L t / \alpha t . \mathrm{dz}$ : Desplazamiento vertical en el centro del vano, gx: Giro según eje de torsión en el centro del vano.

\begin{tabular}{|c|c|c|}
\hline & $\alpha_{t}=\frac{\pi}{12}($ emp TORSIÓN $)$ & $\alpha_{t}=\frac{\pi}{12}$ (emp FLEXIÓN $)$ \\
\hline$\frac{d_{z}\left(\varphi_{K M y T}=1\right)_{\text {Torsión }}}{d_{\mathrm{z}}\left(\varphi_{K M y T}=1\right)_{\text {Carga centrada }}}$ & $2 \%$ & $0 \%$ \\
\hline$\frac{g_{\mathrm{x}}\left(\varphi_{K M y T}=1\right)_{\text {Torsión }}}{g_{\mathrm{x}}\left(\varphi_{K M y T}=1\right)_{\text {Carga centrada }}}$ & $180,5 \%$ & - \\
\hline
\end{tabular}

Tabla 2.6. Comparación deformaciones. $L t=280 \mathrm{~m}, \mathrm{mt}=5 \mathrm{KN} \mathrm{m} / \mathrm{ml}(\mathrm{mx}[\mathrm{s}]=-5 \mathrm{KN} \mathrm{m} / \mathrm{ml}), R t=L t / \alpha t . \mathrm{dz}$ : Desplazamiento vertical en el centro del vano, gx: Giro según eje de torsión en el centro del vano. 


\begin{tabular}{|c|c|c|}
\hline & $\alpha_{t}=\frac{\pi}{12}($ emp TORSIÓN $)$ & $\alpha_{t}=\frac{\pi}{12}($ emp FLEXIÓN $)$ \\
\hline$\frac{d_{z}\left(\varphi_{K M y T}=40\right)_{\text {Torsión }}}{d_{\mathrm{z}}\left(\varphi_{K M y T}=40\right)_{\text {Carga centrada }}}$ & $37 \%$ & $0 \%$ \\
\hline$\frac{g_{\mathrm{x}}\left(\varphi_{K M y T}=40\right)_{\text {Torsión }}}{g_{\mathrm{x}}\left(\varphi_{K M y T}=40\right)_{\text {Carga centrada }}}$ & $342 \%$ & - \\
\hline
\end{tabular}

Tabla 2.7. Comparación deformaciones. $L t=280 \mathrm{~m}, \mathrm{mt}=5 \mathrm{KN} \mathrm{m} / \mathrm{ml}(\mathrm{mx}[\mathrm{s}]=-5 \mathrm{KN} \mathrm{m} / \mathrm{ml}), R t=\mathrm{Lt} / \alpha t$.dz: Desplazamiento vertical en el centro del vano, gx: Giro según eje de torsión en el centro del vano.

\subsection{1 Conclusiones}

Se puede apreciar como el descentramiento de la carga, tiene un efecto limitado sobre aquellos tableros donde el ángulo es mayor (Tabla 2.4 y Tabla 2.5). Esto se debe, fundamentalmente, a que en estos tableros el torsor que se introduce es comparativamente mucho menor frente al que soporta con la carga centrada que en el caso de un tablero de menor ángulo. Por esta misma razón, los tableros con mayor ángulo desarrollado, también son mucho más sensibles cuando variamos su rigidez a torsión con la carga centrada (Tabla 2.2). Hasta ahora, los tableros que desarrollaban un ángulo menor, con la carga centrada, apenas desarrollaban deformaciones en el centro del vano debido a la torsión (porque esta solicitación era mínima), mientras que la torsión que se ha introducido, al descentrar la carga (la misma para los 2 ángulos, ya que la hemos sacado de descentrar la carga en un tablero que suponemos del mismo ancho para los 2 ángulos), supone un incremento enorme (en torno a 44 veces si suponemos un Radio de tablero de $R t=200 \mathrm{~m}$ y un descentramiento de la carga de $\operatorname{des} q=5 \mathrm{~m}$ ), luego pasa a ser determinante la capacidad para contener este giro en los estribos, capacidad dominada por la rigidez a torsión. Esta es la razón por la que se aprecia como incrementan los giros mucho más en los tableros de pequeño ángulo y menor rigidez de torsión.

Por otro lado, se puede apreciar como también son mucho más sensibles a la relación de rigideces $\left(\varphi_{K M y T}=\frac{E I y y}{G J}\right)$, los tableros de pequeño ángulo desarrollado. Como ya se ha comentado antes, cuando el ángulo desarrollado es menor, el incremento de torsor que supone el descentramiento de la carga es mucho mayor, comparativamente, que en los de mayor ángulo. En el caso de tener una relación de rigideces cercana a la unidad, los giros de torsión (gx), para ángulos pequeños y carga centrada son despreciables, y su influencia sobre la flecha $(\mathrm{dz})$ a mitad de vano igualmente despreciable. Esto hace que cuando aumentan los giros (gx), aunque lo hagan de forma drástica (Tabla 2.6), lo hacen sobre valores muy pequeños y con poca influencia, luego el desplazamiento vertical queda muy contenido (2\%). En cambio, a medida que aumentamos esta relación de rigideces $\left(\varphi_{K M y T}=\frac{E I y y}{G J}\right)$, aumenta la importancia tanto de los giros gx, como de su aportación a la deformación vertical dz. Esto hace que cuando aumentan los giros de torsión (gx), como lo hacen al descentrar la carga, el desplazamiento vertical tenga un aumento mucho más drástico que cuando la relación de rigideces $\left(\varphi_{K M Y T}=\frac{E I y y}{G J}\right)$ está en torno a la unidad.

En el caso del tablero empotrado a flexión, se puede ver como no incrementa su desplazamiento vertical. Pero si bien no hemos metido los incrementos de rotación, porque carece de sentido como se explicó en el punto anterior (subapartado 2.1.2.1.1.3), sí que 
merece la pena comentar, que en el caso de meter una solicitación torsora exclusivamente, los giros a torsión van a ser constantes a lo largo de todo el tablero e iguales a los que se producen en el estribo. Van a depender del momento flector, porque recordemos que el torsor es nulo y obviamente de la rigidez del tablero frente al momento flector My. Como el flector es independiente del ángulo, dependiendo solo del radio, lo mismo ocurre con el giro (gx), va a ser contante a lo largo de todo el tablero y solo dependiente del radio del tablero, de la carga torsora introducida y de la rigidez del tablero frente al momento torsor ( $g x=R t \frac{M y}{E I y}$ ). Luego el problema del giro de torsión, resulta igual de grave sea cual sea el ángulo desarrollado por el tablero.

La correcta comprensión de todo esto será de vital importancia cuando estemos con sistemas hiperestáticos, como son los tableros curvos sobre apoyos puntuales (apartado 2.3).

\subsection{Sistema hiperestático, carga vertical, repartida y centrada respecto al eje del tablero}

\subsection{Solicitaciones}

La otra opción, en lo que a condiciones de contorno de los estribos se refiere, sería empotrar completamente el tablero en los estribos (a flexión y a torsión). Como en los apartados anteriores, cobran mucha importancia el ángulo desarrollado por el tablero y la relación que existe entre la rigidez al giro de flexión y la rigidez al giro de torsión del tablero $\left(\varphi_{K M Y T}=\frac{E I y y}{G J}\right)$.

Como ya se ha comentado en el subapartado 2.1.2.1.1, el empotramiento a flexión resulta más efectivo con carga centrada debido a su relación con el momento positivo en el centro del vano, y por consiguiente con el giro gy de la pieza y los desplazamientos verticales. También se ha comentado el efecto aditivo que tiene el empotramiento a torsión sobre este momento positivo en el centro del vano, efecto que se repite con los giros y el desplazamiento vertical, también en el centro del vano.

Luego si partimos del sistema en el que tenemos el empotramiento a flexión en los estribos y añadimos el empotramiento a torsión, hay 2 posibilidades:

1. Que el empotramiento a torsión intente ayudar a estabilizar el sistema neutralizando parte del momento desestabilizador Hest. Esto provocaría que el momento negativo de empotramiento disminuyese, para que el sistema siga siendo estable, el momento positivo aumentase y con ello también el de torsión. Todo esto provocaría mayores giros y con ello un incremento de las deformaciones en el centro del vano, cosa que es incompatible con el punto de partida, que como ya hemos comentado, es el tablero curvo isostático empotrado a flexión en los estribos, debido a que se incrementaría la energía de deformación, contradiciendo el teorema de Menabrea.

2. Que el empotramiento a torsión intente recuperar parte de la deformación de la pieza (cumpliendo el Teorema de Menabrea, disminuyendo la energía de deformación de la fuerza exterior aplicada), causando un momento de 
empotramiento con signo contrario al que sería necesario para contrarrestar el momento desestabilizador Hest. En este caso, parte de este momento tenderá a incrementar el momento de desestabilización Hest y con ello incrementará el momento negativo en los estribos que necesitará estabilizar más que en el estado isostático. De esta manera se disminuirán las deformaciones en el centro del vano produciendo un mayor empotramiento en los estribos.

Como se acaba de analizar, la única posibilidad es la 2, pero queda claro que la capacidad de disminuir las deformaciones en el centro de la pieza, va a depender por un lado de la rigidez de la pieza a torsión y sobre todo del ángulo desarrollado, de forma que a menor ángulo $\alpha t$, el empotramiento del giro a torsión recupera menos deformación de la pieza (geométricamente esta relación entre $\alpha t$ y la capacidad del empotramiento a torsión de los estribos para disminuir la deformación del tablero, resulta intuitiva). Así con ángulos pequeños, el sistema se muestra insensible al empotramiento a torsión en los estribos (en el Diagrama 2.10, se muestran las solicitaciones torsoras del tablero isostático empotrado a flexión y del tablero completamente empotrado, para los ángulos $\frac{\pi}{12} y \frac{\pi}{2}$ ).

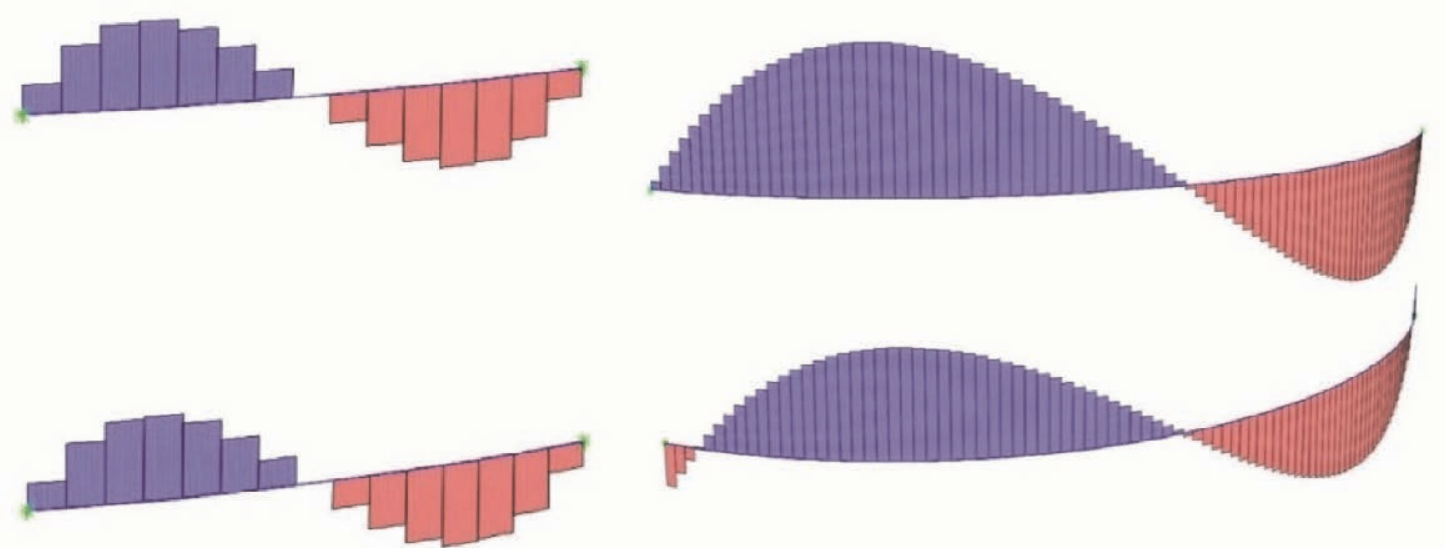

Diagrama 2.10. Momentos torsores sobre tableros empotrado a flexión (My) en los estribos (Graficas superiores) y a flexión (My) y torsión (Mx) en los estribos (Gráficas inferiores). $R t=280 m, \varphi_{K M y T}=1, q=1 \frac{K N}{m l}\left(p z[s]=-1 \frac{K N}{m l}\right)$. $\alpha t=\frac{\pi}{2}($ izquierda $) \alpha t=\frac{\pi}{2}($ derech $a)$.

Si se compara el momento torsor de empotramiento (Txemp) frente al momento flector de empotramiento (Myemp) y por otro lado el flector de empotramiento en el caso isostático $\left(\mathrm{My}_{\text {emp/Isos }}^{-}\right)$con el flector de empotramiento en el hiperestático $\left(\mathrm{My}^{-}{ }_{\text {emp } / \text { Hiper }}\right)$, para diferentes ángulos de arco $(\alpha t)$ con tablero con relación de rigidez $\varphi_{K T M y}=1$ :

\begin{tabular}{|c|c|c|}
\hline & $\alpha_{t}=\frac{\pi}{12}\left(\varphi_{K M y T}=1\right)$ & $\alpha_{t}=\frac{\pi}{2}\left(\varphi_{K M y T}=1\right)$ \\
\hline$\frac{\mathrm{Tx}_{\text {emp } / \text { Hiper }}}{M y_{\text {emp } / \text { Hiper }}^{-}}$ & $0,08 \%$ & $5,38 \%$ \\
\hline$\frac{M y_{\text {emp } / \text { Hiper }}^{-}}{M y_{\text {emp } / \text { Isos }}^{-}}$ & 1,0067 & 1,0568 \\
\hline
\end{tabular}

Tabla 2.8. Comparación de momentos de empotramiento, para diferentes ángulos de arco de tablero $\left(\alpha_{t}\right)$. Con relación de rigidez $\varphi_{K T M y}=1$. 
Si ahora se varía la relación de rigideces a $\varphi_{K T M y}=40$, comprobando su efecto sobre los momentos de empotramiento, relacionándolo de forma similar a como se hizo en la Tabla 2.9:

\begin{tabular}{|c|c|c|}
\hline & $\alpha_{t}=\frac{\pi}{12}\left(\varphi_{\text {KMyT }}=40\right)$ & $\alpha_{t}=\frac{\pi}{2}\left(\varphi_{\text {KMyT }}=40\right)$ \\
\hline$\frac{\mathrm{Tx}_{\text {emp } / \text { Hiper }}}{M y_{\text {emp/Hiper }}^{-}}$ & $0,55 \%$ & $12,58 \%$ \\
\hline$M y_{\text {emp/Hiper }}^{-}$ & 1,043 & 1,144 \\
\hline$M y_{\text {emp/Isos }}^{-}$ & & \\
\hline
\end{tabular}

Tabla 2.9. Comparación de momentos de empotramiento, para diferentes ángulos de arco de tablero $\left(\alpha_{t}\right)$. Con relación de rigidez $\varphi_{K T M y}=40$.

La relación entre rigideces $\left(\varphi_{K M y T}=\frac{E I y y}{G J}\right)$ vuelve a resultar determinante. Como se puede apreciar en las tablas, disminuir la rigidez torsora del tablero (y en consecuencia aumentar el factor de rigidez) supone un inmediato incremento en el empotramiento a flexión en los estribos $\left(\mathrm{My}^{-}{ }_{\text {emp/Hiper }}\right)$ cuando empotramos el torsor en los estribos. El sistema empotrado a flexión exclusivamente en los estribos, no resulta tan efectivo cuando se disminuye la rigidez a torsión de la sección $\left(\varphi_{K M y T}=\frac{E I y y}{G J}=40\right)$, luego los giros a lo largo de la sección son mayores y los desplazamientos verticales también (Tabla 2.2). Esta reducción de la efectividad por parte del empotramiento a flexión, permite al empotramiento a torsión de los estribos, como sistema hiperestático que es, desarrollar mayor trabajo a la hora de reducir los desplazamientos verticales. Debido a que el momento de estabilización, Hest, no varía, este incremento en el empotramiento a torsión $\left(T_{\text {emp } / \text { Hiper }}\right)$ debe llevar consigo un inmediato incremento en el empotramiento a flexión ( $\mathrm{M}^{-}$emp/Hiper $)$, para que su composición siga neutralizando el momento desestabilizador (Hest). De nuevo, esta reducción en la eficiencia del empotramiento a flexión a medida que se disminuye la capacidad de torsión, resulta de vital importancia para los sistemas resistivos más complejos, como el empotramiento elástico "ee" que se verá en el apartado 2.3 .

Como conclusión, se puede decir que, para cargas centradas respecto al eje del tablero, solo se nota la influencia del empotramiento a torsión, cuando se suma a un empotramiento a flexión, en tableros que desarrollan grandes ángulos $(\alpha t)$ y con baja rigidez a torsión $\left(\varphi_{K M y T}=\right.$ $\left.\frac{E I y y}{G J}\right)$.

\subsection{Deformaciones}

Para este tipo de carga, respecto del sistema isostático empotrado a flexión, la influencia es bastante limitada en lo que a rigidez se refiere (como se puede intuir a partir del subapartado 2.1.2.1.3.1), cuando se trata de tableros con alta rigidez a torsión $\left(\varphi_{K M y T}=1\right)$. Como ya se pudo apreciar en el análisis de deformaciones de los sistemas isostáticos, la rigidez del sistema viene fundamentalmente dada por el empotramiento a flexión (Tabla 2.10). 


\begin{tabular}{|l|l|l|}
\hline & $\alpha_{t}=\frac{\pi}{2}$ & $\alpha_{t}=\frac{\pi}{12}$ \\
\hline$\frac{d_{\mathrm{z}}\left(\varphi_{K M y T}=1\right)_{\text {Hiperestático }}}{d_{\mathrm{z}}\left(\varphi_{\text {KMYT }}=1\right)_{\text {Flexion }}}$ & $97,5 \%$ & $100 \%$ \\
\hline
\end{tabular}

Tabla 2.10. Comparativa desplazamientos verticales (dz) en el centro del vano, modelo empotrado a torsión y flexión en los estribos (Hiperestático) frente a modelos empotrado exclusivamente a flexión (Flexión). Carga vertical distribuida.

Al analizar la rigidez del sistema ante la carga centrada respecto del eje del tablero, se evidencia que aun siendo ciertas las conclusiones obtenidas en el subapartado 2.1.2.1.1.3, se amortiguan las diferencias tan abultadas que existían entre secciones de tablero $\left(\varphi_{K M y T}=\right.$ 1 y $\left.\varphi_{K M y T}=40\right)$, que se observaban en la Tabla 2.2. Como se ha podido observar en la Tabla 2.10 (coherente con la Tabla 2.8), el comportamiento del sistema hiperestático con una relación de rigideces del tablero cercana a la unidad $\left(\varphi_{K M y T}=1\right)$, apenas varía respecto al del sistema isostático empotrado a flexión en los estribos, sea cual sea el ángulo del tablero $(\alpha t)$. La diferencia de comportamiento entre sistemas con diferente relación de rigidez del tablero $\left(\varphi_{K M y T}=1\right.$ y $\left.\varphi_{K M y T}=40\right)$ disminuye significativamente para el ángulo más grande $\left(\alpha t=\frac{\pi}{2}\right.$, Tabla 2.11). Esto concuerda con lo visto en las solicitaciones (subapartado 2.1.2.1.3.1), donde se llegó a la conclusión de que el empotramiento de la sección a torsión en los estribos solo produce un cambio significativo en el sistema isostático empotrado a flexión en los estribos, cuando el ángulo desarrollado por el tablero $(\alpha t)$ es alto y la sección tiene baja rigidez torsora $\left(\varphi_{K M y T}=40\right)$. En esta situación, el empotramiento a torsión incrementa el valor de momento negativo empotrado a flexión, disminuyendo las deformaciones verticales del tablero.

\begin{tabular}{|c|c|c|}
\hline & $\alpha_{t}=\frac{\pi}{2}$ & $\alpha_{t}=\frac{\pi}{12}$ \\
\hline$\frac{d_{\mathrm{z}}\left(\varphi_{K M y T}=40\right)-d_{\mathrm{z}}\left(\varphi_{K M y T}=1\right)}{d_{\mathrm{z}}\left(\varphi_{K M y T}=1\right)}$ & $69 \%$ & $1 \%$ \\
\hline$\frac{g_{\mathrm{x}}\left(\varphi_{K M y T}=40\right)-g_{\mathrm{x}}\left(\varphi_{K M y T}=1\right)}{g_{\mathrm{x}}\left(\varphi_{K M y T}=1\right)}$ & $567 \%$ & $1690 \%$ \\
\hline
\end{tabular}

Tabla 2.11. Comparación deformaciones verticales máximas y giros de torsión máximos, según las condiciones de contorno y características de la sección del tablero (dz: Desplazamiento vertical, gx: Giro según eje de torsión), modelo empotrado a torsión y flexión en los estribos (Hiperestático). Carga vertical distribuida.

Como ocurría en el sistema isostático, cuando el ángulo $\alpha t$ es menor, las solicitaciones torsoras son despreciables, así como su influencia sobre las deformaciones y giros a lo largo del vano. A este efecto se le suma la casi nula influencia del empotramiento a torsión en los estribos, en sistemas hiperestáticos, para ángulos $\alpha t$ pequeños. Todo esto hace que la relación de rigideces pierda importancia y las relaciones de deformaciones entre diferentes tableros sean similares a los obtenidos con el sistema isostático ( $\alpha t=\frac{\pi}{12}$, Tabla 2.11 y sistema isostático Tabla 2.2). 
2.1.2.1.4 Sistema hiperestático, carga vertical, repartida y descentrada respecto al eje del tablero

\subsection{Solicitaciones}

Siguiendo el mismo esquema de análisis desarrollado para los sistemas isostáticos, se va a analizar el comportamiento del sistema separando la carga descentrada en carga centrada (cuyo análisis se ha desarrollado en el subapartado 2.1.2.1.3) y un momento torsor, resultado de multiplicar esta carga por la distancia de descentrado (desq). El esquema del modelo de tablero solicitado al momento torsor se puede aprecia en la llustración 2.3.

Por coherencia con el subapartado 2.1.2.1.3, para poder explicar el comportamiento del sistema con estribos completamente empotrados, se va a partir del sistema isostático con empotramiento a flexión en los estribos. En este sistema, existían los siguientes momentos de desestabilización, de empotramiento en los estribos y positivo en el centro del vano, cuando se introducía un momento torsor distribuido sobre el tablero:

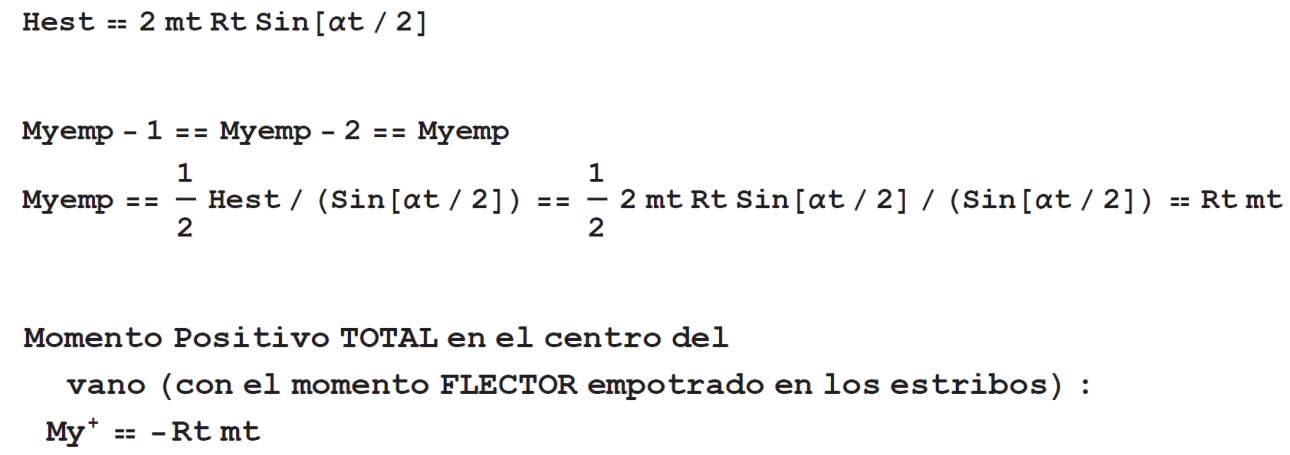

Para tableros en los que se desarrollen grandes ángulos $\alpha t$ ( $\alpha t=\pi / 2$ en nuestro ejemplo), cuál de los 2 empotramientos, de flexión o de torsión, resulta más eficiente va a depender de la relación de rigidez del tablero: $\varphi_{K M y T}=1$, hará más efectivo el empotramiento a torsión y $\varphi_{K M Y T}=40$ hará más efectivo el empotramiento a flexión. Partiendo del modelo empotrado a flexión, si se empotra el torsor, se evita, en el estribo, el giro constante a torsión que se producía a lo largo de todo el tablero. Según sea la rigidez del tablero a torsión (que se ha reflejado con el factor de relación de rigideces, $\varphi_{K M y T}=\frac{E I y y}{G J}$ ), este empotramiento (o recuperación del giro en el estribo) se producirá con mayor o menor momento torsor (se debe recordar que el giro es constante a lo largo del tablero y solo depende del radio, el momento torsor introducido y la rigidez a flexión del tablero). Es obvio, que este torsor de empotramiento será de sentido contrario al momento torsor introducido (y al giro que este produce, como se puede apreciar en la llustración 2.3). Luego, en el caso de que el torsor sea producido por un desq $>0$ este momento torsor de empotramiento se ira transformando a lo largo del tablero, por la curvatura, en un momento flector positivo que disminuirá el momento negativo reinante (que era cte a lo largo de todo el tablero en el sistema isostático, empotrado a flexión), produciendo un desplazamiento vertical negativo en la zona central del tablero (recordamos que el desplazamiento vertical era nulo en el tablero isostático, empotrado a flexión, solicitado por un momento torsor). Mientras que si desq $<0$, 
ocurrirá lo contrario, contrarrestando el momento positivo reinante, con el consiguiente levantamiento de la zona central del tablero.

En los siguientes diagramas se puede apreciar lo comentado en el párrafo anterior:

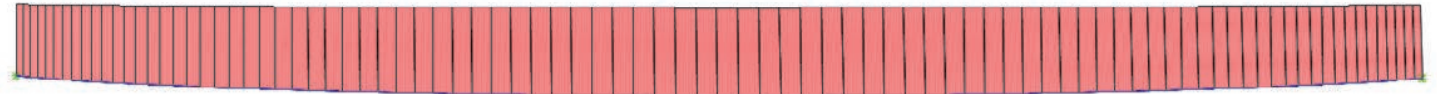

Diagrama 2.11. Diagrama de momento flector, para un sistema isostático empotrado a flexión (superior) y un sistema hiperestático (inferior). $\alpha_{t}=\frac{\pi}{2}$ y $\varphi_{K M y T}=1$.

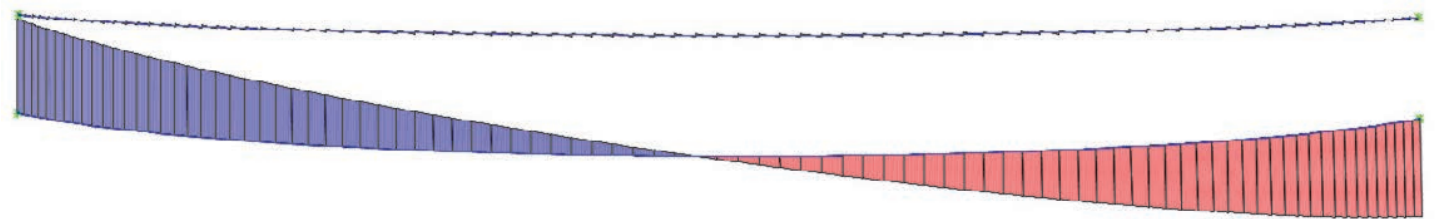

Diagrama 2.12 Diagrama de momento torsor, para un sistema isostático empotrado a flexión (superior) y un sistema hiperestático (inferior). $\alpha_{t}=\frac{\pi}{2}$ y $\varphi_{K M y T}=1$.
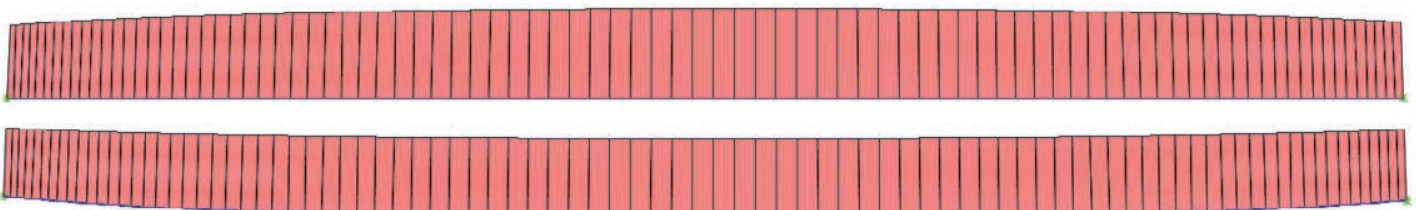

Diagrama 2.13. Diagrama de momento flector, para un sistema isostático empotrado a flexión (superior) y un sistema hiperestático (inferior). $\alpha_{t}=\frac{\pi}{2} \mathrm{y} \varphi_{K M y T}=40$.

Diagrama 2.14. Diagrama de momento flector, para un sistema isostático empotrado a flexión (superior) y un sistema hiperestático (inferior). $\alpha_{t}=\frac{\pi}{2} \mathrm{y} \varphi_{K M y T}=40$.

El comportamiento de los tableros con ángulos $\alpha t$ pequeños $(\alpha t=\pi / 12$ en nuestro ejemplo), queda completamente marcado por la ineficiencia del empotramiento a flexión frente al momento torsor. Mientras el factor de relación de rigideces quede cercano a la unidad $\left(\varphi_{K M y T}=\frac{E I y y}{G J} \approx 1\right)$, el torsor solicitante se contrarresta casi en su totalidad con un torsor de empotramiento que, a su vez, debido a la falta de ángulo, apenas introduce momento flector a lo largo del tablero. Esta tendencia, cambia sensiblemente si se aumenta el factor de relación de rigideces $\left(\varphi_{K M y T}=40\right.$, en nuestro ejemplo). En ese caso, parte de la 
solicitación torsora (aunque sea pequeña, ya que sigue existiendo una gran ineficiencia en el empotramiento a flexión debido a la geometría) se traspasa al empotramiento a flexión, por la pérdida de rigidez del empotramiento a torsión. Esto no resulta muy eficiente, porque como ya se vio en los sistemas isostáticos, el empotramiento a flexión requiere de altos momentos de empotramiento, que acaban convirtiéndose en grandes solicitaciones a flexión para el tablero.

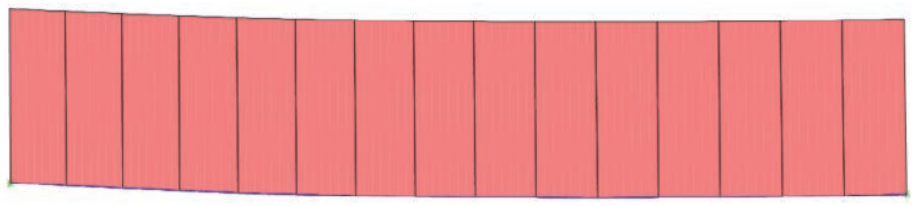

Diagrama 2.15 Diagrama de momento flector, para un sistema isostático empotrado a flexión (superior) y un sistema hiperestático (inferior). $\alpha_{t}=\frac{\pi}{12}$ y $\varphi_{K M Y T}=1$.

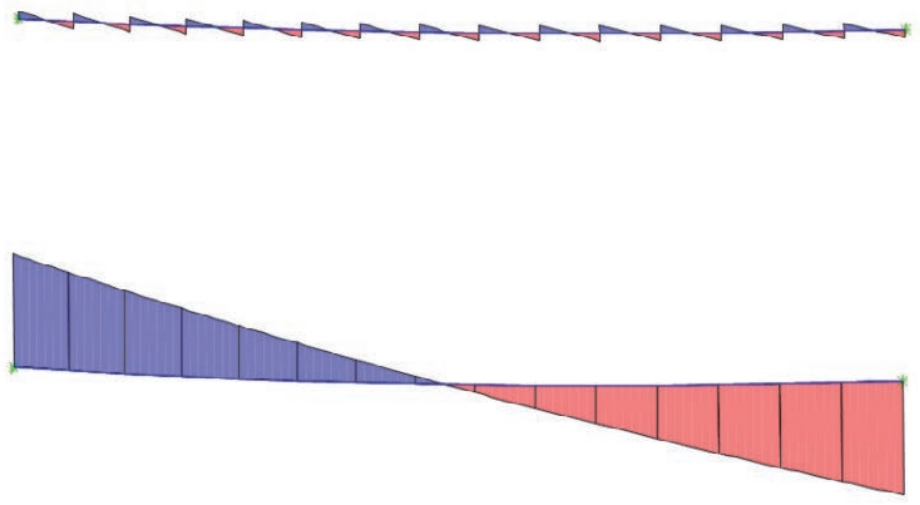

Diagrama 2.16 Diagrama de momento torsor, para un sistema isostático empotrado a flexión (superior) y un sistema hiperestático (inferior). $\alpha_{t}=\frac{\pi}{12}$ y $\varphi_{K M Y T}=1$. 


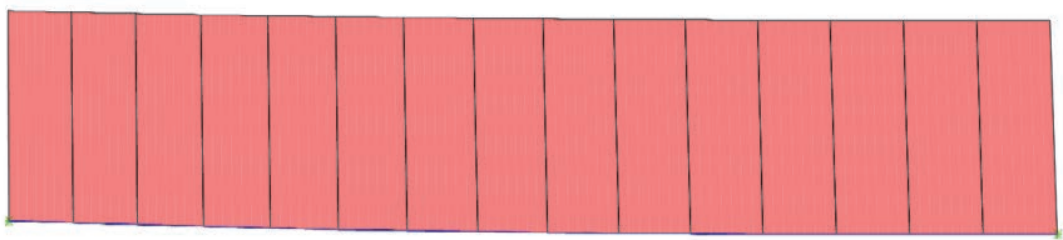

Diagrama 2.17. Diagrama de momento flector, para un sistema isostático empotrado a flexión (superior) y un sistema hiperestático (inferior). $\alpha_{t}=\frac{\pi}{12}$ y $\varphi_{K M y T}=40$.

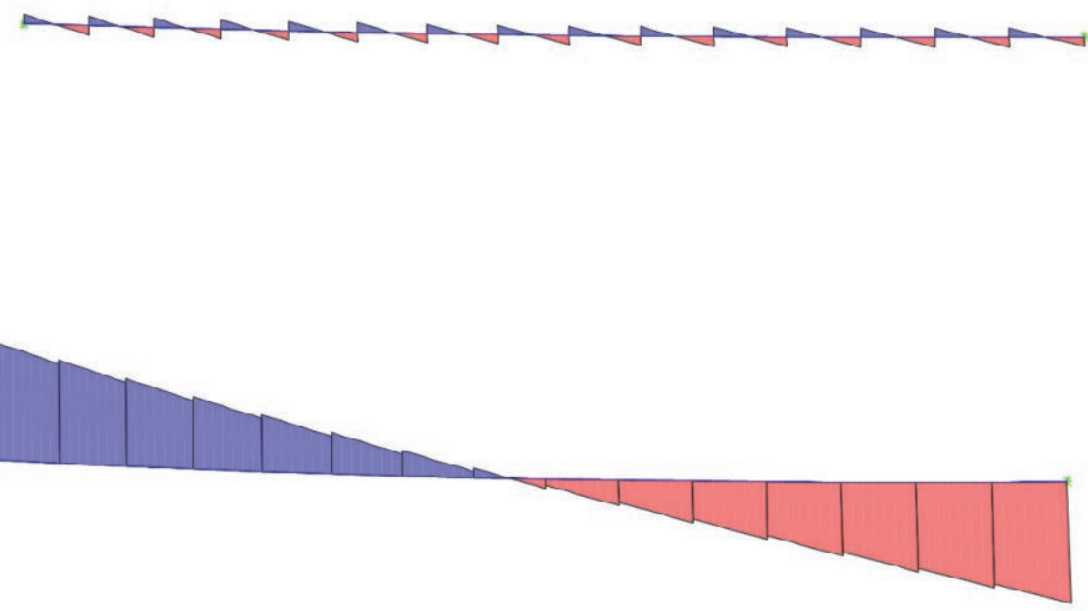

Diagrama 2.18. Diagrama de momento torsor, para un sistema isostático empotrado a flexión (superior) y un sistema hiperestático (inferior). $\alpha_{t}=\frac{\pi}{12}$ y $\varphi_{K M Y T}=40$.

Si se refleja esto en valores todo esto en valores (desq $=5$ ):

\begin{tabular}{|c|c|c|}
\hline & $\alpha_{t}=\frac{\pi}{12}\left(\varphi_{K M Y T}=1\right)$ & $\alpha_{t}=\frac{\pi}{2}\left(\varphi_{K M y T}=1\right)$ \\
\hline$\frac{\mathrm{Tx}_{\text {emp/Hiper }}}{M y^{-}{ }_{\text {emp/Hiper }}}$ & 11,38 & 1,75 \\
\hline$\frac{M y_{\text {emp/Hiper }}^{-}}{M y^{-}{ }_{\text {emp } / \text { Isos }}}$ & $1,14 \%$ & $36,38 \%$ \\
\hline
\end{tabular}

Tabla 2.12. Comparación de momentos de empotramiento, para diferentes ángulos de arco de tablero $\left(\alpha_{t}\right)$. Con relación de rigidez $\varphi_{K T M y}=1$.

Si ahora comprobamos el efecto de la rigidez a torsión y su relación con el nivel de empotramiento que se produce, 


\begin{tabular}{|c|c|c|}
\hline & $\alpha_{t}=\frac{\pi}{12}\left(\varphi_{\text {KMyT }}=40\right)$ & $\alpha_{t}=\frac{\pi}{2}\left(\varphi_{\text {KMyT }}=40\right)$ \\
\hline$\frac{\mathrm{Tx}_{\text {emp } / \text { Hiper }}}{M y_{\text {emp } / \text { Hiper }}^{-}}$ & 0.558 & 0,085 \\
\hline$M y_{\text {emp } / \text { Hiper }}^{-}$ & $19 \%$ & $92,15 \%$ \\
\hline$M y_{\text {emp } / \text { Isos }}^{-}$ & & \\
\hline
\end{tabular}

Tabla 2.13. Comparación de momentos de empotramiento, para diferentes ángulos de arco de tablero $\left(\alpha_{t}\right)$. Con relación de rigidez $\varphi_{K T M y}=40$.

Como dato importante, deducible de los resultados de las tablas anteriores y que permite entender la magnitud de la ineficiencia del empotramiento a flexión de los tableros que desarrollan poco ángulo. El empotramiento a torsión con $\alpha_{t}=\frac{\pi}{12}$, cuando aumentamos el factor de relación de rigideces de $\varphi_{K M y T}=1$ a $\varphi_{K M y T}=40$ disminuye en un $18,13 \%$, mientras que su momento flector de empotramiento se multiplica por 16,7 .

\subsection{1 Conclusiones}

El análisis del sistema hiperestático con carga descentrada, se obtiene conjugando lo visto en este subapartado y en el subapartado 2.1.2.1.3. De la suma de estos análisis, se puede extraer un patrón de comportamiento, en lo que a solicitaciones se refiere, según el tipo de sección utilizada:

1. En el caso de secciones con alta rigidez frente a la torsión (secciones cerradas, $\left.\varphi_{K M y T}=1\right)$

a. Cargas centradas en el eje del tablero: Serán resistidas mediante el empotramiento a flexión casi en su totalidad, sin que el ángulo desarrollado por el tablero tenga mucha importancia.

b. Momento torsor debido al descentramiento de la carga: Será resistido por el empotramiento a torsión casi en su totalidad en el caso de ángulos $\alpha t$ bajos ( $\alpha_{t}=\frac{\pi}{12}$, en nuestro ejemplo). Mientras que se repartirá más entre los 2 sistemas en el caso de ángulos $\alpha t$ altos $\left(\alpha_{t}=\right.$ $\frac{\pi}{2}$, en nuestro ejemplo).

2. En el caso de secciones con baja rigidez frente a la torsión (secciones abiertas, $\left.\varphi_{K M y T} \gg 1\right):$

a. Cargas centradas en el eje del tablero: Serán resistidas mediante el empotramiento a flexión casi en su totalidad, sin que el ángulo desarrollado por el tablero tenga mucha importancia.

b. Momento torsor debido al descentramiento de la carga: Será resistido por el empotramiento a torsión en su gran mayoría en el caso de ángulos $\alpha t$ bajos ( $\alpha_{t}=\frac{\pi}{12}$, en nuestro ejemplo). Mientras que será resistido casi en su totalidad por el empotramiento a flexión en el caso de ángulos $\alpha t$ altos ( $\alpha_{t}=\frac{\pi}{2}$, en nuestro ejemplo). 


\subsection{Deformaciones}

Gran parte del análisis válido para este subapartado sobre la rigidez del sistema, se ha realizado en el subapartado 2.1.2.1.4.1. Partiendo de nuevo del sistema isostático empotrado a flexión, solicitado exclusivamente a un momento torsor. Al sumarle el empotramiento a torsión, se reducen los giros de torsión $(g x)$ en mayor medida cuanto menor sea el ángulo desarrollado por el tablero ( $\alpha t$ cuando gana eficiencia el empotramiento a torsión y la pierde el empotramiento a flexión) y a cambio se produce un incremento en los desplazamientos verticales (se debe recordar que una solicitación torsora constante no crea desplazamientos verticales sobre un sistema isostático empotrado a flexión). El signo de este incremento dependerá del signo del descentramiento de la carga desq (según se produce momento flector positivo o negativo, como se vio en el subapartado 2.1.2.1.4.1). Como ya se vio en el análisis de las solicitaciones, estos efectos serán menos notables cuanto mayor sea el factor de relación de rigideces. Con desq $=5$ (dz: Desplazamiento vertical, gx: Giro según eje de torsión, para el centro del vano del puente):

\begin{tabular}{|c|c|c|}
\hline & $\alpha_{t}=\frac{\pi}{2}$ & $\alpha_{t}=\frac{\pi}{12}$ \\
\hline$\frac{g_{\mathrm{x}}\left(\varphi_{K M y T}=1\right)_{\text {Hiperestático }}}{g_{\mathrm{x}}\left(\varphi_{K M Y T}=1\right)_{\text {ISOS FLEXIÓN }}}$ & $29,5 \%$ & $0,86 \%$ \\
\hline
\end{tabular}

Tabla 2.14. Comparativa giros de torsión (gz) en el centro del vano, modelo empotrado a torsión y flexión en los estribos (Hiperestático) frente a modelo empotrado exclusivamente a flexión (Flexión). Carga torsora distribuida.

\begin{tabular}{|l|c|c|}
\hline & $\alpha_{t}=\frac{\pi}{2}$ & $\alpha_{t}=\frac{\pi}{12}$ \\
\hline$\frac{g_{\mathrm{x}}\left(\varphi_{K M Y T}=40\right)_{\text {Hiperestático }}}{g_{\mathrm{x}}\left(\varphi_{\text {KMYT }}=40\right)_{\text {Isos FLEXIÓN }}}$ & $140 \%$ & $28 \%$ \\
\hline
\end{tabular}

Tabla 2.15. Comparativa giros de torsión (gz) en el centro del vano, modelo empotrado a torsión y flexión en los estribos (Hiperestático) frente a modelo empotrado exclusivamente a flexión (Flexión). Carga torsora distribuida.

Se puede apreciar en la Tabla 2.15, como el giro ha aumentado en el caso de $\alpha t=\frac{\pi}{2} \mathrm{y}$ $\varphi_{K M y T}=40$. Debemos recordar que este valor refleja los valores en el centro del vano, mientras que en el hiperestático se reduce a cero a medida que llegamos a los estribos y en el isostático se mantiene constante a lo largo de toda la trayectoria. Este fenómeno tiene su explicación en que el empotramiento a torsión, reduce el empotramiento a flexión. Cuando el ángulo $\alpha t$ desarrollado es grande, este decremento en el momento de empotramiento a flexión resulta más determinante, debido a la curvatura, sobre el giro de torsión (gx, Diagrama 2.19) en el centro e vano que el incremento de empotramiento a torsión, siempre y cuando la rigidez a torsión es muy pequeña $\left(\varphi_{K M y T} \gg 1\right)$. 


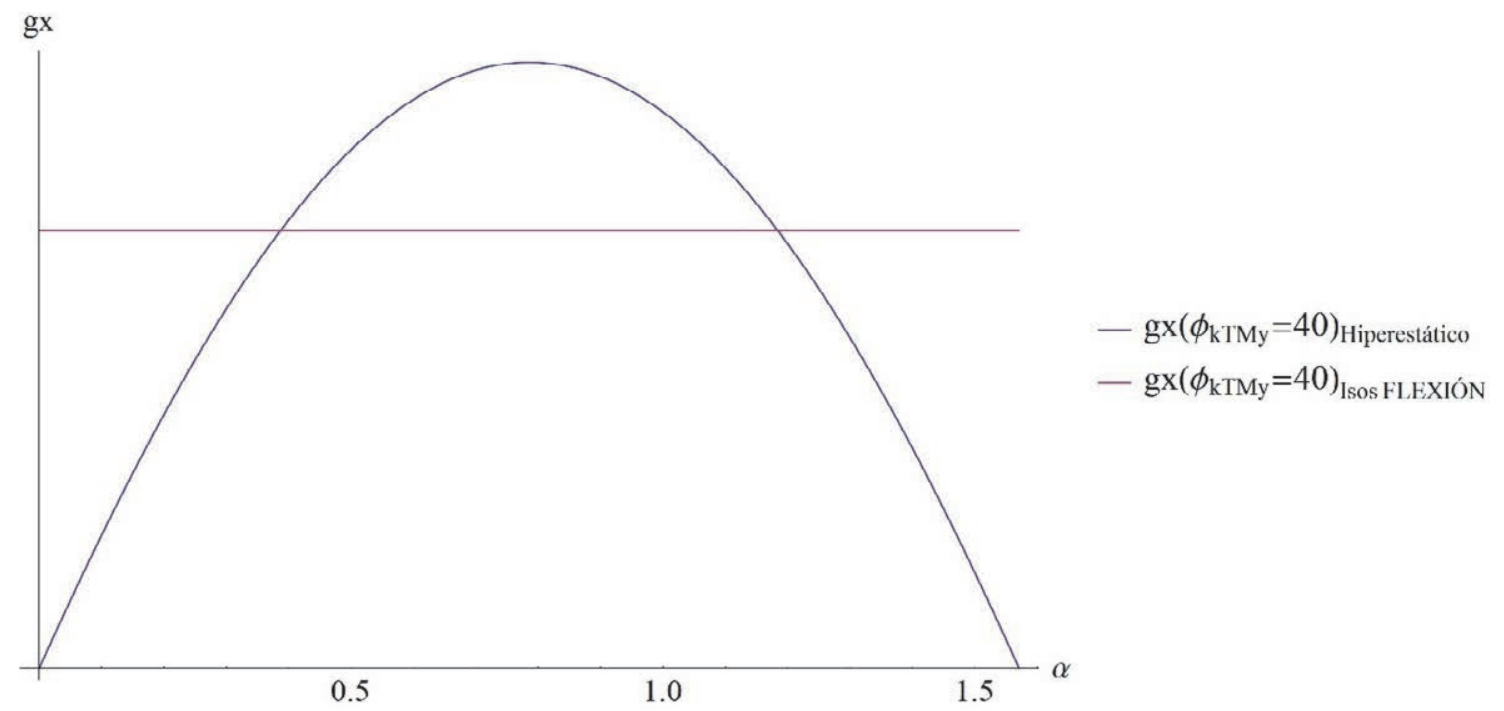

Diagrama 2.19. Comparativa giros de torsión (gz) a lo largo del tablero, modelo empotrado a torsión y flexión en los estribos (Hiperestático) frente a modelo empotrado exclusivamente a flexión (Flexión). Carga torsora distribuida. $\alpha_{t}=\frac{\pi}{2}, \varphi_{K M Y T}=40$.

Si ahora nos concentramos en las diferencias que aparecen cuando descentramos la carga, en el sistema hiperestático, frente a la hipótesis en la que la carga se encuentra centrada.

\begin{tabular}{|c|c|c|}
\hline & $\alpha_{t}=\frac{\pi}{2}$ & $\alpha_{t}=\frac{\pi}{12}$ \\
\hline$\frac{d_{\mathrm{z}}\left(\varphi_{K M y T}=1\right)_{\text {Torsión }}}{d_{\mathrm{z}}\left(\varphi_{K M y T}=1\right)_{\text {Carga centrada }}}$ & $3,35 \%$ & $0,58 \%$ \\
\hline$\frac{g_{\mathrm{x}}\left(\varphi_{K M y T}=1\right)_{\text {Torsión }}}{g_{\mathrm{x}}\left(\varphi_{K M y T}=1\right)_{\text {Carga centrada }}}$ & $24,58 \%$ & $873 \%$ \\
\hline
\end{tabular}

Tabla 2.16. Comparativa desplazamientos verticales (dz) y giros de torsión (gx) en el centro del vano, modelo empotrado a torsión y flexión en los estribos (Hiperestático). Momento torsor distribuido (desq = 5), frente a carga vertical distribuida. $\varphi_{K M Y T}=1$.

\begin{tabular}{|c|c|c|}
\hline & $\alpha_{t}=\frac{\pi}{2}$ & $\alpha_{t}=\frac{\pi}{12}$ \\
\hline$\frac{\left.d_{\mathrm{z}} \varphi_{K M y T}=40\right)_{\text {Torsión }}}{d_{\mathrm{z}}\left(\varphi_{K M Y T}=40\right)_{\text {Carga centrada }}}$ & $5,03 \%$ & $10,1 \%$ \\
\hline$\frac{g_{\mathrm{x}}\left(\varphi_{K M y T}=40\right)_{\text {Torsión }}}{g_{\mathrm{x}}\left(\varphi_{K M y T}=40\right)_{\text {Carga centrada }}}$ & $17,5 \%$ & $1653 \%$ \\
\hline
\end{tabular}

Tabla 2.17. Comparativa desplazamientos verticales (dz) y giros de torsión (gx) en el centro del vano, modelo empotrado a torsión y flexión en los estribos (Hiperestático). Momento torsor distribuido (desq = 5), frente a carga vertical distribuida. $\varphi_{K M Y T}=40$.

Se puede apreciar la similitud que existe entre estas tablas (Tabla 2.16 y Tabla 2.17) y las del subapartado 2.1.2.1.2.2 (Tabla 2.4 -> Tabla 2.7). Como entonces y como se puede deducir del análisis de solicitaciones, la influencia del descentrado de la carga sobre el desplazamiento vertical ( $\mathrm{dz}$ ) es mínimo. Luego los desplazamientos verticales van a venir marcado casi de forma exclusiva por las cargas verticales (esta afirmación se va a ver ratificada en numerosas ocasiones a lo largo de la tesis), teniendo muy poca influencia si esta está o no centrada (esta afirmación es más rotunda si cabe para el modelo hiperestático). 
En cuanto al giro de torsión, como ya se explicó en el subapartado 2.1.2.1.2.2, la torsión introducida (la misma por metro lineal para los 2 ángulos) es en comparación a la que tienen con carga centrada, mucho mayor para los ángulos pequeños que para los ángulos grandes (el límite sería un puente con un ángulo $\alpha t=0$, donde el torsor introducido por la carga centrada sería nulo). En el caso de ángulos más pequeños, la razón del incremento la encontramos en que el comportamiento con carga centrada, se centra casi exclusivamente en su empotramiento a flexión, mientras que su comportamiento frente a la solicitación de torsión, lo hace en su empotramiento a torsión, este cambio de funcionamiento es el que provoca que el salto en giros al desplazar la carga sea tan grande. En el caso de ángulos más grandes, este efecto se ve amortiguado por la eficiencia que le confiere al empotramiento a flexión la curvatura.

\subsubsection{Conclusiones}

1. El momento torsor y el momento flector están conectados en la viga curva mediante la curvatura. Esto hace que las solicitaciones torsoras puedan ser resistidas mediante mecanismos de flexión y viceversa. Esta capacidad, del tablero curvo, va a estar íntimamente ligada al ángulo que se desarrolle en el vano y a su relación entre rigideces $\left(\varphi_{K M y T}=\frac{E I y y}{G J}\right)$.

2. Cuanto mayor sea el ángulo $\alpha t$ desarrollado por el tablero, más importancia tiene que el tablero quede empotrado a flexión, ya que su eficiencia incrementa drásticamente tanto para neutralizar solicitaciones flectoras y torsoras, como para coaccionar el tablero frente a deformaciones y giros. Con ángulos pequeños, la eficiencia del empotramiento a flexión frente a cargas descentradas, es mínimo, siendo necesario para este tipo de solicitaciones un empotramiento a torsión (esto llega a su extremo en el caso de un puente recto).

3. En lo que a la relación de rigideces $\left(\varphi_{K M y T}=\frac{E I y y}{G J}\right)$ se refiere, una relación equilibrada resulta necesaria para tableros en los que se desarrollan grandes ángulos. De lo contrario, no se realiza correctamente la ya comentada transferencia entre momento flector y momento torsor, perdiendo las ventajas que el empotramiento a flexión y/o a torsión y la curvatura le transfieren al sistema, incrementando mucho las deformaciones (sobre todo los giros de torsión: gx). Obviamente la influencia del valor de $\varphi_{K M y T}=\frac{E I y y}{G J}$ es mucho mayor en el caso de tableros empotrados a torsión que en el de aquellos empotrados a flexión. En cuanto a los tableros que desarrollan pequeños ángulos, si bien la influencia de $\varphi_{K M y T}=\frac{E I y y}{G J}$ no se hace tan patente, cuando se descentra la carga, la influencia del factor de relación de rigideces se hace determinante. 


\subsection{Viga curva con carga en su plano}

\subsubsection{Introducción y resumen}

En los puentes curvos atirantados, las cargas en el plano horizontal son a la vez determinantes e inevitables. Estas cargas procederán tanto de acciones externas (viento, tráfico, sismo...) (80), (73), (28) y (59), donde se deben incluir las acciones transversales sobre los tirantes de sujeción (73), como de acciones internas producidas por el subsistema PilaTirantes. Estas últimas, las acciones internas, van a ser las que más solicitaciones van a producir sobre el tablero y las más determinantes en lo que al comportamiento del puente se refiere.

Se comenzará (subapartado 2.2.3.1) analizando las condiciones de contorno de los estribos con el comportamiento de la viga curva isostática, en la que se deja libre una dirección horizontal libre en los apoyos. Se muestran los resultados frente a una carga de dirección $\mathrm{X}$ global, analizando cuál es la dirección óptima para restringir en los apoyos y la estabilidad de ese comportamiento ante hipótesis de carga diferente. Finalmente se analiza un puente curvo atirantado completo, frente a cargas repartidas a lo largo de diferentes zonas del tablero, con estas condiciones de apoyo, para concluir que se deben restringir los desplazamientos horizontales en todas las direcciones en los apoyos.

Una vez establecidas las condiciones de contorno necesarias para el correcto funcionamiento del tablero, se pasa a estudiar la viga curva con 3 tipos diferentes de carga en su plano. Por un lado, posibles cargas exteriores: con carga según el eje global X, Fpx (en el subapartado 2.2.4), y con carga según el eje global Y, Fpy (en el 2.2.5). Por otro lado, la carga interna producida por los tirantes de sujeción sobre el tablero: la carga concéntrica a la pila (subapartado 2.2.6).

Esta última (carga distribuida concéntrica) se va a estudiar en profundidad, por ser intrínseca al sistema de atirantamiento en puentes curvos atirantados y porque, en gran medida, el diseño del puente y su comportamiento van a estar determinados por el rendimiento del tablero ante ellas. La carga concéntrica es resultado directo de la configuración de la pila respecto del tablero. Por esta razón, se dividen los posibles escenarios en 4: pila situada en el centro de la circunferencia (subapartado 2.2.6.1), pila situada en el eje de simetría del tablero $(\alpha p=0)$, en el subapartado 2.2.6.2.1, pila situada en el eje recta radial que pasa por el estribo $\left(\alpha p=\frac{\alpha t}{2}\right)$ y pila situada en la recta que para por el ángulo intermedio entre el eje de simetría del arco del tablero y la recta que pasa por el estribo $\left(\alpha p=\frac{\alpha t}{4}\right)$, que veremos en el subapartado 2.2.6.2.2. En los subapartados donde la pila se sitúa a lo largo de una recta y no de un punto (el 2.2.6.2.1 y el 2.2.6.2.2), se mueve la pila a lo largo de esta línea analizando el comportamiento en cada una de las situaciones.

En todo momento se muestran las ecuaciones matemáticas que resuelven el problema, con la intención de que todo el análisis quede expuesto al lector.

Cojugando la configuración geométrica del problema y las propiedades mecánicas de la sección del tablero con el comportamiento mostrado ante este tipo de cargas, se establece 
una clasificación que va a permitir predecir el comportamiento horizontal del puente mediante fórmulas parametrizadas que muestran la importancia de cada variable en la conducta del puente. Esto permitirá al ingeniero tomar decisiones correctas en busca del comportamiento deseado.

Finalmente, se analiza el comportamiento y las cargas concéntricas para diferentes disposiciones de anclaje de los tirantes de sujeción sobre la cabeza de pila (subapartado 2.2.6.2.3). Se estudia la posibilidad de modificar el módulo de las cargas concéntricas a lo largo del trazado del tablero de cara a aproximar la forma curva circular del tablero a la antifunicular de las cargas transmitidas por los tirantes. Por último, se comparan las diferentes disposiciones de los tirantes entre ellas, mostrando diferencias y similitudes, siempre en lo que a las cargas concéntricas se refiere. 


\subsubsection{Análisis resistivo}

La viga curva, con cargas en su plano, tiene la particularidad de acoplar el axil con el momento transversal. Para este tipo de carga (en su plano), se anularán los siguientes grados de libertad, (17):

a) No van a existir deformaciones verticales, ni rotaciones según el eje radial, lo que supone que tanto el cortante vertical como el momento según el eje radial van a ser nulos: $\mathrm{Qz}=0$ y $\mathrm{My}=0$.

b) No van a existir rotaciones según el eje longitudinal ( $x$ local, apéndice 5.1), lo que supone que el momento torsor va a ser nulos: $\mathrm{Tx}=\mathrm{Mz}=0$.

En la llustración 2.5, se puede apreciar un tramo diferencial de una viga curva (con sus ejes locales), de radio Rt y ángulo d $\alpha$, cargada según las direcciones radial y circunferencial, en su plano. Las simplificaciones adoptadas son, que el centro de cortantes coincide con el de gravedad, entorno al que se concentran todas las propiedades elásticas.

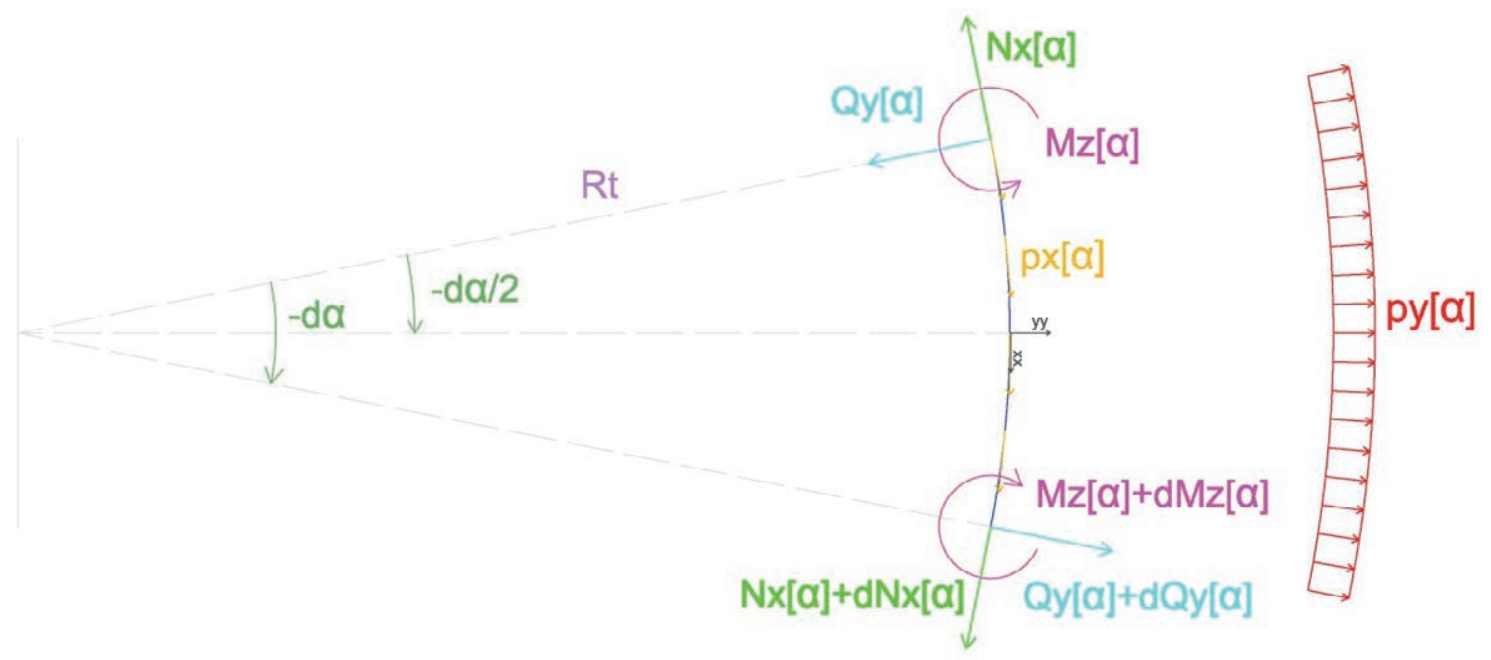

Ilustración 2.5. Modelo de cálculo para un tablero curvo bajo carga en su plano.

Equilibrio de fuerzas en la dirección local yy (eje local del tramo diferencial)

$-p y[\alpha] \operatorname{Rt} d \alpha-Q y[\alpha] \operatorname{Cos}\left[\frac{d \alpha}{2}\right]+(Q y[\alpha]+d Q y[\alpha]) \operatorname{Cos}\left[\frac{d \alpha}{2}\right]+N x[\alpha] \sin \left[\frac{d \alpha}{2}\right]+(N x[\alpha]+d N x[\alpha]) \sin \left[\frac{d \alpha}{2}\right]==0$

Equilibrio de fuerzas en la dirección local xx (eje local del tramo diferencial)

$-\operatorname{px}[\alpha] \operatorname{Rt} d \alpha-N x[\alpha] \operatorname{Cos}\left[\frac{d \alpha}{2}\right]+(N x[\alpha]+d N x[\alpha]) \operatorname{Cos}\left[\frac{d \alpha}{2}\right]-Q y[\alpha] \sin \left[\frac{d \alpha}{2}\right]-(Q y[\alpha]+d Q y[\alpha]) \operatorname{Sin}\left[\frac{d \alpha}{2}\right]==0$

Equilibrio de momentos según el eje local - zz (negativo) y del centro del arco de circunferencia

$-\mathrm{px}[\alpha] \mathrm{Rt} d \alpha \mathrm{Rt}-\mathrm{Nx}[\alpha] \mathrm{Rt}+(\mathrm{Nx}[\alpha]+\mathrm{dNx}[\alpha]) \mathrm{Rt}-\mathrm{Mz}[\alpha]+(\mathrm{Mz}[\alpha]+\mathrm{dMz}[\alpha])==0$

Si se simplifica asumiendo lo siguiente: 


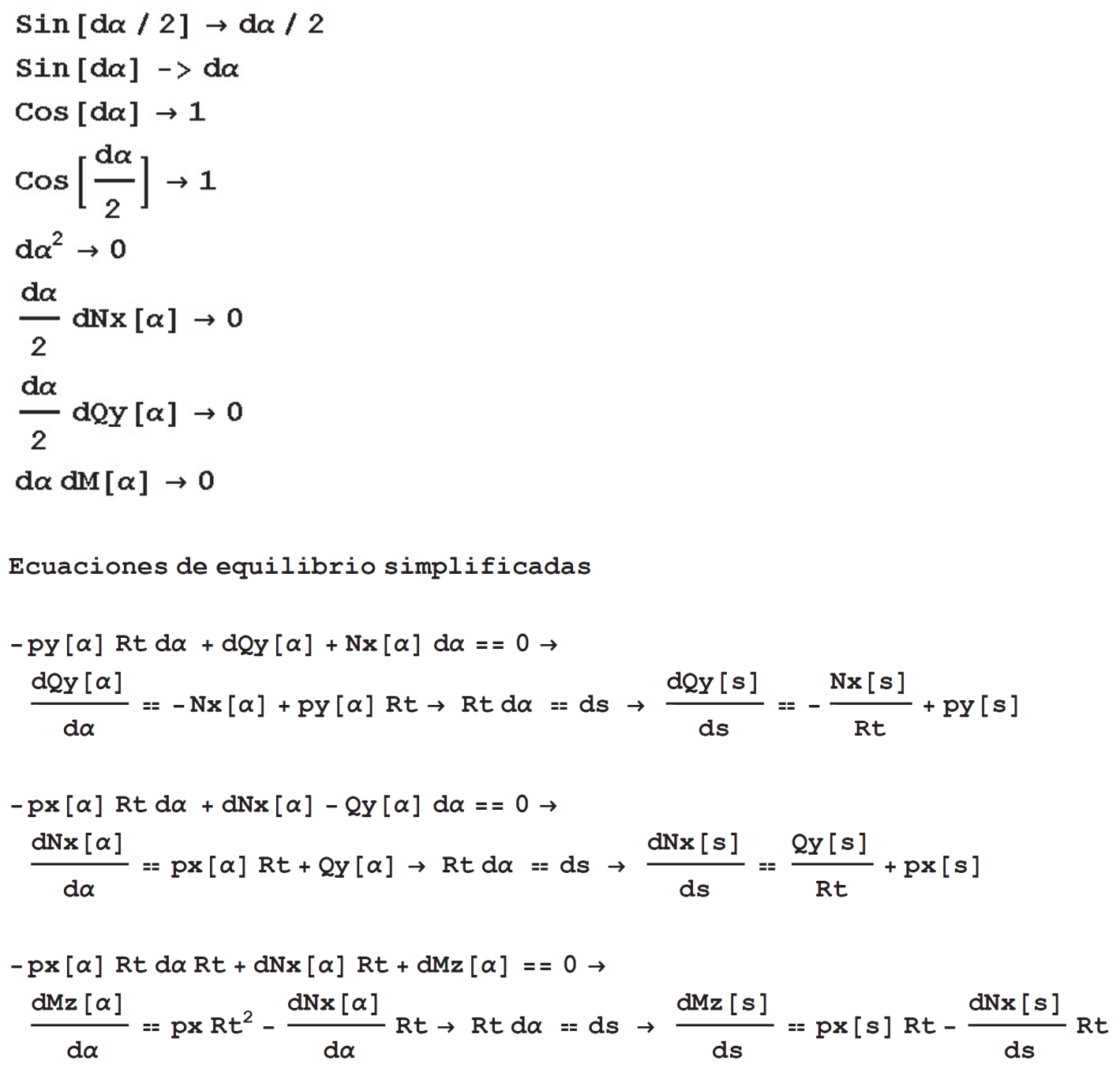

El acoplamiento entre el momento flector en torno al eje z-z (Mz) y el axil (Nx), es en realidad una relación entre el cortante según el eje local y-y (transversal al tablero) y el axil, de forma que a medida que el tablero va girando, parte del cortante se va transformando en axil y viceversa, de forma que el axil del tablero acaba produciendo momento según el eje vertical $(\mathrm{Mz})$.

Este acoplamiento va a ser determinante a la hora de decidir la disposición de la pila frente al tablero. La disposición entre pila y tablero, se puede hacer tal, que proporcione una carga sobre el tablero que contrarreste esta conversión del axil en cortante transversal con la curvatura (un ejemplo de esto es la rueda de una bicicleta). Es la inversión de este principio, el que conduce al diseño del "Tablero AXIL" (apartado 2.5). Los principios que rigen este comportamiento, como ocurría con el acoplamiento entre momento flector y torsor, deben tenerse presentes a lo largo de todo el análisis:

- La conversión es directamente proporcional a la curvatura (este principio, aunque obvio por las ecuaciones vistas, se debe tener muy presente cuando se esté diseñando tableros del tipo Tablero-AXIL (apartado 2.5)). 
- Van a existir 2 tipos de carga principales en el plano XY para puentes curvos atirantados (peatonales y de carretera):

- Por un lado, van a estar las cargas transversales, este va a ser el caso de las cargas debidas a viento, (29) y (53), y peatonales (75), (40) y (59). Estas cargas van a ser, habitualmente, de módulo pequeño y poco determinantes a nivel estático, mientras que a nivel dinámico pueden llegar a ser más problemáticas, (101), (80), (85), (43), (86) y (40) (quedando este estudio fuera del alcance de esta tesis).

o Por otro lado, las cargas concéntricas introducidas por los tirantes al sustentar el tablero. Estas cargas no van a ser unidireccionales, su dirección va a coincidir con la proyección en planta del tirante. Por ello es tan importante la posición de la pila. Mientras que su módulo va a ser proporcional a la relación entre la altura de la pila sobre el tablero y longitud de la línea que forma la proyección del tirante en planta.

- Las condiciones de contorno en los estribos, van a ser cruciales para las solicitaciones en el tablero. En concreto los desplazamientos que vamos a restringir en los estribos (no se va a estudiar un posible un empotramiento del momento en torno al eje vertical, por su difícil ejecución y reducida eficacia). En el caso que nos ocupa, puente curvo atirantado, resulta necesario (en casi todos los casos) un apoyo intraslacional en los estribos para un comportamiento compatible con los usos del puente (los desplazamientos que se producen en los extremos provocarían un tecleo entre el extremo del puente y la vía de acceso). Las diferentes posibilidades se estudiarán en un inicio, descartando las que no se consideren aptas.

Las ecuaciones diferenciales que nos quedan van a ser (con funciones en $\alpha$ y s):

Ecuaciones diferenciales en función de $\alpha$

$$
\begin{aligned}
& \frac{\mathrm{dQY}[\alpha]}{\mathrm{d} \alpha}==\mathrm{py}[\alpha] \mathrm{Rt}-\mathrm{Nx}[\alpha] \rightarrow \frac{\mathrm{d}^{2} Q \mathrm{y}[\alpha]}{\mathrm{d} \alpha^{2}}+\mathrm{QY}[\alpha]==\mathrm{Rt}\left(\frac{\mathrm{dpy}[\alpha]}{\mathrm{d} \alpha}-\mathrm{px}[\alpha]\right) \\
& \frac{\mathrm{dNx}[\alpha]}{\mathrm{d} \alpha}==\mathrm{px}[\alpha] \operatorname{Rt}+\mathrm{QY}[\alpha] \rightarrow \frac{\mathrm{d}^{2} \mathrm{Nx}[\alpha]}{\mathrm{d} \alpha^{2}}+\mathrm{Nx}[\alpha]==\mathrm{Rt}\left(\mathrm{py}[\alpha]+\frac{\mathrm{dpx}[\alpha]}{\mathrm{d} \alpha}\right) \\
& \frac{\mathrm{dMz}[\alpha]}{\mathrm{d} \alpha}==\mathrm{pxRt}{ }^{2}-\frac{\mathrm{dNx}[\alpha]}{\mathrm{d} \alpha} \operatorname{Rt} \rightarrow \frac{\mathrm{dMz}[\alpha]}{\mathrm{d} \alpha}==-\mathrm{QY}[\alpha] \mathrm{Rt} \rightarrow \frac{\mathrm{d}^{3} \mathrm{Mz}[\alpha]}{\mathrm{d} \alpha^{3}}+\frac{\mathrm{dMz}[\alpha]}{\mathrm{d} \alpha}=\mathrm{Rt}^{2}\left(\mathrm{px}[\alpha]-\frac{\mathrm{dpy}[\alpha]}{\mathrm{d} \alpha}\right)
\end{aligned}
$$

Ecuaciones diferenciales en función de s

$$
\begin{aligned}
& \frac{\mathrm{d} Q \mathrm{y}[\mathrm{s}]}{\mathrm{ds}}==\mathrm{py}[\mathrm{s}]-\frac{\mathrm{Nx}[\mathrm{s}]}{\mathrm{Rt}} \rightarrow \frac{\mathrm{d}^{2} \mathrm{QY}[\mathrm{s}]}{\mathrm{ds}^{2}}+\frac{Q \mathrm{y}[\mathrm{s}]}{\mathrm{Rt}^{2}}=\frac{\mathrm{dpy}[\mathrm{s}]}{\mathrm{ds}}-\frac{1}{\mathrm{Rt}} \mathrm{px}[\mathrm{s}] \\
& \frac{\mathrm{dNx}[\mathrm{s}]}{\mathrm{ds}}==\frac{\mathrm{Qy}[\mathrm{s}]}{\mathrm{Rt}}+\mathrm{px}[\mathrm{s}] \rightarrow \frac{\mathrm{d}^{2} \mathrm{Nx}[\mathrm{s}]}{\mathrm{ds^{2 }}}+\frac{\mathrm{Nx}[\mathrm{s}]}{\mathrm{Rt}^{2}}==\frac{1}{\mathrm{Rt}} \mathrm{py}[\mathrm{s}]+\frac{\mathrm{dpx}[\mathrm{s}]}{\mathrm{ds}} \\
& \frac{\mathrm{dMz}[\mathrm{s}]}{\mathrm{ds}}==\mathrm{px}[\mathbf{s}] \mathrm{Rt}-\frac{\mathrm{dNx}[\mathrm{s}]}{\mathrm{ds}} \mathrm{Rt} \rightarrow \frac{\mathrm{dMz}[\mathrm{s}]}{\mathrm{ds}}==-\mathrm{QY}[\mathbf{s}] \rightarrow \frac{\mathrm{d}^{3} \mathrm{Mz}[\mathrm{s}]}{\mathrm{ds}^{3}}+\frac{1}{\mathrm{Rt}^{2}} \frac{\mathrm{dMz}[\mathbf{s}]}{\mathrm{ds}}==\frac{1}{\mathrm{Rt}} \operatorname{px}[\mathbf{s}]-\frac{\mathrm{dpy}[\mathbf{s}]}{\mathrm{ds}}
\end{aligned}
$$




\subsubsection{Condiciones de contorno}

Del análisis resistivo del tablero frente a cargas en su plano, se extrae que en el plano horizontal (Plano XY global, apartado 5.1), la única alternativa posible a un apoyo intraslacional va a ser un sistema isostático en el que se restrinja una sola dirección en los estribos. Se va a estudiar esta posibilidad, para comprobar su viabilidad.

\subsubsection{Sistema isostático, restringiendo el desplazamiento según la directriz del tablero en los estribos, carga en el plano del tablero, dirección X-X global (Fpx)}

Si se solucionan estas ecuaciones diferenciales para una viga curva, restringiendo el desplazamiento en la dirección perimetral del tablero y permitiendo el desplazamiento radial del tablero, introduciendo una carga $F p x=1 \mathrm{KN} / \mathrm{ml}$ (carga lineal con la dirección del eje X-X principal o global) se obtiene, para la siguiente geometría:

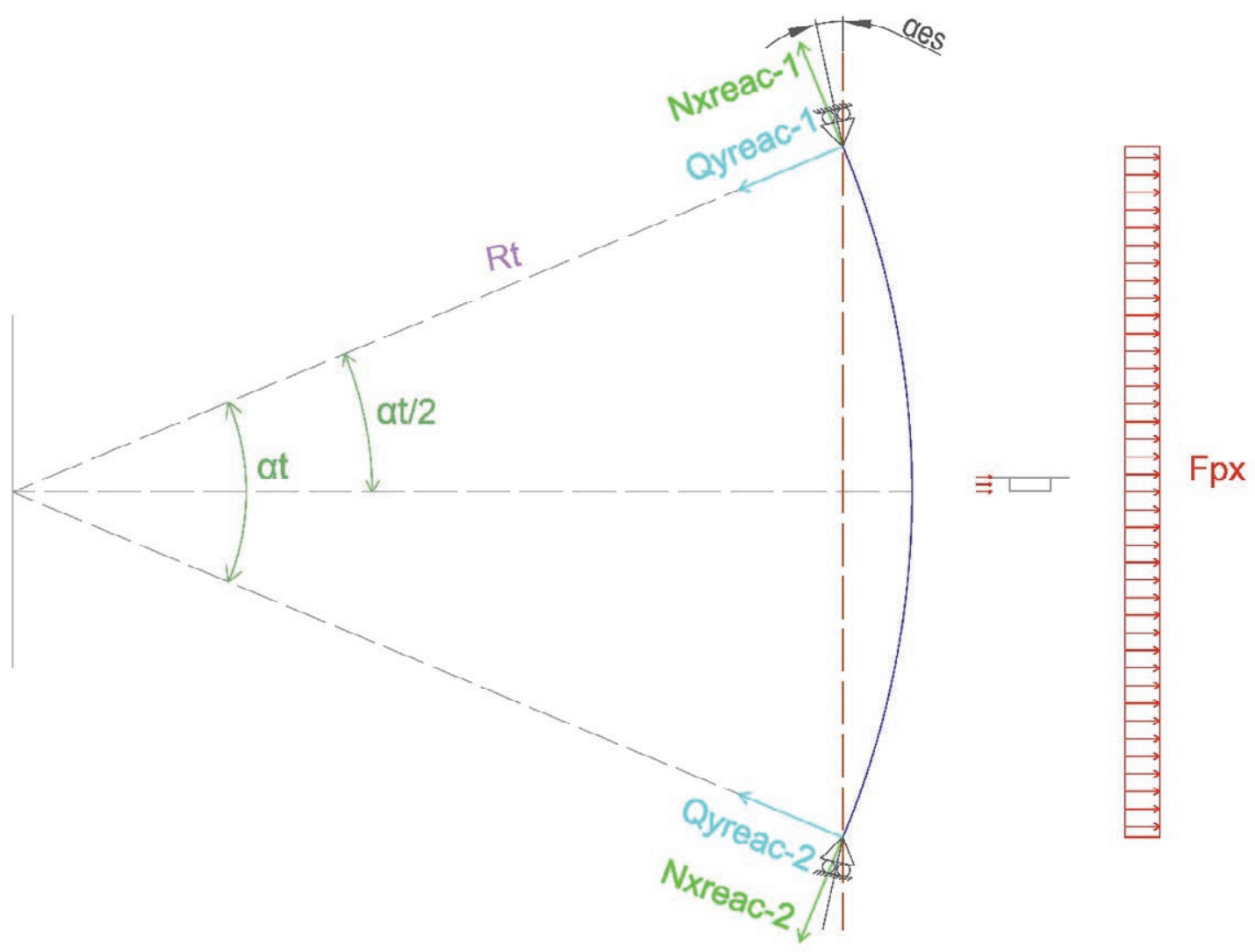

Ilustración 2.6. Modelo de cálculo para un tablero curvo bajo carga distribuida en el plano X global.

Las cargas sobre el tablero, si se aplica una carga distribuida en el eje X global, en ejes locales van a ser (función del ángulo del tablero $\alpha$ ):

$$
\begin{gathered}
p x[\alpha]=F p x \operatorname{Cos}[\alpha] \operatorname{Sin}[\alpha] \\
p y[\alpha]=F p x \operatorname{Cos}[\alpha]^{2}
\end{gathered}
$$




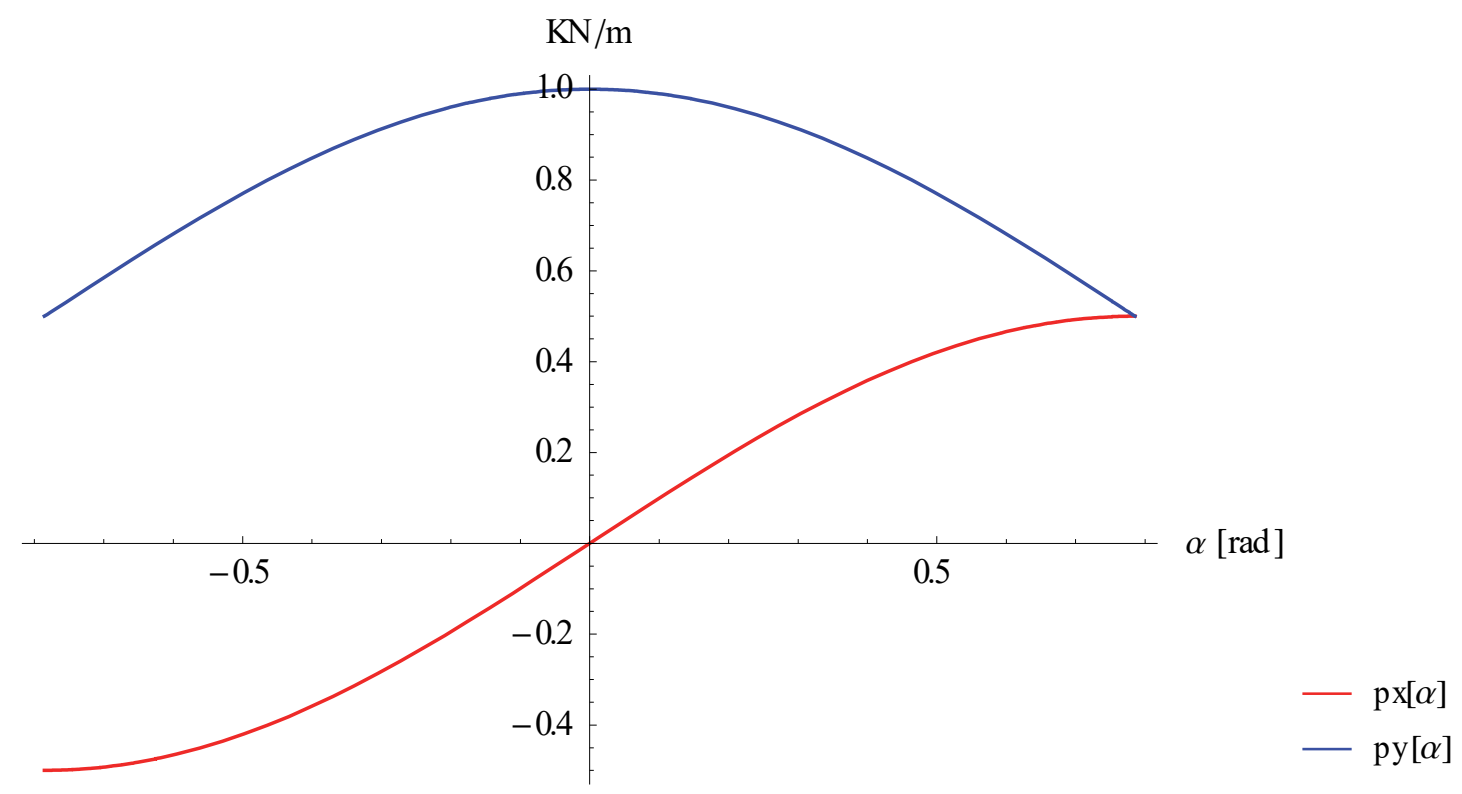

Diagrama 2.20. Proyección en ejes locales de una carga $F p x=1 \mathrm{KN} / \mathrm{ml}$ (eje global X). $\alpha t=\frac{\pi}{2}$.

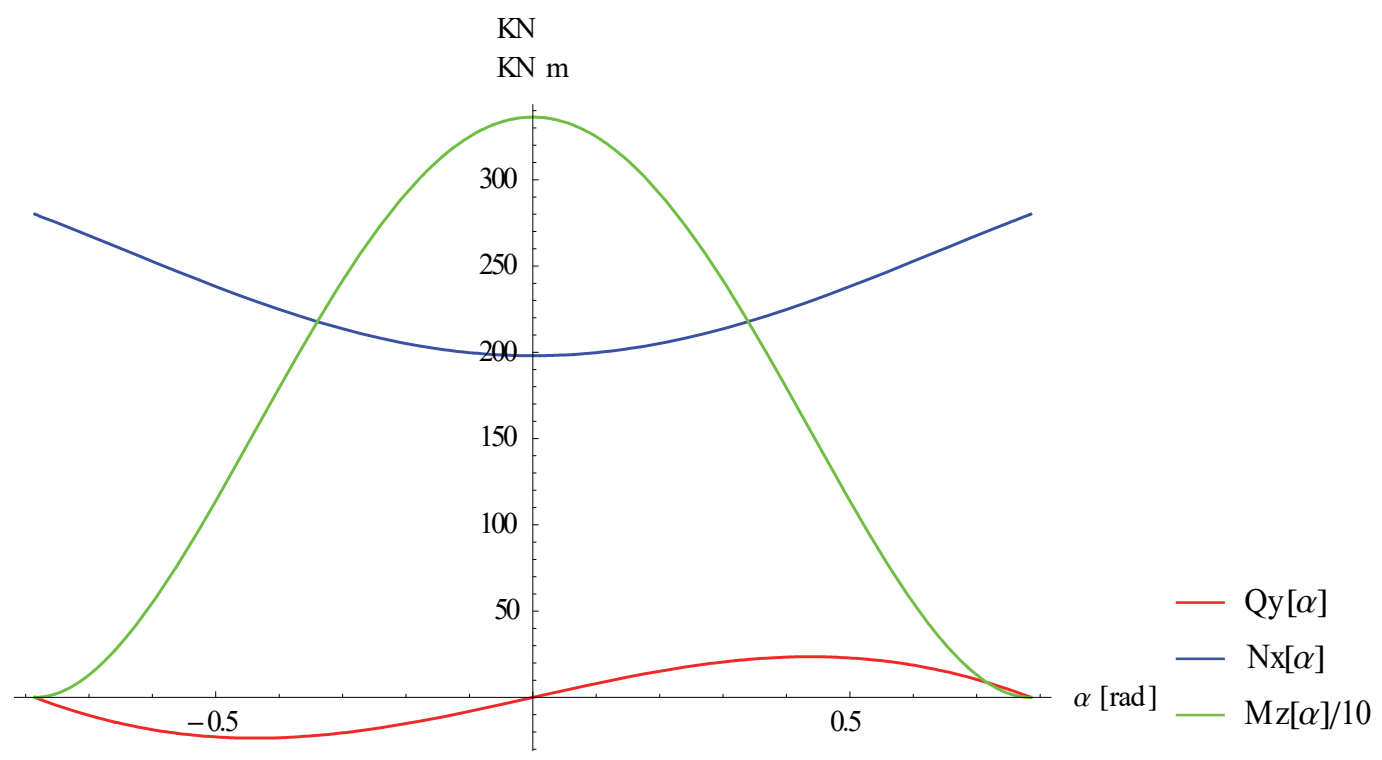

Diagrama 2.21. Solicitaciones sobre el tablero isostático bajo una carga $F p x=1 \mathrm{KN} / \mathrm{ml}$ (eje global X). $\alpha t=\frac{\pi}{2}$, $R t=280 m$, $\alpha e s=\frac{\alpha t}{2}$.

Si se estudia el comportamiento con diferentes ángulos, lo primero que salta a la vista es que la reacción axil que se produce en los estribos solo depende de la carga exterior y del radio del tablero:

$$
N x_{\text {reac }-1}=N x_{\text {reac }-2}=R_{t} * F_{p x}
$$

Esto significa, que la disminución de carga que supone acortar el tablero (disminuir $\alpha t$ ), se ve compensada por el incremento que supone que la reacción se produzca en un ángulo más desfavorable. 
Resulta obvio, que el ángulo elegido para restringir el movimiento en los estribos ( $\alpha e s$ ), es determinante para las solicitaciones y los movimientos del tablero. Esto se puede apreciar en el Diagrama 2.22, donde se muestra el diagrama de momentos flectores $\mathrm{Mz}$ a medida que se modifica el ángulo de apoyo en los estribos $\alpha e s$ (con las mismas condiciones de contorno de los diagramas Diagrama 2.19 y Diagrama 2.20). Como se puede apreciar, existen ángulos $\alpha e s$ para los que, tanto las solicitaciones del tablero, como sus deformaciones se minimizan. Si bien también se puede apreciar, lo rápido que estas solicitaciones incrementan a medida que nos separamos de este ángulo óptimo. El problema surge de las diversas hipótesis de carga a las que se ve expuesto el tablero de un puente curvo atirantado y que cada una de ellas tiene su propio ángulo óptimo (siendo estos bastante dispares en el caso de solicitaciones no simétricas). Como se ha podido comprobar en los modelos completos del puente (Diagrama 2.23), aun introduciendo el ángulo óptimo para las hipótesis más solicitantes, aparecen multitud de hipótesis que producen desplazamientos y solicitaciones incompatibles con un correcto funcionamiento del puente.

Diagramas de momento con diferentes ángulos de apoyo en los estribos

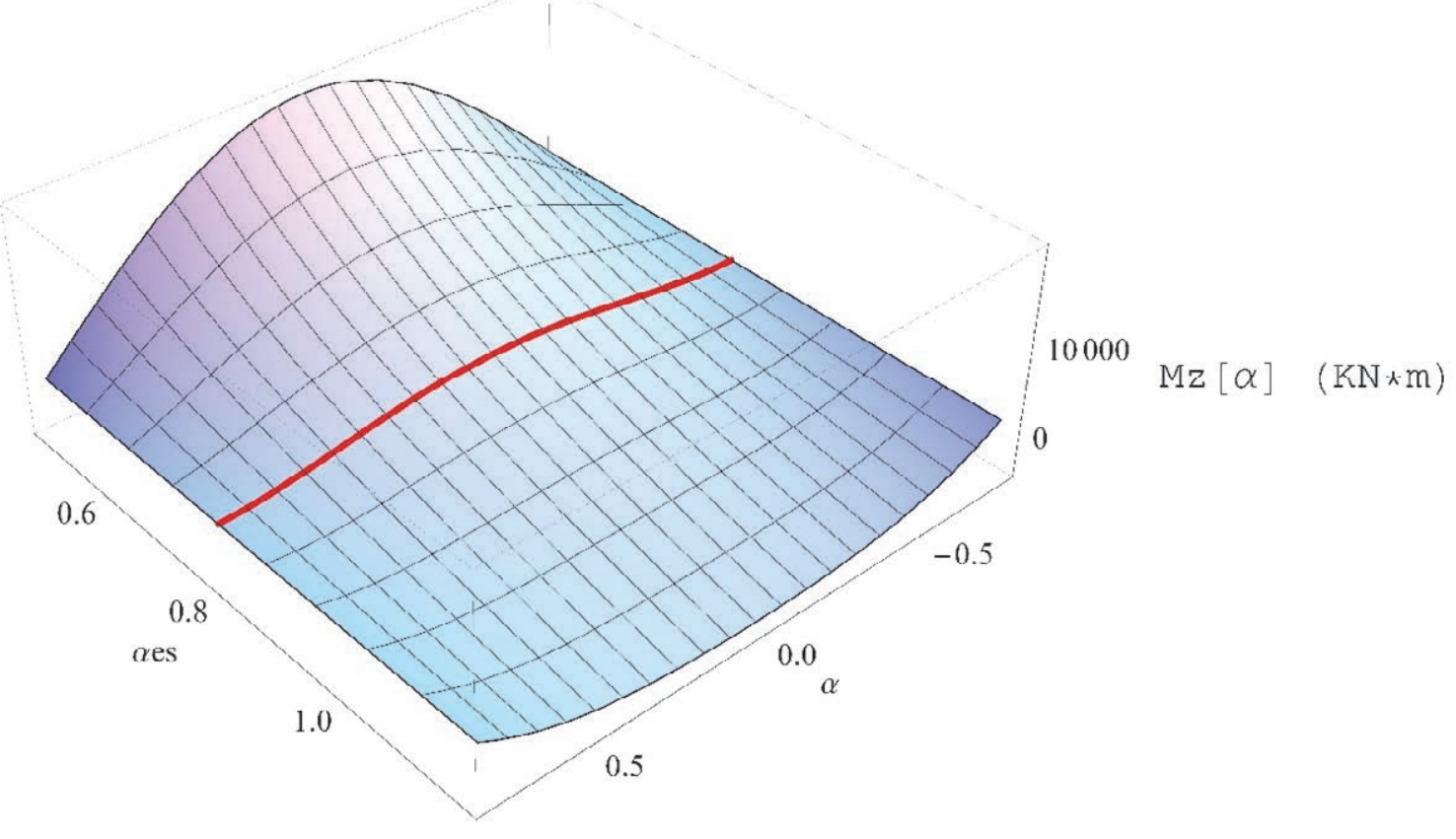

Diagrama 2.22. Momento flector $\mathbf{M z}[\boldsymbol{\alpha}]$ para un tablero isostático bajo una carga $F p x=1 \mathrm{KN} / \mathrm{ml}$, con diferentes ángulos de apoyo en los estribos $(\alpha e s) . \alpha t=\frac{\pi}{2}, R t=280 \mathrm{~m}$. 
Tablero: $\alpha \mathrm{t}=\frac{5 \pi}{6} \mathrm{rad}, \mathrm{Rt}=70 \mathrm{~m}$.

Pila: $\alpha \mathrm{p}=0 \mathrm{rad}, \mathrm{Rp}=0 \mathrm{~m}$.

Alturas: pila $h p=100 \mathrm{~m}$, tablero $\mathrm{ht}=44 \mathrm{~m}$.

Pila inclinada al CDG.

Nudos Tablero $n=101$, Tirantes $(n t-2)=24$.

a)

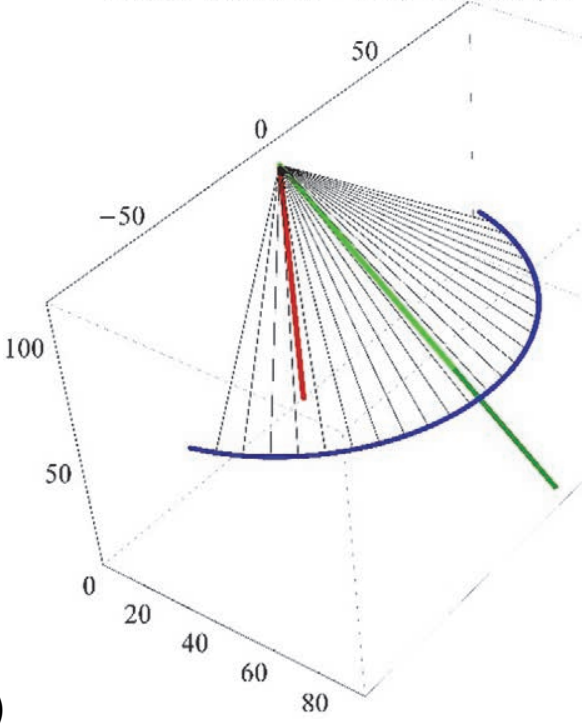

Desplazamientos y Giros

Desplazamiento TANGENCIAL (escala:0)

Desplazamiento RADIAL (escala:1) Desplazamiento Z (escala:1)

Giro $X^{\prime}-X^{\prime}$ (escala:0) Giro $Y^{\prime}-Y^{\prime}$ (escala:0) Giro $Z^{\prime}-Z^{\prime}$ (escala:0) Giro W-W (escala:0)

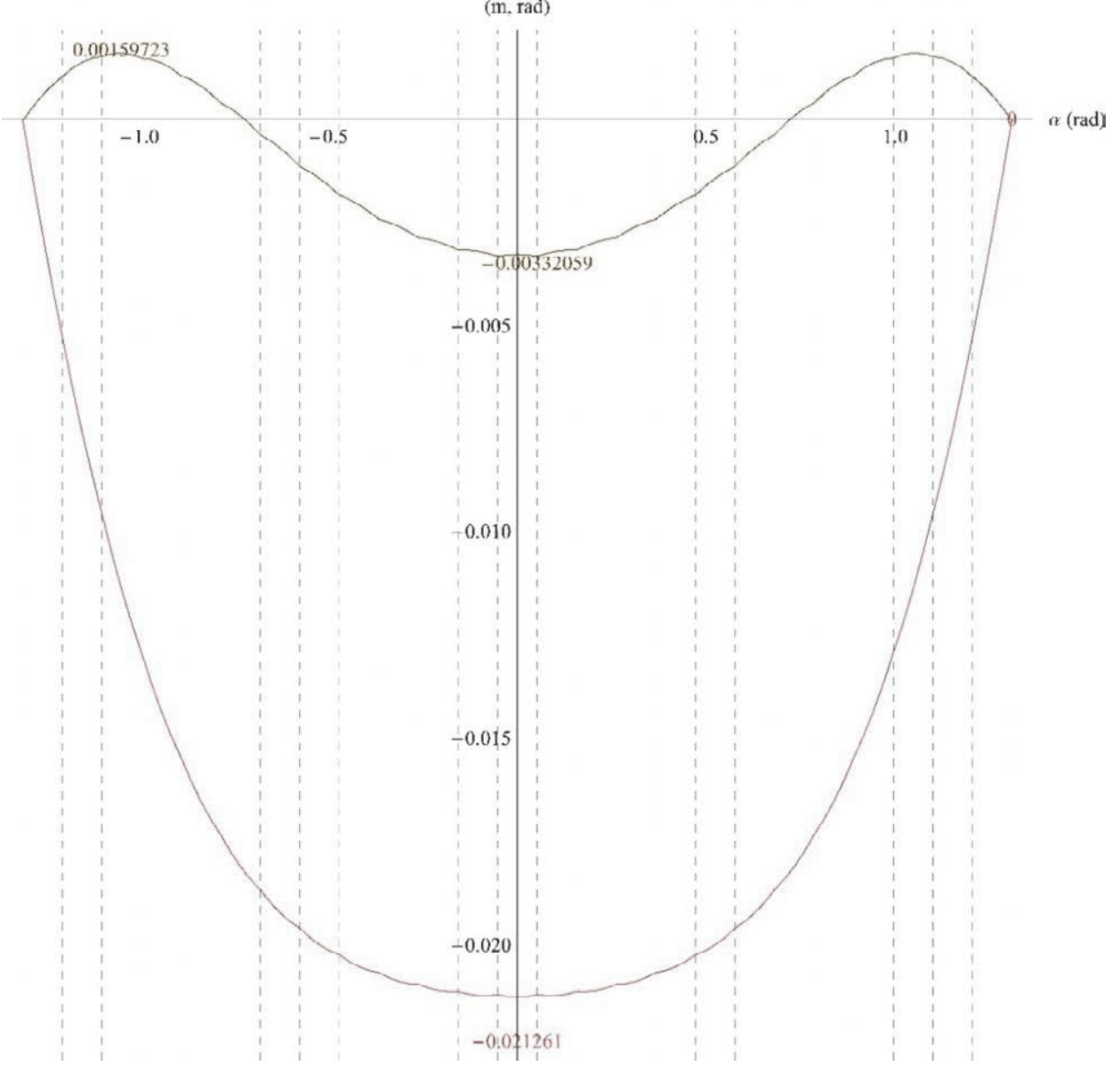




\section{Desplazamientos y Giros}

\section{Desplazamiento TANGENCIAL (escala:0)}

Desplazamiento RADIAL (escala:1) Desplazamiento Z (escala:1)

Giro $X^{\prime}-X^{\prime}$ (escala:0) Giro $Y^{\prime}-Y^{\prime}$ (escala:0) Giro Z'-Z' (escala:0) Giro W-W (escala:0)

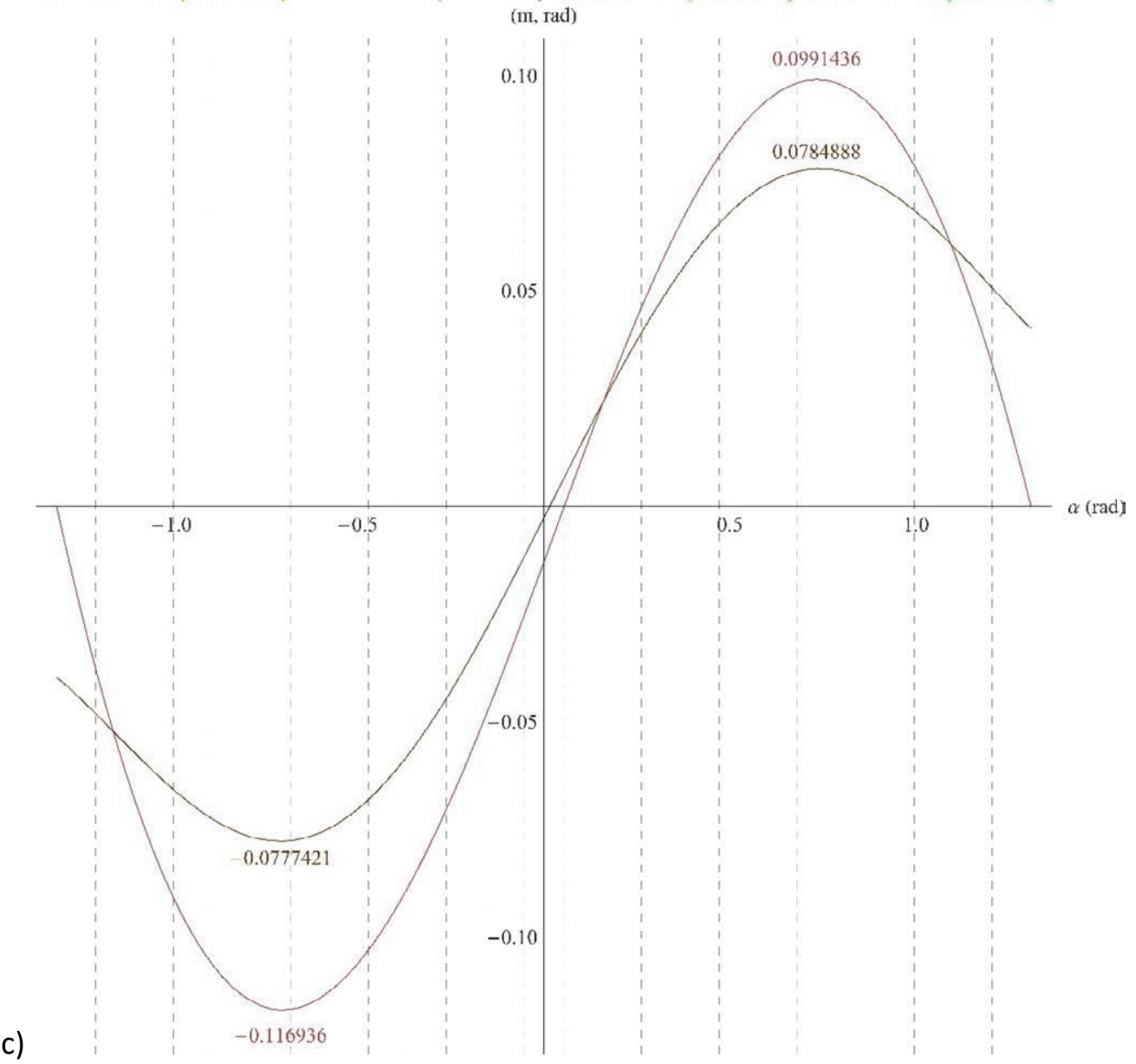

Diagrama 2.23. a) Pasarela peatonal analizada, con apoyos traslacionales en los estribos. Ángulo $\boldsymbol{\alpha e}$ s optimizado para una carga homogénea a lo largo de todo el tablero; b) Deformaciones de la pasarela para la hipótesis de uso frecuente, distribuidas las cargas a lo largo de todo el tablero; c) Deformaciones de la pasarela para la hipótesis de uso frecuente, pero con la carga distribuida solo en una mitad del puente.

\subsection{Conclusiones}

Como conclusión al análisis de los modelos con apoyos traslacionales en los estribos:

1. El comportamiento del tablero queda determinado por el ángulo de apoyo en los estribos $\alpha e s$.

2. Existe un ángulo $\alpha e s$ para cada carga, que optimiza el comportamiento del tablero. Una pequeña variación respecto de este ángulo, empeora drásticamente este comportamiento.

3. Debido a la gran diversidad de hipótesis de carga que se dan, tanto en puentes de carretera como en pasarelas. La probabilidad de que exista una hipótesis de carga que provoque una respuesta incompatible con el uso del puente es muy alta.

4. A partir de aquí se van a estudiar en exclusiva, puentes con apoyos intraslacionales en los estribos. 


\subsubsection{Sistema hiperestático, apoyos intraslacionales en los estribos, carga en el plano del tablero, dirección X-X global (Fpx)}

\subsubsection{Solicitaciones}

Si los apoyos en los estribos son intraslacionales, el sistema tendrá un grado de hiperestatismo, y quedará de la siguiente manera (con las mismas condiciones de contorno geométricas y de carga que el problema isostático de los Diagrama 2.19 y Diagrama 2.20):

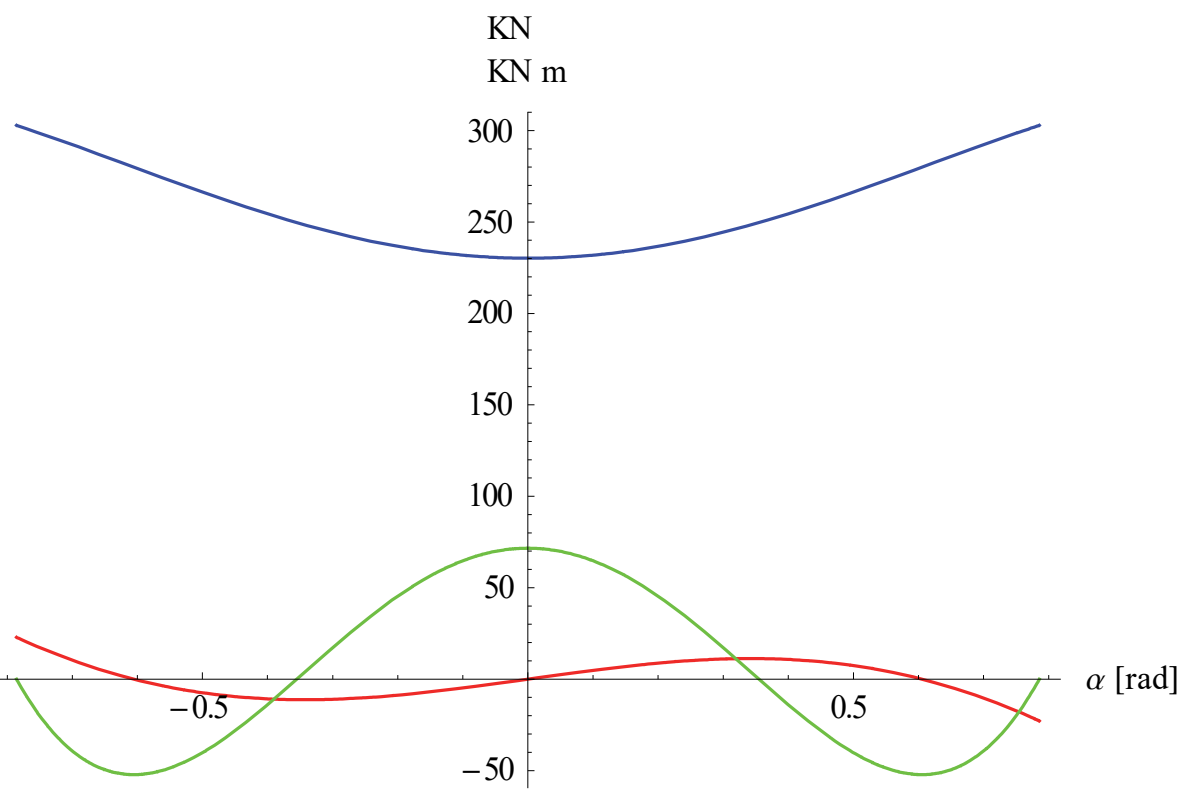

- Qy $[\alpha]$

$-\operatorname{Nx}[\alpha]$

$-\operatorname{Mz}[\alpha] / 10$

Diagrama 2.24. Solicitaciones sobre el tablero hiperestático bajo una carga $F p x=1 \mathrm{KN} / \mathrm{ml}$ (eje global X). $\alpha t=\frac{\pi}{2}$, $R t=280 \mathrm{~m}$, Tablero 1 (Carretera)

Como es habitual en los sistemas hiperestáticos, sus solicitaciones guardan una estrecha relación con las características resistivas de la sección, como ya se vio en el caso del tablero con carga transversal a su plano. En este caso la relación que marca el comportamiento del tablero va a ser el cociente entre el Área de la sección ( $A x$ ) y su Inercia transversal (Izz). Al contrario de lo que ocurría con la relación entre la rigidez a flexión y la rigidez a torsión, las unidades no son coincidentes. Se ha plantea un análisis de cómo se produce la deformación bajo cada una de las solicitaciones ( $\mathrm{Nx}$ y Mz) con el esquema de la llustración 2.7.

La relación entre las solicitaciones transversales en el tablero y las longitudinales para cada hipótesis, va a ser de vital importancia de cara al comportamiento del tablero. Como ya se ha comentado y resulta intuitivo geométricamente, la respuesta que el tablero de a las acciones horizontales que se le apliquen va a determinar el funcionamiento del subsistema Pila-Tirantes (capítulo 3). La rigidez de la respuesta que un tablero puede ofrecer ante solicitaciones longitudinales a su directriz, suele resultar mejor que la que puede ofrecer frente a solicitaciones transversales. 


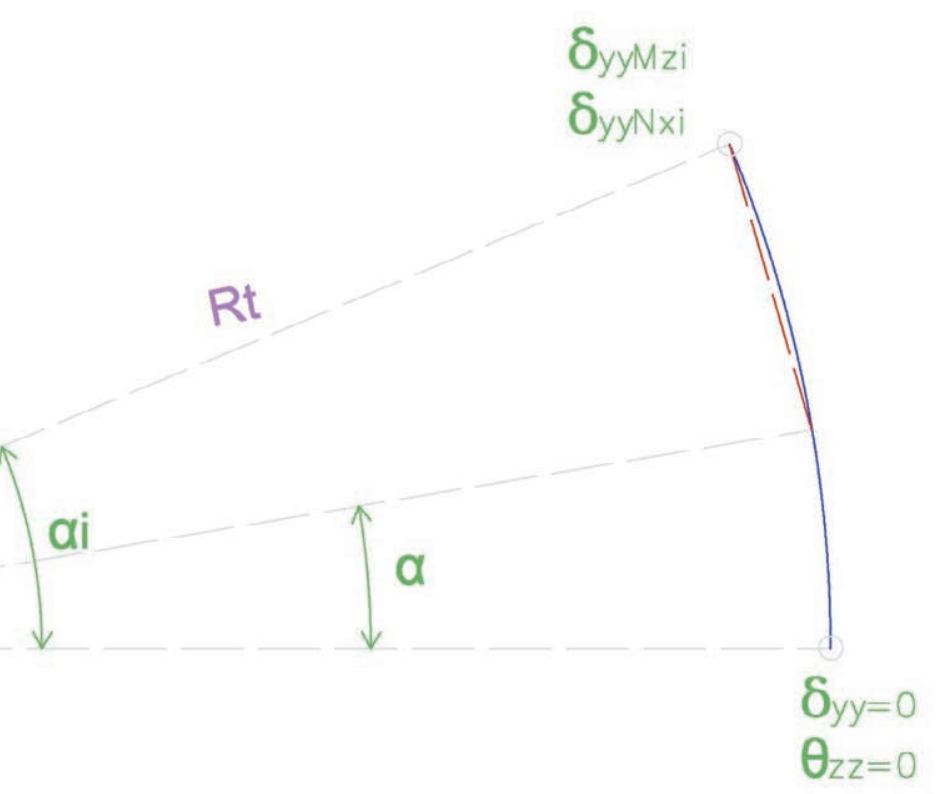

llustración 2.7. Modelo de deformaciones para un tablero solicitado bajo axil ( $\mathrm{Nx}$ ) y momento de eje vertical (Mz).

$\delta$ YYMzi $=\int_{0}^{\alpha i} \frac{2 \mathrm{R}^{2}\left(\sin \left[\frac{\alpha i-\alpha}{2}\right] \cos \left[\frac{\alpha i-\alpha}{2}\right]\right) M z[\alpha]}{\operatorname{Es~I22}} d \alpha$

Simplificando las funciones geométrica

$\delta$ YYMzi $==\frac{\mathrm{R}^{2}}{\mathrm{Es} I 22} \int_{0}^{\alpha i} \sin [\alpha i-\alpha] \mathrm{Mz}[\alpha] d \alpha$

$\mathrm{Y}$ por otro lado

$\delta$ YyNxi $==\frac{\mathrm{R}}{\operatorname{Es~As}} \int_{0}^{\alpha i} \mathrm{Nx}[\alpha] \sin [\alpha i-\alpha] d \alpha$

$\frac{\mathrm{dMz}[\alpha]}{\mathrm{d} \alpha}=-\frac{\mathrm{dNx}[\alpha]}{\mathrm{d} \alpha} \mathrm{R}$ (Haciendo $\mathrm{px}=0$ )

Se llega a la conclusión de que la relación que marca el comportamiento del tablero transversalmente es la siguiente:

$$
\varphi_{K N x M z}^{2}=\frac{A_{x x} E}{I_{z z} E} R t^{2}=\frac{A_{x x}}{I_{z z}} R t^{2}
$$

Si se coge la raíz cuadrada de la anterior igualdad:

$\varphi_{K N x M z}=\sqrt{\frac{A_{x x} E}{I_{z z} E} R t^{2}}=\frac{R t}{r_{z z}}$

Esta forma nos permite una relación más directa con las características mecánicas de la sección del tablero.

En el caso mostrado en el Diagrama 2.24, se ha utilizado el Tablero 1 (Carretera) (Tabla 2.18) y un radio del tablero $\mathrm{Rt}=280 \mathrm{~m}$, obteniendo una relación de rigideces transversal $\varphi_{K N X M Z}=42,88$. 


\begin{tabular}{|c|c|c|c|c|c|c|c|c|c|}
\hline SectionName & Material & Area & TorsConst & Iyy & Izz & Izy & Asz & Asy & Iw \\
\hline Text & Text & $\mathrm{m} 2$ & $\mathrm{~m} 4$ & $\mathrm{~m} 4$ & $\mathrm{~m} 4$ & $\mathrm{~m} 4$ & $\mathrm{~m} 2$ & $\mathrm{~m} 2$ & $\mathrm{~m} 6$ \\
\hline Tablero 1 (Carretera) & $\mathrm{S} 355$ & 1.51041 & 9.18187 & 3.62504 & 64.44081 & 0.00000 & 0.21108 & 1.18458 & 0.00000 \\
\hline Tablero 7 (Peatonal) & $\mathrm{S} 355$ & 0.34922 & 0.00611 & 0.08958 & 0.08264 & 0.00000 & 0.08294 & 0.14293 & 0.00364 \\
\hline
\end{tabular}

Tabla 2.18. Secciones de tablero: propiedades mecánicas.

Si utilizamos un tablero más apropiado para una pasarela, por ejemplo, Tablero 7 (Peatonal) (Tabla 2.18), manteniendo el radio del tablero $\mathrm{Rt}=280$, con $\varphi_{K N x M z}=575.61$, las solicitaciones no varían demasiado, Diagrama 2.25:

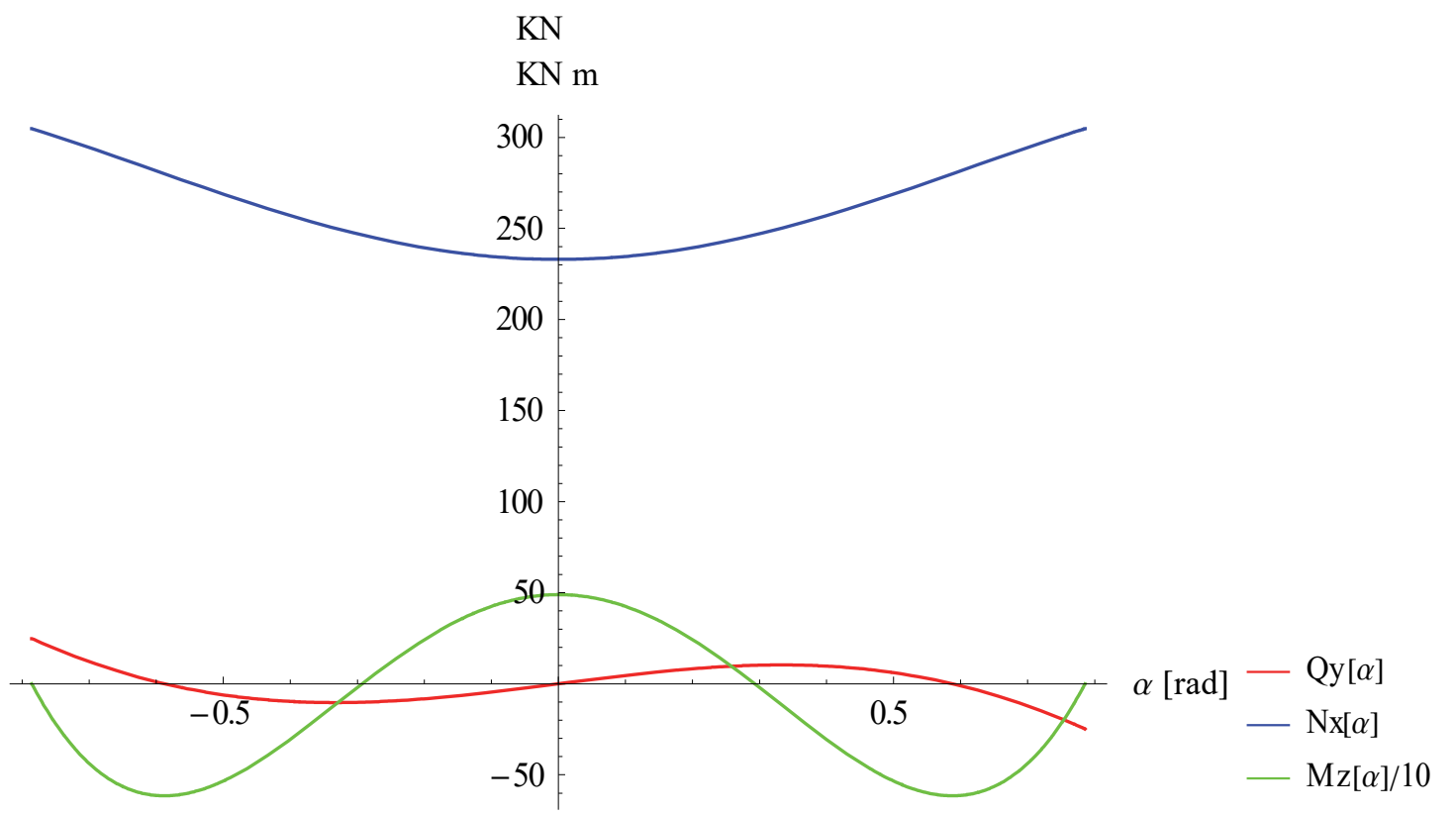

Diagrama 2.25. Solicitaciones sobre el tablero hiperestático bajo una carga $F p x=1 \mathrm{KN} / \mathrm{ml}$ (eje global X). $\alpha t=\frac{\pi}{2}$, $R t=280 \mathrm{~m}$, Tablero 7 (Peatonal)

Se debe recordar que la relación $\varphi_{K N x M z}$, va a estar vinculada a la relación entre el axil $(\mathrm{Nx})$ y el cortante transversal en el tablero (Qy). Si mantenemos $\varphi_{K N X M z}$ constante, la relación entre el axil y el cortante transversal, aun si hemos cambiado de sección, se mantiene constante. Esto parece contradecir el análisis desarrollado a la hora de obtener el coeficiente $\varphi_{K N x M z}$, pero no es así, ya que lo que se ha relacionado es la rigidez transversal (proveniente del giro debido al momento transversal), con la rigidez longitudinal (proveniente del desplazamiento por la acción axil).

El párrafo anterior se entiende mucho mejor con un ejemplo (Diagrama 2.26, Diagrama 2.27, Diagrama 2.28 y Diagrama 2.29). 
Para hacer visible la relación entre Nx-Qy y Nx-Mz, se proponen los factores:

$$
\begin{aligned}
& v Q y N x[\alpha]==\frac{Q y[\alpha]}{N x[\alpha]} \\
& \text { uMzNx}[\alpha]==\frac{\mathrm{Mz}[\alpha] / \mathrm{Rt}}{\mathrm{Nx}[\alpha]}
\end{aligned}
$$

Modificar el radio, no puede tener el mismo efecto sobre las solicitaciones Axil ( $\mathrm{Nx}$ ) y de Cortante transversal (Qy), en cuyas ecuaciones diferenciales aparece con exponente 1, y sobre el momento transversal (Mz), donde aparece al cuadrado. Eso explica a la hora de compararlos, el momento flector $(\mathrm{Mz})$ se divida por el radio a la hora de compararlo con el axil $(\mathrm{Nx})$.

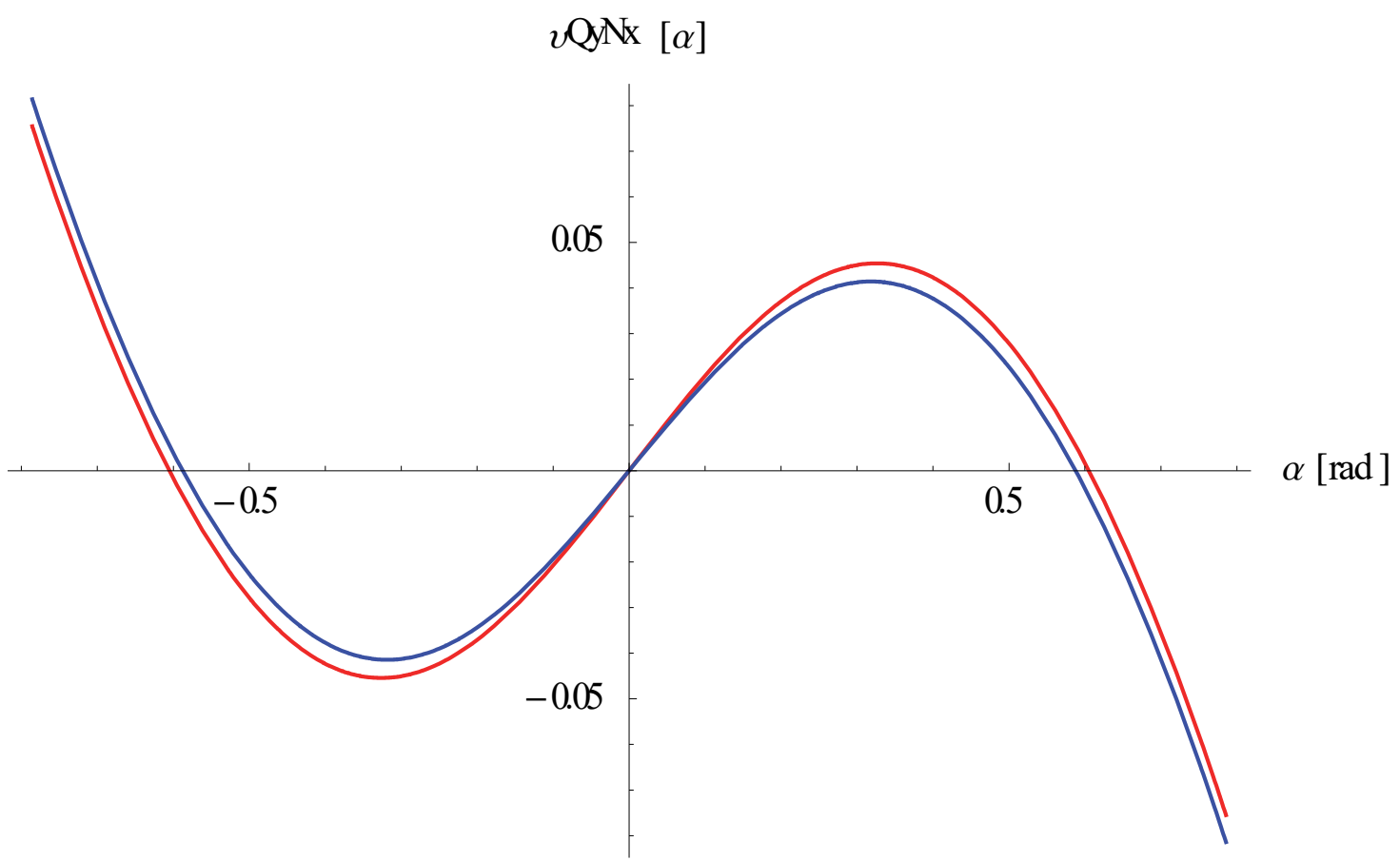

— Tablero 1 (Carretera) $\phi_{\mathrm{KNxMz}}=42,88$

— Tablero 7 (Peatonal) $\phi_{\mathrm{KNxMz}}=575,61$

Diagrama 2.26. Comparativa entre relaciones de solicitaciones transversales y longitudinales $\left(v_{Q y N x}\right)$, para diferentes tipos de tableros. $\alpha t=\frac{\pi}{2}, R t=280 \mathrm{~m}$. 


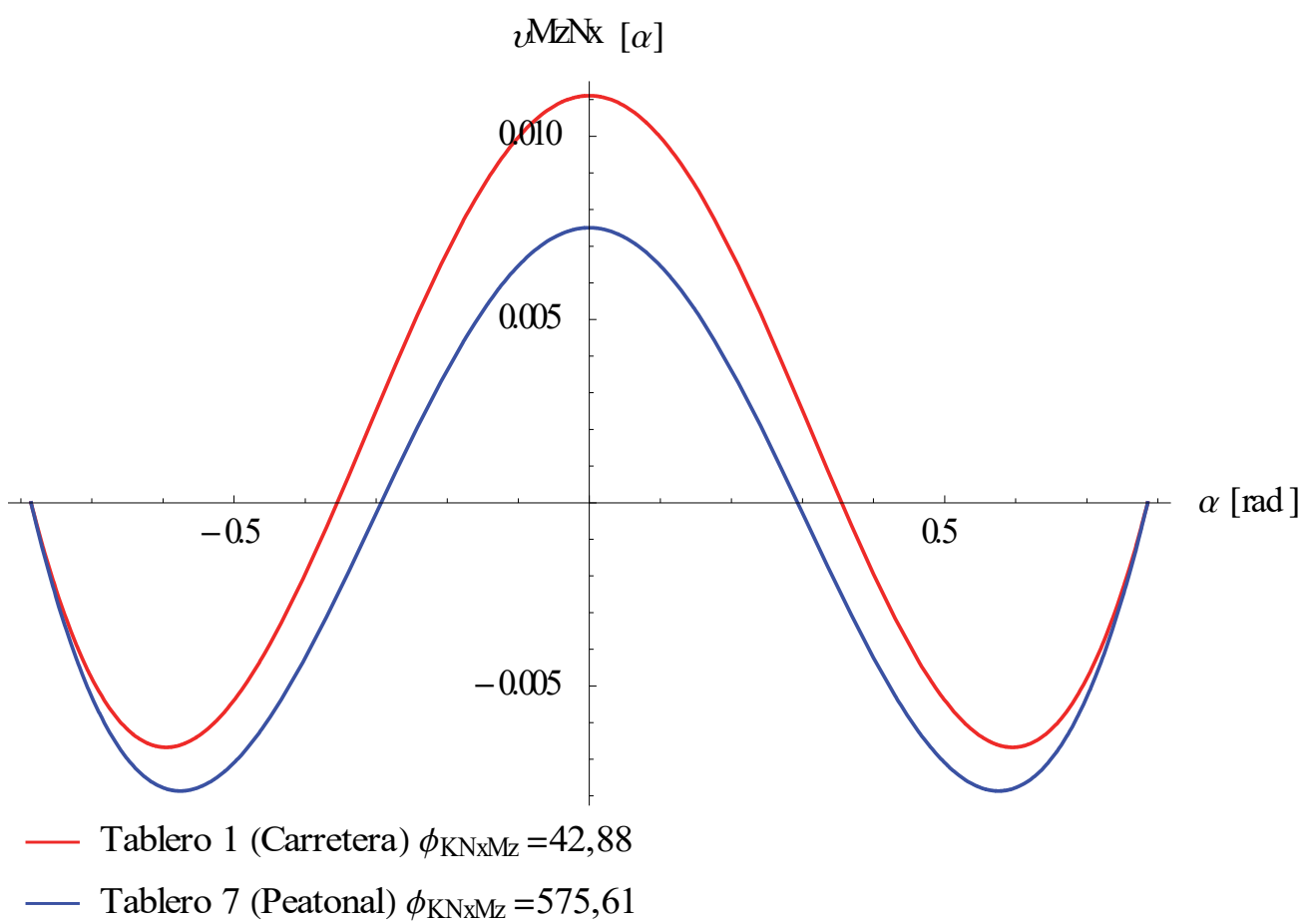

Diagrama 2.27. Comparativa entre relaciones de solicitaciones transversales y longitudinales $\left(v_{M Z N x}\right)$, para diferentes tipos de tableros. $\alpha t=\frac{\pi}{2}, R t=280 \mathrm{~m}$.

Si se igualan ahora las relaciones de rigidez $\varphi_{K N x M z}$ para los 2 tableros, variando el radio del tablero, para el caso del Tablero 1 (Carretera), manteniendo el ángulo $\alpha_{t}$ constante ( $\alpha_{t}=$ $\left.\frac{\pi}{2}\right)$ :

$$
R_{t}=280 m * 13.42=3757.6 m
$$

vyNx $[\alpha]$

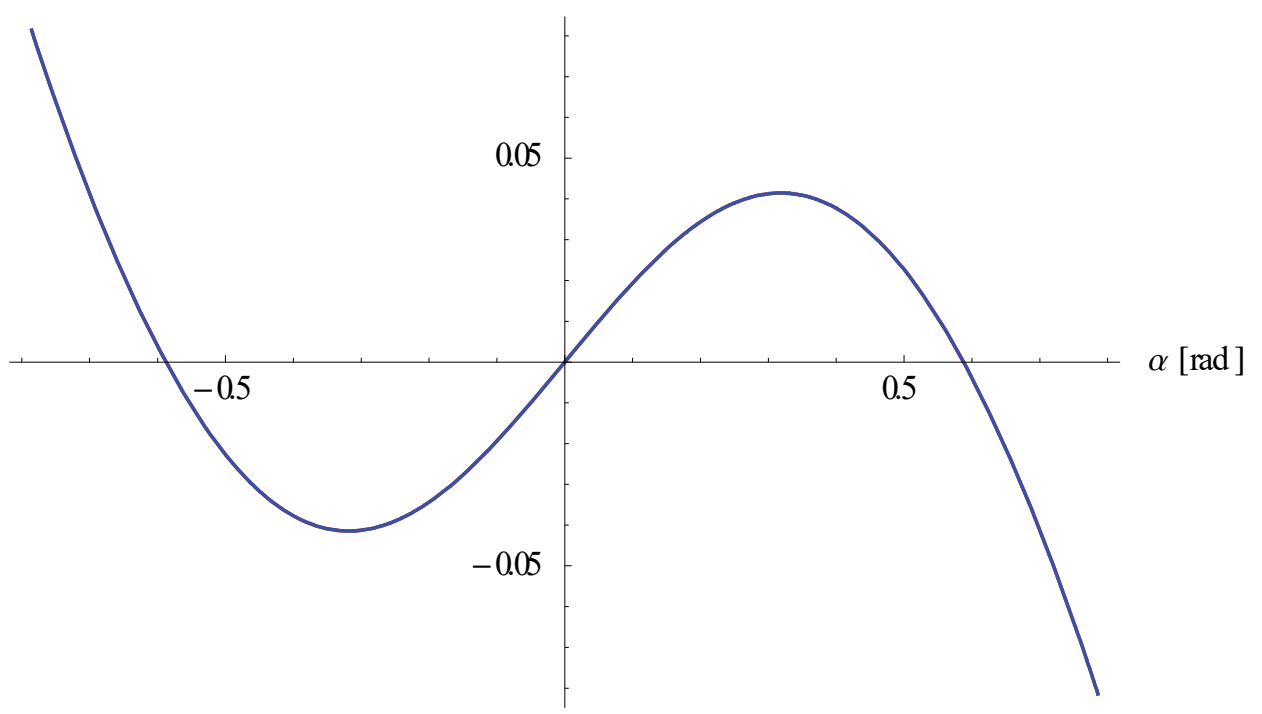

Tablero 1 (Carretera) $\phi_{\mathrm{KNxMz}}=575,61$

Tablero 7 (Peatonal) $\phi_{\mathrm{KNxMz}}=575,61$

Diagrama 2.28. Comparativa entre relaciones de solicitaciones transversales y longitudinales $\left(v_{Q y N x}\right)$, para diferentes tipos de tableros. $\alpha t=\frac{\pi}{2}, R t=280 \mathrm{~m}$ (Tablero 7 (Peatonal)), $R t=$ 3757.6 m (Tablero 1 (Carretera)). 


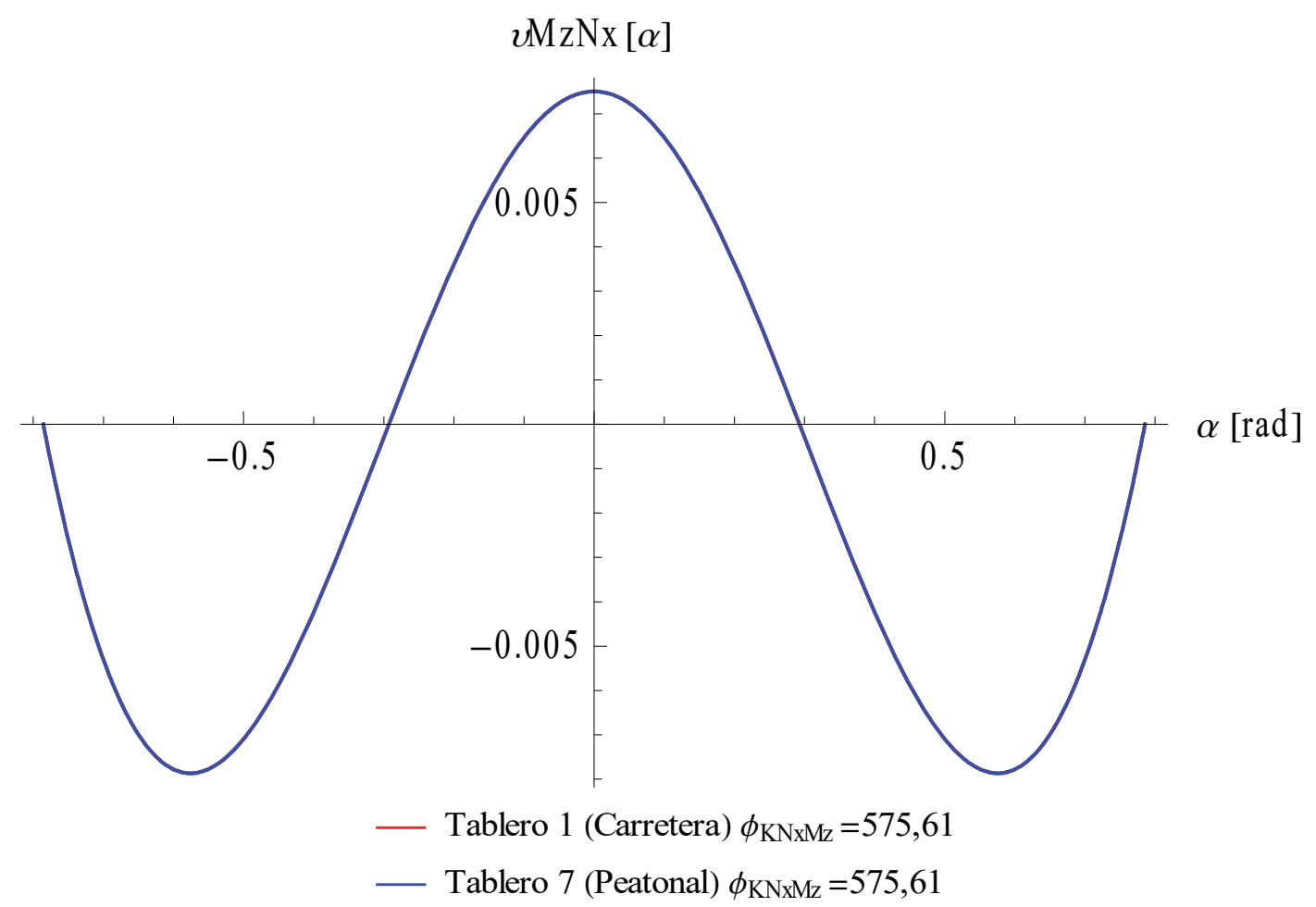

Diagrama 2.29. Comparativa entre relaciones de solicitaciones transversales y longitudinales $\left(v_{M z N x}\right)$, para diferentes tipos de tableros. $\alpha t=\frac{\pi}{2}, R t=280 \mathrm{~m}$ (Tablero 7 (Peatonal)), $R t=$ $3757.6 \mathrm{~m}$ (Tablero 1 (Carretera)).

Se puede apreciar como el comportamiento se iguala. Esto relaciona el comportamiento transversal del tablero, a sus características mecánicas y a la curvatura.

Existen 4 máximos en el caso de $v_{Q y N x}$ (uno en cada estribo y 2 interiores) y 3 en el caso de $v_{M Z N X}$ (Uno en el centro del vano y 2 simétricos al centro del vano), cuando se aplica una carga Fpx distribuida sobre un tablero curvo. Por simetría, vamos a estudiar solo 2 de ellos para cada factor (para $v_{Q y N x}$ el valor en el estribo y uno de los máximos interiores y para $v_{M z N x}$ el máximo en el centro del vano y uno de los otros 2 máximos). Si estudiamos el valor de estos máximos, para diferentes valores de $\varphi_{K N X M Z}$ y diferentes ángulos desarrollados por el tablero:

vQYNxE $\rightarrow$ Valor en el estribo

vQYNxMI $\rightarrow$ Primer máximo desde el centro de vano hasta el estribo 
थyNxE

QyNxMI

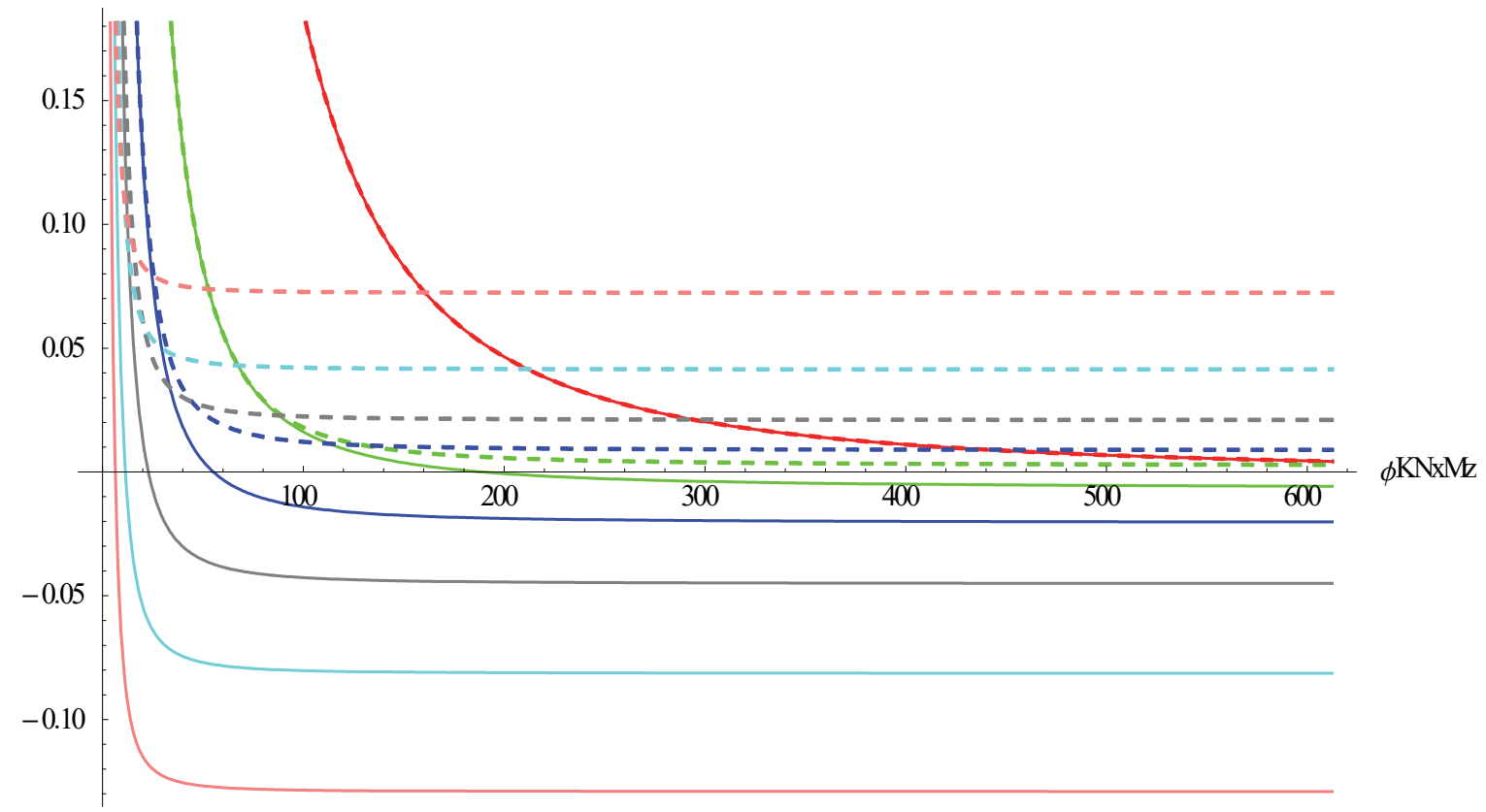

- 2 QyNxE $\alpha=\frac{\pi}{10} \quad \cdots v$ QyNxMI $\alpha=\frac{3 \pi}{10}$

- $2 \operatorname{QyNxE} \alpha=\frac{\pi}{5} \quad \cdots v$ QyNxMI $\alpha=\frac{2 \pi}{5}$

- $\operatorname{QyNxE} \alpha=\frac{3 \pi}{10} \quad \cdots v$ QyNxMI $\alpha=\frac{\pi}{2}$

- $\operatorname{QyNxE} \alpha=\frac{2 \pi}{5} \quad \cdots v$ QyNxMI $\alpha=\frac{3 \pi}{5}$

- $\operatorname{QyNxE} \alpha=\frac{\pi}{2}$

—QyNxE $\alpha=\frac{3 \pi}{5}$

- - 2 QyNxMI $\alpha=\frac{\pi}{10}$

- - 2 QyNxMI $\alpha=\frac{\pi}{5}$

Diagrama 2.30. Comparativa entre relaciones de solicitaciones transversales y longitudinales $\left(v_{Q y N x}\right)$, para diferentes tipos de tableros y diferentes ángulos $\alpha t$.

UMzNxM $\rightarrow$ Primer máximo desde el estribo hasta el centro de vano uMzNxMS $\rightarrow$ Valor en el centro de vano 
$v \mathrm{MzNxM}$

$v \mathrm{MzNxMS}$

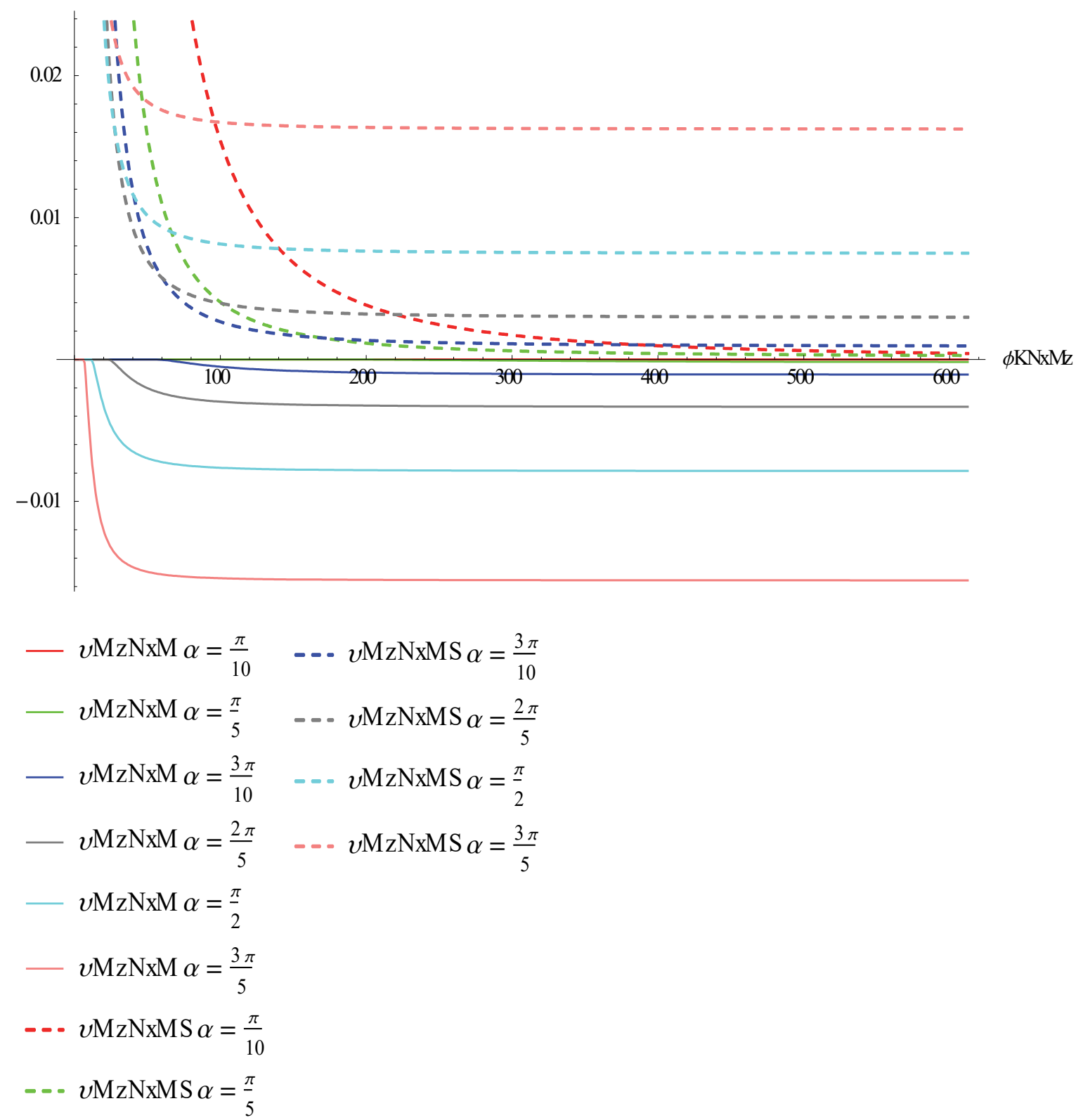

Diagrama 2.31. Comparativa entre relaciones de solicitaciones transversales y longitudinales $\left(v_{Q y N x}\right)$, para diferentes tipos de tableros y diferentes ángulos $\alpha t$.

Del análisis de los anteriores diagramas (Diagrama 2.30 y Diagrama 2.31), se pueden extraer numerosas conclusiones del comportamiento de una viga curva con carga Fpx en su plano. El ángulo $\alpha t$ (el radio está incluido en el coeficiente $\varphi_{K N x M z}$ ), es determinante en el comportamiento del tablero. Ese comportamiento va desde un tablero con un comportamiento similar al de una viga biapoyada, "tipo viga" (con ángulos pequeños, en torno a $\frac{\pi}{10}$ y coeficientes $\varphi_{K N x M z}$ menores a 200), pasando por un comportamiento en el que se ve favorecido el efecto arco, "tipo arco" (con ángulos intermedios, en torno a $\frac{3 \pi}{10}$, y coeficientes $\varphi_{K N X M Z}$ a partir de valores próximos a 75) y llegando a un comportamiento "tipo esfera", con 
alternancia de momentos significativos de diferente signo (con ángulos grandes, por encima de $\frac{4 \pi}{10}$, y coeficientes $\varphi_{K N X M Z}$ desde 50$)$.

Como se puede observar, para sacar de su comportamiento a los tableros de cada rango de ángulos $\alpha t$ (pequeños, medios y grandes, tal y como se han definido en el párrafo anterior), se deberán de introducir valores "extremos" del coeficiente $\varphi_{K N X M z}$ :

- Para los casos en los que el tablero tiene un comportamiento "tipo viga" ( $\alpha t \approx$ $\frac{\pi}{10}$ ), para conseguir un comportamiento más dominado por el esfuerzo axil, "tipo arco", se deberán introducir valores del coeficiente $\varphi_{K N x M z}$ por encima de 300 . Esto, en tableros anchos (ej.: los de carretera) en los que el radio de giro rzz es muy alto, solo va a ser posible con radios $R t$ muy altos, lo que supone vanos muy largos. Como ejemplo, si se escoge un tablero como Tablero 1 (Carretera), el Radio necesario sería de 1960 m, lo que supone, para un ángulo desarrollado por el tablero de $\frac{\pi}{10}$, un puente de $615 \mathrm{~m}$. En el caso de tableros peatonales, como el Tablero 7 (Peatonal), con un radio de $146 \mathrm{~m}$ bastaría para poder obtener un efecto arco. Esto supone, con un ángulo de $\frac{\pi}{10}$, un tablero de $46 \mathrm{~m}$ de longitud.

- Para los casos en los que el tablero tiene un comportamiento "tipo arco" ( $\alpha t \approx$ $\left.\frac{3 \pi}{10}\right)$, su comportamiento está más o menos garantizado con valores de $\varphi_{K N x M z}$ por encima de 75. Esto supone que, con radios de $490 \mathrm{~m}$ o superiores, para tableros de carretera y del entorno de los $36 \mathrm{~m}$, o superiores, para peatonales se cumpliría.

- Para los casos en los que el tablero tiene un "tipo esfera" ( $\left.\alpha t>\frac{4 \pi}{10}\right)$, este comportamiento se empieza a producir con valores de $\varphi_{K N x M z}$ por encima de 70, por debajo de estos valores, se puede hacer desaparecer el momento negativo, aunque a costa de un momento positivo a mitad de vano enorme y de unas reacciones en los estribos también disparadas.

Como síntesis, se puede decir que el comportamiento "tipo arco" requiere de una morfología determinada (esta es la parte más obvia) y a partir de ahí necesita una preponderancia de la rigidez axil frente a la rigidez transversal (normalmente dominada por la rigidez a flexión transversal). La agudeza de esta necesidad, vendrá determinada por lo apropiado de la morfología de la directriz del tablero. Esta preponderancia se consigue, o bien con las características mecánicas del tablero, o bien porque al tablero le damos suficiente radio (que va a ser lo mismo que alargarlo, en caso de mantener constante el ángulo desarrollado). Sabiendo que el radio disminuye de forma diferente la rigidez a flexión $\left(\frac{1}{R t^{3}}\right)$ que la rigidez a axil $\left(\frac{1}{R t}\right)$.

\subsubsection{Deformaciones}

En lo que a deformaciones y rigidez se refiere, es más rígido el sistema dominado por un comportamiento "tipo arco" (dominado por la acción axil), mientras que ese comportamiento no se haya obtenido a base de debilitar el tablero transversalmente. En el caso de haber 
debilitado el tablero transversalmente, es esa flexibilidad propuesta la que permite deformarse al tablero hasta que la solicitación axil es capaz de estabilizar el tablero (comportamiento típicamente hiperestático).

En los diagramas de deformaciones realizados (Diagrama 2.32 -> Diagrama 2.37), se puede comprobar cómo, siguiendo el esquema de análisis descrito en el punto anterior (Diagrama 2.30 y Diagrama 2.31, en el que se separa por rango de ángulos los comportamientos predominantes, "tipo arco" y "tipo viga", a medida que variamos el coeficiente $\varphi_{K N x M z}$ ), van cobrando importancia las características mecánicas de la sección más influyentes en cada tipo de comportamiento:

- "Tipo viga" -> Inercia transversal (Izz).

- "Tipo arco" -> Área (Axx).

- "Tipo esfera"-> Inercia transversal (Izz).

Se puede ver (Diagrama 2.32 -> Diagrama 2.37), cómo se agrupan los de deformaciones de los diferentes tableros. Con ángulos pequeños (donde cobra más importancia el funcionamiento "tipo arco", sobre todo en torno a ángulos del orden de $\frac{\pi}{5}$, por debajo el efecto viga vuelve a cobrar importancia), se agrupan los diagramas de aquellos tableros con área similar, mientras que con ángulos mayores (donde cobra más importancia el funcionamiento "tipo esfera"), se agrupan los diagramas de aquellos tableros con inercia transversal similar (este caso es todavía mucho más claro).

\begin{tabular}{|c|c|c|c|c|c|c|c|c|c|}
\hline SectionName & Material & Area & TorsConst & Iyy & Izz & Izy & Asz & Asy & Iw \\
\hline Text & Text & $\mathrm{m} 2$ & $\mathrm{~m} 4$ & $\mathrm{~m} 4$ & $\mathrm{~m} 4$ & $\mathrm{~m} 4$ & $\mathrm{~m} 2$ & $\mathrm{~m} 2$ & $\mathrm{~m} 6$ \\
\hline Tablero 1 (Carretera) & $\mathrm{S} 355$ & 1.51041 & 9.18187 & 3.62504 & 64.44081 & 0.00000 & 0.21108 & 1.18458 & 0.00000 \\
\hline Tablero 6 (Carretera) & $\mathrm{S} 355$ & 1.50662 & 2.87928 & 3.47567 & 47.22229 & 0.00000 & 0.23412 & 1.02628 & 0.00000 \\
\hline Tablero 1 (Peatonal) & $\mathrm{S} 355$ & 0.23339 & 0.13942 & 0.08372 & 0.16722 & 0.00000 & 0.08559 & 0.14103 & 0.00000 \\
\hline Tablero 5 (Peatonal) & $\mathrm{S} 355$ & 0.24081 & 0.00200 & 0.08495 & 0.07995 & 0.00000 & 0.07477 & 0.12778 & 0.00363 \\
\hline Tablero 7 (Peatonal) & $\mathrm{S} 355$ & 0.34922 & 0.00611 & 0.08958 & 0.08264 & 0.00000 & 0.08294 & 0.14293 & 0.00364 \\
\hline
\end{tabular}

Tabla 2.19. Secciones de tablero: propiedades mecánicas.

— Tablero 1 (Carretera) $\phi \mathrm{KNxMz}=42.86$

— Tablero 6 (Carretera) $\phi \mathrm{KNxMz}=50.01$

$\longrightarrow$ Axx $\longrightarrow$ Tablero 1 (Peatonal) Izz $\longrightarrow$ Tablero 6 (Carretera) $\phi \mathrm{KNxMz}=19.68$

$\longrightarrow$ Axx $\longrightarrow$ Tablero 6 (Carretera) Izz $\longrightarrow$ Tablero 1 (Peatonal) $\phi \mathrm{KNxMz}=840.45$

$\longrightarrow$ Axx $\longrightarrow$ Tablero 6 (Carretera) Izz $\longrightarrow 20 *$ Tablero 1 (Peatonal) $\phi \mathrm{KNxMz}=187.93$

— Tablero 1 (Peatonal) $\phi \mathrm{KNxMz}=330.78$

— Tablero 5 (Peatonal) $\phi \mathrm{KNxMz}=479.58$

— Tablero 7 (Peatonal) $\phi \mathrm{KNxMz}=575.60$ 


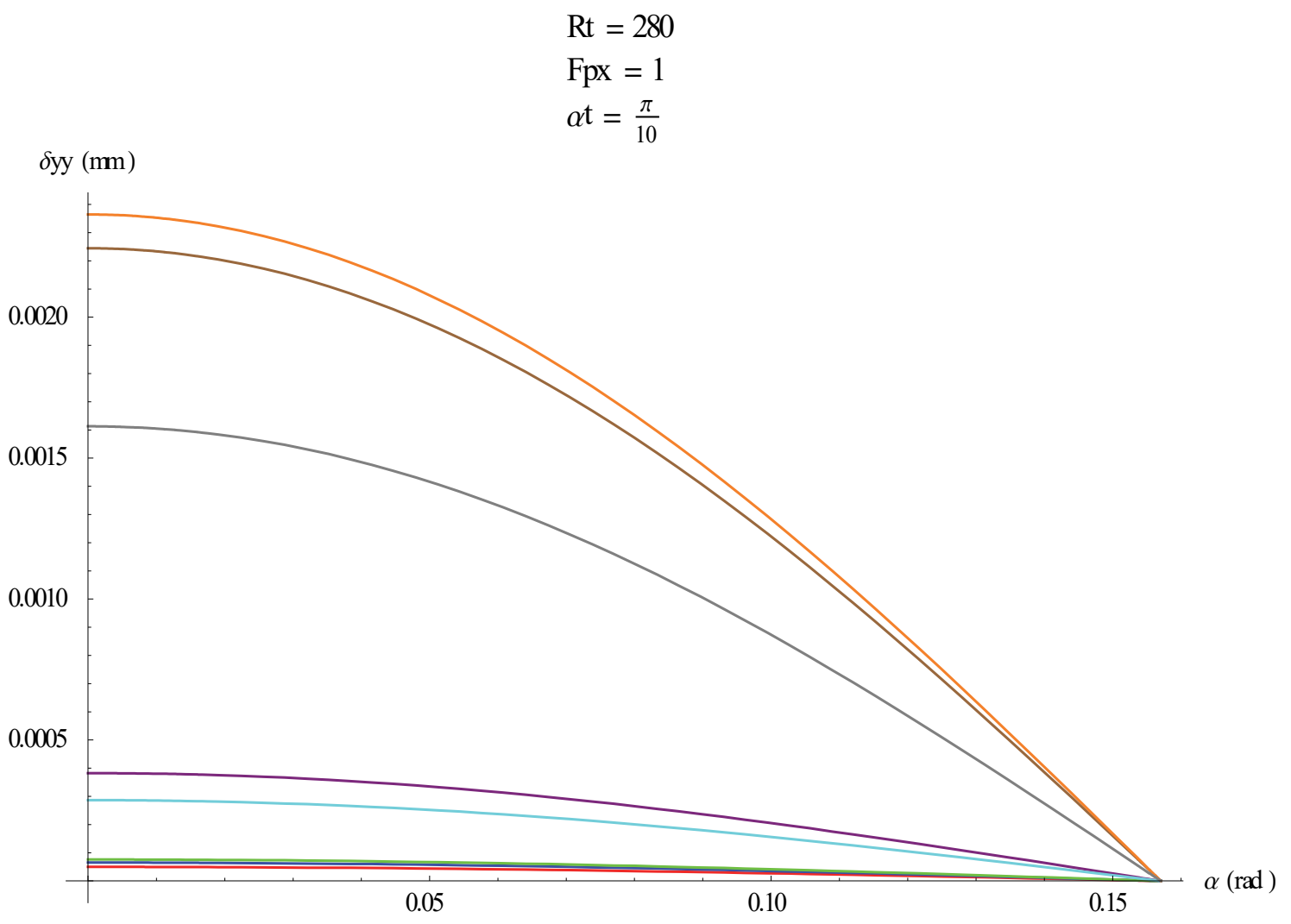

Diagrama 2.32. Deformada horizontal del tablero, para diferentes secciones. $R t=280 m, F p x=1 \frac{K n}{m}, \alpha t=\frac{\pi}{10}$.

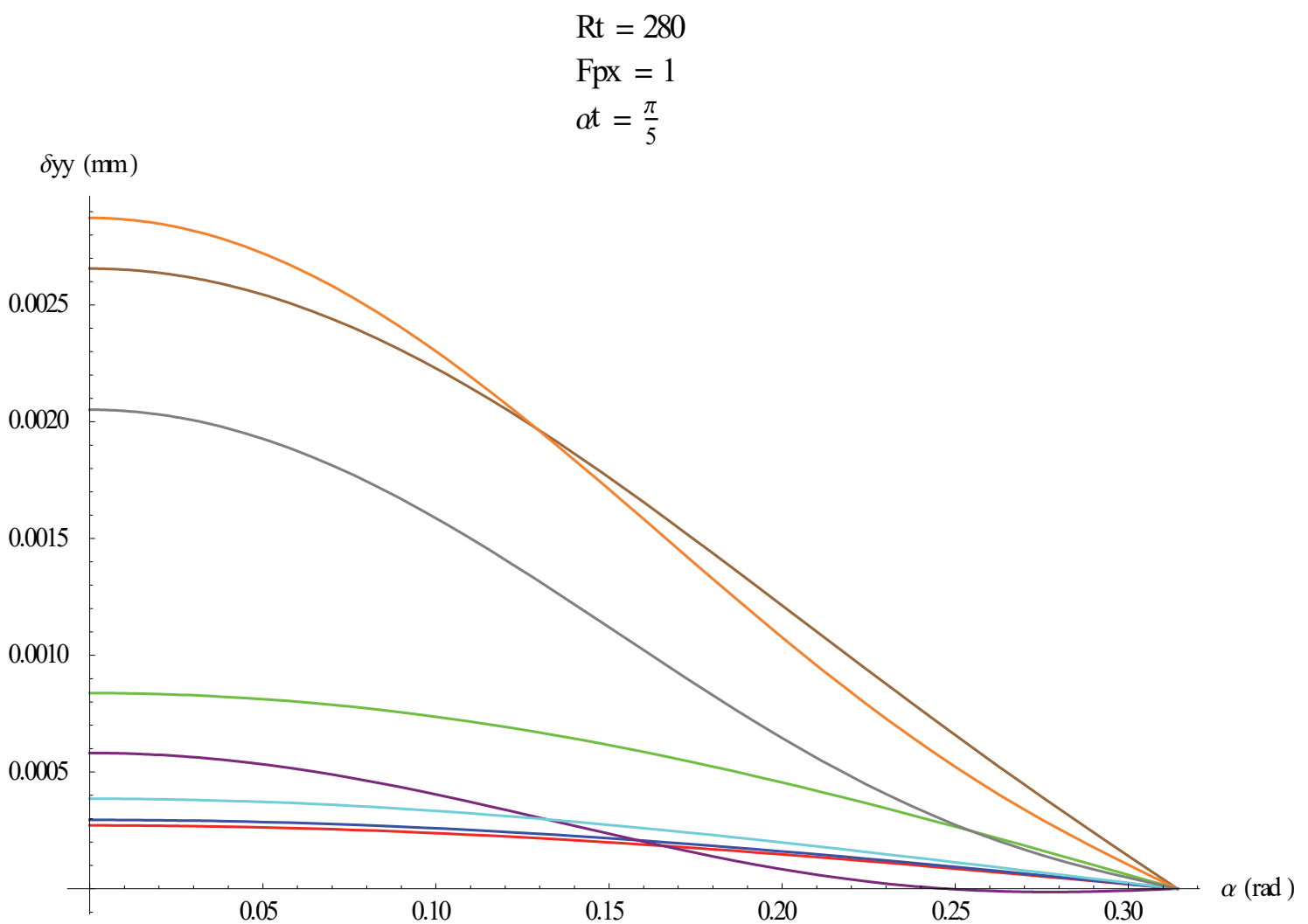

Diagrama 2.33. Deformada horizontal del tablero, para diferentes secciones. $R t=280 \mathrm{~m}, F p x=1 \frac{K n}{\mathrm{~m}}, \alpha t=\frac{\pi}{5}$. 


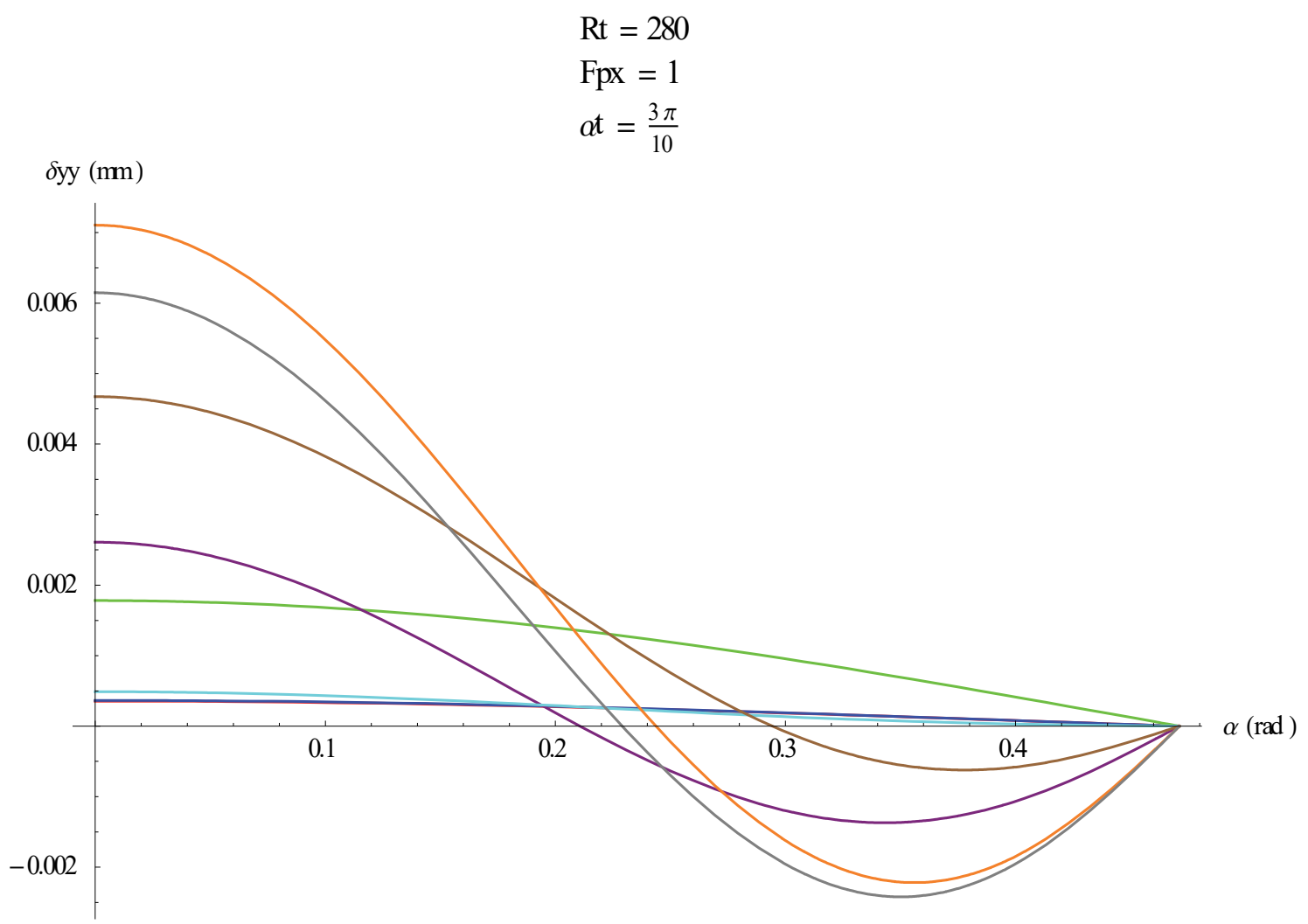

Diagrama 2.34. Deformada horizontal del tablero, para diferentes secciones. $R t=280 \mathrm{~m}, F p x=1 \frac{\mathrm{Kn}}{\mathrm{m}}, \alpha t=\frac{3 \pi}{10}$.

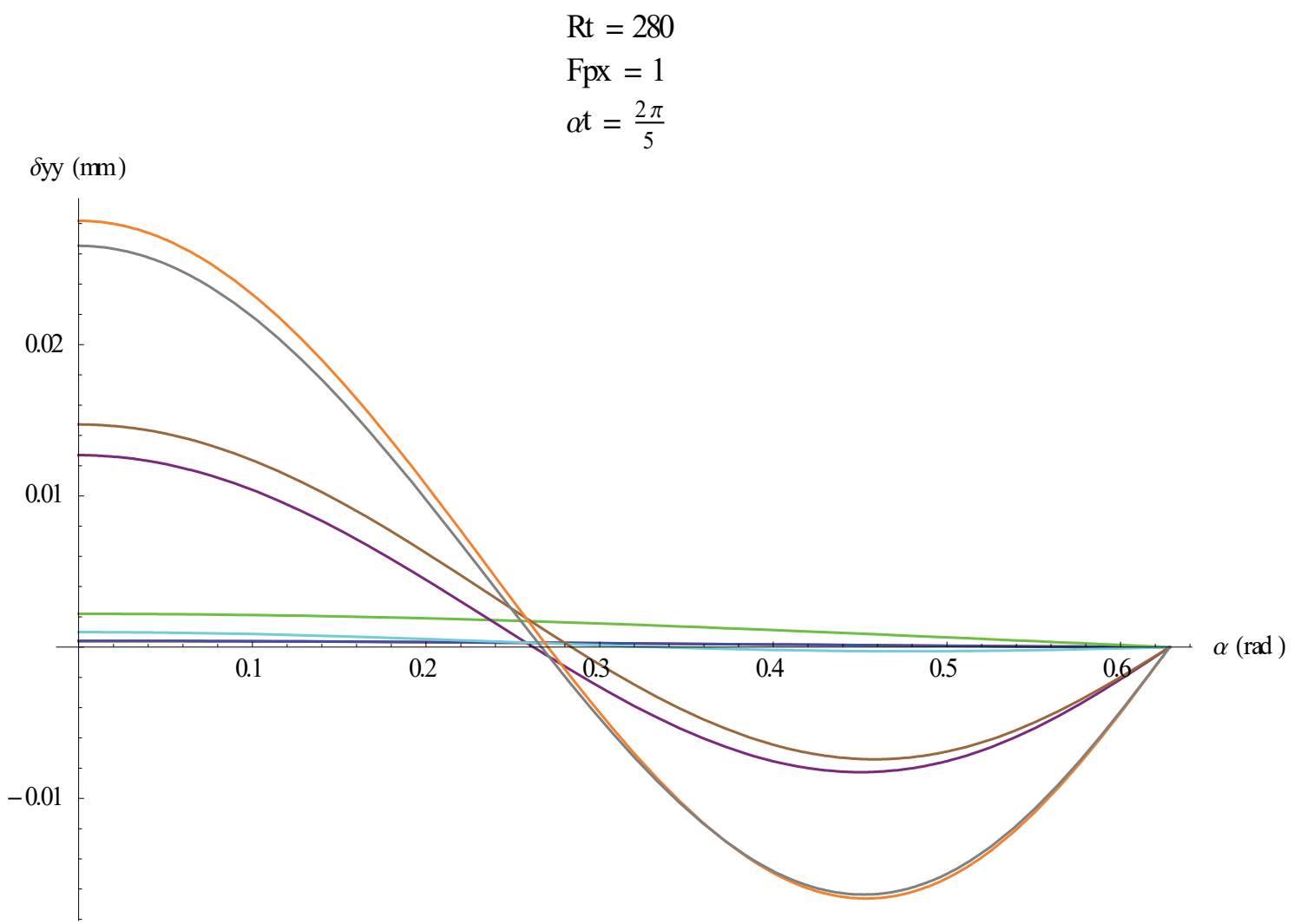

Diagrama 2.35. Deformada horizontal del tablero, para diferentes secciones. $R t=280 \mathrm{~m}, \mathrm{Fpx}=1 \frac{\mathrm{Kn}}{\mathrm{m}}, \alpha t=\frac{2 \pi}{5}$. 

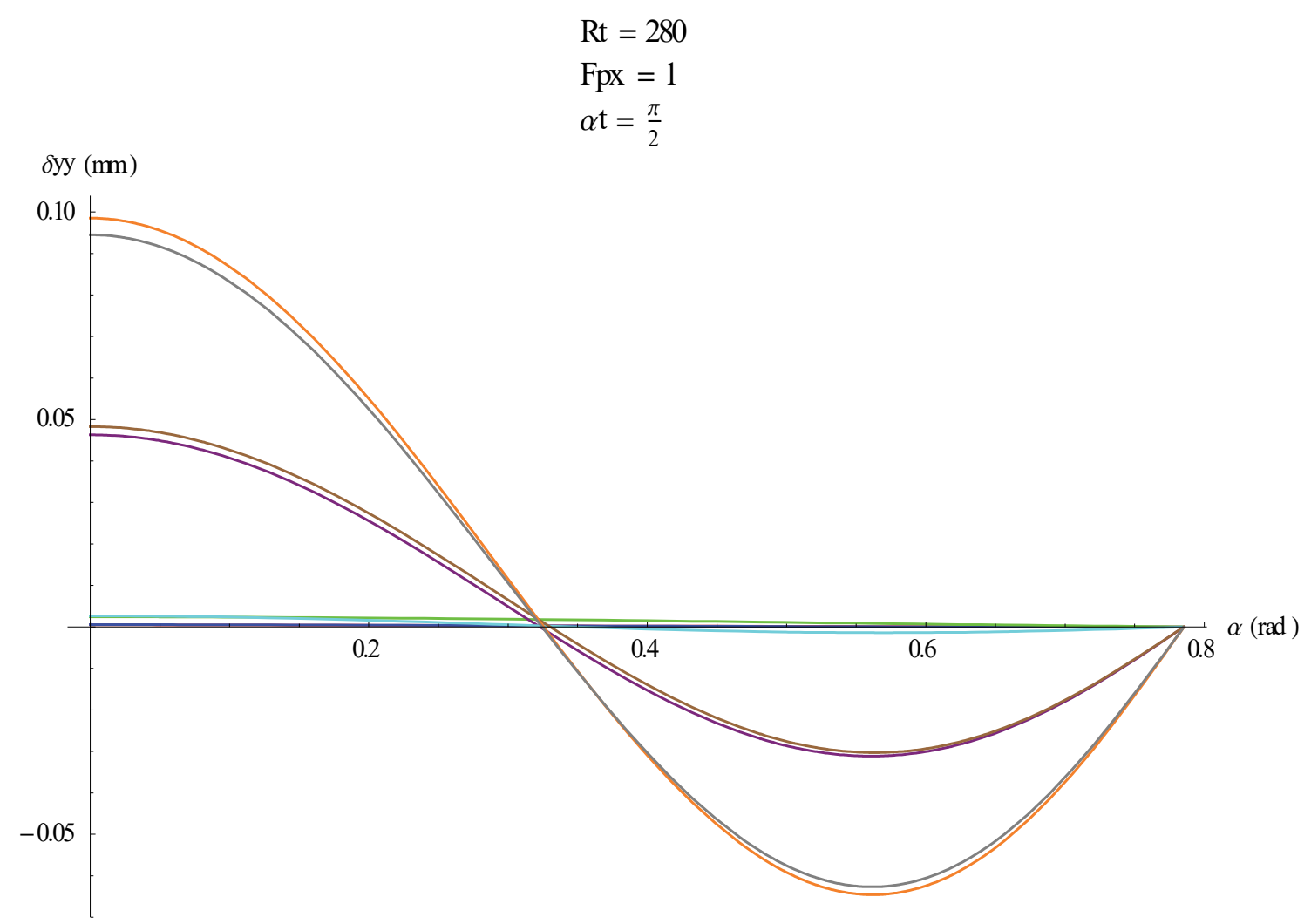

Diagrama 2.36. Deformada horizontal del tablero, para diferentes secciones. $R t=280 \mathrm{~m}, \mathrm{Fpx}=1 \frac{\mathrm{Kn}}{\mathrm{m}}, \alpha t=\frac{\pi}{2}$.

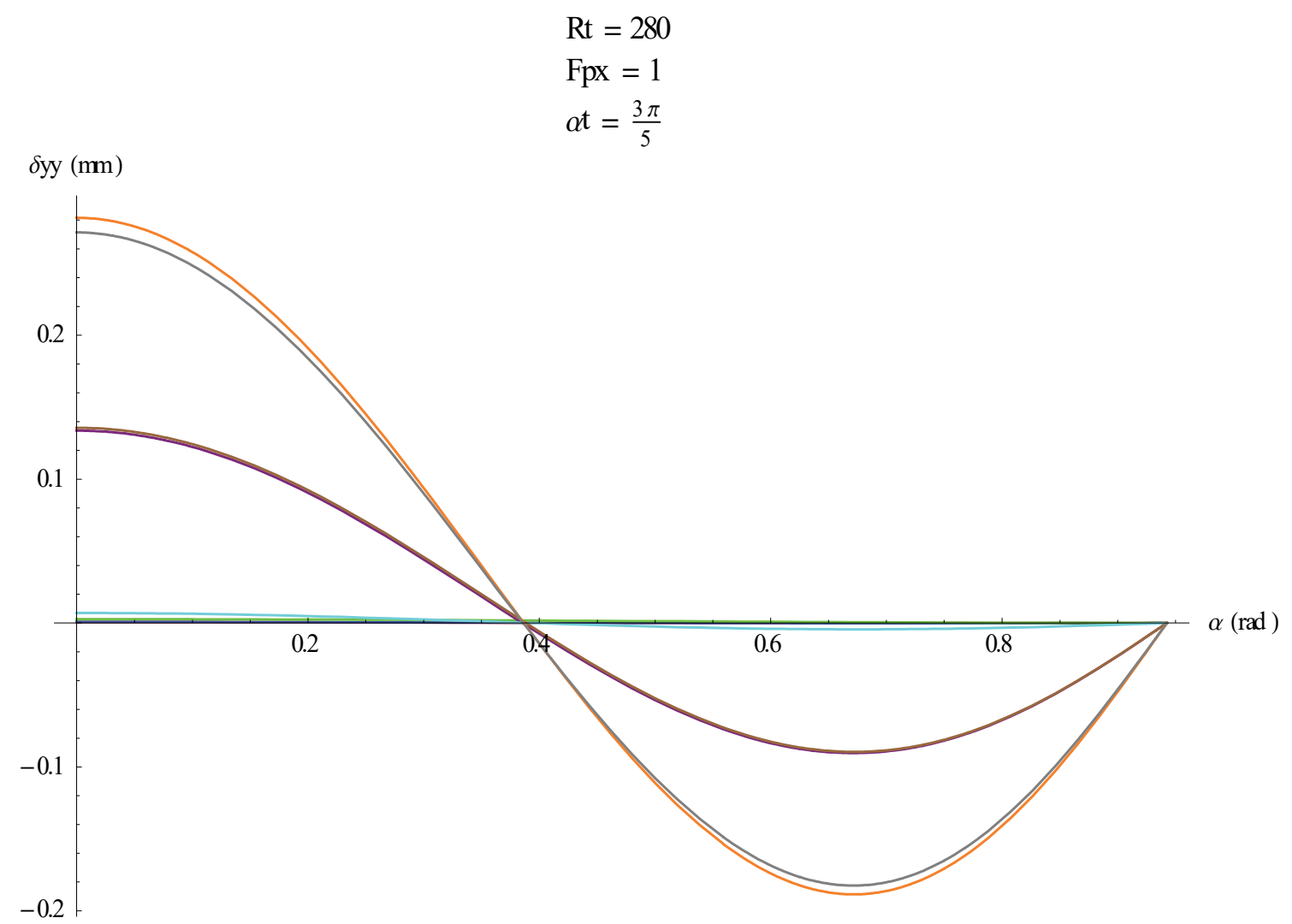

Diagrama 2.37. Deformada horizontal del tablero, para diferentes secciones. $R t=280 \mathrm{~m}, F p x=1 \frac{\mathrm{Kn}}{\mathrm{m}}, \alpha t=\frac{3 \pi}{5}$. 
Este análisis, vuelve a ser muy importante de cara a entender qué tipo de decisiones se pueden tomar en el diseño del tablero, según la morfología del puente, para mejorar el comportamiento del sistema. Como ejemplo, se puede apreciar cómo para este tipo de carga (Fpx), disminuir la rigidez transversal puede ser de mucha ayuda para reducir las solicitaciones de momento, sin que esto flexibilice el sistema demasiado. Mientras que para ángulos $\alpha t$ mayores es imprescindible que el tablero tenga suficiente rigidez transversal, porque toda disminución que se haga en ella, se va a trasladar directamente a la flexibilidad del sistema.

Debe tenerse en cuenta que un puente atirantado curvo dispone, además del tablero, del sistema de pila y tirantes para hacer frente a este tipo de carga (Fpx). La interacción de los 2 subsistemas (Tablero y Pila-Tirantes), reduce notablemente las solicitaciones transversales (Qy y Mz), por tanto, afectando a los comportamientos "tipo esfera" o el "tipo viga" (dependiendo de la situación y la altura de la pila). Generalmente la rigidez en su plano del tablero es mayor a la del subsistema Pila-Tirantes en ese plano. En cualquier caso, el análisis visto sigue siendo válido, porque la repartición resulta parecida (el sistema de Pila-Tirantes, apenas afecta al valor de la solicitación axil del tablero), aunque parte de las solicitaciones transversales las aguanta el subsistema Pila-Tirantes (Diagrama 2.38).

a)

Tablero: $\alpha \mathrm{t}=\frac{\pi}{2} \mathrm{rad}, \mathrm{Rt}=280.113 \mathrm{~m}$.

Pila: $\alpha \mathrm{p}=0 \mathrm{rad}, \mathrm{Rp}=0 . \mathrm{m}$.

Alturas: pila $h p=247.514 \mathrm{~m}$, tablero $h t=44 \mathrm{~m}$.

Pila inclinada al CDG.

Nudos Tablero $n=133$, Tirantes $(n t-2)=43$.

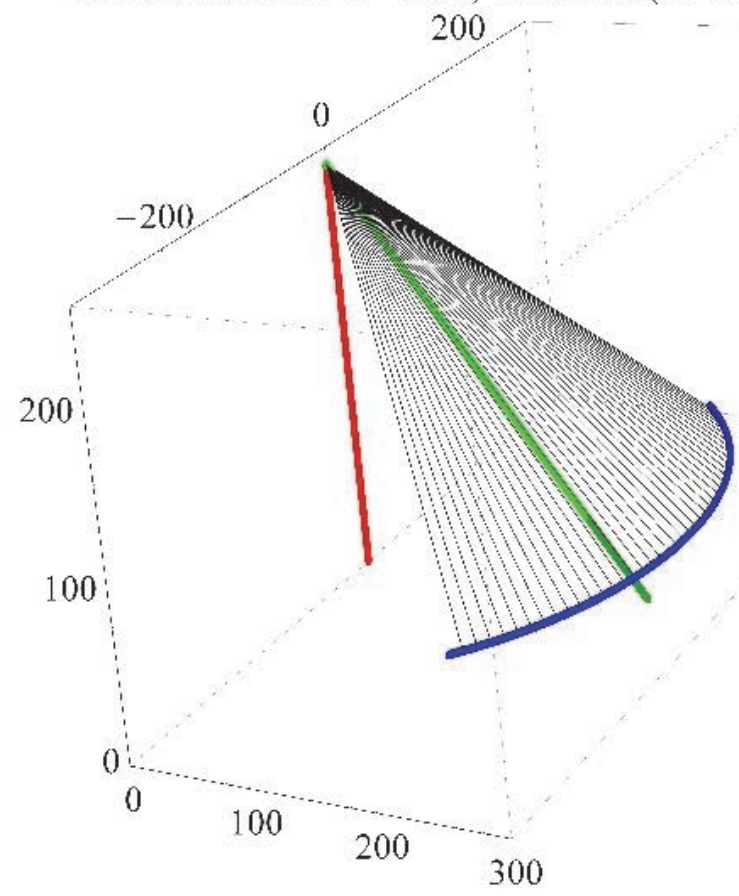


b)

Solicitaciones sobre el tablero

Axil (escala:1) Cortante $Y^{\prime}-Y^{\prime}$ (escala:1) Cortante $Z^{\prime}-Z^{\prime}$ (escala:1)

MOMENTO TORSOR X'-X' (escala:1) MOMENTO FLECTOR Y'-Y' (escala:-1)

MOMENTO FLECTOR Z'-Z' (escala:0.1)

BIMOMENTO W-W (escala:1)

$(\mathrm{KN}, \mathrm{KN} * \mathrm{~m})$

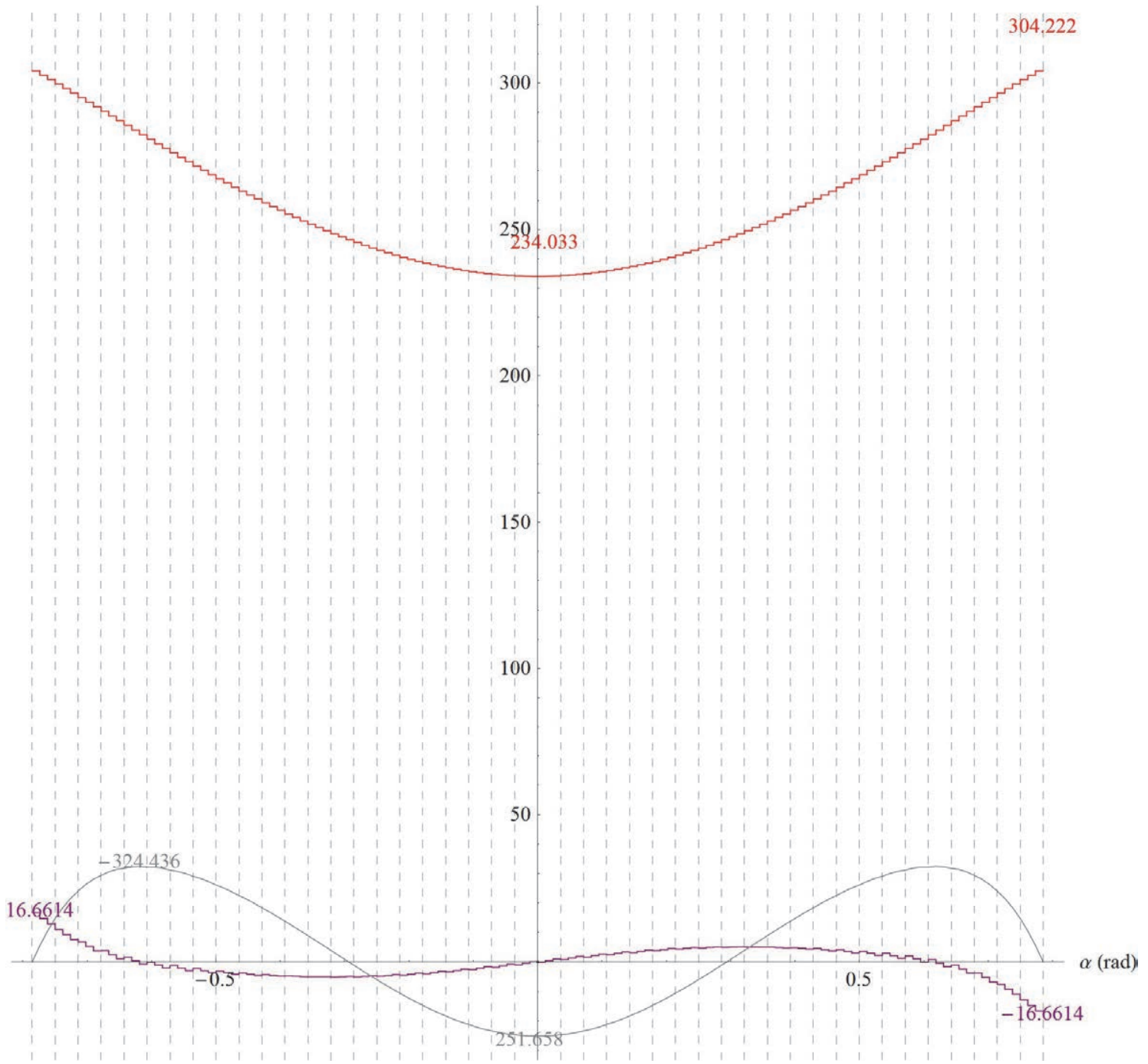


c)

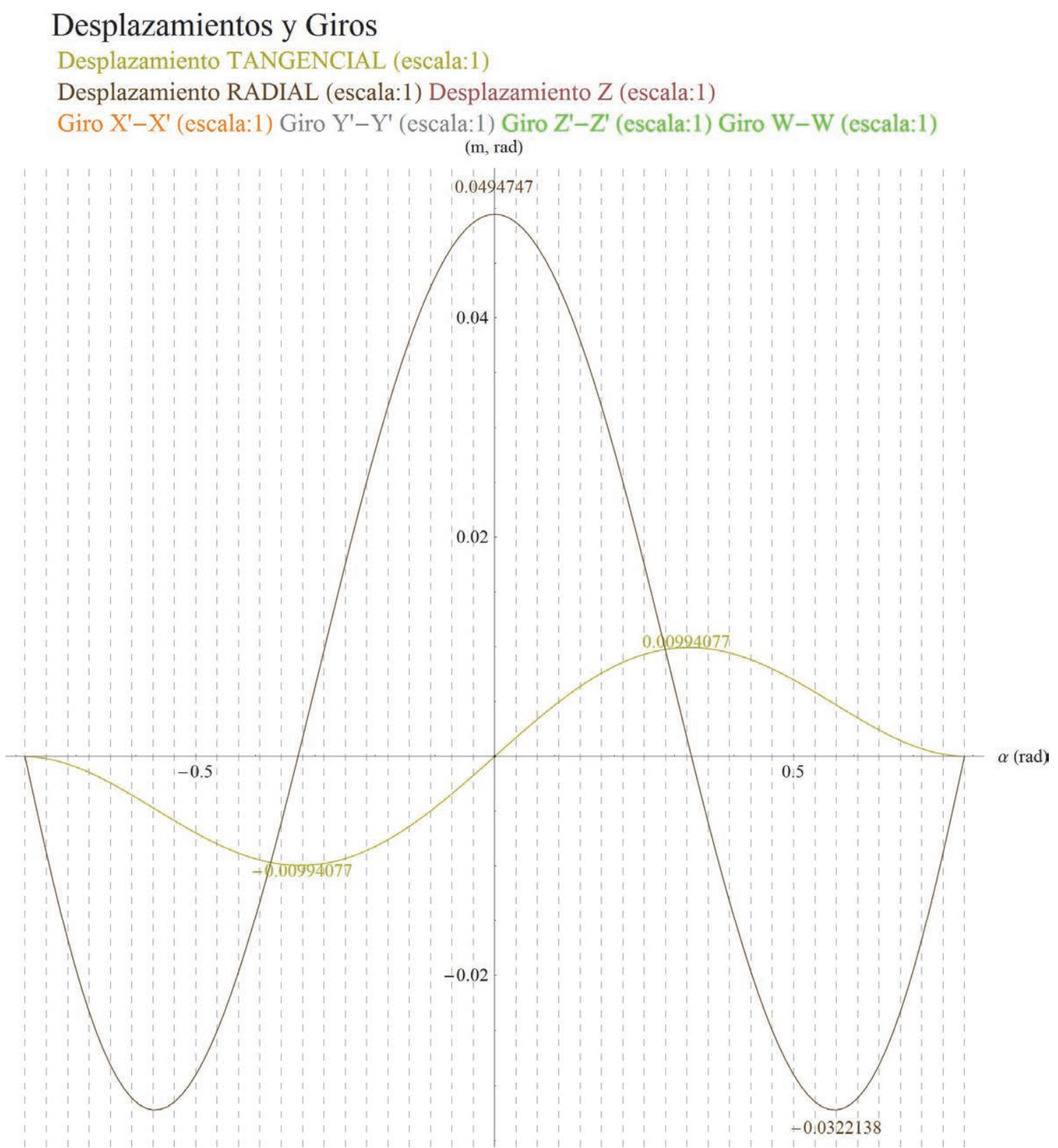

Diagrama 2.38. a) Modelo completo de puente atirantado con sección tipo Tablero 7 (Peatonal); b) Solicitaciones sobre el tablero, producidas por una carga $\mathrm{Fpx}=1$; c) Deformaciones sobre el tablero, producidas por una carga Fpx $=1$

En todos estos análisis se ha obviado la reducción de capacidad axil que se produce en el tablero debida a la posibilidad de inestabilidad. Posibilidad que aumenta al reducir el radio de giro correspondiente, aunque en el caso de tableros atirantados curvos este efecto se puede paliar. este análisis se considera fuera del ámbito de esta tesis. 
2.2.5 Sistema hiperestático, restringiendo los desplazamientos en los tres ejes en los estribos, carga en el plano del tablero, dirección Y-Y global (Fpy)

En este subapartado, se introduce la carga exterior según la dirección del eje global Y y se resuelven las ecuaciones diferenciales de la viga curva (subapartado 2.2.2) restringiendo cualquier desplazamiento en los estribos (subapartado 2.2.3). La carga introducida va a ser Fpy $=1 \mathrm{kN} / \mathrm{ml}$ (carga lineal con la dirección del eje Y-Y principal o global).

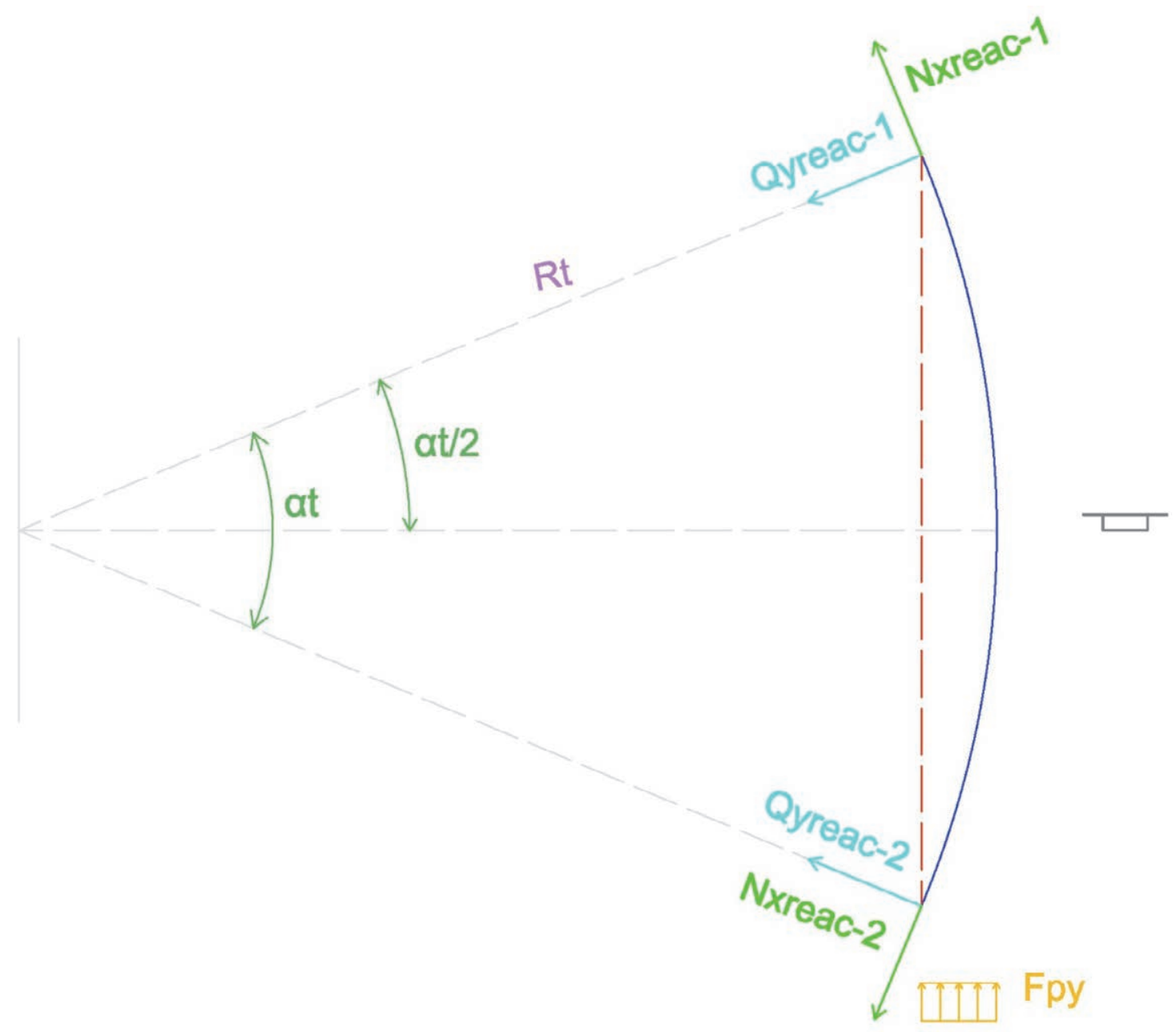

Ilustración 2.8. Modelo de cálculo para un tablero curvo bajo carga distribuida en el plano Y global.

Las cargas sobre el tablero, en ejes locales:

$$
\begin{gathered}
\alpha \geq 0 \\
p x[\alpha]=-F p y \operatorname{Cos}[\alpha] \operatorname{Sin}[\alpha] \\
p y[\alpha]=F p y \operatorname{Sin}[\alpha]^{2} \\
\alpha \leq 0 \\
p x[\alpha]=F p y \operatorname{Cos}[\alpha] \operatorname{Sin}[\alpha] \\
p y[\alpha]=-F p y \operatorname{Sin}[\alpha]^{2}
\end{gathered}
$$




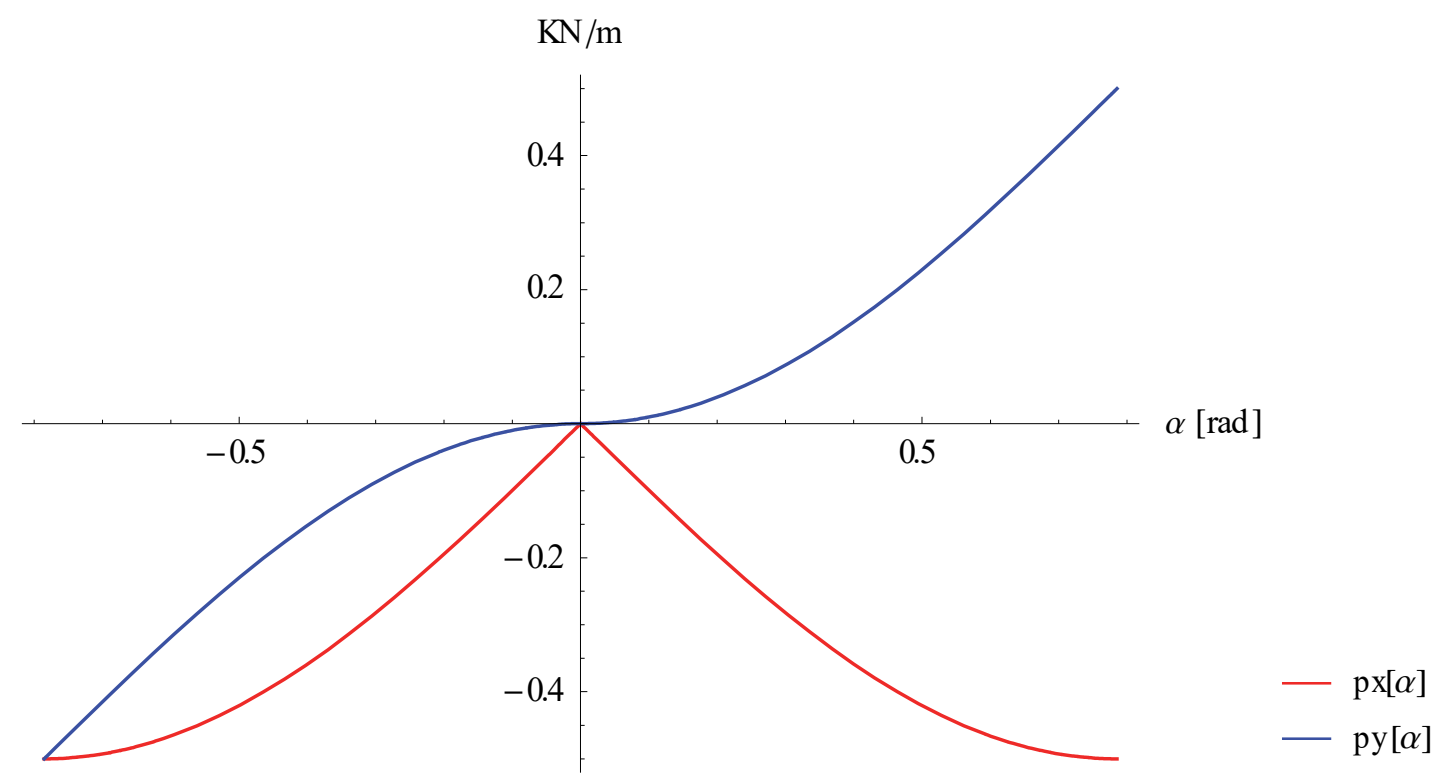

Diagrama 2.39. Proyección en ejes locales de una carga $F p y=1 \mathrm{KN} / \mathrm{ml}$ (eje global X). $\alpha t=\frac{\pi}{2}$.

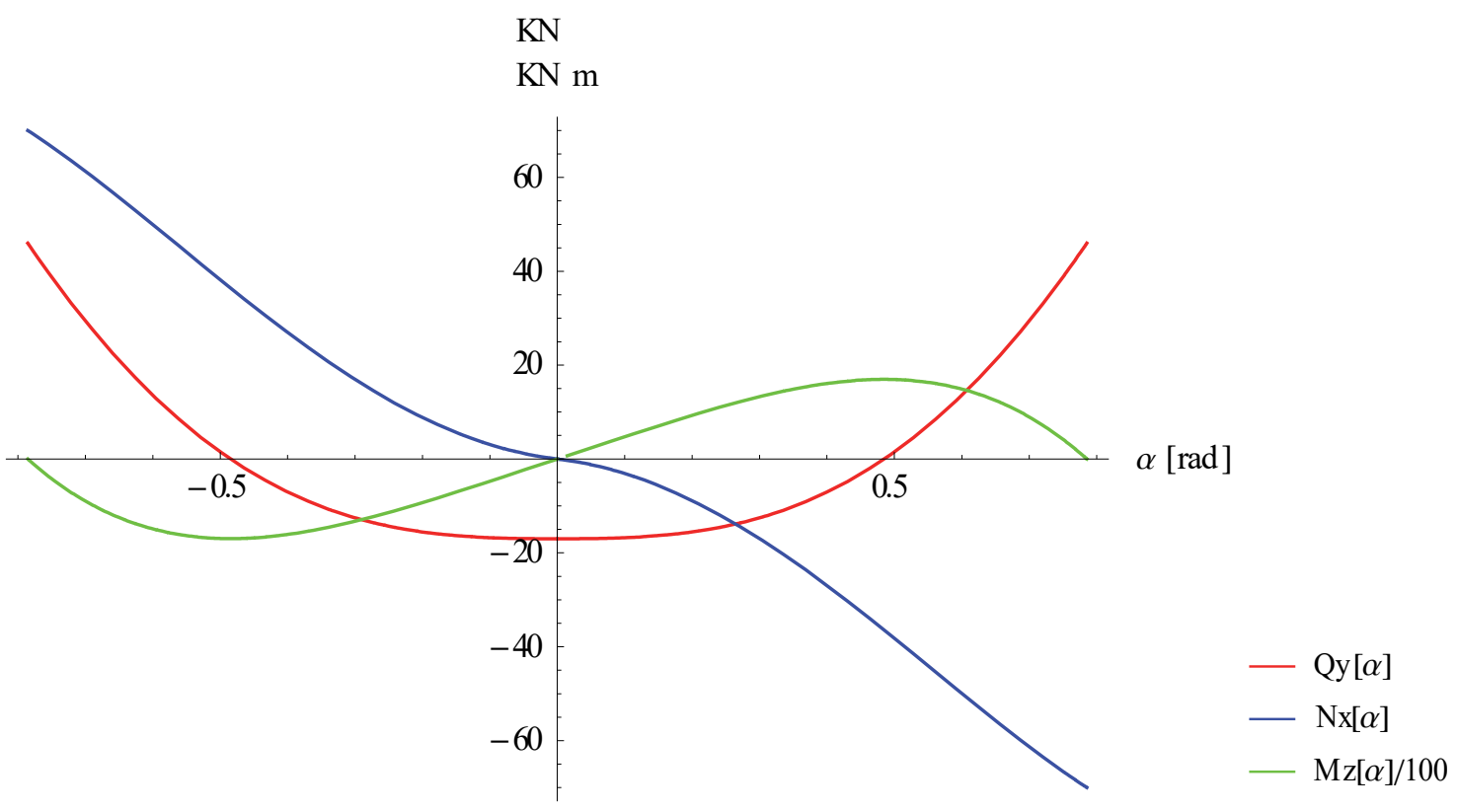

Diagrama 2.40. Solicitaciones sobre el tablero hiperestático bajo una carga $F p y=1 \mathrm{KN} / \mathrm{ml}$ (eje global Y). $\alpha t=\frac{\pi}{2}$, Rt $=280 \mathrm{~m}$, Tablero 7 (Peatonal)

Si analizamos las reacciones que se producen sobre los estribos:

$$
\begin{gathered}
N x_{\text {reac-1 }} \cos \frac{\alpha_{t}}{2}=N x_{\text {reac-2 }} \cos \frac{\alpha_{t}}{2}=F_{p y} \frac{R_{t}}{2}\left(1-\cos \alpha_{t}\right) \\
N x_{\text {reac-1 }} \sin \frac{\alpha_{t}}{2}=-N x_{\text {reac-2 }} \sin \frac{\alpha_{t}}{2}=F_{p y} \frac{R_{t}}{4} \frac{\left(1-\cos \alpha_{t}\right)^{2}}{\sin \alpha_{t}}
\end{gathered}
$$

El funcionamiento es similar al de un pórtico solicitado horizontalmente en su plano. Como se puede apreciar en los diagramas de solicitaciones (Diagrama 2.41), es el momento flector Mz la solicitación más importante que debe resistir el tablero. Esto hace que el 
comportamiento del sistema frente a esta carga (Fpy), quede determinado por la rigidez del tablero (E Izz) frente a esta solicitación (Mz).

Se puede apreciar como la magnitud (por la falta de ayuda por parte del sistema "tipo arco") del momento flector (Mz) es alta, aun cuando la exposición del tablero a esta acción es pequeña (Diagrama 2.40) en comparación con lo visto para Fpx. Por esta razón, resulta imprescindible estudiar atentamente cualquier carga que se pueda producir en esta dirección (viento, frenado, arranque...) en el análisis de puentes curvos atirantados, (53).

De nuevo, como ocurrió en el análisis de la carga Fpx, el subsistema de Pila-Tirantes tiende a reducir los momentos y desplazamientos transversales (dependiendo de la posición y altura de la pila), homogeneizando el comportamiento a lo largo del tablero. Si bien, el análisis realizado seguirá, generalmente, siendo válido. Observando las solicitaciones del Diagrama 2.41 sobre el mismo puente que en el Diagrama 2.38, se concluye de nuevo que el subsistema Pila-Tirantes tiende a reducir las solicitaciones transversales ( $M z$ y $Q y$ ), sin apenas influir sobre la solicitación axil ( $\mathrm{Nx}$, se aprecia la similitud de los valores del Diagrama 2.40 y Diagrama 2.41).

Solicitaciones sobre el tablero
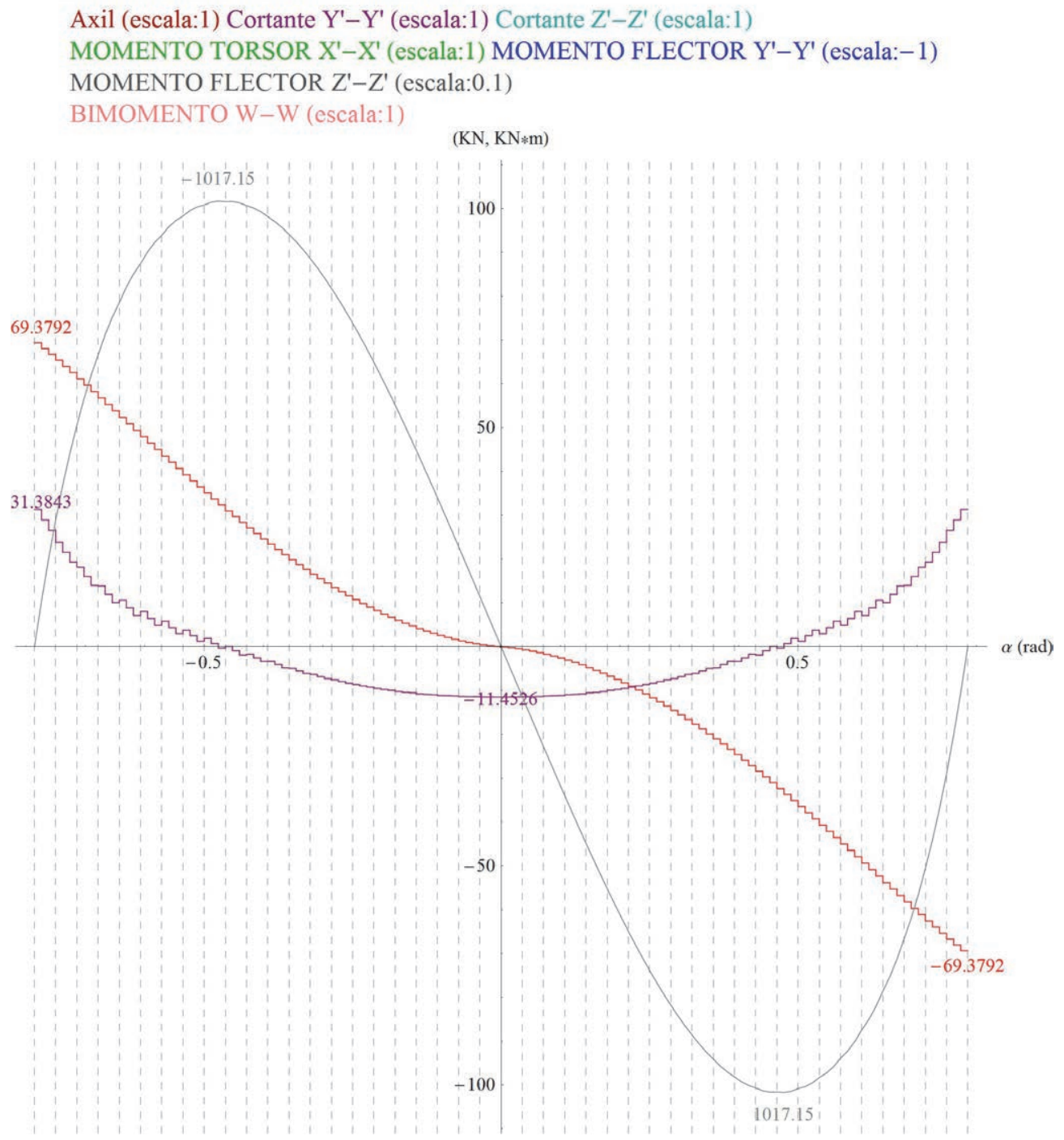

Diagrama 2.41. Solicitaciones sobre el Puente del Diagrama 2.38 a), producidas por una carga Fpy $=1$. 
Aunque en el caso de un puente curvo atirantado, el sistema de pila-tirante harían el sistema estructural estable en el caso de disponer apoyos traslacionales en los estribos. Resulta intuitivo que esta carga aumentaría el problema de desplazamientos laterales en los estribos, visto para la carga Fpx (subapartado 2.1.2.1.1).

No se va a desarrollar la posibilidad de un tablero con asimetría en las restricciones de los estribos, por considerarse una opción muy singular a la que solo se recurriría, posiblemente, por unas características orográficas muy particulares. Este tipo de excepciones quedan fuera del ámbito de esta tesis.

\subsubsection{Sistema hiperestático, restringiendo el desplazamiento en los 3 ejes de los estribos, carga en el plano del tablero y concéntricas}

En los puentes atirantados, las cargas verticales se van a resistir, fundamentalmente, mediante el subsistema Pila-Tirantes (capítulo 3). Luego el comportamiento del puente a "nivel global" (orden de magnitud mayor al de un vano) va a depender del correcto funcionamiento de este sistema resistivo (Pila-Tirantes). Por su configuración, el sistema resistivo Pila-Tirantes requiere de una reacción horizontal del tablero que le permita levantar la carga vertical. En el caso de puentes atirantados rectos, esta reacción proviene del axil del tablero debido a que todo queda en el mismo plano (de no ser así, por ejemplo, una disposición tipo planos convergentes (35) en la pila, las fuerzas transversales se compensan directamente en cada sección de apoyo del tablero, como compresiones locales). En los puentes curvos se rompe este plano, formándose un sistema espacial. La consecuencia inmediata de esta ruptura, es que las cargas horizontales a las que debe responder el tablero no son longitudinales a su directriz, provocando cargas transversales concéntricas a la pila.

El módulo de esta carga y su dirección a lo largo del tablero, va a ser función de la morfología del puente (fundamentalmente de la situación y altura de la pila respecto del tablero). Esto se vuelve una característica muy importante a la hora de analizar las deformaciones a "nivel global", ya que la rigidez que presente el tablero, ya sea mediante un comportamiento "tipo arco", "tipo viga" o "mixto" (subapartado 2.2.6.2), va a ser determinante en el comportamiento global del puente.

\subsubsection{Sistema hiperestático, restringiendo el desplazamiento en los 3 ejes de los estribos, carga en el plano del tablero, concéntrica a la pila situada en el centro del arco del tablero}

\subsection{Solicitaciones}

Si se la pila sobre el centro del arco que forma el tablero, se va a obtener una carga similar a la que introducen los radios de una rueda de bicicleta sobre la llanta, este es el primer caso que se va a estudiar por ser el más sencillo. Pero en muy importante entender que, en la mayoría de los casos, o no va a ser conveniente o no se va a poder posicionar la pila en este punto, luego la carga se vuelve mucho más compleja, tanto en su dirección como en su módulo. Estos casos se estudiarán detalladamente en subapartados posteriores. 
El módulo de la carga concéntrica (Ttir) se va a considerar constante a lo largo de todo el tablero (esto estaría muy próximo a la realidad en el caso de poner los tirantes en carga, (27)), para simplificar el problema.

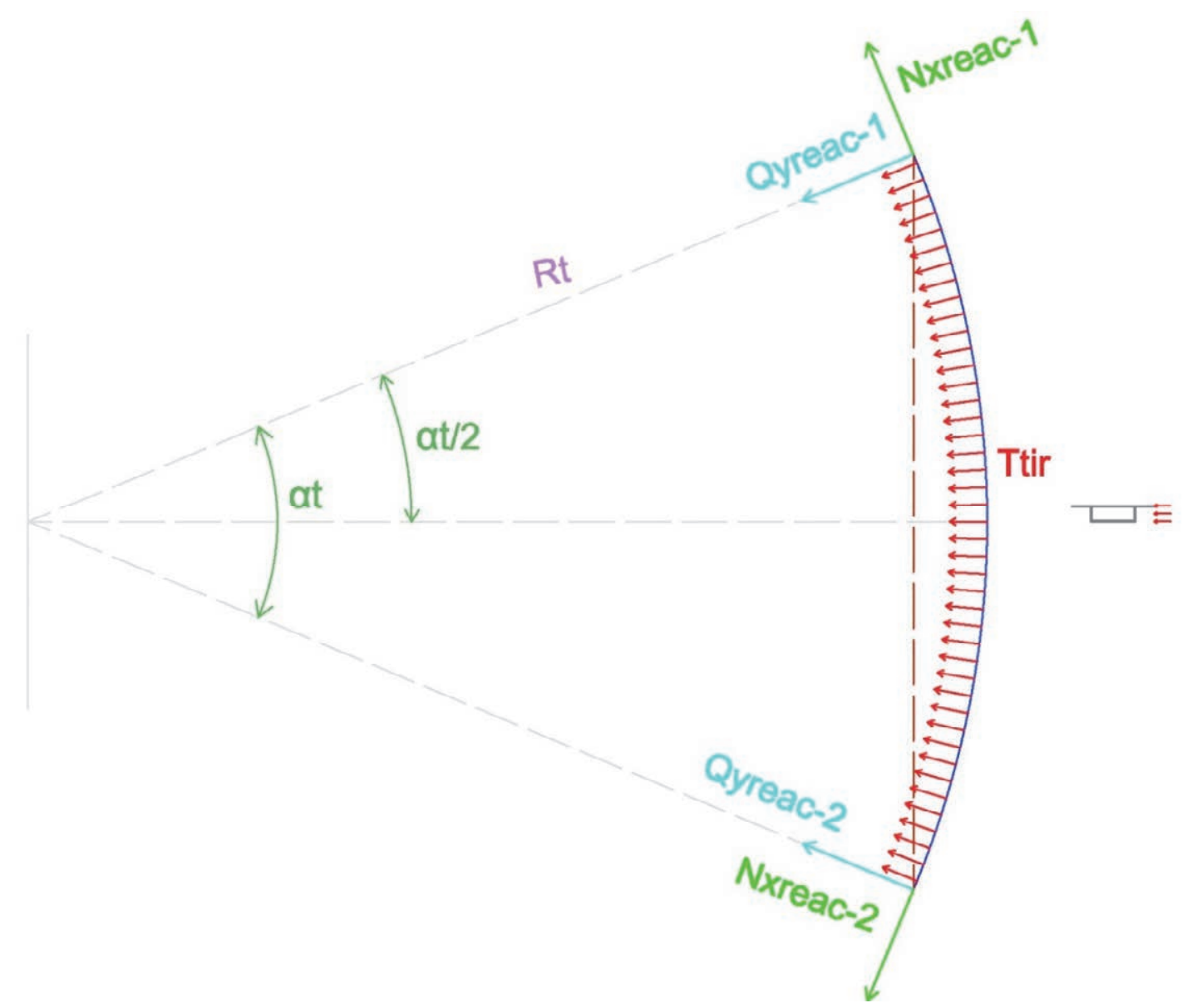

Ilustración 2.9. Modelo de cálculo para un tablero curvo bajo cargas concéntricas a una pila situada en el centro del arco del tablero.

$$
\text { Ttir }=f[\alpha]=1
$$

Donde, existen las siguientes variables geométricas:

$$
\begin{gathered}
x p p=R p \operatorname{Cos}[\alpha p] \\
y p p=R p \operatorname{Sin}[\alpha p] \\
x p t[\alpha]=R t \operatorname{Cos}[\alpha] \\
y p t[\alpha]=R t \operatorname{Sin}[\alpha] \\
\alpha l[\alpha]=\operatorname{ArcTan}[x p t[\alpha]-x p p, y p t[\alpha]-y p p]
\end{gathered}
$$

Carga según ejes locales del tablero:

$$
\begin{gathered}
p x[\alpha]=-\operatorname{Ttir} \operatorname{Sin}[\alpha l[\alpha]+\pi-\alpha] \\
p y[\alpha]=\operatorname{Ttir} \operatorname{Cos}[\alpha l[\alpha]+\pi-\alpha]
\end{gathered}
$$




\section{Carga según ejes globales:}

$$
\begin{aligned}
& F p x[\alpha]=p y[\alpha] \operatorname{Cos}[\alpha]+p x[\alpha] \operatorname{Sin}[\alpha] \\
& F p y[\alpha]=p y[\alpha] \operatorname{Sin}[\alpha]-p x[\alpha] \operatorname{Cos}[\alpha]
\end{aligned}
$$

Valga el siguiente diagrama para definir las diferentes variables geométricas:

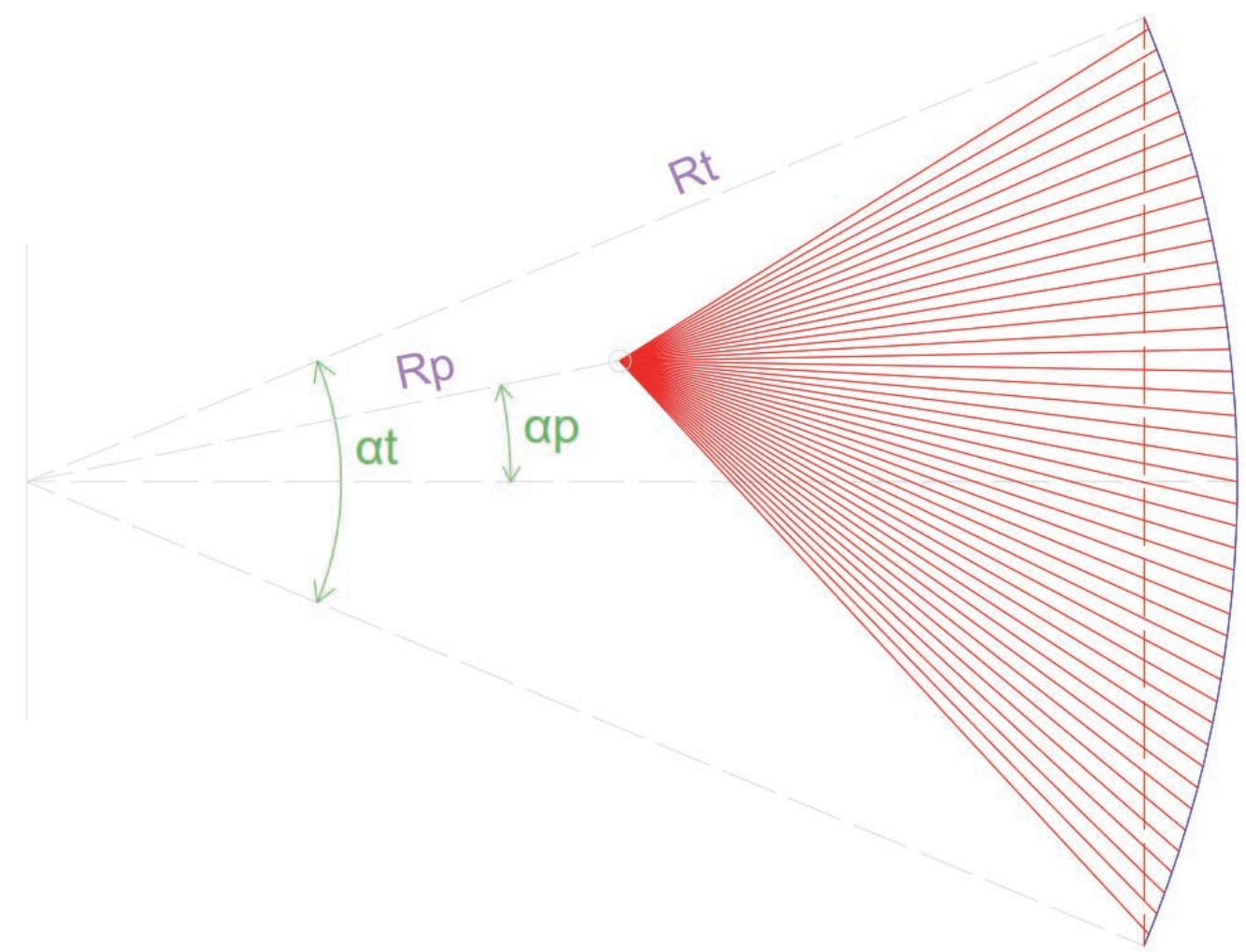

Ilustración 2.10 Modelo explicativo para la dirección de la carga concéntrica a la pila en un puente curvo atirantado.

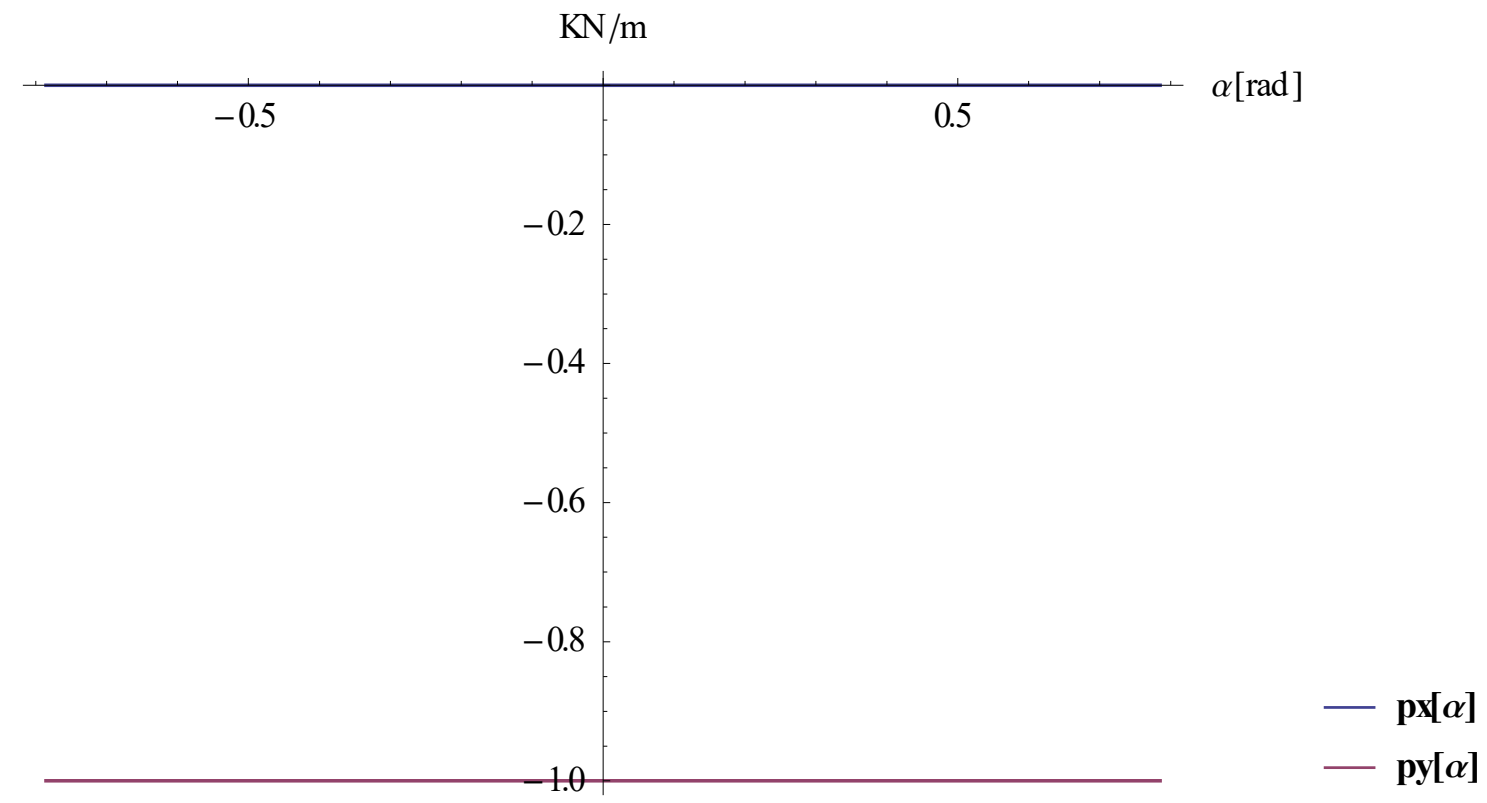

Diagrama 2.42. Carga concéntrica a la pila situada en el centro del arco del tablero, según ejes locales del tablero. $\alpha t=\frac{\pi}{2}$. 


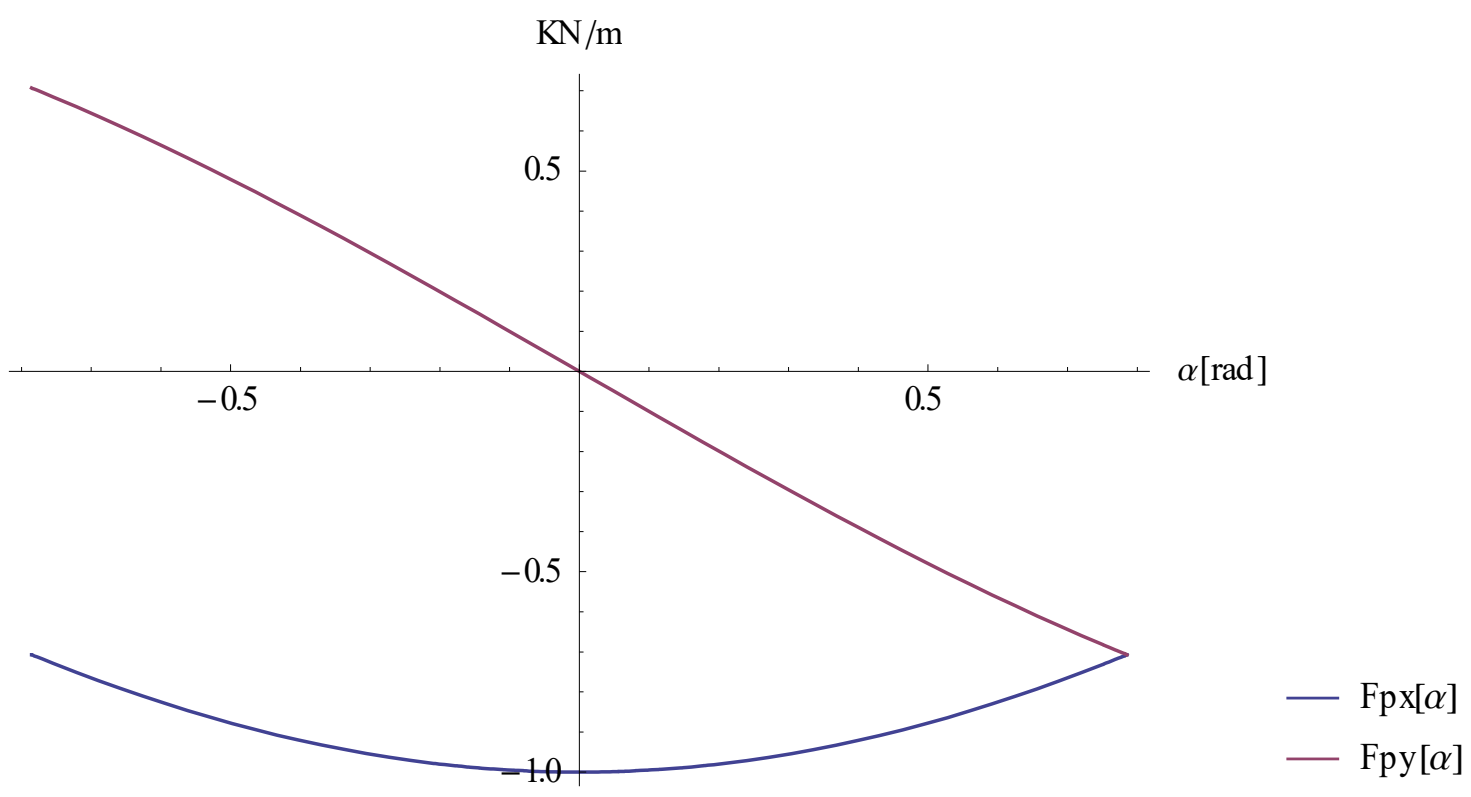

Diagrama 2.43. Carga concéntrica a la pila situada en el centro del arco del tablero, según ejes globales del tablero. $\alpha t=\frac{\pi}{2}$.

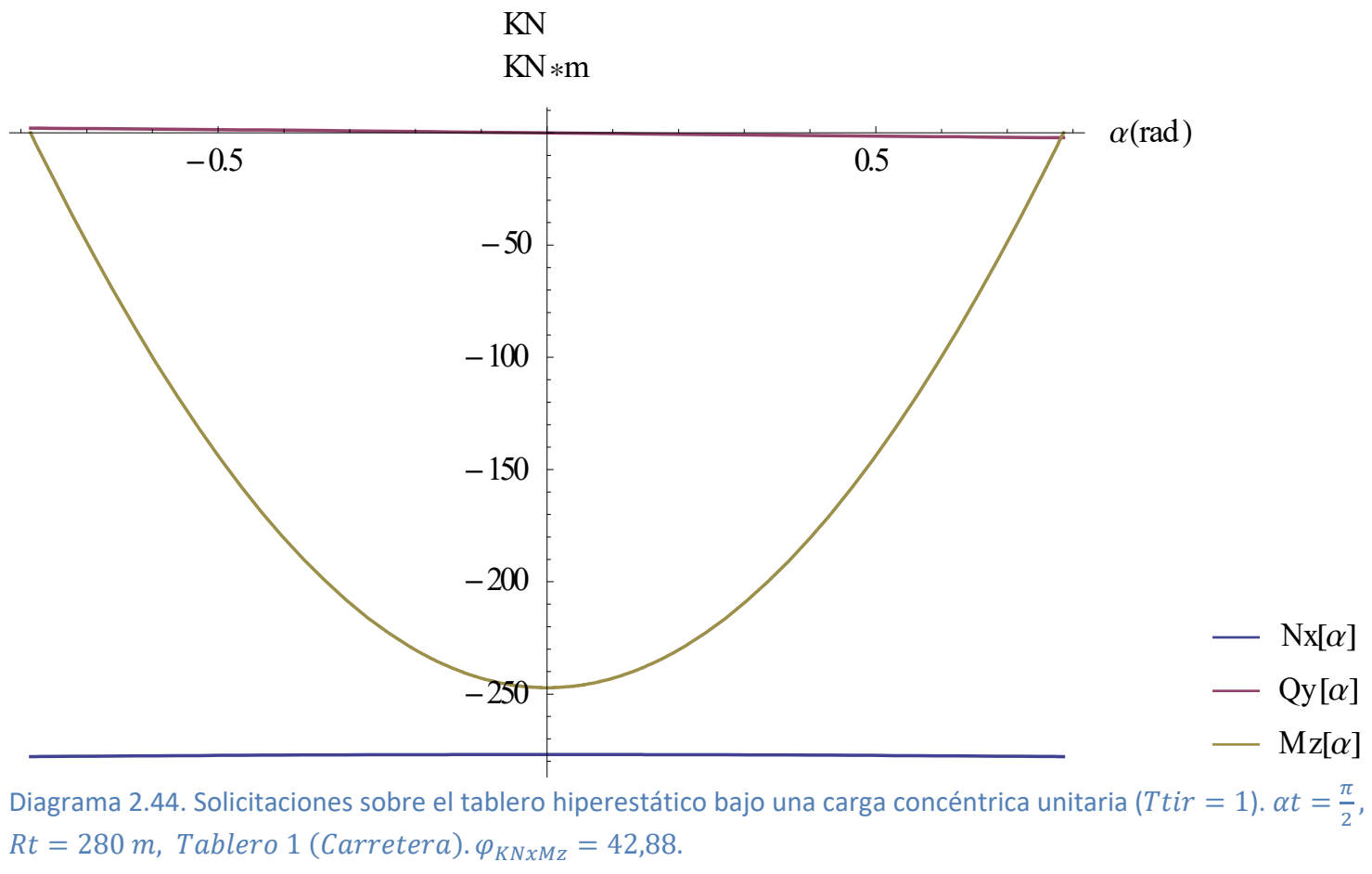

Se puede apreciar (Diagrama 2.44) como el comportamiento predominante es similar al de la llanta de una rueda de bicicleta, con el axil ( $\mathrm{Nx}$ ) como solicitación predominante. La única razón para que el comportamiento del tablero no sea exactamente igual al de una rueda de bicicleta, es que las condiciones de contorno que reproducen los estribos (desplazamiento nulo en todas las condiciones), no coinciden con las que impondría la sección de tablero que daría continuidad hasta cerrar la circunferencia (desplazamiento radial, debido a la compresión del tablero y reacción longitudinal al eje del tablero). 
Resulta obvio, que cuanto menor sea el desplazamiento perpendicular al eje del tablero debido al acortamiento de este por la solicitación axil $(\mathrm{Nx})$ y/o menor sea la rigidez transversal del tablero, menor va a ser este efecto que aleja el comportamiento del tablero del de una llanta de bicicleta, esto ya se ha estudiado en el subapartado 2.2 .4 mediante el factor $\varphi_{K N X M z}$. Si se cambia la tipología de tablero a un Tablero 7 (Peatonal), con $\varphi_{K N x M z}=575.61$, se puede ver en el Diagrama 2.45 como el comportamiento se asemeja todavía más al de la rueda de una bicicleta, anulándose casi por completo las solicitaciones transversales (Mz y Qy).

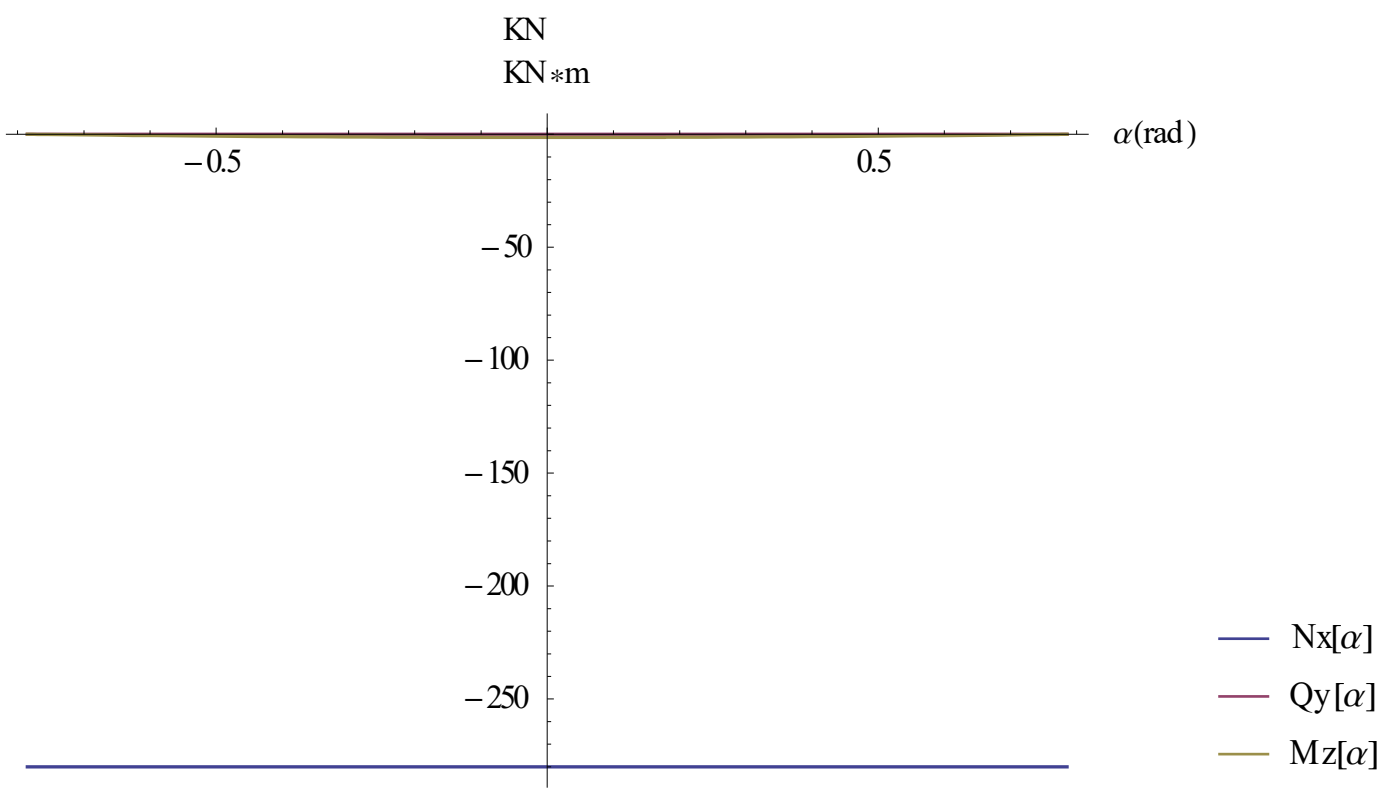

Diagrama 2.45. Solicitaciones sobre el tablero hiperestático bajo una carga concéntrica unitaria $($ Ttir $=1) . \alpha t=\frac{\pi}{2}$, $R t=280 \mathrm{~m}$, Tablero 7 (Peatonal). $\varphi_{K N x M z}=575,61$.

Tal y como ocurría en el subapartado 2.2.4, los coeficientes $v_{Q y N x}$ y $v_{M z N x}$ son completamente dependientes del coeficiente $\varphi_{K N x M z}$. Se va a estudiar su efecto con diferentes ángulos para entender la relación entre rigideces y comportamiento del tablero para todo tipo de cargas y así conservar la línea de razonamiento expuesta en los puntos anteriores.

Es muy importante apreciar como en este caso, en el que la hipótesis está compuesta exclusivamente por la carga $p y(\alpha)$, la relación entre el coeficiente $\varphi_{K N x M z}{ }^{2}$ y la rigidez del tablero es directa, de forma que si esta relación se duplica (manteniendo el radio del tablero constante), la relación en el centro del vano (y en cualquier otro lugar de la viga) entre el axil y el momento transversal también se duplica (llustración 2.7). Además, solo hay un máximo, en el caso del momento, este se produce en el centro del vano, mientras que en el caso del cortante transversal, se produce en los estribos (Diagrama 2.44 y Diagrama 2.45 ).

Se puede apreciar, como la carga concéntrica es mucho más apropiada para un sistema resistivo "tipo arco" que las unidireccionales estudiadas hasta el momento (subapartados 2.2.4 y 2.2.5). El ángulo vuelve a ser determinante para garantizar este comportamiento ("tipo arco") y, para este tipo de carga concéntrica, no existe el comportamiento "tipo esfera" (volverá a aparecer cuando analicemos $R p>0$ ), comentado en el subapartado 2.2.4. Esto hace que el incremento de ángulo desarrollado por el tablero $\alpha t$ siempre sea propicio para que 
el comportamiento del sistema se base en el sistema resistivo "tipo arco". Hasta el punto, de que con un ángulo $\alpha t=\pi$, si se mantiene el sistema isostático permitiendo el desplazamiento transversal del tablero en uno de los estribos, nos encontramos con un sistema "tipo arco" perfecto (como el de la llanta de una rueda de bicicleta).

En sistemas con ángulos desarrollados pequeños $\left(\alpha t<\frac{\pi}{5}\right)$, su comportamiento es muy próximo al que analizamos en el caso de una carga unidireccional Fpx. Es en sistemas con estos ángulos $\alpha t$ pequeños, en los que la carga concéntrica se muestra más unidireccional, mostrando un comportamiento semejante al de una viga biapoyada. Disminuir este comportamiento "tipo viga" (incitando el comportamiento "tipo arco"), pasa por aumentar el factor $\varphi_{K N x M z}$, que se consigue aumentando el radio del tablero o disminuyendo el radio de giro según el eje vertical (rzz). Por encima de $\alpha t=\frac{\pi}{5}$, se puede confirmar que frente a este tipo de carga (concéntrica), el sistema tiene un comportamiento "tipo arco" y las características mecánicas del tablero pierden relevancia (como se puede apreciar en el Diagrama 3.4).

$$
\begin{gathered}
\boldsymbol{v}_{\text {QyNxE }} \rightarrow \text { Valor en el estribo } \\
\boldsymbol{v}_{\text {MzNxMS }} \rightarrow \text { Valor en el centro de vano }
\end{gathered}
$$

a)

$v \mathrm{QyNxE}$

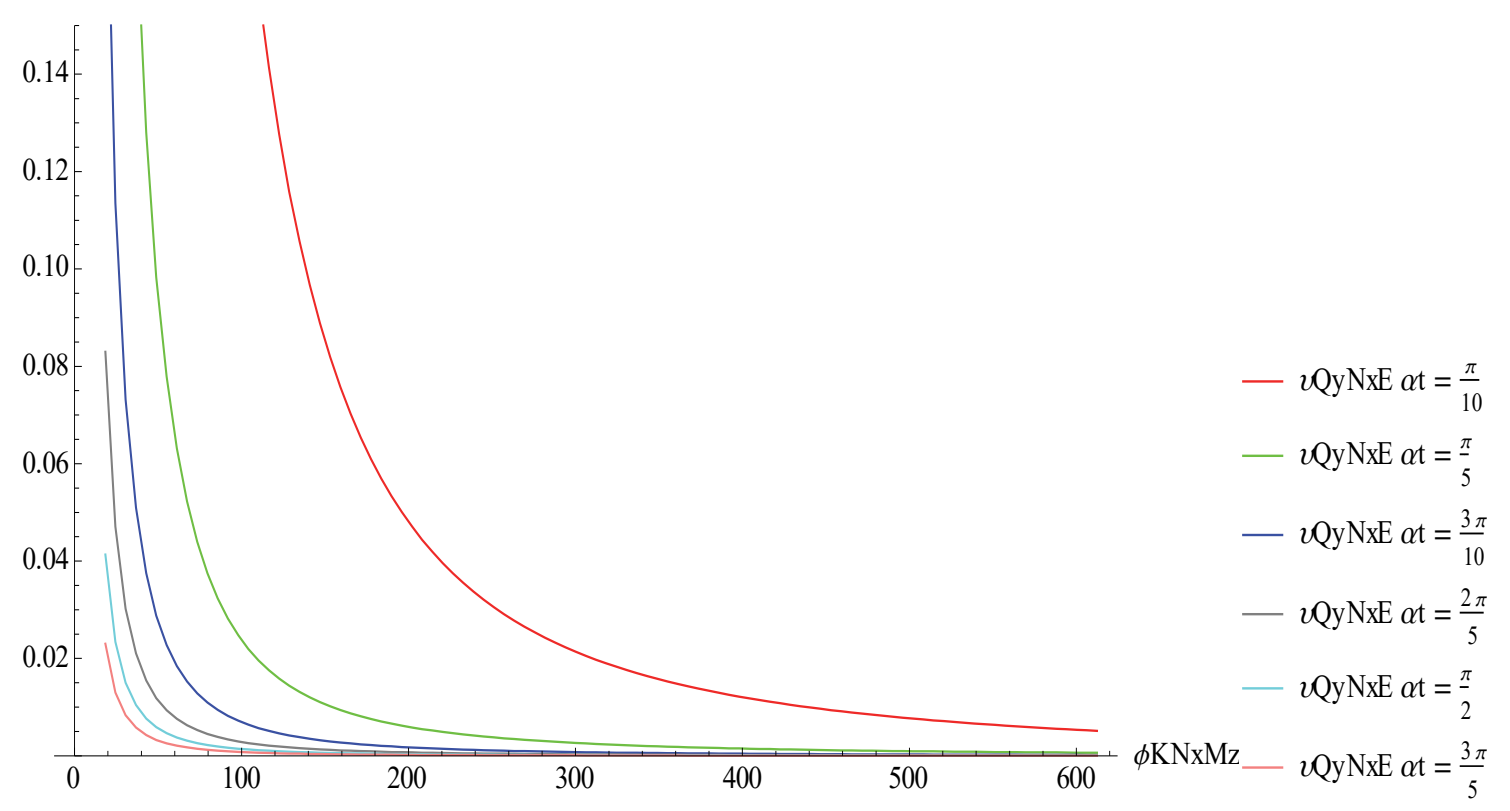


b)

$v \mathrm{MzNxMS}$

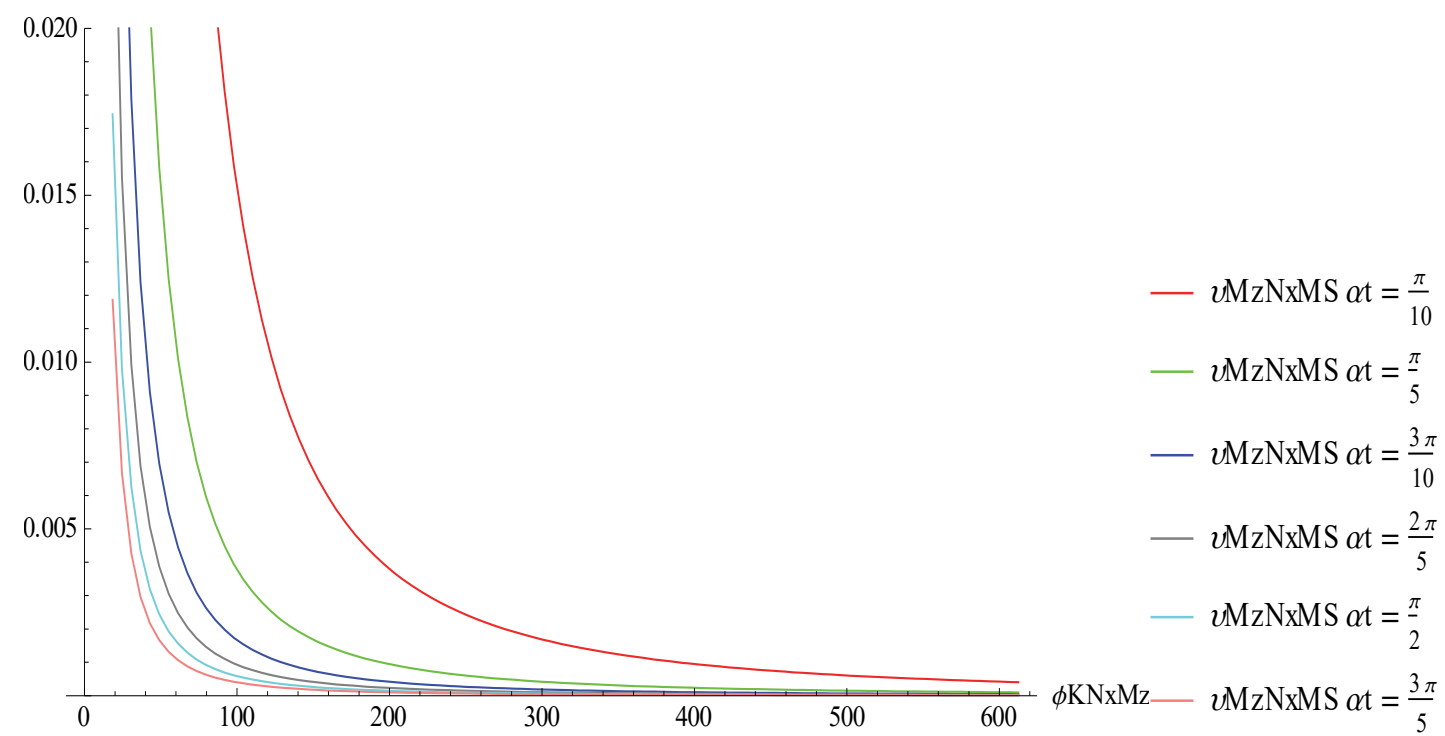

Diagrama 2.46. Solicitaciones frente a características mecánicas del tablero. a) $v_{Q y N x E} v S \varphi_{K N x M z}$ b)

$v_{M z N x M S} v S \varphi_{K N x M z}$.

Del análisis del Diagrama 2.46., se aprecia como el comportamiento de las curvas frente al coeficiente $\varphi_{K N x M z}$, se asemeja al de una función racional. Mientras que también resulta evidente que el incremento de ángulo tiene un efecto inverso sobre los coeficientes $v_{Q y N x} \mathrm{Y}$ $v_{Q y N x}$. Si unimos esto al estudio de las ecuaciones diferenciales que rigen el sistema (Ilustración 2.5), se pueden obtener los siguientes coeficientes y diagramas:

$$
\begin{gathered}
\psi_{Q y N x}=\frac{1}{\alpha t^{3}} * \frac{1}{\varphi_{K N x M z}{ }^{2}}=\frac{1}{\alpha t^{3}} * \frac{I_{z z}}{R t^{2} A_{x x}}=\frac{1}{\alpha t L t^{2}} * i_{z z}{ }^{2} \\
\psi_{M z N x}=\frac{1}{\alpha t^{2}} * \frac{1}{\varphi_{K N x M z}{ }^{2}}=\frac{1}{\alpha t^{2}} * \frac{I_{z z}}{R t^{2} A_{x x}}=\frac{1}{L t^{2}} * i_{z z}{ }^{2}
\end{gathered}
$$

a)

$v$ QyNxE

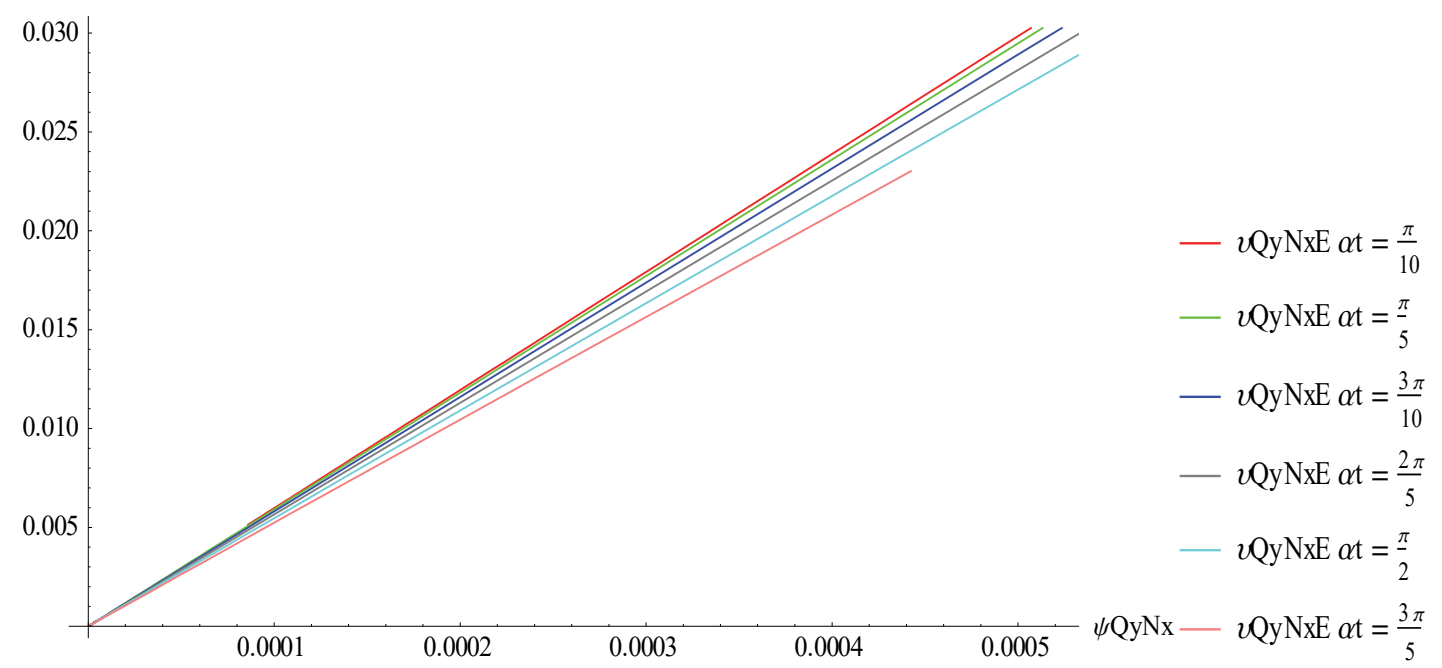


b)

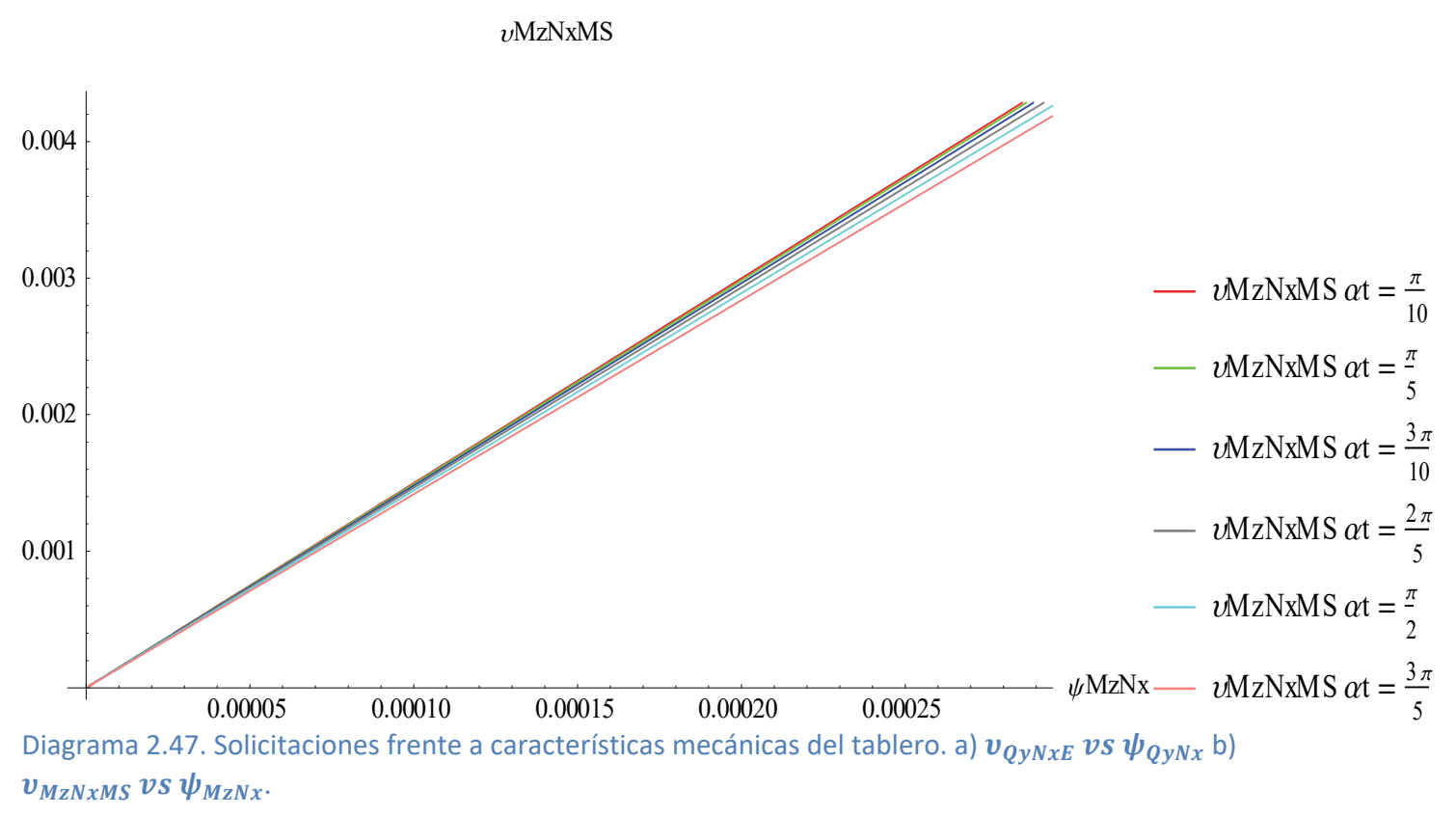

El Diagrama 2.47 muestra que existe una relación lineal entre las características mecánicas de la sección, la directriz del tablero $\left(\psi_{Q y N x}\right.$ y $\left.\psi_{M z N x}\right)$ y su comportamiento. Este comportamiento, mostrándose fundamentalmente lineal, diverge un poco al variar los ángulos. Como la intención de estos coeficientes no es la de obtener solicitaciones exactas, sino la de comparar comportamientos según se varía las características del tablero, mediante regresión lineal se van a sacar las rectas para cada uno de los ángulos. Una vez tenemos esas rectas (que pasan por el origen), se va a sacar una nueva regresión lineal para obtener la pendiente de las rectas en función del ángulo:

$$
\begin{aligned}
& v_{Q y N x E}=(61.62-9.58 \alpha t) \psi_{Q y N x}=(61.62-9.58 \alpha t) \frac{1}{\alpha t L t^{2}} * i_{z z}^{2} \\
& v_{M y N x M S}=(15.55-1.35 \alpha t) \psi_{M z N x}=(15.55-1.35 \alpha t) \frac{1}{L t^{2}} * i_{z z}{ }^{2}
\end{aligned}
$$

\subsection{Deformaciones}

Esta tipología de carga, como se ha comentado anteriormente, estimula fundamentalmente al sistema resistivo "tipo arco". El sistema resistivo "tipo viga" biapoyada (sobre todo para ángulos desarrollados medios y altos, por encima de $\frac{\pi}{4}$ ), solo aparece de forma muy reducida, por las condiciones de contorno de los estribos (como se vio en las solicitaciones, subapartado 2.2.6.1.1). Debido al carácter local de las afecciones que producen estas condiciones de contorno, el axil sobre el tablero apenas cambia al variar la tipología de tablero (Diagrama 2.44 y Diagrama 2.45).

Por otro lado, se ha visto como la solicitación axil $(\mathrm{Nx})$ y momento flector $(\mathrm{Mz})$ del tablero quedan relacionadas mediante el coeficiente $\varphi_{K N x M z}{ }^{2}$ y el ángulo $\alpha t$. De forma que, a medida que el tablero se hace más flexible frente a la solicitación de momento flector (Mz), aumenta la solicitación axil ( $\mathrm{Nx})$. 
En los diagramas de deformaciones (Diagrama 2.48 y Diagrama 2.49), se ha analizado para diferentes ángulos los efectos que produce un cambio en las características mecánicas de la sección, modificando y el valor de $\varphi_{\mathrm{KNXMz}}{ }^{2}$ mediante el radio de giro rzz. Para dichos diagramas, se ha situado la pila en el centro del arco y se ha mantenido la longitud de tablero constante. Se va a recorrer un amplio rango de valores de $\varphi_{\mathrm{KNxMz}}{ }^{2}$, entre los que estarán tableros de carretera tipo Tablero 1 (Carretera), con un radio de giro $r z z=6.53 \mathrm{~m}$, hasta secciones más propias de pasarelas tipo Tablero7 (Peatonal), con $r z z=0.486 \mathrm{~m}$. Como abscisas se ha metido $\varphi_{K N X M Z}$ y no su valor al cuadrado, por mantener una continuidad con el resto de diagramas. Como ordenadas se puede ver la deformación transversal del tablero $\delta y y$ (Dividida por el radio, para poder apreciar varias curvas en la misma gráfica) en el centro del vano (negativa, por ser hacia el interior del arco). En el Diagrama 2.49, se separan las deformaciones debidas a la solicitación axil $(\mathrm{Nx})$ y las debidas a la solicitación flectora (Mz). Al ser un sistema hiperestático, las 2 deformaciones (por Axil ( $\mathrm{Nx}$ ) y por momento flector $(\mathrm{Mz})$ ), quedan relacionadas. Para separarlas, se ha definido la deformada debida al axil en el centro de vano ( $\delta y y N x(\alpha=0)$ ), como aquella del sistema hiperestático (anulando el movimiento en los estribos) producida por la solicitación axil del tablero. Mientras que la deformación debida al momento flector en el centro de vano $(\operatorname{\delta yy} \operatorname{Mz}(\alpha=0))$, se define como la deformación restante. 
Deformación total $(\mathrm{Lt}=440 \mathrm{~m})$

syyTOT/Rt

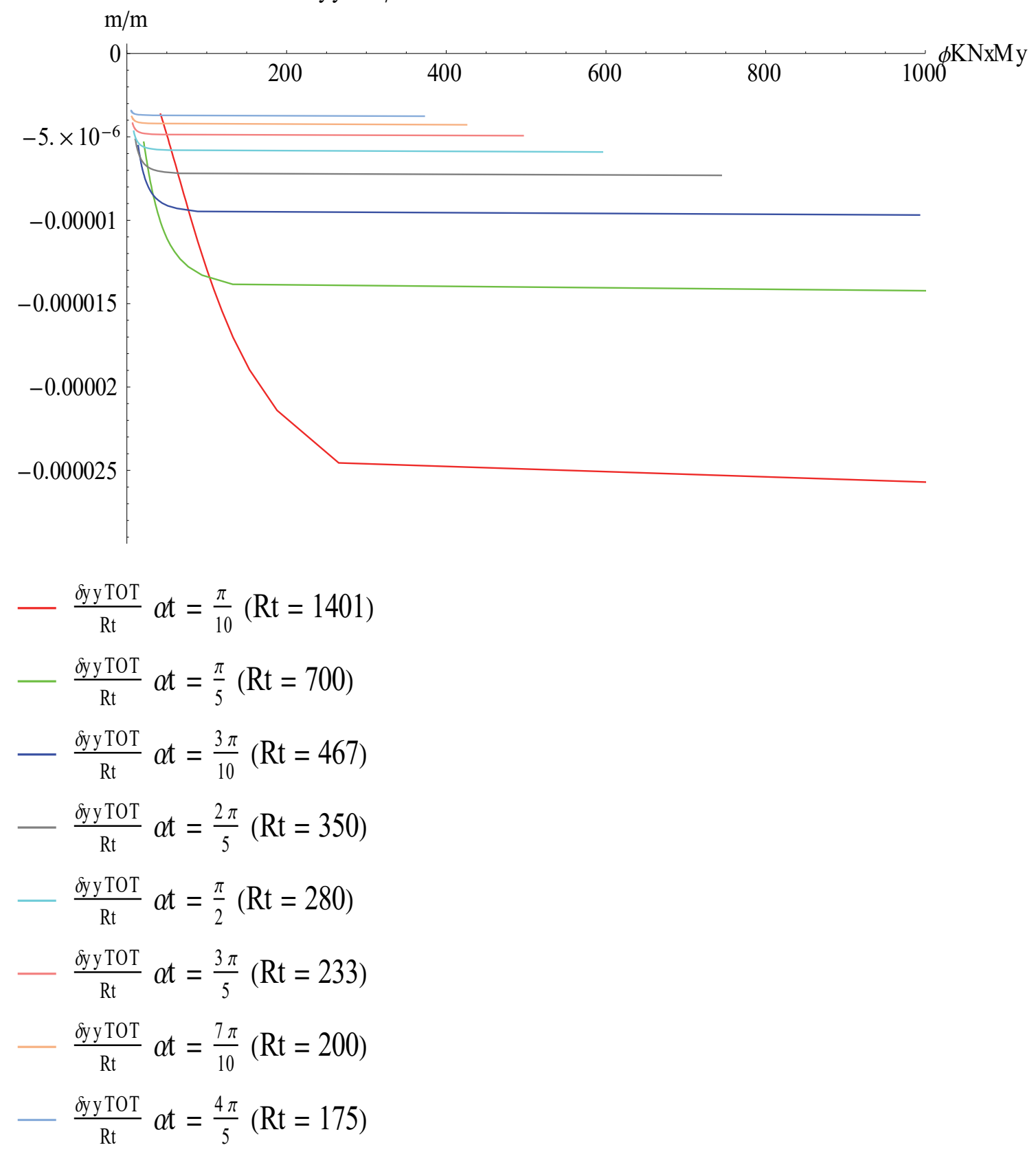

Diagrama 2.48. Deformaciones totales en el centro del vano. 


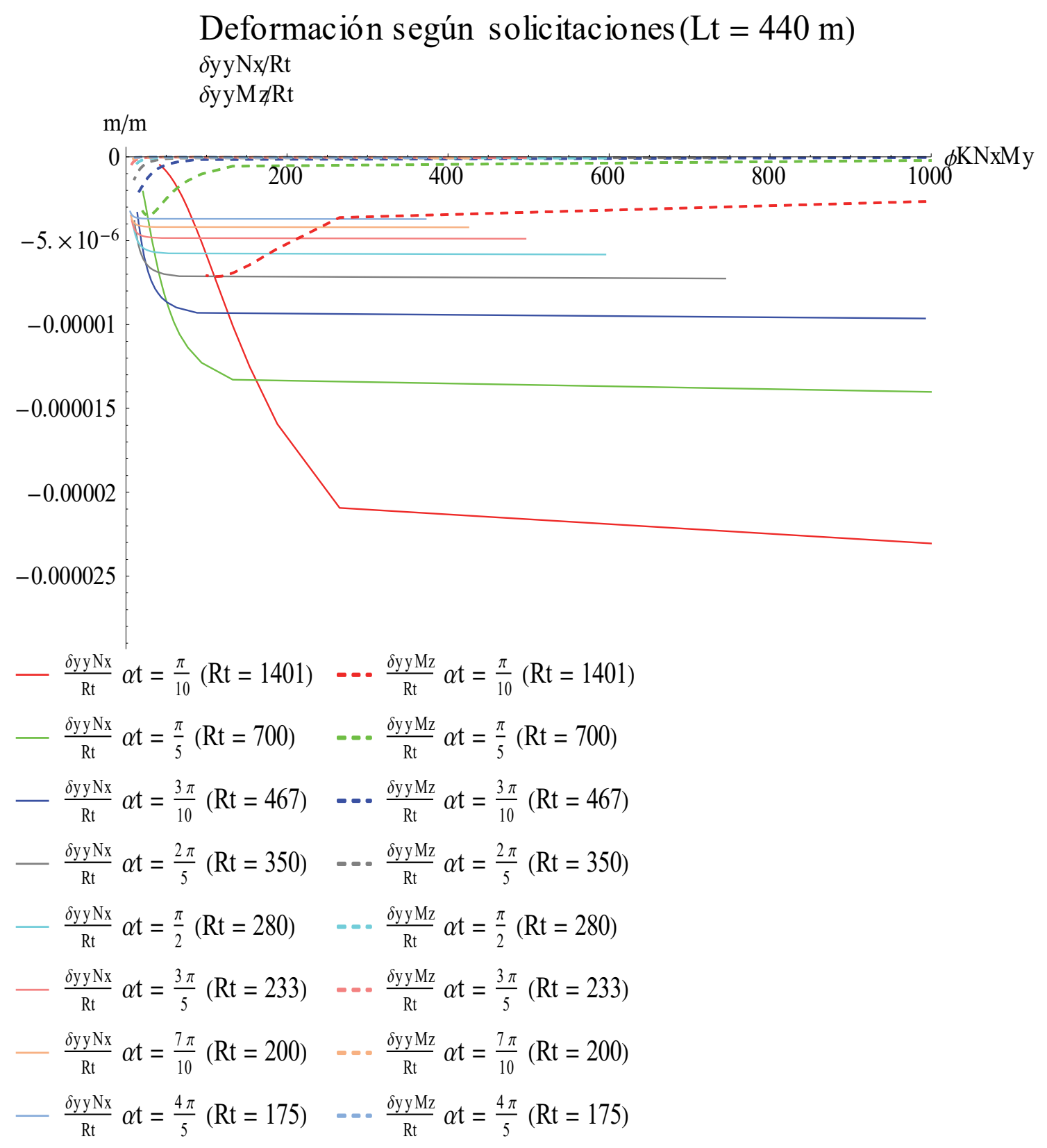

Diagrama 2.49. Deformaciones en el centro de vano por tipo de solicitación.

La conclusión que se obtiene del Diagrama 2.48 y Diagrama 2.49, es que frente a esta hipótesis de carga (py), estimular el sistema resistivo "tipo arco" cuando tenemos un $\varphi_{K N x M z}$ muy bajo, aumentando la flexibilidad frente al momento transversal (disminuyendo la inercia transversal), apenas supone un incremento de flexibilidad del sistema (Diagrama 2.48) se ve como no incrementan las deformaciones del tablero a medida que se hace más flexible), porque se reduce la solicitación de momento transversal (Mz) casi en la misma medida (la medida en que aumenta $\varphi_{K N x M z}{ }^{2}$ ), siempre y cuando el ángulo desarrollado sea suficiente $\left(\alpha t>\frac{\pi}{5}\right.$ ). En caso contrario (cuando tenemos $\alpha t$ muy bajos y $\varphi_{K N x M z}$ también muy bajos), la compensación descrita (disminución de las solicitaciones de momento transversal en la misma medida que el aumento de $\varphi_{K N x M z}{ }^{2}$ ) se ve disminuida, produciéndose un incremento en el axil y una disminución de momento que no compensa la pérdida de rigidez, lo que hace que la 
deformación total incremente. Esta característica, es un importante aliciente a la hora de elegir la morfología del puente atirantado curvo y la sección del tablero.

\subsection{Conclusiones}

De cara al comportamiento de un puente curvo atirantado frente a cargas concéntricas a una pila situada en el centro del arco del tablero, se puede deducir lo siguiente:

1. Con esta morfología de puente $(\mathrm{Rp}=0)$, la solicitación axil $(\mathrm{Nx})$ resulta dominante frente a las solicitaciones transversales ( $\mathrm{y}$ y y $\mathrm{Mz}$ ). Esto se traduce en una deformada también dominada por la deformación Axil ( $N x)$, donde aquellas debidas a las solicitaciones transversales resultan despreciables. Las deformaciones son muy reducidas, quedando determinadas por el área del tablero.

2. El radio del tablero tiene una relación lineal con la solicitación axil ( $\mathrm{Nx}$ ), luego su relación con las deformaciones es parecida (no igual por la hiperestaticidad del sistema). La longitud también tiene una relación casi lineal sobre la deformada (sobre la solicitación axil, apenas tiene influencia), porque como la solicitación axil es casi constante a lo largo del tablero, la longitud resulta casi proporcional a la deformación. La influencia del ángulo desarrollado por el tablero $(\alpha t)$ resulta más complicada. Si bien queda claro que cuanto mayor resulta $\alpha t$, menos influye sobre el tablero la hiperestaticidad, minimizando la influencia de las solicitaciones transversales sobre el comportamiento.

3. El comportamiento de un tablero curvo frente a las cargas concéntricas al centro del $\operatorname{arco}(R p=0)$, es muy rígido. Esto supone que, en un puente atirantado curvo, si se le da una rigidez suficiente al sistema Pila-TirCom (apartado 3.2), se puede aprovechar por completo la capacidad de los tirantes frente a cargas distribuidas gravitatorias. Siendo los tirantes de sujeción, los que determinan la deformación vertical que se va a producir en cada punto. Aunque como se comprobará en el capítulo 3, situar la pila en el centro del arco resulta una posición muy perniciosa para el funcionamiento del subsistema Pila-Tirantes.

4. Frente a cargas distribuidas gravitatorias, la tipología de tablero resultará menos determinante para las deformaciones verticales si la pila se sitúa en el centro del arco. Por un lado, porque como ya se ha comentado, va a existir un trasvase de solicitaciones a medida que se modifiquen las características mecánicas del tablero. Por otro, como se ha descrito en el punto anterior, la deformación vertical va a venir definida por el sistema Pila-Tirante y el área del tablero (que generalmente será suficiente para que su influencia sobre el funcionamiento del sistema no sea importante).

Como muestra de los expuesto en las conclusiones para puentes curvos atirantados. Se van a mostrar los diagramas de deformaciones (Diagrama 2.50) del puente analizado en el Diagrama 2.38, frente a una carga distribuida $q \mathrm{lz}=-10 \mathrm{kN}$, con diferentes tipos de secciones (Tabla 2.18). El Diagrama 2.50 b), muestra un comportamiento más propio de un puente atirantado curvo, donde el subsistema Pila-Tirantes sostiene la carga vertical del tablero casi por completo. Mientras que en el Diagrama 2.50 a), el tablero resulta tan rígido que arrastra 
mucha carga a los estribos, esto supone un desplazamiento de la resultante de la carga sustentada por el subsistema Pila-Tirantes hacia el exterior del arco. Esto provoca que los tirantes centrales deban resistir solicitaciones mayores mientras que los tirantes laterales quedan descargados. Este movimiento de la resultante de la carga vertical sustentada por el sistema Pila-tirantes, se estudia en profundidad en los subapartados 2.4 .3 y 2.4.4.

\section{Desplazamientos y Giros}

Desplazamiento TANGENCIAL (escala:0)

Desplazamiento RADIAL (escala:1) Desplazamiento Z (escala:1)

Giro $X^{\prime}-X^{\prime}$ (escala:0) Giro $Y^{\prime}-Y^{\prime}$ (escala:0) Giro $Z^{\prime}-Z^{\prime}$ (escala:0) Giro W-W (escala:0) $(\mathrm{m}, \mathrm{rad})$

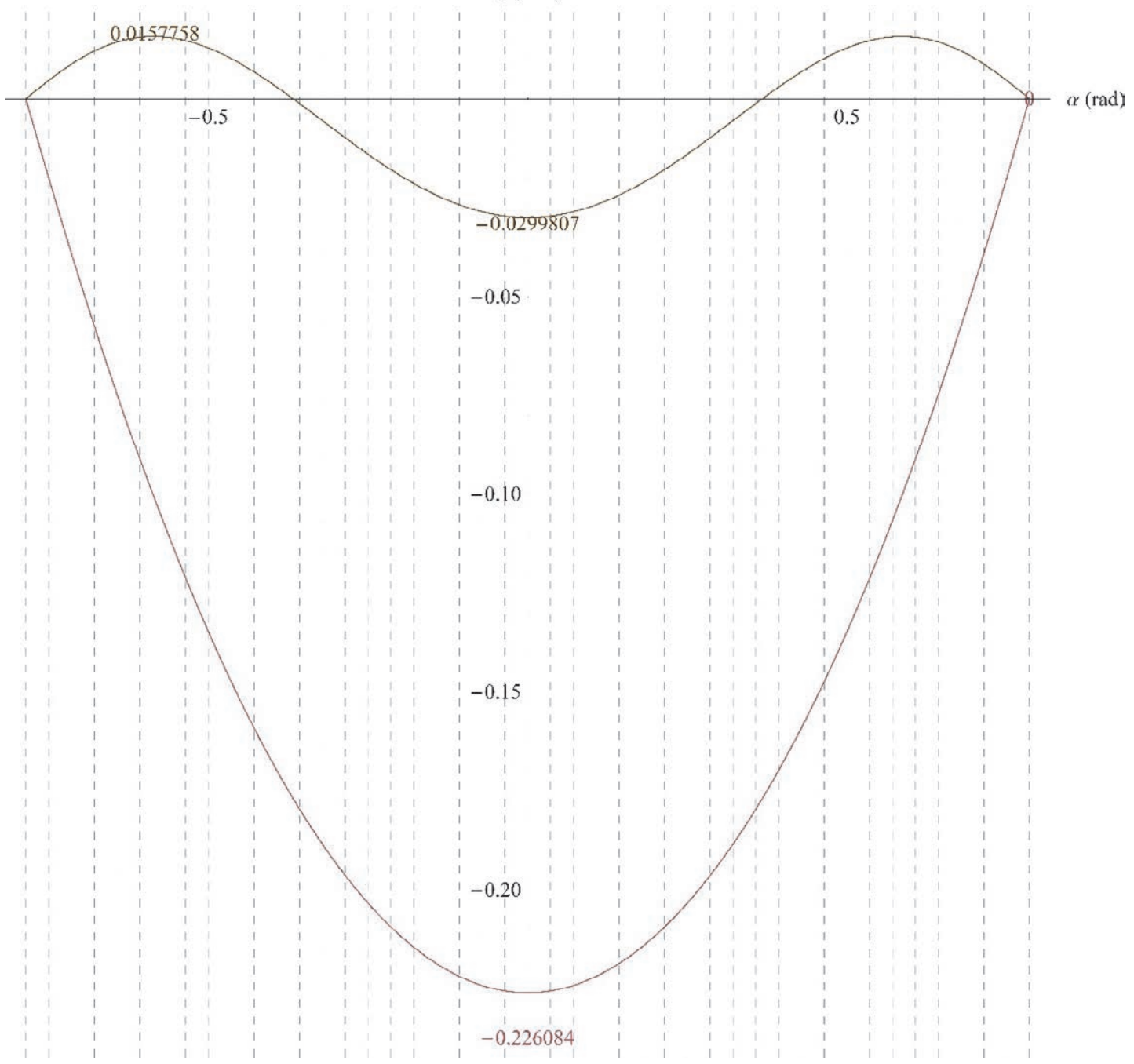




\section{Desplazamientos y Giros}

Desplazamiento TANGENCIAL (escala:0)

Desplazamiento RADIAL (escala:1) Desplazamiento Z (escala:1)

Giro X'-X' (escala:0) Giro Y'-Y' (escala:0) Giro Z'-Z' (escala:0) Giro W-W (escala:0) (m, rad)

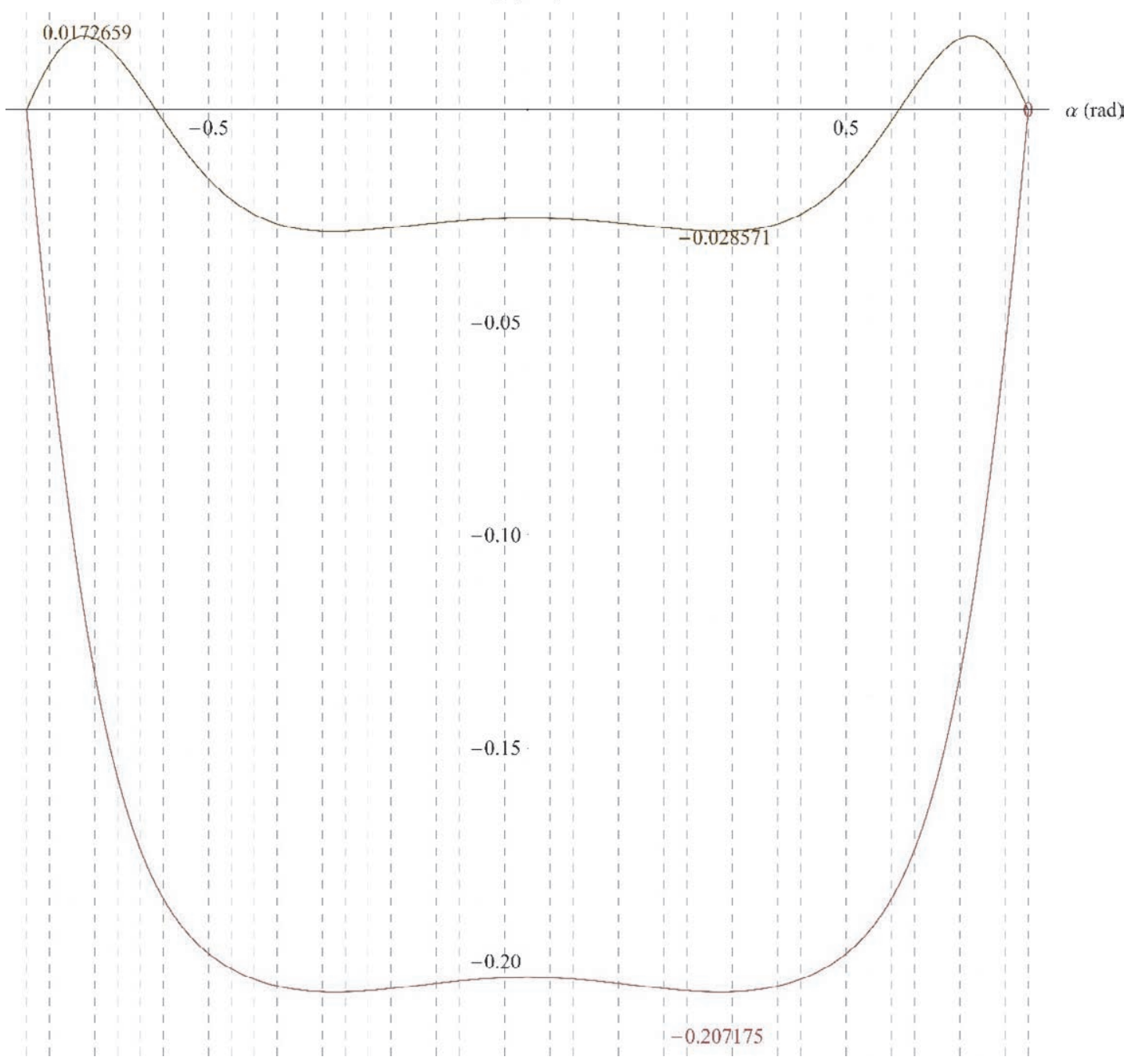

Diagrama 2.50. Deformada vertical y horizontal del tablero de un puente con la morfología presentada en el Diagrama 2.38: $\alpha t=\frac{\pi}{2}, R t=280 \mathrm{~m}, h p=247,5 \mathrm{~m}, \mathrm{ht}=44 \mathrm{~m}, \mathrm{nt}=45$ sometido a una carga distribuida qlz $=-10$ kN/ml. a) Diagrama Superior: Tablero 1 (Carretera); b) Diagrama inferior: Tablero 7 (Peatonal).

2.2.6.2 Sistema hiperestático, restringiendo el desplazamiento en los 3 ejes de los estribos, carga en el plano del tablero, concéntrica, pila no situada en el centro de la circunferencia del tablero

Como se ha comentado en la introducción sobre cargas concéntricas, así como en el apartado 3.2, la posibilidad o conveniencia de introducir la pila en el centro del arco del tablero puede ser pequeña o nula. El abanico de razones va desde una imposibilidad o dificultad geográfica, pasando por unas solicitaciones sobre el subsistema Pila-Tirantes inasumibles, hasta un radio de circunferencia demasiado elevado en comparación con el ángulo que debe sostener el sistema de pila tirantes. Esto último conllevaría una gran 
separación entre la cabeza de la pila y los puntos de unión entre tirantes y tablero, con una altura de pila excesiva (Diagrama 2.38).

Cuando se produzcan las circunstancias que se describen en el punto anterior, la pila no se situará en el centro de la circunferencia, esto complica el problema de las cargas que se van a transmitir por parte del subsistema Pila-Tirantes al tablero. Para poder abordar el problema, se ha dividido la casuística en 3 grupos, según el ángulo $\alpha_{p}$ de la pila (Ilustración 2.10): $\alpha_{p}=0, \alpha_{p}=\frac{\alpha_{t}}{4}$ y $\alpha_{p}=\frac{\alpha_{t}}{2}$ (este último supone poner la pila alineada con el estribo).

Para el estudio de las cargas concéntricas, con pila no situada en el centro del arco, no se va a utilizar una carga unitaria. La razón, es focalizar el estudio en los puentes curvos atirantados y que se puedan comparar sus diferentes tipologías, así, cuanto más separado esté un punto de la pila mayor será el módulo de su carga horizontal, siempre con dirección concéntrica, como ocurriría con las cargas transmitidas por los tirantes entre la cabeza de la pila y el tablero. Como distancia de referencia, se va a tomar el radio del tablero (Rt). De esta forma, si la distancia entre la pila y un punto determinado del tablero es igual al radio del tablero, su carga por metro será igual a la unidad, y si es diferente, la carga se obtiene del cociente entre la distancia que separa al punto del tablero de la pila y el radio del tablero. Esto va a hacer que el análisis sea perfectamente comparable con el que se hizo en el caso de la pila en el centro del arco (subapartado 2.2.6.1), esto supone implícitamente, que la pila siempre tiene la misma altura sobre el tablero.

El módulo de la carga queda como:

$$
\operatorname{Ttir}[\alpha]=\frac{\sqrt{(x p t[\alpha]-x p p)^{2}+(y p t[\alpha]-y p p)^{2}}}{R t}
$$

Donde, las variables geométricas se definen como (llustración 2.10):

$$
\begin{gathered}
x p p=R p \operatorname{Cos}[\alpha p] \\
y p p=R p \operatorname{Sin}[\alpha p] \\
x p t[\alpha]=R t \operatorname{Cos}[\alpha] \\
y p t[\alpha]=R t \operatorname{Sin}[\alpha]
\end{gathered}
$$

2.2.6.2.1 Sistema hiperestático, restringiendo el desplazamiento en los 3 ejes de los estribos, carga en el plano del tablero, concéntrica, pila no situada en el centro de la circunferencia del tablero, situada en el eje de simetría del tablero $\left(\boldsymbol{\alpha}_{\boldsymbol{p}}=\right.$ 0). Sistema de atirantamiento tipo abanico

\subsection{Solicitaciones}

Este caso va a ser el más frecuente, por ser el eje de simetría del puente, con la compensación de fuerzas en dirección del eje $Y$ que eso supone para las cargas uniformes. En el eje Y se va a situar el centro de gravedad de la carga que sustenta el subsistema PilaTirantes, donde la pila no estará sometida a cargas horizontales bajo el peso propio del tablero (que en la mayoría de los casos será la solicitación determinante), capítulo 3. 
Prosiguiendo con la línea de razonamiento seguida desde el subapartado 2.2.4, se van a analizar los diagramas de solicitaciones para 2 tipo de secciones: Tablero 1 (Carretera) y otro Tablero 7 (Peatonal) (Tabla 2.18). En este caso, La pila se va a situar en el centro de gravedad del tablero, y se van a utilizar las características geométricas utilizadas en los ejemplos de apartados anteriores (subapartado 2.2.6.1.1). La dirección de la carga Ttir $[\alpha]$ se muestra en la llustración 2.11 y su valor en el Diagrama 2.51.

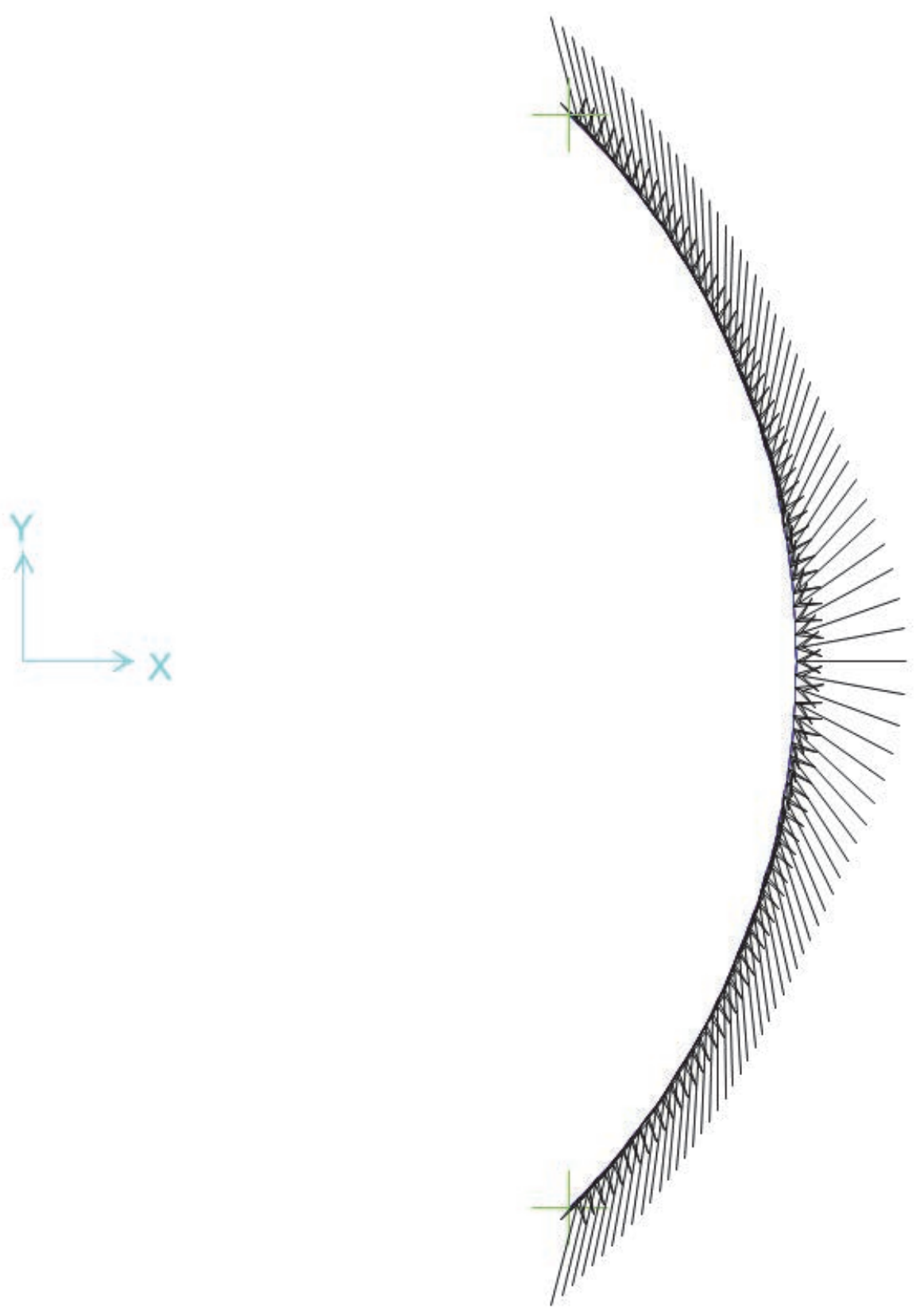

Ilustración 2.11. Dirección de la carga Ttir $[\alpha] . R t=280 m, R p=252.09 m, \alpha t=\frac{\pi}{2}$ y $\alpha p=0$. 


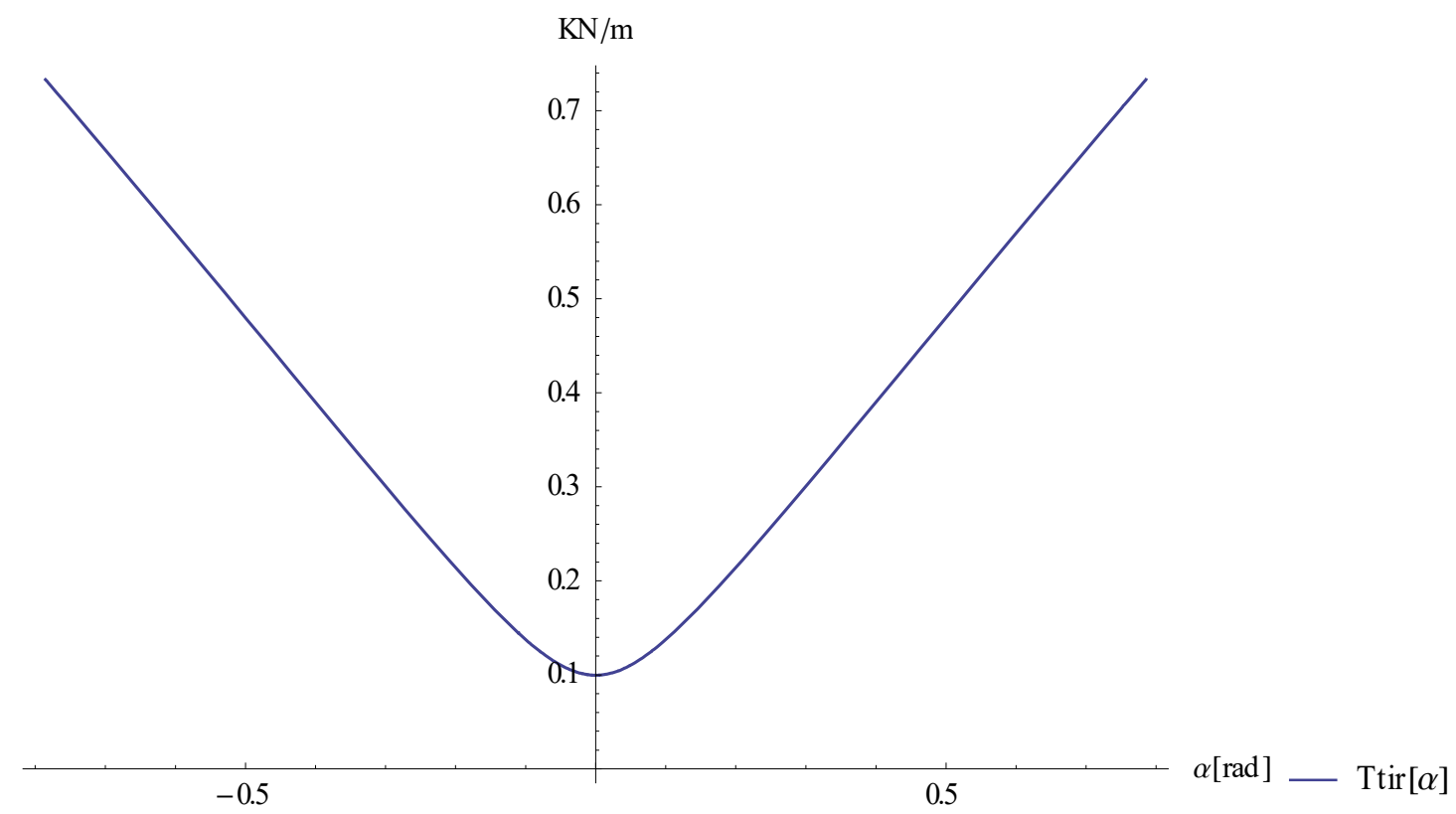

Diagrama 2.51. Valor de la carga Ttir $[\alpha] . R t=280 m, R p=252.09 m, \alpha t=\frac{\pi}{2} y \alpha p=0$.

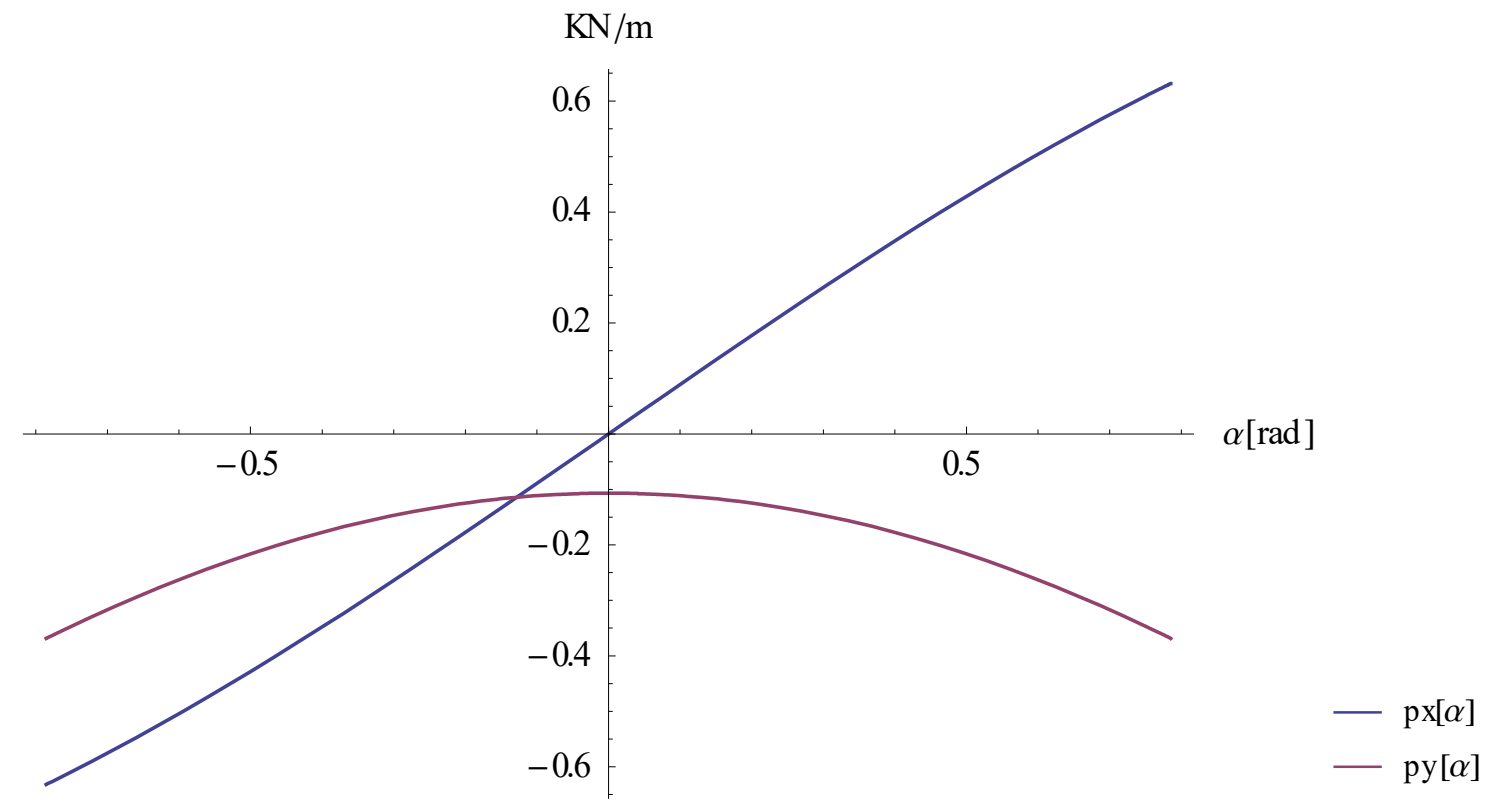

Diagrama 2.52. Valor de la carga según los ejes locales del tablero: $p x[\alpha]$ y $p y[\alpha] . R t=280 \mathrm{~m}, R p=$ $252.09 m, \alpha t=\frac{\pi}{2}$ y $\alpha p=0$. 


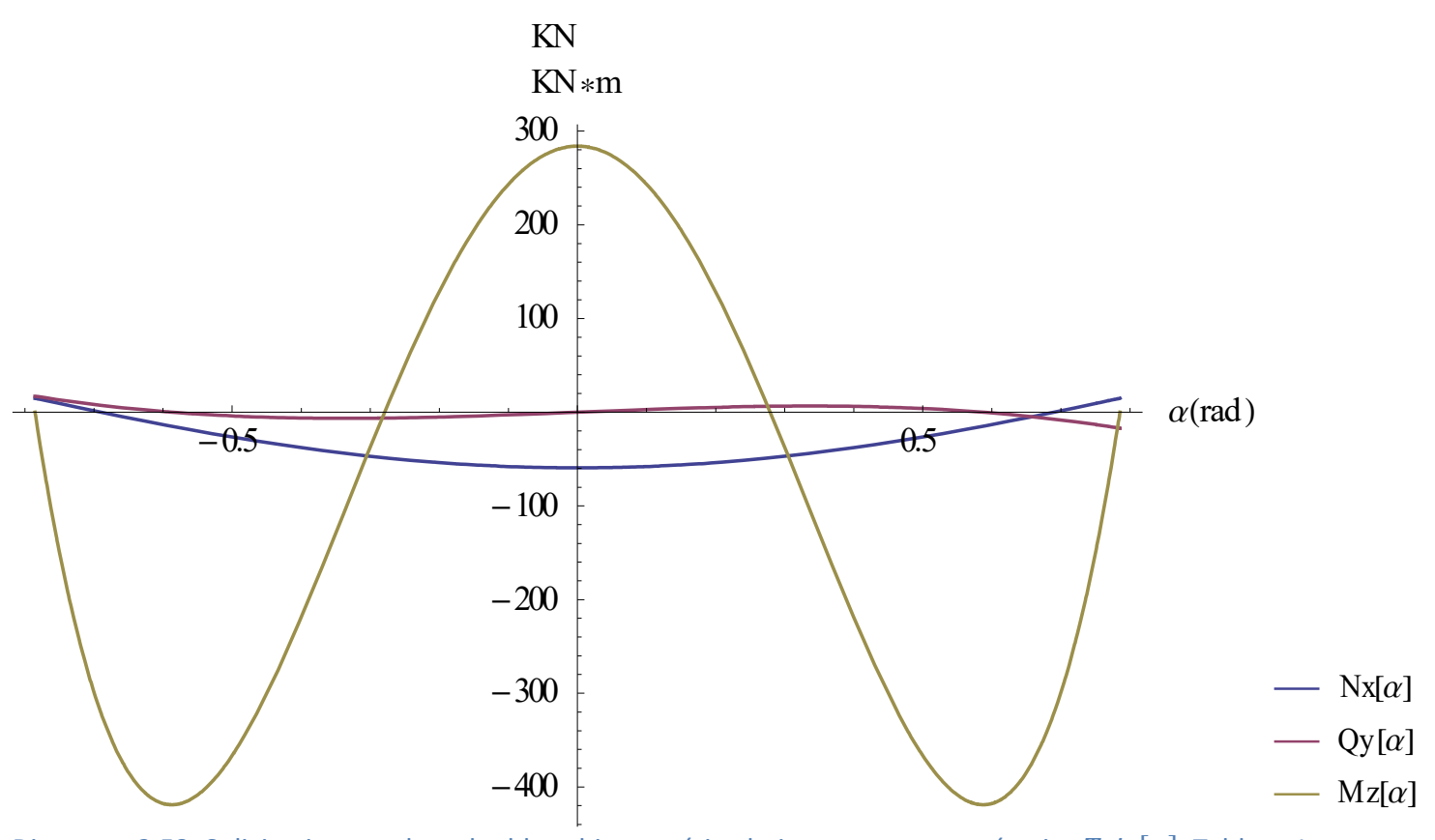

Diagrama 2.53. Solicitaciones sobre el tablero hiperestático bajo una carga concéntrica Ttir $[\alpha]$. Tablero 1

(Carretera), $\varphi_{K N x M z}=42,88 . R t=280 m, R p=252.09 m, \alpha t=\frac{\pi}{2}$ y $\alpha p=0$.

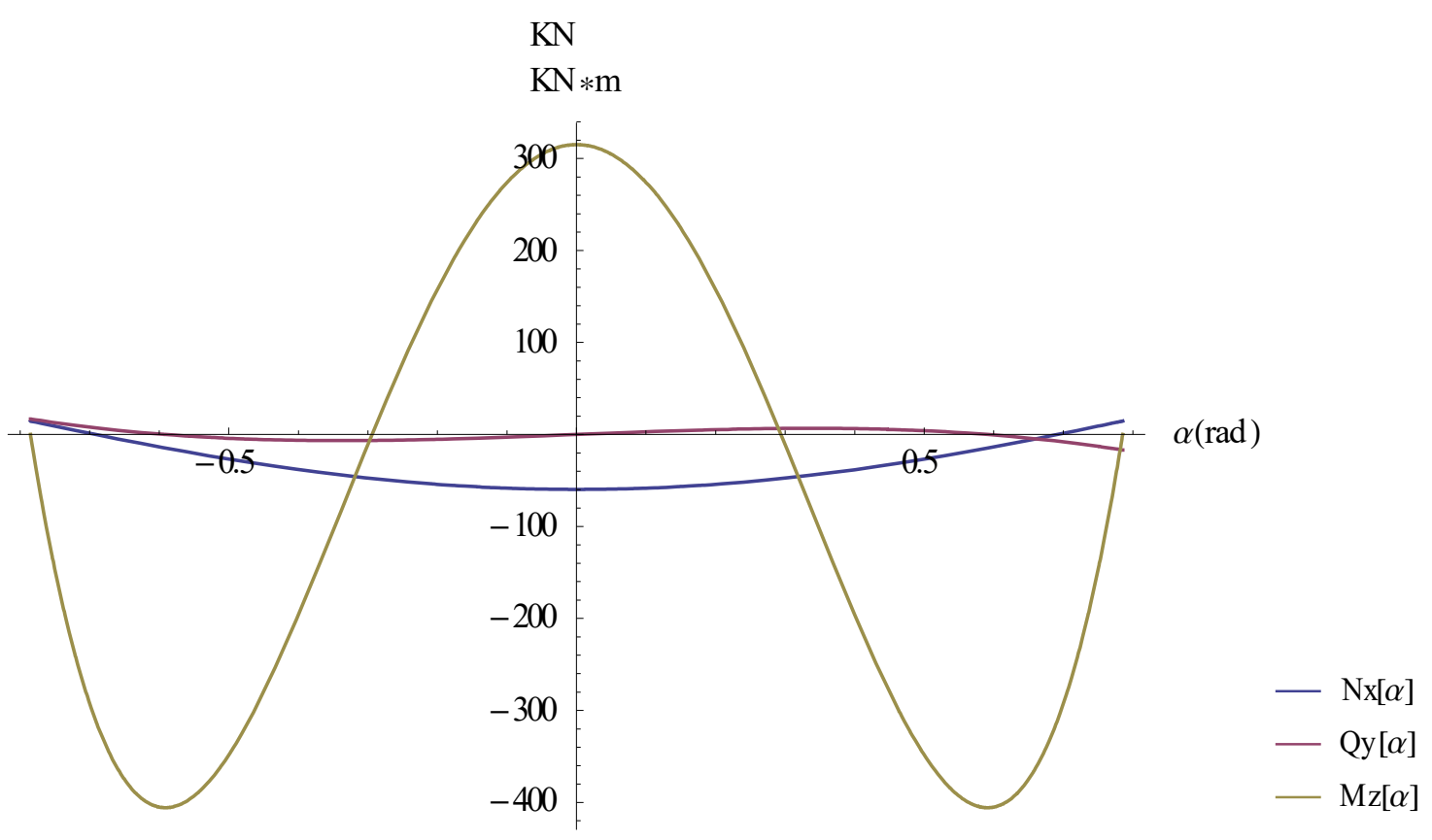

Diagrama 2.54. Solicitaciones sobre el tablero hiperestático bajo una carga concéntrica Ttir $[\alpha]$.

Tablero 7 (Peatonal). $\varphi_{K N x M z}=575,61 . R t=280 m, R p=252.09 m, \alpha t=\frac{\pi}{2} y \alpha p=0$. 
Antes de proseguir con el análisis de cargas concéntricas, se van a redefinir los tipos de comportamiento que va a tener el tablero vistos en el subapartado 2.2.4, con el foco puesto en las cargas concéntricas y la posición de la pila (Rp), con el propósito de poder hacer referencia a ellas sin que exista duda:

1) Comportamiento "tipo viga" (solicitaciones: Diagrama 2.55 y Diagrama 2.56 , deformaciones: Diagrama 2.58 a) y Diagrama 2.59 a)): el comportamiento "tipo viga", viene dado por una gran rigidez transversal del tablero frente a las cargas concéntricas (debida a las características mecánicas de la sección y la forma del tablero) en comparación con la rigidez longitudinal del tablero frente a esas mismas cargas. Como es un sistema hiperestático, esta mayor rigidez provoca que las solicitaciones transversales sean mayores. Si bien, las solicitaciones axiles apenas sufren cambios, sea cual sea el tipo de comportamiento del tablero (sus cambios vienen dados por el posicionamiento de la pila y el radio del tablero Rt). En este tipo de comportamiento, las solicitaciones siempre disminuyen a media que se acerca la pila al tablero, con su mínimo muy próximo al tablero $(R p \approx R t)$.

2) Comportamiento "tipo arco" (solicitaciones: Diagrama 2.55 y Diagrama 2.56, deformaciones: Diagrama $2.58 \mathrm{c}$ ) Diagrama $2.59 \mathrm{c}$ )): solo se produce cuando $\mathrm{Rp}=0$. La rigidez longitudinal del tablero frente a la carga concéntrica, es dominante frente la rigidez transversal. Cuando se incrementa $\mathrm{Rp}$, pasa rápidamente a un comportamiento "tipo esfera":

a. Comportamiento "tipo esfera" (Arco): En este comportamiento, las solicitaciones transversales incrementan linealmente a medida que se acerca la pila al tablero ( $R p>0)$. El diagrama de momentos tiene 3 extremos, como se puede aprecia en el Diagrama 2.53 y en el Diagrama 2.54.

3) Comportamiento "mixto" (solicitaciones: Diagrama 2.55 y Diagrama 2.56, deformaciones: Diagrama 2.58 b) Diagrama 2.59 b)): Este tipo de comportamiento, parte (en $\mathrm{Rp}=0$ ) de un comportamiento intermedio entre el "tipo viga y el "tipo arco". A medida que se acerca la pila al tablero ( $R p>0)$, se distinguen 2 tipos de comportamientos:

a. El primero, se produce cuando se posiciona la pila entre el centro del arco $(\mathrm{Rp}=0)$ y un mínimo de solicitaciones que se produce antes de llegar a al tablero $(0<\mathrm{Rp}<\mathrm{Rt})$. En esta zona, a medida que se incrementa $\mathrm{Rp}$, disminuye tanto el momento flector transversal (Mz) como la solicitación axil y la deformación del tablero. Similar al comportamiento "tipo viga"

b. Comportamiento "tipo esfera" ("Mixto"): El segundo se produce a partir del mínimo de las solicitaciones. A partir de este punto, el momento transversal $(\mathrm{Mz})$ empieza a incrementarse con los 3 extremos del comportamiento "tipo esfera" (subapartado 2.2.4.1).

A partir de los diagramas mostrados (Diagrama 2.51 -> Diagrama 2.54), se deducen las primeras características de este sistema en comparación con el sistema en el que la pila se sitúa en el centro de la circunferencia: 
1) La carga horizontal introducida en el sistema $(\operatorname{Ttir}[\alpha])$, va a ser menor que en el caso de la pila en el centro de la circunferencia (Ttir $[\alpha]$ era igual a la unidad).

2) El sistema resistivo "tipo arco" (subapartado 2.2.4.1) va a ser casi inexistente para las cargas distribuidas sobre el tablero (Peso propio, cargas muertas, uso distribuida...), siendo el sistema resistivo "tipo viga" (subapartado 2.2.4.1) o "tipo esfera" el que va a resistir las solicitaciones transversales. Esto se aprecia cuando se varía la relación de rigideces del tablero $\left(\varphi_{K N X M Z}\right)$, y las solicitaciones apenas cambian (Diagrama 2.53 y Diagrama 2.54).

3) Debido al efecto combinado del punto 1 y 2 , el axil ( $\mathrm{Nx}$ ) en el tablero es mucho menor de lo que era cuando se situaba la pila en el centro del arco del tablero.

4) Las características 1) y 2), se contrarrestan a la hora de obtener la solicitación del momento flector $(\mathrm{Mz})$ y por eso, aunque aumenta significativamente, se mantiene dentro del mismo orden de magnitud (comportamiento tipo "esfera").

Como es lógico, todo esto se produce de forma gradual a medida que se acerca la pila al tablero. Mientras que la pila esté cerca del centro del arco, el sistema resistivo "tipo arco" (visto en el subapartado 2.2.4.1) todavía sigue funcionando, luego el valor del factor $\varphi_{K N x M z}$ sigue influyendo en el tipo de comportamiento que tiene el tablero, sobre todo en sus solicitaciones. La rapidez con la que se pasa de un sistema a otro, a medida que se incrementa $\mathrm{Rp}$, es fundamentalmente función del ángulo que desarrolla el tablero $(\alpha t)$ y del tipo de sección $\left(\varphi_{K N X M z}\right)$. Luego, el ángulo desarrollado por la directriz del tablero $\alpha t$, pasa a ser determinante a medida que la pila queda más cerca del tablero. Se han desarrollado diagramas de las solicitaciones principales, manteniendo el ángulo desarrollado constante, de forma que se puedan apreciar hasta qué punto influyen el resto de variables (Rt, que modificará $\varphi_{K N X M Z}$, $y \mathrm{Lt})$

Debido a la casi desaparición del sistema resistivo "tipo arco", cuando la pila se encuentra cerca del tablero, no tiene sentido estudiar las solicitaciones comparadas $\left(v_{Q y N x} \mathrm{Y}\right.$ $v_{M Z N x}$ ) frente al factor $\varphi_{K N X M Z}$ como se hizo en el subapartado 2.2.4. Aunque sí se va a mostrar la procedencia de las deformaciones de cara a resaltar las características mecánicas de la sección que van a permitir mejorar el funcionamiento del puente. Como la carga horizontal $\operatorname{Ttir}[\alpha]$, sí que se ha relacionado con las del sistema con pila en el centro de la circunferencia, se van a poder equiparar los valores más representativos de axil ( $\mathrm{Nx})$, momento ( $\mathrm{Mz})$ y cortante (Qy) a medida que se va moviendo la pila (Rp) a lo largo de la línea con ángulo $\alpha_{p}=$ 0 . Sabiendo que es la posición más ventajosa para la pila $\left(\alpha_{p}=0\right)$, se va a analizar con mayor profundidad que el resto el caso (capítulo 3).

Se van a analizar 3 ángulos representativos, $\alpha t: \frac{\pi}{5}, \frac{\pi}{2}, \frac{4 \pi}{5}$ y los radios de tablero Rt: $180 \mathrm{~m}$, $280 \mathrm{~m}, 380 \mathrm{~m}, 480 \mathrm{~m}$ y $580 \mathrm{~m}$. De cara a verificar el efecto de la curvatura. Para poder comparar las solicitaciones con diferente longitud de tablero, se han dividido las solicitaciones de la siguiente manera: $\frac{Q y}{L t}, \frac{M z}{L t^{2}}$ y $\frac{N x}{L t}$. Se han analizado 2 tipologías de tablero: Tablero 7 (Peatonal) y Tablero 1 (Carretera) (Tabla 2.18). Para este ángulo de pila $(\alpha p=0)$, los valores representativos de las solicitaciones para los diagramas, van a ser: 
$Q y E \rightarrow$ Valor del cortante en el estribo.

QyMI $\rightarrow$ Valor del cortante máximo.

$N x E \rightarrow$ Valor del axil en el estribo.

$N x M S \rightarrow$ Valor del axil en el centro del tablero.

MzMS $\rightarrow$ Valor del momento en el centro del tablero.

$M z M \rightarrow$ Valor del momento máximo.

Tablero7 (Peatonal)

$\alpha \mathrm{t}=\frac{\pi}{5}$

QyE/Lt

QyMYLt

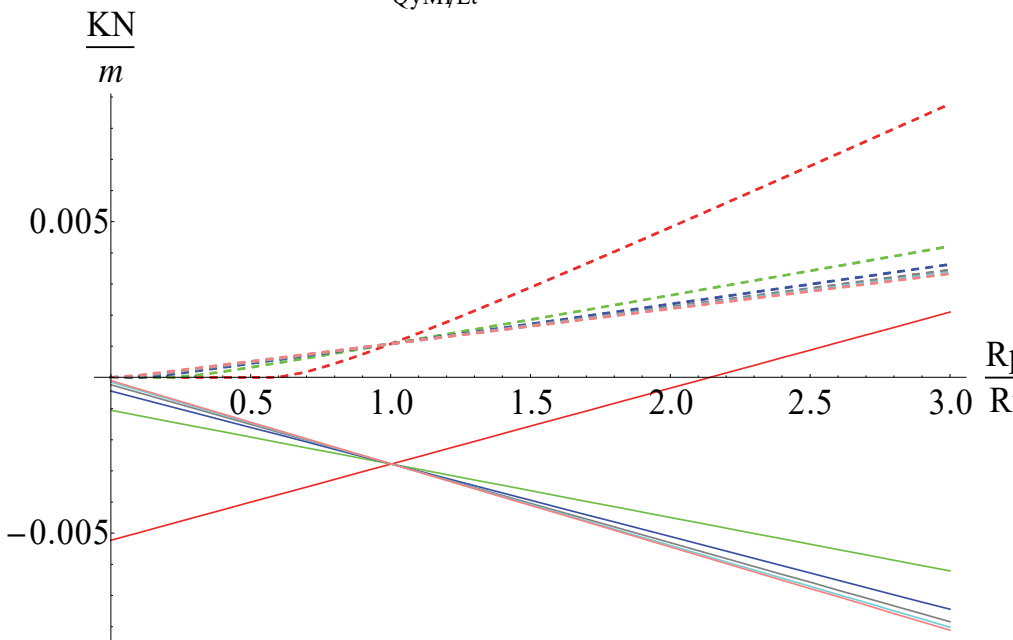

Tablero7 (Peatonal)

$\alpha \mathrm{t}=\frac{\pi}{5}$

$\mathrm{MzM} / \mathrm{Lt} t^{2}$

$\mathrm{MzMS} / \mathrm{Lt}^{2}$

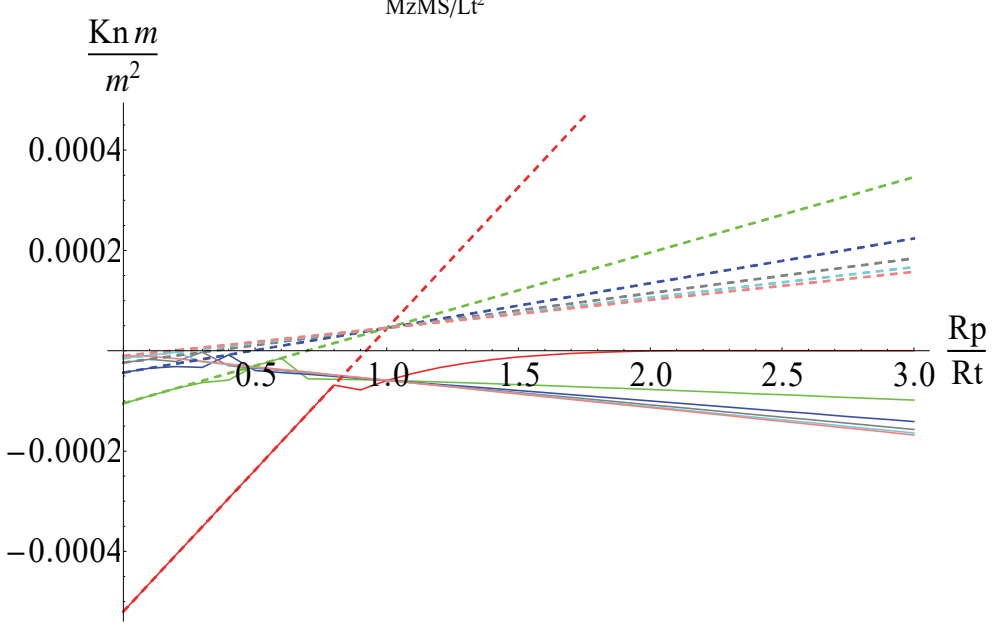

$\begin{aligned}-\mathrm{QyE} / \mathrm{Lt} \mathrm{Rt} & =80 \\ \underline{\mathrm{Rp}}-\mathrm{QyE} / \mathrm{Lt} \mathrm{Rt} & =180\end{aligned}$

- QyE/Lt Rt $=280$

- $\mathrm{QyE} / \mathrm{Lt} \mathrm{Rt}=380$

- $\mathrm{QyE} / \mathrm{Lt} \mathrm{Rt}=480$

- $\mathrm{QyE} / \mathrm{Lt} \mathrm{Rt}=580$

-.. QyMI/Lt Rt $=80$

- - . QyMI/Lt Rt = 180

-.. QyMI/Lt Rt $=280$

- . QyMI/Lt Rt $=380$

- - $\quad$ QyMI/Lt Rt = 480

- .. QyMI/Lt Rt $=580$

- $\mathrm{MzM} / \mathrm{Lt}^{2} \mathrm{Rt}=80$

- $\mathrm{MzM} / \mathrm{Lt}^{2} \mathrm{Rt}=180$

- $\mathrm{MzM} / \mathrm{Lt}^{2} \mathrm{Rt}=280$

- MzM/ $/ \mathrm{Lt}^{2} \mathrm{Rt}=380$

- $\mathrm{MzM} / \mathrm{Lt}^{2} \mathrm{Rt}=480$

- $\mathrm{MzM} / \mathrm{Lt}^{2} \mathrm{Rt}=580$

-.. MzMS/Lt $/ t^{2} \mathrm{Rt}=80$

-. MzMS/Lt ${ }^{2} \mathrm{Rt}=180$ 
Tablero7 (Peatonal)

$\alpha \mathrm{t}=\frac{\pi}{5}$

$\mathrm{NxE} / \mathrm{Lt}$

NxMS/Lt

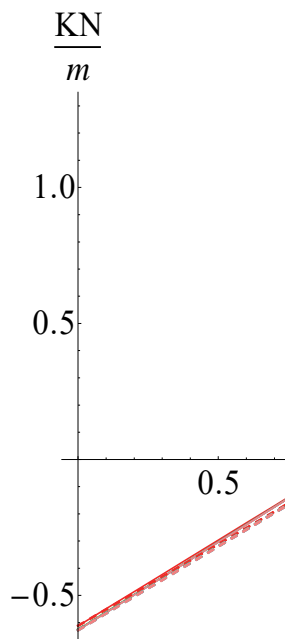

- NxE/Lt Rt $=80 \quad$-. $. ~ N x M S / L t ~ R t ~=280$

- NxE/Lt Rt $=180 \quad$ - $. . \mathrm{NxMS} / \mathrm{Lt} \mathrm{Rt}=380$

- NxE/Lt Rt $=280 \quad \ldots . \mathrm{NxMS} / \mathrm{Lt} \mathrm{Rt}=480$

a)

Tablero7 (Peatonal)

$\alpha \mathrm{t}=\frac{\pi}{2}$

QyE/Lt

$\frac{\mathrm{KN}}{m}$

QyM/Lt

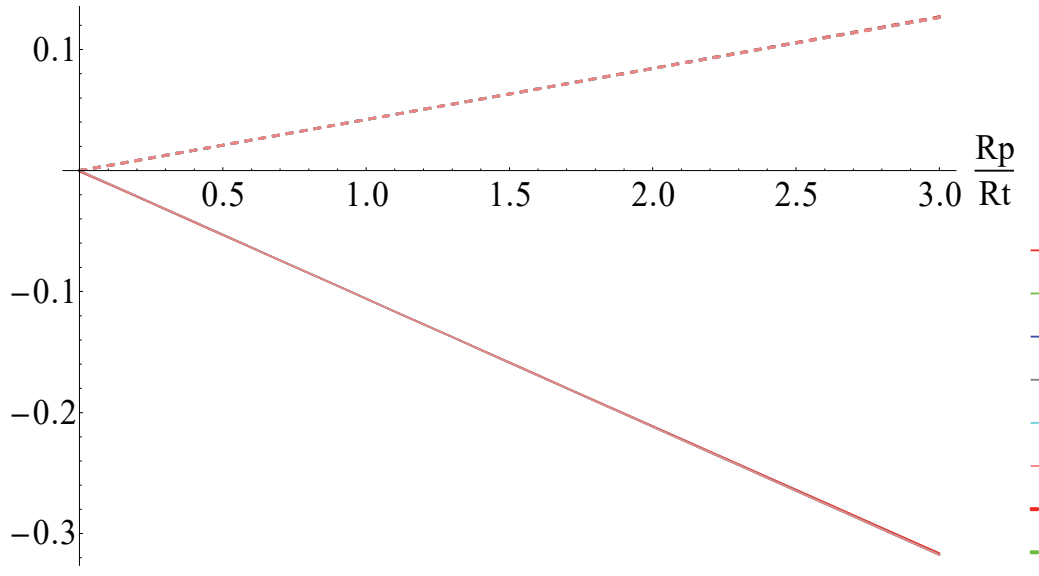

Tablero7 (Peatonal)

$\mathrm{Rp}-\mathrm{NxE} / \mathrm{Lt} \mathrm{Rt}=380 \quad-. . \mathrm{NxMS} / \mathrm{Lt} \mathrm{Rt}=580$

$\alpha \mathrm{t}=\frac{\pi}{2}$

$\mathrm{MzM} / \mathrm{L} t^{2}$

$\mathrm{MzMS} / \mathrm{Lt}^{2}$

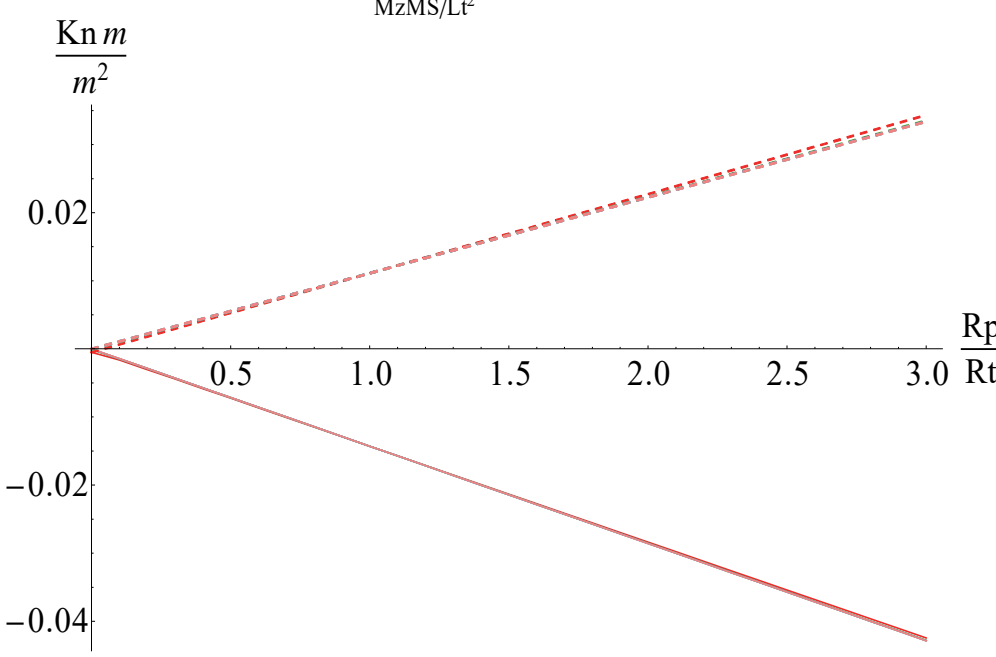

- $\mathrm{QyE} / \mathrm{Lt} \mathrm{Rt}=80 \quad-. . \mathrm{QyMI} / \mathrm{Lt} \mathrm{Rt}=280$

— QyE/Lt Rt $=180 \quad \ldots$ QyMI/Lt Rt $=380$

— QyE/Lt Rt $=280 \quad-. \quad$ QyMI/Lt Rt $=480$

QyE/Lt Rt $=380 \quad$-. Q QyMI/Lt Rt $=580$

- $\mathrm{QyE} / \mathrm{Lt} \mathrm{Rt}=480$

- $\mathrm{QyE} / \mathrm{Lt} \mathrm{Rt}=580$

-.. QyMI/Lt Rt $=80$

-.. QyMI/Lt Rt = 180 
Tablero 7 (Peatonal)

$\alpha \mathrm{t}=\frac{\pi}{2}$

$\mathrm{NxE} / \mathrm{Lt}$

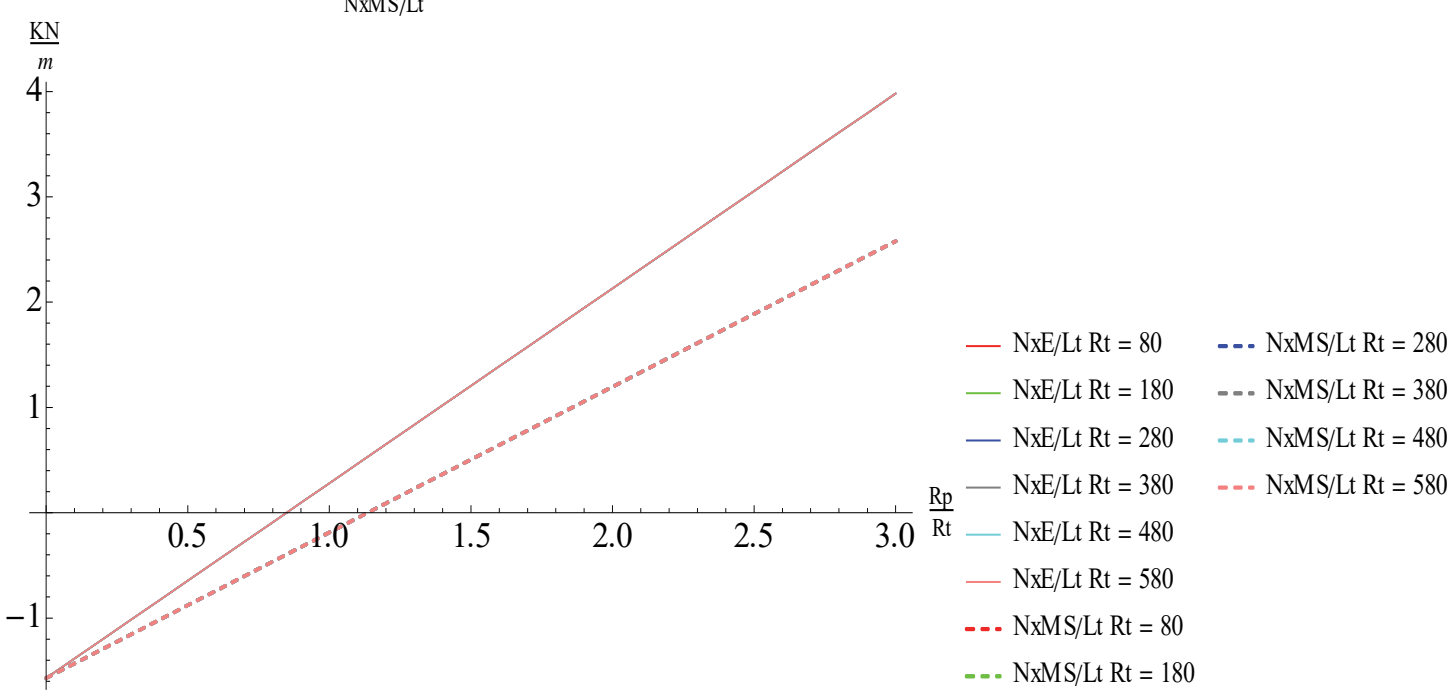

b)

Tablero1 (Carretera)

$\alpha \mathrm{t}=\frac{\pi}{5}$

QyE/Lt

$\frac{\mathrm{KN}}{\mathrm{m}}$

QyMyLt

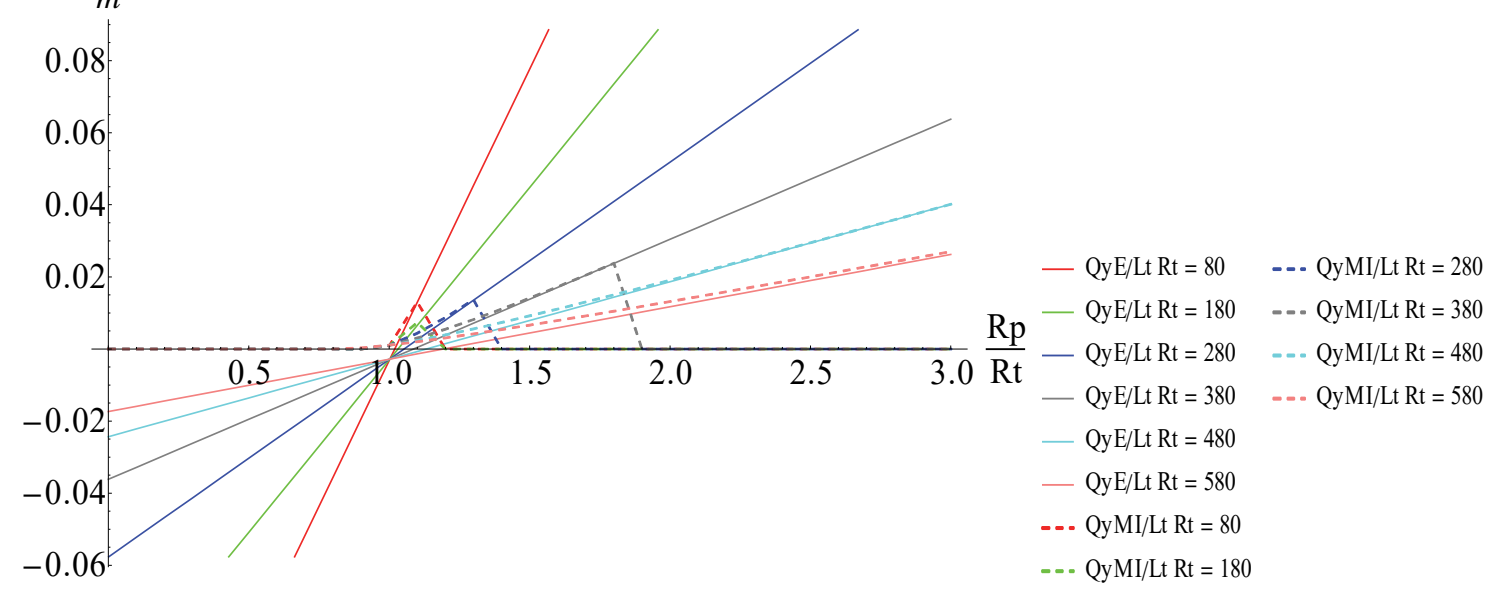


Tablerol (Carretera)

$\alpha \mathrm{t}=\frac{\pi}{5}$

$\mathrm{MzM} / \mathrm{Lt}^{2}$

$\mathrm{MzMS} / \mathrm{Lt}^{2}$

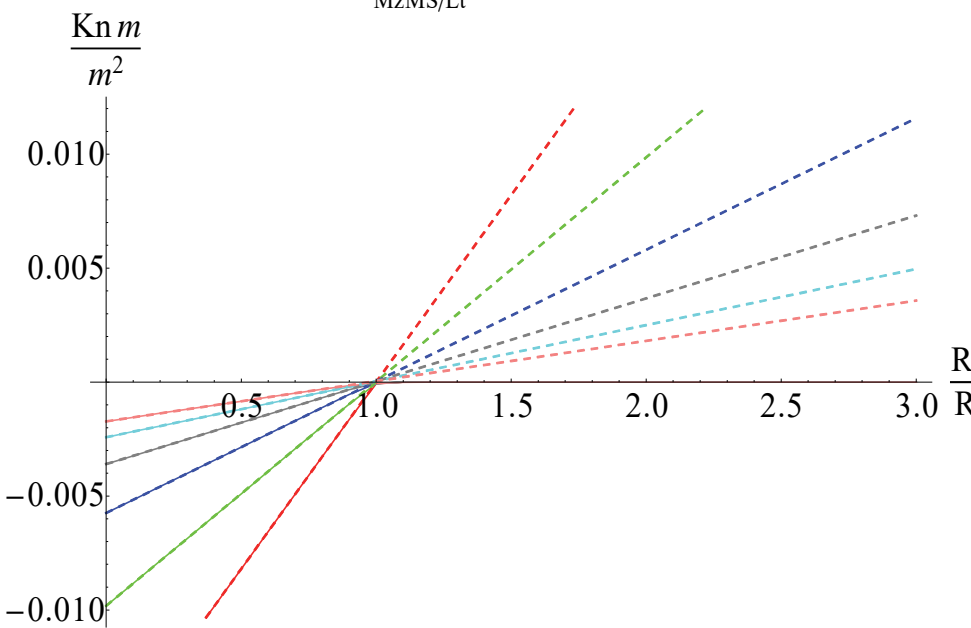

Tablero1 (Carretera)

$$
\begin{aligned}
& -\mathrm{MzM} / \mathrm{Lt}^{2} \mathrm{Rt}=80 \quad--. \mathrm{MzMS} / \mathrm{Lt}^{2} \mathrm{Rt}=280 \\
& \text { - MzM/Lt } / t^{2} \mathrm{Rt}=180 \quad \ldots \mathrm{MzMS} / \mathrm{Lt}^{2} \mathrm{Rt}=380 \\
& \mathrm{Rp}-\mathrm{MzM} / \mathrm{Lt}^{2} \mathrm{Rt}=280 \quad \ldots \mathrm{MzMS} / \mathrm{Lt}^{2} \mathrm{Rt}=480 \\
& -\mathrm{MzM} / \mathrm{Lt}^{2} \mathrm{Rt}=380 \quad \ldots \mathrm{MzMS} / \mathrm{Lt}^{2} \mathrm{Rt}=580 \\
& \text { - } \mathrm{MzM} / \mathrm{Lt}^{2} \mathrm{Rt}=480 \\
& \text { - } \mathrm{MzM} / \mathrm{Lt}^{2} \mathrm{Rt}=580 \\
& \therefore \mathrm{MzMS} / \mathrm{Lt}^{2} \mathrm{Rt}=80 \\
& =-\mathrm{MzMS} / \mathrm{Lt}^{2} \mathrm{Rt}=180
\end{aligned}
$$

$\alpha \mathrm{t}=\frac{\pi}{5}$
$\mathrm{NxE} / \mathrm{Lt}$

NxMS/Lt

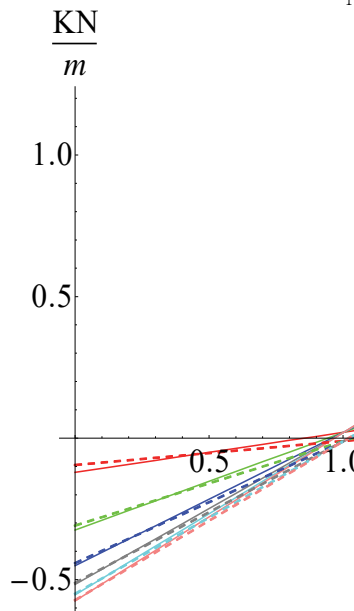

c) 
Tablerol (Carretera)

$\alpha \mathrm{t}=\frac{\pi}{2}$

QyE/Lt

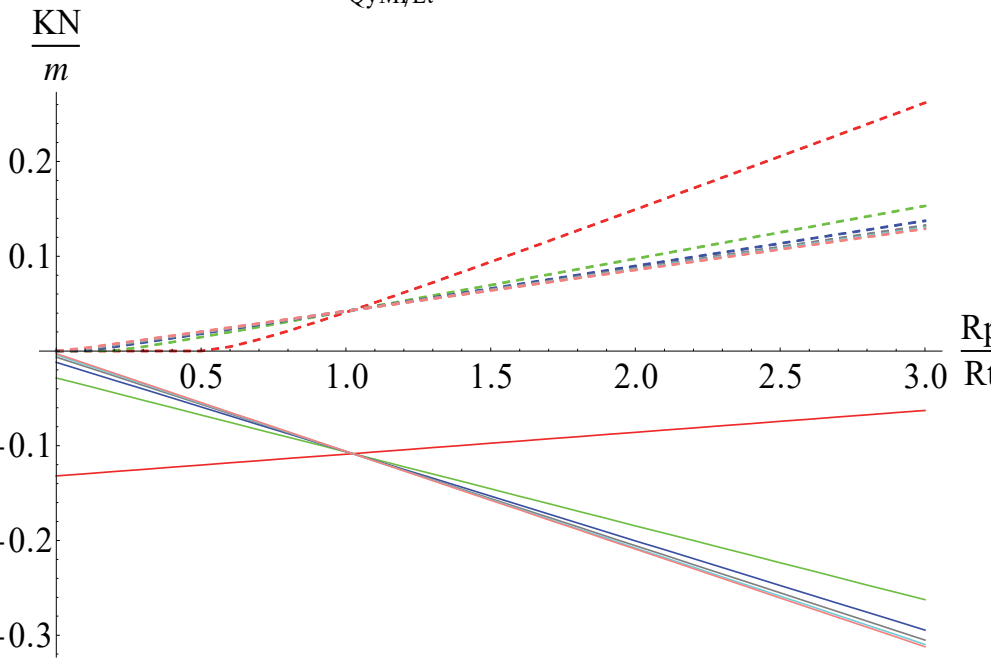

$\underline{\mathrm{Rp}}-\mathrm{QyE} / \mathrm{Lt} \mathrm{Rt}=80 \quad \ldots \mathrm{QyM} / \mathrm{Lt} \mathrm{Rt}=280$

- $\mathrm{QyE} / \mathrm{Lt} \mathrm{Rt}=180$

- .. QyMI/Lt Rt $=380$

- $\mathrm{QyE} / \mathrm{Lt} \mathrm{Rt}=280$

- - Q QyMI/Lt Rt $=480$

- $\mathrm{QyE} / \mathrm{Lt} \mathrm{Rt}=380$

- -. QyMI/Lt Rt $=580$

Tablerol (Carretera)

$\alpha \mathrm{t}=\frac{\pi}{2}$

$\mathrm{MzM} / \mathrm{Lt}^{2}$

$\mathrm{MzMS} / \mathrm{Lt}^{2}$

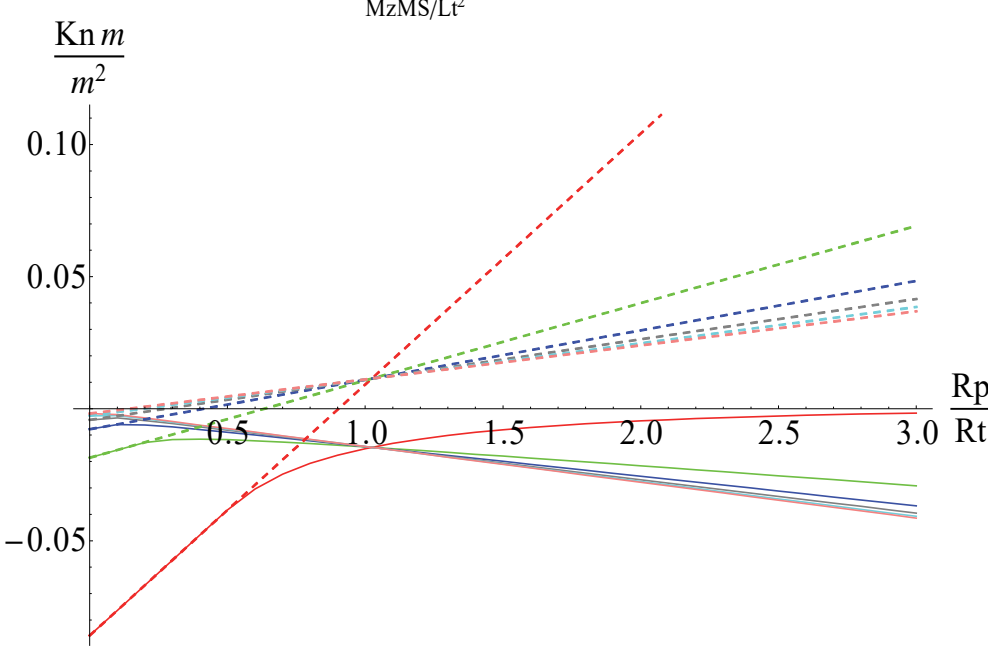

$$
\begin{aligned}
& \text { - MzM/Lt }{ }^{2} \mathrm{Rt}=80 \quad-. \cdot \mathrm{MzMS} / \mathrm{Lt}^{2} \mathrm{Rt}=280 \\
& \text { - } \mathrm{MzM} / \mathrm{Lt}^{2} \mathrm{Rt}=180 \quad-.-\mathrm{MzMS} / \mathrm{Lt}^{2} \mathrm{Rt}=380 \\
& \mathrm{Rp}-\mathrm{MzM} / \mathrm{Lt}^{2} \mathrm{Rt}=280 \quad--\cdot \mathrm{MzMS} / \mathrm{Lt}^{2} \mathrm{Rt}=480 \\
& --\cdot \mathrm{MzMS} / \mathrm{Lt}^{2} \mathrm{Rt}=58
\end{aligned}
$$

Tablero1 (Carretera)

$\alpha \mathrm{t}=\frac{\pi}{2}$

$\mathrm{NxE} / \mathrm{Lt}$

$\mathrm{NxMS} / \mathrm{Lt}$

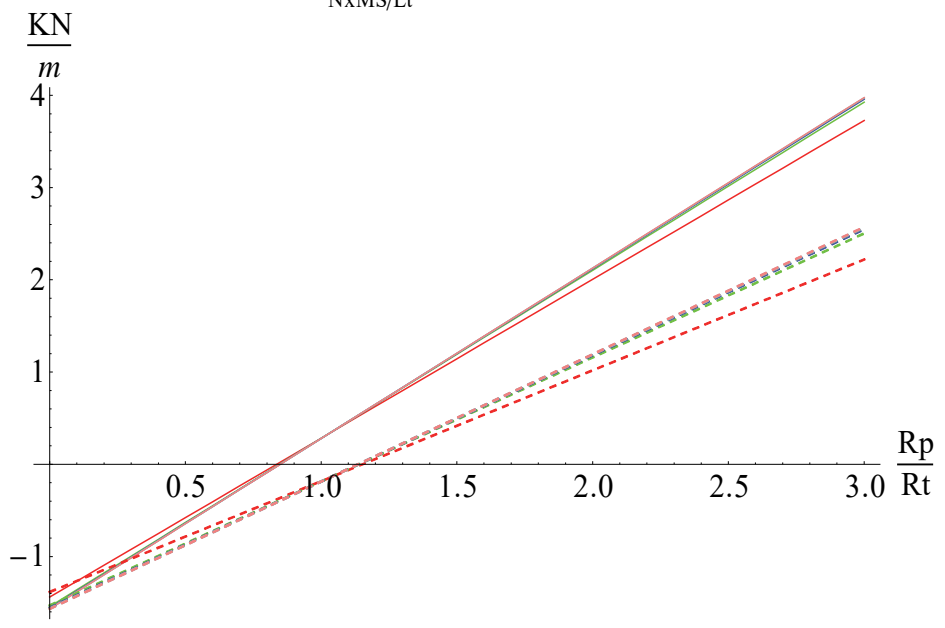

- NxE/Lt Rt $=80 \quad-.-\mathrm{NxMS} / \mathrm{Lt}$ Rt $=280$

- NxE/Lt Rt $=180$

- . - NxMS/Lt Rt $=380$

- NxE/Lt Rt $=280$

$=-\mathrm{NxMS} / \mathrm{Lt} \mathrm{Rt}=480$

- NxE/Lt Rt $=380$

- . - NxMS/Lt Rt $=580$ 
Tablerol (Carretera)

$\alpha \mathrm{t}=\frac{4 \pi}{5}$

$\mathrm{QyE} / \mathrm{Lt}$

QyMI/Lt

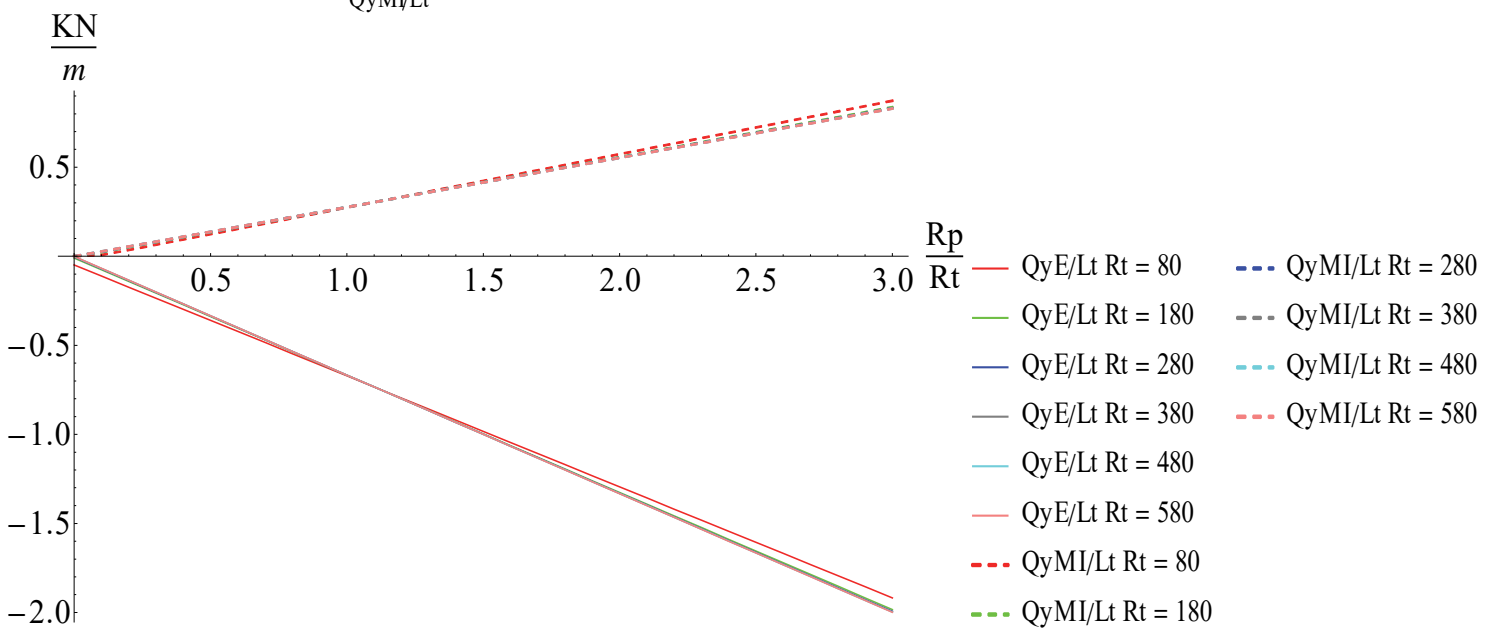

Tablero1 (Carretera)

$\alpha \mathrm{t}=\frac{4 \pi}{5}$

$\mathrm{MzM} / \mathrm{Lt}^{2}$

$\frac{\mathrm{Kn} m}{m^{2}}$

$\mathrm{MzMS} / \mathrm{Lt}^{2}$

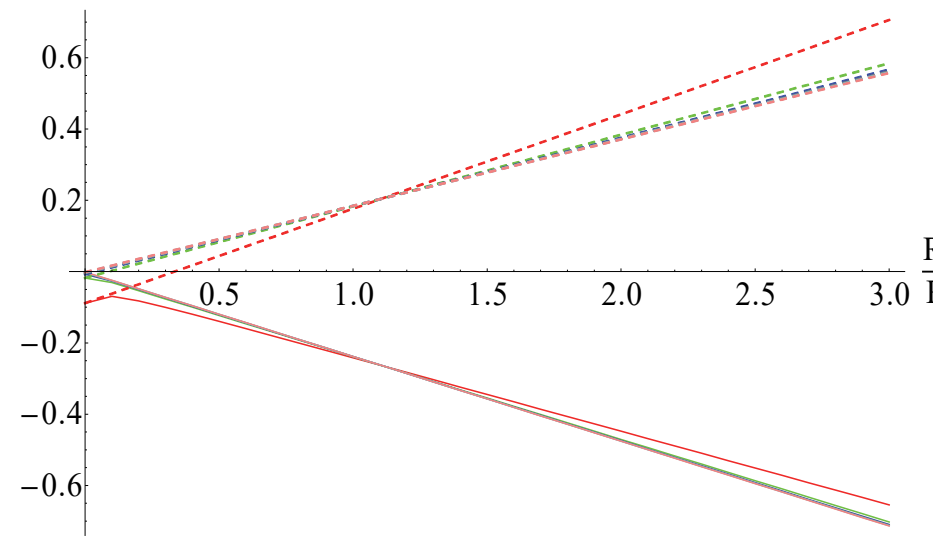

- MzM/Lt $/ \mathrm{Lt}^{2} \mathrm{Rt}=80 \quad \ldots \mathrm{MzMS} / \mathrm{Lt}^{2} \mathrm{Rt}=280$

$-\mathrm{MzM} / \mathrm{Lt}^{2} \mathrm{Rt}=180 \quad \ldots \mathrm{MzMS} / \mathrm{Lt}^{2} \mathrm{Rt}=380$

$\underline{\mathrm{Rp}}-\mathrm{MzM} / \mathrm{Lt}^{2} \mathrm{Rt}=280 \quad-\cdots \mathrm{MzMS} / \mathrm{Lt}^{2} \mathrm{Rt}=480$

$-\mathrm{MzM} / \mathrm{Lt}^{2} \mathrm{Rt}=380 \quad--\mathrm{MzMS} / \mathrm{Lt}^{2} \mathrm{Rt}=580$

- MzM/Lt ${ }^{2} \mathrm{Rt}=480$

$-\mathrm{MzM} / \mathrm{Lt}^{2} \mathrm{Rt}=580$

- . MzMS/Lt ${ }^{2} \mathrm{Rt}=80$

- - MzMS/Lt $/ t^{2} \mathrm{Rt}=180$ 


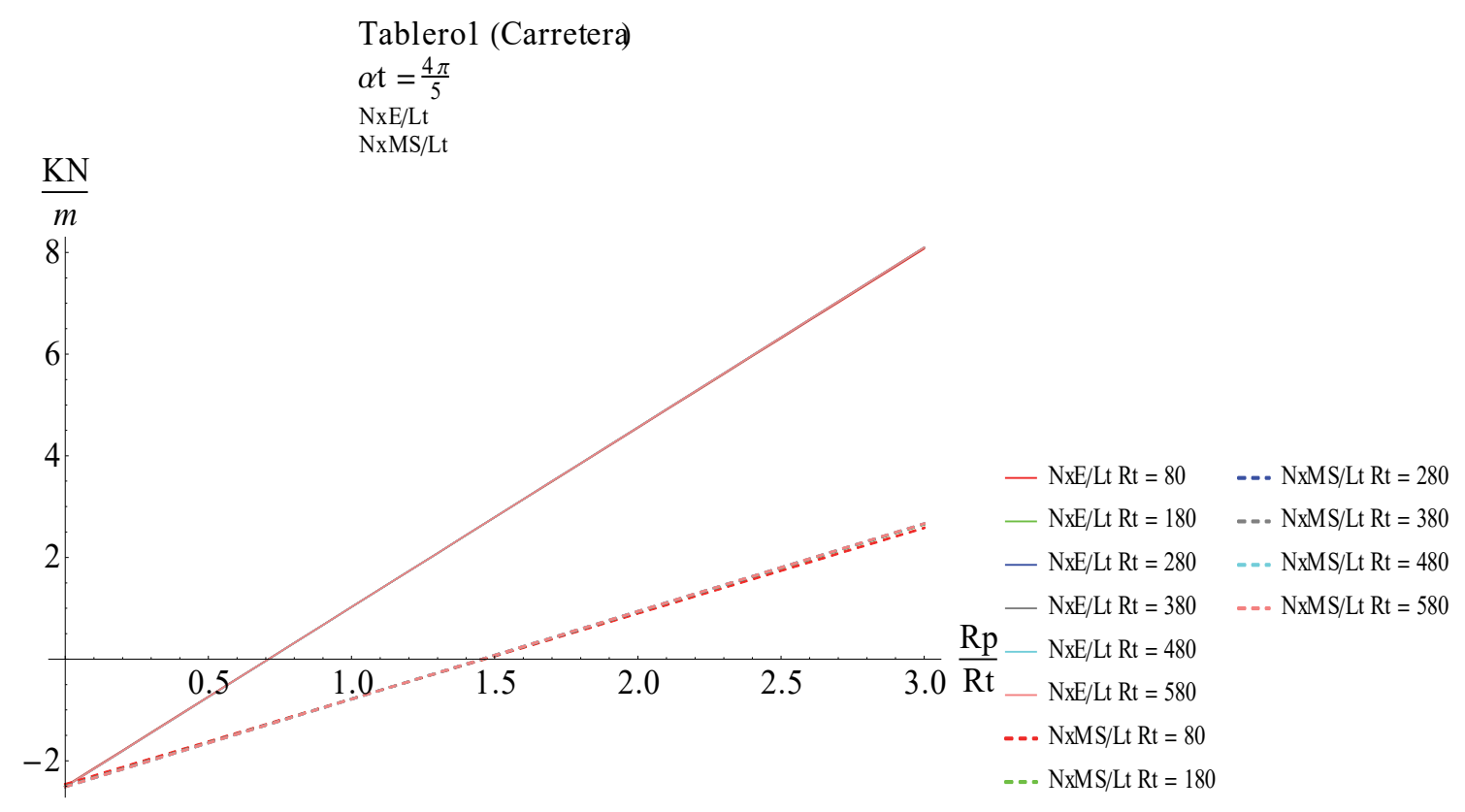

Diagrama 2.55. Solicitaciones del tablero $\left(\frac{Q y}{L t}, \frac{M z}{L t^{2}} y \frac{N x}{L t}\right) . \alpha t=\frac{\pi}{5}$, Tablero 7 (Peatonal); $\alpha t=\frac{\pi}{2}$, Tablero 7 (Peatonal); $\alpha t=\frac{\pi}{5}$, Tablero 1 (Carretera); $\alpha t=\frac{\pi}{2}$, Tablero 1 (Carretera); $\alpha t=\frac{4 \pi}{5}$, Tablero 1 (Carretera);

El Diagrama 2.55 muestra un comportamiento muy homogéneo para casi todo tipo de configuraciones y tipo de tablero, menos para el caso de $\alpha t$ y $\varphi_{K N x M z}$ muy pequeños. El funcionamiento "tipo viga" ( $\alpha$ t y $\varphi_{K N x M z}$ muy pequeños), cuando se acerca la pila al tablero es mucho más sensible a la disminución de carga (Ttir $[\alpha])$, que al cambio de dirección que se produce en la carga transversal que se le transmite al tablero (geométricamente es intuitivo). Esto se traduce en una clara disminución de solicitaciones a medida que se incrementa el valor de Rp. En cambio, cuando se pasa de un sistema resistivo "tipo arco" al "tipo esfera" (arco) directamente, lo más influyente para las solicitaciones es el cambio de dirección que se produce en la carga transversal. Por esta razón las solicitaciones (Qy y Mz) no dejan de incrementar su valor a medida que se aumenta $\mathrm{Rp}$. Cuando los diagramas de solicitaciones se hacen independientes de $\varphi_{K N X M Z}$ (como ocurre en el sistema resistivo "tipo esfera"), no se producirán los "trasvases" de solicitaciones analizados en el Diagrama 2.49, que mantenían las deformaciones estables. Esto va a hacer que las deformaciones pasen a ser directamente proporcionales a las características mecánicas de la sección (fundamentalmente: E Izz).

Se va a centrar el análisis en los cambios que se producen en las solicitaciones a medida que se varía el ángulo desarrollado por el arco del tablero $\alpha t$. Como se ve en el Diagrama 2.55, se puede concluir que la variable $\alpha t$ resulta determinante en el comportamiento del tablero frente a las cargas concéntricas horizontales cuando $R p>0$. De esta manera, se va a buscar clasificar el comportamiento transversal del tablero a partir de las características mecánicas de la sección y su morfología. Con este propósito, se van a estudiar 4 configuraciones, en lo que a longitud de tablero se refiere. Las 2 primeras, van a corresponder a pasarelas y sus longitudes de tablero, van a ser de Lt $=140 \mathrm{~m}$ y $280 \mathrm{~m}$, con una sección tipo Tablero 7 (Peatonal) (Tabla 2.18). Mientras que las 2 segundas van a corresponder a un viaducto, con longitudes de tablero, Lt = $220 \mathrm{~m}$ y $440 \mathrm{~m}$ y sección tipo Tablero 1 (Carretera) (Tabla 2.18). A partir del análisis de los resultados, se ha observado un vínculo con el factor $\frac{1}{\alpha^{2}}$, tanto para el cortante 
Qy, como para el momento flector $\mathrm{Mz}$. Se puede observar como el vínculo es aproximado, esto se debe a que el exponente 2 de $\frac{1}{\alpha^{2}}$ no resulta exacto (su valor exacto parece ser un poco menor que 2). Como ya se ha comentado, no se pretende obtener de este análisis la capacidad de obtener solicitaciones exactas, para eso se debe disponer de modelos de cálculos exactos, sino predecir el comportamiento transversal del tablero (vital en este tipo de puentes) en las fases preliminares del diseño del puente, permitiendo establecer unas bases para poder tomar decisiones correctamente encaminadas desde el inicio del proyecto.
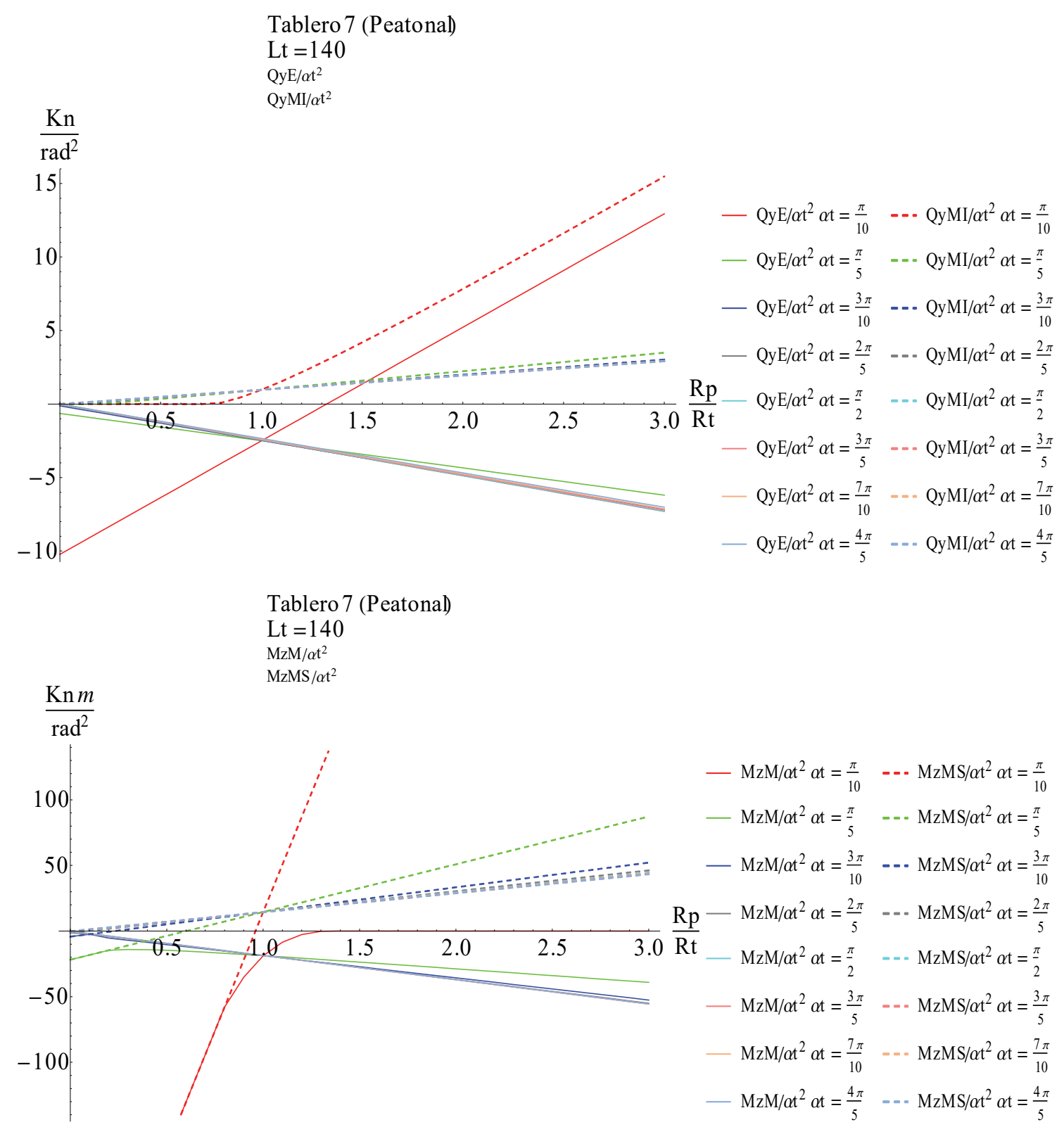


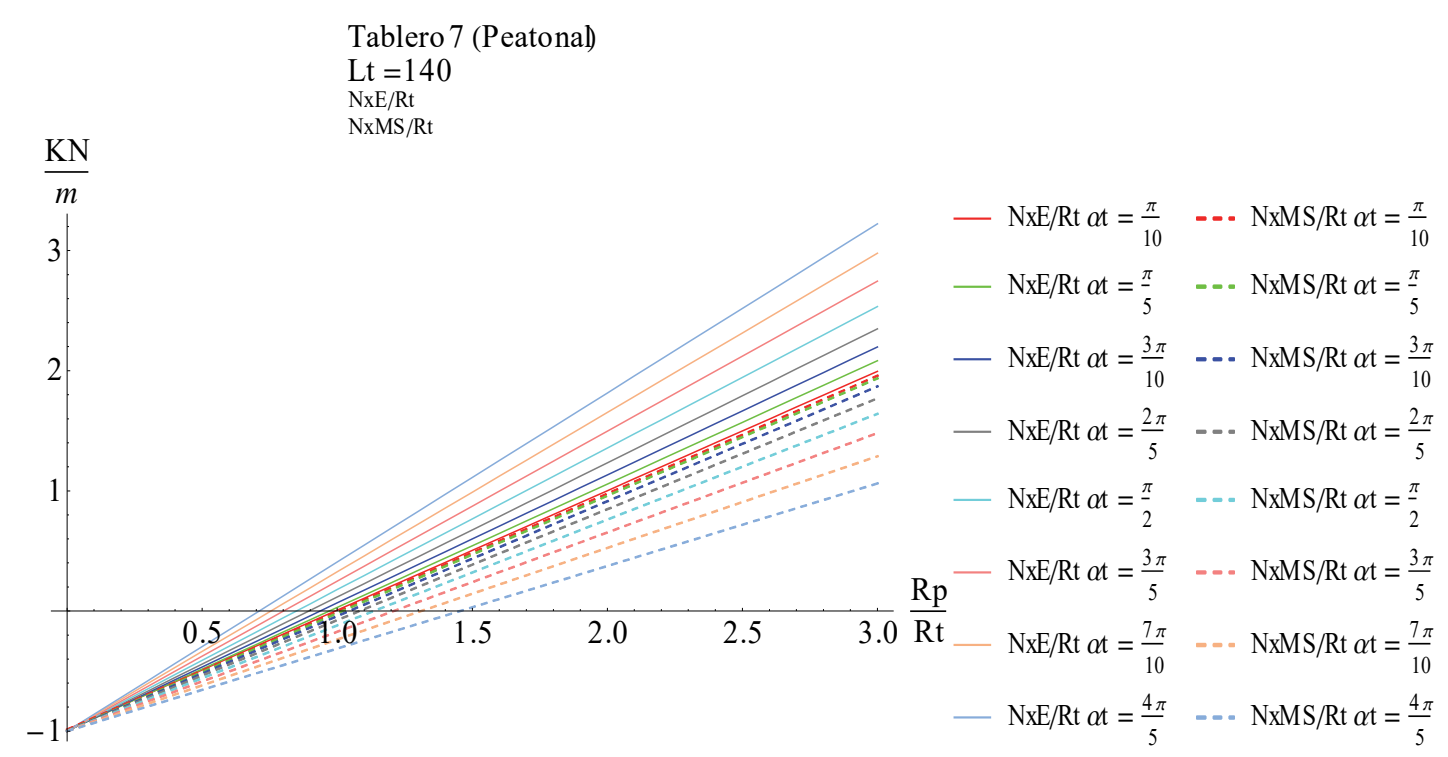

Tablero 7 (Peatonal)

$\mathrm{Lt}=280$

$\mathrm{QyE} / \alpha \mathrm{t}^{2}$

$\mathrm{QyMI} / \alpha \mathrm{t}^{2}$

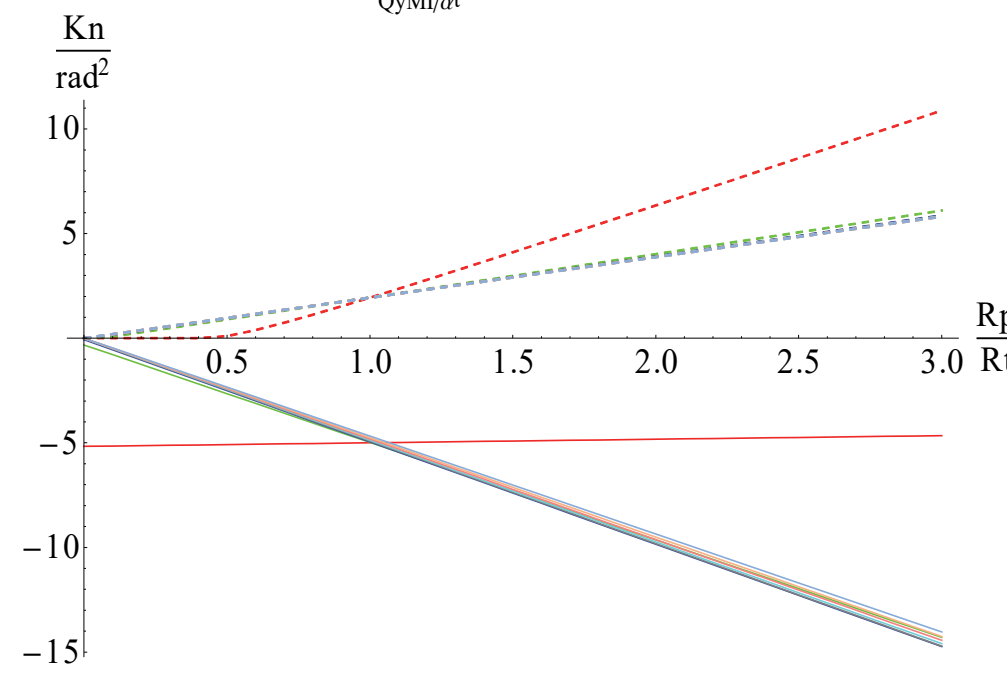
- $\mathrm{QyE} / \alpha \mathrm{t}^{2} \alpha \mathrm{t}=\frac{\pi}{10} \quad \cdots \mathrm{QyMI} / \alpha \mathrm{t}^{2} \alpha \mathrm{t}=\frac{\pi}{10}$
- QyE $/ \alpha t^{2} \alpha t=\frac{\pi}{5} \quad-\cdots \mathrm{QyMI} / \alpha t^{2} \alpha t=\frac{\pi}{5}$
$\mathrm{Rp}-\mathrm{QyE} / \alpha t^{2} \alpha \mathrm{t}=\frac{3 \pi}{10}-\cdots \mathrm{QyMI} / \alpha \mathrm{t}^{2} \alpha \mathrm{t}=\frac{3 \pi}{10}$
- QyE $/ \alpha t^{2} \alpha \mathrm{t}=\frac{2 \pi}{5} \quad \cdots \mathrm{QyML} / \alpha \mathrm{t}^{2} \alpha \mathrm{t}=\frac{2 \pi}{5}$
- $\mathrm{QyE} / \alpha \mathrm{t}^{2} \alpha \mathrm{t}=\frac{\pi}{2} \quad \cdots \mathrm{QyMI} / \alpha \mathrm{t}^{2} \alpha \mathrm{t}=\frac{\pi}{2}$
- $\mathrm{QyE} / \alpha \mathrm{t}^{2} \alpha \mathrm{t}=\frac{3 \pi}{5} \quad--\mathrm{QyMI} / \alpha t^{2} \alpha \mathrm{t}=\frac{3 \pi}{5}$
- $\mathrm{QyE} / \alpha \mathrm{t}^{2} \alpha \mathrm{t}=\frac{7 \pi}{10}-\cdots \mathrm{QyMI} / \alpha \mathrm{t}^{2} \alpha \mathrm{t}=\frac{7 \pi}{10}$
- $\mathrm{QyE} / \alpha \mathrm{t}^{2} \alpha \mathrm{t}=\frac{4 \pi}{5}-\cdots \mathrm{QyMI} / \alpha t^{2} \alpha \mathrm{t}=\frac{4 \pi}{5}$

Tablero 7 (Peatonal)

$\mathrm{Lt}=280$

$\mathrm{MzM} / \alpha \mathrm{t}^{2}$

$\mathrm{MzMS} / \alpha \mathrm{t}^{2}$

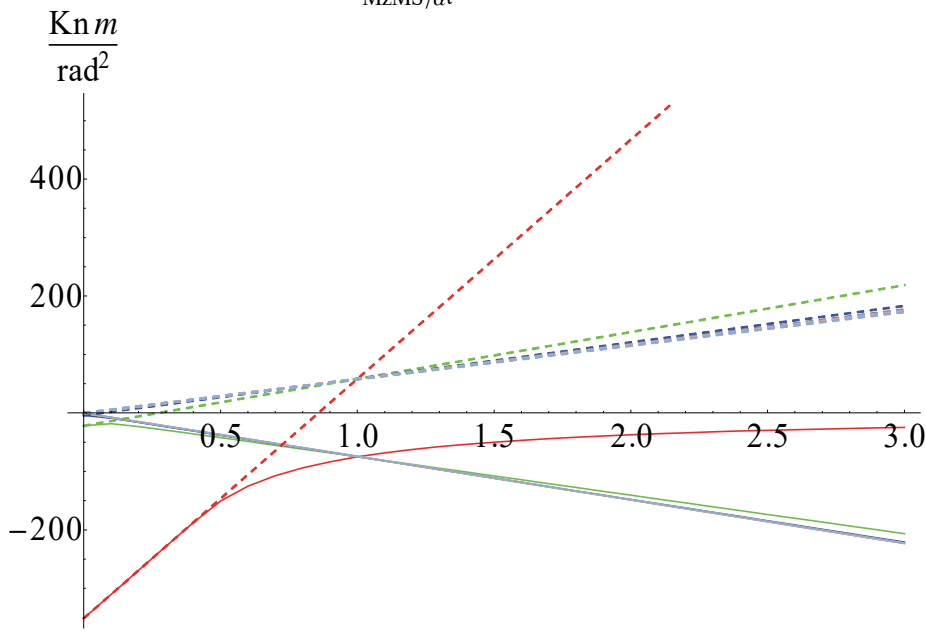

$$
\begin{aligned}
& \text { - MzM/ } / \alpha \mathrm{t}^{2} \alpha \mathrm{t}=\frac{\pi}{10} \quad \cdots \mathrm{MzMS} / \alpha \mathrm{t}^{2} \alpha \mathrm{t}=\frac{\pi}{10} \\
& \text { - } \mathrm{MzM} / \alpha \mathrm{t}^{2} \alpha \mathrm{t}=\frac{\pi}{5} \quad-\cdots \mathrm{MzMS} / \alpha \mathrm{t}^{2} \alpha \mathrm{t}=\frac{\pi}{5} \\
& \text { - MzM/ } / \alpha \mathrm{t}^{2} \alpha \mathrm{t}=\frac{3 \pi}{10} \quad-. \cdot \mathrm{MzMS} / \alpha \mathrm{t}^{2} \alpha \mathrm{t}=\frac{3 \pi}{10} \\
& \text { - MzM/ } / \alpha t^{2} \alpha t=\frac{2 \pi}{5} \quad-.-M \mathrm{MzS} / \alpha \mathrm{t}^{2} \alpha \mathrm{t}=\frac{2 \pi}{5} \\
& \frac{\mathrm{Rp}}{\mathrm{Rt}}-\mathrm{MzM} / \alpha \mathrm{t}^{2} \alpha \mathrm{t}=\frac{\pi}{2} \quad=-\mathrm{MzMS} / \alpha \mathrm{t}^{2} \alpha \mathrm{t}=\frac{\pi}{2} \\
& -\mathrm{MzM} / \alpha \mathrm{t}^{2} \alpha \mathrm{t}=\frac{3 \pi}{5} \quad-. \mathrm{MzMS} / \alpha \mathrm{t}^{2} \alpha \mathrm{t}=\frac{3 \pi}{5} \\
& -\mathrm{MzM} / \alpha \mathrm{t}^{2} \alpha \mathrm{t}=\frac{7 \pi}{10} \quad--\mathrm{MzMS} / \alpha \mathrm{t}^{2} \alpha \mathrm{t}=\frac{7 \pi}{10} \\
& -\mathrm{MzM} / \alpha \mathrm{t}^{2} \alpha \mathrm{t}=\frac{4 \pi}{5} \quad--\mathrm{MzMS} / \alpha \mathrm{t}^{2} \alpha \mathrm{t}=\frac{4 \pi}{5}
\end{aligned}
$$




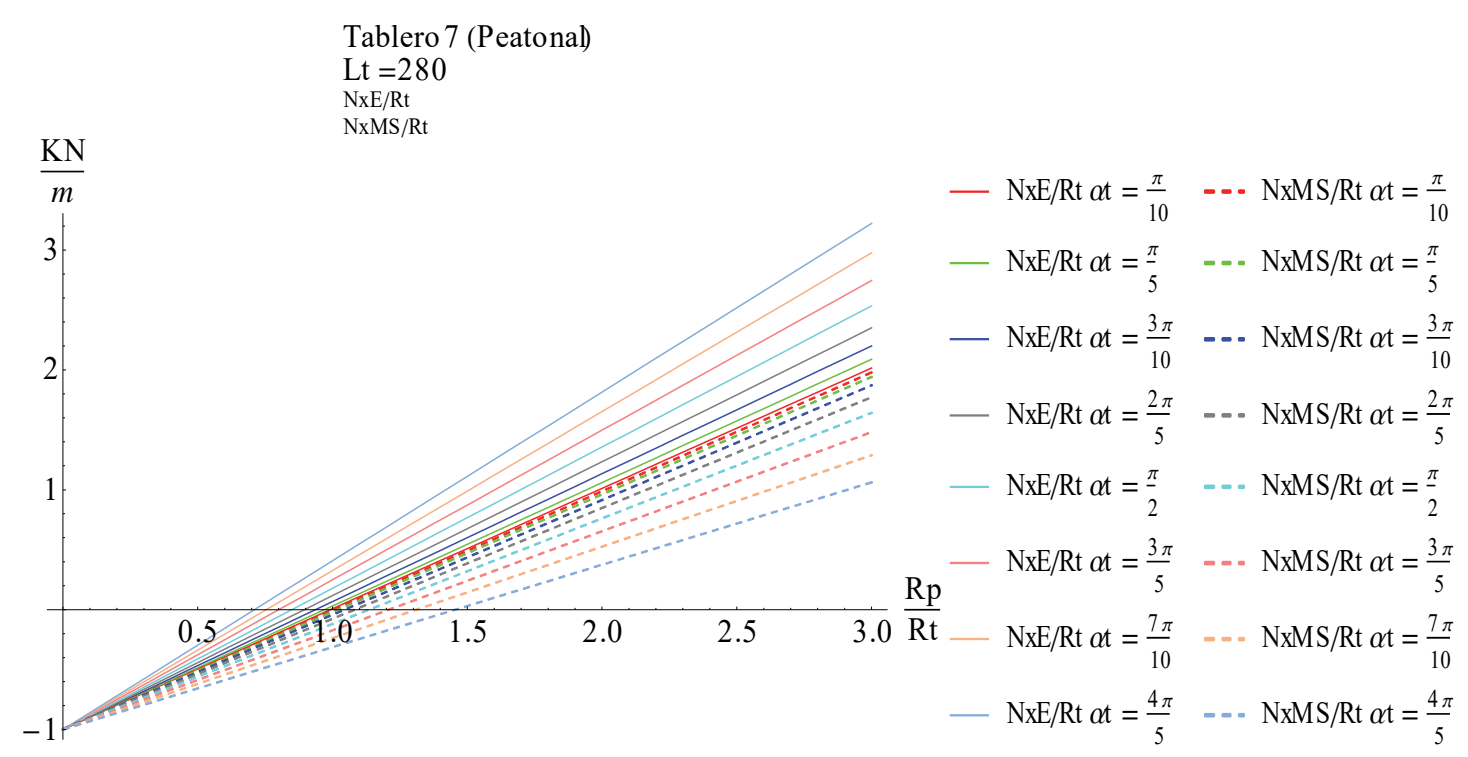

Tablero 1 (Carretera)

$\mathrm{Lt}=280$

$\mathrm{QyE} / \alpha \mathrm{t}^{2}$

QyMI $/ \alpha t^{2}$

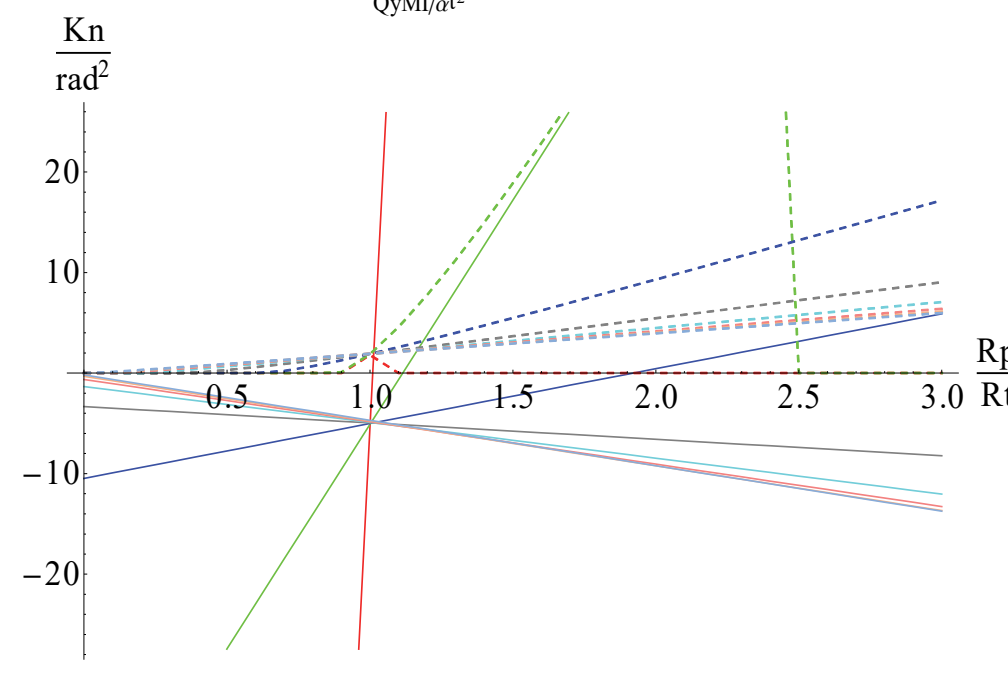

- $\mathrm{QyE} / \alpha t^{2} \alpha \mathrm{t}=\frac{\pi}{10} \quad \cdots \mathrm{QyMI} / \alpha t^{2} \alpha \mathrm{t}=\frac{\pi}{10}$

- $\mathrm{QyE} / \alpha \mathrm{t}^{2} \alpha \mathrm{t}=\frac{\pi}{5} \quad--\mathrm{QyMI} / \alpha \mathrm{t}^{2} \alpha \mathrm{t}=\frac{\pi}{5}$

- QyE $/ \alpha t^{2} \alpha t=\frac{3 \pi}{10}-\cdots Q \mathrm{QyMI} / \alpha t^{2} \alpha \mathrm{t}=\frac{3 \pi}{10}$

$\frac{\mathrm{Rp}}{\mathrm{Rt}}-\mathrm{QyE} / \alpha \mathrm{t}^{2} \alpha \mathrm{t}=\frac{2 \pi}{5}-\cdots \mathrm{QyMI} / \alpha \mathrm{t}^{2} \alpha \mathrm{t}=\frac{2 \pi}{5}$

- $\mathrm{QyE} / \alpha \mathrm{t}^{2} \alpha \mathrm{t}=\frac{\pi}{2} \quad \cdots \quad \mathrm{QyMI} / \alpha \mathrm{t}^{2} \alpha \mathrm{t}=\frac{\pi}{2}$

- QyE $/ \alpha t^{2} \alpha t=\frac{3 \pi}{5} \quad--Q$ QyMI $/ \alpha t^{2} \alpha t=\frac{3 \pi}{5}$

- $\mathrm{QyE} / \alpha \mathrm{t}^{2} \alpha \mathrm{t}=\frac{7 \pi}{10} \quad \cdots \mathrm{QyMI} / \alpha \mathrm{t}^{2} \alpha \mathrm{t}=\frac{7 \pi}{10}$

- $\mathrm{QyE} / \alpha t^{2} \alpha \mathrm{t}=\frac{4 \pi}{5} \quad \cdots \mathrm{QyMI} / \alpha t^{2} \alpha \mathrm{t}=\frac{4 \pi}{5}$

Tablero 1 (Carretera)

$\mathrm{Lt}=280$

$\mathrm{MzM} / \alpha \mathrm{t}^{2}$

$\operatorname{MzMS} / \alpha t^{2}$

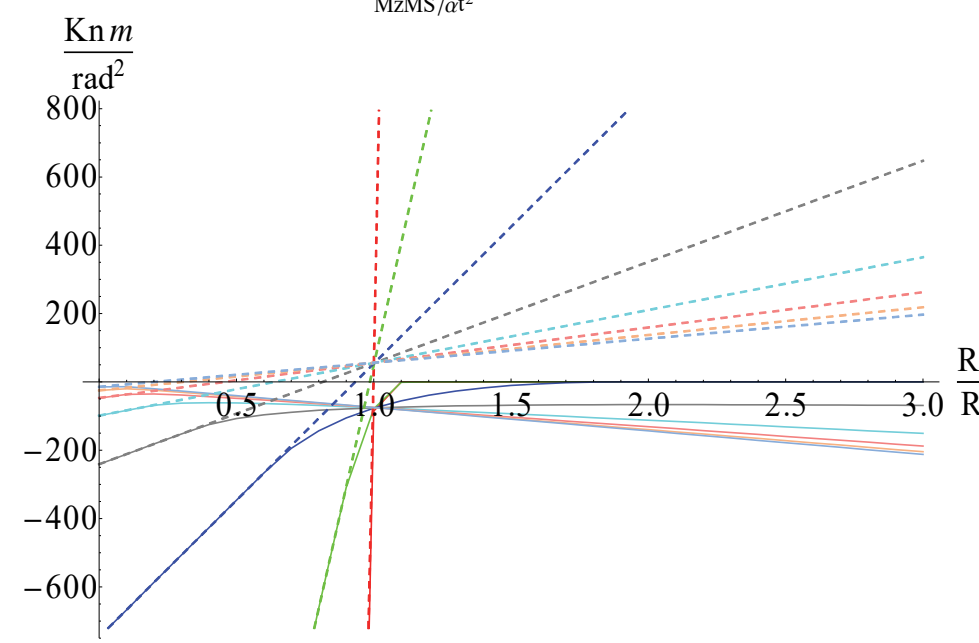

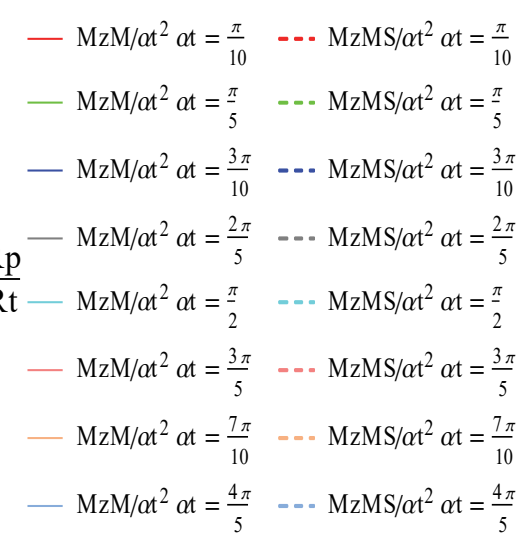



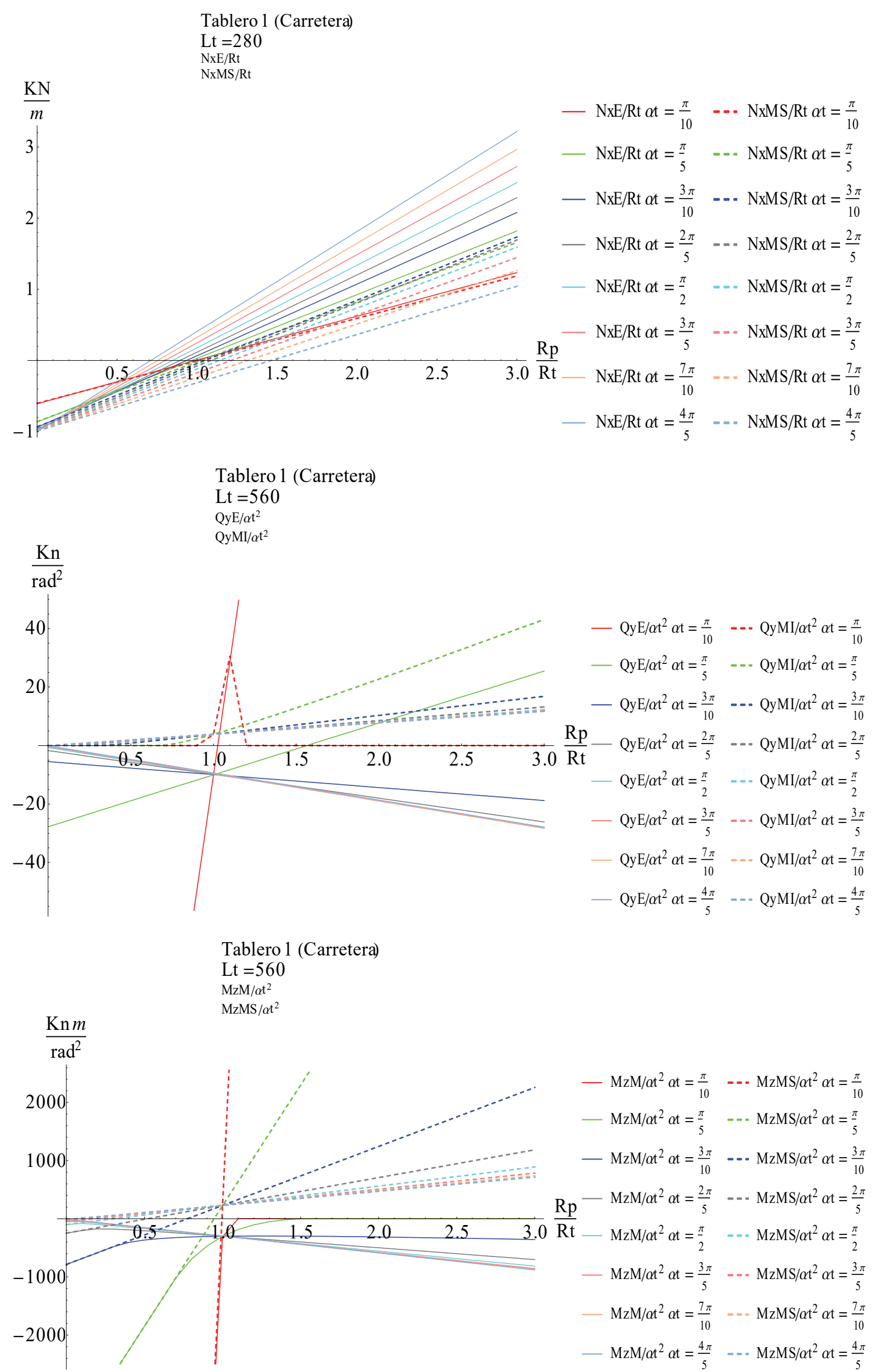


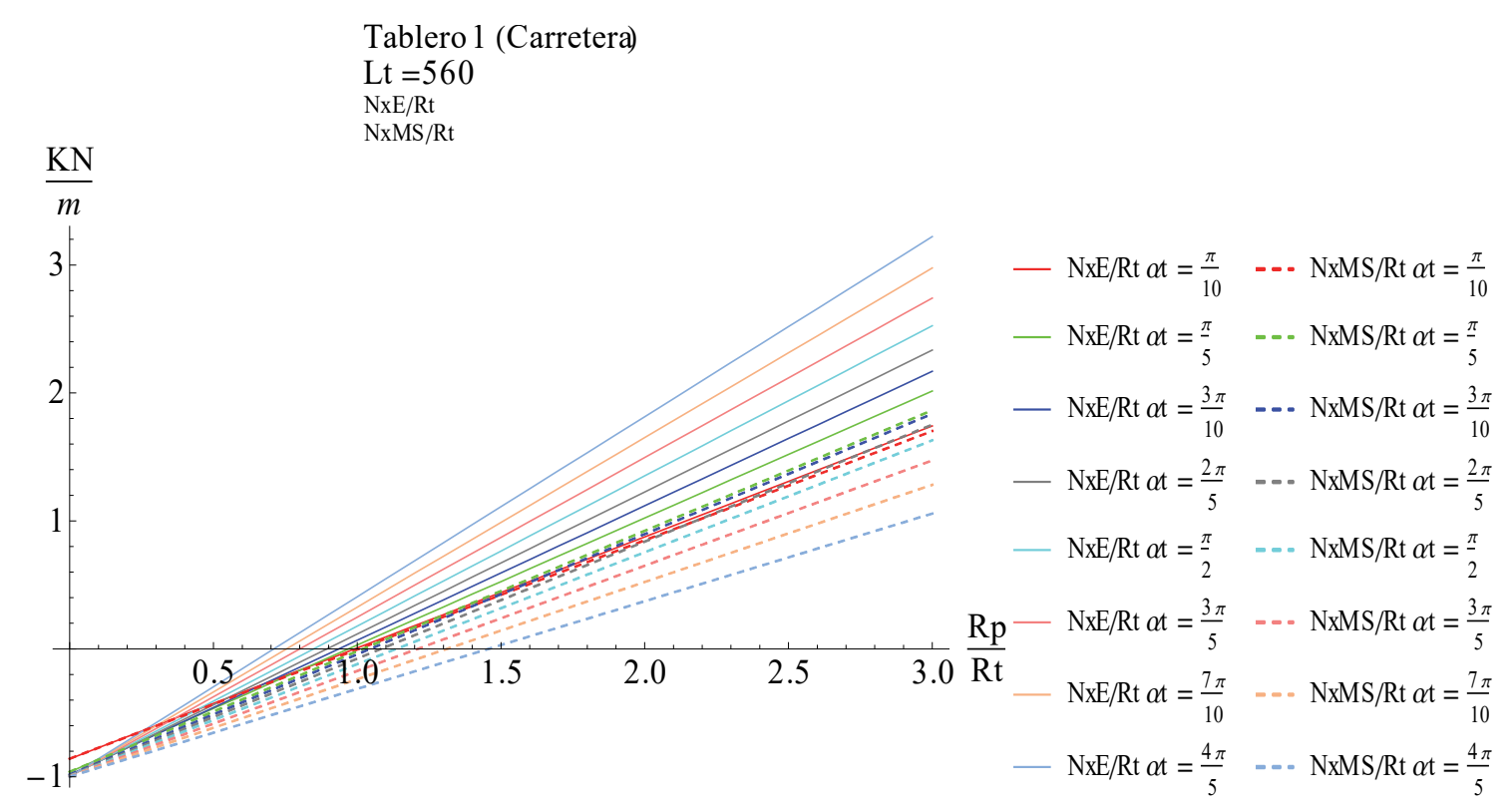

Diagrama 2.56. Solicitaciones del tablero $\left(\frac{Q y}{\alpha t^{2}}, \frac{\boldsymbol{M z}}{\alpha t^{2}} \boldsymbol{y} \frac{\boldsymbol{N x}}{\boldsymbol{R t}}\right)$. a) $\boldsymbol{L t}=\mathbf{1 4 0} \boldsymbol{m}$, Tablero 7 (Peatonal); b) $\boldsymbol{L t}=\mathbf{2 8 0} \boldsymbol{m}$, Tablero 7 (Peatonal); c) $\boldsymbol{L} \boldsymbol{t}=\mathbf{2 8 0} \boldsymbol{m}$, Tablero 1 (Carretera); d) $\boldsymbol{L} \boldsymbol{t}=\mathbf{5 6 0} \boldsymbol{m}$, Tablero 1 (Carretera); e) $\boldsymbol{\alpha} \boldsymbol{t}=\frac{\mathbf{4 \pi}}{\mathbf{5}}$, Tablero 1 (Carretera);

Analizando las gráficas, se puede llegar a una solución numérica que nos permita una clasificación de los sistemas resistivos nombrados hasta el momento: "tipo arco", "tipo viga" y "mixto":

- Existe un epicentro en los diagramas de cortante Qy, a partir del cual las rectas giran. Este epicentro en los diagramas de cortante, solo depende de la longitud $\mathrm{Lt}$, porque coincide cuando Lt no varía y se duplica cuando Lt se duplica. EI epicentro se sitúa en $\frac{R p}{R t} \approx 1$.

- Si se divide el valor que toma el diagrama de cortante en el estribo $\frac{Q y E}{\alpha t^{2}}$, en el epicentro, por la longitud total del tablero, se obtiene un valor constante para cualquier longitud de tablero:

$$
\frac{\frac{Q y E}{\alpha t^{2}}}{L t} \approx-0.071
$$

- La pendiente de la recta que representa el cortante en el estribo $\frac{Q y E}{\alpha t^{2}}$, marca el comportamiento del tablero a medida que se incrementa Rp. Si la pendiente es positiva, las solicitaciones transversales van a tener su mínimo en $\frac{R p}{R t}=1$ o en sus proximidades. Mientras que, si es negativa, el mínimo de solicitaciones va a depender de nuevo de la pendiente de la recta.

Con estas observaciones y sabiendo que el punto de partida $(R p=0)$ se ha obtenido ya, a partir de las características mecánicas de la sección y la morfología del puente, en el subapartado dedicado a fuerzas concéntricas con $\mathrm{Rp}=0$ (subapartado 2.2.6.1). Se van a realizar las siguientes definiciones: 
1) Comportamiento "tipo viga":

$$
\begin{gathered}
\frac{Q y E}{\frac{\alpha t^{2} L t}{N x}}(R p=0)=\frac{\frac{Q y E}{\alpha t^{3} R t}}{\frac{N x}{R t}}(R p=0)=v_{Q y N x E} \frac{R t}{\alpha t^{3} R t} \geq 0.071 \\
v_{Q y N x E}=\frac{Q y E}{N x}=(61.62-9.58 \alpha t) \psi_{Q y N x}=(61.62-9.58 \alpha t) \frac{1}{\alpha t L t^{2}} * i_{z z}{ }^{2}
\end{gathered}
$$

2) Comportamiento "mixto":

$$
\begin{gathered}
0.071 \geq \frac{\frac{Q y E}{\alpha t^{2} L t}}{\frac{N x}{R t}}(R p=0)=\frac{\frac{Q y E}{\alpha t^{3} R t}}{\frac{N x}{R t}}(R p=0)=v_{Q y N x E} \frac{R t}{\alpha t^{3} R t} \geq 0.0008 \\
v_{Q y N x E}=\frac{Q y E}{N x}=(61.62-9.58 \alpha t) \psi_{Q y N x}=(61.62-9.58 \alpha t) \frac{1}{\alpha t L t^{2}} * i_{z z}{ }^{2}
\end{gathered}
$$

3) Comportamiento "tipo arco":

$$
\begin{gathered}
\frac{Q y E}{\frac{\alpha t^{2} L t}{\frac{N x}{R t}}}(R p=0)=\frac{\frac{Q y E}{\alpha t^{3} R t}}{\frac{N x}{R t}}(R p=0)=v_{Q y N x E} \frac{R t}{\alpha t^{3} R t} \leq 0.0008 \\
v_{Q y N x E}=\frac{Q y E}{N x}=(61.62-9.58 \alpha t) \psi_{Q y N x}=(61.62-9.58 \alpha t) \frac{1}{\alpha t L t^{2}} * i_{z z}{ }^{2}
\end{gathered}
$$

4) Comportamiento "tipo esfera":

Este comportamiento se produce después del punto de mínimas solicitaciones en los comportamientos tipo "mixto" y "tipo arco". En el "tipo arco" es cuando Rp $>0$, mientras que en el "mixto" es en algún punto entre $0<R p<R t$. A partir de ese punto, surgen 2 máximos en el diagrama de momentos $\mathrm{Mz}$ :

o El primero entre el estribo y el centro de vano, de valor negativo (Obviamente la simetría de solicitaciones hace que exista otro similar entre el centro y el siguiente estribo).

o El segundo en el centro del vano, de valor positivo.

Ya se han definido los tipos de comportamiento y sus características principales. Incluso se ha dado una definición matemática aproximada que, a partir de datos preliminares del proyecto, permite saber cuál va a ser el comportamiento transversal del tablero (crucial en puentes curvos atirantados). Con la intención de aclarar una de las diferencias fundamentales de los tipos de comportamiento, se va a mostrar un diagrama en el que se recoge la carga horizontal total aplicada sobre el tablero a medida que modificamos la posición de la pila.

La carga total sobre el tablero es una medida de la solicitación horizontal $\left(\sqrt{p_{x}{ }^{2}+p_{y}{ }^{2}}\right)$ total que se introduce al tablero según la posición de la pila. Por eso se integra la carga sin 
tener en cuenta el signo de cada componente, sin que se contrarresten las cargas a lo largo de la integración. Para que el análisis sea más productivo, se ha dividido la carga por la longitud del tablero (Lt), de forma que lo que aparece es carga total por unidad de longitud (de esta manera se analizan todos los casos en una sola gráfica).

$$
\text { Ttot }=\frac{\int_{-\frac{\alpha t}{2}}^{\frac{\alpha t}{2}} \sqrt{p_{x}^{2}+p_{y}^{2}} d \alpha}{R t \alpha t}
$$

Las líneas discontinuas corresponden a la carga horizontal total por metro de un puente recto de luz igual al curvo. Se ha dibujado una recta para mejorar la representación de los datos, pero en este caso la pila cae sobre el tablero.

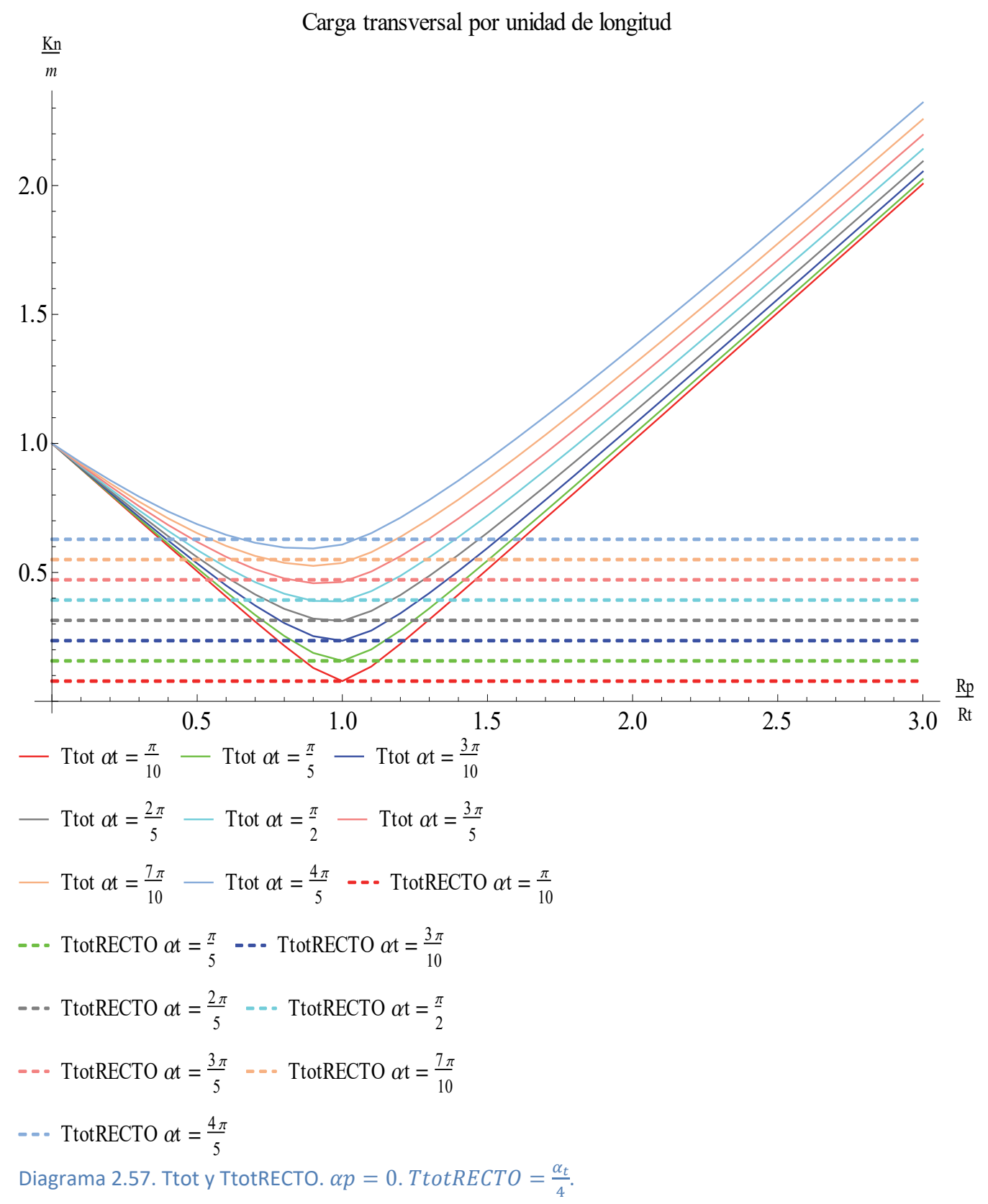




\subsection{1 Análisis: cargas y solicitaciones}

\subsection{1.1 Carga total sobre el tablero (Ttot)}

o La carga total Ttot, va a ser una medida de la cantidad de carga horizontal por metro lineal que debe soportar el subsistema tablero, así como el subsistema Pila-Tirantes. Aunque en el caso del subsistema Pila-tirantes, debido a la simetría, se equilibrarán parte de estas fuerzas horizontales para cargas uniformemente repartidas en el tablero.

- La carga se reduce a su mínimo, cuando se sitúa la pila en el centro de gravedad del tablero. El C.D.G. del tablero varía según sea el ángulo desarrollado por el tablero. Cuanto más pequeño sea el ángulo desarrollado por el tablero, más cerca se sitúa el centro de gravedad del tablero.

$$
\text { - } X_{c d g}=R p_{c d g}=\frac{2 R_{t} \sin \left(\frac{\alpha_{t}}{2}\right)}{\alpha_{t}}
$$

A esto, se le suma que en ese punto es donde se compensan todas las cargas horizontales (la pila recibiría solo una carga vertical). Pero como hemos visto en los puntos anteriores, esto no garantiza un mejor funcionamiento siempre (como en aquellos tableros con grandes $\alpha_{t}$, cuyo comportamiento es "tipo esfera" (arco)), desarrollando grandes cortantes y momentos transversales ( $Q y, M z$ ). En este mínimo, la carga horizontal total (Ttot) que introducimos en el puente, es similar a la de un puente recto con la misma longitud de vano (esta similitud se vuelve más exacta cuanto menor sea el ángulo $\alpha_{t}$ ).

o Como los valores de la carga están por unidad de longitud, todas las curvas se unen cuando situamos la pila en el centro de la circunferencia, donde Ttot $=$ Ttir (Diagrama 2.51).

\subsection{1.2 Axil (Nx)}

- La reacción axil en los estribos se anula cuando la pila se introduce cerca del CDG de cada tablero. Es cerca y no exacto, por el grado de hiperestaticidad en los estribos. A partir de ese punto, si se sigue desplazando la pila alejándola del centro del arco, las reacciones axiles en los estribos cambian de signo.

- Al contrario de lo que ocurría cuando la pila se situaba en el centro del arco (donde la carga Ttir era siempre radial), cuando se aleja la pila de ese punto, la carga concéntrica Ttir $[\alpha]$ introduce una componente tangencial al tablero. Esto hace que la variación de axil sea más pronunciada y no solo dependa de la curvatura (esto se aprecia en las variaciones del diagrama de axil (Nx)).

o Con ángulos medios-grandes $\left(\alpha_{t}>\frac{2 \pi}{5}\right)$, correspondiente a tableros de comportamiento "mixto" y "tipo arco", a medida que se incrementa el radio donde se sitúa la pila (Rp), el axil a mitad de vano se hace más dependiente de la componente longitudinal de la carga (px). Esto compensa cierta parte de la pérdida de axil en los estribos, diferenciándose el valor del axil ( $\mathrm{Nx}$ ) en el estribo y en el centro del tablero.

o Cuanto más cerca está la pila del centro del arco menos varía el axil a lo largo del tablero (esto verifica todo lo visto hasta ahora en cargas concéntricas). Es bueno recordar que en un efecto arco ideal, daría igual por donde se cortase la circunferencia, porque se obtendría siempre el mismo axil. 
- En aquellos tableros con comportamiento "tipo viga", los axiles varían menos a medida que se aleja la pila del centro de la circunferencia. Como se verá en los análisis de cortante transversal ( $\mathrm{Qy}$ ) y momento transversal (Mz), en estos casos, es beneficioso llevarse la pila cerca del tablero.

\section{Ecuaciones diferenciales en función de $\alpha$}

$$
\begin{aligned}
& \frac{\mathrm{dQY}[\alpha]}{\mathrm{d} \alpha}==\operatorname{py}[\alpha] \mathrm{R}-\mathrm{Nx}[\alpha] \rightarrow \frac{\mathrm{d}^{2} \mathrm{QY}[\alpha]}{\mathrm{d} \alpha^{2}}+\mathrm{QY}[\alpha]=\mathrm{R}\left(\frac{\mathrm{dpy}[\alpha]}{\mathrm{d} \alpha}-\mathrm{px}[\alpha]\right) \\
& \frac{\mathrm{dNx}[\alpha]}{\mathrm{d} \alpha}==\mathrm{QY}[\alpha]+\operatorname{px}[\alpha] \mathrm{R} \rightarrow \frac{\mathrm{d}^{2} \mathrm{Nx}[\alpha]}{\mathrm{d} \alpha^{2}}+\mathrm{Nx}[\alpha]==\mathrm{R}\left(\mathrm{py}[\alpha]+\frac{\mathrm{dpx}[\alpha]}{\mathrm{d} \alpha}\right) \\
& \frac{\mathrm{dMz}[\alpha]}{\mathrm{d} \alpha}=\mathrm{pxR} \mathrm{R}^{2}-\frac{\mathrm{dNx}[\alpha]}{\mathrm{d} \alpha} \mathrm{R} \rightarrow \\
& \frac{\mathrm{dMz}[\alpha]}{\mathrm{d} \alpha}=-\mathrm{QY}[\alpha] \mathrm{R} \rightarrow \frac{\mathrm{d}^{3} \mathrm{Mz}[\alpha]}{\mathrm{d} \alpha^{3}}+\frac{\mathrm{dMz}[\alpha]}{\mathrm{d} \alpha}=\mathrm{R}^{2}\left(\operatorname{px}[\alpha]-\frac{\mathrm{dpy}[\alpha]}{\mathrm{d} \alpha}\right)
\end{aligned}
$$

Se muestran de nuevo las ecuaciones diferenciales que rigen el comportamiento del sistema, para que sumadas al análisis de la solicitación axil, se obtenga una visión más completa del problema.

\subsection{1.3 Cortante transversal (Qy)}

o En el caso del cortante (Qy), el comportamiento "tipo arco-esfera" implica que será menor cerca del centro del arco (la carga transversal y el axil, con la curvatura, se van neutralizando manteniendo el cortante transversal nulo) e irá aumentando a medida que separamos la pila del centro de la circunferencia, acercándola al tablero.

- En el caso de tableros con comportamiento "tipo viga", el efecto del axil y la curvatura no se ven compensados, sino superados, por la carga transversal $(p y[\alpha])$. Siendo la carga transversal $p y[\alpha]$, la que domina el cortante (Qy) a lo largo de todo el tablero. En estos casos, alejar la pila del centro de la circunferencia, aumentando el radio donde se sitúa la pila, disminuye esta carga transversal $(p y[\alpha])$ consiguiendo devolver en parte el equilibrio. Esto Ilega hasta el extremo en el tablero recto, donde el sitio idóneo está sobre el tablero.

- En el caso de tableros con comportamiento "tipo arco", a medida que se incrementa el radio donde se sitúa la pila (Rp), se rompe el equilibrio entre el axil con la curvatura y la carga transversal $(p y[\alpha])$. Así, queda el cortante transversal (su pendiente) de la zona más próxima a los estribos dominado por la acción transversal $p y[\alpha]$, con axiles reducidos, y el de la zona central dominado por la acción axil, donde este incrementa debido a la aportación de 
la carga tangencial px, llegando a cambiar el signo de la pendiente del cortante, creándose un máximo.

o En el caso de tableros de comportamiento "mixto", su comportamiento empieza $(R p \approx 0)$ como uno de "tipo viga", hasta que llega a un mínimo, a partir del cual se pasa a un comportamiento "tipo esfera" como los tableros de comportamiento "tipo arco".

\subsection{1.4 Momento transversal (Mz)}

- En el caso del Momento (Mz), el comportamiento "tipo arco-esfera" implica que será menor cerca del centro del arco (en las ecuaciones diferenciales, se puede ver cómo el momento depende directamente del cortante) e irá aumentando a medida que a separamos la pila del centro de la circunferencia, acercándola al tablero.

o En el caso de tableros con comportamiento "tipo viga", el momento transversal $(\mathrm{Mz})$ se asimila mucho al de una viga isostática con carga transversal. En estos casos, alejar la pila del centro de la circunferencia, aumentando el radio donde se sitúa la pila, disminuye esta carga transversal disminuyendo el momento.

- En el caso de tableros de comportamiento "tipo esfera", a medida que se incrementa el radio donde se sitúa la pila (Rp), se reproducen las 2 zonas que se han comentado en el análisis del cortante transversal (Qy). Aparece un máximo cerca del estribo, debido al cortante dominado por la carga transversal $p y[\alpha]$, y otro en el centro del vano, debido al cortante de la zona más centrada dominado por el axil ( $\mathrm{Nx}$ ), que puede llegar a ser de signo contrario. La bifurcación de estos 2 máximos (el del centro del vano y el simétrico en cada mitad de vano), se produce casi en el inicio $(\mathrm{Rp}=0)$ en el caso de aquellos tableros de comportamiento "tipo arco" y en un punto intermedio $(0<R p<R t)$ en el caso de los tableros con comportamiento "mixto".

o La bifurcación entre máximos momentos transversales ( $\mathrm{Mz}$ ) del punto 3), en el caso de tableros de comportamiento "mixto", es el punto en el que se pasa de 1 extremo a 3 extremos en el diagrama (a medida que disminuye el axil y tenemos mayor influencia de la carga transversal $p y[\alpha]$, en el cortante (Qy) cercano al estribo). En torno a este punto, el momento transversal ( $\mathrm{Mz}$ ) máximo absoluto del tablero disminuye a medida que se acerca la pila al tablero. Esto se produce hasta que se crea una "meseta" entre los 3 extremos, creando un punto que puede llegar a ser atractivo a la hora de posicionar la pila.

\subsection{2 Conclusiones}

1. La posición más apropiada para la pila, en lo que a acciones horizontales se refiere, para tableros con comportamiento "tipo arco", es cerca del centro de la circunferencia. En torno a esta posición casi todo el axil va a quedar compensando por las cargas transversales. Los inconvenientes que tiene esta configuración, se han comentado ya: alta solicitación axil (si bien el tablero es un elementos que debe ser capaz de absorberlo a menos que sea un tablero 
muy largo), gran distancia que va a existir tener entre la pila y el tablero, con tirantes muy largos, y altas solicitaciones sobre el subsistema Pila-Tirantes (este inconveniente es sin duda el más determinante y por ello Schlaich lo intenta remediar mediante el puente colgante curvo (87), (88) y 89)).

2. En el caso de tableros con comportamiento "mixto", si se acerca la pila hacia el tablero, hay un punto intermedio $(0<R p<R t)$ en el que se consigue compensar el cortante producido por ese grado de hiperestaticidad del tablero en los estribos (esto ocurre porque se descompensa la carga transversal py y el axil con la curvatura, disminuyendo más la segunda que la primera), disminuyendo el momento máximo y el axil que debe resistir el tablero.

3. Para tableros con comportamiento "tipo viga", lo óptimo pasa por acercar la pila al tablero y en concreto al CDG de este. Es en este punto o su entorno (en este caso también afecta el grado de hiperestaticidad del tablero en los estribos) donde se reducen todas las solicitaciones y se minimiza la carga horizontal introducida o lo que es lo mismo, se reduce la distancia entre pila y tablero y con ello la longitud de los tirantes de sujeción (Diagrama 2.9). 


\subsection{Deformaciones}

Las deformaciones transversales, van a tener una importancia enorme de cara a la capacidad del subsistema Pila-Tirantes de sustentar el tablero. Es esta función de contrarrestar las solicitaciones transversales introducidas por los tirantes, la más importante de la rigidez transversal del tablero. Para poder analizar correctamente esta función, las deformaciones transversales que se van a estudiar son las alineadas con los tirantes de sujeción, en el plano XY (esto es, la deformación horizontal del tablero en la dirección de la carga concéntrica, en cada punto, negativa si se acerca al centro de la carga y positiva si se aleja).

En los 3 primeros gráficos de cada apartado del Diagrama 2.58 y del Diagrama 2.59 se muestra la deformada debida al momento flector transversal ( $\delta x t x t M z)$ y la deformada debida a la solicitación axil ( $\delta x t x t N x$ ) de casos particulares, que se consideran relevantes y que a su vez van a permitir una mejor comprensión del último gráfico de cada apartado. Se ve como la forma de la deformada debida al axil $(\delta x t x t N x)$, tiene un solo extremo en el centro del vano, que se va a denominar $\delta x \operatorname{txtNxMAX}$. La deformada debida al momento flector $(\delta x t x t M z$ ), tiene 3 extremos (como el diagrama de momento $\mathrm{Mz}$ ), uno en el centro del vano $\mathrm{y}$ otros 2 , simétricos, entre el centro de vano y los estribos (Solo en los casos de $R p \approx 0$, puede tener un solo extremo). $\delta x t x t M z M I N$ va a corresponder con al extremo con menor módulo y $\delta x t x t M z M A X$ al extremo de mayor módulo. En el caso de la deformada total del tablero,

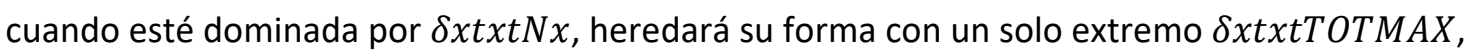
mientras que cuando esté dominada por la deformada del momento, tendrá 2 extremos $\delta x t x t T O T M A X$ y $\delta x t x t T O T M I N$. Es conveniente recordar que lo que se muestra es el desplazamiento en dirección al centro de la fuerza, siendo negativo si se acerca al centro y positivo si se aleja.

Deformación $(\mathrm{Lt}=140 \mathrm{~m})$

Sección : Tablero 7 (Peatonal)

$\mathrm{Rp} / \mathrm{Rt}=0.1 \alpha \mathrm{t}=\frac{\pi}{10}$

$\{\delta x \mathrm{xtxtTOT}, \delta \mathrm{xtxtNx}, \delta x \mathrm{xtxtMz}$ )

$\mathrm{m}$

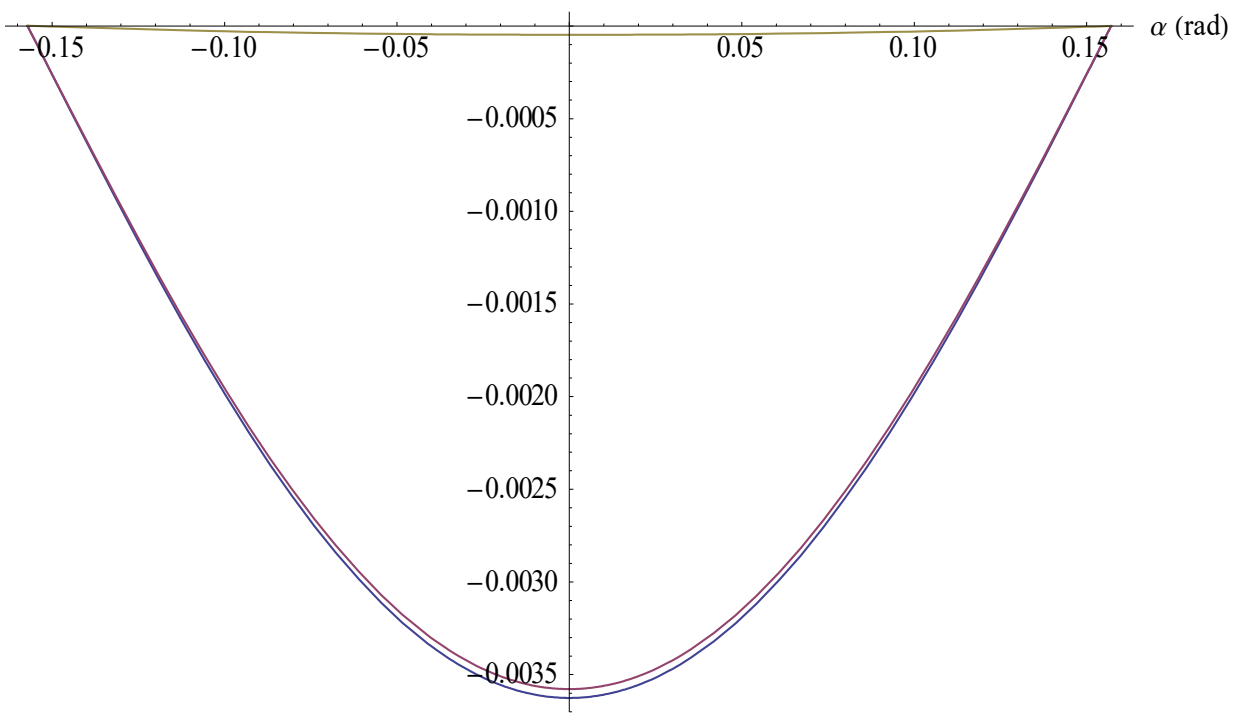

$-\delta$ xtxtTOT

- $\delta \mathrm{xtxtNx}$

$-\delta \mathrm{xtxtMz}$ 
Deformación $(\mathrm{Lt}=140 \mathrm{~m})$

Sección: Tablero 7 (Peatonal)

$\mathrm{Rp} / \mathrm{Rt}=0.9 \alpha \mathrm{t}=\frac{\pi}{10}$

$\{\delta x t x t T O T, \delta x t x t N x, \delta x t x t M z)$

$\mathrm{m}$

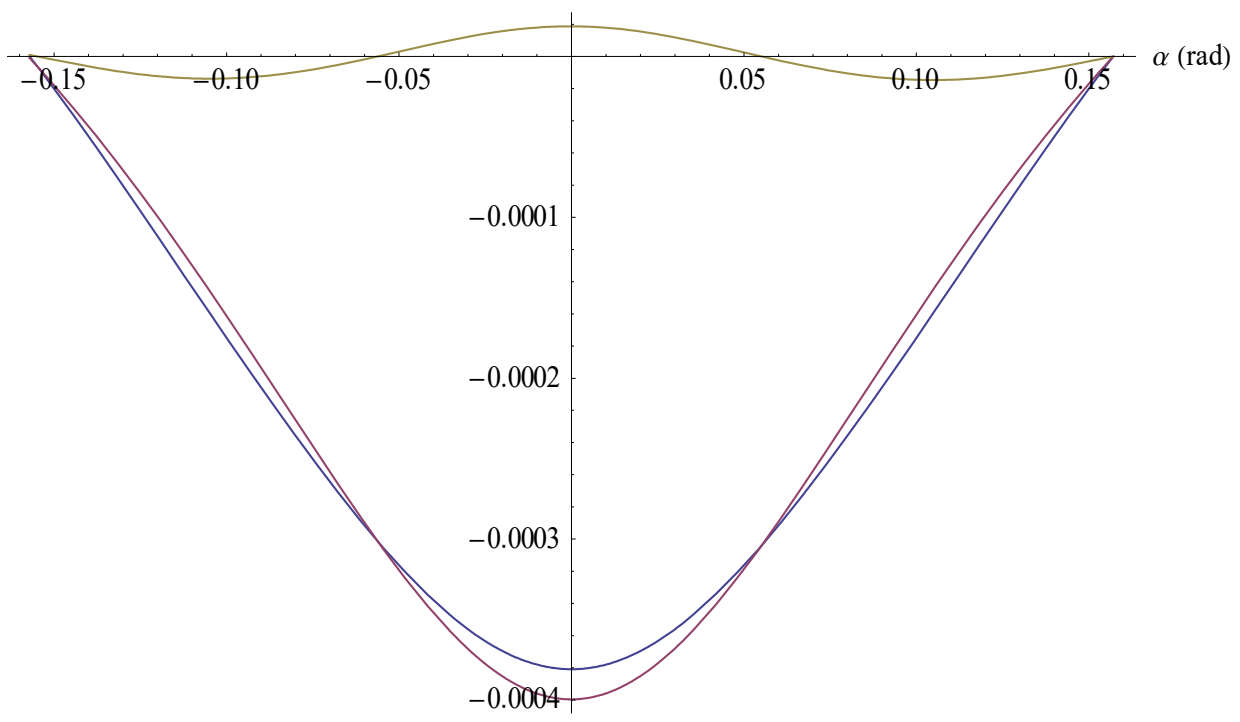

$-\delta x t x t T O T$

Deformación $(\mathrm{Lt}=140 \mathrm{~m})$

Sección : Tablero 7 (Peatonal)

$\mathrm{Rp} / \mathrm{Rt}=1.5 \alpha \mathrm{t}=\frac{\pi}{10}$

$\{\delta$ xtxtTOT $, \delta x t x t N x, \delta x t x t M z)$

$\mathrm{m}$

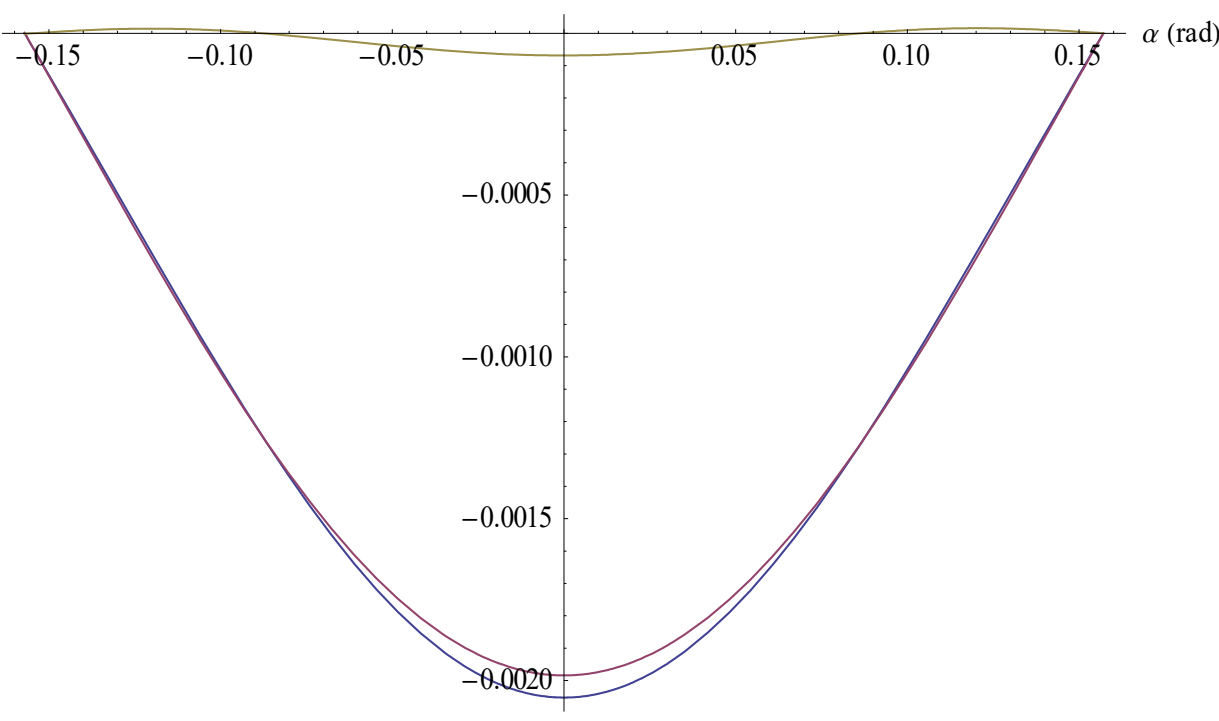

- $\delta$ xtxtTOT

$-\delta \mathrm{xtxtNx}$

- $\delta \mathrm{xtxtMz}$ 
Deformación $(\mathrm{Lt}=140 \mathrm{~m})$

Sección: Tablero7 (Peatonal)

$\{\delta$ xtxtTOTMAX,$\delta$ xtxtTOTMIN,$\delta$ xtxtNxMAX $, \delta x t x t M z M A X, \delta x t x t M z M I N\}$

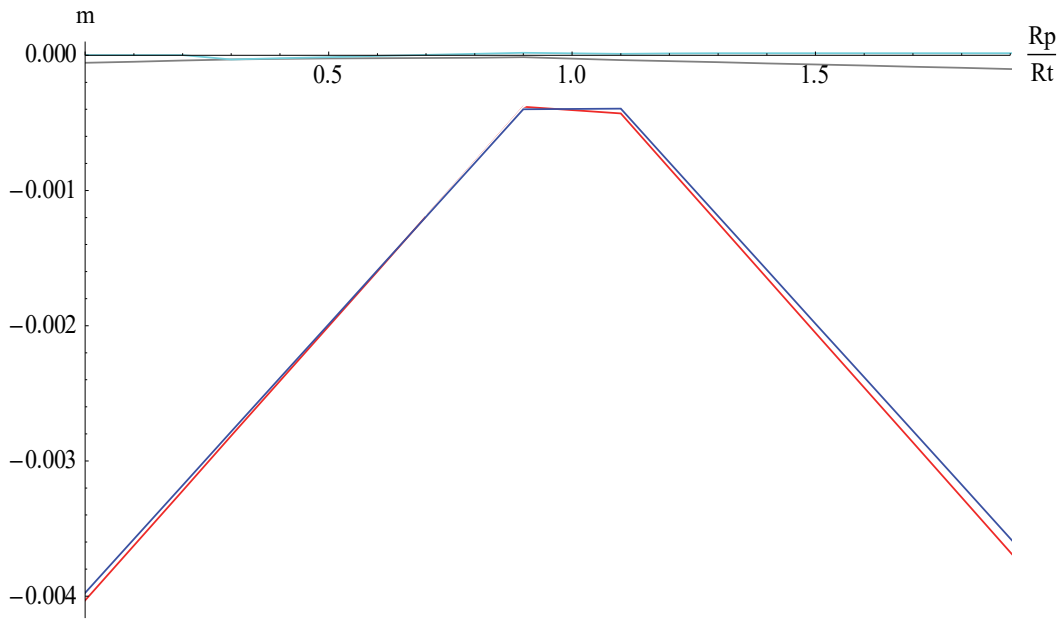

$-\delta$ xtxtTOTMAX $\alpha \mathrm{t}=\frac{\pi}{10}(\mathrm{Rt}=446)$
$\delta$ xtxtTOTMIN $\alpha \mathrm{t}=\frac{\pi}{10}(\mathrm{Rt}=446)$
$-\delta \mathrm{xtxtNxMAX} \alpha \mathrm{t}=\frac{\pi}{10}(\mathrm{Rt}=446)$
$-\delta \mathrm{xtxtMzMAX} \alpha \mathrm{t}=\frac{\pi}{10}(\mathrm{Rt}=446)$
$-\delta \mathrm{xtxtMzMIN} \alpha \mathrm{t}=\frac{\pi}{10}(\mathrm{Rt}=446)$

Deformación $(\mathrm{Lt}=280 \mathrm{~m})$

Sección : Tablero 7 (Peatonal)

$\mathrm{Rp} / \mathrm{Rt}=0.1 \alpha \mathrm{t}=\frac{\pi}{5}$

$\{\delta \mathrm{xtxtTOT}, \delta \mathrm{xtxtNx}, \delta \mathrm{xtxtMz})$

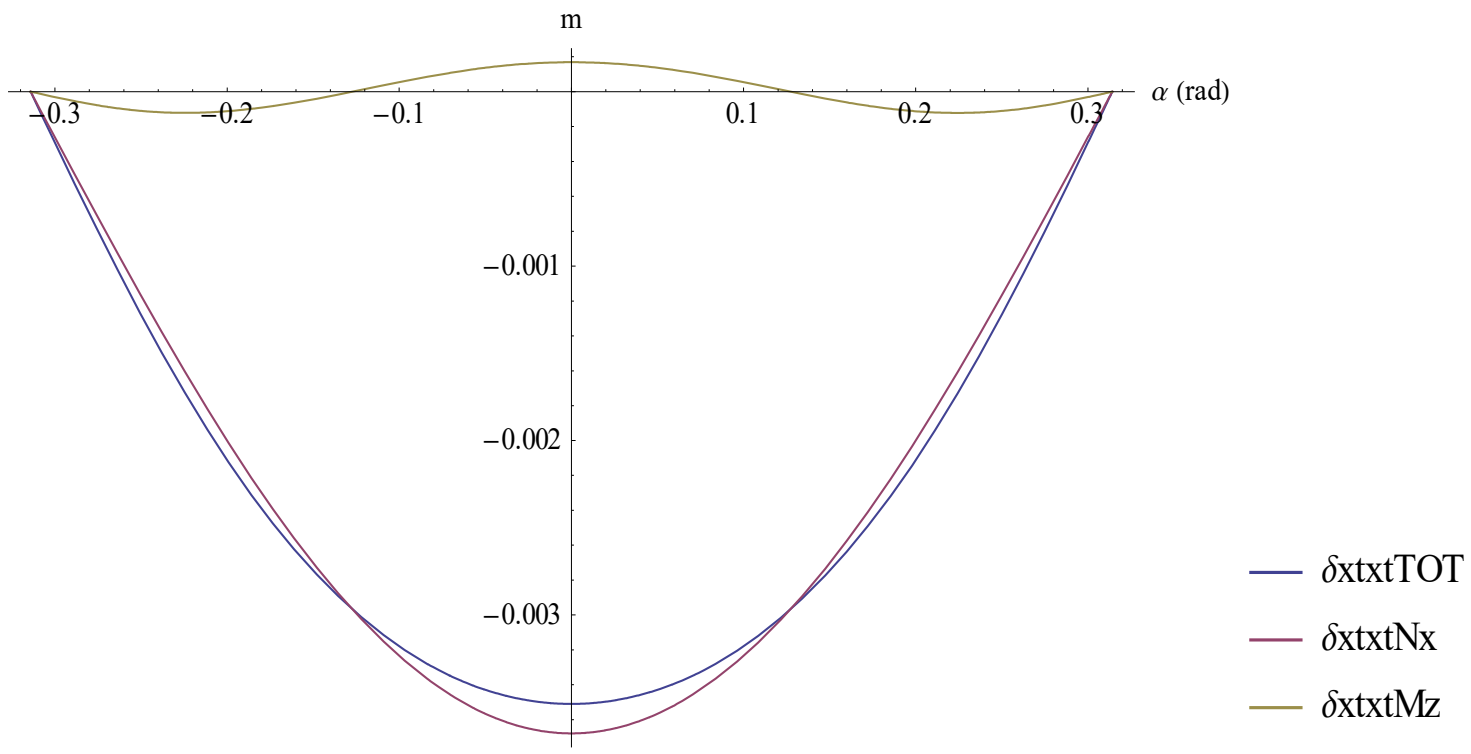


Deformación $(\mathrm{Lt}=280 \mathrm{~m})$

Sección: Tablero 7 (Peatonal)

$\mathrm{Rp} / \mathrm{Rt}=0.9 \alpha \mathrm{t}=\frac{\pi}{5}$

$\{\delta$ xtxtTOT, $\delta$ xtxtNx,$\delta x t x t M z$ )

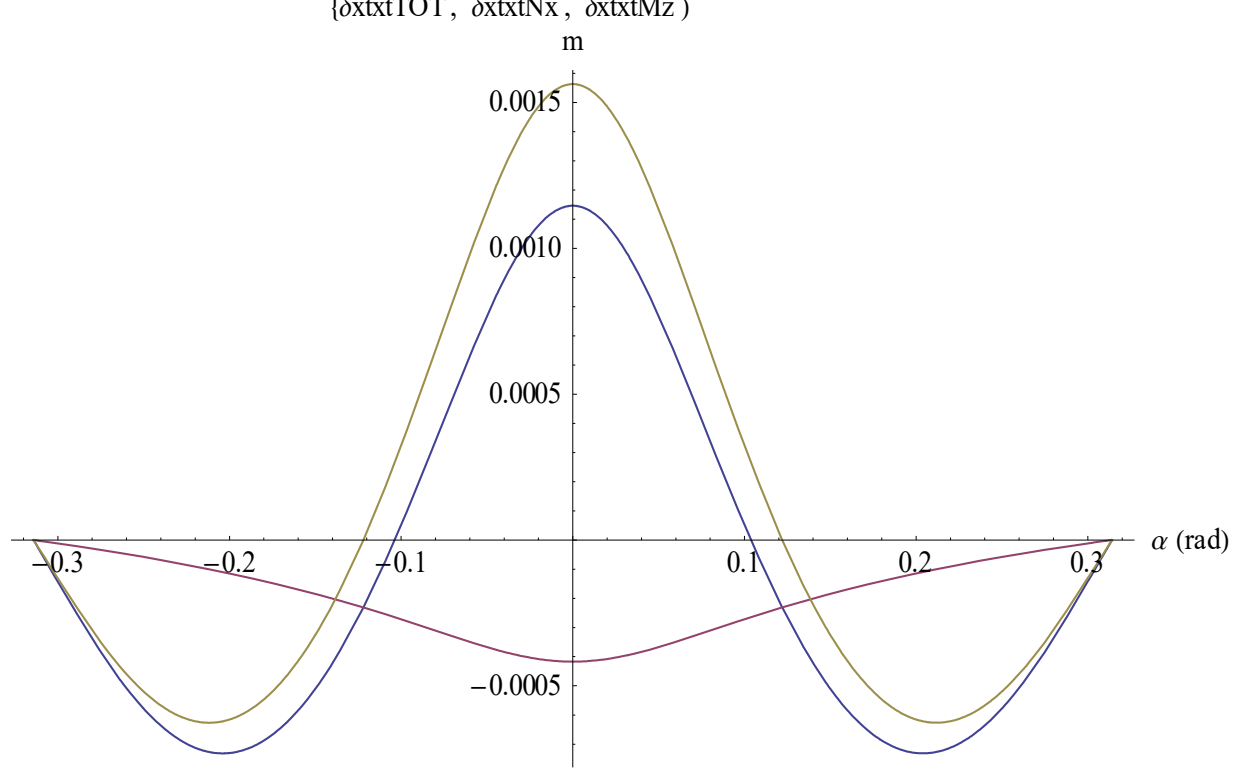

- $\delta$ xtxtTOT

$-\delta \mathrm{xtxtNx}$

- $\delta$ xtxtMz

Deformación $(\mathrm{Lt}=280 \mathrm{~m})$

Sección: Tablero 7 (Peatonal)

$\mathrm{Rp} / \mathrm{Rt}=1.5 \alpha \mathrm{t}=\frac{\pi}{5}$

$\{\delta x t x t T O T, \delta x t x t N x, \delta x t x t M z$ )

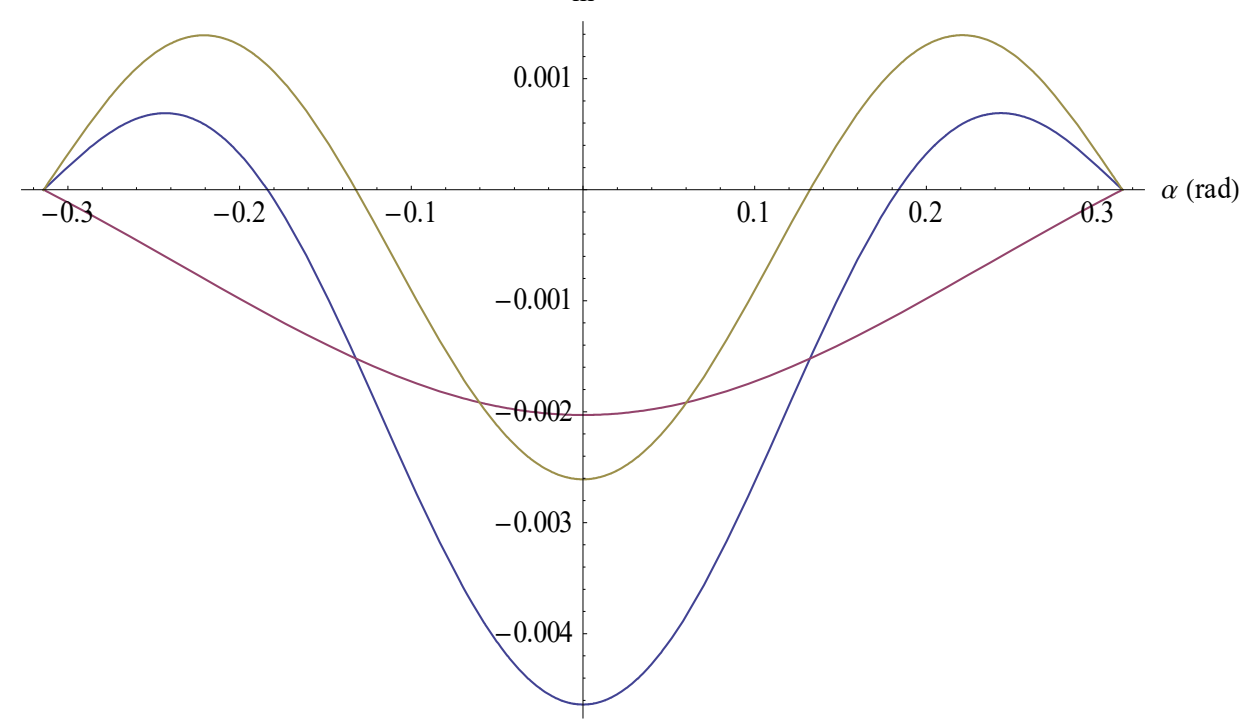

- $\delta$ xtxtTOT

$-\delta \mathrm{xtxtNx}$

- $\delta$ xtxtMz 
Deformación $(\mathrm{Lt}=280 \mathrm{~m})$

Sección : Tablero 7 (Peatonal)

$\{\delta$ xtxtTOTMAX, $\delta$ xtxtTOTMIN, $\delta$ xtxtNxMAX, $\delta$ xtxtMzMAX, $\delta$ xtxtMzMIN $\}$

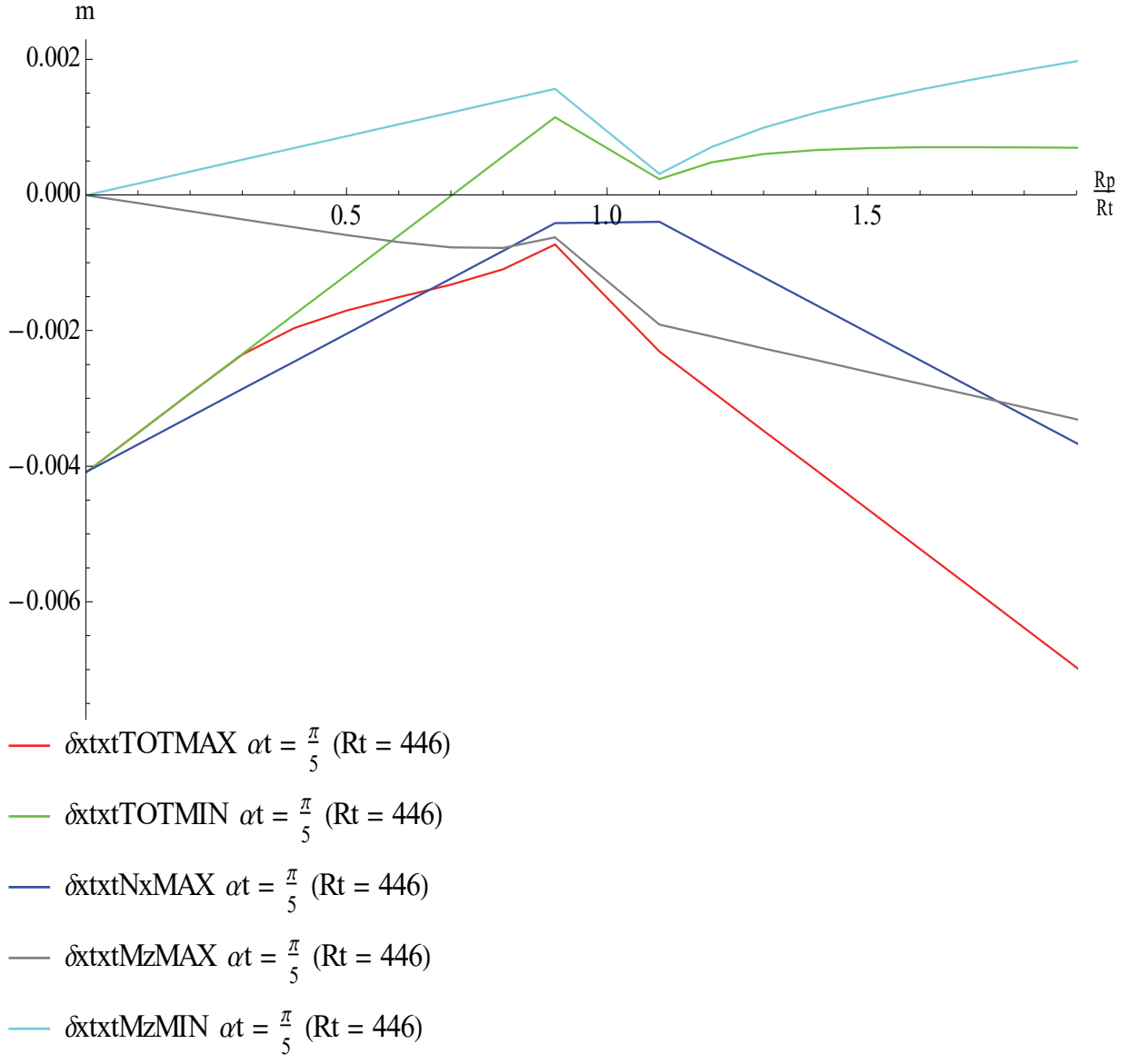

Deformación $(\mathrm{Lt}=280 \mathrm{~m})$

Sección: Tablero 7 (Peatonal)

$\mathrm{Rp} / \mathrm{Rt}=0.1 \quad \alpha \mathrm{t}=\frac{\pi}{2}$

$\{\delta \mathrm{xtxtTOT}, \delta \mathrm{xtxtNx}, \delta \mathrm{xtxtMz})$

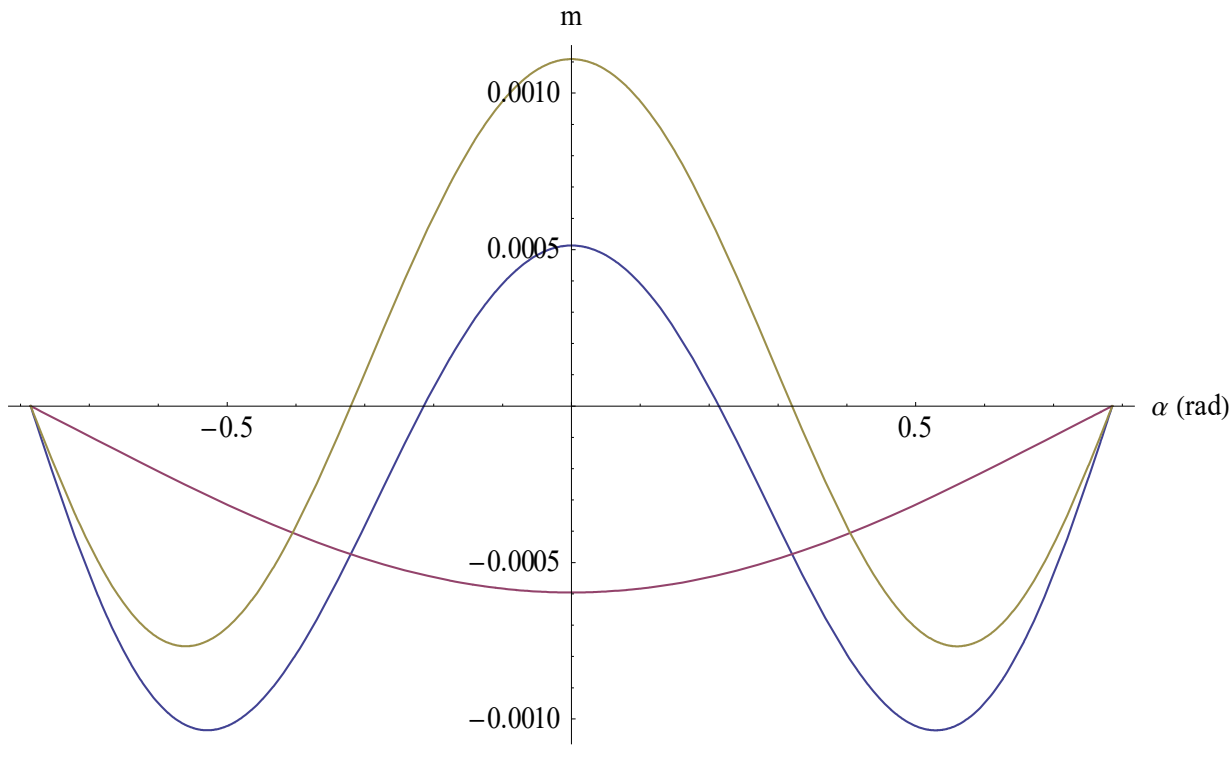

- $\delta$ xtxtTOT

$-\delta \mathrm{xtxtNx}$

- - xtxtMz 
Deformación $(\mathrm{Lt}=280 \mathrm{~m})$

Sección: Tablero 7 (Peatonal)

$\mathrm{Rp} / \mathrm{Rt}=0.9 \alpha \mathrm{t}=\frac{\pi}{2}$

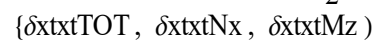

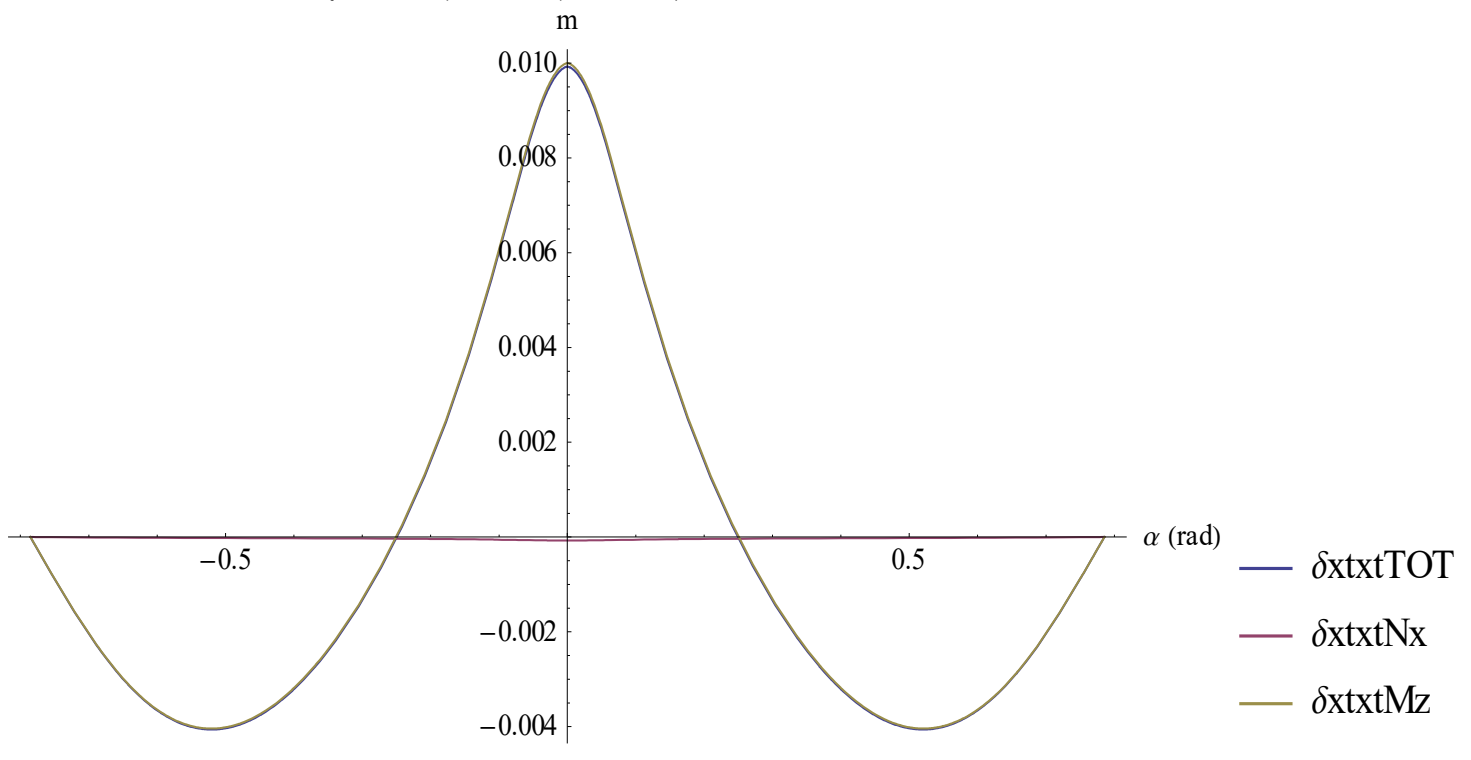

Deformación $(\mathrm{Lt}=280 \mathrm{~m})$

Sección: Tablero 7 (Peatonal)

$\mathrm{Rp} / \mathrm{Rt}=1.5 \alpha \mathrm{t}=\frac{\pi}{2}$

$\{\delta x t x t T O T, \delta x t x t N x, \delta x t x t M z$ )

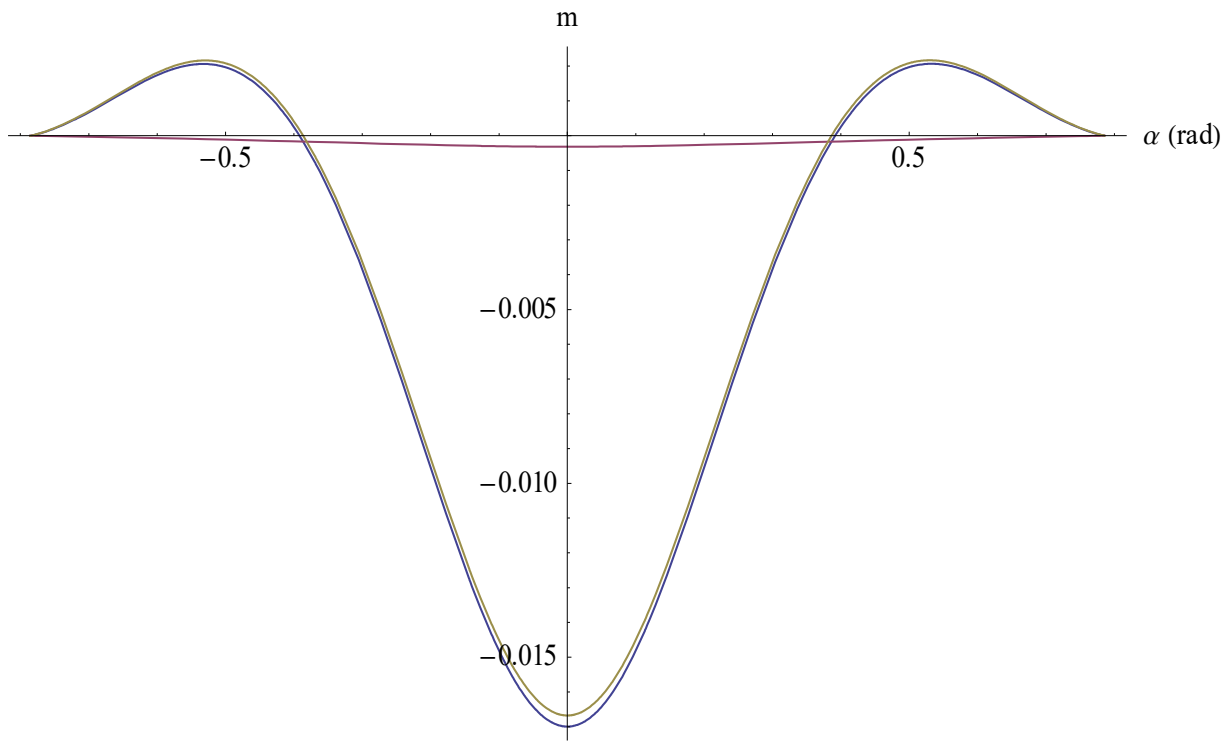

- $\delta$ xtxtTOT

- $\delta \mathrm{xtxtNx}$

$-\delta \mathrm{xtxtMz}$ 
Deformación $(\mathrm{Lt}=280 \mathrm{~m})$

Sección: Tablero7 (Peatonal)

$\{\delta x t x t T O T M A X, \delta x t x t T O T M I N, \delta x t x t N x M A X, \delta x t x t M z M A X, \delta x t x t M z M I N\}$

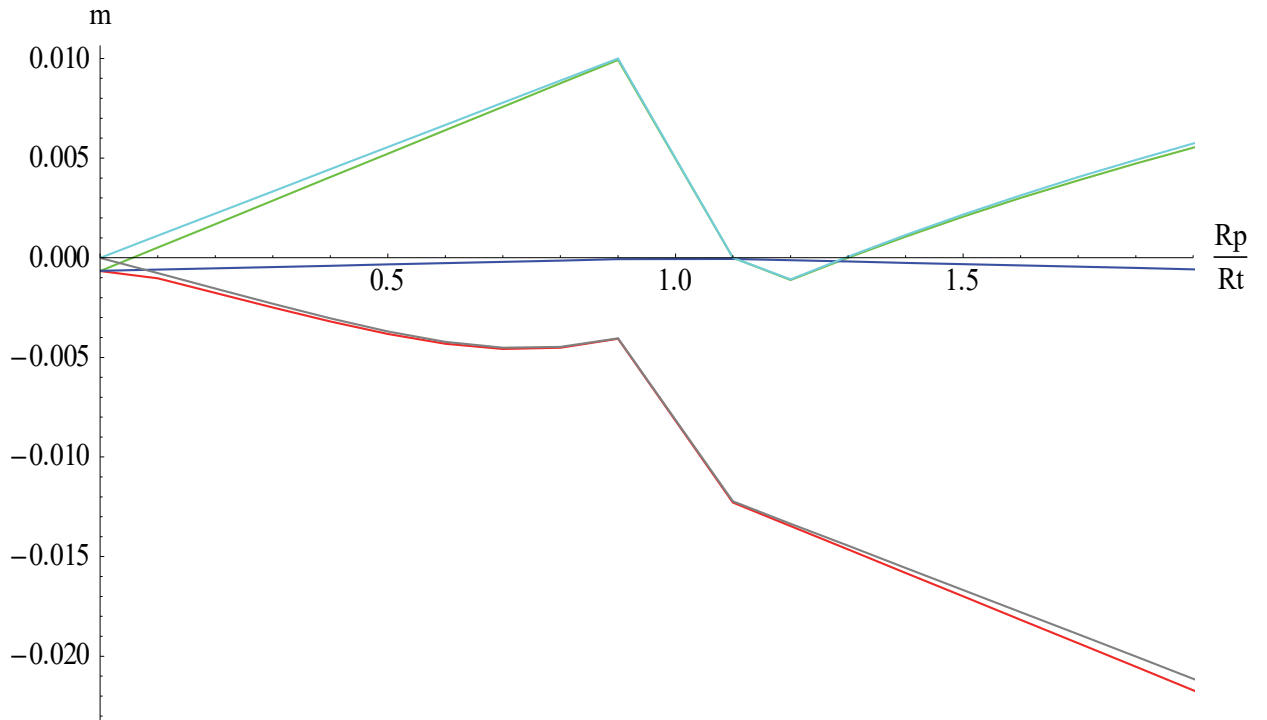

- $\delta$ xtxtTOTMAX $\alpha \mathrm{t}=\frac{\pi}{2}(\mathrm{Rt}=178)$

$-\delta$ xtxtTOTMIN $\alpha \mathrm{t}=\frac{\pi}{2}(\mathrm{Rt}=178)$

$-\delta \mathrm{xtxtNxMAX} \alpha \mathrm{t}=\frac{\pi}{2}(\mathrm{Rt}=178)$

$-\delta \mathrm{xtxtMzMAX} \alpha \mathrm{t}=\frac{\pi}{2}(\mathrm{Rt}=178)$

$-\delta \mathrm{xtxtMzMIN} \alpha \mathrm{t}=\frac{\pi}{2}(\mathrm{Rt}=178)$

Diagrama 2.58. Deformaciones del tablero: Comportamiento "tipo viga" ( $L t=140 \mathrm{~m}, \alpha t=\frac{\pi}{10}$, Tablero 7 (Peatonal)). Comportamiento “mixto" ( $L t=280 m, \alpha t=\frac{2 \pi}{10}$, Tablero 7 (Peatonal)). Comportamiento "tipo arco" $\left(L t=280 m, \alpha t=\frac{\pi}{2}\right.$, Tablero 7 (Peatonal)).

Deformación $(\mathrm{Lt}=280 \mathrm{~m})$

Sección : Tablero 1 (Carretera)

$\mathrm{Rp} / \mathrm{Rt}=0.1 \alpha \mathrm{t}=\frac{\pi}{5}$

$\{\delta$ xtxtTOT, $\delta$ xtxtNx, $\delta$ xtxtMz)

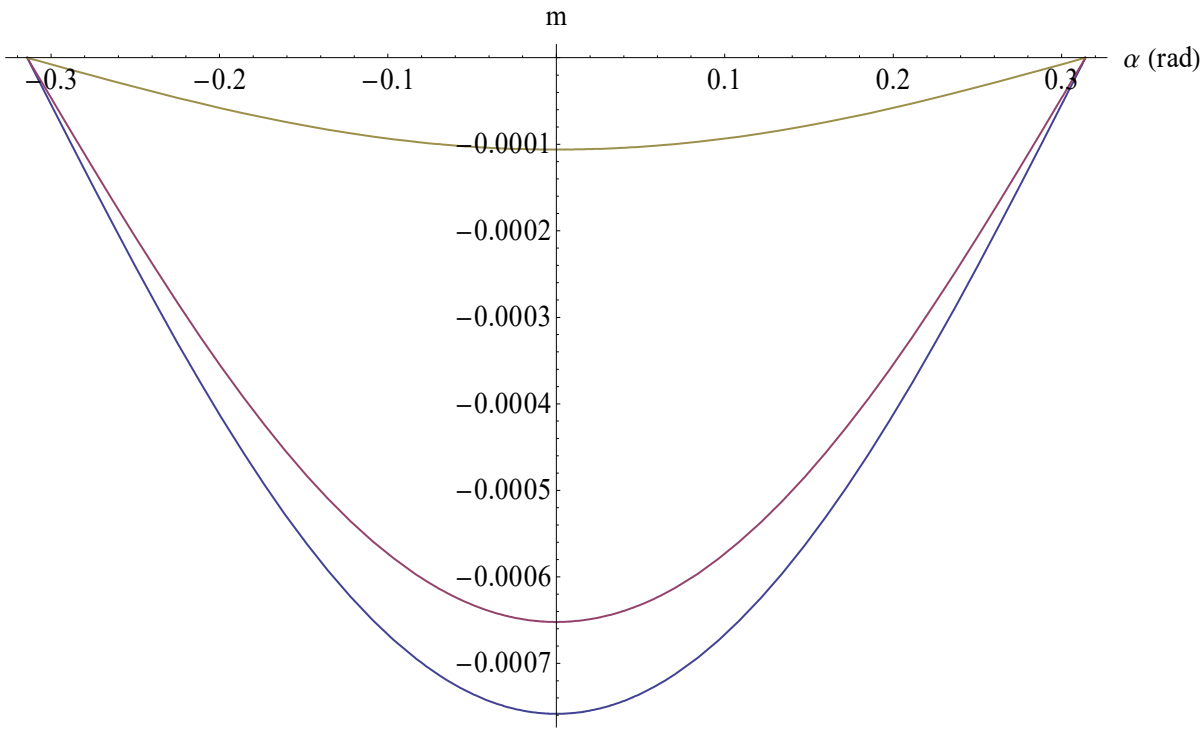

- $\delta$ xtxtTOT

$-\delta \mathrm{xtxtNx}$

$-\delta \mathrm{xtxtMz}$ 
Deformación $(\mathrm{Lt}=280 \mathrm{~m})$

Sección : Tablero 1 (Carretera)

$\mathrm{Rp} / \mathrm{Rt}=0.9 \alpha \mathrm{t}=\frac{\pi}{5}$

$\{\delta \mathrm{xtxtTOT}, \delta \mathrm{xtxtNx}, \delta \mathrm{xtxtMz}\}$

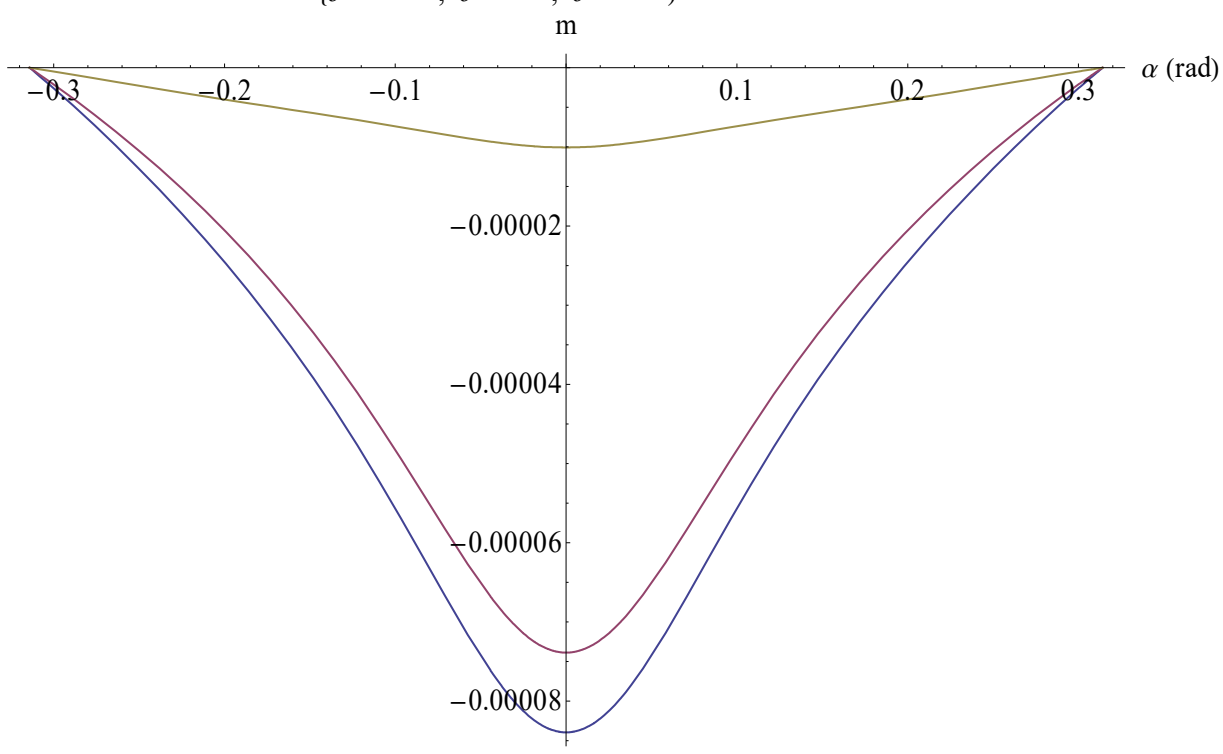

- $\delta$ xtxtTOT

$-\delta \mathrm{xtxtNx}$

$-\delta \mathrm{xtxtMz}$

Deformación $(\mathrm{Lt}=280 \mathrm{~m})$

Sección : Tablero 1 (Carretera)

$\mathrm{Rp} / \mathrm{Rt}=1.5 \alpha \mathrm{t}=\frac{\pi}{5}$

$\{\delta \mathrm{xtxtTOT}, \delta \mathrm{xtxtNx}, \delta \mathrm{xtxtMz}\}$

$\mathrm{m}$

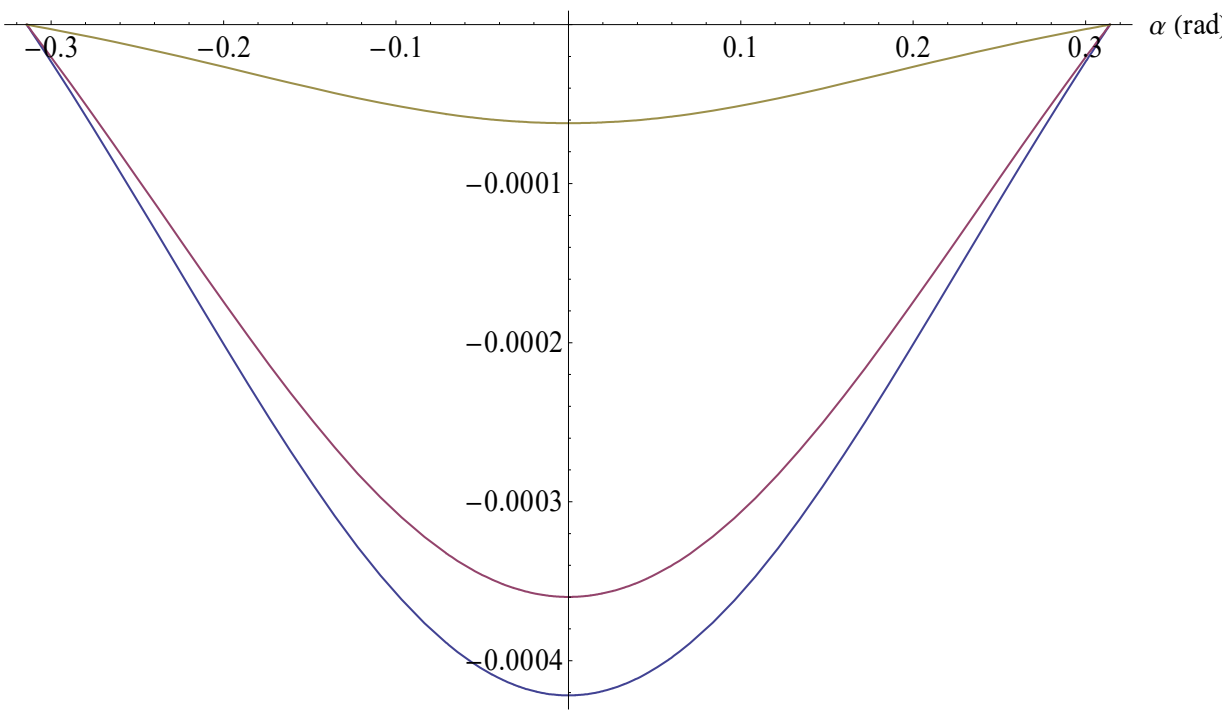

$-\delta$ xtxtTOT

- $\delta \mathrm{xtxtNx}$

$-\delta \mathrm{xtxtMz}$ 
Deformación $(\mathrm{Lt}=280 \mathrm{~m})$

Sección : Tablero 1 (Carretera)

$\{\delta$ xtxtTOTMAX, $\delta$ xtxtTOTMIN, $\delta$ xtxtNxMAX, $\delta$ xtxtMzMAX, $\delta x t x t M z M I N\}$
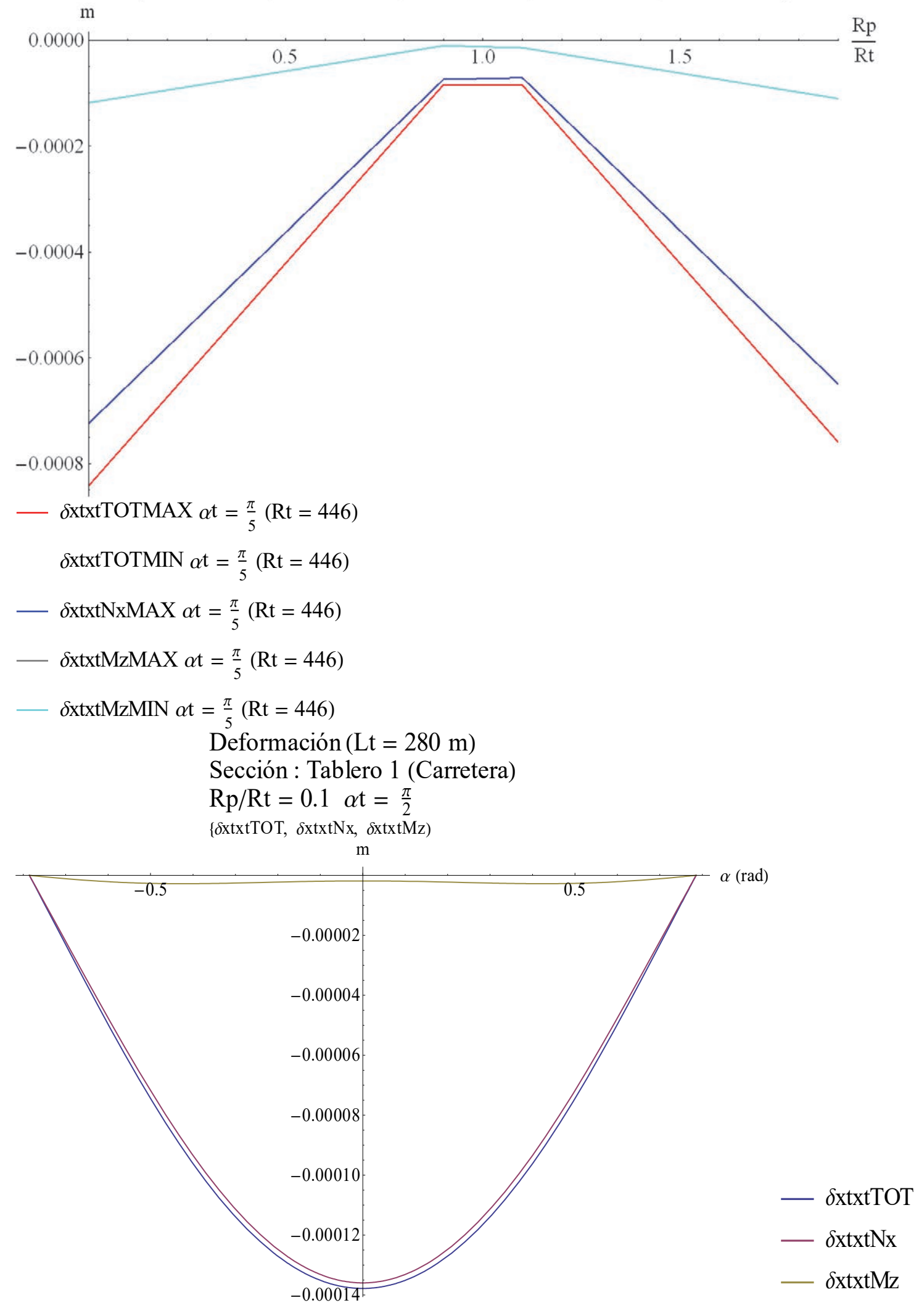
Deformación $(\mathrm{Lt}=280 \mathrm{~m})$

Sección : Tablero 1 (Carretera)

$\mathrm{Rp} / \mathrm{Rt}=0.9 \alpha \mathrm{t}=\frac{\pi}{2}$

$\{\delta \mathrm{xtxtTOT}, \delta \mathrm{xtxtNx}, \delta \mathrm{xtxtMz}\}$

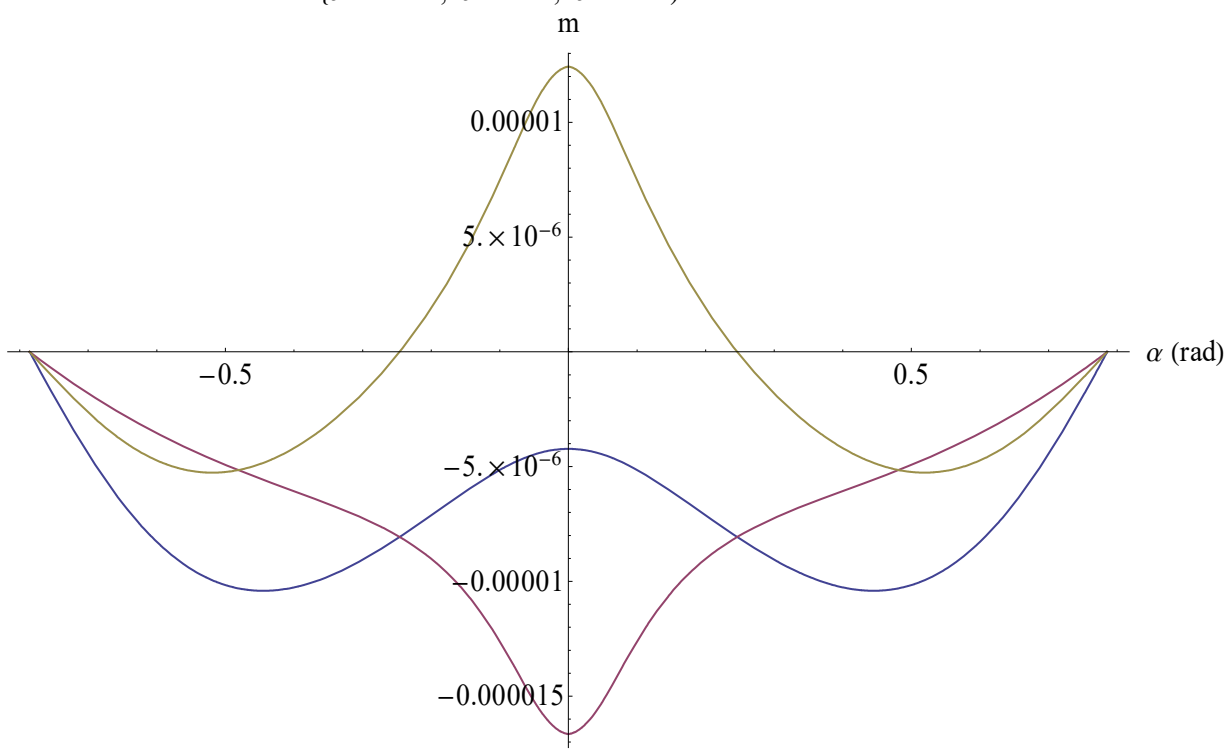

- $\delta$ xtxtTOT

$-\delta \mathrm{xtxtNx}$

- $\delta$ xtxtMz

Deformación $(\mathrm{Lt}=280 \mathrm{~m})$

Sección : Tablero 1 (Carretera)

$\mathrm{Rp} / \mathrm{Rt}=1.5 \alpha \mathrm{t}=\frac{\pi}{2}$

$\{\delta x \operatorname{txtTOT}, \delta x \operatorname{txtNx}, \delta x+x t M z)$

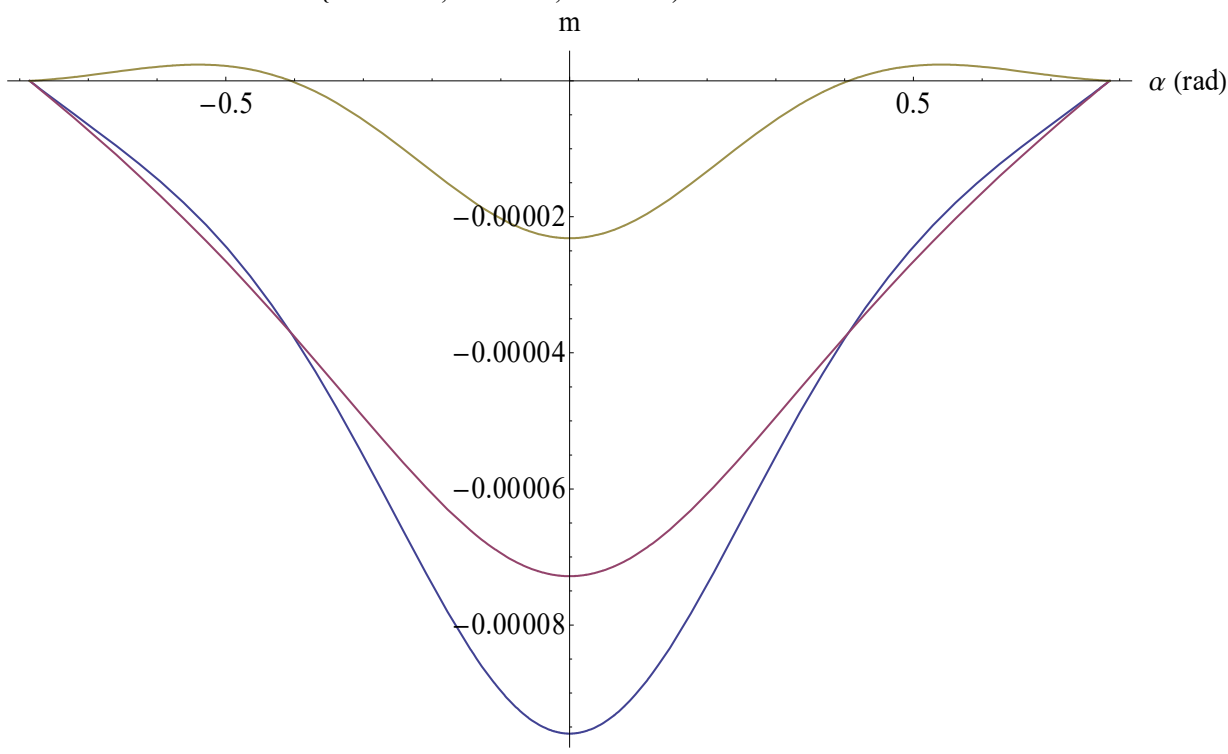

- $\delta$ xtxtTOT

- $\delta$ xtxtNx

- $\delta \mathrm{xtxtMz}$ 
Deformación $(\mathrm{Lt}=280 \mathrm{~m})$

Sección : Tablero 1 (Carretera)

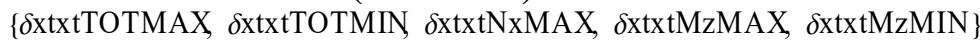

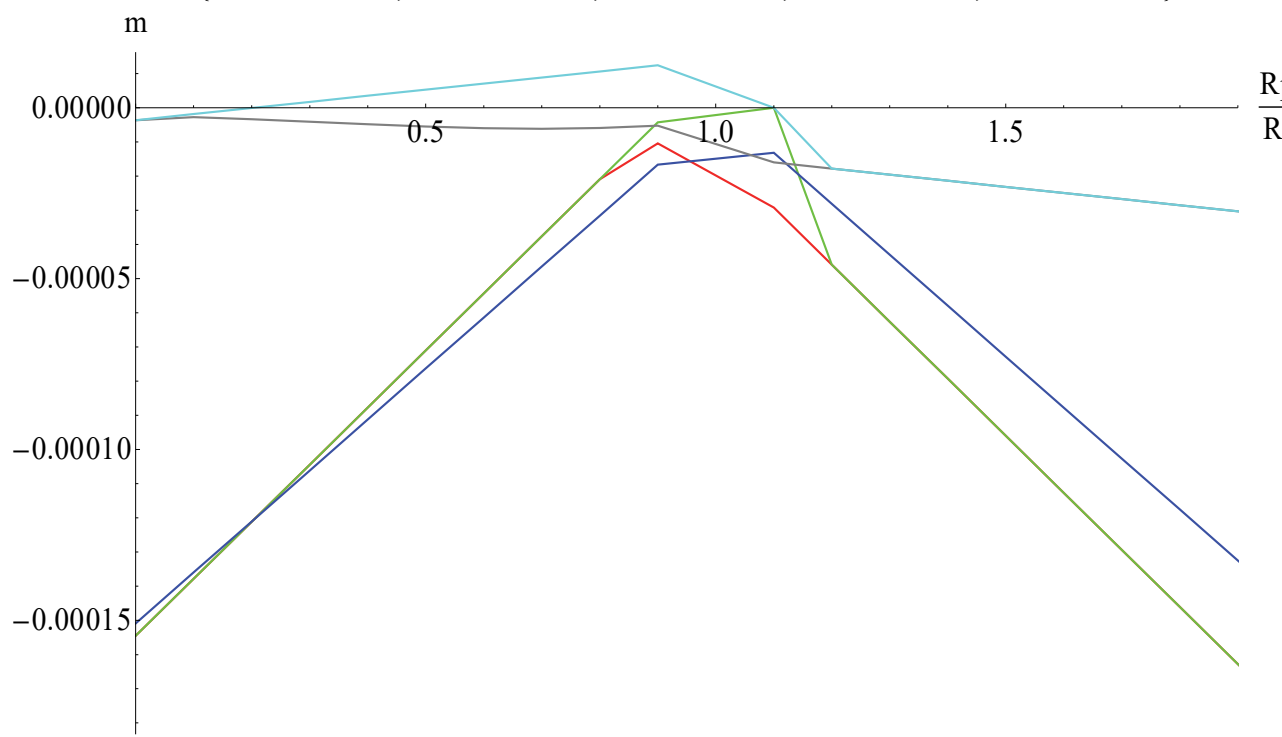

- $\delta$ xtxtTOTMAX $\alpha \mathrm{t}=\frac{\pi}{2}(\mathrm{Rt}=178)$

$-\delta$ xtxtTOTMIN $\alpha \mathrm{t}=\frac{\pi}{2}(\mathrm{Rt}=178)$

$-\delta \mathrm{xtxtNxMAX} \alpha \mathrm{t}=\frac{\pi}{2}(\mathrm{Rt}=178)$

$-\delta x \operatorname{xtMzMAX} \alpha \mathrm{t}=\frac{\pi}{2}(\mathrm{Rt}=178)$

$-\delta x \operatorname{xtMzMIN} \alpha \mathrm{t}=\frac{\pi}{2}(\mathrm{Rt}=178)$

Deformación $(\mathrm{Lt}=280 \mathrm{~m})$

Sección : Tablero 1 (Carretera)

$\mathrm{Rp} / \mathrm{Rt}=0.1 \quad \alpha \mathrm{t}=\frac{4 \pi}{5}$

$\{\delta \mathrm{xtxtTOT}, \delta \mathrm{xtxtNx}, \delta \mathrm{xtxtMz}\}$

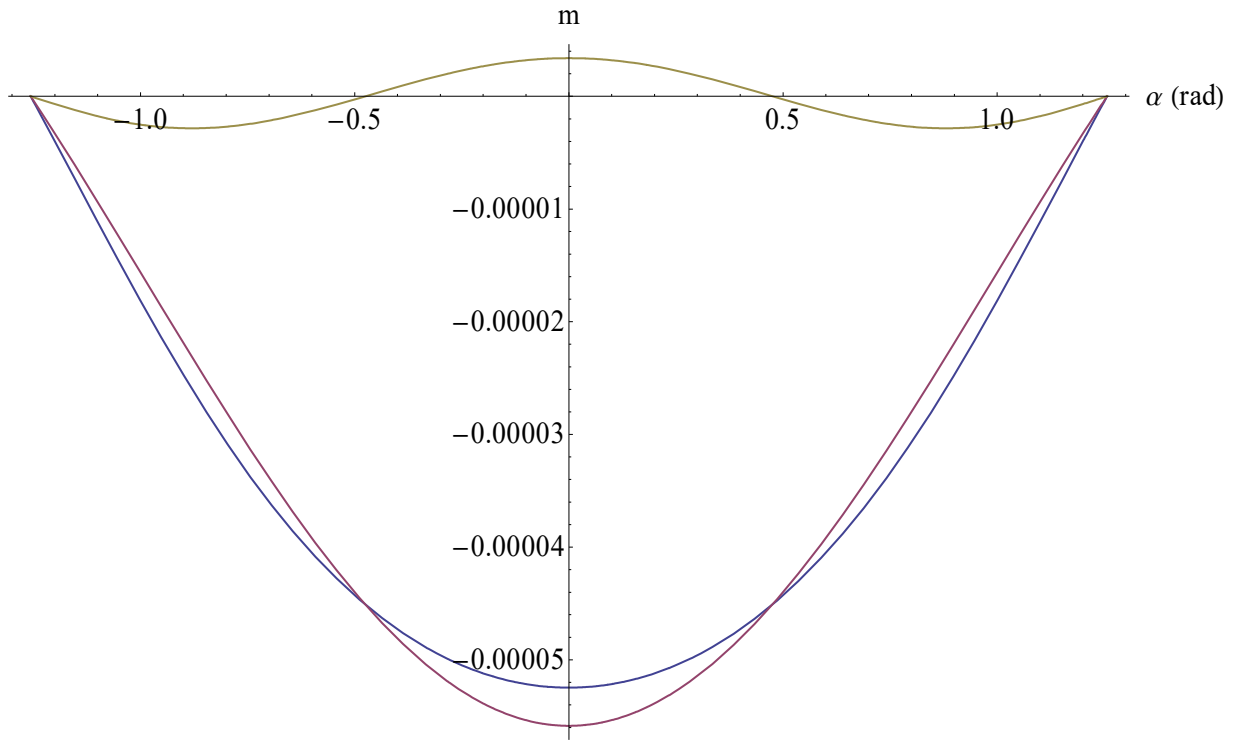

- $\delta$ xtxtTOT

$-\delta \mathrm{xtxtNx}$

- $\delta \mathrm{xtxtMz}$ 
Deformación $(\mathrm{Lt}=280 \mathrm{~m})$

Sección : Tablero 1 (Carretera)

$\mathrm{Rp} / \mathrm{Rt}=0.9 \alpha \mathrm{t}=\frac{4 \pi}{5}$

$\{\delta x t x t T O T, \delta x t x t N x, \delta x t x t M z)$

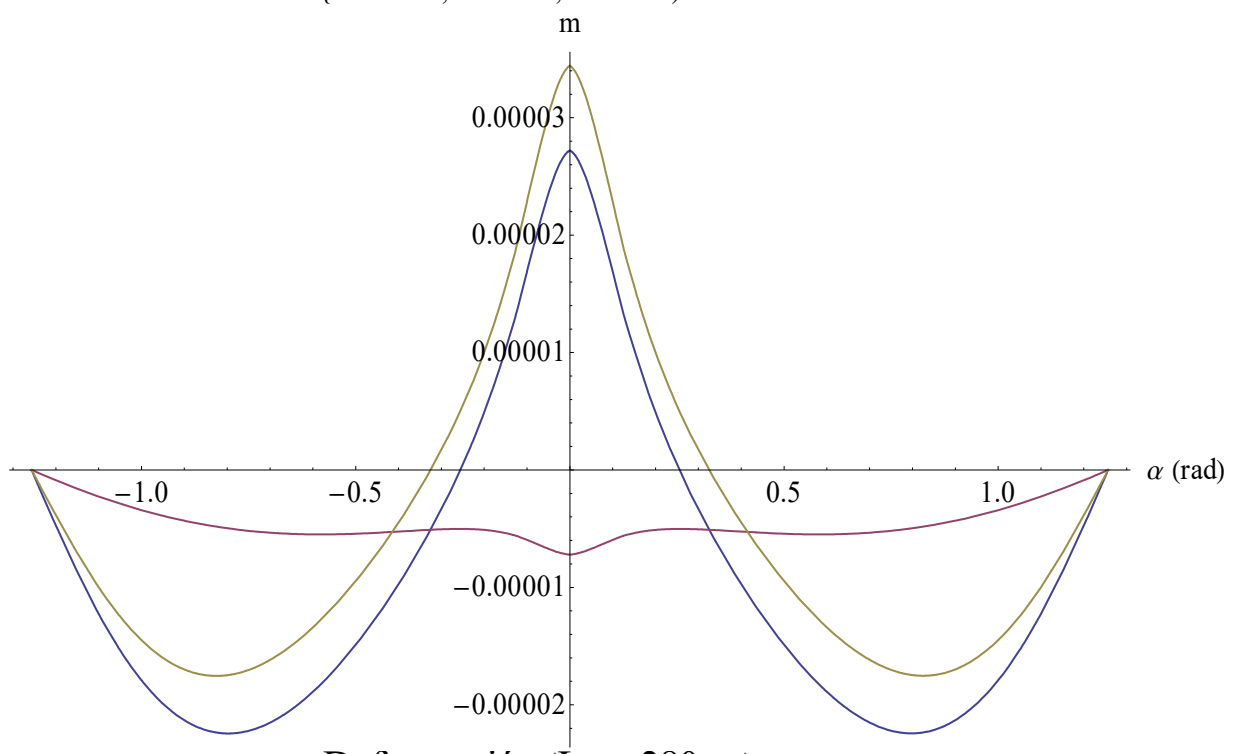

- $\delta$ xtxtTOT

Deformación $(\mathrm{Lt}=280 \mathrm{~m})$

Sección : Tablero 1 (Carretera)

$\mathrm{Rp} / \mathrm{Rt}=1.5 \alpha \mathrm{t}=\frac{4 \pi}{5}$

$\{\delta x t x t T O T, \delta x \operatorname{txtNx}, \delta x t x t M z)$

$\mathrm{m}$

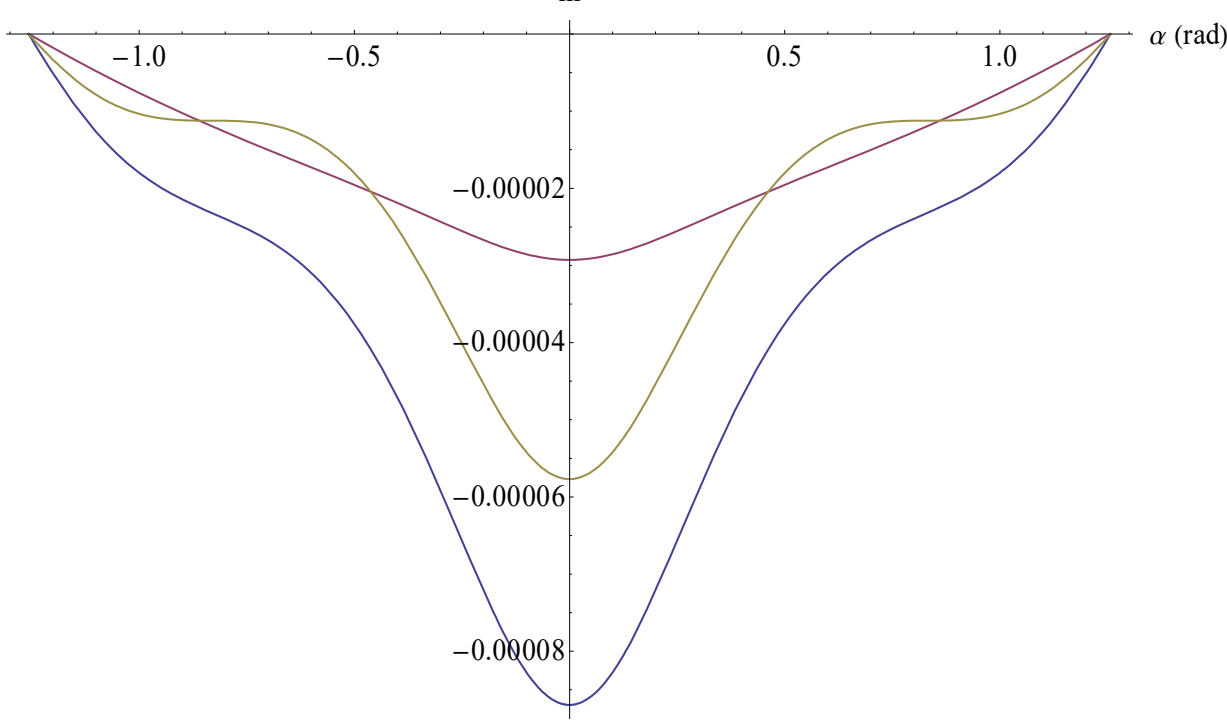

- $\delta$ xtxtTOT

- $\delta \mathrm{xtxtNx}$

- $\delta \mathrm{xtxtMz}$ 
Deformación $(\mathrm{Lt}=280 \mathrm{~m})$

Sección : Tablero 1 (Carretera)

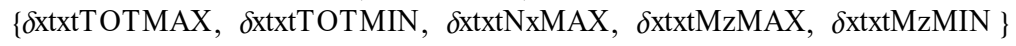

$\mathrm{m}$

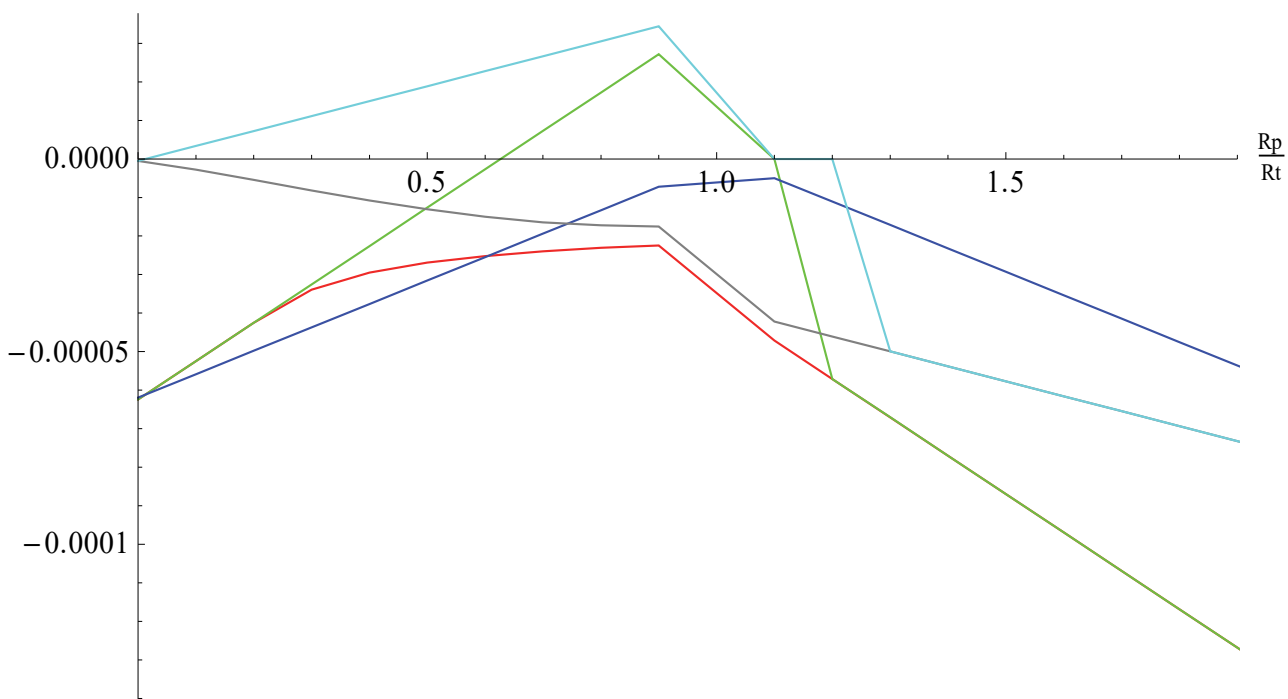

- $\delta \mathrm{xtxtTOTMAX} \alpha \mathrm{t}=\frac{4 \pi}{5}(\mathrm{Rt}=111)$

$-\delta$ xtxtTOTMIN $\alpha \mathrm{t}=\frac{4 \pi}{5}(\mathrm{Rt}=111)$

$-\delta \operatorname{xtxtNxMAX} \alpha \mathrm{t}=\frac{4 \pi}{5}(\mathrm{Rt}=111)$

$-\delta \mathrm{xtxtMzMAX} \alpha \mathrm{t}=\frac{4 \pi}{5}(\mathrm{Rt}=111)$

$-\delta \mathrm{xtxtMzMIN} \alpha \mathrm{t}=\frac{4 \pi}{5}(\mathrm{Rt}=111)$

Diagrama 2.59. Deformaciones del tablero: Comportamiento "tipo viga" ( $\boldsymbol{L} \boldsymbol{t}=\mathbf{2 8 0} \boldsymbol{m}, \boldsymbol{\alpha} \boldsymbol{t}=\frac{\boldsymbol{\pi}}{\mathbf{5}}$, Tablero 1

(Carretera)). Comportamiento "mixto" ( $\boldsymbol{L} \boldsymbol{t}=\mathbf{2 8 0} \boldsymbol{m}, \boldsymbol{\alpha} \boldsymbol{t}=\frac{\pi}{2}$, Tablero 1 (Carretera)). Comportamiento "tipo arco" $\left(\boldsymbol{L t}=\mathbf{2 8 0} \boldsymbol{m}, \boldsymbol{\alpha t}=\frac{4 \pi}{5}\right.$, Tablero 1 (Carretera)).

\subsection{1 Análisis y Conclusiones}

Si atendemos a las solicitaciones y a los diagramas de deformaciones: Diagrama 2.58 y Diagrama 2.59, es evidente que los 3 tipos de comportamiento van a tener sus deformadas dominadas por las siguientes características mecánicas:

- Comportamiento "tipo viga" (Diagrama 2.58 a) y Diagrama 2.59 a)): El funcionamiento "tipo viga", viene dado por una gran rigidez a flexión transversal, frente a las cargas concéntricas (debida a las características mecánicas de la sección y la forma del tablero), en comparación con la rigidez del tablero a axil frente a esas mismas cargas. Como es un sistema hiperestático, esta mayor rigidez provoca que las solicitaciones transversales sean mayores. Si bien, como se ha podido ver hasta ahora, las solicitaciones axiles apenas sufren cambios, sea cual sea el tipo de comportamiento que se de en las solicitaciones transversales. Todo esto lleva a lo que se puede apreciar en los diagramas de deformaciones (Diagrama $2.58 \mathrm{y}$ Diagrama 2.59): 
o Las deformaciones, en tableros con comportamiento "tipo viga", vienen determinadas por la solicitación axil. Siendo la deformación debida al momento transversal pequeña.

o Las solicitaciones transversales (Qy y Mz), de este tipo de comportamiento vienen determinadas por el módulo de la carga que se aplica (a medida que aumenta Rp). Disminuyendo la carga aplicada sobre el tablero, se disminuyen las solicitaciones y con ello las deformaciones del tablero.

- El área del tablero, es la característica mecánica de la sección que va a resultar más determinante a la hora de variar las deformaciones transversales.

- Comportamiento "tipo arco" (Diagrama 2.58 c) Diagrama 2.59 c)): solo se produce cuando $\mathrm{Rp}=0$. Cuando $\mathrm{Rp}=0$, las deformaciones se ven dominadas por la solicitación axil y en consecuencia por el área del tablero. Esto se produce, porque la rigidez a axil frente a la carga concéntrica es dominante frente la rigidez a flexión transversal (Mz). Cuando se incrementa Rp, pasa rápidamente a un comportamiento "tipo esfera":

o Comportamiento "tipo esfera" (Arco): En este comportamiento, las solicitaciones transversales incrementan linealmente a medida que se acerca la pila al tablero $(R p>0)$. Esto provoca que, debido a la naturaleza de las deformaciones por momento flector y la falta de rigidez del sistema frente a estas solicitaciones (es esta falta de rigidez la que provoca el comportamiento "tipo arco", con $\mathrm{Rp}=0$ ), desde valores muy bajos de Rp, la deformación del tablero quede determinada por la inercia del tablero, de eje vertical (Izz). La deformada, al quedar dominada por la solicitación de momento transversal (Mz), copia su forma con 3 extremos:

- Un mínimo (en módulo) en el centro del vano.

- Dos máximos (en módulo) simétricos respecto del centro de vano, cerca de los estribos.

- Comportamiento "mixto" (Diagrama 2.58 b) Diagrama 2.59 b)): Este tipo de comportamiento, parte (en $\mathrm{Rp}=0$ ) de un comportamiento muy similar al "tipo viga", en el que las deformaciones vienen dadas por la solicitación axil (con el área del tablero como característica mecánica determinante). A medida que se acerca la pila al tablero ( $R p>0$ ), se distinguen 2 tipos de comportamientos:

o El primero, se produce cuando se posiciona la pila entre el centro del arco y un mínimo de solicitaciones antes de llegar a al tablero $(0<R p<R t)$. A medida que se acerca la pila al tablero, disminuye tanto el momento flector transversal (Mz) como la solicitación axil y la deformación del tablero. En esta zona, en la que la pila no ha llegado al punto en el que las solicitaciones sobre el tablero se minimizan, la deformación debida la solicitación axil dominará la deformación total del tablero, como ocurría en el comportamiento "tipo viga". Luego el área del tablero resulta la característica determinante.

o Comportamiento "tipo esfera" ("Mixto"): El segundo se produce a partir del mínimo de las solicitaciones. A partir de este punto, el momento transversal ( $\mathrm{Mz}$ ) empieza a incrementarse con los 3 extremos del comportamiento "tipo esfera". La deformación debida al momento transversal, se va haciendo cada vez más importante, hasta volverse más determinante que la deformación 
debida a la solicitación axil. Esto hace que la deformación del tablero pase, poco a poco, de una forma que solo tiene un extremo mínimo en el centro del tablero, a la ya comentada forma compuesta por 3 extremos, propia del comportamiento "tipo esfera".

Se llega a la conclusión, de que aquellos casos en los que el comportamiento del tablero se asemejaba al de una viga, tienen un comportamiento más homogéneo a medida que acercamos la pila al tablero, haciendo $R p>0$, en el que el área es la característica mecánica que nos marca la deformación del tablero. Mientras que el tablero de comportamiento "tipo arco", pasa bruscamente de un comportamiento (tipo arco) en el que la deformada está determinada por el área del tablero, a uno ("tipo esfera") en el que la deformación viene determinada por la inercia de eje vertical (Izz) del tablero. El comportamiento "tipo mixto", pasa por diferentes tipos de comportamiento, empezando como un "tipo viga" hasta un mínimo de solicitaciones en el que su comportamiento pasa a ser "tipo esfera". Teniendo cada tipo de comportamiento una característica que marca la deformación del tablero ("tipo viga", área del tablero, y "tipo esfera”, inercia de eje vertical (Izz)).

También queda claro, fuera de los tipos de comportamiento:

- Solo con ver la deformada del tablero, se puede deducir cual es la solicitación que está dominando la deformación y con ello la característica mecánica de del tablero que resulta determinante.

- Cuanto mayor es el valor del factor $\varphi_{K N x M z}$, más radical se muestra el dominio por parte de una solicitación y con ello la característica mecánica del tablero que resulta determinante.

2.2.6.2.2 Sistema hiperestático, restringiendo el desplazamiento en los 3 ejes de los estribos, carga en el plano del tablero, concéntrica, pila no situada en el centro de la circunferencia del tablero $(\alpha p=\alpha t / 4$ y $\alpha p=\alpha t / 2)$. Sistema de atirantamiento tipo abanico

\subsection{Solicitaciones}

Hay numerosas razones para que la pila no pueda disponerse en el eje de simetría del tablero curvo. Se van a analizar conjuntamente las solicitaciones transversales del tablero para 2 posibles $\alpha p$ donde posicionar la pila (Ilustración 2.10). La asimetría creada, hace disminuir los casos dominados por el sistema resistivo "tipo viga", quedando el sistema resistivo "tipo esfera" como principal.

Se van a analizar, siguiendo la línea de los apartado anteriores, una sección tipo Tablero 1 (Carretera), Diagrama 2.62, y otra tipo Tablero 7 (Peatonal), Diagrama 2.63, bajo las cargas concéntricas con la dirección que se muestra en la llustración 2.12 (donde también se muestra la resultante) y el valor que se muestra en el Diagrama 2.60 . 


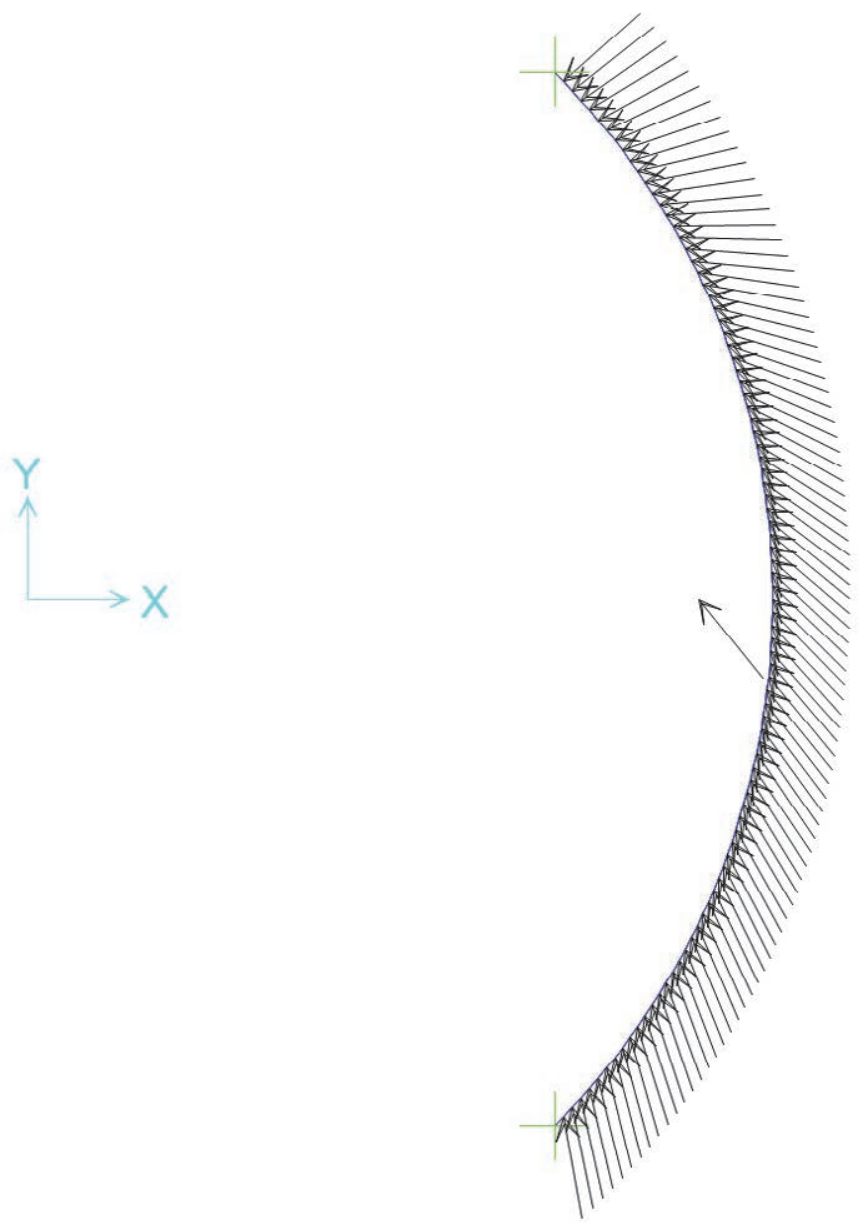

Ilustración 2.12 Dirección de la carga Ttir $[\alpha] . R t=280 m, R p=0.7 R t, \alpha t=\frac{\pi}{2} y \alpha p=\alpha t / 2$.

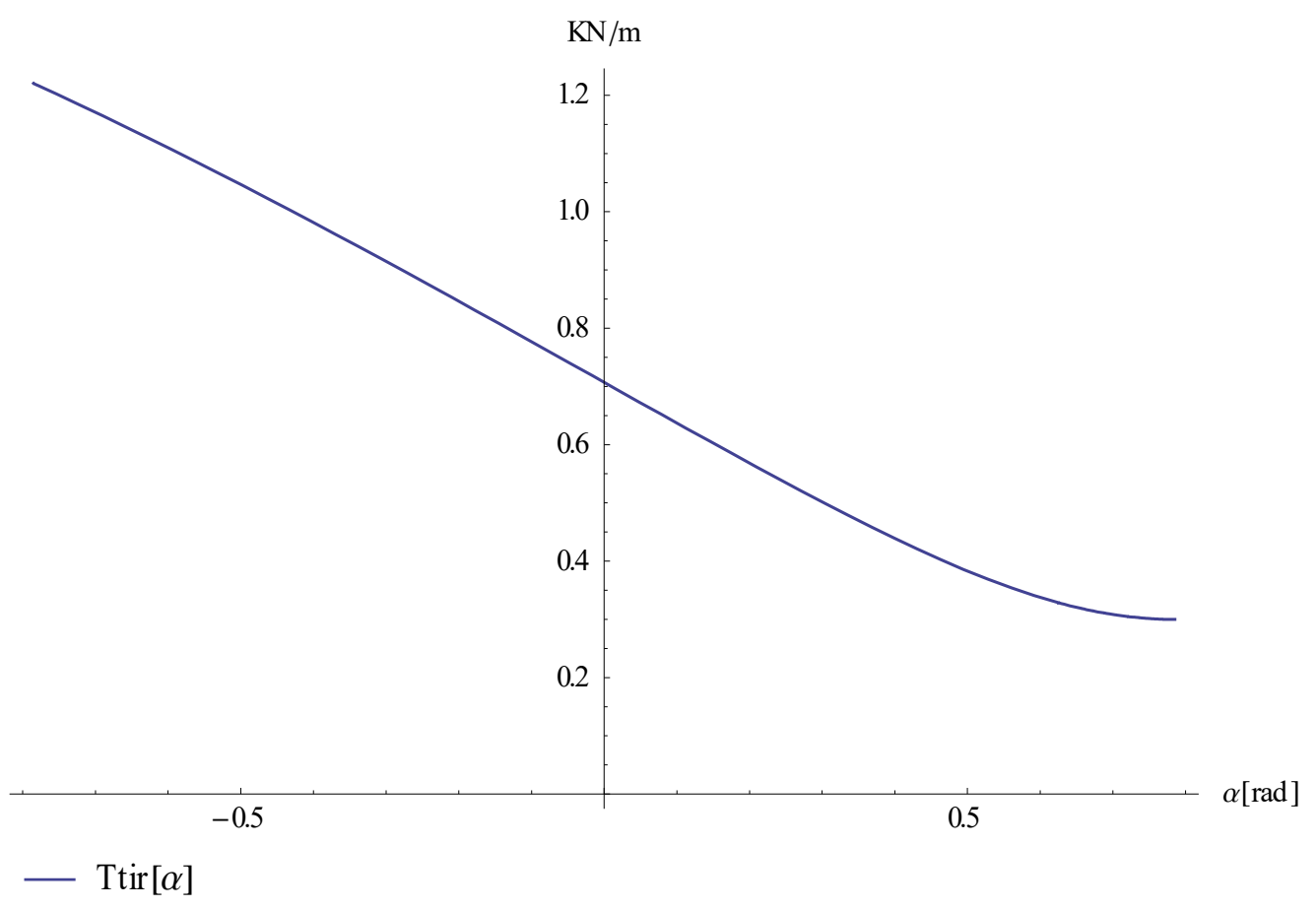

Diagrama 2.60. Valor de la carga $\operatorname{Ttir}[\alpha] . R t=280 \mathrm{~m}, R p=0.7 R t, \alpha t=\frac{\pi}{2} y \alpha p=\alpha t / 2$. 


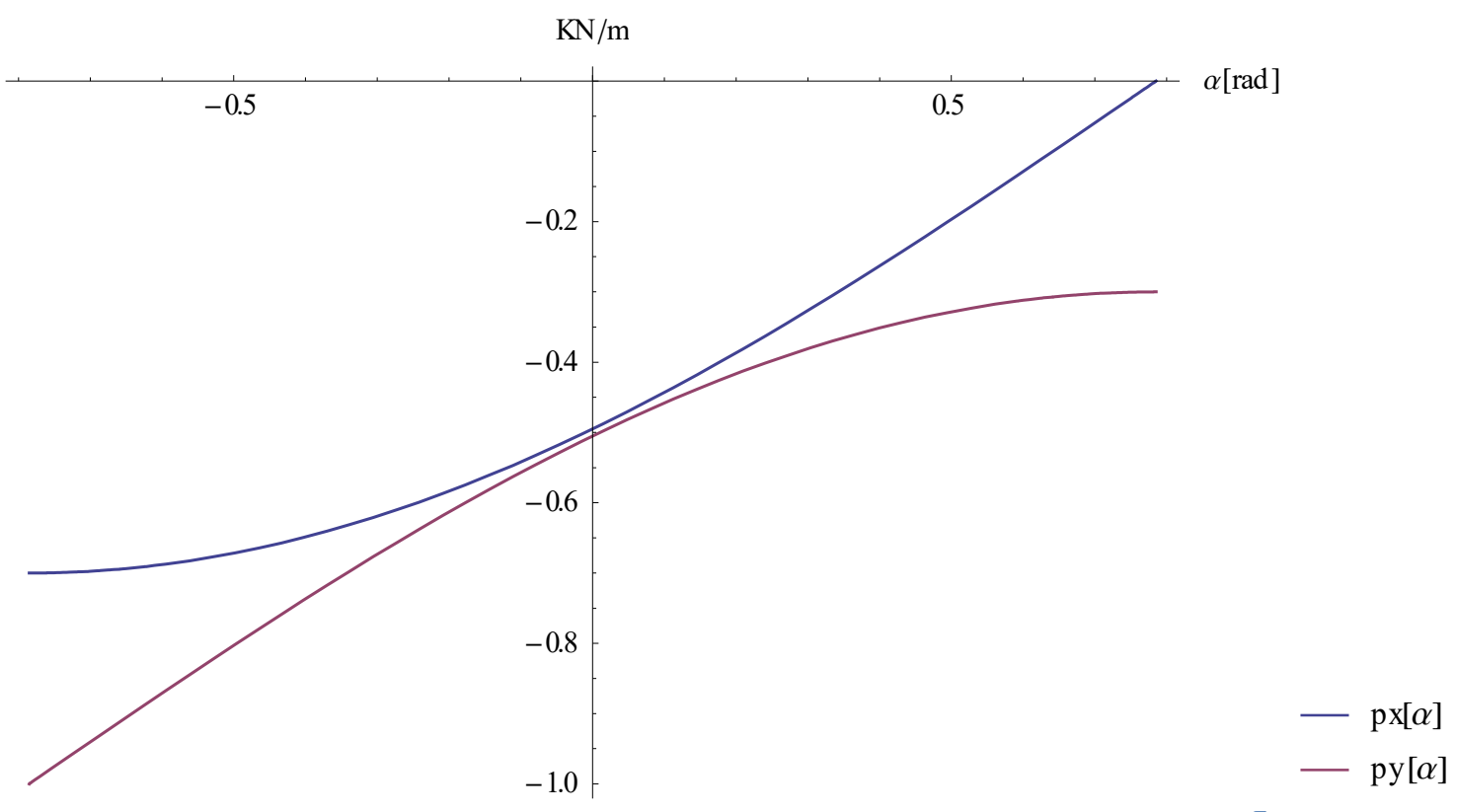

Diagrama 2.61. Valor de la carga según los ejes locales del tablero: $R t=280 \mathrm{~m}, R p=0.7 R t, \alpha t=\frac{\pi}{2}$ y $\alpha p=\alpha t / 2$.

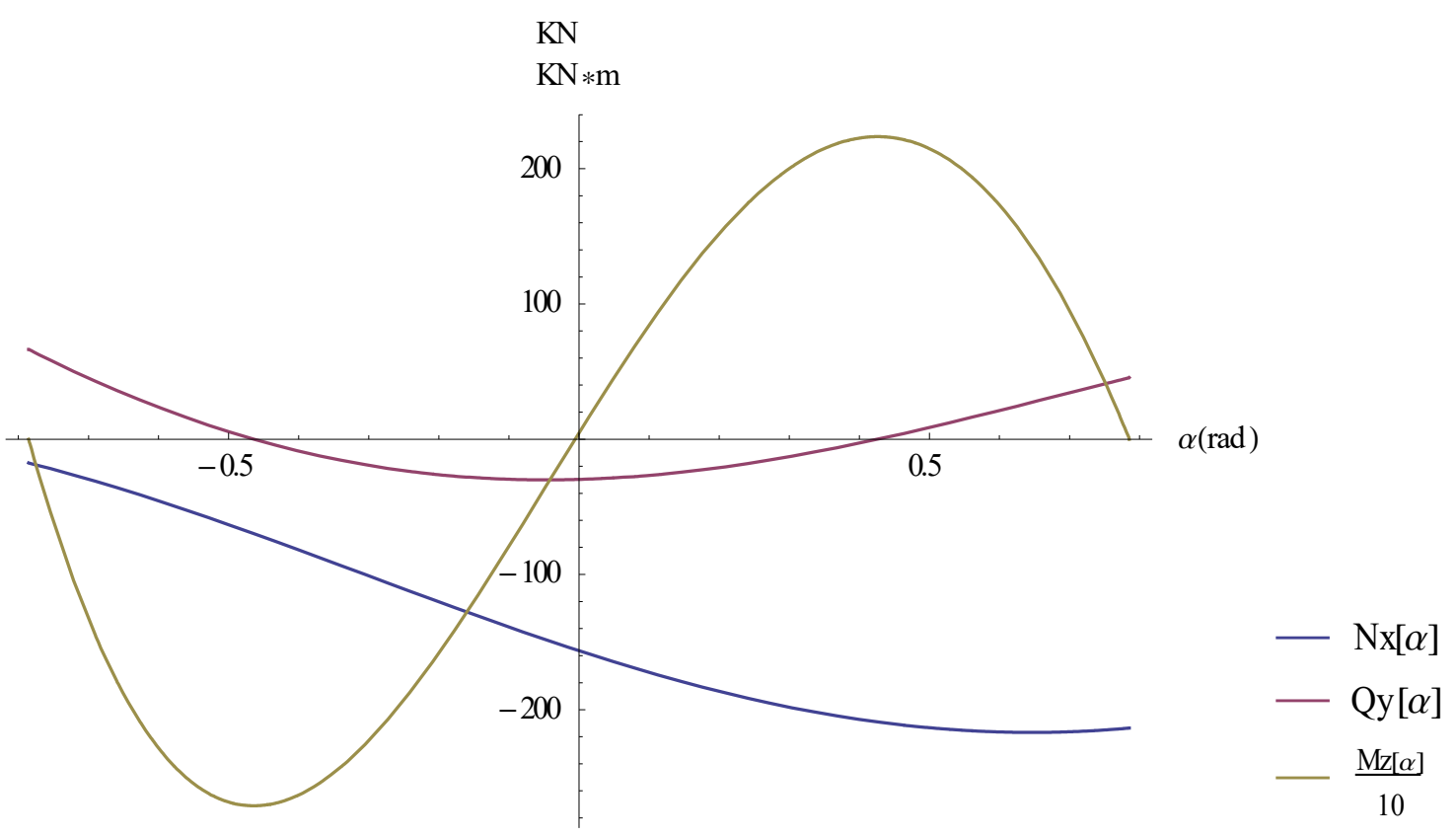

Diagrama 2.62. Solicitaciones sobre el tablero hiperestático bajo una carga concéntrica Ttir $[\alpha]$. Tablero 1 (Carretera), $\varphi_{K N x M z}=42,88 . R t=280 \mathrm{~m}, R p=0.7 R t, \alpha t=\frac{\pi}{2} y \alpha p=\alpha t / 2$. 


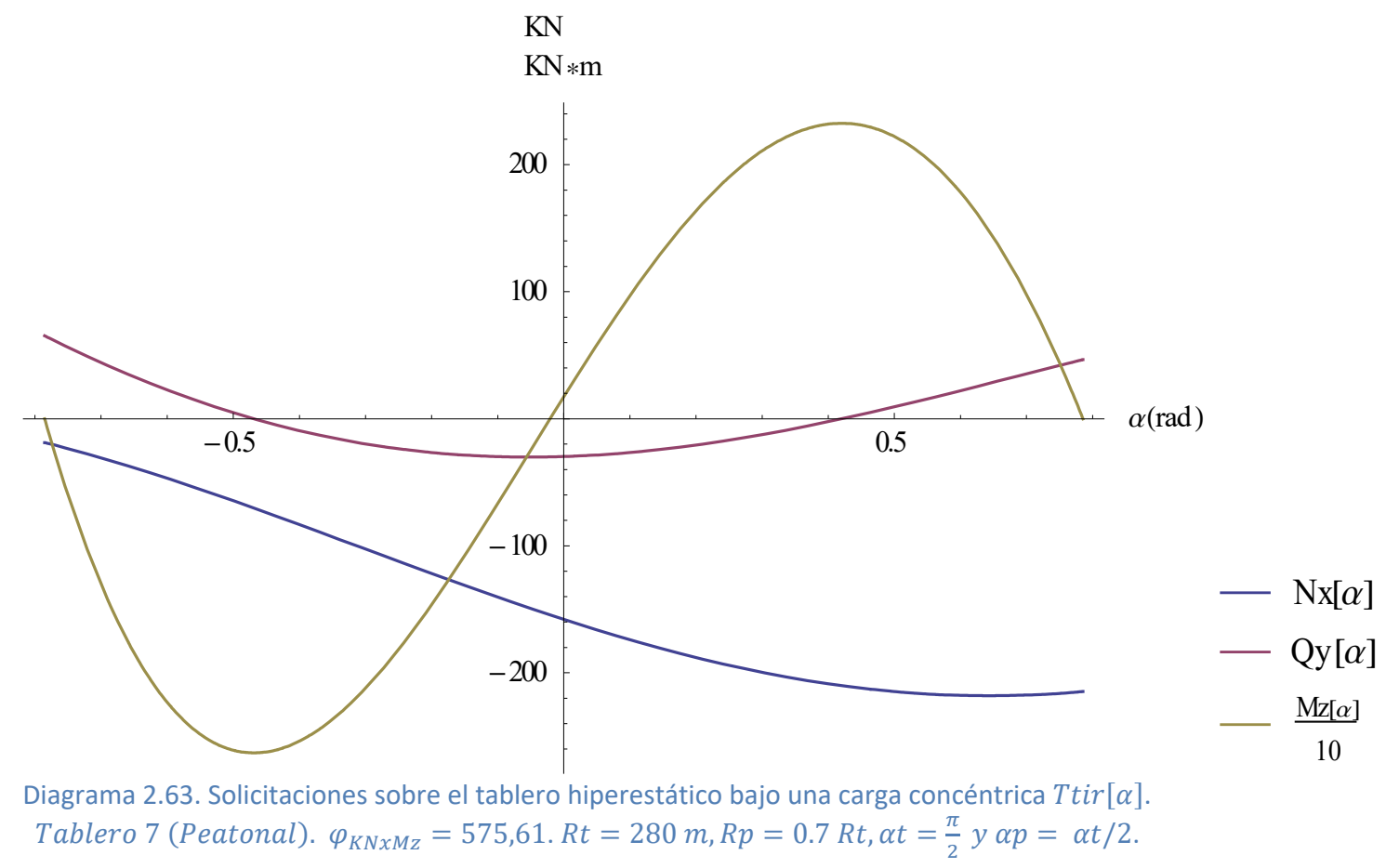

La primera conclusión que se puede extraer es que la rigidez del tablero, de nuevo, apenas tiene influencia sobre las solicitaciones a lo largo del tablero. Esto confirma que el tablero tiene un comportamiento que se asemeja en cierta manera al "tipo esfera", pero sin simetría respecto del eje de ordenadas. Si se comparan los diagramas de solicitaciones (Diagrama 2.63 y Diagrama 2.64), con los obtenidos para el sistema con $\alpha p=0$ y comportamiento "tipo esfera" (Diagrama 2.53 y Diagrama 2.54), se puede apreciar el gran parecido existente (entre uno y la mitad del otro).

Para el análisis de las reacciones en los estribos, es muy interesante observar la posición y sobre todo la dirección de la resultante de las fuerzas aplicadas, Ilustración 2.12. Como se puede apreciar, la resultante se va a seguir situando en el eje de simetría ( $Y=0$, porque las acciones Fpx van a depender solo de la posición en $x$ de la pila), y va a ir cambiando su posición a lo largo del eje $X$ a medida que se desplace la pila. Su vector siempre va a pasar por el punto que ocupa la pila en planta. Como se puede observar en los diagramas de cargas (Diagrama 2.62 y Diagrama 2.63), la reacción en el estribo más próximo a la pila es notablemente mayor que en el estribo más alejado. Analizando la dirección y posición de la resultante, se observa como por un lado la distancia perpendicular a su vector es mucho menor al estribo más cercano, así como su dirección queda casi alineada con la resultante Axil (estos 2 factores están relacionados). Esto hace que el apoyo sobre el estribo más cercano a la pila sea más rígido, atrayendo más carga que el opuesto.

Para el análisis de las solicitaciones, se separa el tablero por el eje $\mathrm{X}$ en 2 partes (La mitad más cercana a la pila se va a denominar "zona positiva", por su ángulo, y la mitad más alejada de la pila se va a denominar "zona negativa").

La gran reacción axil en el estribo cercano a la pila (estribo de la "zona positiva"), provoca un axil muy elevado en la "zona positiva", que permanece relativamente estable. Este elevado axil, con la ayuda de la curvatura del tablero, domina el cortante transversal y con ello 
el momento transversal. A este dominio del cortante (Qy) por parte del axil ( $\mathrm{Nx}$ ), ayuda una carga transversal $p y[\alpha]$ menor que en la "zona negativa".

El axil ( $\mathrm{Nx}$ ) disminuye con una pendiente pronunciada a medida que nos metemos en la "zona negativa", a su vez la carga transversal incrementa $p y[\alpha]$ debido a la lejanía de la pila. Este doble efecto provoca que el cortante transversal (Qy) pase a estar dominado por la carga transversal, $p y[\alpha]$, cambiando el signo de su pendiente, generando un mínimo.

A medida que se disminuye el ángulo desarrollado por el tablero, si se mantiene el radio donde disponemos la pila (Rp), la resultante se inclina incrementando su componente en el eje $\mathrm{X}$ (como muestra el Diagrama 2.69, para $R p<R t$ ). Esto provoca que las cargas tangenciales y la diferencia entre las reacciones en los 2 estribos disminuyan. Todo esto conlleva que el cortante quede dominado por la carga transversal $p y[\alpha]$ (que no varía al cambiar el ángulo por unidad de ángulo) a lo largo de todo el tablero, asimilando el comportamiento al de una viga recta solicitada a una carga transversal variable.

Para mostrar el comportamiento descrito, manteniendo una coherencia con el subapartado 2.2.6.2.1 (donde se mantenía $\alpha p=0$ ), se va a realizar un estudio similar, analizando 3 ángulos representativos, $\alpha t: \frac{\pi}{5}, \frac{\pi}{2}, \frac{4 \pi}{5}$ y los radios de tablero Rt: $180 \mathrm{~m}, 280 \mathrm{~m}, 380$ $\mathrm{m}, 480 \mathrm{~m}$ y $580 \mathrm{~m}$. De cara a verificar el efecto de la curvatura. Para poder comparar las solicitaciones con diferente longitud de tablero, se dividen las solicitaciones de la siguiente manera: $\frac{Q y}{L t}, \frac{M z}{L t^{2}} y \frac{N x}{L t}$. Por otro lado, se han analizado 2 tipologías de tablero: Tablero 7 (Peatonal) y Tablero 1 (Carretera) (Tabla 2.18). A su vez, se van a estudiar 2 ángulos diferentes para la disposición de la pila, $\alpha p: \frac{\alpha t}{2} y \frac{\alpha t}{4}$. Para este caso, los valores representativos de las solicitaciones van a ser: 
QyEp $\rightarrow$ Valor del cortante en el estribo positivo.

QyEn $\rightarrow$ Valor del cortante en el estribo negativo.

QyMI $\rightarrow$ Valor del cortante máximo.

$N x E p \rightarrow$ Valor del axil en el estribo positivo.

$N x E n \rightarrow$ Valor del axil en el estribo negativo.

$N x M I \rightarrow$ Valor del axil máximo.

MzMax $\rightarrow$ Extremo del momento en la "zona positiva".

MzMin $\rightarrow$ Extremo del momento en la "zona negativa".

Tablero7 (Peatonal)

$\alpha \mathrm{t}=\frac{\pi}{5} \quad \alpha p=\frac{\alpha t}{2}$

QyEp/Lt

QyEn/Lt

QyEn/Lt

— $\frac{\mathrm{QyEp}}{\mathrm{Lt}} \mathrm{Rt}=80 \quad \ldots \frac{\mathrm{QyEn}}{\mathrm{Lt}} \mathrm{Rt}=480$

$\frac{\mathrm{KN}}{\mathrm{m}}$

— $\frac{\mathrm{QyEp}}{\mathrm{Lt}} \mathrm{Rt}=180 \quad \ldots \frac{\mathrm{QyEn}}{\mathrm{Lt}} \mathrm{Rt}=580$

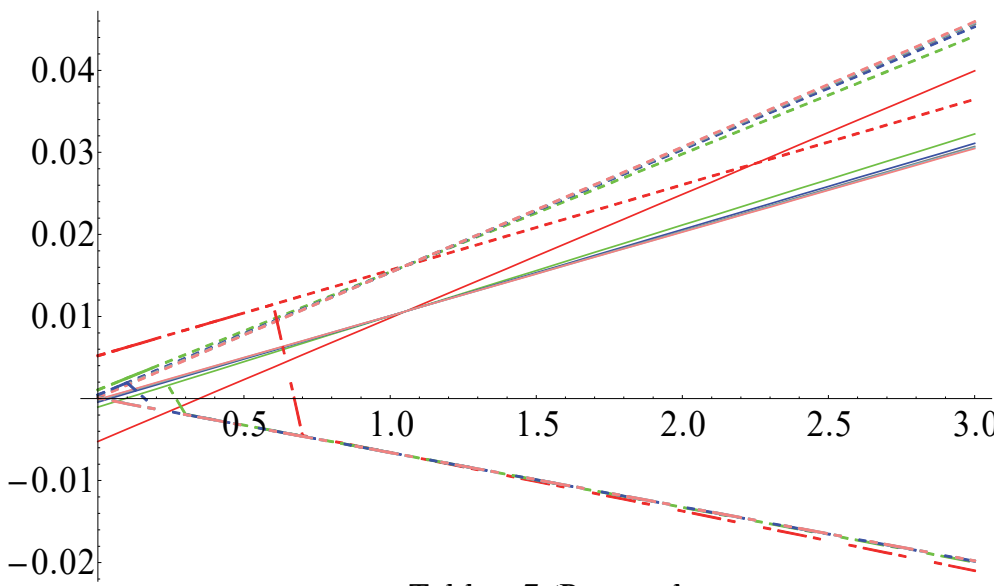

- $\frac{\mathrm{QyEp}}{\mathrm{Lt}} \mathrm{Rt}=280 \quad--\frac{\mathrm{Q} \mathrm{yMI}}{\mathrm{Lt}} \mathrm{Rt}=80$

$-\frac{\mathrm{QyEp}}{\mathrm{Lt}} \mathrm{Rt}=380 \quad--\frac{\mathrm{QyMI}}{\mathrm{Lt}} \mathrm{Rt}=180$

- $\frac{\mathrm{QyEp}}{\mathrm{Lt}} \mathrm{Rt}=480 \quad-\quad-\frac{\mathrm{QyMI}}{\mathrm{Lt}} \mathrm{Rt}=280$

- $\frac{\text { QyEp }}{\mathrm{Lt}} \mathrm{Rt}=580 \quad-\frac{\mathrm{QyMI}}{\mathrm{Lt}} \mathrm{Rt}=380$

$--\frac{\mathrm{QyEn}}{\mathrm{Lt}} \mathrm{Rt}=80 \quad--\frac{\mathrm{QyMI}}{\mathrm{Lt}} \mathrm{Rt}=480$

$\frac{\mathrm{Rp}}{\mathrm{Rt}}=-\frac{\mathrm{QyEn}}{\mathrm{Lt}} \mathrm{Rt}=180 \quad--\frac{\mathrm{QyMI}}{\mathrm{Lt}} \mathrm{Rt}=580$

Tablero7 (Peatonal)

$\alpha \mathrm{t}=\frac{\pi}{5} \quad \alpha \mathrm{p}=\frac{\alpha \mathrm{t}}{2}$

$\mathrm{MzMax} / \mathrm{Lt}^{2}$

$\mathrm{MzMin} / \mathrm{Lt}^{2}$

-.. $\frac{\mathrm{QyEn}}{\mathrm{Lt}} \mathrm{Rt}=280$

-.. $\frac{\mathrm{QyEn}}{\mathrm{Lt}} \mathrm{Rt}=380$

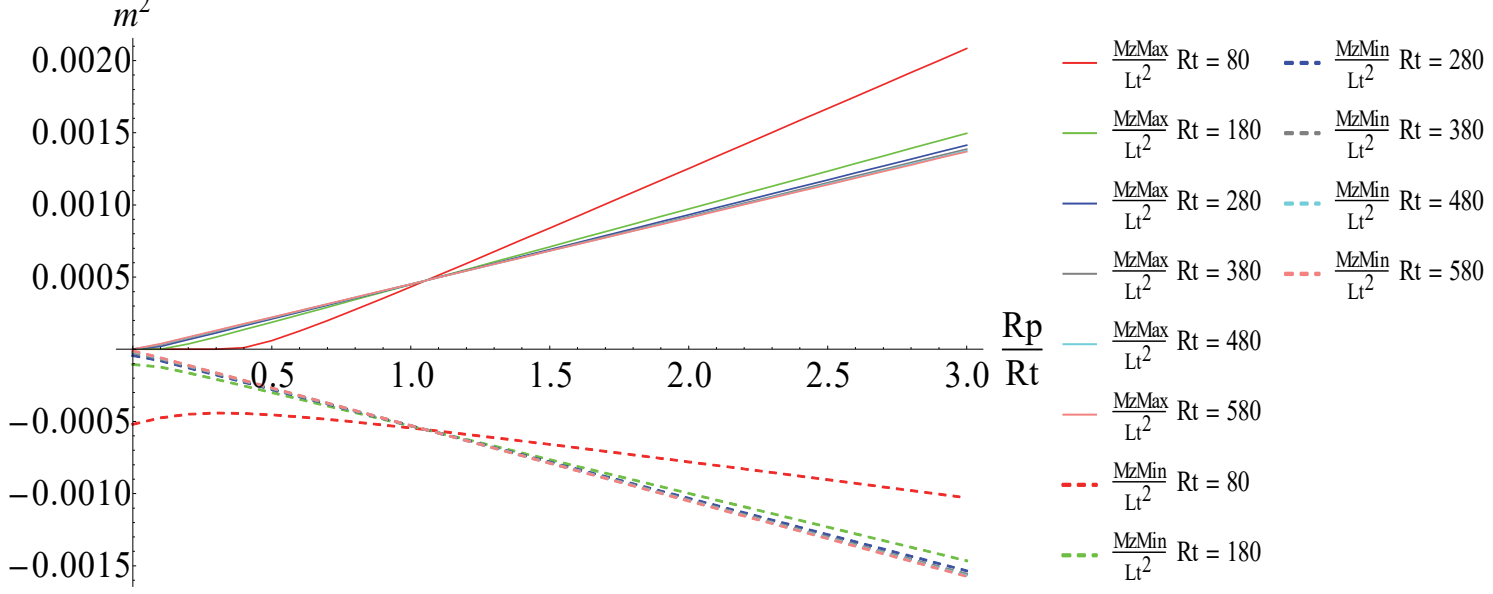


Tablero7 (Peatonal)

$$
\alpha \mathrm{t}=\frac{\pi}{5} \quad \alpha \mathrm{p}=\frac{\alpha \mathrm{t}}{2}
$$

$\mathrm{NxEp} / \mathrm{Lt}$

$\mathrm{NxEn} / \mathrm{Lt}$

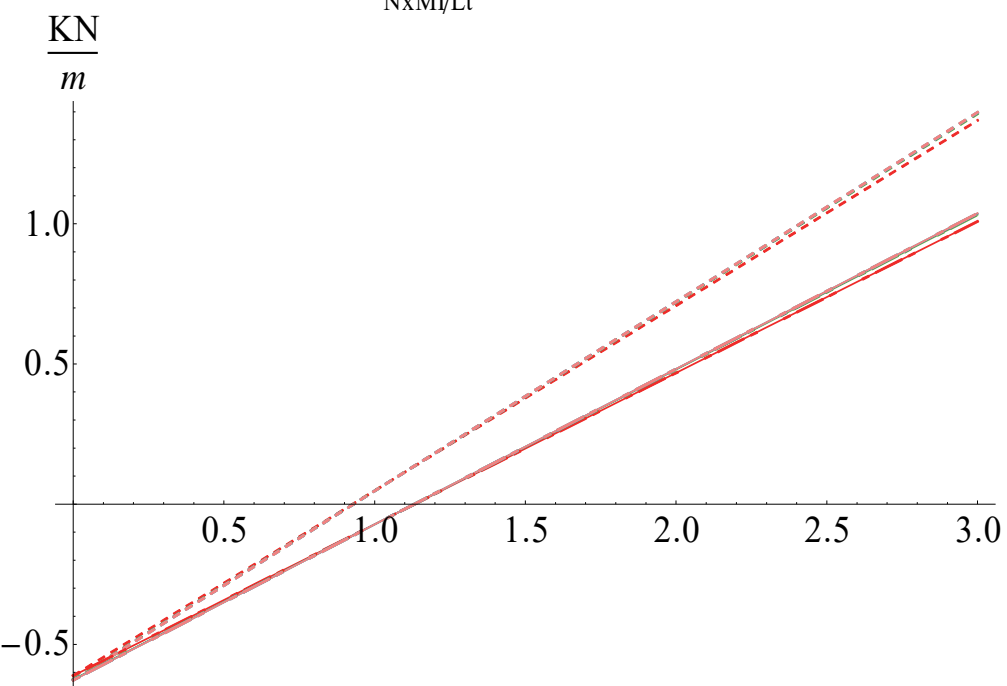

$-\frac{\mathrm{NxEp}}{\mathrm{Lt}} \mathrm{Rt}=80 \quad-\ldots \frac{\mathrm{NxEn}}{\mathrm{Lt}} \mathrm{Rt}=480$

- $\frac{\mathrm{N} \times \mathrm{EP}}{\mathrm{Lt}} \mathrm{Rt}=180 \quad-.-\frac{\mathrm{N} \times \mathrm{En}}{\mathrm{Lt}} \mathrm{Rt}=580$

$-\frac{\mathrm{N} \times \mathrm{Ep}}{\mathrm{Lt}} \mathrm{Rt}=280 \quad-\frac{\mathrm{N} \times \mathrm{MI}}{\mathrm{Lt}} \mathrm{Rt}=80$

$-\frac{\mathrm{N} \times \mathrm{Ep}}{\mathrm{Lt}} \mathrm{Rt}=380 \quad-\frac{\mathrm{NxMI}}{\mathrm{Lt}} \mathrm{Rt}=180$

- $\frac{\mathrm{N} \times \mathrm{EP}}{\mathrm{Lt}} \mathrm{Rt}=480 \quad-\frac{\mathrm{N} \times \mathrm{MI}}{\mathrm{Lt}} \mathrm{Rt}=280$

- $\frac{\mathrm{N} \times \mathrm{EP}}{\mathrm{Lt}} \mathrm{Rt}=580 \quad-\frac{\mathrm{NxMI}}{\mathrm{Lt}} \mathrm{Rt}=380$

$\frac{\mathrm{Rp}}{\mathrm{Rt}}$

-. $\frac{\mathrm{NxEn}}{\mathrm{Lt}} \mathrm{Rt}=80 \quad-\frac{\mathrm{NxMI}}{\mathrm{Lt}} \mathrm{Rt}=480$

- - $\frac{\mathrm{NxEn}}{\mathrm{Lt}} \mathrm{Rt}=180 \quad--\frac{\mathrm{NxMI}}{\mathrm{Lt}} \mathrm{Rt}=580$

-.. $\frac{\mathrm{NxEn}}{\mathrm{Lt}} \mathrm{Rt}=280$

-. $\frac{\mathrm{NxEn}}{\mathrm{Lt}} \mathrm{Rt}=380$

Tablero7 (Peatonal)

$\alpha \mathrm{t}=\frac{\pi}{2} \quad \alpha \mathrm{p}=\frac{\alpha t}{2}$

$\mathrm{QyEp} / \mathrm{Lt}$

QyEn/Lt

QyEn/Lt

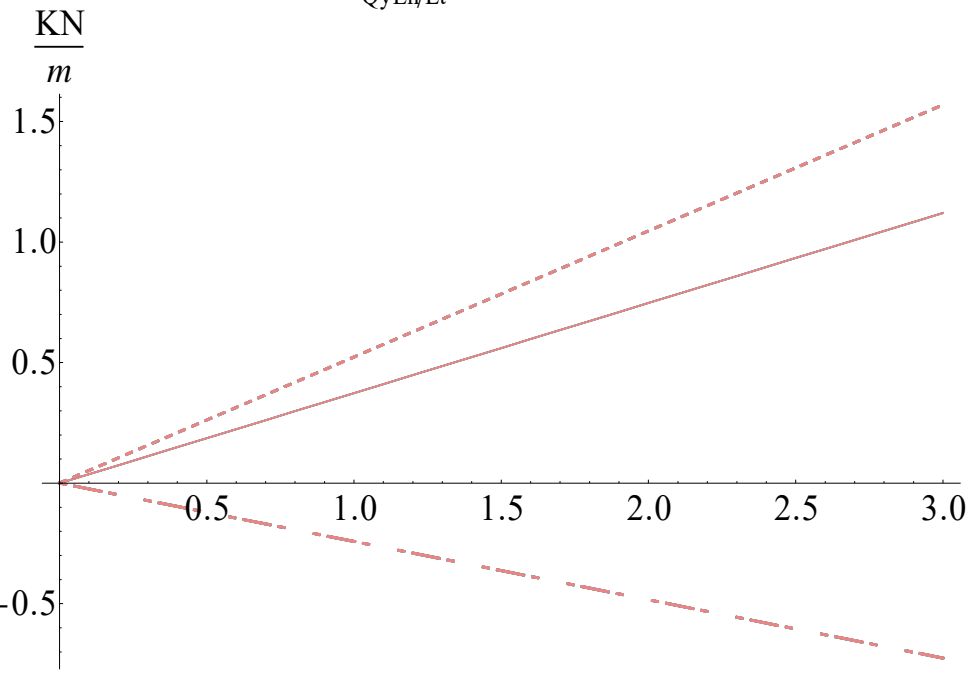

- $\frac{\mathrm{QyEp}}{\mathrm{Lt}} \mathrm{Rt}=80 \quad-\ldots \frac{\mathrm{QyEn}}{\mathrm{Lt}} \mathrm{Rt}=480$

- $\frac{\mathrm{QyEp}}{\mathrm{Lt}} \mathrm{Rt}=180 \quad \ldots \frac{\mathrm{QyEn}}{\mathrm{Lt}} \mathrm{Rt}=580$

- $\frac{\text { QyEp }}{\mathrm{Lt}} \mathrm{Rt}=280--\frac{\mathrm{QyMI}}{\mathrm{Lt}} \mathrm{Rt}=80$

- $\frac{\mathrm{QyEp}}{\mathrm{Lt}} \mathrm{Rt}=380--\frac{\mathrm{QyMI}}{\mathrm{Lt}} \mathrm{Rt}=180$

- $\frac{\mathrm{QyEp}}{\mathrm{Lt}} \mathrm{Rt}=480 \quad-\frac{\mathrm{QyMI}}{\mathrm{Lt}} \mathrm{Rt}=280$

- $\frac{\mathrm{QyEp}}{\mathrm{Lt}} \mathrm{Rt}=580 \quad-\quad-\frac{\mathrm{QyMI}}{\mathrm{Lt}} \mathrm{Rt}=380$

$-. . \frac{\mathrm{Q} y \mathrm{En}}{\mathrm{Lt}} \mathrm{Rt}=80 \quad--\frac{\mathrm{QyMI}}{\mathrm{Lt}} \mathrm{Rt}=480$

$\frac{\mathrm{Rp}}{\mathrm{Rt}}$

- - $\frac{\text { QyEn }}{\mathrm{Lt}} \mathrm{Rt}=180--\frac{\text { QyMI }}{\mathrm{Lt}} \mathrm{Rt}=580$

- . $\frac{\text { QyEn }}{\mathrm{Lt}} \mathrm{Rt}=280$

- . - $\frac{\text { QyEn }}{\mathrm{Lt}} \mathrm{Rt}=380$ 
Tablero7 (Peatonal)

$\alpha \mathrm{t}=\frac{\pi}{2} \quad \alpha \mathrm{p}=\frac{\alpha \mathrm{t}}{2}$

$\operatorname{MzMax} / \mathrm{Lt}^{2}$

$\frac{\mathrm{Kn} / \mathrm{m}}{\mathrm{m}^{2}}$

$\mathrm{MzMin} / \mathrm{Lt}^{2}$

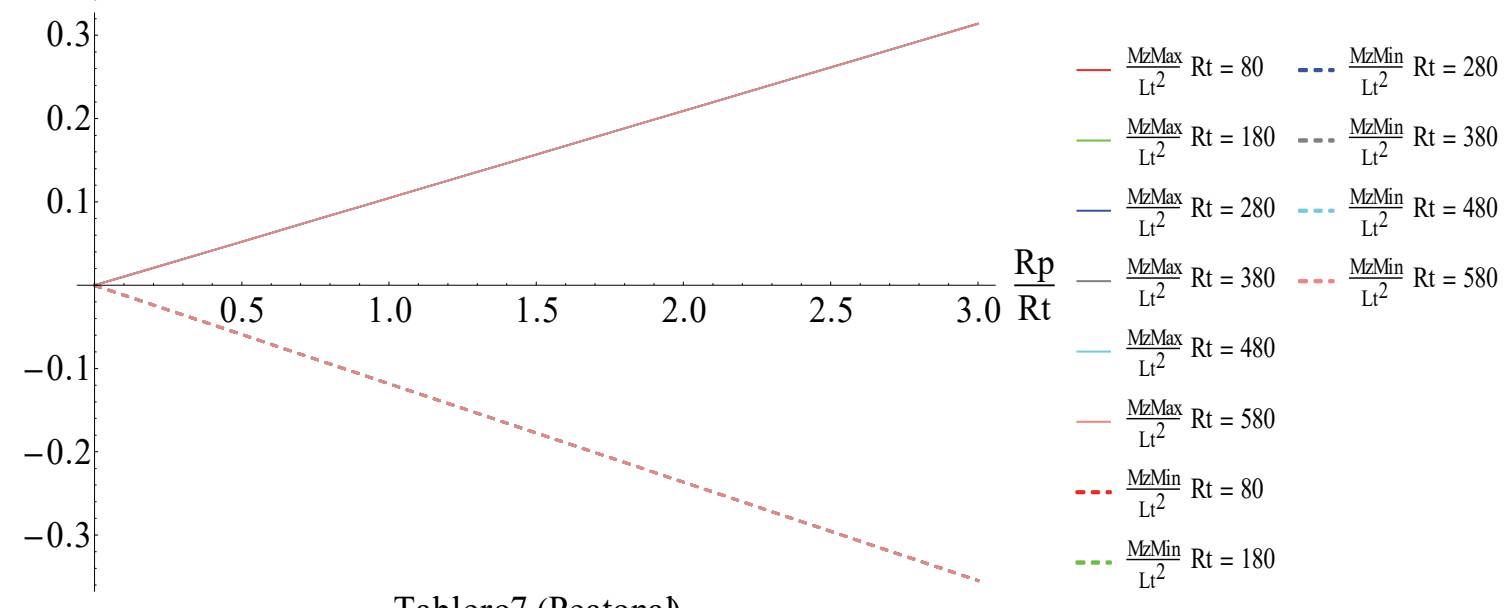

Tablero7 (Peatonal)

$\alpha \mathrm{t}=\frac{\pi}{2} \quad \alpha \mathrm{p}=\frac{\alpha \mathrm{t}}{2}$

$\mathrm{NxEp} / \mathrm{Lt}$

$\mathrm{NxEn} / \mathrm{Lt}$

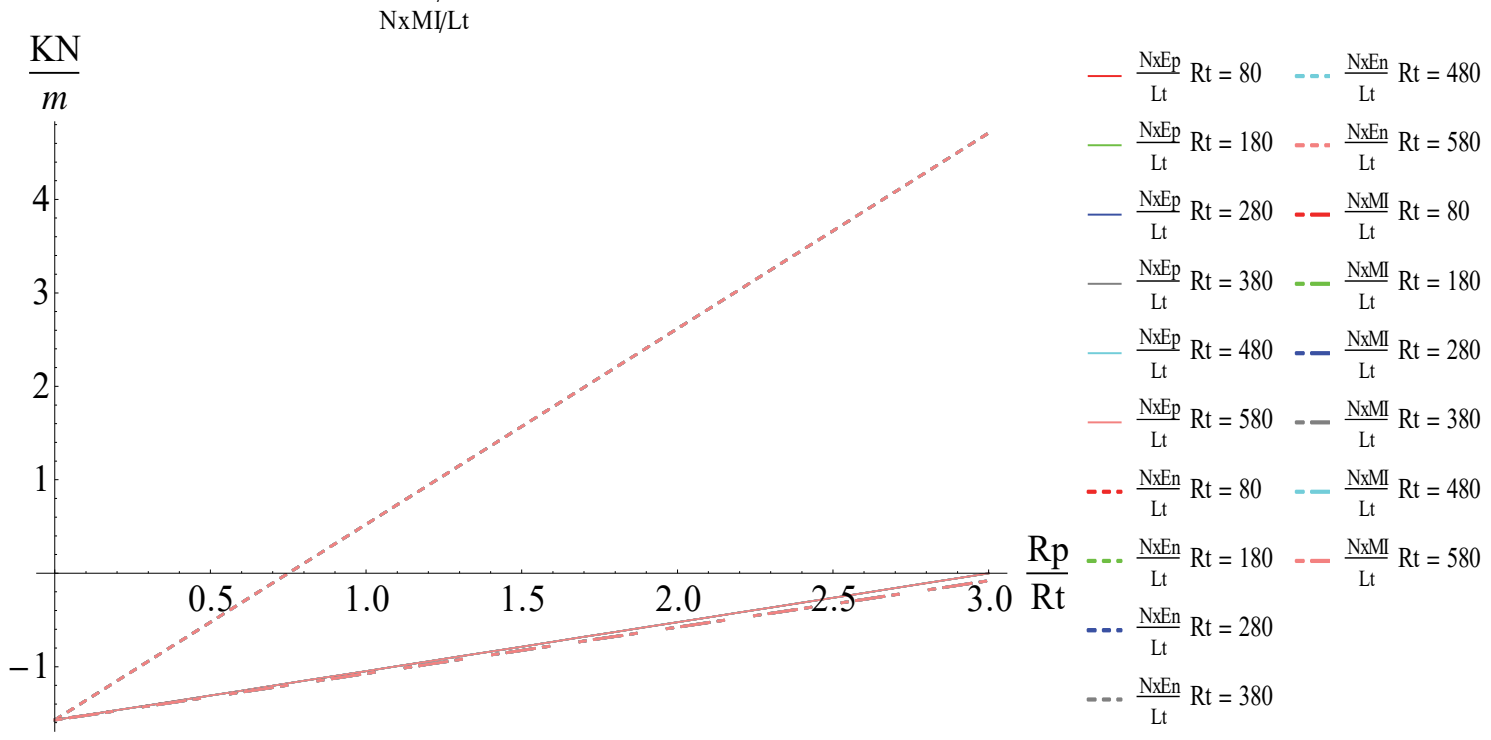


Tablero1 (Carretera)

$\alpha \mathrm{t}=\frac{\pi}{5} \quad \alpha \mathrm{p}=\frac{a t}{2}$

QyEp/Lt

QyEn/Lt

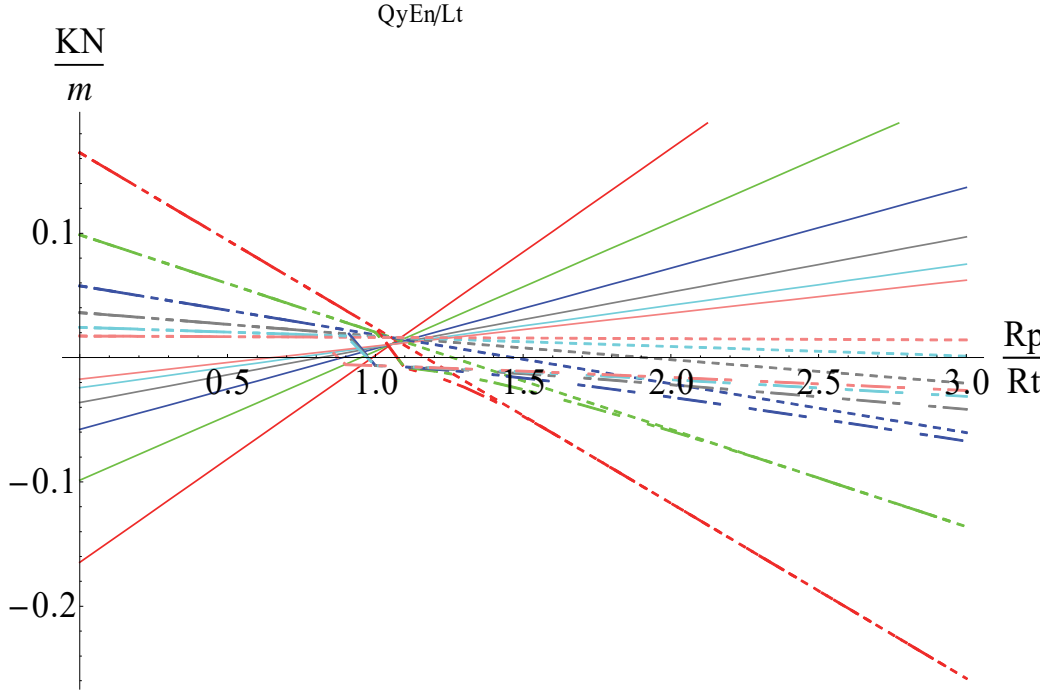

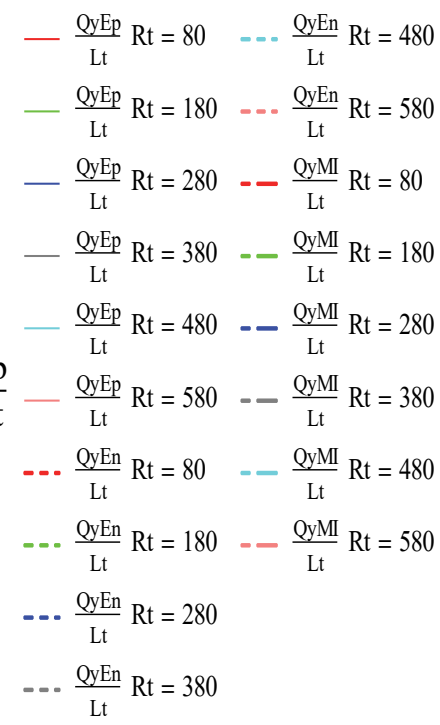

Tablero 1 (Carretera)

$\alpha \mathrm{t}=\frac{\pi}{5} \quad \alpha \mathrm{p}=\frac{\alpha \mathrm{t}}{2}$

$\operatorname{MzMax} / \mathrm{Lt}^{2}$

$\mathrm{MzMin} / \mathrm{Lt}^{2}$

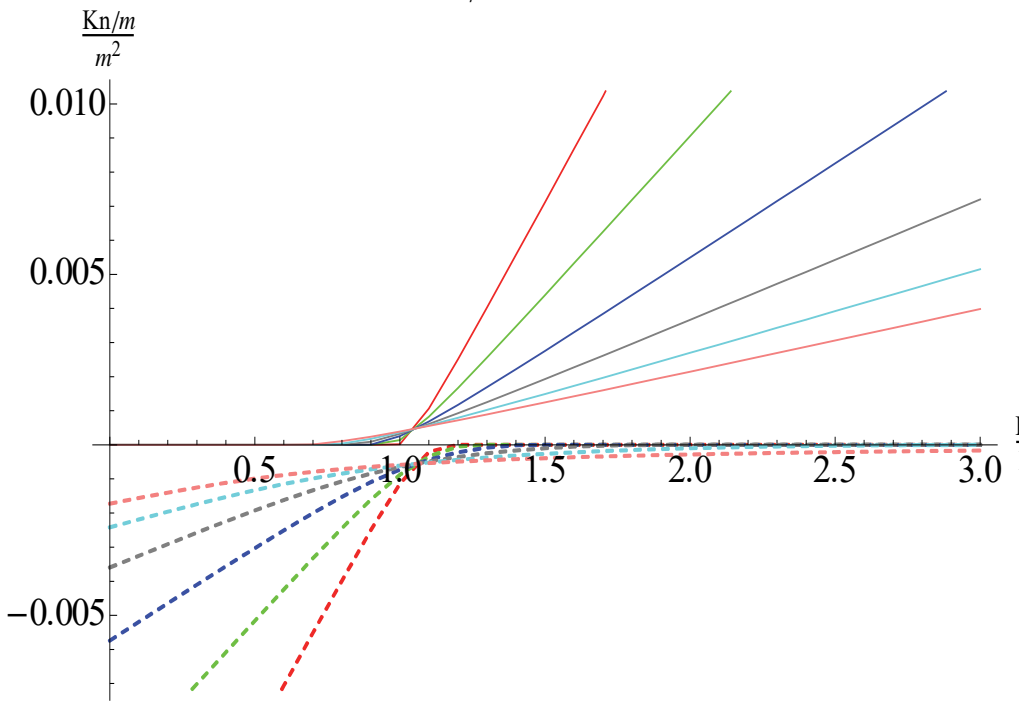

- $\frac{\mathrm{MzMax}}{\mathrm{Lt}^{2}} \mathrm{Rt}=80 \quad \ldots \frac{\mathrm{MzMin}}{\mathrm{Lt}^{2}} \mathrm{Rt}=280$

$-\frac{\mathrm{MzMax}}{\mathrm{Lt}^{2}} \mathrm{Rt}=180 \quad \ldots \frac{\mathrm{MzMin}}{\mathrm{Lt}^{2}} \mathrm{Rt}=380$

- $\frac{\mathrm{MzMax}}{\mathrm{Lt}^{2}} \mathrm{Rt}=280 \quad \ldots \frac{\mathrm{MzMin}^{2}}{\mathrm{Lt}^{2}} \mathrm{Rt}=480$

- $\frac{\mathrm{MzMax}}{\mathrm{Lt}^{2}} \mathrm{Rt}=380 \quad \ldots \frac{\mathrm{MzMin}}{\mathrm{Lt}^{2}} \mathrm{Rt}=580$

$\frac{\mathrm{Rp}}{\mathrm{R}}$

$\frac{\mathrm{MzMax}}{\mathrm{Lt}^{2}} \mathrm{Rt}=480$

- $\frac{\mathrm{Mz} \text { Max }}{\mathrm{Lt}^{2}} \mathrm{Rt}=580$

-.- $\frac{\mathrm{MzMin}}{\mathrm{Lt}^{2}} \mathrm{Rt}=80$

$=-\frac{\mathrm{Mz} M i n}{\mathrm{Lt}^{2}} \mathrm{Rt}=180$ 
Tablero1 (Carretera)

$$
\begin{aligned}
& \alpha \mathrm{t}=\frac{\pi}{5} \quad \alpha \mathrm{p}=\frac{\alpha t}{2} \\
& \mathrm{NxEp} / \mathrm{Lt} \\
& \mathrm{NxEn} / \mathrm{Lt}
\end{aligned}
$$

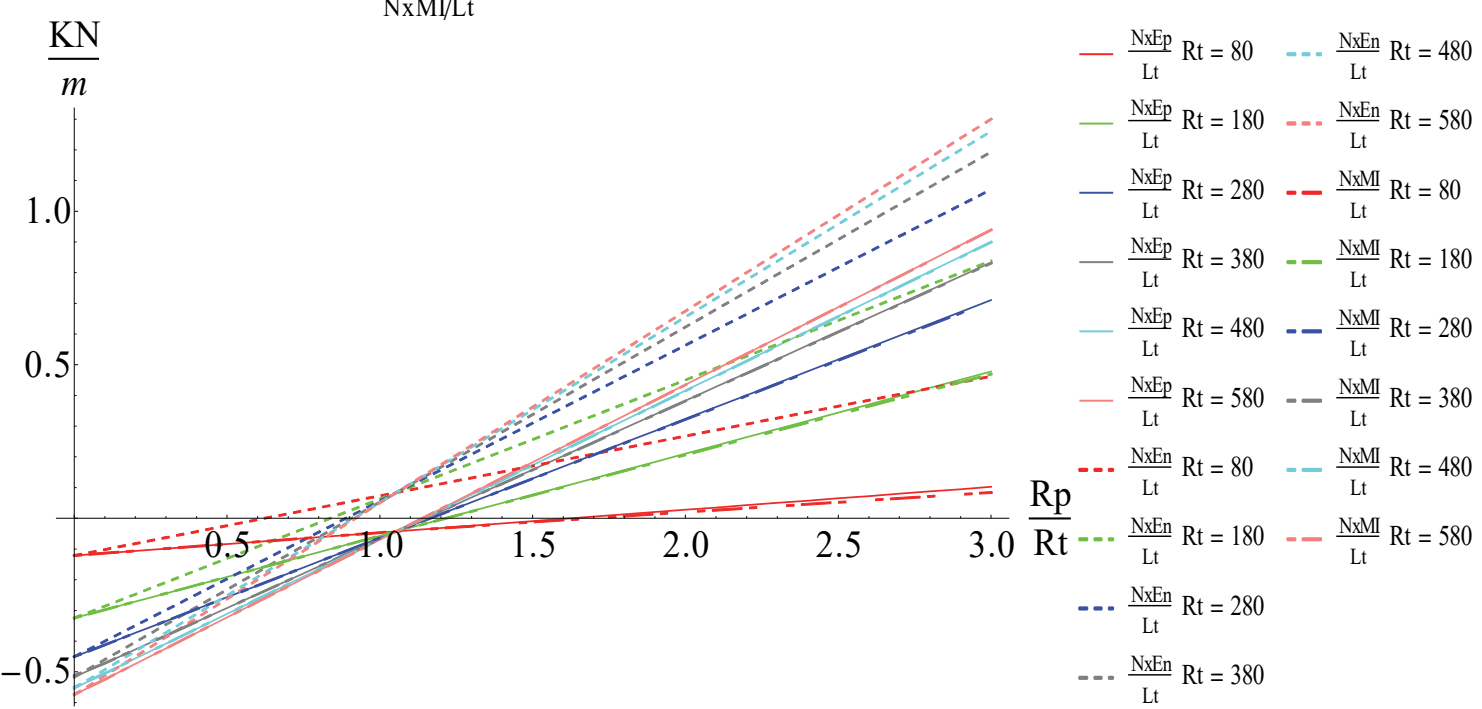

Tablero1 (Carretera)

$\alpha \mathrm{t}=\frac{\pi}{2} \quad \alpha p=\frac{\alpha t}{2}$

QyEp/Lt

QyEn/Lt

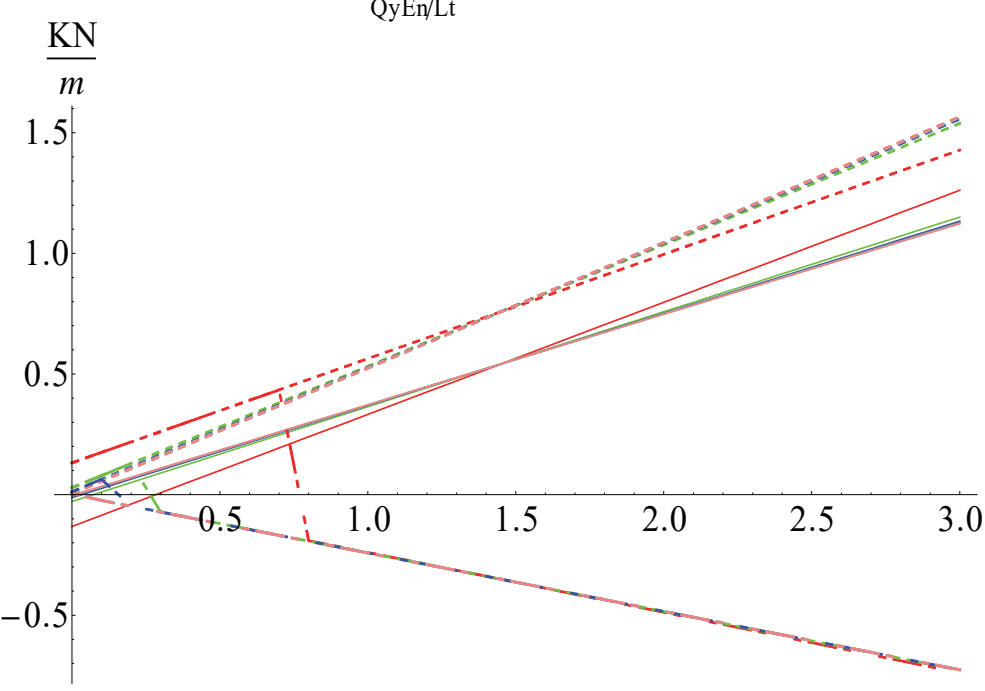

— $\frac{\mathrm{QyEp}}{\mathrm{Lt}} \mathrm{Rt}=80 \quad \ldots \frac{\mathrm{QyEn}}{\mathrm{Lt}} \mathrm{Rt}=480$

— $\frac{\text { QyEp }}{\mathrm{Lt}} \mathrm{Rt}=180 \quad \ldots \frac{\text { QyEn }}{\mathrm{Lt}} \mathrm{Rt}=580$

$-\frac{\text { QyEp }}{\mathrm{Lt}} \mathrm{Rt}=280 \quad-\quad \frac{\mathrm{QyM}}{\mathrm{Lt}} \mathrm{Rt}=80$

$-\frac{\mathrm{QyEp}}{\mathrm{Lt}} \mathrm{Rt}=380--\frac{\mathrm{QyMI}}{\mathrm{Lt}} \mathrm{Rt}=180$

— $\frac{\mathrm{QyEp}}{\mathrm{Lt}} \mathrm{Rt}=480 \quad-\frac{\mathrm{QyMI}}{\mathrm{Lt}} \mathrm{Rt}=280$

— $\frac{\text { QyEp }}{\mathrm{Lt}} \mathrm{Rt}=580 \quad-\quad-\frac{\mathrm{QyMI}}{\mathrm{Lt}} \mathrm{Rt}=380$

- $\frac{\text { QyEn }}{\mathrm{Lt}} \mathrm{Rt}=80 \quad-$ - $\frac{\mathrm{QyMI}}{\mathrm{Lt}} \mathrm{Rt}=480$

$\frac{\mathrm{Rp}}{\mathrm{Rt}}=-\frac{\mathrm{QyEn}}{\mathrm{Lt}} \mathrm{Rt}=180 \quad--\frac{\mathrm{QyMI}}{\mathrm{Lt}} \mathrm{Rt}=580$

... $\frac{\mathrm{QyEn}}{\mathrm{Lt}} \mathrm{Rt}=280$

.. $\frac{\mathrm{QyEn}}{\mathrm{Lt}} \mathrm{Rt}=380$ 
Tablerol (Carretera)

$\alpha \mathrm{t}=\frac{\pi}{2} \quad \alpha p=\frac{\alpha t}{2}$

$\mathrm{MzMax} / \mathrm{Lt}^{2}$

$\frac{\mathrm{Kn} / m}{m^{2}}$

$\mathrm{MzMin} / \mathrm{Lt} t^{2}$

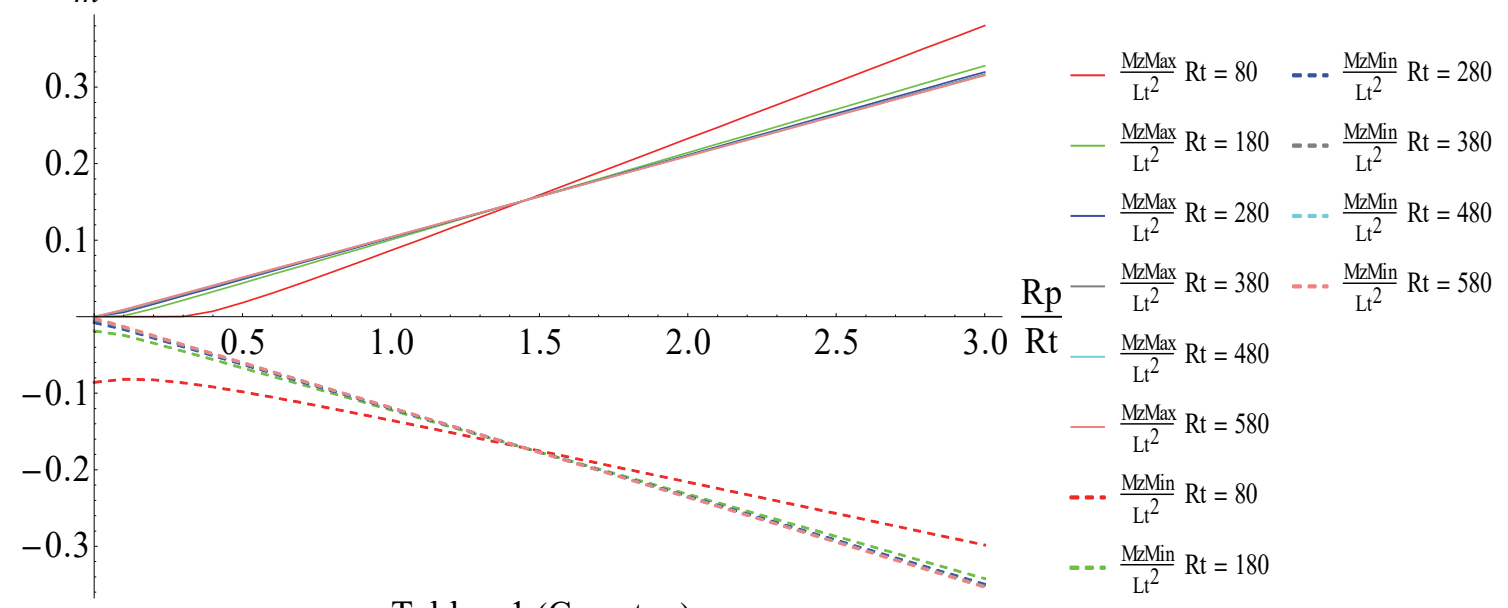

Tablerol (Carretera)

$\alpha \mathrm{t}=\frac{\pi}{2} \quad \alpha \mathrm{p}=\frac{\alpha \mathrm{t}}{2}$

$\mathrm{NxEp} / \mathrm{Lt}$

$\mathrm{NxEn} / \mathrm{Lt}$

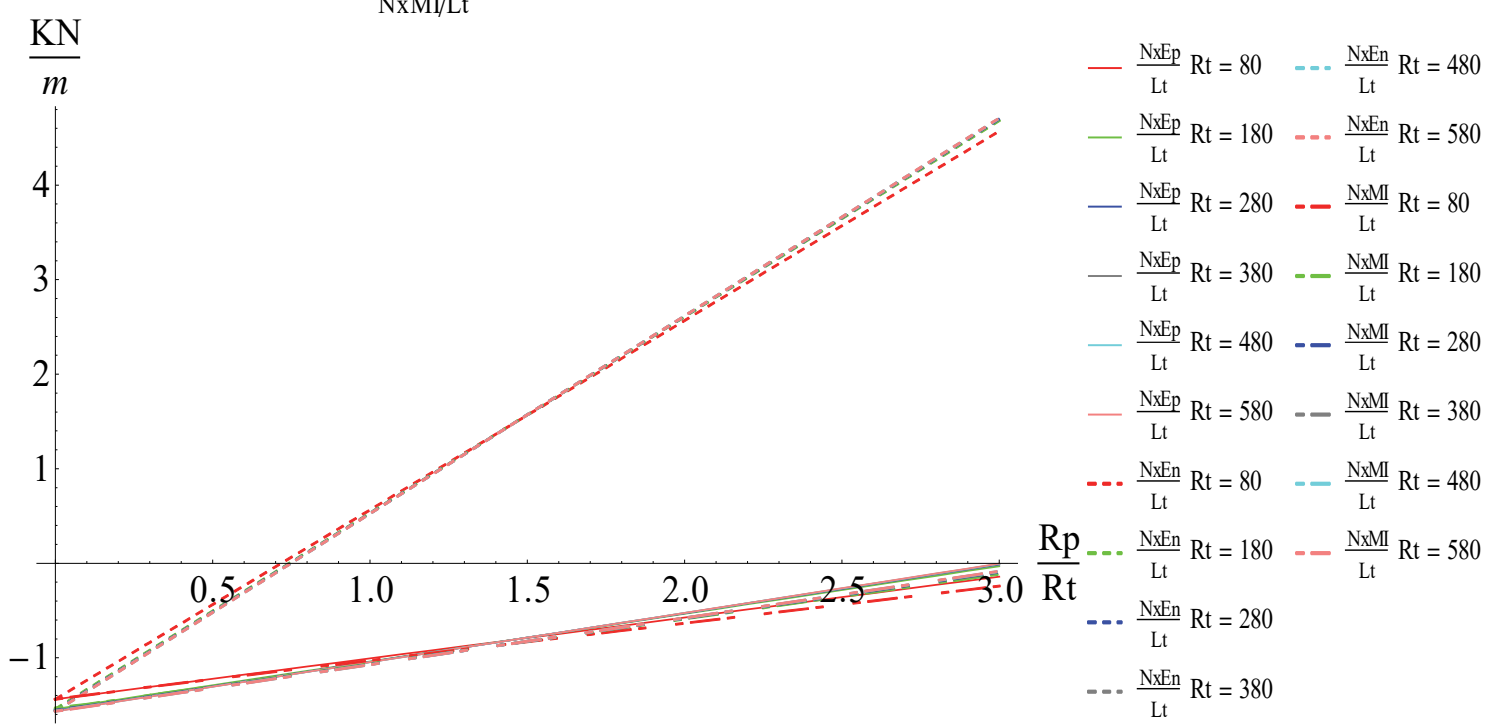


Tablerol (Carretera)

$\alpha \mathrm{t}=\frac{4 \pi}{5} \quad \alpha \mathrm{p}=\frac{\alpha \mathrm{t}}{2}$

QyEp/Lt

QyEn/Lt

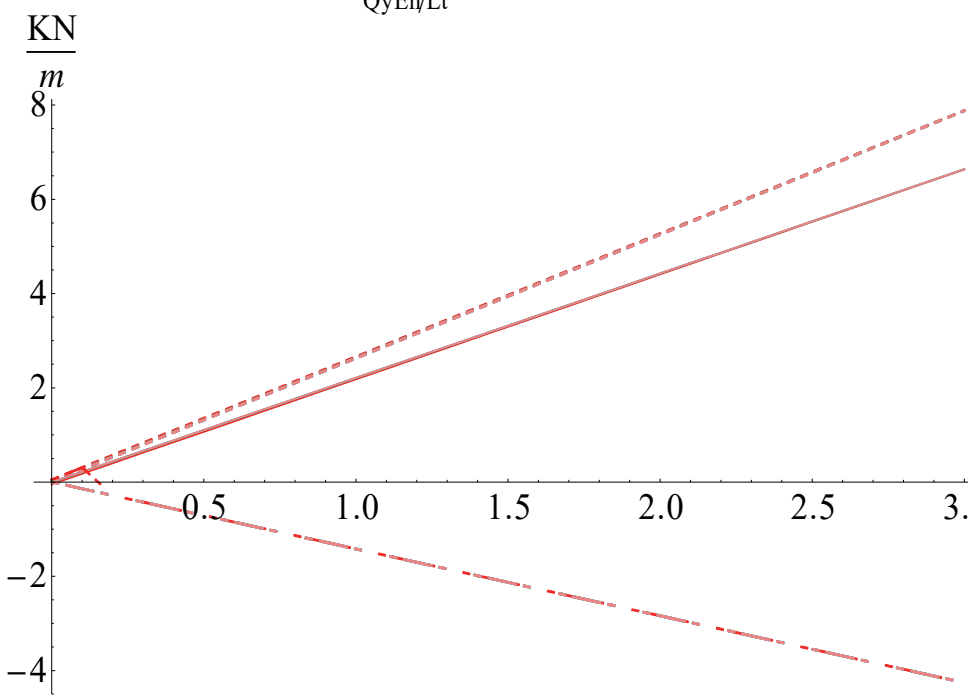

— $\frac{\text { QyEp }}{\mathrm{Lt}} \mathrm{Rt}=80 \quad \ldots \frac{\mathrm{QyEn}}{\mathrm{Lt}} \mathrm{Rt}=480$

— $\frac{\mathrm{QyEp}}{\mathrm{Lt}} \mathrm{Rt}=180 \quad \ldots \frac{\mathrm{QyEn}}{\mathrm{Lt}} \mathrm{Rt}=580$

— $\frac{\mathrm{QyEp}}{\mathrm{Lt}} \mathrm{Rt}=280 \quad-\frac{\mathrm{QyMI}}{\mathrm{Lt}} \mathrm{Rt}=80$

- $\frac{\mathrm{QyEp}}{\mathrm{Lt}} \mathrm{Rt}=380 \quad-\quad-\frac{\mathrm{QyMI}}{\mathrm{Lt}} \mathrm{Rt}=180$

— $\frac{\mathrm{QyEp}}{\mathrm{Lt}} \mathrm{Rt}=480 \quad-\frac{\mathrm{QyMI}}{\mathrm{Lt}} \mathrm{Rt}=280$

- $\frac{\mathrm{QyEp}}{\mathrm{Lt}} \mathrm{Rt}=580 \quad-\quad-\frac{\mathrm{QyMI}}{\mathrm{Lt}} \mathrm{Rt}=380$

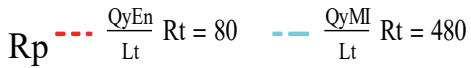

$\frac{\mathrm{Rt}}{\text {-. }} \frac{\mathrm{QyEn}}{\mathrm{Lt}} \mathrm{Rt}=180 \quad-\frac{\mathrm{Q} \mathrm{MM}}{\mathrm{Lt}} \mathrm{Rt}=580$

Tablero1 (Carretera)

$\alpha \mathrm{t}=\frac{4 \pi}{5} \quad \alpha \mathrm{p}=\frac{\alpha \mathrm{t}}{2}$

$\mathrm{MzMax} / \mathrm{Lt}^{2}$

$\mathrm{MzMin} / \mathrm{Lt}^{2}$

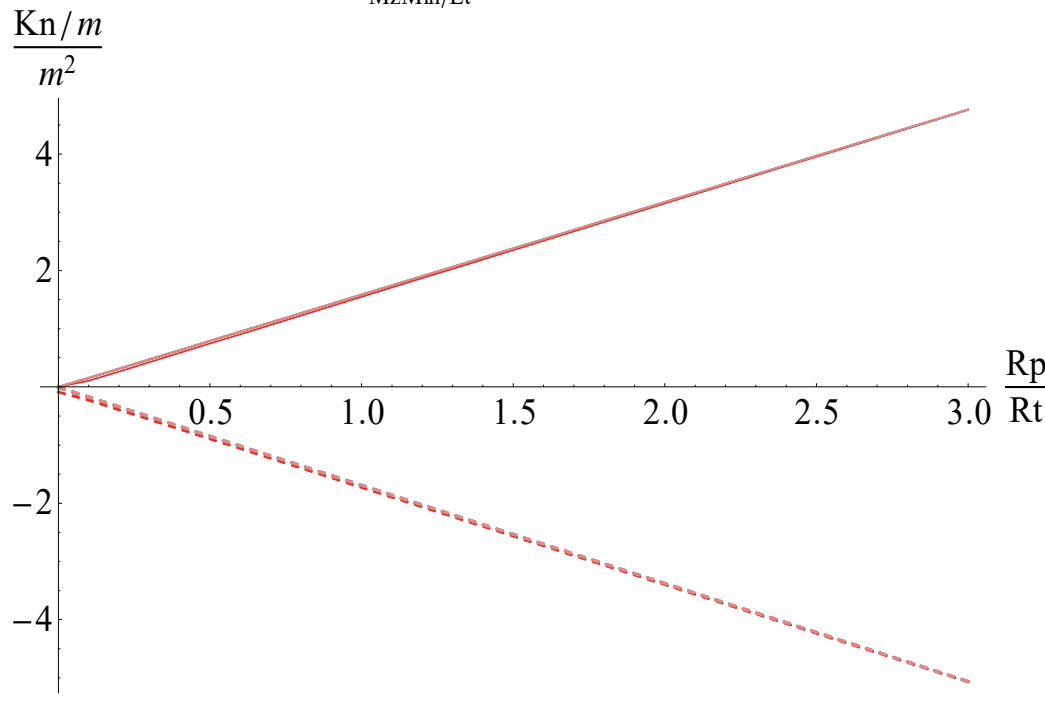

- $\frac{\mathrm{MzMax}}{\mathrm{Lt}^{2}} \mathrm{Rt}=80 \quad \ldots \frac{\mathrm{MzMin}}{\mathrm{Lt}^{2}} \mathrm{Rt}=280$

- $\frac{\mathrm{MzMax}}{\mathrm{Lt}^{2}} \mathrm{Rt}=180 \quad \ldots \frac{\mathrm{MzMin}}{\mathrm{Lt}^{2}} \mathrm{Rt}=380$

- $\frac{\mathrm{MzMax}}{\mathrm{Lt}^{2}} \mathrm{Rt}=280 \quad \ldots \frac{\mathrm{MzMin}}{\mathrm{Lt}^{2}} \mathrm{Rt}=480$

$\frac{\mathrm{Rp}}{\mathrm{Rt}}-\frac{\mathrm{MzMax}}{\mathrm{Lt}^{2}} \mathrm{Rt}=380 \quad \ldots \frac{\mathrm{MzMin}}{\mathrm{Lt}^{2}} \mathrm{Rt}=580$

- $\frac{\mathrm{MzMax}}{\mathrm{Lt}^{2}} \mathrm{Rt}=480$

- $\frac{\mathrm{MzMax}}{\mathrm{Lt}^{2}} \mathrm{Rt}=580$

-.. $\frac{\mathrm{MzMin}}{\mathrm{Lt}^{2}} \mathrm{Rt}=80$

- . $\frac{\mathrm{MzMin}}{\mathrm{Lt}^{2}} \mathrm{Rt}=180$ 


\section{Tablerol (Carretera)}

$$
\alpha \mathrm{t}=\frac{4 \pi}{5} \quad \alpha \mathrm{p}=\frac{\alpha \mathrm{t}}{2}
$$

$\mathrm{NxEp} / \mathrm{Lt}$

$\mathrm{NxEn} / \mathrm{Lt}$

NxMI/Lt

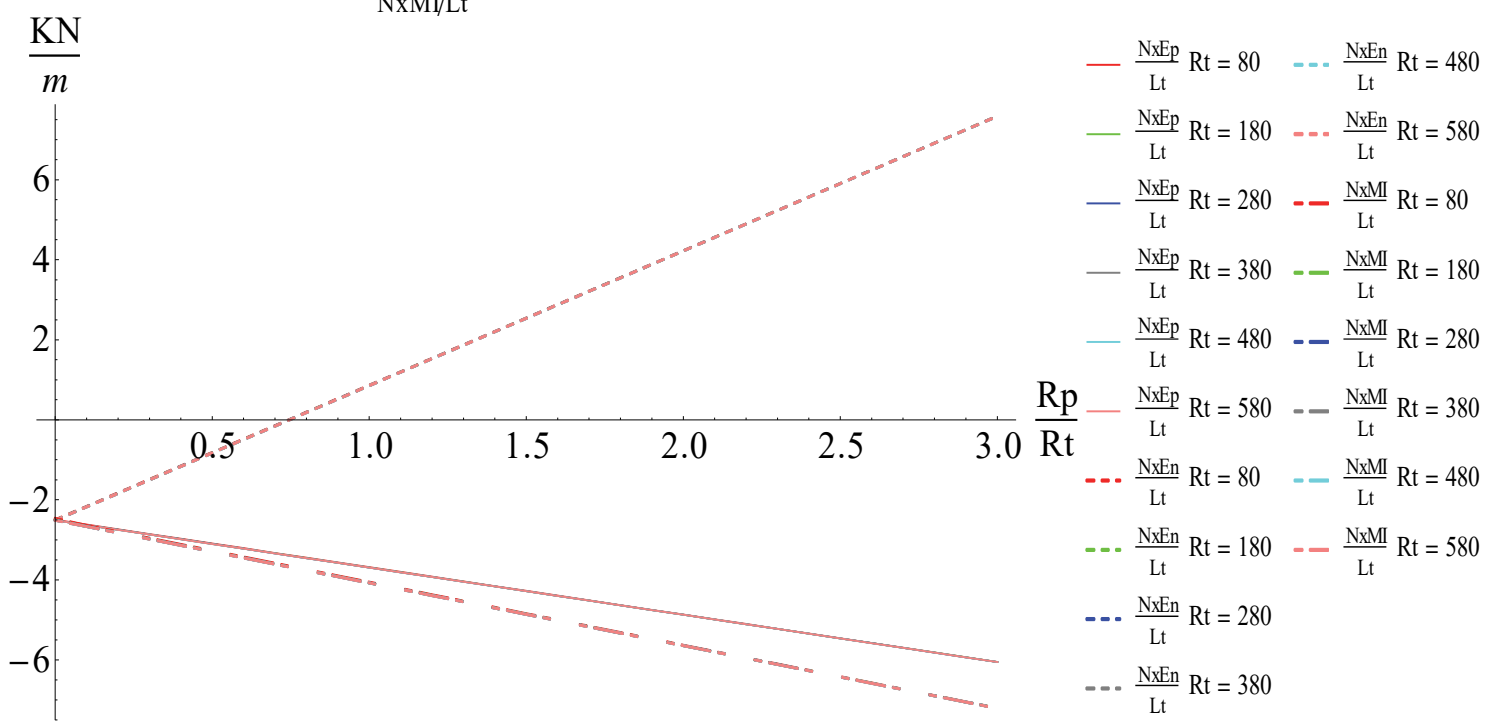

Diagrama 2.64 Solicitaciones del tablero $\left(\frac{Q y}{L t}, \frac{M z}{L t^{2}} y \frac{N x}{L t}\right) . \alpha t=\frac{\pi}{5}, \alpha p=\frac{\alpha t}{2}$, Tablero 7 (Peatonal); $\alpha t=\frac{\pi}{2}, \alpha p=\frac{\alpha t}{2}$, Tablero 7 (Peatonal); $\boldsymbol{\alpha} \boldsymbol{t}=\frac{\pi}{5}, \boldsymbol{\alpha p}=\frac{\alpha \boldsymbol{t}}{2}$, Tablero 1 (Carretera); $\boldsymbol{\alpha} \boldsymbol{t}=\frac{\pi}{2}, \boldsymbol{\alpha} \boldsymbol{p}=\frac{\boldsymbol{\alpha} \boldsymbol{t}}{2}$, Tablero 1 (Carretera); $\boldsymbol{\alpha} \boldsymbol{t}=$ $\frac{4 \pi}{5}, \alpha p=\frac{\alpha t}{2}$, Tablero 1 (Carretera);

Tablero7 (Peatonal)

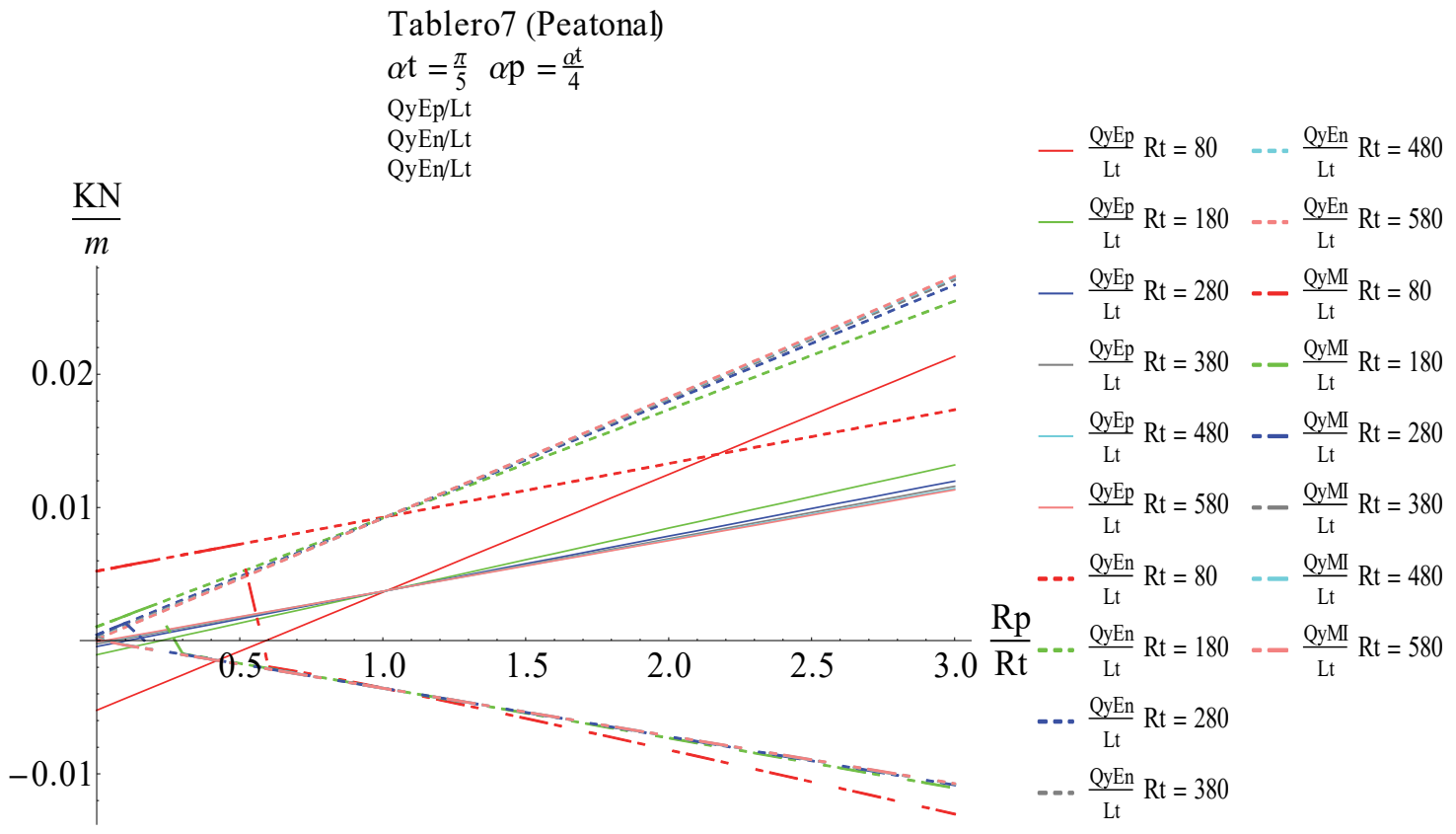


Tablero7 (Peatonal)

$\alpha \mathrm{t}=\frac{\pi}{5} \quad \alpha \mathrm{p}=\frac{\alpha \mathrm{t}}{4}$

MzMax/Lt ${ }^{2}$

$\frac{\mathrm{Kn} / \mathrm{m}}{\mathrm{m}^{2}}$

$\mathrm{MzMin} / \mathrm{Lt}^{2}$

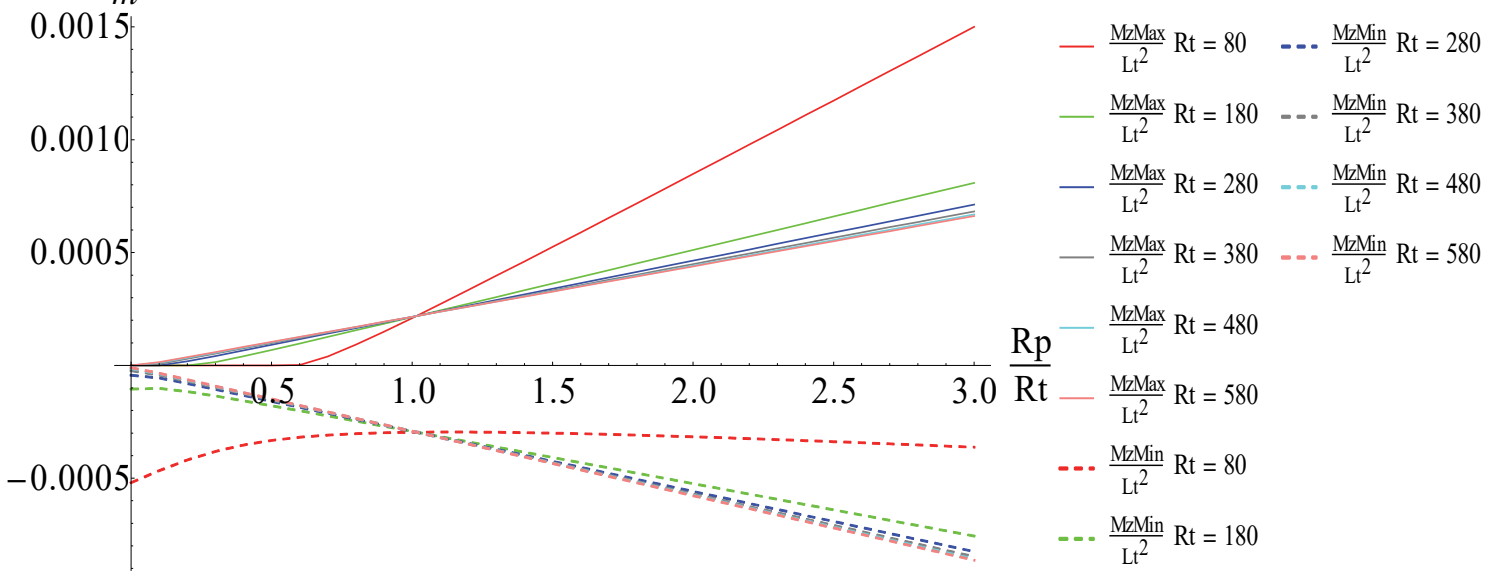

Tablero7 (Peatonal)

$\alpha \mathrm{t}=\frac{\pi}{5} \quad \alpha \mathrm{p}=\frac{\alpha \mathrm{t}}{4}$

$\mathrm{NxEp} / \mathrm{Lt}$

$\mathrm{NxEn} / \mathrm{Lt}$

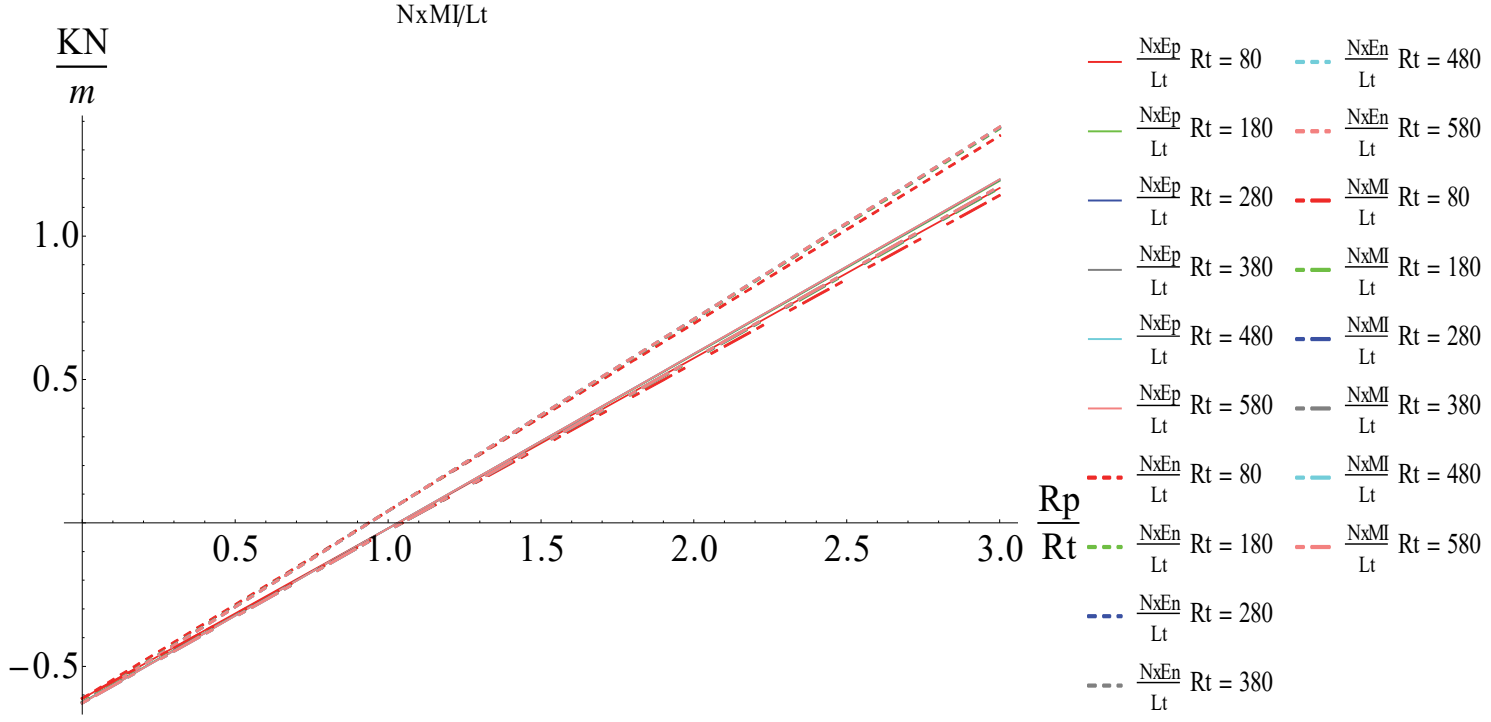


Tablero7 (Peatonal)

$\alpha \mathrm{t}=\frac{\pi}{2} \quad \alpha \mathrm{p}=\frac{\alpha \mathrm{t}}{4}$

QyEp/Lt

$\mathrm{QyEn} / \mathrm{Lt}$

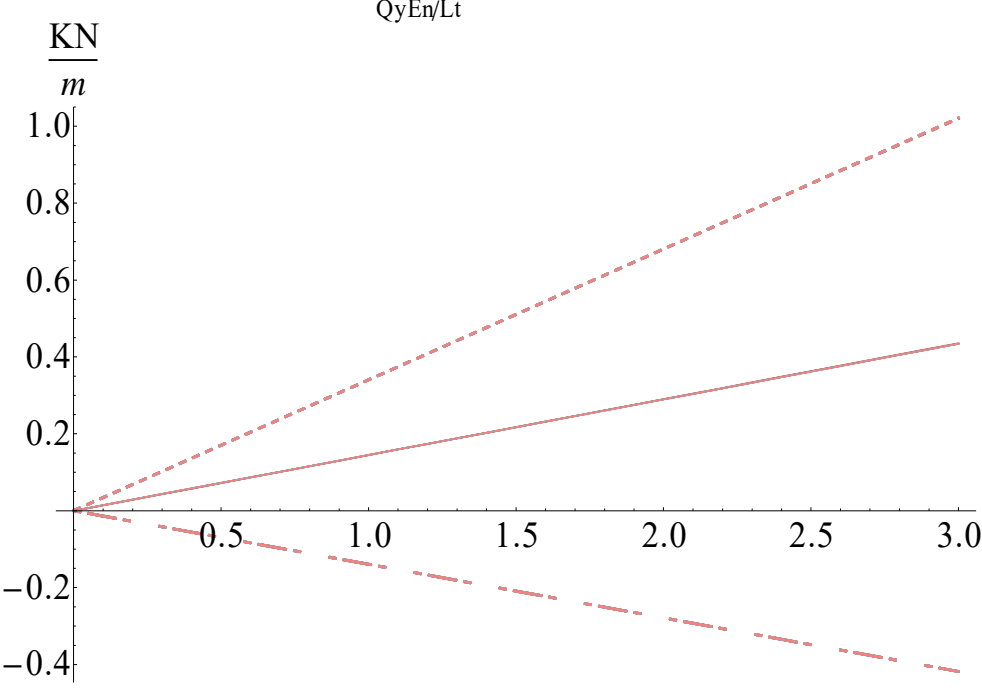

$$
\begin{aligned}
& \text { — } \frac{\mathrm{QyEp}}{\mathrm{Lt}} \mathrm{Rt}=80 \quad \ldots \frac{\mathrm{QyEn}}{\mathrm{Lt}} \mathrm{Rt}=480 \\
& \text { — } \frac{\text { QyEp }}{\mathrm{Lt}} \mathrm{Rt}=180 \quad \ldots \frac{\mathrm{QyEn}}{\mathrm{Lt}} \mathrm{Rt}=580 \\
& \text { — } \frac{\text { QyEp }}{\mathrm{Lt}} \mathrm{Rt}=280 \quad-\frac{\mathrm{QyMI}}{\mathrm{Lt}} \mathrm{Rt}=80 \\
& \text { — } \frac{\text { QyEp }}{\mathrm{Lt}} \mathrm{Rt}=380--\frac{\mathrm{QyMI}}{\mathrm{Lt}} \mathrm{Rt}=180 \\
& \text { — } \frac{\text { QyEp }}{\mathrm{Lt}} \mathrm{Rt}=480 \quad-\quad \frac{\mathrm{QyMI}}{\mathrm{Lt}} \mathrm{Rt}=280 \\
& \text { - } \frac{\text { QyEp }}{\mathrm{Lt}} \mathrm{Rt}=580 \quad--\frac{\mathrm{QyMI}}{\mathrm{Lt}} \mathrm{Rt}=380 \\
& \ldots \frac{\mathrm{QyEn}}{\mathrm{Lt}} \mathrm{Rt}=80 \quad-\quad \frac{\mathrm{QyMI}}{\mathrm{Lt}} \mathrm{Rt}=480 \\
& \frac{\mathrm{Rp}}{\mathrm{Rt}}=-\frac{\mathrm{QyEn}}{\mathrm{Lt}} \mathrm{Rt}=180 \quad-\frac{\mathrm{QyMI}}{\mathrm{Lt}} \mathrm{Rt}=580 \\
& \text {-.. } \frac{\mathrm{QyEn}}{\mathrm{Lt}} \mathrm{Rt}=280 \\
& \text { - . } \frac{\mathrm{QyEn}}{\mathrm{Lt}} \mathrm{Rt}=380
\end{aligned}
$$

Tablero7 (Peatonal)

$\alpha \mathrm{t}=\frac{\pi}{2} \quad \alpha \mathrm{p}=\frac{\alpha \mathrm{t}}{4}$

$\operatorname{MzMax} / \mathrm{Lt}^{2}$

$\operatorname{MzMin} / \mathrm{Lt}^{2}$

\section{$\frac{\mathrm{Kn} / m}{m^{2}}$}

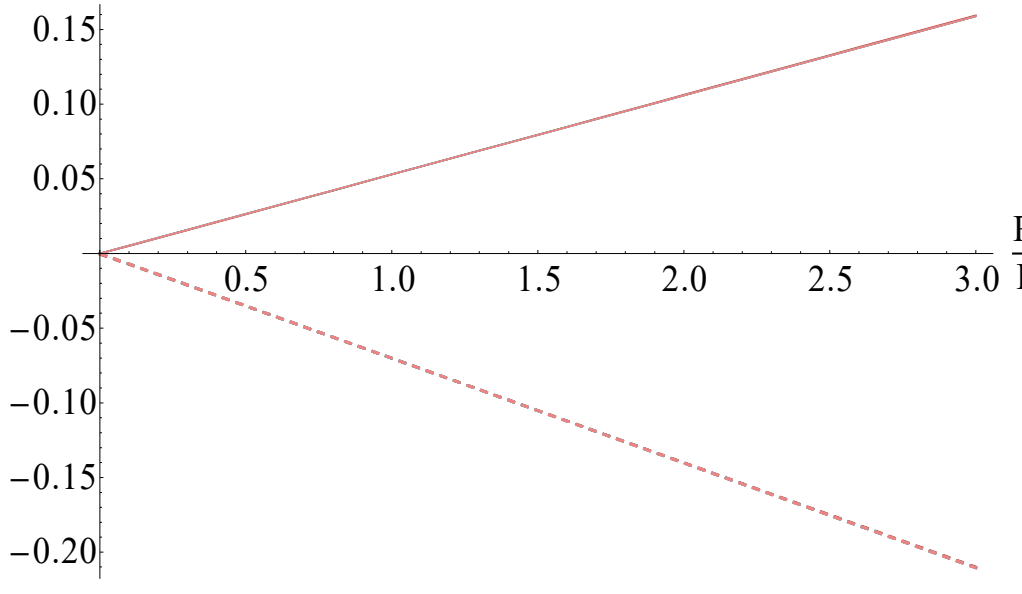

- $\frac{\mathrm{MzMax}}{\mathrm{Lt}^{2}} \mathrm{Rt}=80 \quad \ldots \frac{\mathrm{MzMin}}{\mathrm{Lt}^{2}} \mathrm{Rt}=280$

$-\frac{\mathrm{MzMax}}{\mathrm{Lt}^{2}} \mathrm{Rt}=180 \quad \ldots \frac{\mathrm{MzMin}}{\mathrm{Lt}^{2}} \mathrm{Rt}=380$

$\mathrm{Rp}$

- $\frac{\mathrm{MzMax}}{\mathrm{Lt}^{2}} \mathrm{Rt}=280 \quad \ldots \frac{\mathrm{MzMin}}{\mathrm{Lt}^{2}} \mathrm{Rt}=480$ $\frac{\mathrm{Mz} M a x}{\mathrm{Lt}^{2}} \mathrm{Rt}=380 \quad-=\frac{\mathrm{MzMin}}{\mathrm{Lt}^{2}} \mathrm{Rt}=580$

- $\frac{\mathrm{MzMax}}{\mathrm{Lt}^{2}} \mathrm{Rt}=480$

- $\frac{\mathrm{MzMax}}{\mathrm{Lt}^{2}} \mathrm{Rt}=580$

-.. $\frac{\mathrm{MzMin}}{\mathrm{Lt}^{2}} \mathrm{Rt}=80$

$=\ldots \frac{\mathrm{MzMin}}{\mathrm{Lt}^{2}} \mathrm{Rt}=180$ 
Tablero7 (Peatonal)

$\alpha \mathrm{t}=\frac{\pi}{2} \quad \alpha \mathrm{p}=\frac{\alpha \mathrm{t}}{4}$

$\mathrm{NxEp} / \mathrm{Lt}$

$\mathrm{NxEn} / \mathrm{Lt}$

NxMI/Lt

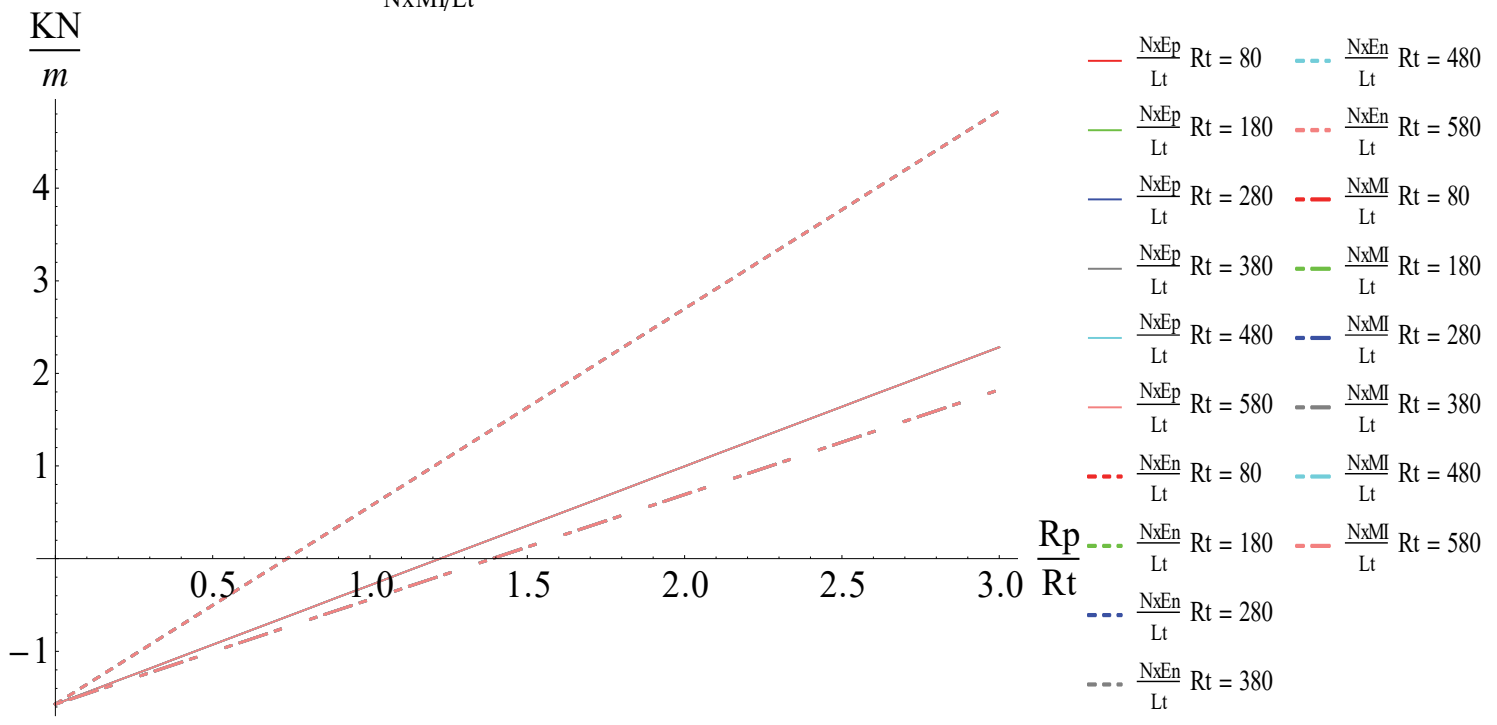

Tablero1 (Carretera)

$\alpha \mathrm{t}=\frac{\pi}{5} \quad \alpha \mathrm{p}=\frac{\alpha t}{4}$

QyEp/Lt

QyEn/Lt

— $\frac{\text { QyEp }}{\mathrm{Lt}} \mathrm{Rt}=80 \quad==-\frac{\text { QyEn }}{\mathrm{Lt}} \mathrm{Rt}=480$

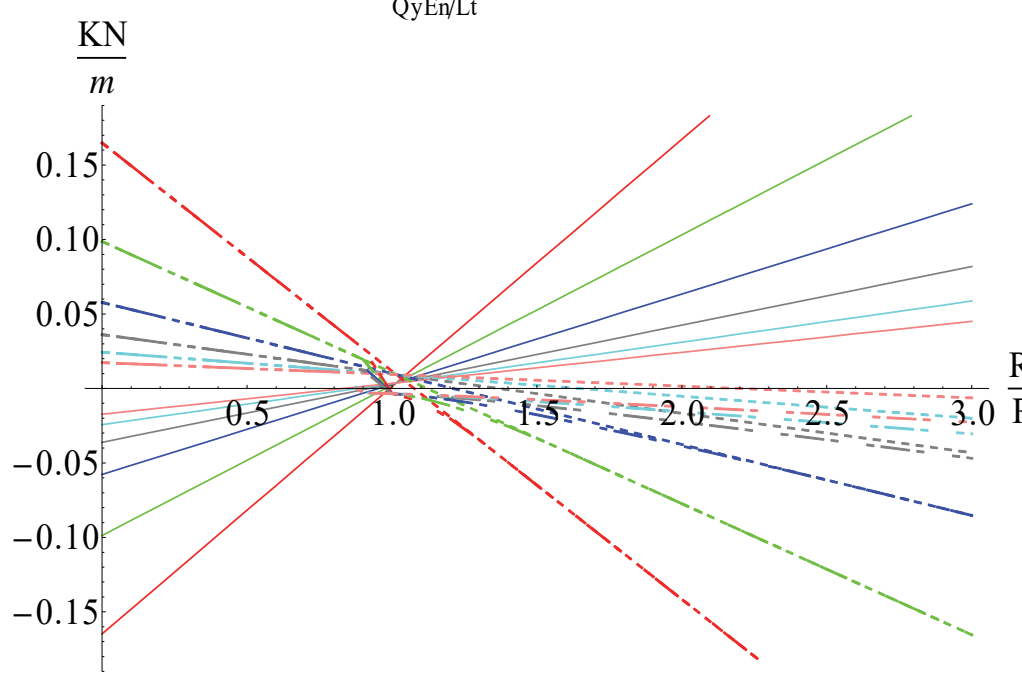

— $\frac{\mathrm{QyEp}}{\mathrm{Lt}} \mathrm{Rt}=180 \quad \ldots \frac{\mathrm{QyEn}}{\mathrm{Lt}} \mathrm{Rt}=580$

$-\frac{\mathrm{QyEp}}{\mathrm{Lt}} \mathrm{Rt}=280--\frac{\mathrm{QyMI}}{\mathrm{Lt}} \mathrm{Rt}=80$

$-\frac{\mathrm{QyEp}}{\mathrm{Lt}} \mathrm{Rt}=380--\frac{\mathrm{QyMI}}{\mathrm{Lt}} \mathrm{Rt}=180$

$-\frac{\mathrm{QyEp}}{\mathrm{Lt}} \mathrm{Rt}=480 \quad-\frac{\mathrm{QyMI}}{\mathrm{Lt}} \mathrm{Rt}=280$

$\mathrm{Rp}-\frac{\mathrm{QyEp}}{\mathrm{Lt}} \mathrm{Rt}=580 \quad--\frac{\mathrm{QyMI}}{\mathrm{Lt}} \mathrm{Rt}=380$

$\overline{\mathrm{Rt}}$-.- $\frac{\mathrm{QyEn}}{\mathrm{Lt}} \mathrm{Rt}=80 \quad--\frac{\mathrm{QyMI}}{\mathrm{Lt}} \mathrm{Rt}=480$

$\ldots \frac{\mathrm{QyEn}}{\mathrm{Lt}} \mathrm{Rt}=180 \quad-\quad-\frac{\mathrm{QyMI}}{\mathrm{Lt}} \mathrm{Rt}=580$

-.. $\frac{\mathrm{QyEn}}{\mathrm{Lt}} \mathrm{Rt}=280$

-.. $\frac{\mathrm{QyEn}}{\mathrm{Lt}} \mathrm{Rt}=380$ 


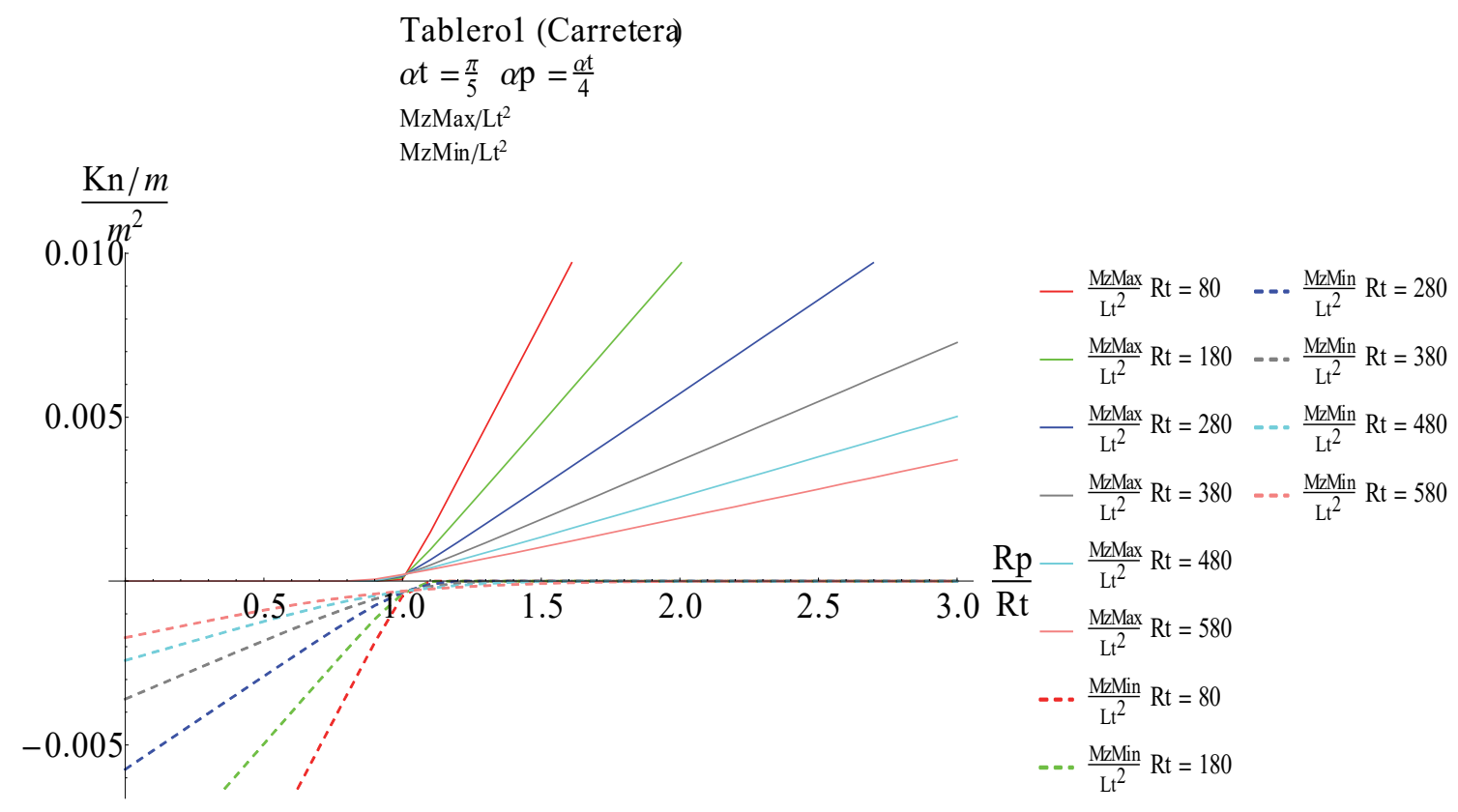

Tablerol (Carretera)

$\alpha \mathrm{t}=\frac{\pi}{5} \quad \alpha \mathrm{p}=\frac{\alpha t}{4}$

$\mathrm{NxEp} / \mathrm{Lt}$

$\mathrm{NxEn} / \mathrm{Lt}$

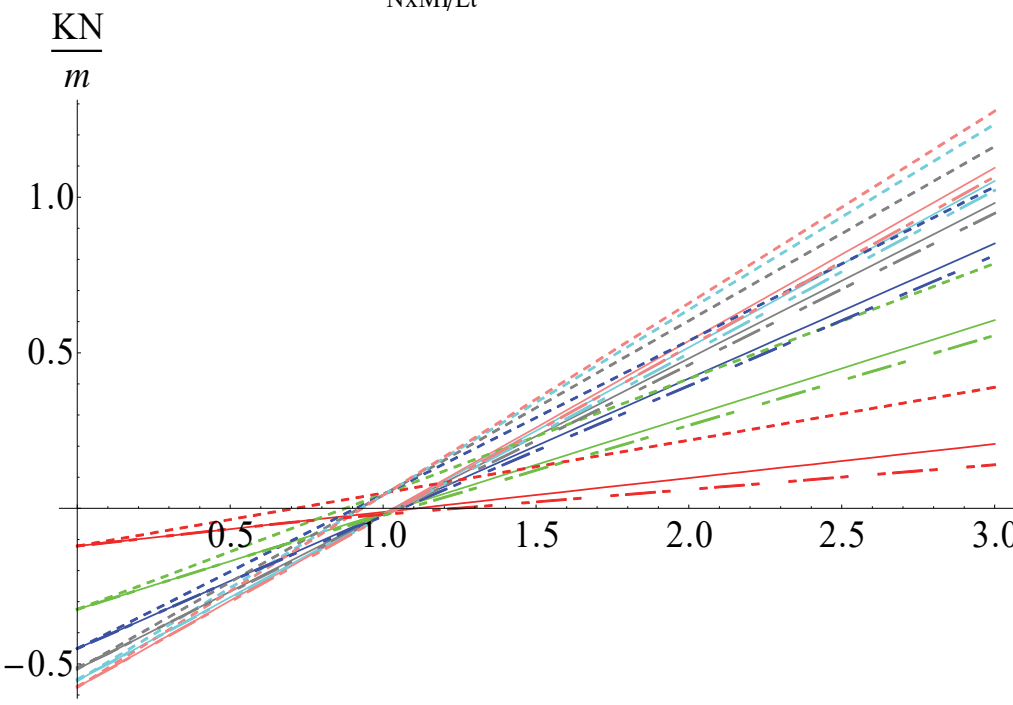

- $\frac{\mathrm{NxEp}}{\mathrm{Lt}} \mathrm{Rt}=80 \quad-=\frac{\mathrm{NxEn}}{\mathrm{Lt}} \mathrm{Rt}=480$

- $\frac{\mathrm{NxEp}}{\mathrm{Lt}} \mathrm{Rt}=180 \quad \ldots-\frac{\mathrm{NxEn}}{\mathrm{Lt}} \mathrm{Rt}=580$

- $\frac{\mathrm{NxEp}}{\mathrm{Lt}} \mathrm{Rt}=280 \quad-\quad \frac{\mathrm{NxMI}}{\mathrm{Lt}} \mathrm{Rt}=80$

$-\frac{\mathrm{NxEp}}{\mathrm{Lt}} \mathrm{Rt}=380--\frac{\mathrm{NxMI}}{\mathrm{Lt}} \mathrm{Rt}=180$

$-\frac{\mathrm{NxEp}}{\mathrm{Lt}} \mathrm{Rt}=480 \quad-\frac{\mathrm{NxMI}}{\mathrm{Lt}} \mathrm{Rt}=280$

$-\frac{\mathrm{NxEp}}{\mathrm{Lt}} \mathrm{Rt}=580 \quad-\frac{\mathrm{NxMI}}{\mathrm{Lt}} \mathrm{Rt}=380$

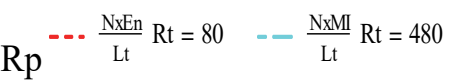

$\frac{\mathrm{Rp}}{\mathrm{Rt}}-\ldots \frac{\mathrm{NxEn}}{\mathrm{Lt}} \mathrm{Rt}=180 \quad--\frac{\mathrm{NxMI}}{\mathrm{Lt}} \mathrm{Rt}=580$

-.. $\frac{\mathrm{NxEn}}{\mathrm{Lt}} \mathrm{Rt}=280$

-.. $\frac{\mathrm{NxEn}}{\mathrm{Lt}} \mathrm{Rt}=380$ 
Tablerol (Carretera)

$\alpha \mathrm{t}=\frac{\pi}{2} \quad \alpha p=\frac{a t}{4}$

QyEp/Lt

QyEn/Lt

QyEn/Lt

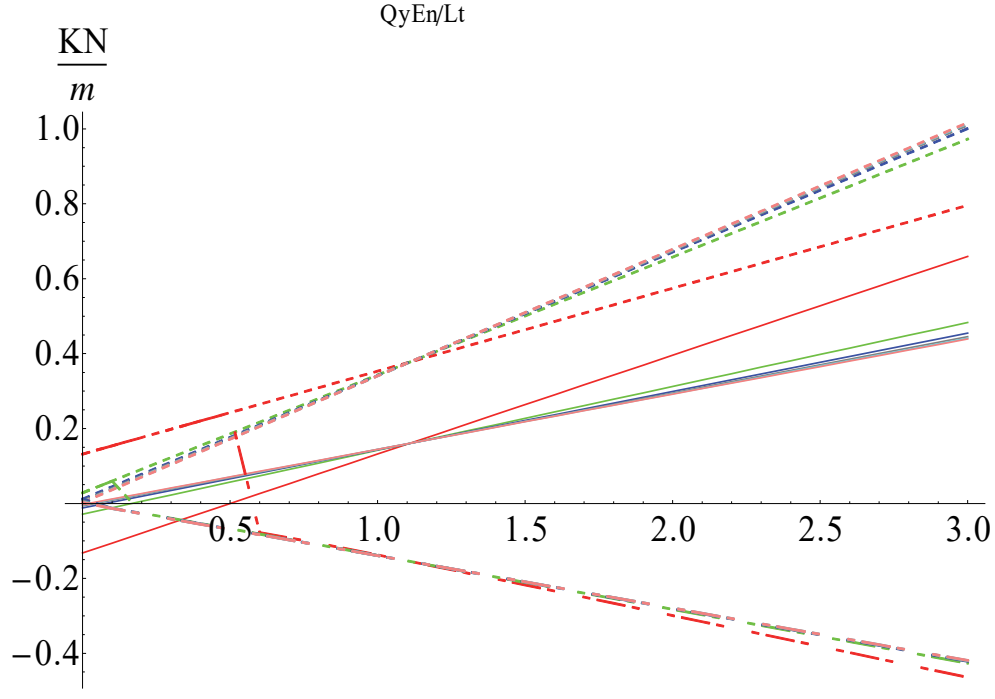

$$
\begin{aligned}
& \text { — } \frac{\mathrm{QyEp}}{\mathrm{Lt}} \mathrm{Rt}=80 \quad \ldots \frac{\mathrm{QyEn}}{\mathrm{Lt}} \mathrm{Rt}=480 \\
& \text { — } \frac{\mathrm{QyEp}}{\mathrm{Lt}} \mathrm{Rt}=180 \quad \ldots \frac{\mathrm{QyEn}}{\mathrm{Lt}} \mathrm{Rt}=580 \\
& \text { - } \frac{\text { QyEp }}{\mathrm{Lt}} \mathrm{Rt}=280--\frac{\mathrm{QyMI}}{\mathrm{Lt}} \mathrm{Rt}=80 \\
& \text { - } \frac{\mathrm{QyEp}}{\mathrm{Lt}} \mathrm{Rt}=380 \quad-\frac{\mathrm{QyMI}}{\mathrm{Lt}} \mathrm{Rt}=180 \\
& \text { - } \frac{\mathrm{QyEp}}{\mathrm{Lt}} \mathrm{Rt}=480 \quad-\frac{\mathrm{QyMI}}{\mathrm{Lt}} \mathrm{Rt}=280 \\
& \text { - } \frac{\mathrm{QyEp}}{\mathrm{Lt}} \mathrm{Rt}=580 \quad-\frac{\mathrm{QyMI}}{\mathrm{Lt}} \mathrm{Rt}=380 \\
& \text {-.. } \frac{\mathrm{Q} y E n}{\mathrm{Lt}} \mathrm{Rt}=80 \quad--\frac{\mathrm{QyMI}}{\mathrm{Lt}} \mathrm{Rt}=480 \\
& \frac{\mathrm{Rp}}{\mathrm{Rt}}=-\frac{\mathrm{QyEn}}{\mathrm{Lt}} \mathrm{Rt}=180 \quad--\frac{\mathrm{QyMI}}{\mathrm{Lt}} \mathrm{Rt}=580
\end{aligned}
$$

Tablero1 (Carretera)

$\alpha \mathrm{t}=\frac{\pi}{2} \quad \alpha \mathrm{p}=\frac{\alpha \mathrm{t}}{4}$

$\operatorname{MzMax} / \mathrm{Lt}^{2}$

$\frac{\mathrm{Kn} / m}{m^{2}}$

$\mathrm{MzMin} / \mathrm{Lt}^{2}$

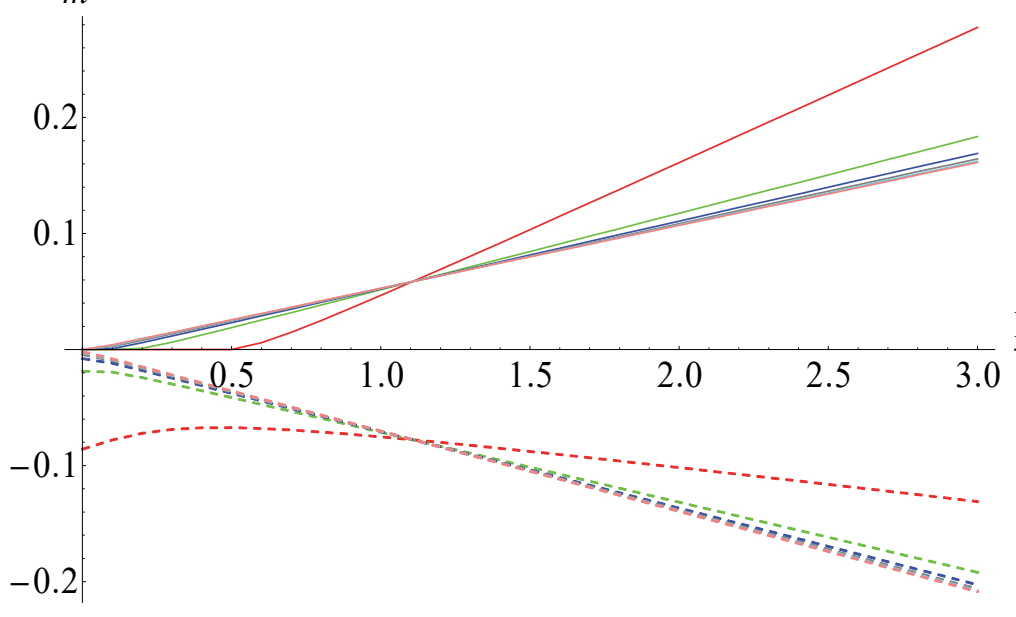

- $\frac{\mathrm{MzMax}}{\mathrm{Lt}^{2}} \mathrm{Rt}=80 \quad \ldots \frac{\mathrm{MzMin}^{2}}{\mathrm{Lt}^{2}} \mathrm{Rt}=280$

- $\frac{\mathrm{MzMax}}{\mathrm{Lt}^{2}} \mathrm{Rt}=180 \quad-. \frac{\mathrm{MzMin}}{\mathrm{Lt}^{2}} \mathrm{Rt}=380$

$-\frac{\mathrm{MzMax}}{\mathrm{Lt}^{2}} \mathrm{Rt}=280 \quad \ldots \frac{\mathrm{MzMin}}{\mathrm{Lt}^{2}} \mathrm{Rt}=480$

$\frac{\mathrm{Rp}}{\mathrm{Rt}}$

- $\frac{\mathrm{MzMax}}{\mathrm{Lt}^{2}} \mathrm{Rt}=380 \quad \ldots \frac{\mathrm{MzMin}}{\mathrm{Lt}^{2}} \mathrm{Rt}=580$

$\frac{\mathrm{MzMax}}{\mathrm{Lt}^{2}} \mathrm{Rt}=480$

- $\frac{\mathrm{MzMax}}{\mathrm{Lt}^{2}} \mathrm{Rt}=580$

- .. $\frac{\mathrm{MzMin}}{\mathrm{Lt}^{2}} \mathrm{Rt}=80$

-. $\frac{\mathrm{Mz} \mathrm{Min}}{\mathrm{Lt}^{2}} \mathrm{Rt}=180$ 


\section{Tablerol (Carretera)}

$$
\begin{aligned}
& \alpha \mathrm{t}=\frac{\pi}{2} \quad \alpha \mathrm{p}=\frac{\alpha \mathrm{t}}{4} \\
& \mathrm{NxEp} / \mathrm{Lt} \\
& \mathrm{NxEn} / \mathrm{Lt}
\end{aligned}
$$

NxMy/Lt

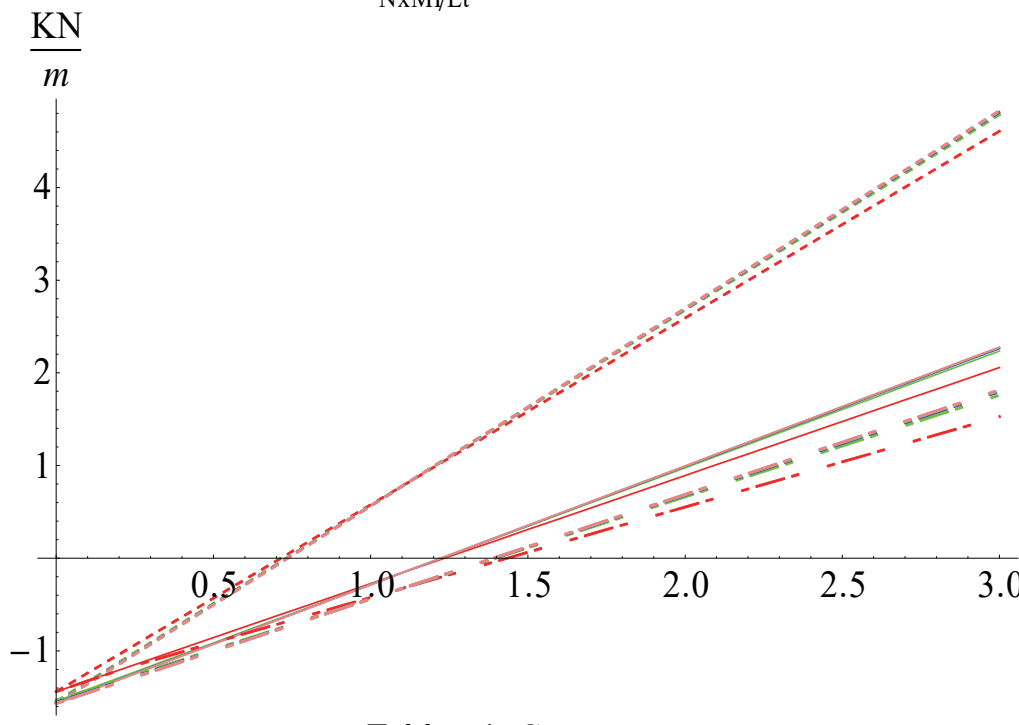

$$
\begin{aligned}
& -\frac{\mathrm{NxEp}}{\mathrm{Lt}} \mathrm{Rt}=80 \quad \ldots=\frac{\mathrm{NxEn}}{\mathrm{Lt}} \mathrm{Rt}=480 \\
& \text { — } \frac{\mathrm{NxEp}}{\mathrm{Lt}} \mathrm{Rt}=180 \quad \ldots-\frac{\mathrm{NxEn}}{\mathrm{Lt}} \mathrm{Rt}=580 \\
& \text { - } \frac{\mathrm{NxEp}}{\mathrm{Lt}} \mathrm{Rt}=280 \quad-\frac{\mathrm{NxMI}}{\mathrm{Lt}} \mathrm{Rt}=80 \\
& -\frac{\mathrm{NxEp}}{\mathrm{Lt}} \mathrm{Rt}=380--\frac{\mathrm{NxMI}}{\mathrm{Lt}} \mathrm{Rt}=180 \\
& -\frac{\mathrm{NxEp}}{\mathrm{Lt}} \mathrm{Rt}=480--\frac{\mathrm{NxMI}}{\mathrm{Lt}} \mathrm{Rt}=280 \\
& -\frac{\mathrm{NxEp}}{\mathrm{Lt}} \mathrm{Rt}=580 \quad--\frac{\mathrm{NxMI}}{\mathrm{Lt}} \mathrm{Rt}=380 \\
& \ldots \frac{\mathrm{NxEn}}{\mathrm{Lt}} \mathrm{Rt}=80 \quad--\frac{\mathrm{NxMI}}{\mathrm{Lt}} \mathrm{Rt}=480 \\
& \frac{\mathrm{Rp}}{\mathrm{Rt}}--\frac{\mathrm{NxEn}}{\mathrm{Lt}} \mathrm{Rt}=180 \quad--\frac{\mathrm{NxMI}}{\mathrm{Lt}} \mathrm{Rt}=580 \\
& \text {-.. } \frac{\mathrm{NxEn}}{\mathrm{Lt}} \mathrm{Rt}=280 \\
& \text { - - } \frac{\mathrm{NxEn}}{\mathrm{Lt}} \mathrm{Rt}=380
\end{aligned}
$$

\section{Tablerol (Carretera)}

$\alpha \mathrm{t}=\frac{4 \pi}{5} \quad \alpha \mathrm{p}=\frac{\alpha \mathrm{t}}{4}$

QyEp/Lt

QyEn/Lt

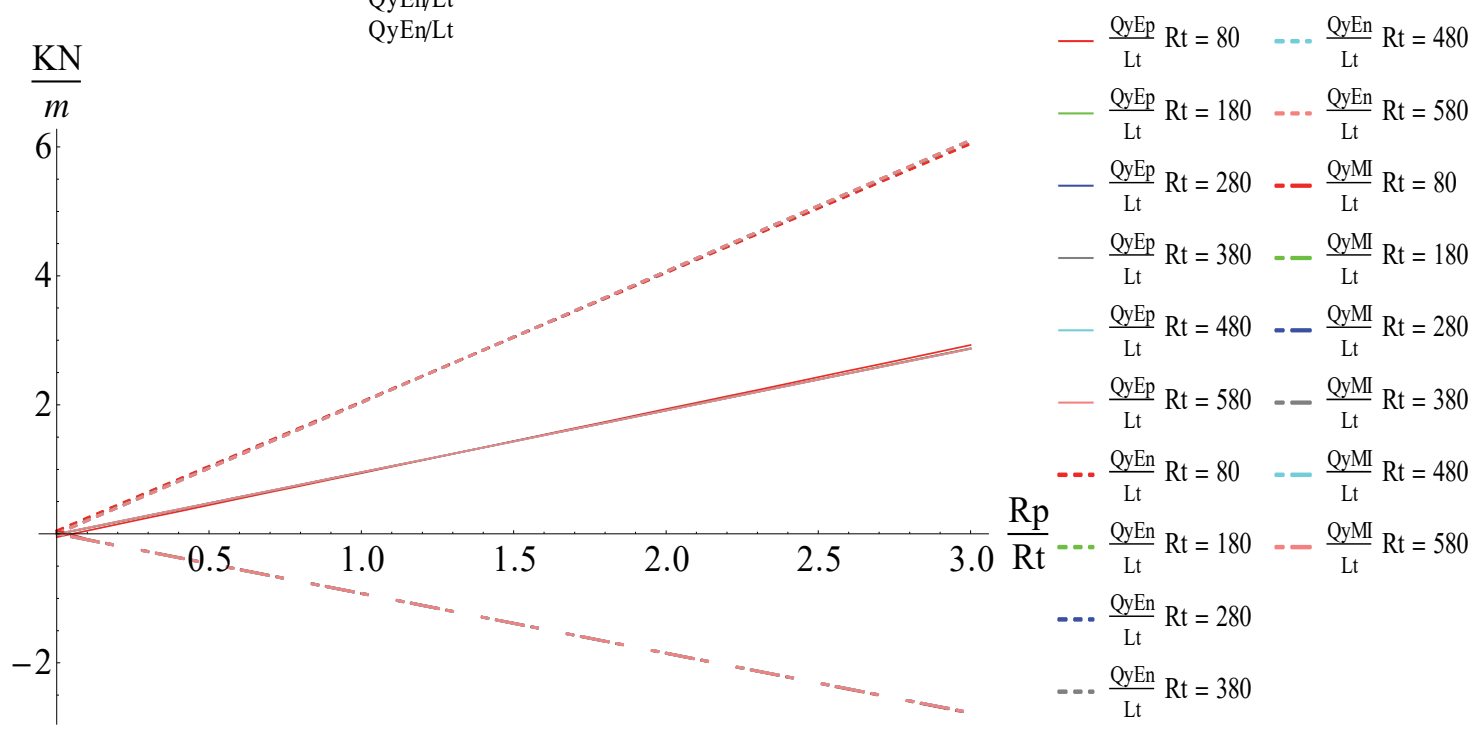


Tablerol (Carretera)

$\alpha \mathrm{t}=\frac{4 \pi}{5} \quad \alpha \mathrm{p}=\frac{\alpha \mathrm{t}}{4}$

$\mathrm{MzMax} / \mathrm{Lt}^{2}$

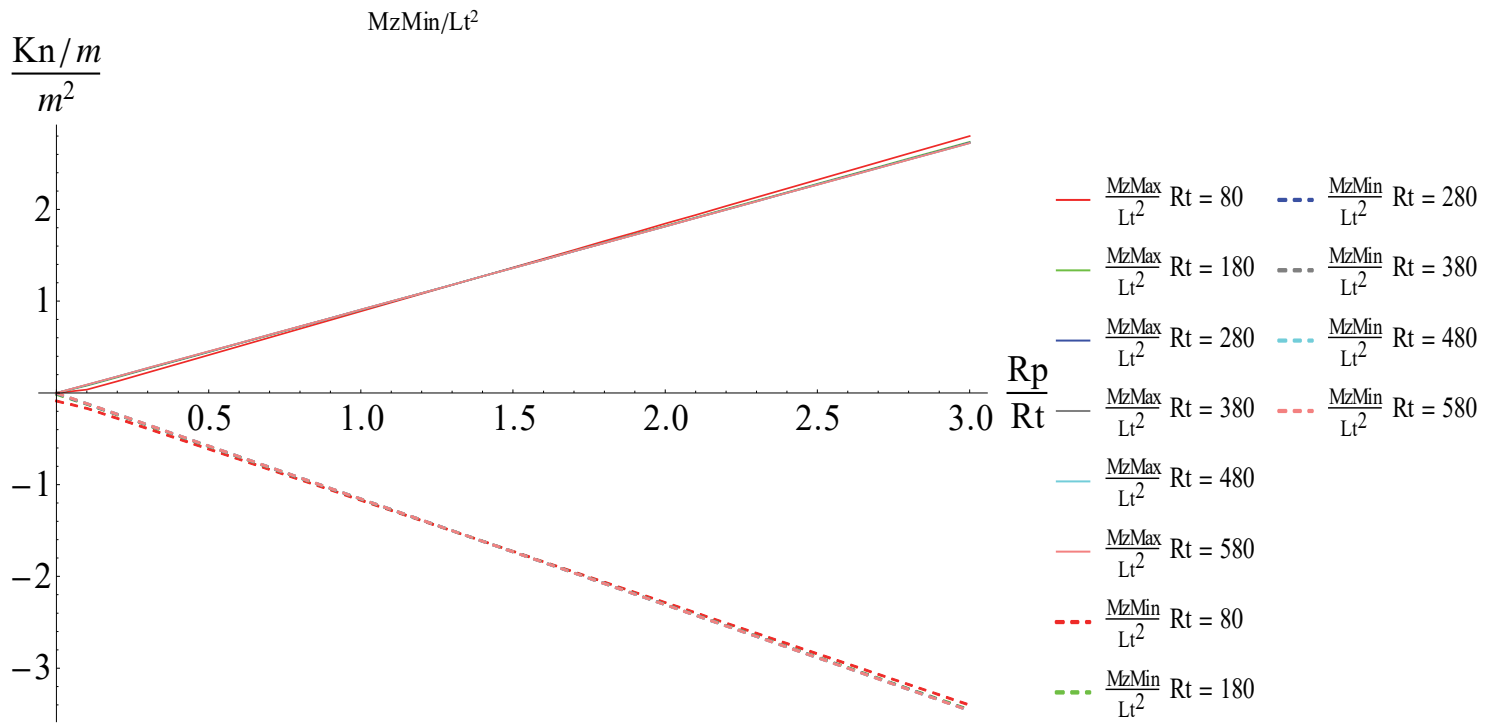

Tablero1 (Carretera)

$\alpha \mathrm{t}=\frac{4 \pi}{5} \quad \alpha \mathrm{p}=\frac{\alpha \mathrm{t}}{4}$

$\mathrm{NxEp} / \mathrm{Lt}$

$\mathrm{NxEn} / \mathrm{Lt}$

$\mathrm{NxMl} / \mathrm{Lt}$

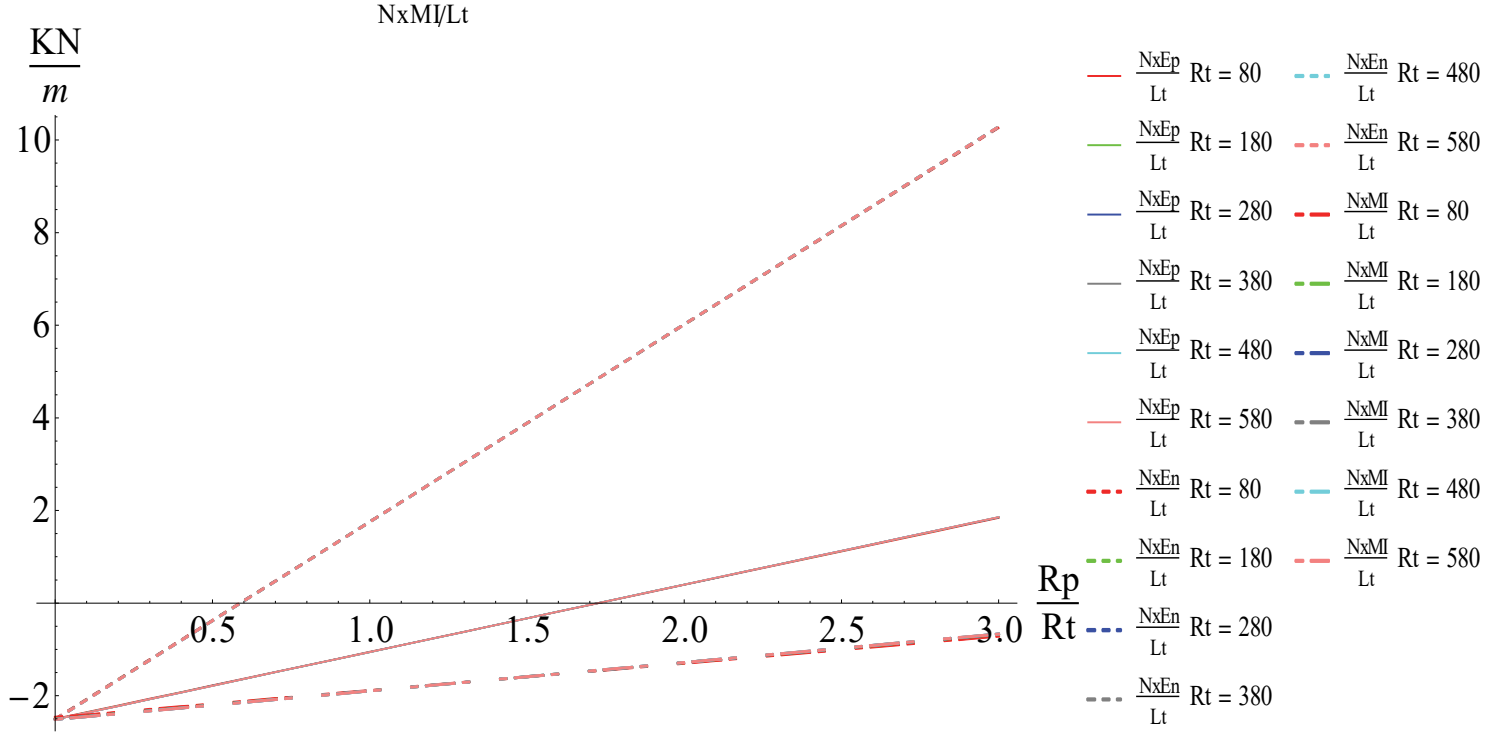

Diagrama 2.65 Solicitaciones del tablero $\left(\frac{Q y}{L t}, \frac{M z}{L t^{2}} y \frac{N x}{L t}\right) . \alpha t=\frac{\pi}{5}, \alpha p=\frac{\alpha t}{4}$, Tablero 7 (Peatonal); $\alpha \boldsymbol{t}=\frac{\pi}{2}, \alpha \boldsymbol{p}=\frac{\alpha t}{4}$,

Tablero 7 (Peatonal); $\boldsymbol{\alpha t}=\frac{\pi}{5}, \alpha \boldsymbol{p}=\frac{\alpha t}{4}$, Tablero 1 (Carretera); $\boldsymbol{\alpha t}=\frac{\pi}{2}, \boldsymbol{\alpha p}=\frac{\alpha t}{4}$, Tablero 1 (Carretera); $\boldsymbol{\alpha t}=$ $\frac{4 \pi}{5}, \alpha p=\frac{\alpha t}{4}$, Tablero 1 (Carretera);

Los patrones de comportamiento resultan similares a los vistos en el análisis ya realizado para la hipótesis con $\alpha p=0$. La pauta a medida que se mueve la pila se vuelve más homogénea, el comportamiento "tipo viga" apenas se produce (Diagrama 2.64 y Diagrama

2.65). Esto tiene lógica, si consideramos que tiene cierta similitud disponer la pila en $\alpha p=\frac{\alpha t}{2} y$ mantener $\alpha p=0$, duplicando el ángulo desarrollado por el tablero a $\alpha t^{\prime}=2 \alpha t$. Se aprecia 
como domina el comportamiento "tipo esfera" a medida que se acerca la pila al tablero Rp $>0$. Todo lo expuesto se acentúa más a medida que aumentamos $\alpha p$.

De nuevo, en aquellos tableros que muestran un comportamiento "tipo viga", se puede apreciar cómo los valores de las solicitaciones son mucho más sensibles a la disminución de carga (Ttir $[\alpha]$ ), mientras que (ahora mucho más predominantes) cuando pasamos de un sistema resistivo "tipo arco" al "tipo esfera" directamente, vemos como lo más influyente para las solicitaciones es el cambio de dirección que se produce en la carga transversal. Sigue siendo válido el análisis realizado para el caso en el que la pila se situaba en el eje de simetría del tablero $(\alpha p=0)$.

En este caso resulta todavía más claro, que la variable $\alpha t$ es la que marca el comportamiento del tablero frente a las cargas concéntricas horizontales cuando $R p>0$. Con el propósito de encontrar nuevas definiciones para los diferentes tipos de comportamiento, se vuelven a estudiar las 4 configuraciones que se estudiaron para $\alpha p=0$. Se muestran de nuevo: las 2 primeras, van a corresponder a pasarelas y sus longitudes de tablero, van a ser de $\mathrm{Lt}=140 \mathrm{~m}$ y $280 \mathrm{~m}$, con una sección tipo Tablero 7 (Peatonal) (Tabla 2.18). Mientras que las 2 segundas van a corresponder a un viaducto, con longitudes de tablero, Lt $=220 \mathrm{~m}$ y $440 \mathrm{~m}$ y sección tipo Tablero 1 (Carretera) (Tabla 2.18). De nuevo se va a utilizar el factor $\frac{1}{\alpha^{2}}$ y los puntos estudiados van a coincidir con los estudiados en el Diagrama 2.64 y el Diagrama 2.65.

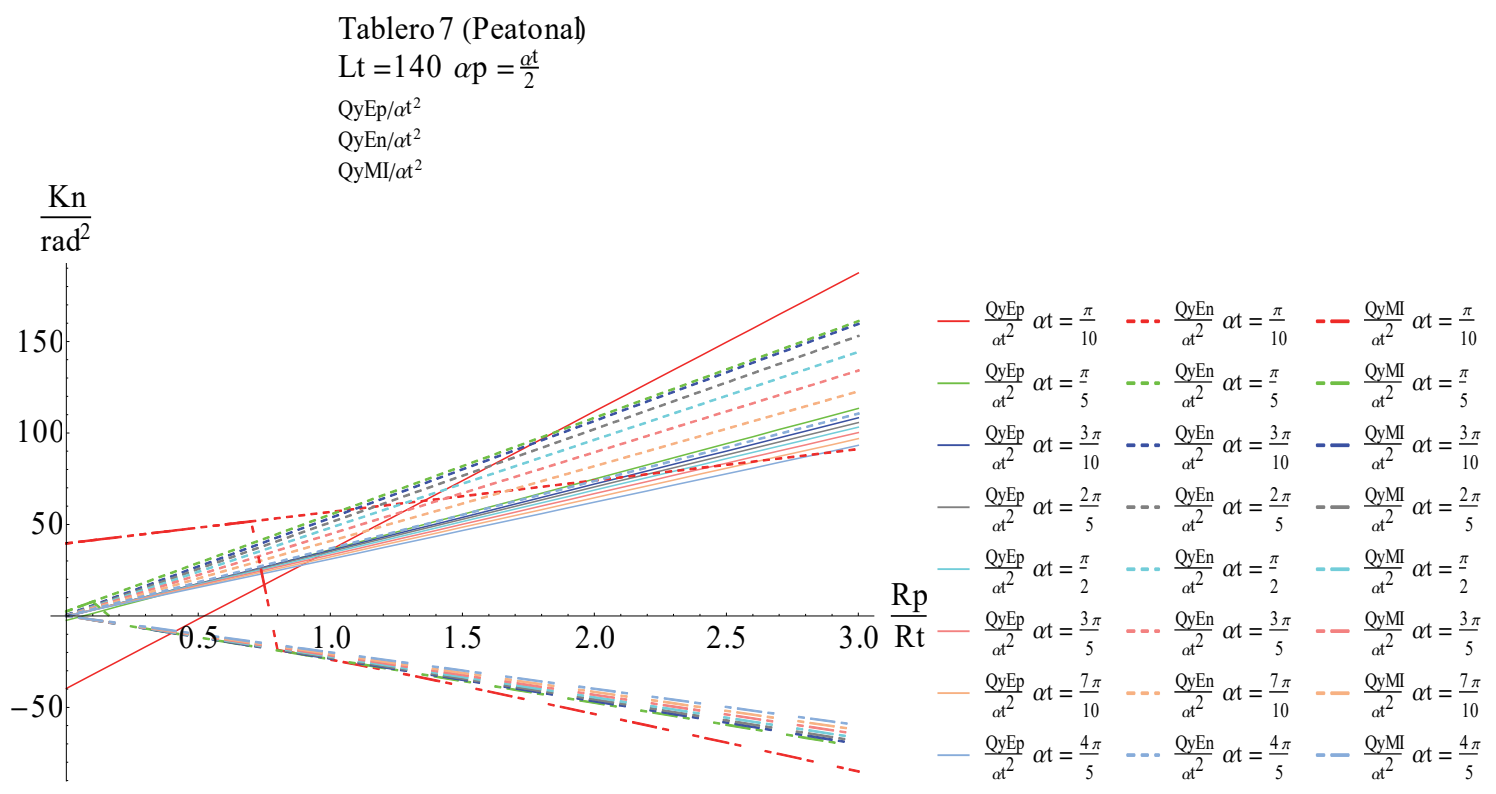


Tablero 7 (Peatonal)

$\mathrm{Lt}=140 \alpha \mathrm{p}=\frac{\alpha \mathrm{t}}{2}$

$\operatorname{MzMax} / \alpha \mathrm{t}^{2}$

$\operatorname{MzMin} / \alpha \mathrm{t}^{2}$

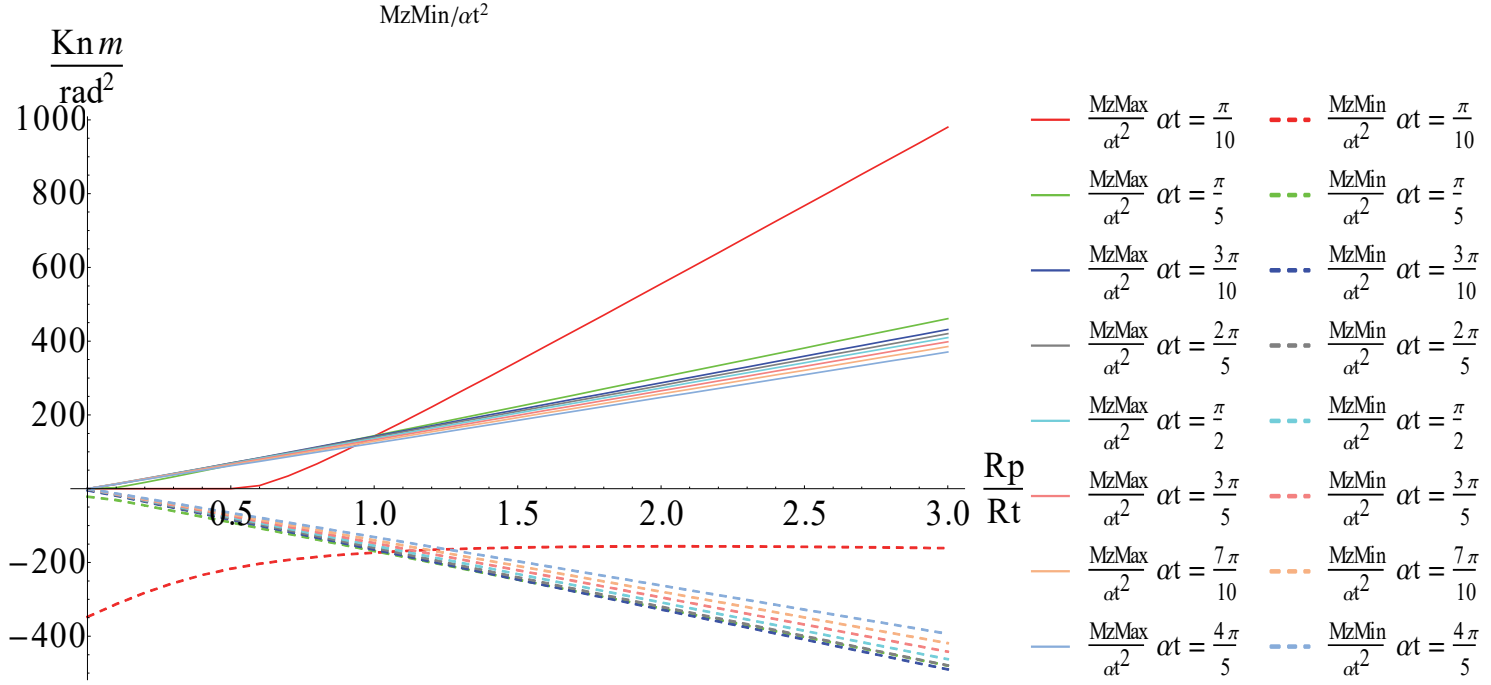

Tablero 7 (Peatonal)

$\mathrm{Lt}=140 \alpha \mathrm{p}=\frac{\alpha \mathrm{t}}{2}$

$\mathrm{NxEp} / \mathrm{Rt}$

$\mathrm{NxEn} / \mathrm{Rt}$

$\underline{\mathrm{KN}}$

$\mathrm{NxML} / \mathrm{Rt}$

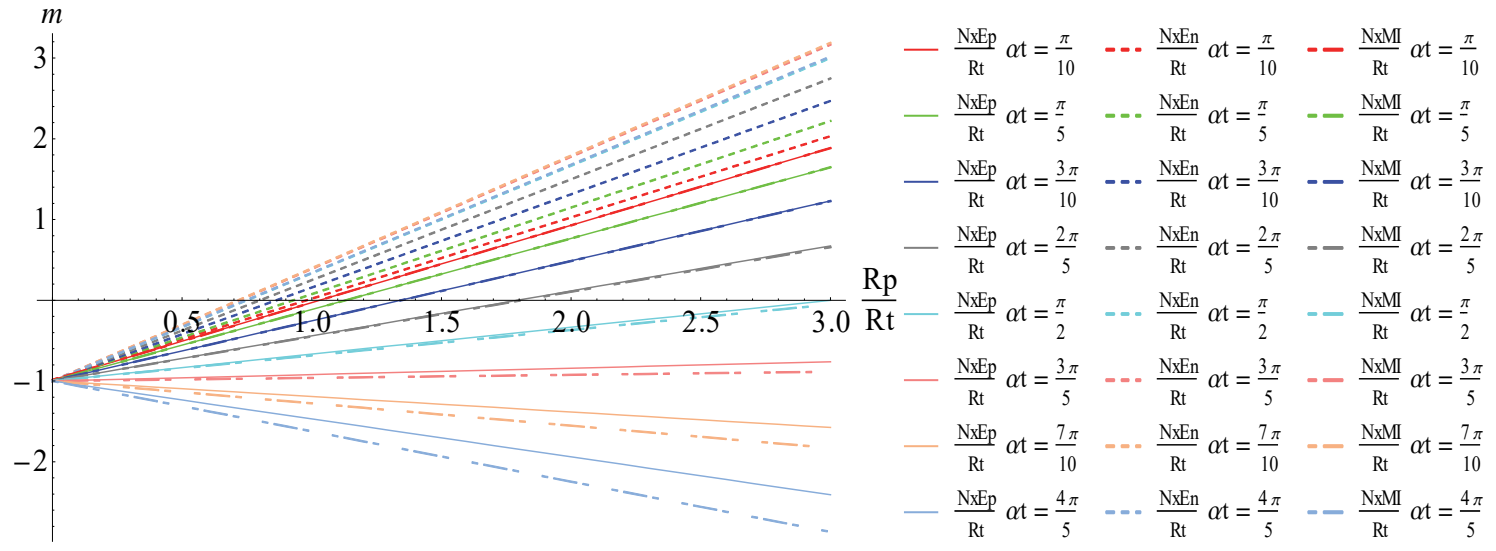

Tablero 7 (Peatonal)

$\mathrm{Lt}=280 \alpha \mathrm{p}=\frac{\alpha \mathrm{t}}{2}$

$\mathrm{QyEp} / \alpha t^{2}$

QyEn/ $/ t^{2}$

QyMI $/ t^{2}$

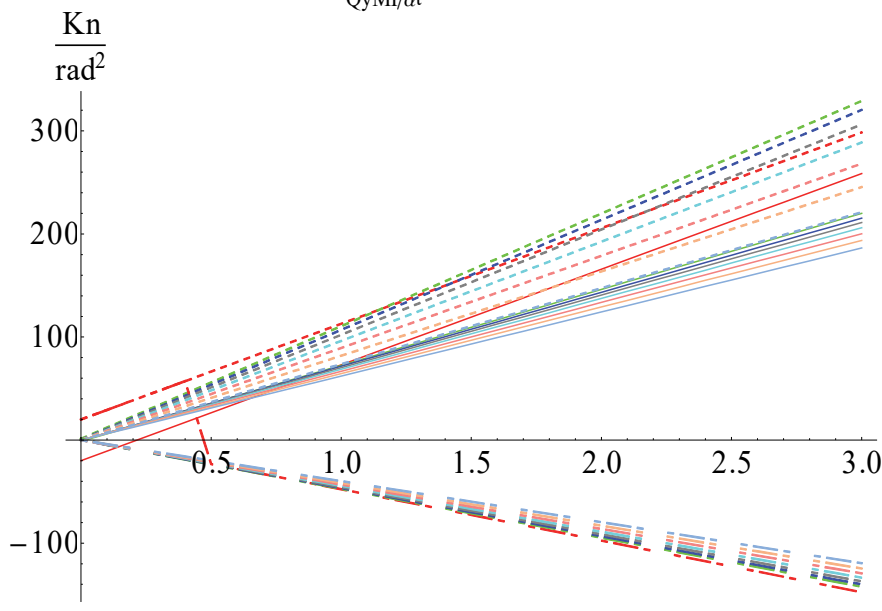

- $\frac{\text { QyEp }}{\alpha \mathrm{t}^{2}} \alpha \mathrm{t}=\frac{\pi}{10} \quad-\ldots \frac{\mathrm{QyEn}}{\alpha \mathrm{t}^{2}} \alpha \mathrm{t}=\frac{\pi}{10} \quad-\quad-\frac{\mathrm{QyMI}}{a \mathrm{t}^{2}} \alpha \mathrm{t}=\frac{\pi}{10}$

$-\frac{\mathrm{QyEp}}{d \mathrm{t}^{2}} \alpha \mathrm{t}=\frac{\pi}{5} \quad \ldots \frac{\mathrm{QyEn}}{\alpha \mathrm{t}^{2}} \alpha \mathrm{t}=\frac{\pi}{5} \quad--\frac{\mathrm{QyMI}}{d \mathrm{t}^{2}} \alpha \mathrm{t}=\frac{\pi}{5}$

- $\frac{\mathrm{QyEp}}{\mathrm{\alpha}^{2}} \alpha \mathrm{t}=\frac{3 \pi}{10} \quad \cdots \frac{\mathrm{QyEn}}{\mathrm{at}^{2}} \alpha \mathrm{t}=\frac{3 \pi}{10} \quad-\quad-\frac{\mathrm{QyMI}}{\mathrm{t}^{2}} \alpha \mathrm{t}=\frac{3 \pi}{10}$

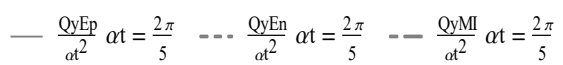

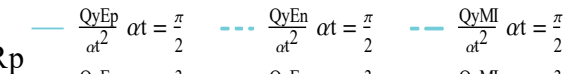

$\frac{\mathrm{Rp}}{\mathrm{Rt}}-\frac{\mathrm{QyEp}}{a \mathrm{t}^{2}} \alpha \mathrm{t}=\frac{3 \pi}{5} \quad \ldots \frac{\mathrm{QyEn}}{\mathrm{dt^{2 }}} \alpha \mathrm{t}=\frac{3 \pi}{5} \quad-\frac{\mathrm{QyMI}}{\mathrm{dt^{2 }}} \alpha \mathrm{t}=\frac{3 \pi}{5}$

$-\frac{\mathrm{QyEp}}{\alpha \mathrm{t}^{2}} \alpha \mathrm{t}=\frac{7 \pi}{10} \quad-\ldots \frac{\mathrm{QyEn}}{\mathrm{at}^{2}} \alpha \mathrm{t}=\frac{7 \pi}{10} \quad-\frac{\mathrm{QyMI}}{\mathrm{d \textrm {t } ^ { 2 }}} \alpha \mathrm{t}=\frac{7 \pi}{10}$

- $\frac{\mathrm{QyEp}}{a \mathrm{t}^{2}} \alpha \mathrm{t}=\frac{4 \pi}{5} \quad \ldots \frac{\mathrm{QyEn}}{a t^{2}} \alpha \mathrm{t}=\frac{4 \pi}{5} \quad=-\frac{\mathrm{QyMI}}{a t^{2}} \alpha \mathrm{t}=\frac{4 \pi}{5}$ 
Tablero 7 (Peatonal)

$\mathrm{Lt}=280 \alpha \mathrm{p}=\frac{\alpha \mathrm{t}}{2}$

$\operatorname{MzMax} / \alpha \mathrm{t}^{2}$

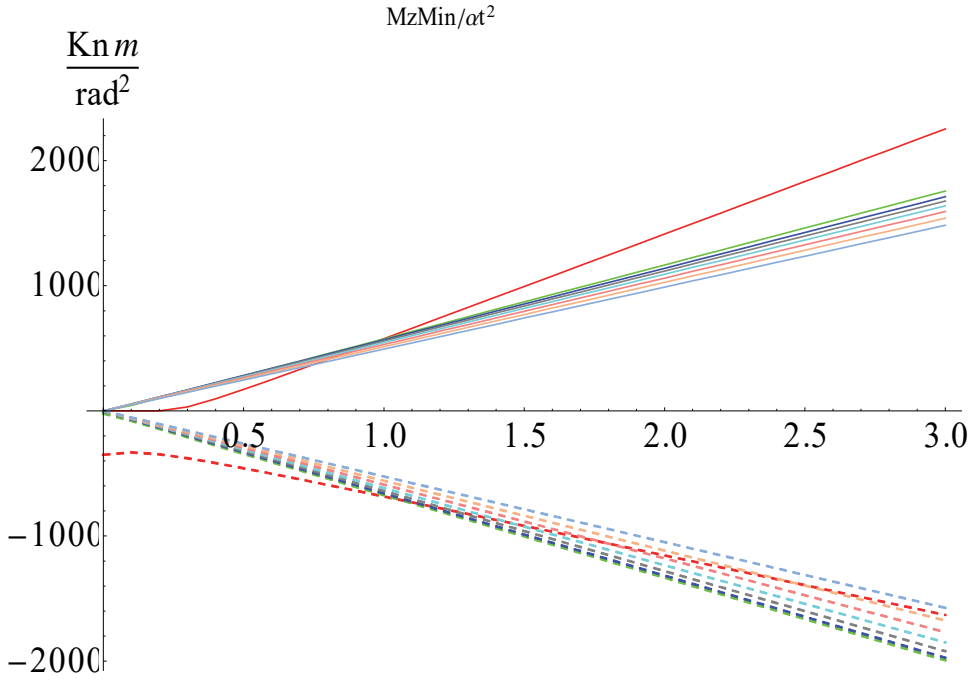

$$
\begin{aligned}
& \text { - } \frac{\mathrm{Mz}_{2} \mathrm{Max}}{\mathrm{at}{ }^{2}} \alpha \mathrm{t}=\frac{\pi}{10} \quad \cdots \frac{\mathrm{MzZMin}^{2}}{\mathrm{at} \mathrm{t}^{2}} \alpha \mathrm{t}=\frac{\pi}{10} \\
& \text { - } \frac{\mathrm{MzMax}_{\mathrm{z}}}{\mathrm{dt}^{2}} \alpha \mathrm{t}=\frac{\pi}{5} \quad-\cdots \frac{\mathrm{MzMin}}{\alpha \mathrm{t}^{2}} \alpha \mathrm{t}=\frac{\pi}{5}
\end{aligned}
$$

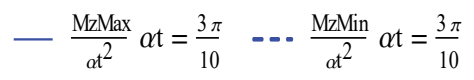

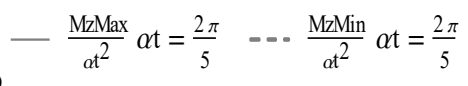

$$
\begin{aligned}
& \frac{\mathrm{Rp}}{\mathrm{Rt}}-\frac{\mathrm{MzMax}}{c \mathrm{t}^{2}} \alpha \mathrm{t}=\frac{\pi}{2} \quad-\cdots \frac{\mathrm{MzMin}}{\mathrm{at} \mathrm{t}^{2}} \alpha \mathrm{t}=\frac{\pi}{2} \\
& \text { - } \frac{\mathrm{MzMax}^{2}}{\mathrm{at} \mathrm{t}^{2}} \alpha \mathrm{t}=\frac{3 \pi}{5} \quad-. \frac{\mathrm{MzMin}}{\mathrm{dt} \mathrm{t}^{2}} \alpha \mathrm{t}=\frac{3 \pi}{5} \\
& -\frac{\mathrm{M}_{2} \mathrm{Max}}{\mathrm{ct}^{2}} \alpha \mathrm{t}=\frac{7 \pi}{10} \quad \ldots \frac{\mathrm{Mz}_{2} \mathrm{Min}}{\mathrm{dt}} \alpha \mathrm{t}=\frac{7 \pi}{10} \\
& -\frac{\mathrm{MzMax}}{\alpha t^{2}} \alpha \mathrm{t}=\frac{4 \pi}{5} \quad \ldots \frac{\mathrm{MzNin}^{2}}{\alpha \mathrm{t}^{2}} \alpha \mathrm{t}=\frac{4 \pi}{5}
\end{aligned}
$$

Tablero 7 (Peatonal)

$\mathrm{Lt}=280 \alpha \mathrm{p}=\frac{\alpha t}{2}$

$\mathrm{NxEp} / \mathrm{Rt}$

$\mathrm{NxEn} / \mathrm{Rt}$
$\mathrm{NxMI} / \mathrm{Rt}$

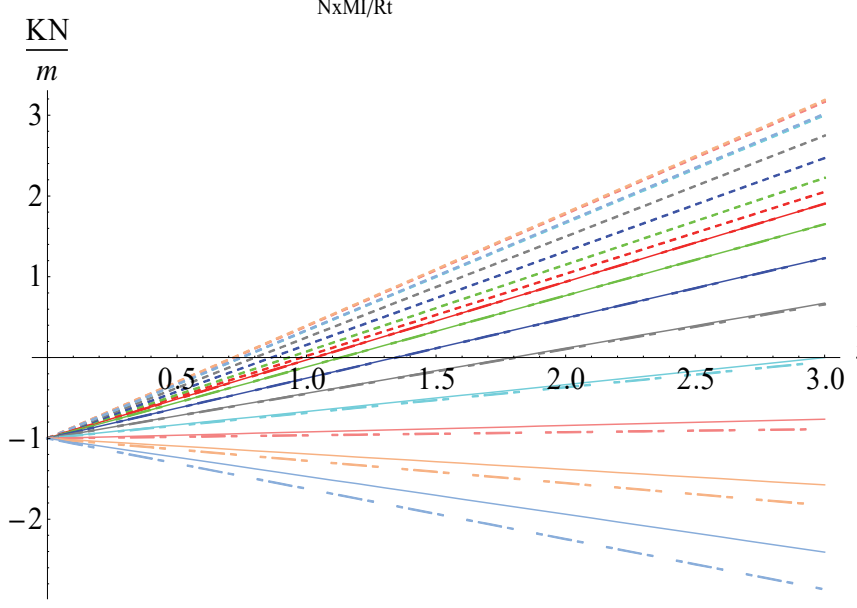

$-\frac{\mathrm{NxEp}}{\mathrm{Rt}} \alpha \mathrm{t}=\frac{\pi}{10} \quad--\frac{\mathrm{NxEn}}{\mathrm{Rt}} \alpha \mathrm{t}=\frac{\pi}{10} \quad-\quad-\frac{\mathrm{NxMI}}{\mathrm{Rt}} \alpha \mathrm{t}=\frac{\pi}{10}$

$-\frac{\mathrm{NxEp}}{\mathrm{Rt}} \alpha \mathrm{t}=\frac{\pi}{5} \quad-\cdots \frac{\mathrm{NxEn}}{\mathrm{Rt}} \alpha \mathrm{t}=\frac{\pi}{5} \quad--\frac{\mathrm{NxMI}}{\mathrm{Rt}} \alpha \mathrm{t}=\frac{\pi}{5}$

$-\frac{\mathrm{NxEp}}{\mathrm{Rt}} \alpha \mathrm{t}=\frac{3 \pi}{10} \quad \ldots \frac{\mathrm{NxEn}}{\mathrm{Rt}} \alpha \mathrm{t}=\frac{3 \pi}{10} \quad-\frac{\mathrm{NxMI}}{\mathrm{Rt}} \alpha \mathrm{t}=\frac{3 \pi}{10}$

$-\frac{\mathrm{NxEp}}{\mathrm{Rt}} \alpha \mathrm{t}=\frac{2 \pi}{5} \quad-. \frac{\mathrm{NxEn}}{\mathrm{Rt}} \alpha \mathrm{t}=\frac{2 \pi}{5} \quad-\frac{\mathrm{NxMI}}{\mathrm{Rt}} \alpha \mathrm{t}=\frac{2 \pi}{5}$

$\frac{\mathrm{Rp}}{\mathrm{Rt}}-\frac{\mathrm{NxEp}}{\mathrm{Rt}} \alpha \mathrm{t}=\frac{\pi}{2} \quad-=\frac{\mathrm{NxEn}}{\mathrm{Rt}} \alpha \mathrm{t}=\frac{\pi}{2} \quad--\frac{\mathrm{NxMI}}{\mathrm{Rt}} \alpha \mathrm{t}=\frac{\pi}{2}$

$-\frac{\mathrm{NxEp}}{\mathrm{Rt}} \alpha \mathrm{t}=\frac{3 \pi}{5} \quad-\cdots \frac{\mathrm{NxEn}}{\mathrm{Rt}} \alpha \mathrm{t}=\frac{3 \pi}{5} \quad--\frac{\mathrm{NxMI}}{\mathrm{Rt}} \alpha \mathrm{t}=\frac{3 \pi}{5}$

$-\frac{\mathrm{NxEp}}{\mathrm{Rt}} \alpha \mathrm{t}=\frac{7 \pi}{10} \quad-\cdots \frac{\mathrm{NxEn}}{\mathrm{Rt}} \alpha \mathrm{t}=\frac{7 \pi}{10} \quad--\frac{\mathrm{NxMI}}{\mathrm{Rt}} \alpha \mathrm{t}=\frac{7 \pi}{10}$

$-\frac{\mathrm{NxEp}}{\mathrm{Rt}} \alpha \mathrm{t}=\frac{4 \pi}{5} \quad \cdots \frac{\mathrm{NxEn}}{\mathrm{Rt}} \alpha \mathrm{t}=\frac{4 \pi}{5} \quad--\frac{\mathrm{NxMI}}{\mathrm{Rt}} \alpha \mathrm{t}=\frac{4 \pi}{5}$

Tablero 7 (Peatonal)

$\mathrm{Lt}=420 \alpha \mathrm{p}=\frac{\alpha \mathrm{t}}{2}$

QyEp/ $/ t^{2}$

QyEn/ot ${ }^{2}$

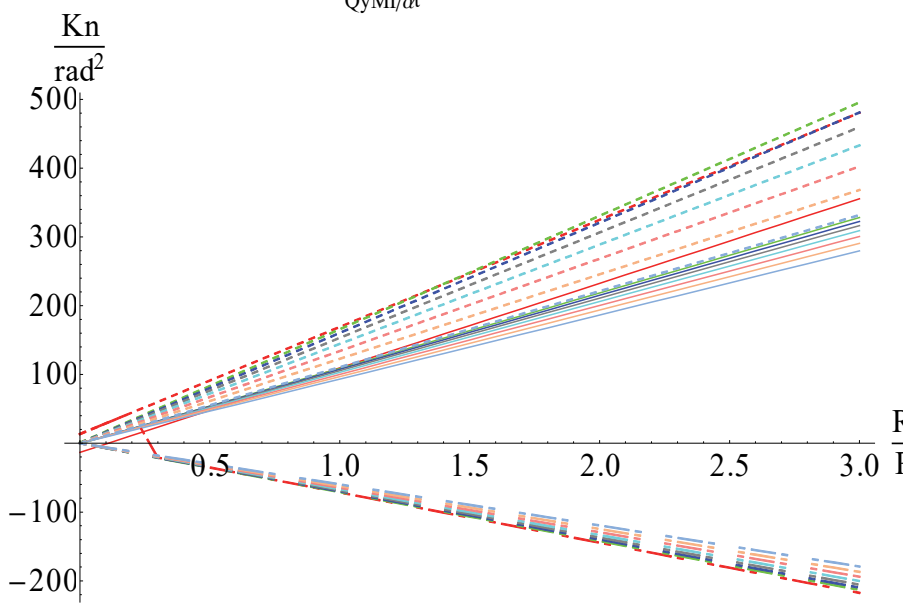

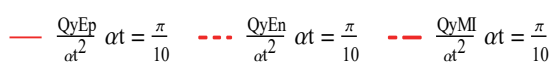

$-\frac{\mathrm{QyEp}}{\alpha \mathrm{t}^{2}} \alpha \mathrm{t}=\frac{\pi}{5} \quad-\ldots \frac{\mathrm{QyEn}}{\alpha \mathrm{t}^{2}} \alpha \mathrm{t}=\frac{\pi}{5} \quad--\frac{\mathrm{QyMI}}{\alpha \mathrm{t}^{2}} \alpha \mathrm{t}=\frac{\pi}{5}$

$-\frac{\mathrm{QyEp}}{\alpha \mathrm{t}^{2}} \alpha \mathrm{t}=\frac{3 \pi}{10} \quad-\cdots \frac{\mathrm{QyEn}}{\alpha \mathrm{t}^{2}} \alpha \mathrm{t}=\frac{3 \pi}{10} \quad--\frac{\mathrm{QyMI}}{\alpha \mathrm{t}^{2}} \alpha \mathrm{t}=\frac{3 \pi}{10}$

$-\frac{Q \mathrm{yEp}}{\alpha \mathrm{t}^{2}} \alpha \mathrm{t}=\frac{2 \pi}{5} \quad-\ldots \frac{\mathrm{QyEn}}{\alpha \mathrm{t}^{2}} \alpha \mathrm{t}=\frac{2 \pi}{5} \quad--\frac{\mathrm{QyMI}}{\alpha \mathrm{t}^{2}} \alpha \mathrm{t}=\frac{2 \pi}{5}$

$-\frac{\mathrm{QyEp}}{\alpha t^{2}} \alpha \mathrm{t}=\frac{\pi}{2} \quad-\cdots \frac{\mathrm{QyEn}}{\alpha \mathrm{t}^{2}} \alpha \mathrm{t}=\frac{\pi}{2} \quad--\frac{\mathrm{QyMI}}{d \mathrm{t}^{2}} \alpha \mathrm{t}=\frac{\pi}{2}$

$\frac{\mathrm{Rp}}{\mathrm{Rt}}-\frac{\mathrm{QyEp}}{\alpha t^{2}} \alpha \mathrm{t}=\frac{3 \pi}{5} \quad--\frac{\mathrm{QyEn}}{\alpha t^{2}} \alpha \mathrm{t}=\frac{3 \pi}{5} \quad--\frac{\mathrm{QyMI}}{\alpha t^{2}} \alpha \mathrm{t}=\frac{3 \pi}{5}$

$-\frac{\mathrm{QyEp}}{\alpha \mathrm{t}^{2}} \alpha \mathrm{t}=\frac{7 \pi}{10} \quad--\frac{\mathrm{QyEn}}{\alpha \mathrm{t}^{2}} \alpha \mathrm{t}=\frac{7 \pi}{10} \quad--\frac{\mathrm{QyMI}}{\alpha \mathrm{t}^{2}} \alpha \mathrm{t}=\frac{7 \pi}{10}$

$-\frac{\mathrm{QyEp}}{\alpha \mathrm{t}^{2}} \alpha \mathrm{t}=\frac{4 \pi}{5} \quad-=\frac{\mathrm{Q} \mathrm{yEn}}{\alpha \mathrm{t}^{2}} \alpha \mathrm{t}=\frac{4 \pi}{5} \quad--\frac{\mathrm{QyMI}}{\alpha \mathrm{t}^{2}} \alpha \mathrm{t}=\frac{4 \pi}{5}$ 
Tablero 7 (Peatonal)

$\mathrm{Lt}=420 \alpha \mathrm{p}=\frac{\alpha \mathrm{t}}{2}$

$\operatorname{MzMax} / \alpha \mathrm{t}^{2}$

$\operatorname{MzMin} / \alpha \mathrm{t}^{2}$

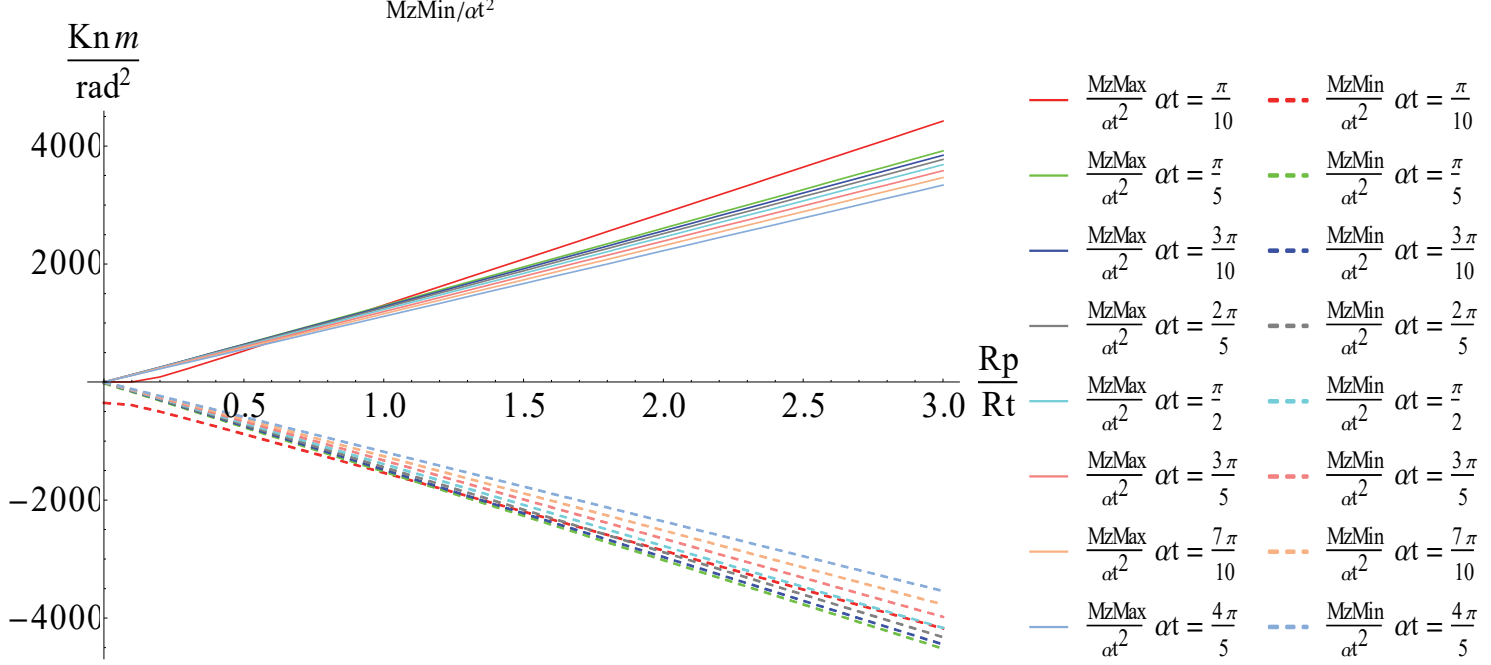

Tablero 7 (Peatonal)

$\mathrm{Lt}=420 \alpha \mathrm{p}=\frac{\alpha \mathrm{t}}{2}$

$\mathrm{NxEp} / \mathrm{Rt}$

$\mathrm{NxEn} / \mathrm{Rt}$
$\mathrm{NxMI} / \mathrm{Rt}$

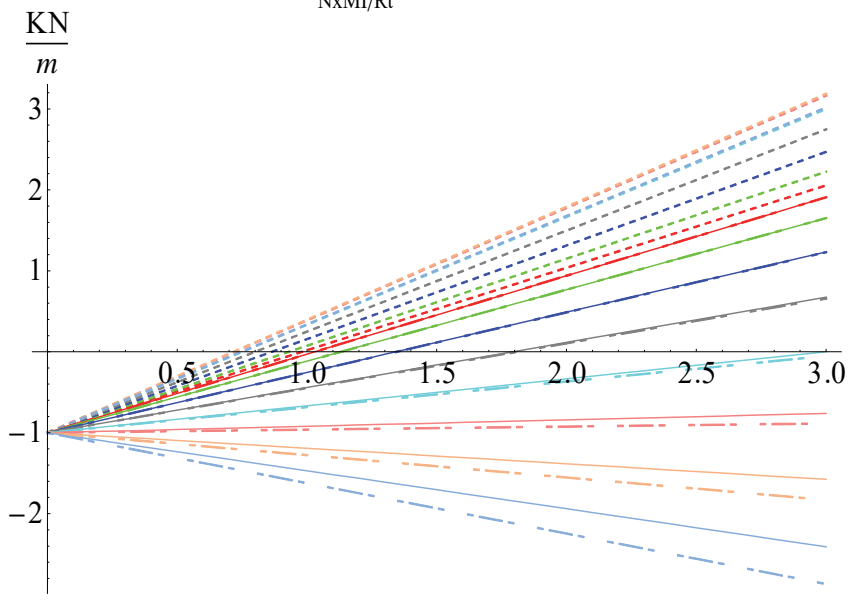

$-\frac{\mathrm{NxEp}}{\mathrm{Rt}} \alpha \mathrm{t}=\frac{\pi}{10} \quad--\frac{\mathrm{NxEn}}{\mathrm{Rt}} \alpha \mathrm{t}=\frac{\pi}{10} \quad-\quad-\frac{\mathrm{NxMI}}{\mathrm{Rt}} \alpha \mathrm{t}=\frac{\pi}{10}$

$-\frac{\mathrm{NxEp}}{\mathrm{Rt}} \alpha \mathrm{t}=\frac{\pi}{5} \quad--\frac{\mathrm{NxEn}}{\mathrm{Rt}} \alpha \mathrm{t}=\frac{\pi}{5} \quad--\frac{\mathrm{NxMI}}{\mathrm{Rt}} \alpha \mathrm{t}=\frac{\pi}{5}$

$-\frac{\mathrm{NxEp}}{\mathrm{Rt}} \alpha \mathrm{t}=\frac{3 \pi}{10} \quad \cdots \frac{\mathrm{NxEn}}{\mathrm{Rt}} \alpha \mathrm{t}=\frac{3 \pi}{10} \quad-\quad \frac{\mathrm{NxMI}}{\mathrm{Rt}} \alpha \mathrm{t}=\frac{3 \pi}{10}$

$\mathrm{Rp}-\frac{\mathrm{NxEp}}{\mathrm{Rt}} \alpha \mathrm{t}=\frac{2 \pi}{5} \quad \ldots \frac{\mathrm{NxEn}}{\mathrm{Rt}} \alpha \mathrm{t}=\frac{2 \pi}{5} \quad--\frac{\mathrm{NxMI}}{\mathrm{Rt}} \alpha \mathrm{t}=\frac{2 \pi}{5}$

$\frac{\mathrm{Rp}}{\mathrm{Rt}}-\frac{\mathrm{NxEp}}{\mathrm{Rt}} \alpha \mathrm{t}=\frac{\pi}{2} \quad-\cdots \frac{\mathrm{NxEn}}{\mathrm{Rt}} \alpha \mathrm{t}=\frac{\pi}{2} \quad--\frac{\mathrm{NxMI}}{\mathrm{Rt}} \alpha \mathrm{t}=\frac{\pi}{2}$

$-\frac{\mathrm{NxEp}}{\mathrm{Rt}} \alpha \mathrm{t}=\frac{3 \pi}{5} \quad-=\frac{\mathrm{NxEn}}{\mathrm{Rt}} \alpha \mathrm{t}=\frac{3 \pi}{5} \quad-\quad-\frac{\mathrm{NxMI}}{\mathrm{Rt}} \alpha \mathrm{t}=\frac{3 \pi}{5}$

$-\frac{\mathrm{NxEp}}{\mathrm{Rt}} \alpha \mathrm{t}=\frac{7 \pi}{10} \quad \cdots \frac{\mathrm{NxEn}}{\mathrm{Rt}} \alpha \mathrm{t}=\frac{7 \pi}{10} \quad-\frac{\mathrm{NxMI}}{\mathrm{Rt}} \alpha \mathrm{t}=\frac{7 \pi}{10}$

$-\frac{\mathrm{NxEp}}{\mathrm{Rt}} \alpha \mathrm{t}=\frac{4 \pi}{5} \quad-\cdots \frac{\mathrm{NxEn}}{\mathrm{Rt}} \alpha \mathrm{t}=\frac{4 \pi}{5} \quad--\frac{\mathrm{NxMI}}{\mathrm{Rt}} \alpha \mathrm{t}=\frac{4 \pi}{5}$

Tablero 1 (Carretera)

$\mathrm{Lt}=280 \alpha \mathrm{p}=\frac{\alpha \mathrm{t}}{2}$

$\mathrm{QyEp} / \mathrm{ct}^{2}$

$\mathrm{QyEn} / \alpha \mathrm{t}^{2}$

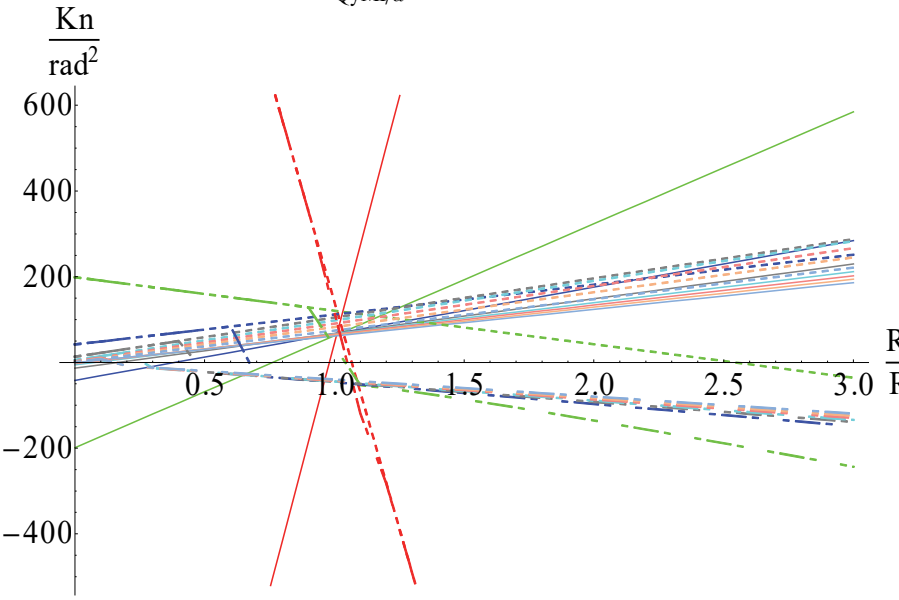

- $\frac{\mathrm{QyEp}}{\alpha \mathrm{t}^{2}} \alpha \mathrm{t}=\frac{\pi}{10} \quad--\frac{\mathrm{QyEn}}{\mathrm{at} \mathrm{t}^{2}} \alpha \mathrm{t}=\frac{\pi}{10} \quad--\frac{\mathrm{QyMI}}{\mathrm{\alpha t} \mathrm{t}^{2}} \alpha \mathrm{t}=\frac{\pi}{10}$

- $\frac{\mathrm{QyEp}}{\alpha \mathrm{t}^{2}} \alpha \mathrm{t}=\frac{\pi}{5} \quad--\frac{\mathrm{QyEn}}{\mathrm{d \textrm {t } ^ { 2 }}} \alpha \mathrm{t}=\frac{\pi}{5} \quad--\frac{\mathrm{QyMI}}{\alpha \mathrm{t}^{2}} \alpha \mathrm{t}=\frac{\pi}{5}$

- $\frac{\mathrm{QyEp}}{\alpha \mathrm{t}^{2}} \alpha \mathrm{t}=\frac{3 \pi}{10} \quad--\frac{\mathrm{QyEn}}{\alpha \mathrm{t}^{2}} \alpha \mathrm{t}=\frac{3 \pi}{10} \quad-\frac{\mathrm{QyMI}}{\alpha \mathrm{t}^{2}} \alpha \mathrm{t}=\frac{3 \pi}{10}$

$\mathrm{Rp}-\frac{\mathrm{QyEp}}{\alpha \mathrm{t}^{2}} \alpha \mathrm{t}=\frac{2 \pi}{5} \quad--\frac{\mathrm{QyEn}}{\mathrm{\alpha t} \mathrm{t}^{2}} \alpha \mathrm{t}=\frac{2 \pi}{5} \quad-\frac{\mathrm{QyMI}}{\mathrm{\alpha t} \mathrm{t}^{2}} \alpha \mathrm{t}=\frac{2 \pi}{5}$

$\mathrm{Rt}-\frac{\mathrm{QyEp}}{d \mathrm{t}^{2}} \alpha \mathrm{t}=\frac{\pi}{2} \quad--\frac{\mathrm{QyEn}}{d \mathrm{t}^{2}} \alpha \mathrm{t}=\frac{\pi}{2} \quad--\frac{\mathrm{QyMI}}{\mathrm{t}^{2}} \alpha \mathrm{t}=\frac{\pi}{2}$

- $\frac{\mathrm{QyEp}}{\alpha \mathrm{t}^{2}} \alpha \mathrm{t}=\frac{3 \pi}{5} \quad--\frac{\mathrm{QyEn}}{\mathrm{ct}^{2}} \alpha \mathrm{t}=\frac{3 \pi}{5} \quad-\quad-\frac{\mathrm{QyMI}}{\alpha \mathrm{t}^{2}} \alpha \mathrm{t}=\frac{3 \pi}{5}$

$\frac{\mathrm{QyEp}}{\mathrm{at} \mathrm{t}^{2}} \alpha \mathrm{t}=\frac{7 \pi}{10} \quad \ldots \frac{\mathrm{QyEn}}{\mathrm{at} \mathrm{t}^{2}} \alpha \mathrm{t}=\frac{7 \pi}{10} \quad-\frac{\mathrm{QyMI}}{\mathrm{dt} \mathrm{t}^{2}} \alpha \mathrm{t}=\frac{7 \pi}{10}$

- $\frac{\mathrm{QyEp}}{\alpha \mathrm{t}^{2}} \alpha \mathrm{t}=\frac{4 \pi}{5} \quad-\cdots \frac{\mathrm{QyEn}}{\alpha \mathrm{t}^{2}} \alpha \mathrm{t}=\frac{4 \pi}{5} \quad-\frac{\mathrm{QyMI}}{\alpha \mathrm{t}^{2}} \alpha \mathrm{t}=\frac{4 \pi}{5}$ 
Tablero 1 (Carretera)

$\mathrm{Lt}=280 \alpha \mathrm{p}=\frac{\alpha \mathrm{t}}{2}$

$\mathrm{MzMax} / \alpha \mathrm{t}^{2}$

$\mathrm{MzMin} / \alpha \mathrm{t}^{2}$

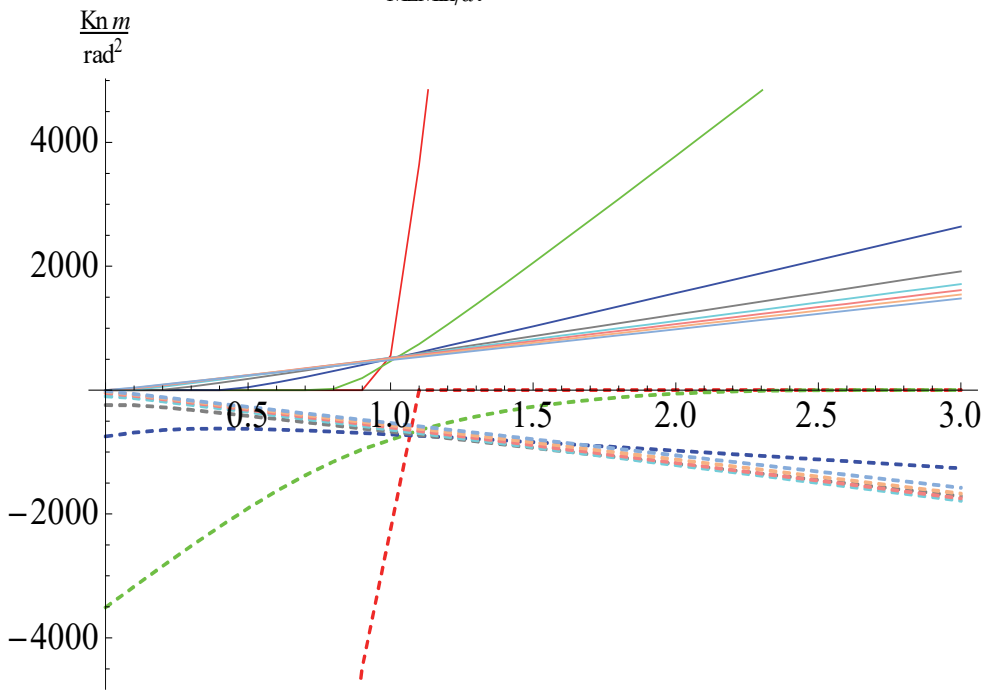

$$
\begin{aligned}
& -\frac{\mathrm{Mz} \mathrm{Max}}{d \mathrm{t}^{2}} \alpha \mathrm{t}=\frac{\pi}{10} \quad-\cdots \frac{\mathrm{MzMin}}{a \mathrm{t}^{2}} \alpha \mathrm{t}=\frac{\pi}{10} \\
& -\frac{\mathrm{MzMax}}{\alpha \mathrm{t}^{2}} \alpha \mathrm{t}=\frac{\pi}{5} \quad--=\frac{\mathrm{MzMin}}{\alpha \mathrm{t}^{2}} \alpha \mathrm{t}=\frac{\pi}{5} \\
& -\frac{\mathrm{MzMax}}{a t^{2}} \alpha \mathrm{t}=\frac{3 \pi}{10} \quad \ldots \frac{\mathrm{MzMin}}{a t^{2}} \alpha \mathrm{t}=\frac{3 \pi}{10} \\
& \text { Rp }-\frac{\mathrm{MzMax}}{a \mathrm{t}^{2}} \alpha \mathrm{t}=\frac{2 \pi}{5} \quad \ldots \frac{\mathrm{Mz} \mathrm{Min}}{\alpha \mathrm{t}^{2}} \alpha \mathrm{t}=\frac{2 \pi}{5} \\
& \text { Rt } \\
& \frac{\mathrm{MzMax}}{a \mathrm{t}^{2}} \alpha \mathrm{t}=\frac{\pi}{2} \quad \cdots \frac{\mathrm{MzMin}}{a \mathrm{t}^{2}} \alpha \mathrm{t}=\frac{\pi}{2} \\
& \text { - } \frac{\mathrm{MzMax}}{d \mathrm{t}^{2}} \alpha \mathrm{t}=\frac{3 \pi}{5} \quad \cdots \frac{\mathrm{MzMin}}{\mathrm{at} \mathrm{t}^{2}} \alpha \mathrm{t}=\frac{3 \pi}{5} \\
& -\frac{\mathrm{MzMax}}{a t^{2}} \alpha \mathrm{t}=\frac{7 \pi}{10}=-=\frac{\mathrm{MzMin}}{a \mathrm{t}^{2}} \alpha \mathrm{t}=\frac{7 \pi}{10} \\
& -\frac{\mathrm{MzMax}}{d t^{2}} \alpha \mathrm{t}=\frac{4 \pi}{5} \quad=-\frac{\mathrm{MzMin}}{d \mathrm{t}^{2}} \alpha \mathrm{t}=\frac{4 \pi}{5}
\end{aligned}
$$

Tablero 1 (Carretera)

$\mathrm{Lt}=280 \alpha \mathrm{p}=\frac{\alpha \mathrm{t}}{2}$

$\mathrm{NxEp} / \mathrm{Rt}$

$\mathrm{NxMI} / \mathrm{Rt}$

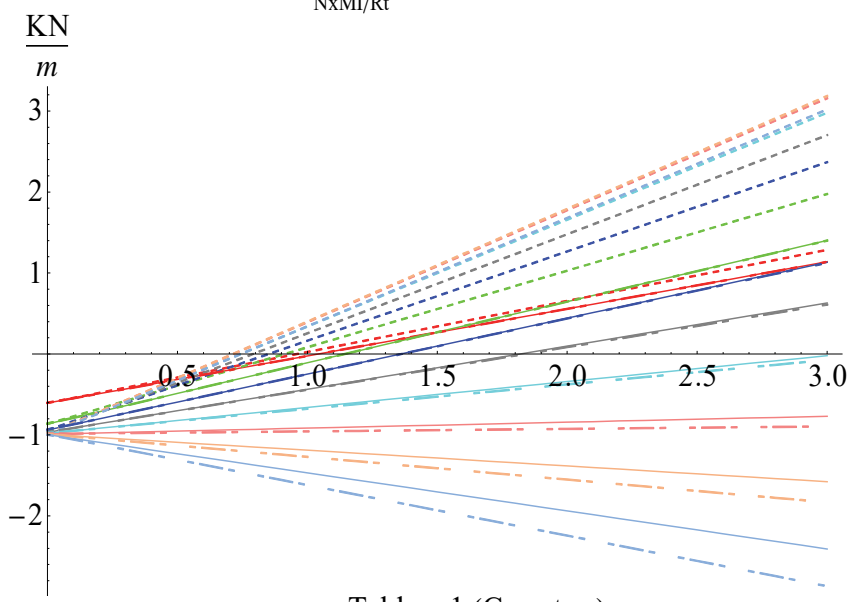

Tablero 1 (Carretera)

$$
\begin{aligned}
& -\frac{\mathrm{NxEp}}{\mathrm{Rt}} \alpha \mathrm{t}=\frac{\pi}{10} \quad--\frac{\mathrm{NxEn}}{\mathrm{Rt}} \alpha \mathrm{t}=\frac{\pi}{10} \quad-\quad-\frac{\mathrm{NxMI}}{\mathrm{Rt}} \alpha \mathrm{t}=\frac{\pi}{10} \\
& -\frac{\mathrm{NxEp}}{\mathrm{Rt}} \alpha \mathrm{t}=\frac{\pi}{5} \quad=-\frac{\mathrm{NxEn}}{\mathrm{Rt}} \alpha \mathrm{t}=\frac{\pi}{5} \quad--\frac{\mathrm{NxMI}}{\mathrm{Rt}} \alpha \mathrm{t}=\frac{\pi}{5} \\
& -\frac{\mathrm{NxEp}}{\mathrm{Rt}} \alpha \mathrm{t}=\frac{3 \pi}{10} \quad-. \frac{\mathrm{NxEn}}{\mathrm{Rt}} \alpha \mathrm{t}=\frac{3 \pi}{10} \quad-\quad \frac{\mathrm{NxMI}}{\mathrm{Rt}} \alpha \mathrm{t}=\frac{3 \pi}{10} \\
& -\frac{\mathrm{NxEp}}{\mathrm{Rt}} \alpha \mathrm{t}=\frac{2 \pi}{5} \quad-=\frac{\mathrm{NxEn}}{\mathrm{Rt}} \alpha \mathrm{t}=\frac{2 \pi}{5} \quad-\frac{\mathrm{NxMI}}{\mathrm{Rt}} \alpha \mathrm{t}=\frac{2 \pi}{5} \\
& \frac{\mathrm{Rp}}{\mathrm{Rt}}-\frac{\mathrm{NxEp}}{\mathrm{Rt}} \alpha \mathrm{t}=\frac{\pi}{2} \quad--\frac{\mathrm{NxEn}}{\mathrm{Rt}} \alpha \mathrm{t}=\frac{\pi}{2} \quad--\frac{\mathrm{NxMI}}{\mathrm{Rt}} \alpha \mathrm{t}=\frac{\pi}{2} \\
& -\frac{\mathrm{NxEp}}{\mathrm{Rt}} \alpha \mathrm{t}=\frac{3 \pi}{5} \quad--\frac{\mathrm{NxEn}}{\mathrm{Rt}} \alpha \mathrm{t}=\frac{3 \pi}{5} \quad--\frac{\mathrm{NxMI}}{\mathrm{Rt}} \alpha \mathrm{t}=\frac{3 \pi}{5} \\
& -\frac{\mathrm{NxEp}}{\mathrm{Rt}} \alpha \mathrm{t}=\frac{7 \pi}{10}=-\frac{\mathrm{NxEn}}{\mathrm{Rt}} \alpha \mathrm{t}=\frac{7 \pi}{10} \quad-\frac{\mathrm{NxMI}}{\mathrm{Rt}} \alpha \mathrm{t}=\frac{7 \pi}{10} \\
& -\frac{\mathrm{NxEp}}{\mathrm{Rt}} \alpha \mathrm{t}=\frac{4 \pi}{5} \quad \ldots \frac{\mathrm{NxEn}}{\mathrm{Rt}} \alpha \mathrm{t}=\frac{4 \pi}{5} \quad--\frac{\mathrm{NxMI}}{\mathrm{Rt}} \alpha \mathrm{t}=\frac{4 \pi}{5}
\end{aligned}
$$$$
\mathrm{Lt}=560 \alpha \mathrm{p}=\frac{\alpha \mathrm{t}}{2}
$$$$
\text { QyEp/ } / t^{2}
$$$$
\text { QyEn/ } / t^{2}
$$$$
\text { QyMI } / \alpha t^{2}
$$

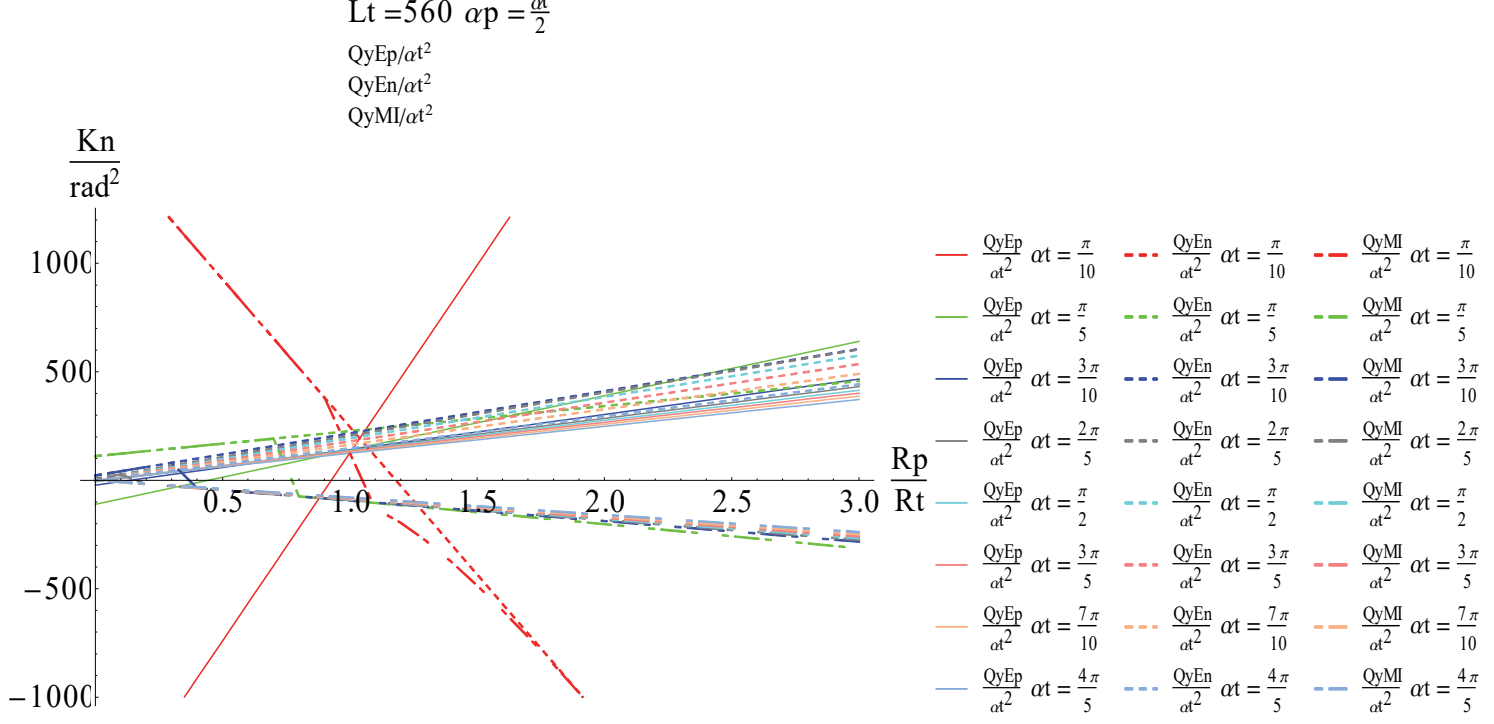


Tablero 1 (Carretera)

$\mathrm{Lt}=560 \alpha \mathrm{p}=\frac{\alpha \mathrm{t}}{2}$

$\operatorname{MzMax} / \alpha t^{2}$

$\operatorname{MzMin} / \alpha t^{2}$

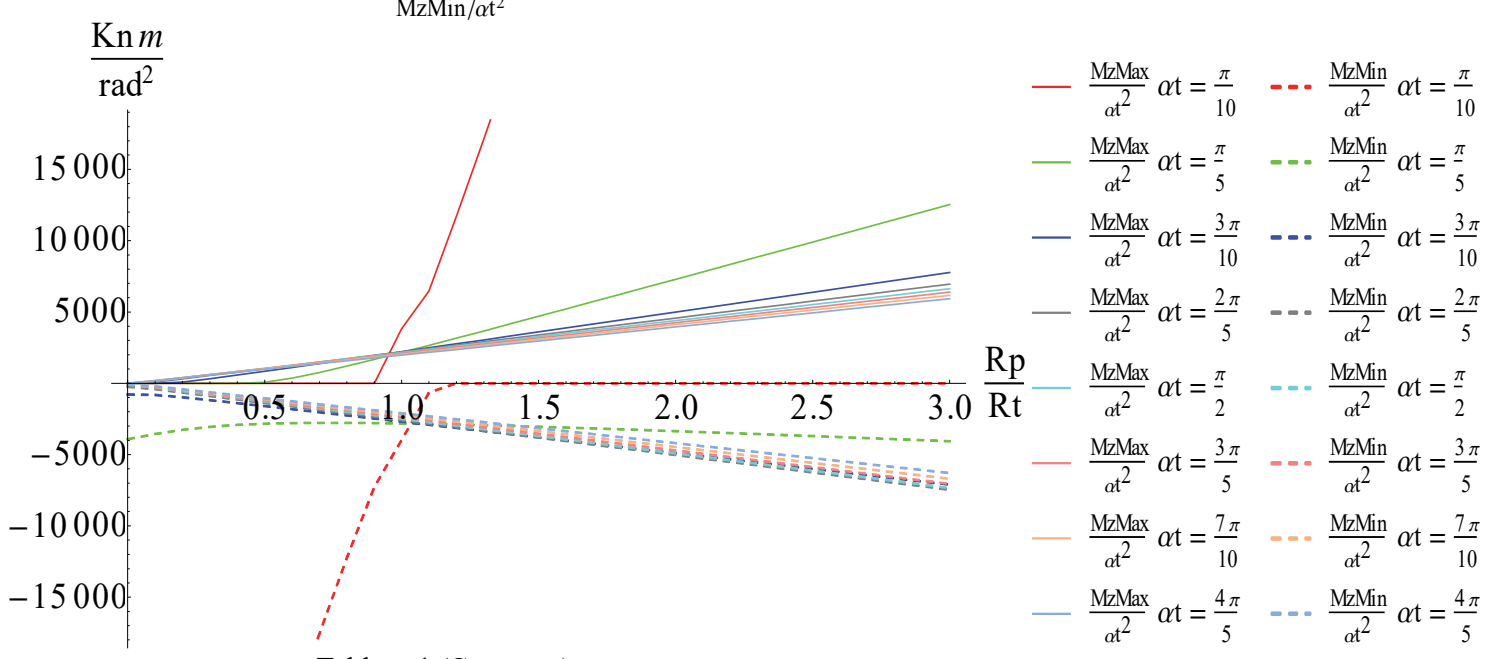

Tablero 1 (Carretera)

$\mathrm{Lt}=560 \alpha \mathrm{p}=\frac{\alpha \mathrm{t}}{2}$

$\mathrm{NxEp} / \mathrm{Rt}$

$\mathrm{NxEn} / \mathrm{Rt}$

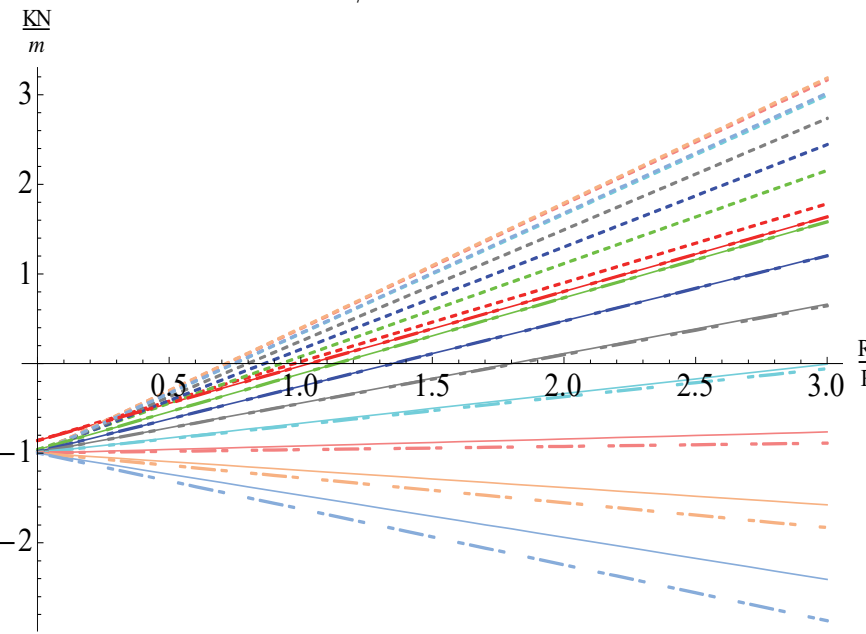

$-\frac{\mathrm{NxEp}}{\mathrm{Rt}} \alpha \mathrm{t}=\frac{\pi}{10} \quad--\frac{\mathrm{NxEn}}{\mathrm{Rt}} \alpha \mathrm{t}=\frac{\pi}{10} \quad--\frac{\mathrm{NxMI}}{\mathrm{Rt}} \alpha \mathrm{t}=\frac{\pi}{10}$

$-\frac{\mathrm{NxEp}}{\mathrm{Rt}} \alpha \mathrm{t}=\frac{\pi}{5} \quad=-\frac{\mathrm{NxEn}}{\mathrm{Rt}} \alpha \mathrm{t}=\frac{\pi}{5} \quad--\frac{\mathrm{NxMI}}{\mathrm{Rt}} \alpha \mathrm{t}=\frac{\pi}{5}$

$-\frac{\mathrm{NxEp}}{\mathrm{Rt}} \alpha \mathrm{t}=\frac{3 \pi}{10} \quad \ldots \frac{\mathrm{NxEn}}{\mathrm{Rt}} \alpha \mathrm{t}=\frac{3 \pi}{10} \quad-\quad \frac{\mathrm{NxMI}}{\mathrm{Rt}} \alpha \mathrm{t}=\frac{3 \pi}{10}$

$\frac{\mathrm{Rp}}{\mathrm{Rt}}-\frac{\mathrm{NxEp}}{\mathrm{Rt}} \alpha \mathrm{t}=\frac{2 \pi}{5} \quad--\frac{\mathrm{NxEn}}{\mathrm{Rt}} \alpha \mathrm{t}=\frac{2 \pi}{5} \quad--\frac{\mathrm{NxMI}}{\mathrm{Rt}} \alpha \mathrm{t}=\frac{2 \pi}{5}$

$-\frac{\mathrm{NxEp}}{\mathrm{Rt}} \alpha \mathrm{t}=\frac{\pi}{2} \quad--\frac{\mathrm{NxEn}}{\mathrm{Rt}} \alpha \mathrm{t}=\frac{\pi}{2} \quad--\frac{\mathrm{NxMI}}{\mathrm{Rt}} \alpha \mathrm{t}=\frac{\pi}{2}$

$-\frac{\mathrm{NxEp}}{\mathrm{Rt}} \alpha \mathrm{t}=\frac{3 \pi}{5} \quad--\frac{\mathrm{NxEn}}{\mathrm{Rt}} \alpha \mathrm{t}=\frac{3 \pi}{5} \quad--\frac{\mathrm{NxMI}}{\mathrm{Rt}} \alpha \mathrm{t}=\frac{3 \pi}{5}$

$-\frac{\mathrm{NxEp}}{\mathrm{Rt}} \alpha \mathrm{t}=\frac{7 \pi}{10} \quad=-\frac{\mathrm{NxEn}}{\mathrm{Rt}} \alpha \mathrm{t}=\frac{7 \pi}{10} \quad-\quad-\frac{\mathrm{NxMI}}{\mathrm{Rt}} \alpha \mathrm{t}=\frac{7 \pi}{10}$

$-\frac{\mathrm{NxEp}}{\mathrm{Rt}} \alpha \mathrm{t}=\frac{4 \pi}{5} \quad=-\frac{\mathrm{NxEn}}{\mathrm{Rt}} \alpha \mathrm{t}=\frac{4 \pi}{5} \quad--\frac{\mathrm{NxMI}}{\mathrm{Rt}} \alpha \mathrm{t}=\frac{4 \pi}{5}$

Tablero 1 (Carretera)

$\mathrm{Lt}=840 \alpha \mathrm{p}=\frac{\alpha \mathrm{t}}{2}$

QyEp/ $/ \alpha \mathrm{t}^{2}$

$\mathrm{QyEn} / \alpha \mathrm{t}^{2}$

QyMI $/ \alpha \mathrm{t}^{2}$

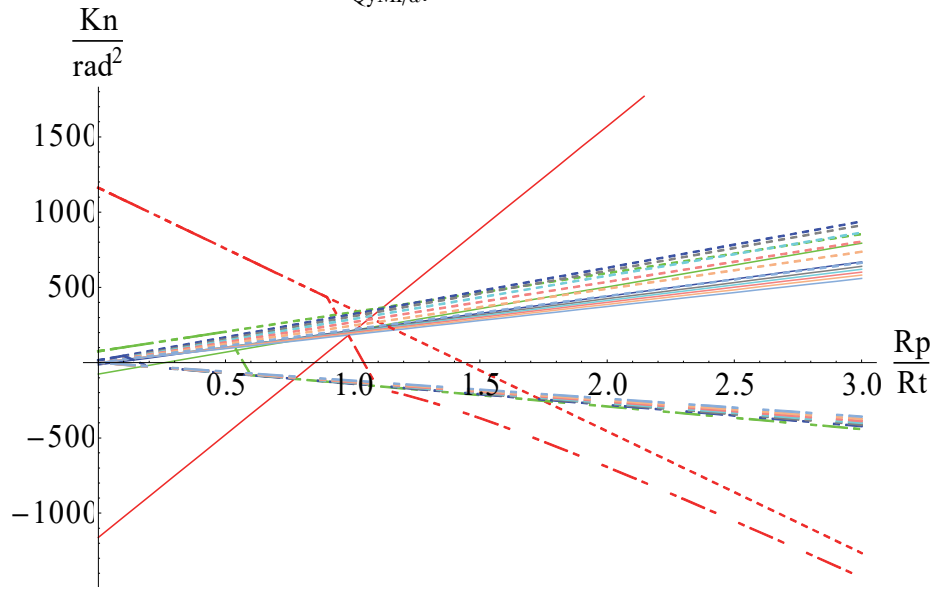

- $\frac{\mathrm{QyEp}}{\alpha \mathrm{t}^{2}} \alpha \mathrm{t}=\frac{\pi}{10} \quad-. \frac{\mathrm{QyEn}}{\alpha \mathrm{t}^{2}} \alpha \mathrm{t}=\frac{\pi}{10} \quad--\frac{\mathrm{QyMI}}{\alpha \mathrm{t}^{2}} \alpha \mathrm{t}=\frac{\pi}{10}$

$-\frac{\mathrm{QyEp}}{\mathrm{\alpha t}^{2}} \alpha \mathrm{t}=\frac{\pi}{5} \quad-\cdots \frac{\mathrm{QyEn}}{\alpha \mathrm{t}^{2}} \alpha \mathrm{t}=\frac{\pi}{5} \quad--\frac{\mathrm{QyMI}}{\alpha \mathrm{t}^{2}} \alpha \mathrm{t}=\frac{\pi}{5}$

- $\frac{\mathrm{QyEp}}{\alpha \mathrm{t}^{2}} \alpha \mathrm{t}=\frac{3 \pi}{10} \quad-\cdots \frac{\mathrm{QyEn}}{\mathrm{\alpha t}^{2}} \alpha \mathrm{t}=\frac{3 \pi}{10} \quad-\frac{\mathrm{QyMI}}{\mathrm{ct}^{2}} \alpha \mathrm{t}=\frac{3 \pi}{10}$

$-\frac{\mathrm{QyEp}}{\alpha \mathrm{t}^{2}} \alpha \mathrm{t}=\frac{2 \pi}{5} \quad-\cdots \frac{\mathrm{QyEn}}{\alpha \mathrm{t}^{2}} \alpha \mathrm{t}=\frac{2 \pi}{5} \quad--\frac{\mathrm{QyMI}}{\alpha \mathrm{t}^{2}} \alpha \mathrm{t}=\frac{2 \pi}{5}$

$\frac{\mathrm{Rp}}{\mathrm{Rt}}-\frac{\mathrm{QyEp}}{\mathrm{at}^{2}} \alpha \mathrm{t}=\frac{\pi}{2} \quad--\frac{\mathrm{QyEn}}{\alpha \mathrm{t}^{2}} \alpha \mathrm{t}=\frac{\pi}{2} \quad--\frac{\mathrm{QyMI}}{a \mathrm{t}^{2}} \alpha \mathrm{t}=\frac{\pi}{2}$

$-\frac{\mathrm{QyEp}}{\alpha \mathrm{t}^{2}} \alpha \mathrm{t}=\frac{3 \pi}{5} \quad-. \frac{\mathrm{QyEn}}{\alpha \mathrm{t}^{2}} \alpha \mathrm{t}=\frac{3 \pi}{5} \quad-\frac{\mathrm{QyMI}}{\alpha \mathrm{t}^{2}} \alpha \mathrm{t}=\frac{3 \pi}{5}$

- $\frac{\mathrm{QyEp}}{\alpha \mathrm{t}^{2}} \alpha \mathrm{t}=\frac{7 \pi}{10} \quad-\cdots \frac{\mathrm{QyEn}}{\mathrm{\alpha t}^{2}} \alpha \mathrm{t}=\frac{7 \pi}{10} \quad-\frac{\mathrm{QyMI}}{\mathrm{ct}^{2}} \alpha \mathrm{t}=\frac{7 \pi}{10}$

$-\frac{\mathrm{QyEp}}{\alpha \mathrm{t}^{2}} \alpha \mathrm{t}=\frac{4 \pi}{5} \quad \ldots \frac{\mathrm{QyEn}}{\alpha t^{2}} \alpha \mathrm{t}=\frac{4 \pi}{5} \quad-\quad-\frac{\mathrm{QyMI}}{\alpha t^{2}} \alpha \mathrm{t}=\frac{4 \pi}{5}$ 
Tablero 1 (Carretera)

$\mathrm{Lt}=840 \alpha \mathrm{p}=\frac{\alpha \mathrm{t}}{2}$

$\operatorname{MzMax} / \alpha \mathrm{t}^{2}$

$\operatorname{MzMin} / \alpha \mathrm{t}^{2}$

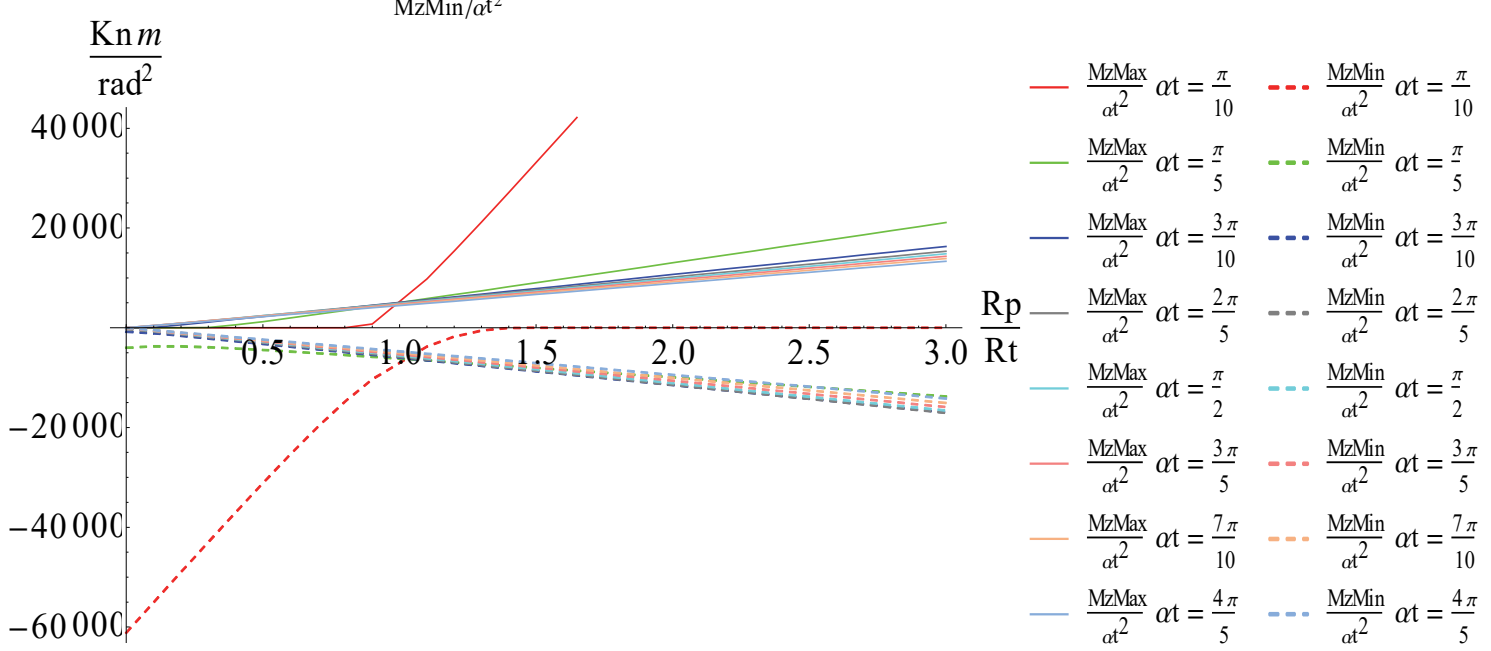

Tablero 1 (Carretera)

$\mathrm{Lt}=840 \alpha \mathrm{p}=\frac{\alpha \mathrm{t}}{2}$

$\mathrm{NxEp} / \mathrm{Rt}$

$\mathrm{NxEn/Rt}$

$\frac{\mathrm{KN}}{m}$

$\mathrm{NxML} / \mathrm{Rt}$

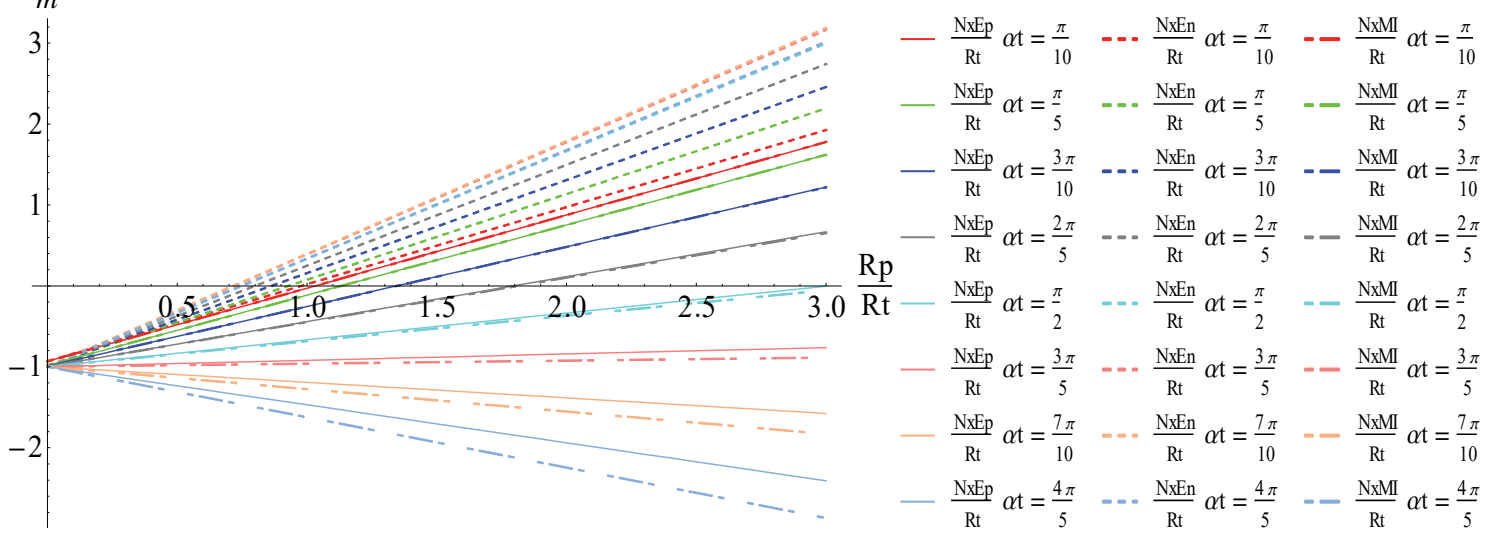

Diagrama 2.66. Solicitaciones del tablero $\left(\frac{Q y}{\alpha t^{2}}, \frac{M z}{\alpha t^{2}} y \frac{N x}{R t}\right) . \boldsymbol{L t}=\mathbf{1 4 0}, \alpha \boldsymbol{p}=\frac{\alpha t}{2}$, Tablero 7 (Peatonal); $\boldsymbol{L t}=\mathbf{2 8 0}, \boldsymbol{\alpha p}=$ $\frac{\alpha t}{2}$, Tablero 7 (Peatonal); $\boldsymbol{L t}=\mathbf{4 2 0}, \boldsymbol{\alpha p}=\frac{\alpha t}{2}$, Tablero 7 (Peatonal); $\boldsymbol{L t}=\mathbf{2 8 0}, \boldsymbol{\alpha p}=\frac{\alpha t}{2}$, Tablero 1 (Carretera); $\boldsymbol{L t}=$ $\mathbf{5 6 0}, \boldsymbol{\alpha p}=\frac{\boldsymbol{\alpha} \boldsymbol{t}}{2}$, Tablero 1 (Carretera); $\boldsymbol{L} \boldsymbol{t}=\mathbf{8 4 0}, \boldsymbol{\alpha p}=\frac{\boldsymbol{\alpha} \boldsymbol{t}}{2}$, Tablero 1 (Carretera); 
Tablero 7 (Peatonal)

$\mathrm{Lt}=140 \alpha \mathrm{p}=\frac{\alpha \mathrm{t}}{4}$

QyEp/ $/ \alpha t^{2}$

QyEn/ $\alpha t^{2}$

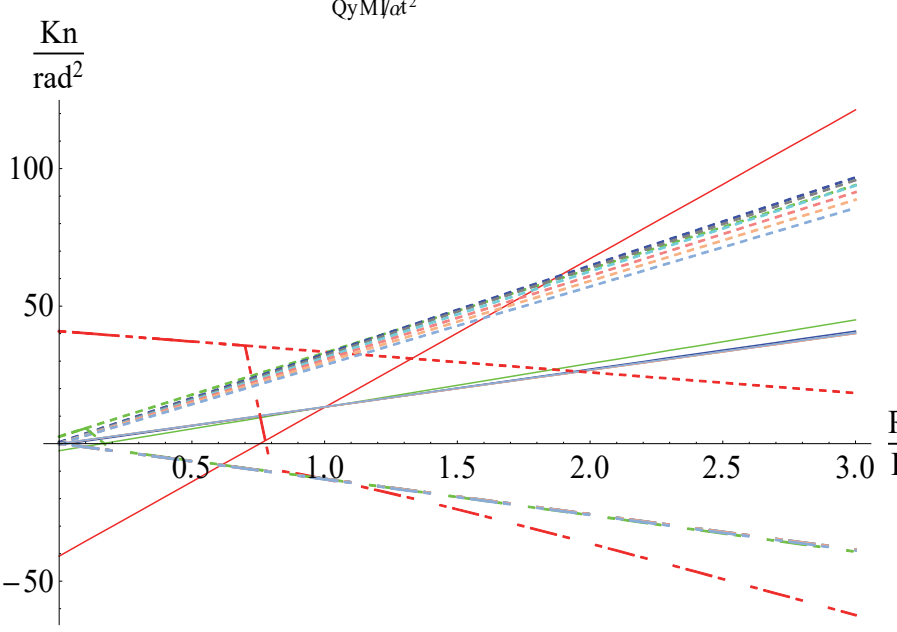

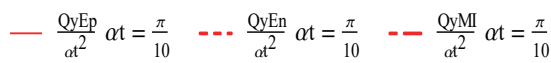

$-\frac{\mathrm{QyEp}}{\alpha t^{2}} \alpha \mathrm{t}=\frac{\pi}{5} \quad-\ldots \frac{\mathrm{QyEn}}{\alpha \mathrm{t}^{2}} \alpha \mathrm{t}=\frac{\pi}{5} \quad--\frac{\mathrm{QyMI}}{\alpha \mathrm{t}^{2}} \alpha \mathrm{t}=\frac{\pi}{5}$

- $\frac{\mathrm{QyEp}}{\mathrm{dt}^{2}} \alpha \mathrm{t}=\frac{3 \pi}{10} \quad-\cdots \frac{\mathrm{QyEn}}{\mathrm{d}^{2}} \alpha \mathrm{t}=\frac{3 \pi}{10} \quad-\quad \frac{\mathrm{QyMI}}{\mathrm{dt}^{2}} \alpha \mathrm{t}=\frac{3 \pi}{10}$

$-\frac{\mathrm{QyEp}}{\alpha \mathrm{t}^{2}} \alpha \mathrm{t}=\frac{2 \pi}{5} \quad--\frac{\mathrm{QyEn}}{\alpha \mathrm{t}^{2}} \alpha \mathrm{t}=\frac{2 \pi}{5} \quad--\frac{\mathrm{QyMI}}{\alpha \mathrm{t}^{2}} \alpha \mathrm{t}=\frac{2 \pi}{5}$

$\underline{\mathrm{Rp}}-\frac{\mathrm{QyEp}}{\alpha \mathrm{t}^{2}} \alpha \mathrm{t}=\frac{\pi}{2} \quad-\cdots \frac{\mathrm{QyEn}}{\alpha \mathrm{t}^{2}} \alpha \mathrm{t}=\frac{\pi}{2} \quad--\frac{\mathrm{QyMI}}{\alpha \mathrm{t}^{2}} \alpha \mathrm{t}=\frac{\pi}{2}$

$0 \mathrm{Rt}-\frac{\mathrm{QyEp}}{\alpha \mathrm{t}^{2}} \alpha \mathrm{t}=\frac{3 \pi}{5} \quad \ldots \frac{\mathrm{QyEn}}{\alpha \mathrm{t}^{2}} \alpha \mathrm{t}=\frac{3 \pi}{5} \quad-\frac{\mathrm{QyMI}}{\alpha \mathrm{t}^{2}} \alpha \mathrm{t}=\frac{3 \pi}{5}$

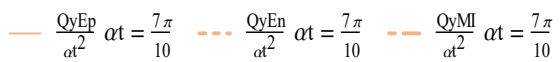

Tablero 7 (Peatonal)

$\mathrm{Lt}=140 \alpha \mathrm{p}=\frac{\alpha \mathrm{t}}{4}$

$\operatorname{MzMax} / \alpha \mathrm{t}^{2}$

$\frac{\mathrm{Kn} m}{\operatorname{rad}^{2}}$

$\mathrm{MzMin} / \alpha \mathrm{t}^{2}$

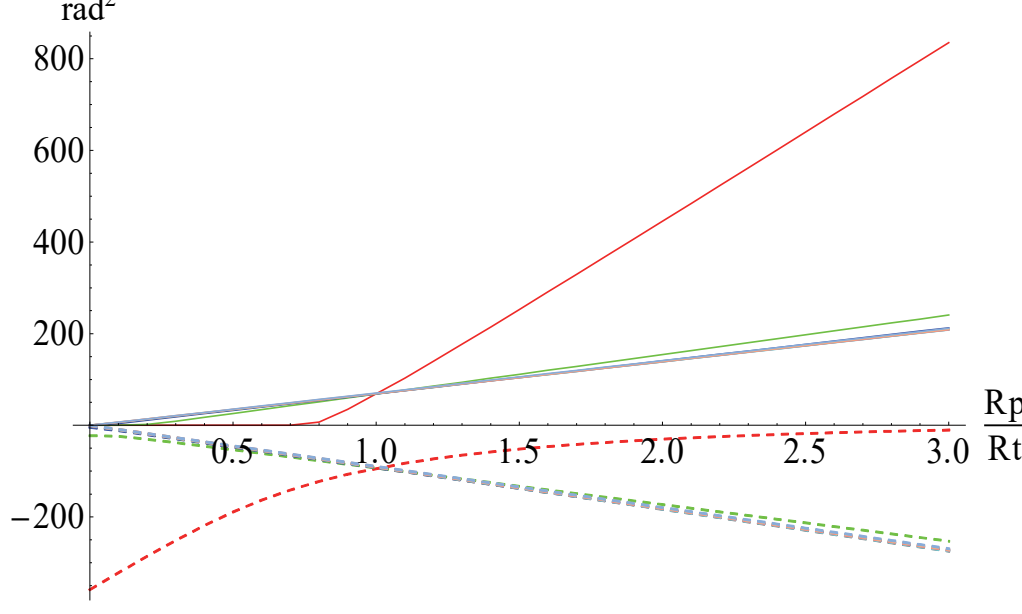

$$
\begin{aligned}
& \text { - } \frac{\mathrm{MzMax}}{d \mathrm{t}^{2}} \alpha \mathrm{t}=\frac{\pi}{10} \quad \cdots \frac{\mathrm{MzMin}}{\alpha \mathrm{t}^{2}} \alpha \mathrm{t}=\frac{\pi}{10} \\
& -\frac{\mathrm{MzMax}}{a \mathrm{t}^{2}} \alpha \mathrm{t}=\frac{\pi}{5} \quad \ldots \frac{\mathrm{MzMin}}{\alpha \mathrm{t}^{2}} \alpha \mathrm{t}=\frac{\pi}{5} \\
& \text { - } \frac{\mathrm{MzMax}}{a \mathrm{t}^{2}} \alpha \mathrm{t}=\frac{3 \pi}{10} \quad \ldots \frac{\mathrm{MzMin}}{\mathrm{at} \mathrm{t}^{2}} \alpha \mathrm{t}=\frac{3 \pi}{10} \\
& -\frac{\mathrm{MzMax}}{a \mathrm{t}^{2}} \alpha \mathrm{t}=\frac{2 \pi}{5} \quad \ldots \frac{\mathrm{MzMin}}{a \mathrm{t}^{2}} \alpha \mathrm{t}=\frac{2 \pi}{5} \\
& -\frac{\mathrm{MzMax}}{\alpha \mathrm{t}^{2}} \alpha \mathrm{t}=\frac{\pi}{2} \quad=-\frac{\mathrm{MzMin}}{\alpha \mathrm{t}^{2}} \alpha \mathrm{t}=\frac{\pi}{2} \\
& \frac{\mathrm{Rp}}{\mathrm{Rt}}-\frac{\mathrm{MzMax}}{\alpha \mathrm{t}^{2}} \alpha \mathrm{t}=\frac{3 \pi}{5} \quad \ldots \frac{\mathrm{MzMin}}{\alpha \mathrm{t}^{2}} \alpha \mathrm{t}=\frac{3 \pi}{5} \\
& \frac{\mathrm{MzMax}}{a t^{2}} \alpha \mathrm{t}=\frac{7 \pi}{10} \quad-=\frac{\mathrm{MzMin}}{a t^{2}} \alpha \mathrm{t}=\frac{7 \pi}{10} \\
& \frac{\mathrm{MzMax}}{c \mathrm{t}^{2}} \alpha \mathrm{t}=\frac{4 \pi}{5} \quad \ldots \frac{\mathrm{MzMin}}{\mathrm{d} \mathrm{t}^{2}} \alpha \mathrm{t}=\frac{4 \pi}{5}
\end{aligned}
$$

Tablero 7 (Peatonal)

$\mathrm{Lt}=140 \alpha \mathrm{p}=\frac{\alpha t}{4}$

$\mathrm{NxEp} / \mathrm{Rt}$
$\mathrm{NxEn} / \mathrm{Rt}$

$\mathrm{NxEn} / \mathrm{Rt}$
$\mathrm{NxMI} / \mathrm{Rt}$

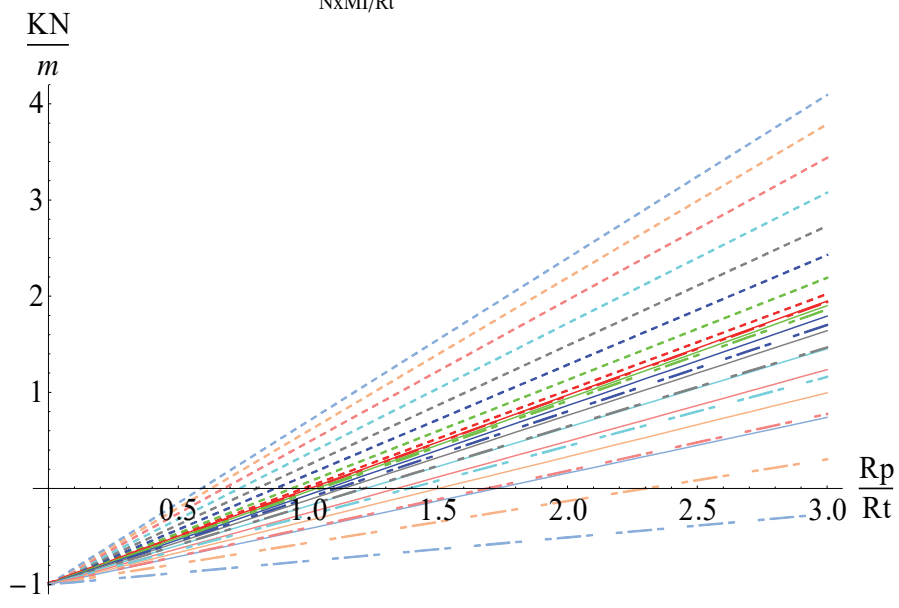

$$
\begin{aligned}
& -\frac{\mathrm{NxEp}}{\mathrm{Rt}} \alpha \mathrm{t}=\frac{\pi}{10} \quad-\ldots \frac{\mathrm{NxEn}}{\mathrm{Rt}} \alpha \mathrm{t}=\frac{\pi}{10} \quad--\frac{\mathrm{NxMI}}{\mathrm{Rt}} \alpha \mathrm{t}=\frac{\pi}{10} \\
& -\frac{\mathrm{NxEp}}{\mathrm{Rt}} \alpha \mathrm{t}=\frac{\pi}{5} \quad-\cdots \frac{\mathrm{NxEn}}{\mathrm{Rt}} \alpha \mathrm{t}=\frac{\pi}{5} \quad--\frac{\mathrm{NxMI}}{\mathrm{Rt}} \alpha \mathrm{t}=\frac{\pi}{5} \\
& -\frac{\mathrm{NxEp}}{\mathrm{Rt}} \alpha \mathrm{t}=\frac{3 \pi}{10} \quad--\frac{\mathrm{NxEn}}{\mathrm{Rt}} \alpha \mathrm{t}=\frac{3 \pi}{10} \quad-\quad \frac{\mathrm{NxMI}}{\mathrm{Rt}} \alpha \mathrm{t}=\frac{3 \pi}{10} \\
& -\frac{\mathrm{NxEp}}{\mathrm{Rt}} \alpha \mathrm{t}=\frac{2 \pi}{5} \quad--\frac{\mathrm{NxEn}}{\mathrm{Rt}} \alpha \mathrm{t}=\frac{2 \pi}{5} \quad--\frac{\mathrm{NxMI}}{\mathrm{Rt}} \alpha \mathrm{t}=\frac{2 \pi}{5} \\
& -\frac{\mathrm{NxEp}}{\mathrm{Rt}} \alpha \mathrm{t}=\frac{\pi}{2} \quad-\cdots \frac{\mathrm{NxEn}}{\mathrm{Rt}} \alpha \mathrm{t}=\frac{\pi}{2} \quad--\frac{\mathrm{NxMI}}{\mathrm{Rt}} \alpha \mathrm{t}=\frac{\pi}{2} \\
& -\frac{\mathrm{NxEp}}{\mathrm{Rt}} \alpha \mathrm{t}=\frac{3 \pi}{5} \quad-\frac{\mathrm{NxEn}}{\mathrm{Rt}} \alpha \mathrm{t}=\frac{3 \pi}{5} \quad-\frac{\mathrm{NxMI}}{\mathrm{Rt}} \alpha \mathrm{t}=\frac{3 \pi}{5} \\
& \mathrm{Rt}-\frac{\mathrm{NxEp}}{\mathrm{Rt}} \alpha \mathrm{t}=\frac{7 \pi}{10} \quad=-\frac{\mathrm{NxEn}}{\mathrm{Rt}} \alpha \mathrm{t}=\frac{7 \pi}{10} \quad--\frac{\mathrm{NxMI}}{\mathrm{Rt}} \alpha \mathrm{t}=\frac{7 \pi}{10} \\
& -\frac{\mathrm{NxEp}}{\mathrm{Rt}} \alpha \mathrm{t}=\frac{4 \pi}{5} \quad-=\frac{\mathrm{NxEn}}{\mathrm{Rt}} \alpha \mathrm{t}=\frac{4 \pi}{5} \quad-\frac{\mathrm{NxMI}}{\mathrm{Rt}} \alpha \mathrm{t}=\frac{4 \pi}{5}
\end{aligned}
$$


Tablero 7 (Peatonal)

$\mathrm{Lt}=280 \alpha \mathrm{p}=\frac{\alpha \mathrm{t}}{4}$

QyEp/ $/ \alpha t^{2}$

QyEn/ $\alpha \mathrm{t}^{2}$

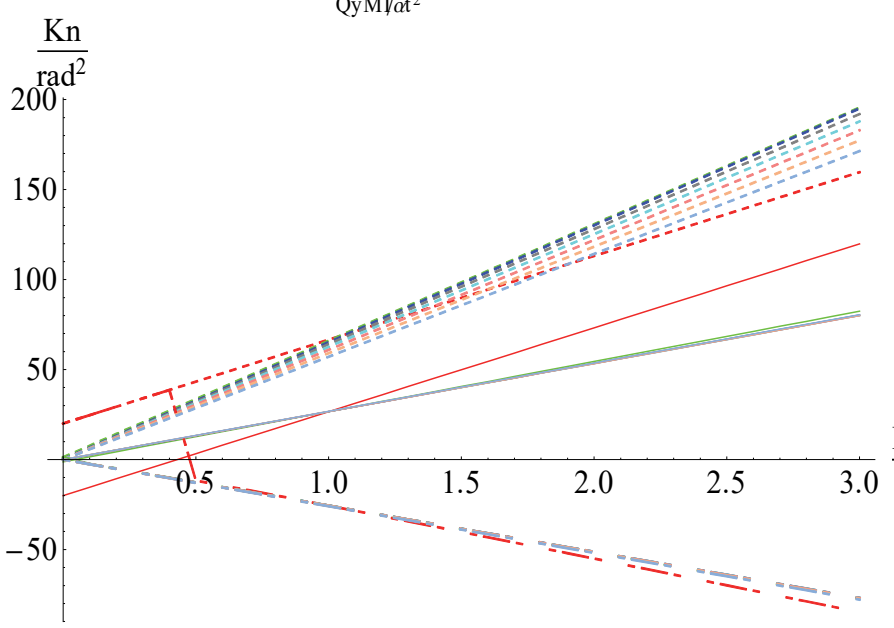

- $\frac{\mathrm{QyEp}}{\alpha \mathrm{t}^{2}} \alpha \mathrm{t}=\frac{\pi}{10} \quad \ldots \frac{\mathrm{QyEn}}{\alpha \mathrm{t}^{2}} \alpha \mathrm{t}=\frac{\pi}{10} \quad-\quad-\frac{\mathrm{QyMI}}{\alpha \mathrm{t}^{2}} \alpha \mathrm{t}=\frac{\pi}{10}$

$-\frac{\mathrm{QyEp}}{d \mathrm{t}^{2}} \alpha \mathrm{t}=\frac{\pi}{5} \quad--\frac{\mathrm{QyEn}}{d \mathrm{t}^{2}} \alpha \mathrm{t}=\frac{\pi}{5} \quad--\frac{\mathrm{QyMI}}{\alpha \mathrm{t}^{2}} \alpha \mathrm{t}=\frac{\pi}{5}$

- $\frac{\mathrm{QyEp}}{\alpha \mathrm{t}^{2}} \alpha \mathrm{t}=\frac{3 \pi}{10} \quad-\ldots \frac{\mathrm{QyEn}}{\alpha \mathrm{t}^{2}} \alpha \mathrm{t}=\frac{3 \pi}{10} \quad-\quad \frac{\mathrm{QyMI}}{\alpha \mathrm{t}^{2}} \alpha \mathrm{t}=\frac{3 \pi}{10}$

$-\frac{\mathrm{QyEp}}{\alpha \mathrm{t}^{2}} \alpha \mathrm{t}=\frac{2 \pi}{5} \quad--\frac{\mathrm{QyEn}}{\alpha \mathrm{t}^{2}} \alpha \mathrm{t}=\frac{2 \pi}{5} \quad--\frac{\mathrm{QyMI}}{\alpha \mathrm{t}^{2}} \alpha \mathrm{t}=\frac{2 \pi}{5}$

$\mathrm{Rp}-\frac{\mathrm{QyEp}}{d \mathrm{t}^{2}} \alpha \mathrm{t}=\frac{\pi}{2} \quad-\cdots \frac{\mathrm{QyEn}}{\alpha \mathrm{t}^{2}} \alpha \mathrm{t}=\frac{\pi}{2} \quad--\frac{\mathrm{QyMI}}{\alpha \mathrm{t}^{2}} \alpha \mathrm{t}=\frac{\pi}{2}$

$\frac{\mathrm{Rp}}{\mathrm{Rt}}-\frac{\mathrm{QyEp}}{\alpha \mathrm{t}^{2}} \alpha \mathrm{t}=\frac{3 \pi}{5} \quad-\cdots \frac{\mathrm{QyEn}}{\mathrm{\alpha t}^{2}} \alpha \mathrm{t}=\frac{3 \pi}{5} \quad--\frac{\mathrm{QyMI}}{\alpha \mathrm{t}^{2}} \alpha \mathrm{t}=\frac{3 \pi}{5}$

Tablero 7 (Peatonal)

$\mathrm{Lt}=280 \quad \alpha \mathrm{p}=\frac{\alpha \mathrm{t}}{4}$

$\operatorname{MzMax} / \alpha \mathrm{t}^{2}$

$\mathrm{MzMin} / \alpha \mathrm{t}^{2}$

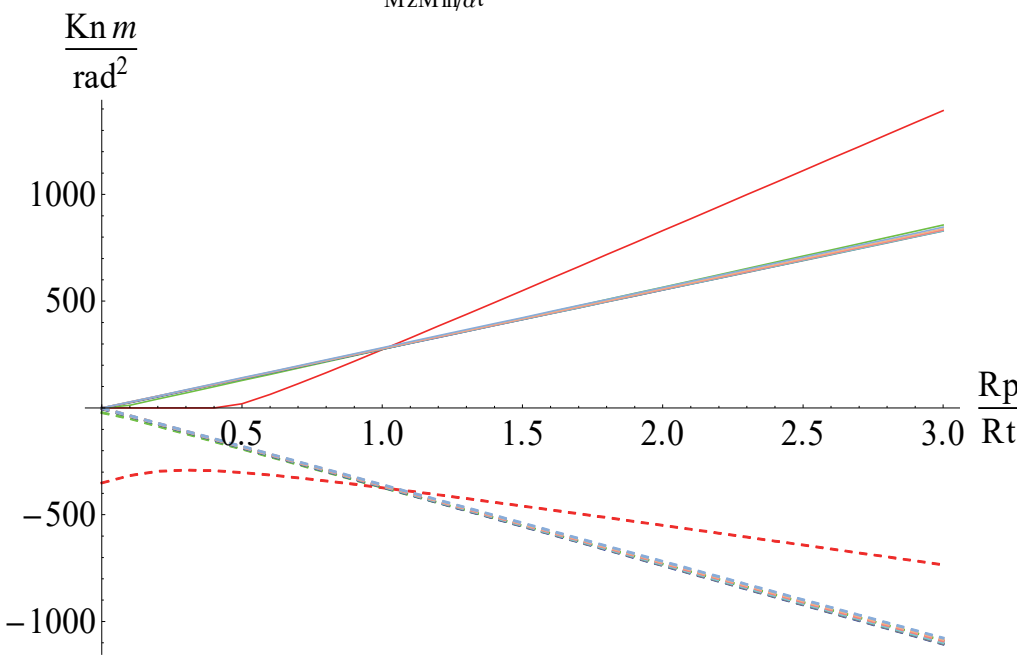

$$
\begin{aligned}
& -\frac{\mathrm{MzMax}}{\alpha t^{2}} \alpha \mathrm{t}=\frac{\pi}{10} \quad \ldots \frac{\mathrm{MzMin}}{\alpha t^{2}} \alpha \mathrm{t}=\frac{\pi}{10} \\
& -\frac{\mathrm{MzMax}}{d t^{2}} \alpha \mathrm{t}=\frac{\pi}{5} \quad-.-\frac{\mathrm{MzMin}}{\alpha \mathrm{t}^{2}} \alpha \mathrm{t}=\frac{\pi}{5} \\
& \text { - } \frac{\text { MzMax }}{a t^{2}} \alpha \mathrm{t}=\frac{3 \pi}{10} \quad \ldots \frac{\text { MzMin }}{a t^{2}} \alpha \mathrm{t}=\frac{3 \pi}{10} \\
& \text { - } \frac{\text { MzMax }}{d t^{2}} \alpha t=\frac{2 \pi}{5} \quad \ldots \frac{\text { MzMin }}{\alpha t^{2}} \alpha t=\frac{2 \pi}{5} \\
& \frac{\mathrm{Rp}}{\mathrm{Rt}}-\frac{\mathrm{MzMax}}{\alpha \mathrm{t}^{2}} \alpha \mathrm{t}=\frac{\pi}{2} \quad=-\frac{\mathrm{MzMin}}{\alpha \mathrm{t}^{2}} \alpha \mathrm{t}=\frac{\pi}{2} \\
& -\frac{\mathrm{MzMax}}{\alpha t^{2}} \alpha \mathrm{t}=\frac{3 \pi}{5} \quad-\cdots \frac{\mathrm{MzMin}}{\alpha t^{2}} \alpha \mathrm{t}=\frac{3 \pi}{5} \\
& \frac{\mathrm{MzMax}}{\alpha \mathrm{t}^{2}} \alpha \mathrm{t}=\frac{7 \pi}{10} \quad=-\frac{\mathrm{MzMin}}{\alpha \mathrm{t}^{2}} \alpha \mathrm{t}=\frac{7 \pi}{10} \\
& \frac{\mathrm{MzMax}}{a t^{2}} \alpha \mathrm{t}=\frac{4 \pi}{5} \quad=-\frac{\mathrm{MzMin}}{a \mathrm{t}^{2}} \alpha \mathrm{t}=\frac{4 \pi}{5}
\end{aligned}
$$

Tablero 7 (Peatonal)

$\mathrm{Lt}=280 \alpha \mathrm{p}=\frac{\alpha \mathrm{t}}{4}$

$\mathrm{NxEp} / \mathrm{Rt}$

NxMI/Rt

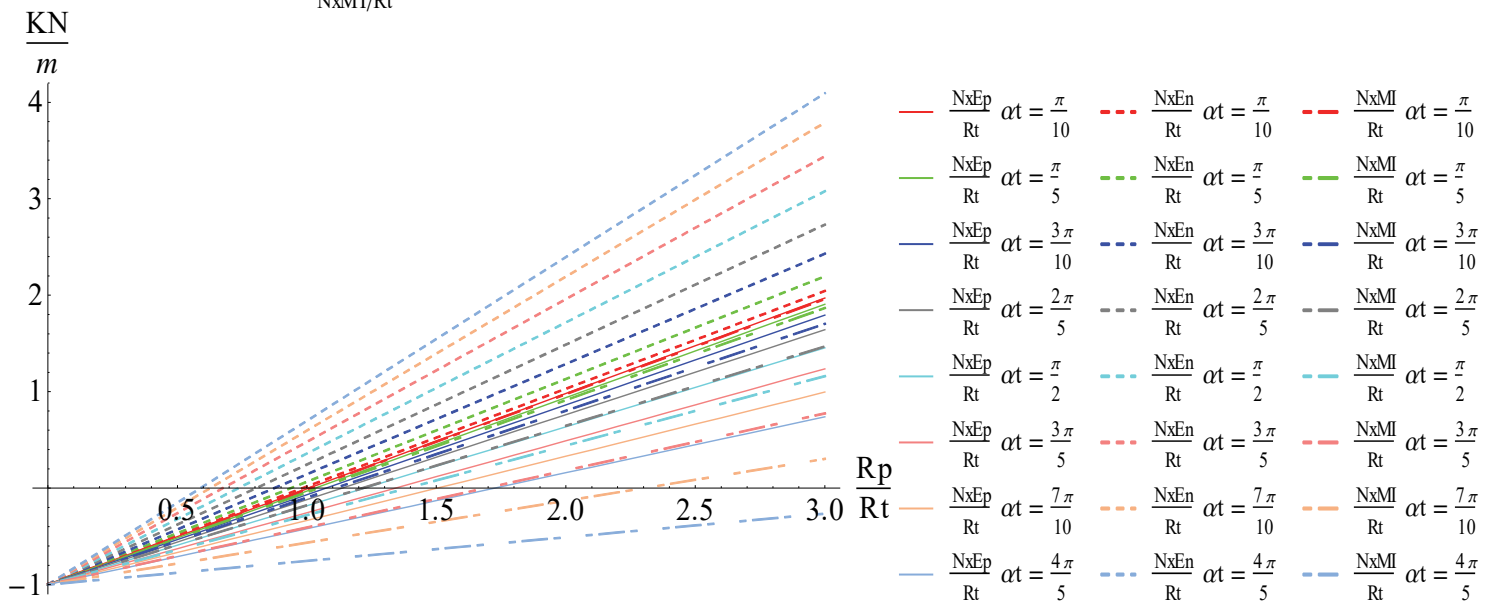


Tablero 7 (Peatonal)

$\mathrm{Lt}=420 \alpha \mathrm{p}=\frac{\alpha \mathrm{t}}{4}$

QyEp/ $\alpha \mathrm{t}^{2}$

QyEn/ $\alpha t^{2}$

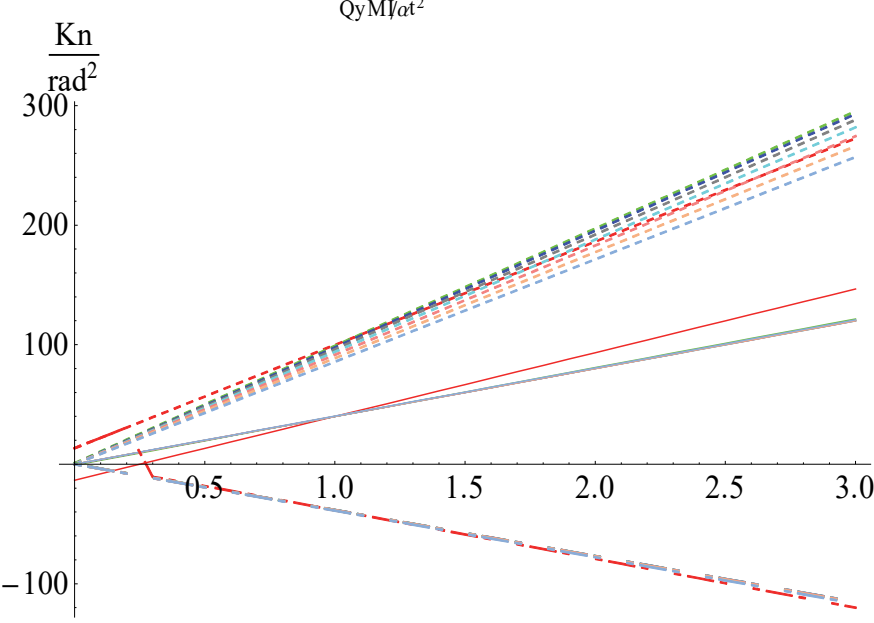

Tablero 7 (Peatonal)

- $\frac{\mathrm{QyEp}}{\alpha \mathrm{t}^{2}} \alpha \mathrm{t}=\frac{\pi}{10} \quad \ldots \frac{\mathrm{Q} \mathrm{yEn}}{\alpha \mathrm{t}^{2}} \alpha \mathrm{t}=\frac{\pi}{10} \quad-\quad-\frac{\mathrm{QyMI}}{\alpha \mathrm{t}^{2}} \alpha \mathrm{t}=\frac{\pi}{10}$

$-\frac{\mathrm{QyEp}}{d \mathrm{t}^{2}} \alpha \mathrm{t}=\frac{\pi}{5} \quad-\cdots \frac{\mathrm{QyEn}}{\alpha \mathrm{t}^{2}} \alpha \mathrm{t}=\frac{\pi}{5} \quad--\frac{\mathrm{QyMI}}{d \mathrm{t}^{2}} \alpha \mathrm{t}=\frac{\pi}{5}$

$-\frac{\mathrm{QyEp}}{\alpha \mathrm{t}^{2}} \alpha \mathrm{t}=\frac{3 \pi}{10} \quad-. \frac{\mathrm{QyEn}}{\alpha \mathrm{t}^{2}} \alpha \mathrm{t}=\frac{3 \pi}{10} \quad--\frac{\mathrm{QyMI}}{\alpha \mathrm{t}^{2}} \alpha \mathrm{t}=\frac{3 \pi}{10}$

$-\frac{Q \mathrm{yEp}}{\alpha \mathrm{t}^{2}} \alpha \mathrm{t}=\frac{2 \pi}{5} \quad-. \frac{\mathrm{QyEn}}{\alpha \mathrm{t}^{2}} \alpha \mathrm{t}=\frac{2 \pi}{5} \quad--\frac{\mathrm{QyMI}}{\alpha \mathrm{t}^{2}} \alpha \mathrm{t}=\frac{2 \pi}{5}$

- $\frac{\mathrm{QyEp}}{\mathrm{t}^{2}} \alpha \mathrm{t}=\frac{\pi}{2} \quad--\frac{\mathrm{QyEn}}{\alpha \mathrm{t}^{2}} \alpha \mathrm{t}=\frac{\pi}{2} \quad--\frac{\mathrm{QyMI}}{\alpha \mathrm{t}^{2}} \alpha \mathrm{t}=\frac{\pi}{2}$

$\frac{\mathrm{Rp}}{\mathrm{Rt}}-\frac{\mathrm{QyEp}}{\alpha \mathrm{t}^{2}} \alpha \mathrm{t}=\frac{3 \pi}{5} \quad-. \frac{\mathrm{QyEn}}{\alpha \mathrm{t}^{2}} \alpha \mathrm{t}=\frac{3 \pi}{5} \quad--\frac{\mathrm{QyMI}}{\alpha \mathrm{t}^{2}} \alpha \mathrm{t}=\frac{3 \pi}{5}$

$-\frac{\mathrm{QyEp}}{\alpha \mathrm{t}^{2}} \alpha \mathrm{t}=\frac{7 \pi}{10} \quad--\frac{\mathrm{QyEn}}{\alpha \mathrm{t}^{2}} \alpha \mathrm{t}=\frac{7 \pi}{10} \quad--\frac{\mathrm{QyMI}}{\alpha \mathrm{t}^{2}} \alpha \mathrm{t}=\frac{7 \pi}{10}$

$\mathrm{Lt}=420 \quad \alpha \mathrm{p}=\frac{\alpha \mathrm{t}}{4}$

MzMax/at ${ }^{2}$

$\operatorname{MzMin} / \alpha \mathrm{t}^{2}$

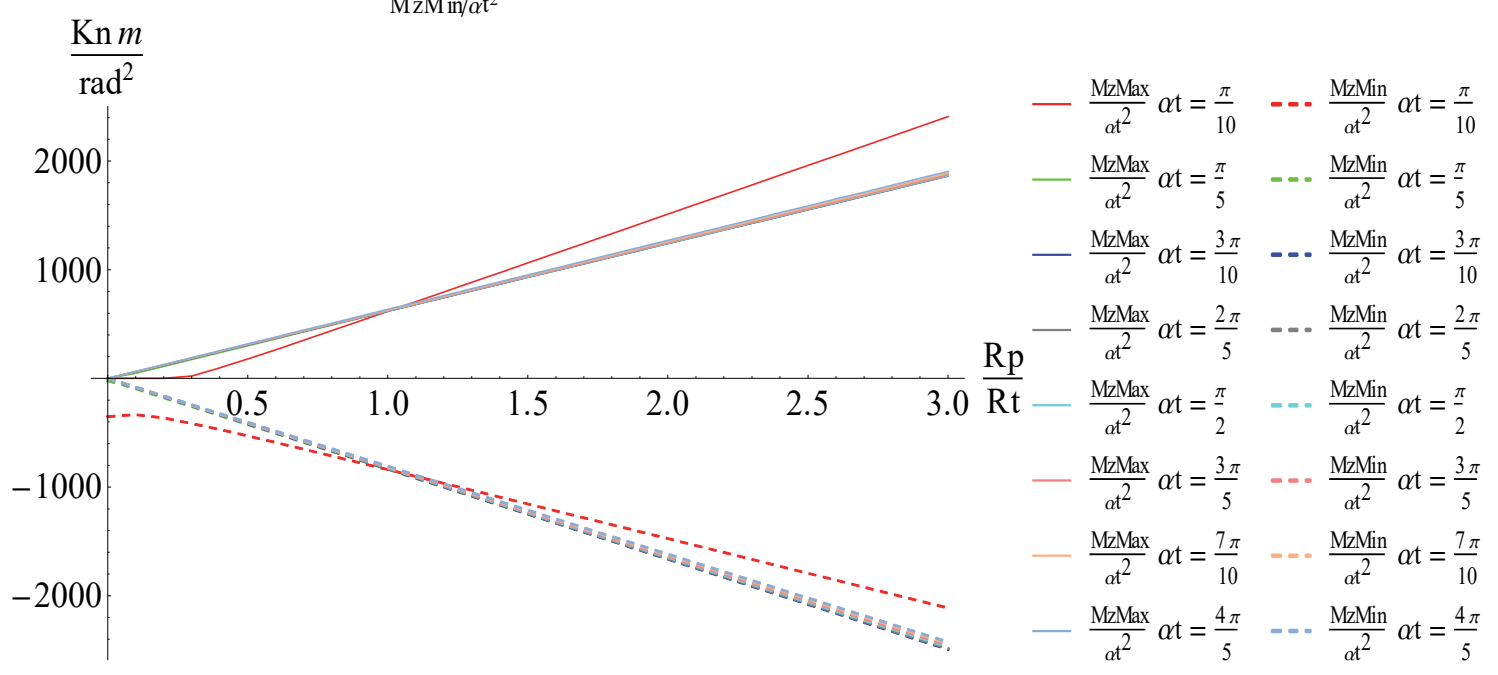

Tablero 7 (Peatonal)

$\mathrm{Lt}=420 \alpha \mathrm{p}=\frac{\alpha \mathrm{t}}{4}$

NxEp/Rt

$\mathrm{NxEn} / \mathrm{Rt}$

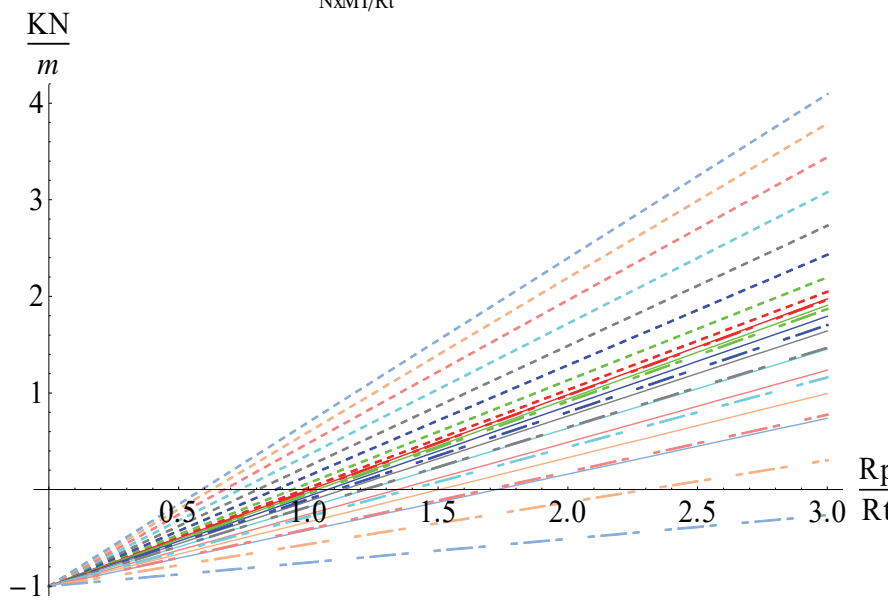

$$
\begin{aligned}
& -\frac{\mathrm{NxEp}}{\mathrm{Rt}} \alpha \mathrm{t}=\frac{\pi}{10} \quad-\ldots \frac{\mathrm{NxEn}}{\mathrm{Rt}} \alpha \mathrm{t}=\frac{\pi}{10} \quad--\frac{\mathrm{NxMI}}{\mathrm{Rt}} \alpha \mathrm{t}=\frac{\pi}{10} \\
& -\frac{\mathrm{NxEp}}{\mathrm{Rt}} \alpha \mathrm{t}=\frac{\pi}{5} \quad-\cdots \frac{\mathrm{NxEn}}{\mathrm{Rt}} \alpha \mathrm{t}=\frac{\pi}{5} \quad--\frac{\mathrm{NxMI}}{\mathrm{Rt}} \alpha \mathrm{t}=\frac{\pi}{5} \\
& -\frac{\mathrm{NxEp}}{\mathrm{Rt}} \alpha \mathrm{t}=\frac{3 \pi}{10} \quad \ldots \frac{\mathrm{NxEn}}{\mathrm{Rt}} \alpha \mathrm{t}=\frac{3 \pi}{10} \quad-\frac{\mathrm{NxMI}}{\mathrm{Rt}} \alpha \mathrm{t}=\frac{3 \pi}{10} \\
& -\frac{\mathrm{NxEp}}{\mathrm{Rt}} \alpha \mathrm{t}=\frac{2 \pi}{5} \quad-=\frac{\mathrm{NxEn}}{\mathrm{Rt}} \alpha \mathrm{t}=\frac{2 \pi}{5} \quad-\frac{\mathrm{NxMI}}{\mathrm{Rt}} \alpha \mathrm{t}=\frac{2 \pi}{5} \\
& -\frac{\mathrm{NxEp}}{\mathrm{Rt}} \alpha \mathrm{t}=\frac{\pi}{2} \quad=-\frac{\mathrm{NxEn}}{\mathrm{Rt}} \alpha \mathrm{t}=\frac{\pi}{2} \quad--\frac{\mathrm{NxMI}}{\mathrm{Rt}} \alpha \mathrm{t}=\frac{\pi}{2} \\
& \mathrm{Rp}-\frac{\mathrm{NxEp}}{\mathrm{Rt}} \alpha \mathrm{t}=\frac{3 \pi}{5} \quad \ldots \frac{\mathrm{NxEn}}{\mathrm{Rt}} \alpha \mathrm{t}=\frac{3 \pi}{5} \quad=-\frac{\mathrm{NxMI}}{\mathrm{Rt}} \alpha \mathrm{t}=\frac{3 \pi}{5} \\
& \frac{\mathrm{Rt}}{\mathrm{Rt}}-\frac{\mathrm{NxEp}}{\mathrm{Rt}} \alpha \mathrm{t}=\frac{7 \pi}{10}==\frac{\mathrm{NxEn}}{\mathrm{Rt}} \alpha \mathrm{t}=\frac{7 \pi}{10}=-\frac{\mathrm{NxMI}}{\mathrm{Rt}} \alpha \mathrm{t}=\frac{7 \pi}{10} \\
& -\frac{\mathrm{NxEp}}{\mathrm{Rt}} \alpha \mathrm{t}=\frac{4 \pi}{5} \quad-=\frac{\mathrm{NxEn}}{\mathrm{Rt}} \alpha \mathrm{t}=\frac{4 \pi}{5} \quad--\frac{\mathrm{NxMI}}{\mathrm{Rt}} \alpha \mathrm{t}=\frac{4 \pi}{5}
\end{aligned}
$$




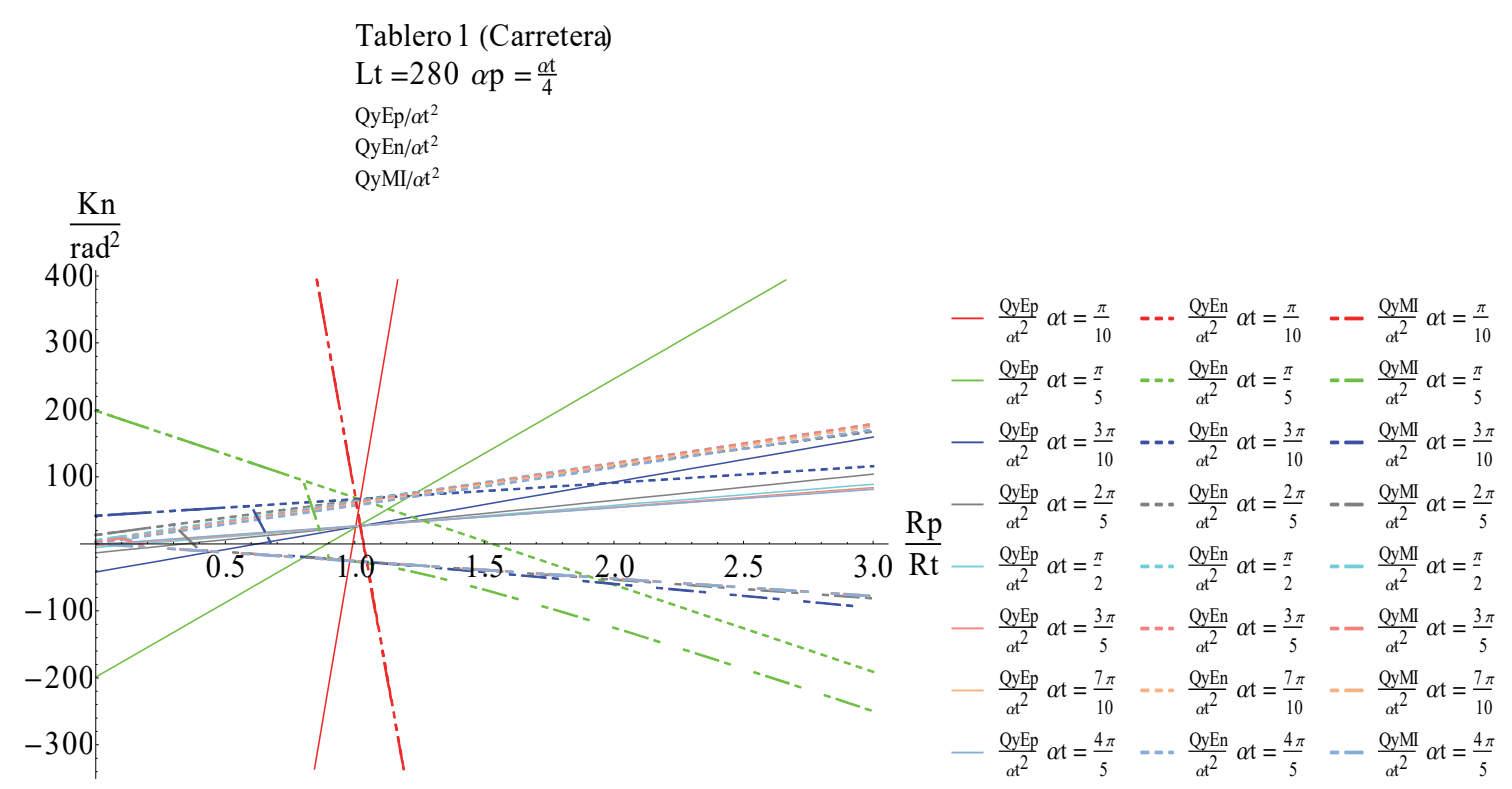

Tablero 1 (Carretera)

$\mathrm{Lt}=280 \alpha \mathrm{p}=\frac{a \mathrm{t}}{4}$

$\operatorname{MzMax} / \alpha \mathrm{t}^{2}$

$\operatorname{MzMin} / \alpha \mathrm{t}^{2}$

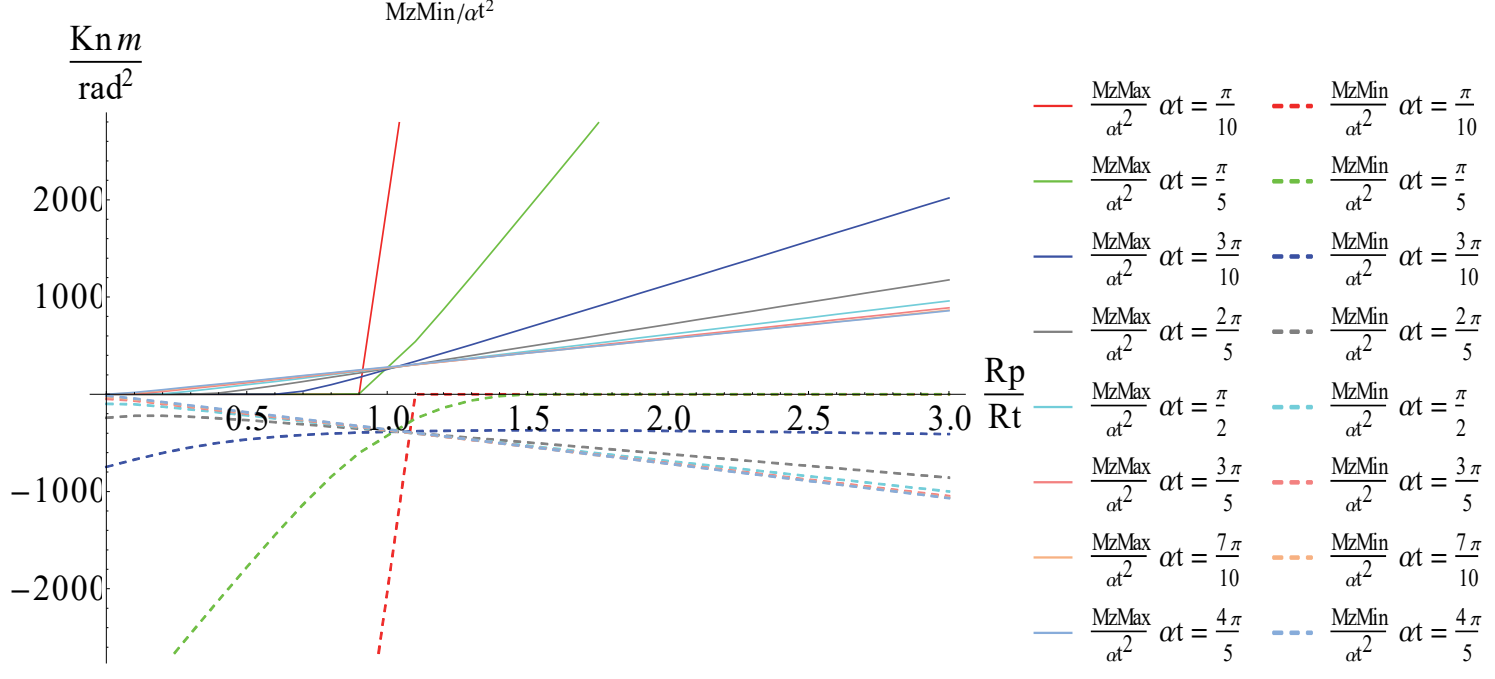

Tablero 1 (Carretera)

$\mathrm{Lt}=280 \alpha \mathrm{p}=\frac{\alpha \mathrm{t}}{4}$

$\mathrm{NxEp} / \mathrm{Rt}$

NxEn/Rt
NxMI/Rt

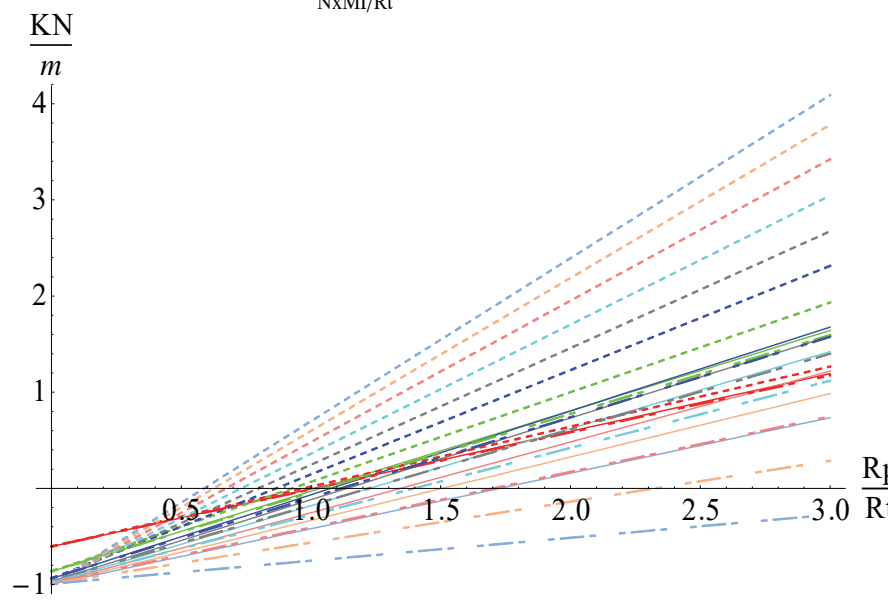

$$
\begin{aligned}
& -\frac{\mathrm{NxEp}}{\mathrm{Rt}} \alpha \mathrm{t}=\frac{\pi}{10} \quad--\frac{\mathrm{NxEn}}{\mathrm{Rt}} \alpha \mathrm{t}=\frac{\pi}{10} \quad-\quad \frac{\mathrm{NxMI}}{\mathrm{Rt}} \alpha \mathrm{t}=\frac{\pi}{10} \\
& -\frac{\mathrm{NxEp}}{\mathrm{Rt}} \alpha \mathrm{t}=\frac{\pi}{5} \quad-\cdots \frac{\mathrm{NxEn}}{\mathrm{Rt}} \alpha \mathrm{t}=\frac{\pi}{5} \quad--\frac{\mathrm{NxMI}}{\mathrm{Rt}} \alpha \mathrm{t}=\frac{\pi}{5} \\
& -\frac{\mathrm{NxEp}}{\mathrm{Rt}} \alpha \mathrm{t}=\frac{3 \pi}{10} \quad \ldots \frac{\mathrm{NxEn}}{\mathrm{Rt}} \alpha \mathrm{t}=\frac{3 \pi}{10} \quad-\quad \frac{\mathrm{NxMI}}{\mathrm{Rt}} \alpha \mathrm{t}=\frac{3 \pi}{10} \\
& -\frac{\mathrm{NxEp}}{\mathrm{Rt}} \alpha \mathrm{t}=\frac{2 \pi}{5} \quad--\frac{\mathrm{NxEn}}{\mathrm{Rt}} \alpha \mathrm{t}=\frac{2 \pi}{5} \quad-\quad \frac{\mathrm{NxMI}}{\mathrm{Rt}} \alpha \mathrm{t}=\frac{2 \pi}{5} \\
& -\frac{\mathrm{NxEp}}{\mathrm{Rt}} \alpha \mathrm{t}=\frac{\pi}{2} \quad-\cdots \frac{\mathrm{NxEn}}{\mathrm{Rt}} \alpha \mathrm{t}=\frac{\pi}{2} \quad--\frac{\mathrm{NxMI}}{\mathrm{Rt}} \alpha \mathrm{t}=\frac{\pi}{2} \\
& -\frac{\mathrm{NxEp}}{\mathrm{Rt}} \alpha \mathrm{t}=\frac{3 \pi}{5} \quad-\cdots \frac{\mathrm{NxEn}}{\mathrm{Rt}} \alpha \mathrm{t}=\frac{3 \pi}{5} \quad-\frac{\mathrm{NxMI}}{\mathrm{Rt}} \alpha \mathrm{t}=\frac{3 \pi}{5} \\
& \frac{\mathrm{R}}{\mathrm{Rt}}-\frac{\mathrm{NxEp}}{\mathrm{Rt}} \alpha \mathrm{t}=\frac{7 \pi}{10} \quad--\frac{\mathrm{NxEn}}{\mathrm{Rt}} \alpha \mathrm{t}=\frac{7 \pi}{10} \quad--\frac{\mathrm{NxMI}}{\mathrm{Rt}} \alpha \mathrm{t}=\frac{7 \pi}{10} \\
& -\frac{\mathrm{NxEp}}{\mathrm{Rt}} \alpha \mathrm{t}=\frac{4 \pi}{5} \quad--\frac{\mathrm{NxEn}}{\mathrm{Rt}} \alpha \mathrm{t}=\frac{4 \pi}{5} \quad-\frac{\mathrm{NxMI}}{\mathrm{Rt}} \alpha \mathrm{t}=\frac{4 \pi}{5}
\end{aligned}
$$




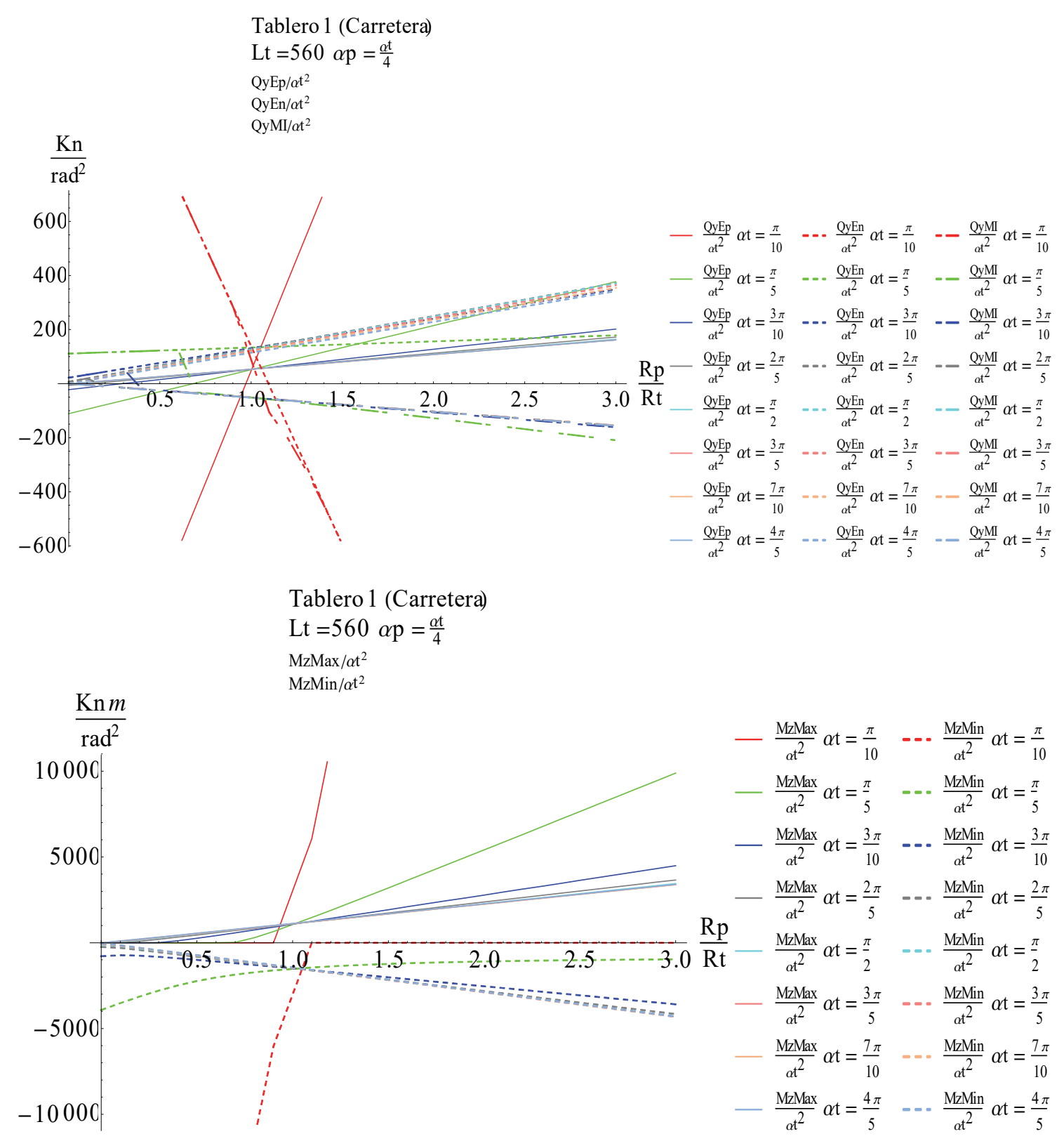

Tablero 1 (Carretera)

$\mathrm{Lt}=560 \alpha \mathrm{p}=\frac{\alpha \mathrm{t}}{4}$

$\mathrm{NxEp} / \mathrm{Rt}$
$\mathrm{NxEn} / \mathrm{Rt}$

NxMI/Rt

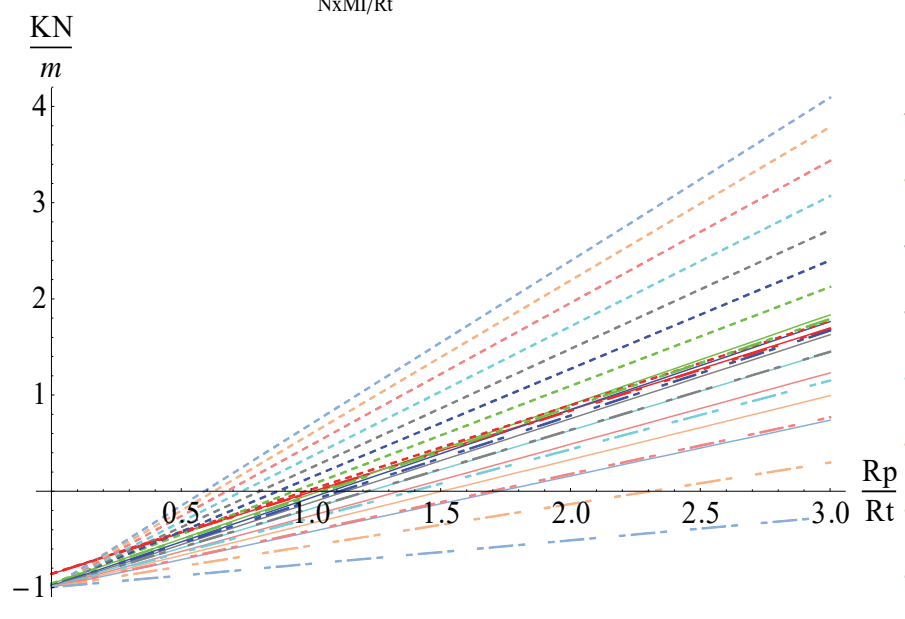

$-\frac{\mathrm{NxEp}}{\mathrm{Rt}} \alpha \mathrm{t}=\frac{\pi}{10} \quad-\cdots \frac{\mathrm{NxEn}}{\mathrm{Rt}} \alpha \mathrm{t}=\frac{\pi}{10} \quad-\quad \frac{\mathrm{NxMI}}{\mathrm{Rt}} \alpha \mathrm{t}=\frac{\pi}{10}$

$-\frac{\mathrm{NxEp}}{\mathrm{Rt}} \alpha \mathrm{t}=\frac{\pi}{5} \quad-\ldots \frac{\mathrm{NxEn}}{\mathrm{Rt}} \alpha \mathrm{t}=\frac{\pi}{5} \quad--\frac{\mathrm{NxMI}}{\mathrm{Rt}} \alpha \mathrm{t}=\frac{\pi}{5}$

$-\frac{\mathrm{NxEp}}{\mathrm{Rt}} \alpha \mathrm{t}=\frac{3 \pi}{10} \quad \cdots \frac{\mathrm{NxEn}}{\mathrm{Rt}} \alpha \mathrm{t}=\frac{3 \pi}{10} \quad-\quad \frac{\mathrm{NxMI}}{\mathrm{Rt}} \alpha \mathrm{t}=\frac{3 \pi}{10}$

$-\frac{\mathrm{NxEp}}{\mathrm{Rt}} \alpha \mathrm{t}=\frac{2 \pi}{5} \quad--\frac{\mathrm{NxEn}}{\mathrm{Rt}} \alpha \mathrm{t}=\frac{2 \pi}{5} \quad-\frac{\mathrm{NxMI}}{\mathrm{Rt}} \alpha \mathrm{t}=\frac{2 \pi}{5}$

$-\frac{\mathrm{NxEp}}{\mathrm{Rt}} \alpha \mathrm{t}=\frac{\pi}{2} \quad--\frac{\mathrm{NxEn}}{\mathrm{Rt}} \alpha \mathrm{t}=\frac{\pi}{2} \quad--\frac{\mathrm{NxMI}}{\mathrm{Rt}} \alpha \mathrm{t}=\frac{\pi}{2}$

$-\frac{\mathrm{NxEp}}{\mathrm{Rt}} \alpha \mathrm{t}=\frac{3 \pi}{5} \quad--\frac{\mathrm{NxEn}}{\mathrm{Rt}} \alpha \mathrm{t}=\frac{3 \pi}{5} \quad--\frac{\mathrm{NxMI}}{\mathrm{Rt}} \alpha \mathrm{t}=\frac{3 \pi}{5}$

$\frac{\mathrm{Rp}}{\mathrm{Rt}}-\frac{\mathrm{NxEp}}{\mathrm{Rt}} \alpha \mathrm{t}=\frac{7 \pi}{10} \quad-\cdots \frac{\mathrm{NxEn}}{\mathrm{Rt}} \alpha \mathrm{t}=\frac{7 \pi}{10} \quad-\frac{\mathrm{NxMI}}{\mathrm{Rt}} \alpha \mathrm{t}=\frac{7 \pi}{10}$

$-\frac{\mathrm{NxEp}}{\mathrm{Rt}} \alpha \mathrm{t}=\frac{4 \pi}{5} \quad=-\frac{\mathrm{NxEn}}{\mathrm{Rt}} \alpha \mathrm{t}=\frac{4 \pi}{5} \quad-\frac{\mathrm{NxMI}}{\mathrm{Rt}} \alpha \mathrm{t}=\frac{4 \pi}{5}$ 
Tablero 1 (Carretera)

$\mathrm{Lt}=840 \alpha \mathrm{p}=\frac{\alpha \mathrm{t}}{4}$

QyEp/ $/ \alpha t^{2}$

QyEn/ $\alpha \mathrm{t}^{2}$

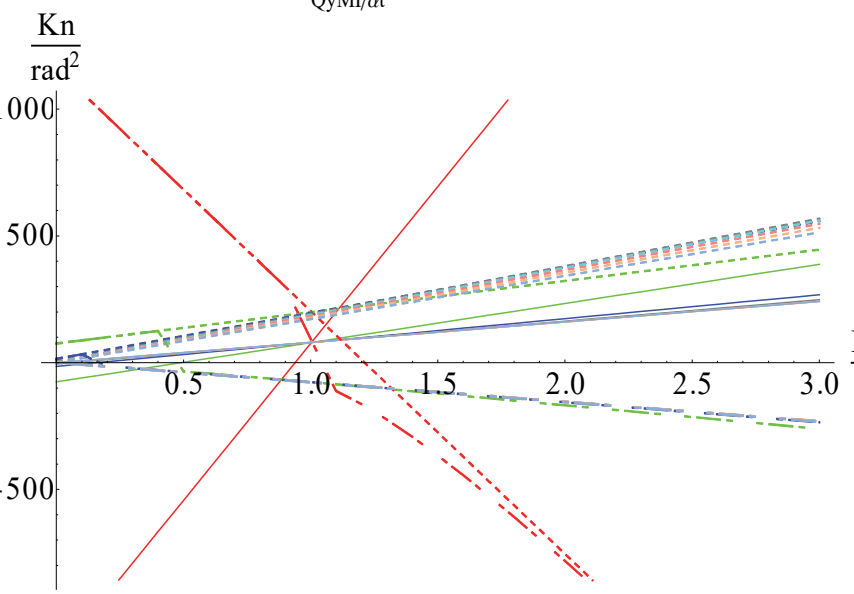

$$
\begin{aligned}
& -\frac{Q \mathrm{yEp}}{\alpha \mathrm{t}^{2}} \alpha \mathrm{t}=\frac{\pi}{10} \quad-\cdots \frac{\mathrm{QyEn}}{\alpha \mathrm{t}^{2}} \alpha \mathrm{t}=\frac{\pi}{10} \quad-\quad \frac{\mathrm{QyMI}}{\alpha \mathrm{t}^{2}} \alpha \mathrm{t}=\frac{\pi}{10}
\end{aligned}
$$

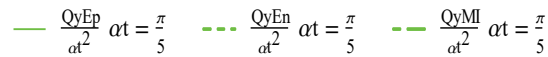

$$
\begin{aligned}
& \text { - } \frac{\mathrm{QyEp}}{\mathrm{t}^{2}} \alpha \mathrm{t}=\frac{3 \pi}{10} \quad-\cdots \frac{\mathrm{QyEn}}{\mathrm{d \textrm {t } ^ { 2 }}} \alpha \mathrm{t}=\frac{3 \pi}{10} \quad-\quad-\frac{\mathrm{QyMI}}{\mathrm{d \textrm {t } ^ { 2 }}} \alpha \mathrm{t}=\frac{3 \pi}{10} \\
& \mathrm{Rp}-\frac{\mathrm{QyEp}}{a \mathrm{t}^{2}} \alpha \mathrm{t}=\frac{2 \pi}{5} \quad-\cdots \frac{\mathrm{QyEn}}{\alpha \mathrm{t}^{2}} \alpha \mathrm{t}=\frac{2 \pi}{5} \quad--\frac{\mathrm{QyMI}}{\partial \mathrm{t}^{2}} \alpha \mathrm{t}=\frac{2 \pi}{5} \\
& \frac{\mathrm{Rp}}{\mathrm{Rt}}-\frac{\mathrm{QyEp}}{\alpha \mathrm{t}^{2}} \alpha \mathrm{t}=\frac{\pi}{2} \quad=-\frac{\mathrm{QyEn}}{\alpha \mathrm{t}^{2}} \alpha \mathrm{t}=\frac{\pi}{2} \quad--\frac{\mathrm{QyMI}}{\alpha \mathrm{t}^{2}} \alpha \mathrm{t}=\frac{\pi}{2} \\
& \text { - } \frac{\mathrm{QyEp}}{\mathrm{t}^{2}} \alpha \mathrm{t}=\frac{3 \pi}{5} \quad--\frac{\mathrm{QyEn}}{\mathrm{t}^{2}} \alpha \mathrm{t}=\frac{3 \pi}{5} \quad-\frac{\mathrm{QyMI}}{\mathrm{d \textrm {t } ^ { 2 }}} \alpha \mathrm{t}=\frac{3 \pi}{5} \\
& \text { - } \frac{\mathrm{QyEp}}{\alpha \mathrm{t}^{2}} \alpha \mathrm{t}=\frac{7 \pi}{10} \quad--\frac{\mathrm{QyEn}}{\alpha \mathrm{t}^{2}} \alpha \mathrm{t}=\frac{7 \pi}{10} \quad-\frac{\mathrm{QyMI}}{\alpha \mathrm{t}^{2}} \alpha \mathrm{t}=\frac{7 \pi}{10} \\
& \text { - } \frac{\mathrm{QyEp}}{\mathrm{at} \mathrm{t}^{2}} \alpha \mathrm{t}=\frac{4 \pi}{5} \quad--\frac{\mathrm{QyEn}}{\mathrm{at} \mathrm{t}^{2}} \alpha \mathrm{t}=\frac{4 \pi}{5} \quad-\frac{\mathrm{QyMI}}{\mathrm{at} \mathrm{t}^{2}} \alpha \mathrm{t}=\frac{4 \pi}{5}
\end{aligned}
$$

Tablero 1 (Carretera) $\mathrm{Lt}=840 \alpha \mathrm{p}=\frac{\alpha \mathrm{t}}{4}$

$\operatorname{MzMax} / \alpha \mathrm{t}^{2}$

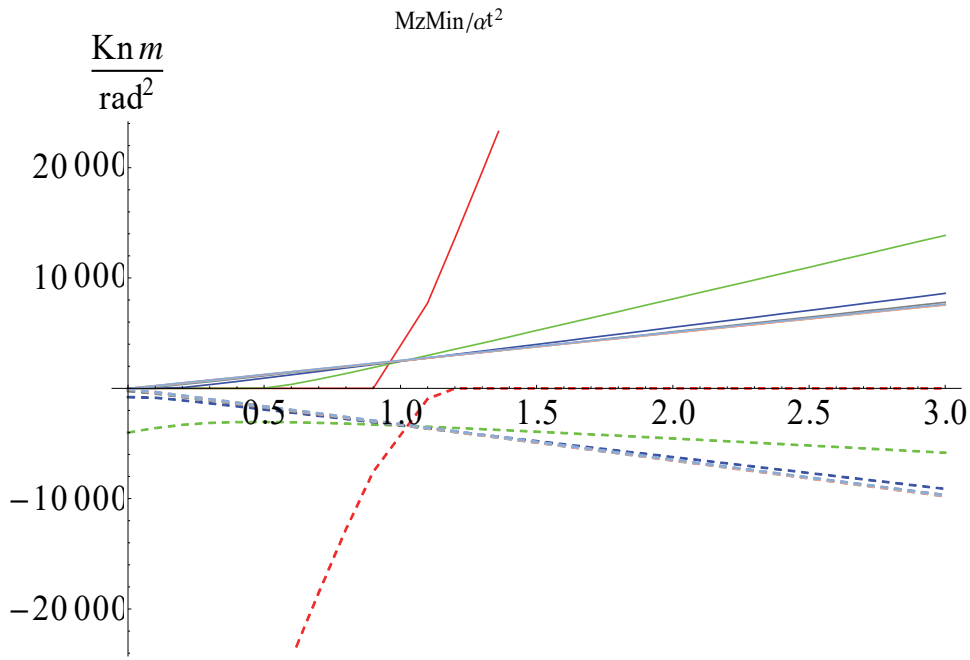

$$
\begin{aligned}
& -\frac{\mathrm{MzMax}}{\alpha \mathrm{t}^{2}} \alpha \mathrm{t}=\frac{\pi}{10} \quad \ldots \frac{\mathrm{MzMin}}{\mathrm{ct}^{2}} \alpha \mathrm{t}=\frac{\pi}{10} \\
& -\frac{\mathrm{MzMax}}{a t^{2}} \alpha \mathrm{t}=\frac{\pi}{5} \quad \ldots \frac{\mathrm{MzMin}}{a t^{2}} \alpha \mathrm{t}=\frac{\pi}{5} \\
& -\frac{\mathrm{MzMax}}{a t^{2}} \alpha \mathrm{t}=\frac{3 \pi}{10} \quad \ldots \frac{\mathrm{MzMin}}{a t^{2}} \alpha \mathrm{t}=\frac{3 \pi}{10} \\
& -\frac{\mathrm{MzMax}}{a t^{2}} \alpha \mathrm{t}=\frac{2 \pi}{5} \quad \cdots \frac{\mathrm{MzMin}}{a \mathrm{t}^{2}} \alpha \mathrm{t}=\frac{2 \pi}{5} \\
& \frac{\mathrm{Rp}}{\mathrm{Rt}}-\frac{\mathrm{MzMax}}{a \mathrm{t}^{2}} \alpha \mathrm{t}=\frac{\pi}{2} \quad=-\frac{\mathrm{MzMin}}{\alpha \mathrm{t}^{2}} \alpha \mathrm{t}=\frac{\pi}{2} \\
& -\frac{\mathrm{MzMax}}{d t^{2}} \alpha \mathrm{t}=\frac{3 \pi}{5} \quad \cdots=\frac{\mathrm{MzMin}}{\alpha t^{2}} \alpha \mathrm{t}=\frac{3 \pi}{5} \\
& \frac{\mathrm{MzMax}}{\alpha \mathrm{t}^{2}} \alpha \mathrm{t}=\frac{7 \pi}{10} \quad--\frac{\mathrm{Mz} \mathrm{Min}}{\alpha \mathrm{t}^{2}} \alpha \mathrm{t}=\frac{7 \pi}{10} \\
& -\frac{\mathrm{MzMax}}{d \mathrm{t}^{2}} \alpha \mathrm{t}=\frac{4 \pi}{5} \quad \cdots \frac{\mathrm{MzMin}}{\alpha \mathrm{t}^{2}} \alpha \mathrm{t}=\frac{4 \pi}{5}
\end{aligned}
$$




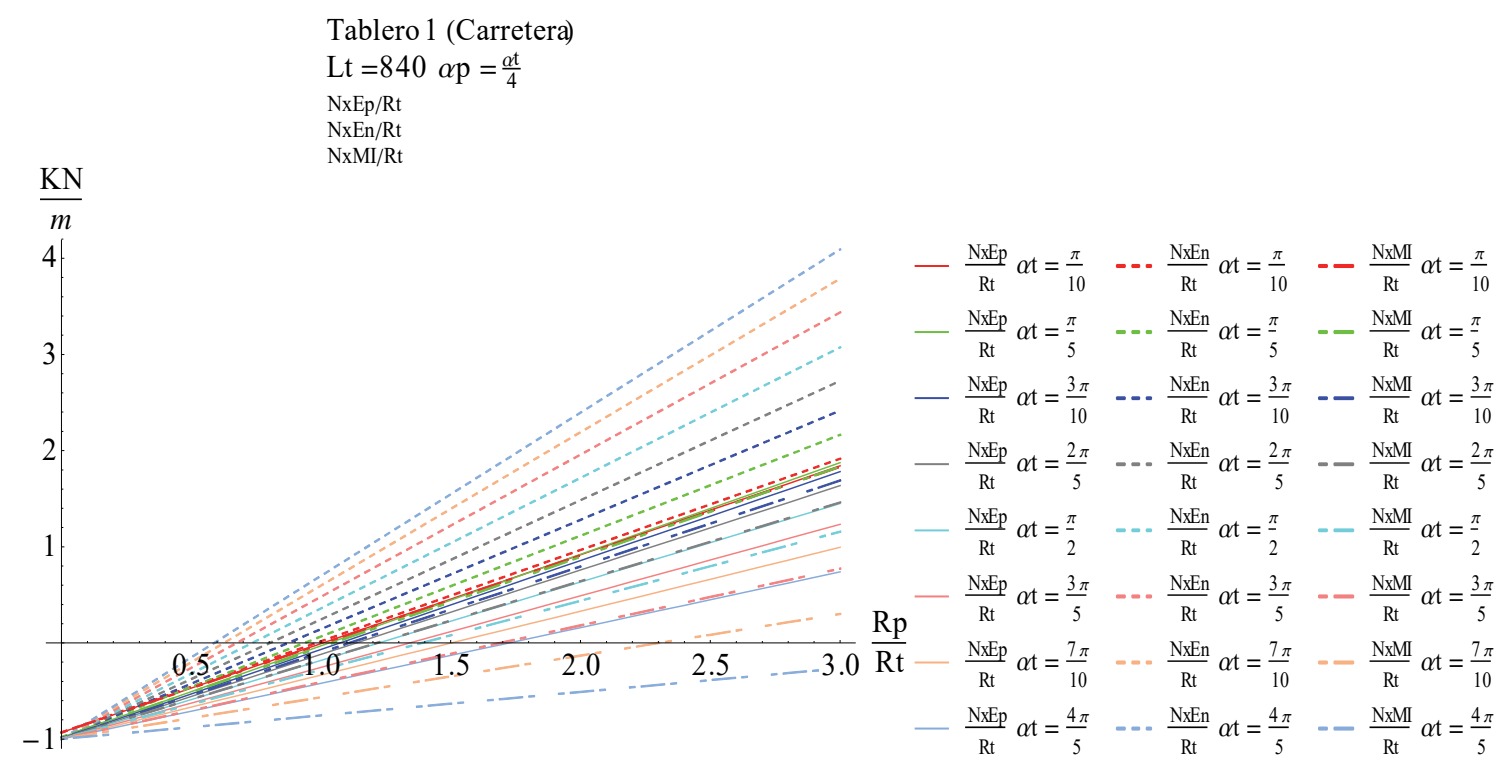

Diagrama 2.67. Solicitaciones del tablero $\left(\frac{Q y}{\alpha t^{2}}, \frac{M z}{\alpha t^{2}} y \frac{N x}{R t}\right) . \boldsymbol{L t}=\mathbf{1 4 0}, \alpha \boldsymbol{p}=\frac{\alpha t}{4}$, Tablero 7 (Peatonal); $\boldsymbol{L t}=\mathbf{2 8 0}$, $\alpha \boldsymbol{p}=\frac{\alpha t}{4}$, Tablero 7 (Peatonal); $\boldsymbol{L t}=\mathbf{4 2 0}, \alpha \boldsymbol{p}=\frac{\alpha t}{4}$, Tablero 7 (Peatonal); $\boldsymbol{L t}=\mathbf{2 8 0}, \boldsymbol{\alpha p}=\frac{\alpha t}{4}$, Tablero 1 (Carretera); $\boldsymbol{L t}=\mathbf{5 6 0}, \boldsymbol{\alpha p}=\frac{\alpha \boldsymbol{t}}{4}$, Tablero 1 (Carretera); $\boldsymbol{L t}=\mathbf{8 4 0 ,} \boldsymbol{\alpha p}=\frac{\alpha \boldsymbol{t}}{4}$, Tablero 1 (Carretera);

Existen unas pautas similares al caso en el que la pila se situaba en el eje de simetría $(\alpha p=0)$, que se van repitiendo a medida que se varían las características del tablero. Si bien, está a la vista (sobre todo en el caso del de $\alpha p=\frac{\alpha t}{2}$ ) que la solución numérica va a ser menos exacta que lo que se obtuvo para $\alpha p=0$. Se va a continuar con los tipos de comportamiento que ya se definieron en el subapartado anterior: "tipo arco", "tipo viga", "mixto" y "tipo esfera":

- El epicentro alrededor del cual giran las rectas de los diagramas de cortante Qy, es más difuso, siendo su valor menos estable a medida que se modifica el ángulo del tablero $(\alpha t)$. La influencia de $L t$ sobre el valor del epicentro, también se hace menos exacta (sobre todo para $\alpha p=\frac{\alpha t}{2}$ y $\alpha t$ bajos). Aunque se puede seguir aproximando esta influencia de forma lineal y en abscisas se puede seguir situando en $\frac{R p}{R t} \approx 1$.

- Por la asimetría del problema, se obtienen 2 valores diferentes de cortante (Qy) en los estribos ( $Q y E p$, estribo positivo, el más cercano a la pila, $Q y E n$, estribo negativo). QyEn va a ser el que determine el comportamiento del sistema (Diagrama 2.64 -> Diagrama 2.67). Si se obtiene el valor de este cortante en su epicentro (se ha aproximado lo más posible al valor que toma la recta cuya pendiente sea más próxima a cero), para cada uno de los casos en los que situamos la pila ( $\alpha p=\frac{\alpha t}{2}$ y $\alpha p=\frac{\alpha t}{4}$ ), divididos por la longitud total del tablero:

$$
\alpha p=\frac{\alpha t}{2} \rightarrow \frac{\frac{Q y E n}{\alpha t^{2}}}{L t} \approx 0.41
$$




$$
\alpha p=\frac{\alpha t}{4} \rightarrow \frac{\frac{Q y E n}{\alpha t^{2}}}{L t} \approx 0.237
$$

- La pendiente de la recta que representa el cortante en el estribo negativo $\frac{Q y E n}{\alpha t^{2}}$, es para los $2 \operatorname{casos}\left(\alpha p=\frac{\alpha t}{2}\right.$ y $\left.\alpha p=\frac{\alpha t}{4}\right)$, la que marca el comportamiento del tablero a medida que aumenta $\mathrm{Rp}$. Si la pendiente es positiva, las solicitaciones transversales van a tener su mínimo en $\frac{R p}{R t}=1$ o sus proximidades. Mientras que, si es negativa, va a depender del valor de la pendiente, donde se presente el mínimo de las solicitaciones.

Si se prosigue con un procedimiento semejante a desarrollado para $\alpha p=0$, teniendo en cuenta el punto de partida de los diagramas $(R p=0)$. Cuando $R p=0$, no existe estribo positivo ni negativo, por esto se va escribir como $Q y E$, para el valor en $R p=0$ (siguiendo la nomenclatura utilizada en su subapartado). Se obtiene:

1) Comportamiento "tipo viga":

$$
\begin{gathered}
\alpha p=\frac{\alpha t}{2} \rightarrow \frac{\frac{Q y E}{\alpha t^{2} L t}}{\frac{N x}{R t}}(R p=0)=\frac{\frac{Q y E}{\alpha t^{3} R t}}{\frac{N x}{R t}}(R p=0)=v_{Q y N x E} \frac{R t}{\alpha t^{3} R t} \geq 0.41 \\
\alpha p=\frac{\alpha t}{4} \rightarrow \frac{\frac{Q y E}{\alpha t^{2} L t}}{\frac{N x}{R t}}(R p=0)=\frac{\frac{Q y E}{\alpha t^{3} R t}}{\frac{N x}{R t}}(R p=0)=v_{Q y N x E} \frac{R t}{\alpha t^{3} R t} \geq 0.237 \\
v_{Q Y N x E}=\frac{Q y E}{N x}=(61.62-9.58 \alpha t) \psi_{Q y N x}=(61.62-9.58 \alpha t) \frac{1}{\alpha t L t^{2}} * i_{z z}{ }^{2}
\end{gathered}
$$

2) Comportamiento "mixto":

$$
\begin{gathered}
\alpha p=\frac{\alpha t}{2} \rightarrow 0.012 \leq \frac{\frac{Q y E}{\alpha t^{2} L t}}{\frac{N x}{R t}}(R p=0)=\frac{\frac{Q y E}{\alpha t^{3} R t}}{\frac{N x}{R t}}(R p=0)=v_{Q y N x E} \frac{R t}{\alpha t^{3} R t} \leq 0.41 \\
\alpha p=\frac{\alpha t}{4} \rightarrow 0.006 \leq \frac{\frac{Q y E}{\alpha t^{2} L t}}{\frac{N x}{R t}}(R p=0)=\frac{\frac{Q y E}{\alpha t^{3} R t}}{\frac{N x}{R t}}(R p=0)=v_{Q y N x E} \frac{R t}{\alpha t^{3} R t} \leq 0.237 \\
v_{Q y N x E}=\frac{Q y E}{N x}=(61.62-9.58 \alpha t) \psi_{Q y N x}=(61.62-9.58 \alpha t) \frac{1}{\alpha t L t^{2}} * i_{z z}{ }^{2}
\end{gathered}
$$

3) Comportamiento "tipo arco":

$$
\begin{aligned}
& \alpha p=\frac{\alpha t}{2} \rightarrow \frac{\frac{Q y E}{\alpha t^{2} L t}}{\frac{N x}{R t}}(R p=0)=\frac{\frac{Q y E}{\alpha t^{3} R t}}{\frac{N x}{R t}}(R p=0)=v_{Q y N x E} \frac{R t}{\alpha t^{3} R t} \leq 0.012 \\
& \alpha p=\frac{\alpha t}{4} \rightarrow \frac{\frac{Q y E}{\alpha t^{2} L t}}{\frac{N x}{R t}}(R p=0)=\frac{\frac{Q y E}{\alpha t^{3} R t}}{\frac{N x}{R t}}(R p=0)=v_{Q y N x E} \frac{R t}{\alpha t^{3} R t} \leq 0.006
\end{aligned}
$$




$$
v_{Q y N x E}=\frac{Q y E}{N x}=(61.62-9.58 \alpha t) \psi_{Q y N x}=(61.62-9.58 \alpha t) \frac{1}{\alpha t L t^{2}} * i_{z z}^{2}
$$

4) Comportamiento "tipo esfera":

Este comportamiento, vuelve a producirse después del punto de mínimas solicitaciones en los comportamientos "tipo mixto" e inmediatamente después de separar la pila del centro del arco en el "tipo arco" $(R p>0)$. surgiendo 2 máximos en el diagrama de momentos $\mathrm{Mz}$ :

o El primero, entre el estribo positivo (el más cercano a la pila) y el centro de vano, de valor positivo.

o El segundo, entre el centro de vano y el estribo negativo (el más alejado a la pila), de valor negativo.

Se va a volver a analizar la variación de la carga total aplicada al tablero a medida que se modifica el valor Rp. Como ya se ha comentado, esta es la variable fundamental en lo que a las solicitaciones de los tableros con comportamiento "tipo viga" se refiere.

Se va a utilizar las mismas expresiones, con los mismos significados que en el subapartado 2.2.6.2.1.1 y el Diagrama 2.57: La carga total sobre el tablero, como ya se ha comentado, es una medida de la solicitación horizontal $\left(\sqrt{p_{x}{ }^{2}+p_{y}{ }^{2}}\right)$ total que se introduce al tablero. Para que el análisis sea más productivo, se ha dividido la carga por la longitud del tablero (Lt), de forma que lo que aparece es carga total por unidad de longitud (de esta manera se analizan todos los casos en una sola gráfica).

$$
T t o t=\frac{\int_{-\frac{\alpha t}{2}}^{\frac{\alpha t}{2}} \sqrt{p_{x}^{2}+p_{y}^{2}} d \alpha}{R t \alpha t}
$$

Las líneas discontinuas corresponden a la carga horizontal total de un puente recto de luz igual al curvo (según el ángulo desarrollado) y con la pila situada en el estribo, para el caso de $\alpha_{\mathrm{p}}=\frac{\alpha_{\mathrm{t}}}{2}$, y a un cuarto de la luz total, para el caso de $\alpha_{\mathrm{p}}=\frac{\alpha_{\mathrm{t}}}{4}$, también por unidad de longitud. Se ha dibujado una recta, para mejorar la representación de los datos, pero en este caso la pila cae sobre el tablero. El valor de la carga total del puente recto equivalente: 


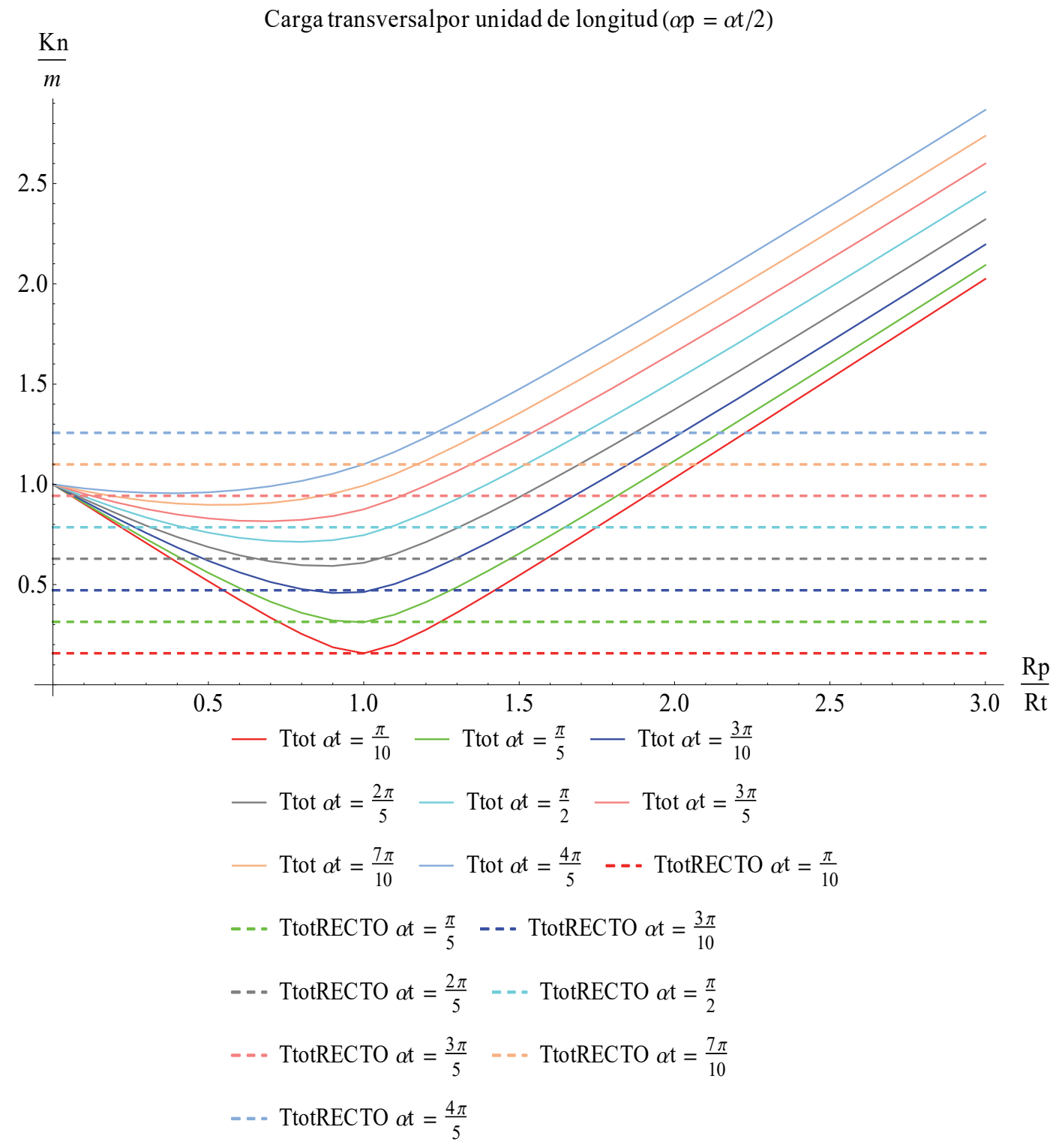




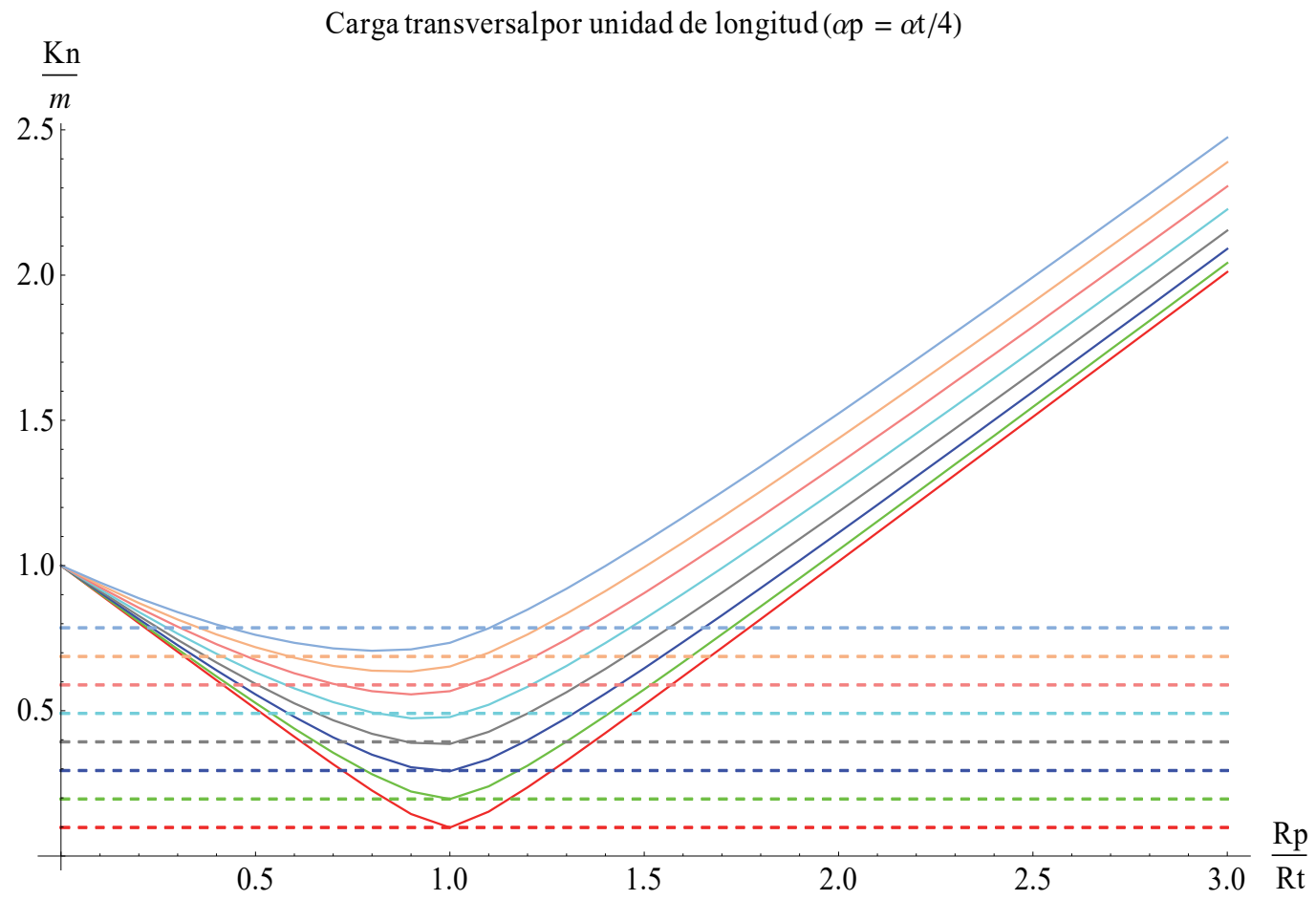

- Ttot $\alpha \mathrm{t}=\frac{\pi}{10}-$ Ttot $\alpha \mathrm{t}=\frac{\pi}{5} \quad-$ Ttot $\alpha \mathrm{t}=\frac{3 \pi}{10}$

- Ttot $\alpha$ t $=\frac{2 \pi}{5}-\operatorname{Ttot} \alpha \mathrm{t}=\frac{\pi}{2}-$ Ttot $\alpha \mathrm{t}=\frac{3 \pi}{5}$

- Ttot $\alpha \mathrm{t}=\frac{7 \pi}{10}-$ Ttot $\alpha \mathrm{t}=\frac{4 \pi}{5} \quad--\operatorname{TtotRECTO} \alpha \mathrm{t}=\frac{\pi}{10}$

- - TtotRECTO $\alpha \mathrm{t}=\frac{\pi}{5} \quad---\operatorname{TtotRECTO} \alpha \mathrm{t}=\frac{3 \pi}{10}$

- - TtotRECTO $\alpha \mathrm{t}=\frac{2 \pi}{5} \quad---$ TtotRECTO $\alpha \mathrm{t}=\frac{\pi}{2}$

- - TtotRECTO $\alpha \mathrm{t}=\frac{3 \pi}{5} \quad-=-$ TtotRECTO $\alpha \mathrm{t}=\frac{7 \pi}{10}$

- - TtotRECTO at $=\frac{4 \pi}{5}$

Diagrama 2.68. Ttot. TtotRECTO $O_{\alpha_{p}=\frac{\alpha_{t}}{2}}=\frac{\alpha_{t}}{2}$, TtotRECTO $O_{\alpha_{p}=\frac{\alpha_{t}}{4}}=5 \frac{\alpha_{t}}{16}$. 

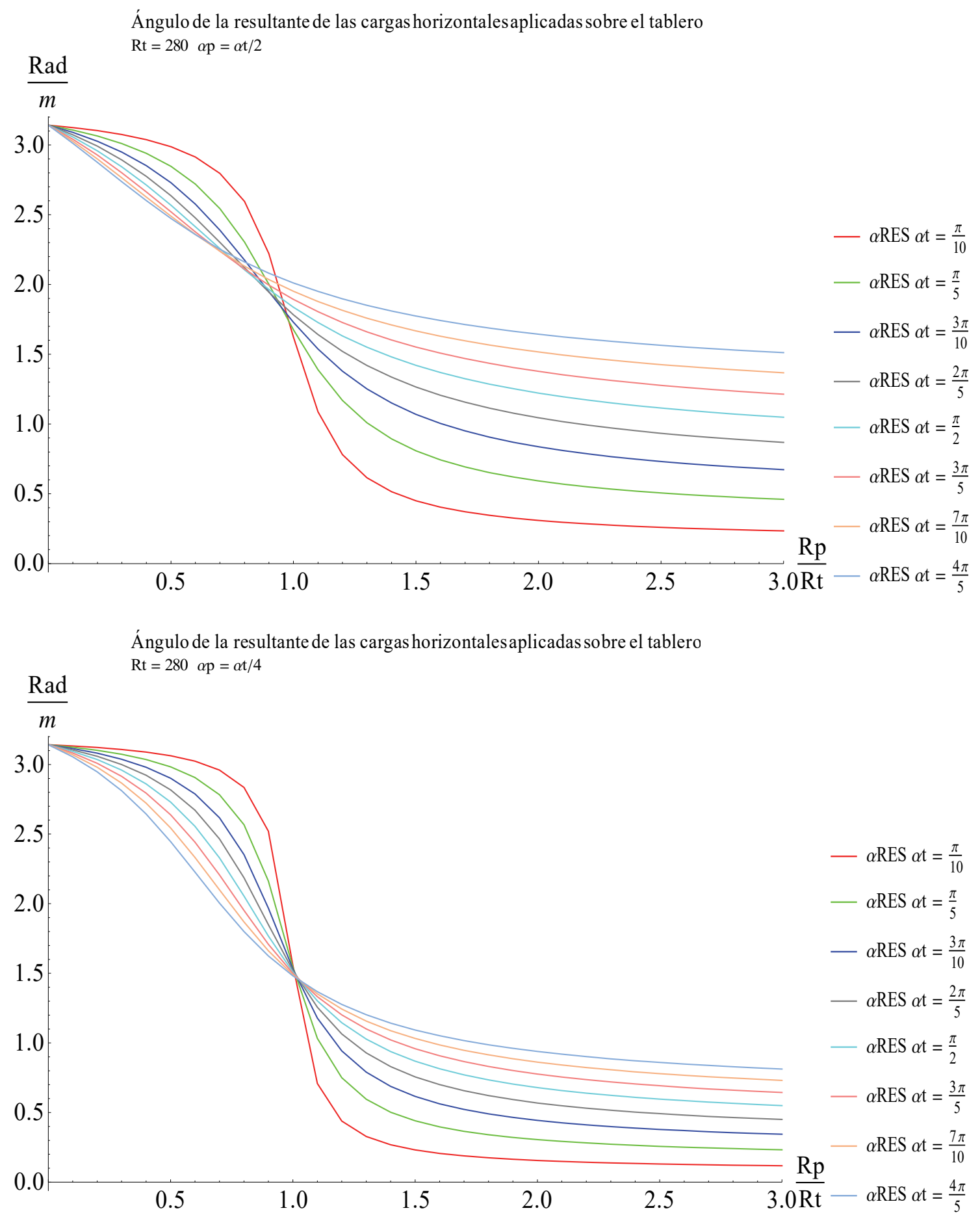

Diagrama 2.69. $\boldsymbol{\alpha} \boldsymbol{R} \boldsymbol{E}$ S. Ángulo de la resultante de las cargas horizontales transmitidas al tablero.

\subsection{1 Análisis detallado: cargas y solicitaciones}

\subsection{1.1 Carga total sobre el tablero (Ttot)}

o Ttot va a seguir siendo una medida de la cantidad de carga horizontal que van tener que aguantar el sistema de tirantes de sujeción y el subsistema PilaTirantes. En estas configuraciones, la compensación de fuerzas en la cabeza de 
la pila va a ser mucho menor, esto va a obligar a desarrollar sistema de compensación más complejos (capítulo 3).

o El mínimo para cada ángulo desarrollado por el tablero $\left(\alpha_{t}\right)$, ya no se alinean de una forma tan clara en torno al centro de gravedad del tablero, porque con $\alpha_{p} \neq 0$, la pila no se puede situar en este punto. En cambio, el punto de menor carga total, se va a situar en:

$$
\text { - } R p_{\text {Ttotmin }}=\frac{R_{t} \sin \left(\left(\frac{1}{b}+\frac{1}{2}\right) \alpha_{t}\right)+\sin \left(\left(\frac{1}{2}-\frac{1}{b}\right) \alpha_{t}\right)}{\alpha_{t}}\left(\operatorname{con} \frac{1}{b}=\frac{\alpha_{p}}{\alpha_{t}}\right)
$$

Para el caso de $\alpha_{p}=\frac{\alpha_{t}}{2}, R p_{\text {Ttotmin }}$ va a coincidir con el $R p_{c d g}$ de un tablero con el doble de ángulo desarrollado $\left(\alpha_{t}{ }^{\prime}=2 \alpha_{t}\right)$. Esa es la razón por la que difieren más los Rp donde se producen los mínimos a medida que se incrementa $\alpha_{p}$. En este mínimo, la carga horizontal total que introducimos en el puente, es similar a la de un puente recto con la misma longitud de vano (esta similitud es casi exacta cuanto menor sea $\alpha_{t}$ ). Este punto, para ángulos desarrollados altos $\left(\alpha_{t}>\frac{3 \pi}{10}\right)$, resulta muy perjudicial en cuanto a solicitaciones horizontales (Qy y $\mathrm{Mz}$ ).

- De nuevo todas las curvas se unen cuando se sitúa la pila en el centro de la circunferencia, por estar la carga por unidad de longitud.

\subsection{1.2 Axil (Nx)}

o El radio del tablero ( $\mathrm{Rt}$ ) pierde mucha influencia en aquellos tableros de comportamiento "tipo arco" o "tipo arco" (que pasarán a un comportamiento "tipo esfera" a medida que incrementemos Rp) sobre los diagramas de axil. La única influencia a parte del ángulo $\alpha t$ va a ser la longitud del tablero (Diagrama 2.64 y Diagrama 2.65 ).

o Igual que ocurría en el caso de $\alpha p=0$, el incremento de la longitud del tablero o el incremento del ángulo, hace que se aproximen las solicitaciones axiles y el comportamiento para todos los ángulos. El comportamiento dominante pasa a ser el "mixto" y el "tipo arco". Otra alternativa que ya se vio en el subapartado de $\mathrm{Rp}=0$, es el incremento de la flexibilidad transversal de la sección. Al final de lo que se trata, es del debilitamiento de su sistema resistivo "tipo viga" (aumenta el factor $\varphi_{\mathrm{KNxMz}}=\sqrt{\frac{\mathrm{A}_{\mathrm{xx}} \mathrm{E}}{\mathrm{I}_{\mathrm{zz}} \mathrm{E}} \mathrm{Rt}^{2}}=\frac{\mathrm{Rt}}{\mathrm{r}_{\mathrm{zz}}}$, sin que ello conlleve un decremento del ángulo), y con ello una aproximación al comportamiento del resto de ángulos.

o En tableros de comportamiento "tipo mixto" o "arco", cuanto mayor es el radio de la pila (Rp), más se incrementa la diferencia entre los axiles de las 2 zonas, positiva y negativa. La resultante, se va alineando con el tablero en el estribo positivo a medida que se incrementa el radio (Rp).

o El valor máximo interior ( $N x M I)$ queda muy próximo, tanto en valor como en distancia relativa, al estribo positivo.

- Para tableros con comportamiento "tipo viga", el ángulo de la resultante varía de forma más brusca a medida que se incrementa el radio de la pila (Rp), acercándose al valor del radio del tablero (Rt). Esto hace, que sea dominante la acción en el eje $\mathrm{X}$ (hasta $R p \approx R t$ ) y se igualen las reacciones y 
comportamiento en las 2 zonas, comportándose como una viga bajo carga horizontal.

o Si se sitúa la pila en un ángulo $\alpha_{\mathrm{p}}=\frac{\alpha_{\mathrm{t}}}{4}$, el cambio de ángulo de la resultante es, en general para todos los ángulos $\alpha t$ estudiados, más brusco a medida que se incrementa el radio de la pila (Rp) acercándose al del tablero (Rt) (Diagrama 2.69). Esto provoca que la acción en el eje $X$ sea más dominante y la división en zonas a lo largo del tablero, en lo que a axil se refiere, menos pronunciada.

o Cuanto más cerca está la pila al centro del arco, menos varía el axil a lo largo del tablero (esto verifica todo lo visto hasta ahora en cargas concéntricas). Resulta útil recordar que en un efecto "arco ideal", daría igual por donde cortases la circunferencia, porque se obtiene siempre el mismo axil.

Ecuaciones diferenciales en función de $\alpha$

$$
\begin{aligned}
& \frac{\mathrm{dQY}[\alpha]}{\mathrm{d} \alpha}==\operatorname{py}[\alpha] \mathrm{R}-\mathrm{Nx}[\alpha] \rightarrow \frac{\mathrm{d}^{2} \mathrm{QY}[\alpha]}{\mathrm{d} \alpha^{2}}+\mathrm{QY}[\alpha]=\mathrm{R}\left(\frac{\mathrm{dpy}[\alpha]}{\mathrm{d} \alpha}-\mathrm{px}[\alpha]\right) \\
& \frac{\mathrm{dNx}[\alpha]}{\mathrm{d} \alpha}==\mathrm{QY}[\alpha]+\operatorname{px}[\alpha] \mathrm{R} \rightarrow \frac{\mathrm{d}^{2} \mathrm{Nx}[\alpha]}{\mathrm{d} \alpha^{2}}+\mathrm{Nx}[\alpha]==\mathrm{R}\left(\mathrm{py}[\alpha]+\frac{\mathrm{dpx}[\alpha]}{\mathrm{d} \alpha}\right) \\
& \frac{\mathrm{dMz}[\alpha]}{\mathrm{d} \alpha}==\operatorname{px~R}-\frac{\mathrm{dNx}[\alpha]}{\mathrm{d} \alpha} \mathrm{R} \rightarrow \\
& \frac{\mathrm{dMz}[\alpha]}{\mathrm{d} \alpha}=-\mathrm{QY}[\alpha] \mathrm{R} \rightarrow \frac{\mathrm{d}^{3} \mathrm{Mz}[\alpha]}{\mathrm{d} \alpha^{3}}+\frac{\mathrm{dMz}[\alpha]}{\mathrm{d} \alpha}=\mathrm{R}^{2}\left(\mathrm{px}[\alpha]-\frac{\mathrm{dpy}[\alpha]}{\mathrm{d} \alpha}\right)
\end{aligned}
$$

Se muestran de nuevo las ecuaciones diferenciales que rigen el comportamiento del sistema, para que sumadas al análisis de la solicitación axil, se obtenga una visión más completa del problema.

\subsection{1.3 Cortante transversal (Qy)}

o Como en el caso del Axil ( $\mathrm{Nx}$ ), el radio del tablero no se muestra determinante en el comportamiento de aquellos tableros con ángulos desarrollados medios y grandes $\left(\alpha_{t}>\frac{\pi}{5}\right)$. La característica fundamental de las solicitaciones de cortante para estos sistemas ( $\alpha p \neq 0)$, es que las reacciones en los estribos son de signo apuesto (es lo que provoca que el cortante en los estribos negativo y positivo sea del mismo signo). La razón de este efecto, se ha desarrollado al inicio del subapartado 2.2.6.2.2.1.1, junto a los diagramas: Diagrama 2.60 -> Diagrama 2.63.

o Para el cortante (y con ello para el momento), el ángulo en el que se posiciona la pila no es demasiado influyente en la forma de las gráficas. Si bien, cuanto mayor sea este ángulo (hasta $\alpha_{\mathrm{p}}=\frac{\alpha_{\mathrm{t}}}{2}$ ), más se aproximan los módulos de las reacciones cortantes de los estribos, haciendo la gráfica de cortantes más simétrica y la de momentos más anti-simétrica. 
- En el caso de los tableros con comportamiento "tipo viga", el comportamiento "tipo viga" con carga transversal, conlleva reacciones a cortante del mismo signo y sin diferenciar entre zonas. A medida que se incrementa la longitud del tablero (Lt) o el ángulo $(\alpha t)$, su comportamiento se va asimilando al del resto de ángulos diferenciando 2 zonas (positiva y negativa) y comportamiento "tipo esfera".

\subsection{1.4 Momento transversal (Mz)}

o La característica fundamental de los momentos, para los tableros con comportamiento "tipo esfera", es que las gráficas muestran un alto grado de anti-simetría entre la zona positiva y la negativa, con un máximo en la primera y un mínimo en la segunda. La causa de este efecto se ha desarrollado al inicio del subapartado 2.2.6.2.2.1.1, junto a los diagramas: Diagrama 2.60 -> Diagrama 2.63.

O El comportamiento "tipo viga" resulta similar a los vistos hasta ahora, con un enorme parecido al de una viga isostática biapoyada y su decremento de solicitaciones transversales a medida que se acerca la pila (Rp) al tablero (Rt).

o Como se comentó para el cortante (y con ello para el momento), el ángulo en el que se posiciona la pila no es demasiado influyente en la forma de las gráficas. Si bien, cuanto mayor sea este ángulo (hasta $\alpha_{p}=\frac{\alpha_{t}}{2}$ ), más se aproxima el módulo de los máximos, haciendo la gráfica de momentos más anti-simétrica.

\subsection{2 Conclusiones}

1) El rango de aquellos tableros con comportamiento "tipo arco", cuya posición más apropiada para la pila, en lo que a acciones transversales ( $Q$ y y $\mathrm{Mz}$ ) se refiere, es cerca del centro de la circunferencia, se ha incrementado respecto de los tableros con $\alpha_{p}=0$ (esto se ha hecho patente en los valores numéricos que definen los diferentes rangos). Para estos tableros, a medida que incrementamos $\mathrm{Rp}$, su comportamiento pasa a ser "tipo esfera", aumentando tanto el cortante transversal (Qy) como el momento flector $(\mathrm{Mz})$ y creándose 2 zonas (zona positiva, más próxima a la pila, y zona negativa) con cierta simetría en el diagrama de cortante y antisimetría en el de momentos. En la zona positiva, las solicitaciones transversales (Qy y $\mathrm{Mz}$ ) se ven dominadas por la combinación del axil Nx y la curvatura, mientras que en la zona negativa se ven dominadas por la carga transversal $p y[\alpha]$.

2) Como es obvio, el rango de aquellos tableros con comportamiento "tipo viga" ha disminuido respecto a los que tienen $\alpha_{p}=0$. Para este tipo de sistemas, lo óptimo, desde el punto de vista de solicitaciones frente a cargas concéntricas distribuidas, sigue siendo acercar la pila al tablero y en concreto al $R p_{\text {Ttotmin }}$. Es en este punto o su entorno (en este caso también afecta el grado de hiperestaticidad del tablero en los estribos) en el que se reducen todas las solicitaciones y se minimiza la carga horizontal introducida (o lo que es lo mismo, la longitud de los tirantes de sujeción).

3) Los tableros con comportamiento "mixto", vuelven a ser una opción muy atractiva de cara a posicionar la pila en un radio Rp intermedio entre el centro del arco y Rt. De 
nuevo (si bien el rango ha variado un poco), este rango de ángulos resulta el más flexible (estable) en lo que al posicionamiento de la pila se refiere.

4) Todas las solicitaciones han sufrido un incremento muy significativo respecto de los tableros con $\alpha_{p}=0$, menos para el posicionamiento óptimo de la pila para cada clase de comportamiento, donde las solicitaciones transversales se mantienen en valores similares. Pero cuando la hipótesis de carga haga variar las cargas transversales, también lo va a hacer la posición óptima de la pila. Esto hace de esta morfología una opción muy poco atractiva frente a la de $\alpha_{p}=0$, siempre en cuanto a solicitaciones en el tableo se refiere. 


\subsection{Deformaciones}

De la misma manera que ocurría cuando se situaba la pila en el eje de simetría del tablero, las deformaciones transversales que se van a estudiar, son las alineadas con los tirantes de sujeción, en el plano XY (negativa si se acerca al centro de la carga y positiva si se aleja).

La presentación de las gráficas va a seguir el mismo patrón del subapartado 2.2.6.2.1.2, con 3 gráficas iniciales en cada apartado, con ejemplos destacables. A diferencia de lo que ocurría para el caso de $\alpha p=0$, no existe simetría ni en la deformada $\delta x \operatorname{txtNx}$ ni en la deformada $\delta x t x t M z$. Aunque, en el caso del diagrama de la deformada $\delta x t x t N x$, se puede

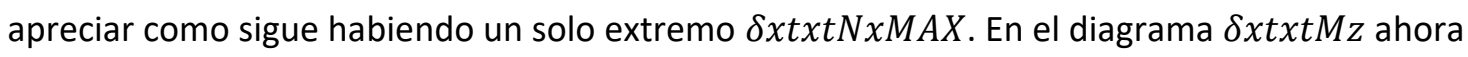
hay 2, que se van a denominar $\delta x t x t M z M I N$, al extremo con menor módulo y $\delta x t x t M z M A X$, al extremo de mayor módulo. El diagrama de la deformada total se asemejará al diagrama de la deformada dominante. Con un solo extremo $\delta x \operatorname{txtTOTMAX}$, cuando la deformada dominante sea $\delta x t x t N x$ y con 2 extremos $\delta x t x t T O T M A X$ y $\delta x t x t T O T M I N$ (con el mismo criterio dde módulos que para $\delta x t x t M z$ ) cuando esté dominada por $\delta x t x t M z$. Es conveniente recordar que lo que se muestra es el desplazamiento en dirección al centro de la fuerza, siendo negativo si se acerca al centro y positivo si se aleja.

Deformación $(\mathrm{Lt}=140 \mathrm{~m})$

Sección : Tablero 7 (Peatonal)

$\mathrm{Rp} / \mathrm{Rt}=0.1 \quad \alpha \mathrm{t}=\frac{\pi}{10} \quad \alpha \mathrm{p}=0.25 \alpha \mathrm{t}$

$\{\delta x t x t T O T, \delta x t x t N x, \delta x t x t M z)$

$\mathrm{m}$

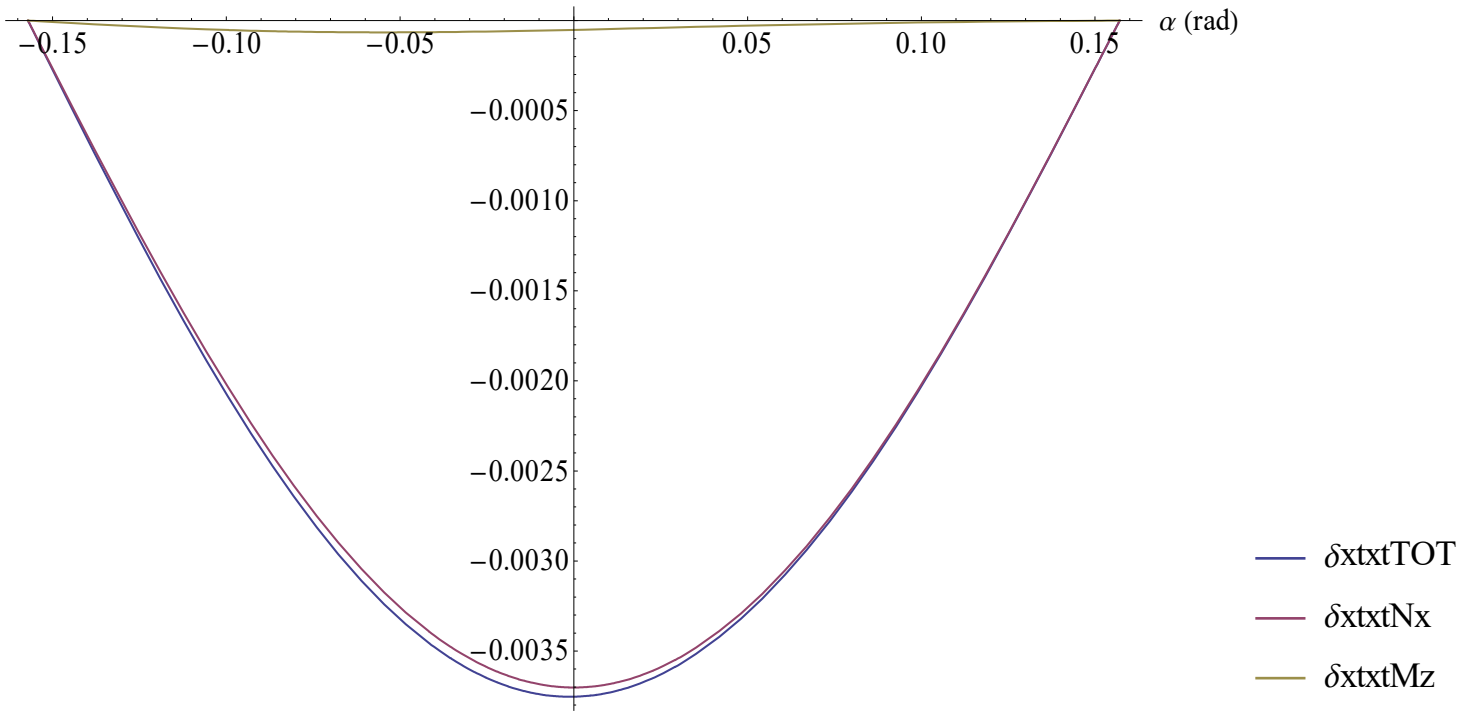


Deformación $(\mathrm{Lt}=140 \mathrm{~m})$

Sección : Tablero 7 (Peatonal)

$\mathrm{Rp} / \mathrm{Rt}=0.9 \alpha \mathrm{t}=\frac{\pi}{10} \quad \alpha \mathrm{p}=0.25 \alpha \mathrm{t}$

$\{\delta \mathrm{xtxtTOT}, \delta x \operatorname{xtN\mathrm {N}x}, \delta \mathrm{xtxtMz}\}$

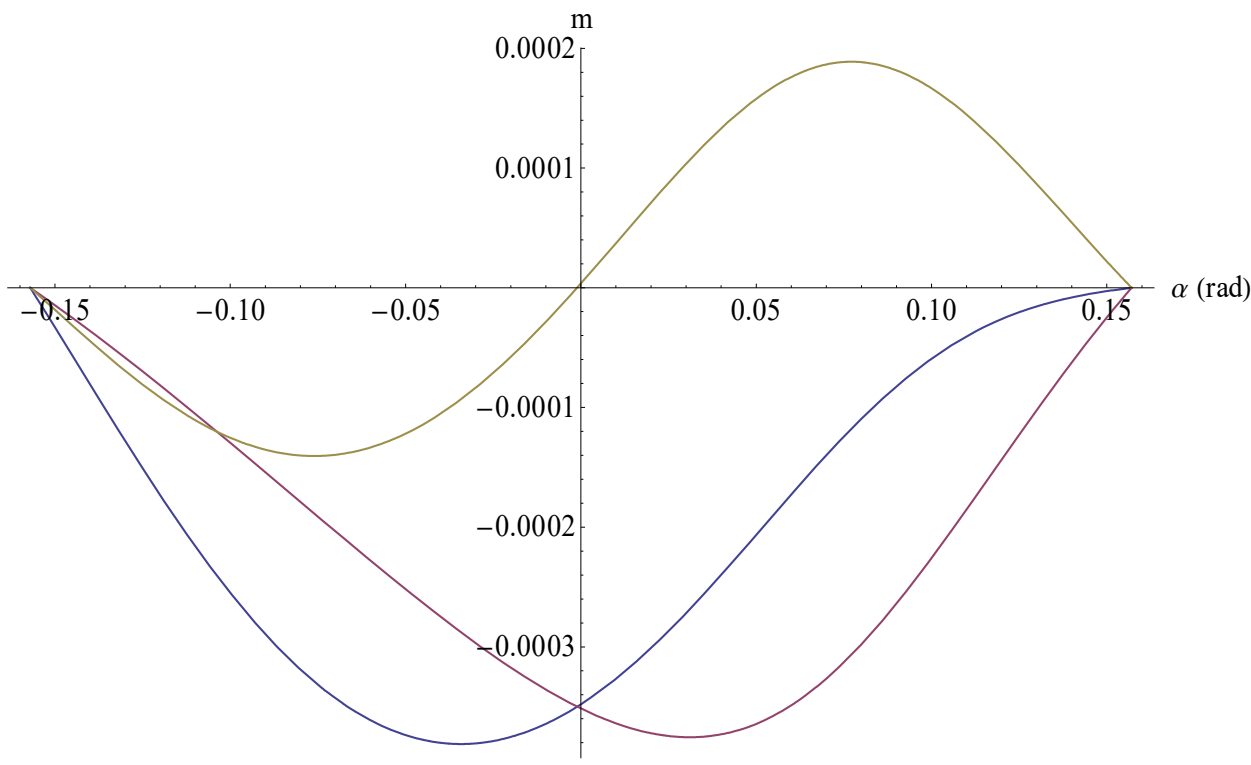

- $\delta$ xtxtTOT

$-\delta \mathrm{xtxtNx}$

$-\delta \mathrm{xtxtMz}$

Deformación $(\mathrm{Lt}=140 \mathrm{~m})$

Sección : Tablero 7 (Peatonal)

$\mathrm{Rp} / \mathrm{Rt}=1.5 \quad \alpha \mathrm{t}=\frac{\pi}{10} \quad \alpha \mathrm{p}=0.25 \alpha \mathrm{t}$

$\{\delta \mathrm{xtxtTOT}, \delta \mathrm{xtxtNx}, \delta \mathrm{xtxtMz})$

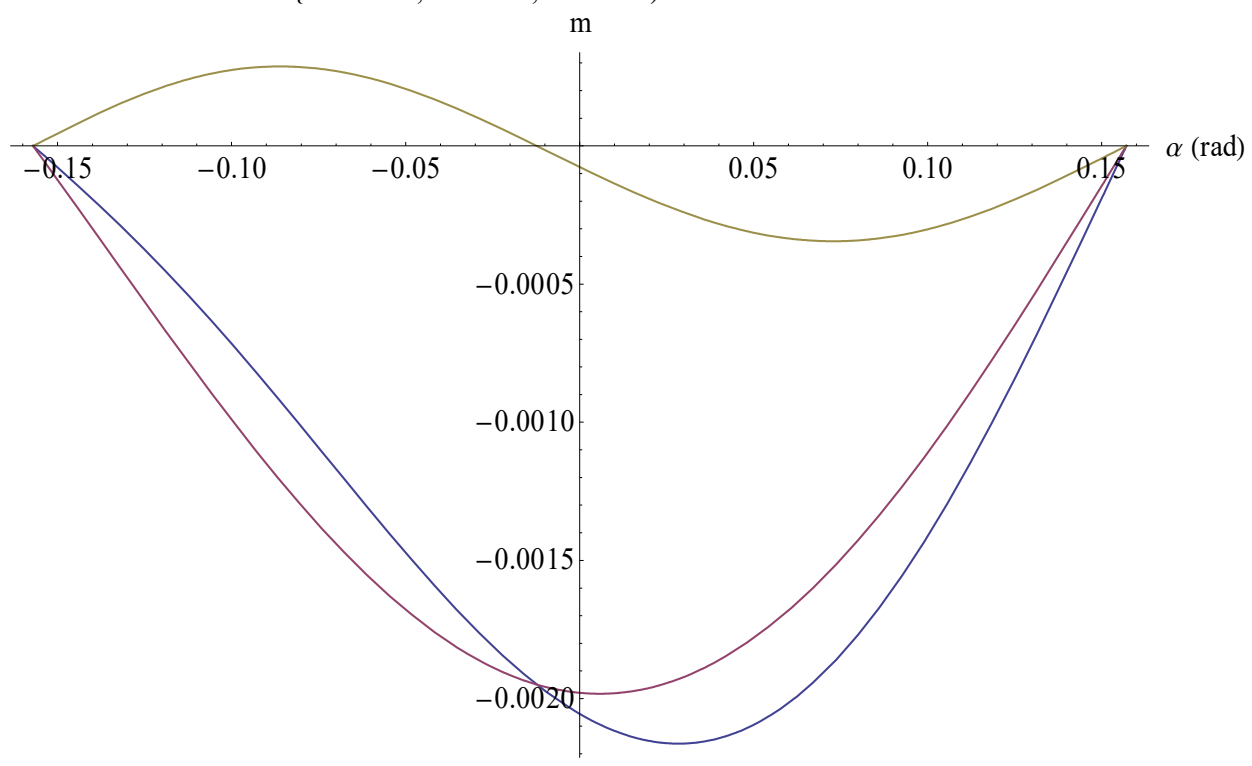

- $\delta$ xtxtTOT

$-\delta \mathrm{xtxtNx}$

$-\delta \mathrm{xtxtMz}$ 
Deformación $(\mathrm{Lt}=140 \mathrm{~m})$

Sección: Tablero 7 (Peatonal)

$\alpha \mathrm{p}=0.25 \alpha \mathrm{t}$

$\{\delta$ xtxtTOTMAX $\delta$ xtxtTOTMIN $\delta$ xtxtNxMAX $\delta$ xtxtMzMAX $\delta$ xtxtMzMIN $\}$

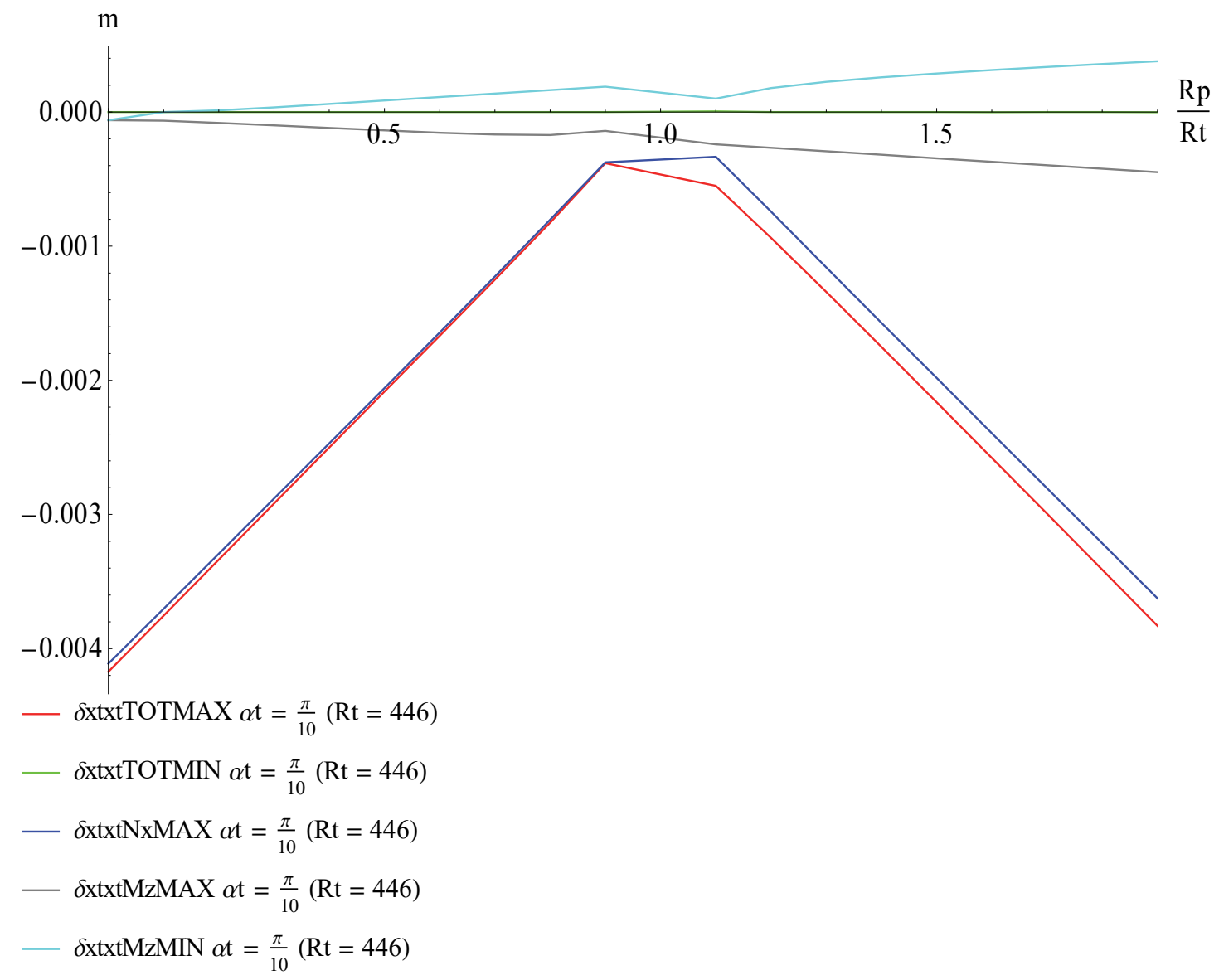

Deformación $(\mathrm{Lt}=280 \mathrm{~m})$

Sección: Tablero 7 (Peatonal)

$\mathrm{Rp} / \mathrm{Rt}=0.1 \alpha \mathrm{t}=\frac{\pi}{10} \alpha \mathrm{p}=0.5 \alpha \mathrm{t}$

$\{\delta \mathrm{xtxtTOT}, \delta \mathrm{xtxtNx}, \delta \mathrm{xtxtMz})$

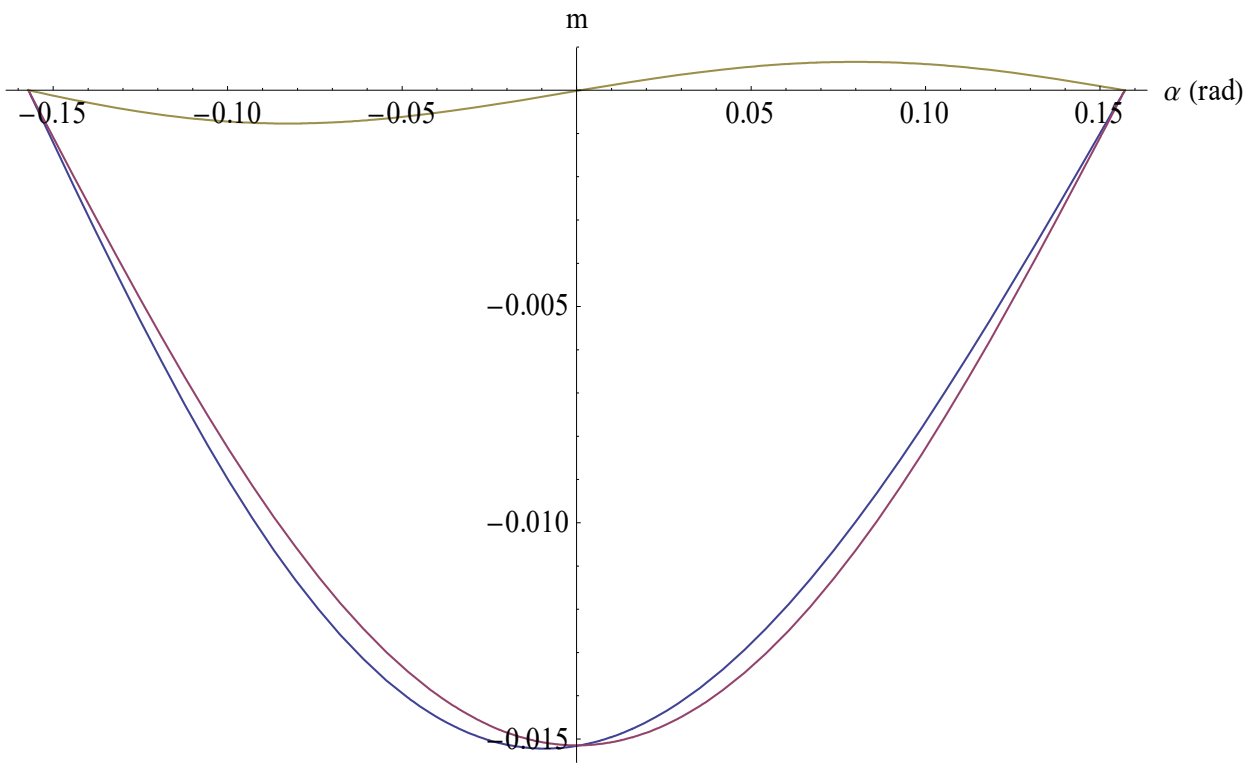

- $\delta$ xtxtTOT

$-\delta \mathrm{xtxtNx}$

$-\delta \mathrm{xtxtMz}$ 
Deformación $(\mathrm{Lt}=280 \mathrm{~m})$

Sección: Tablero 7 (Peatonal)

$\mathrm{Rp} / \mathrm{Rt}=0.9 \alpha \mathrm{t}=\frac{\pi}{10} \quad \alpha \mathrm{p}=0.5 \alpha \mathrm{t}$

$\{\delta$ xtxtTOT, $\delta$ xtxtNx, $\delta$ xtxtMz $)$

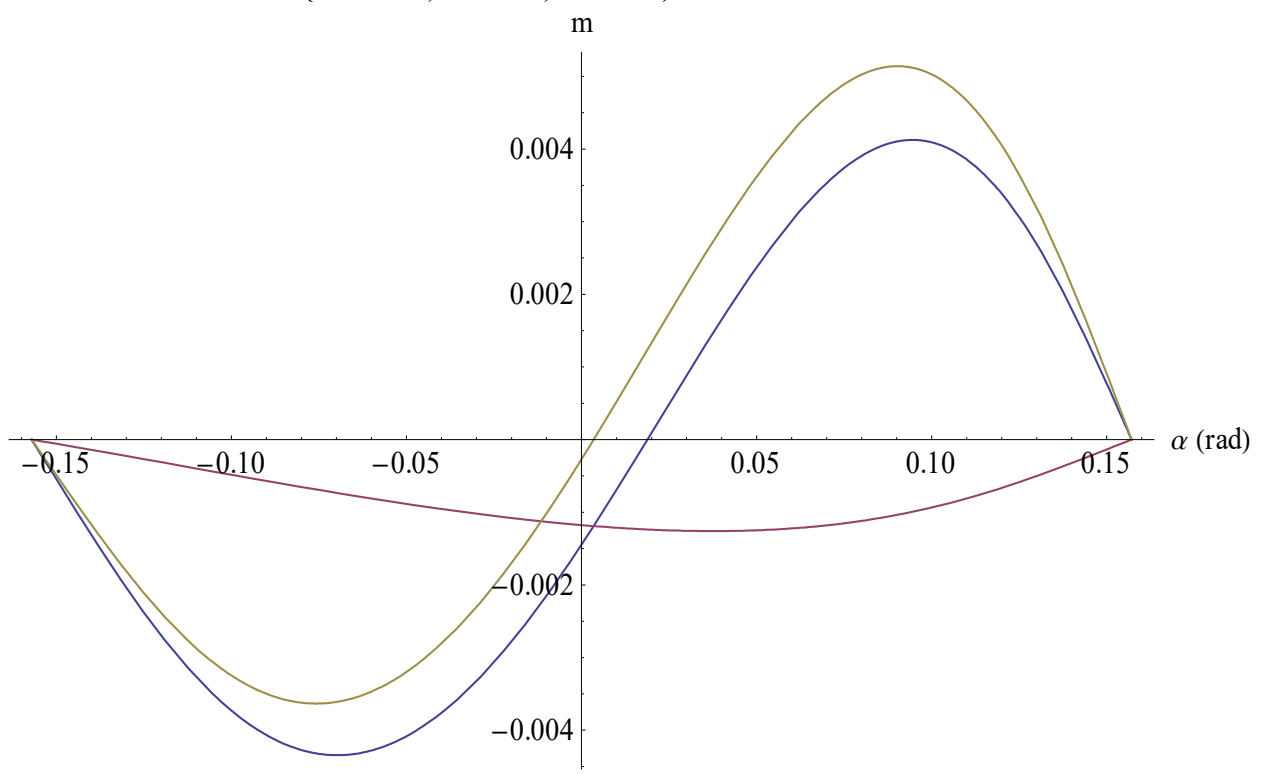

$-\delta \mathrm{xtxtTOT}$

- $\delta \mathrm{xtxtNx}$

- $\delta$ xtxtMz

Deformación $(\mathrm{Lt}=280 \mathrm{~m})$

Sección: Tablero 7 (Peatonal)

$\mathrm{Rp} / \mathrm{Rt}=1.5 \alpha \mathrm{t}=\frac{\pi}{10} \alpha \mathrm{p}=0.5 \alpha \mathrm{t}$

$\{\delta x t x t T O T, \delta x \operatorname{txtNx}, \delta x t x t M z)$

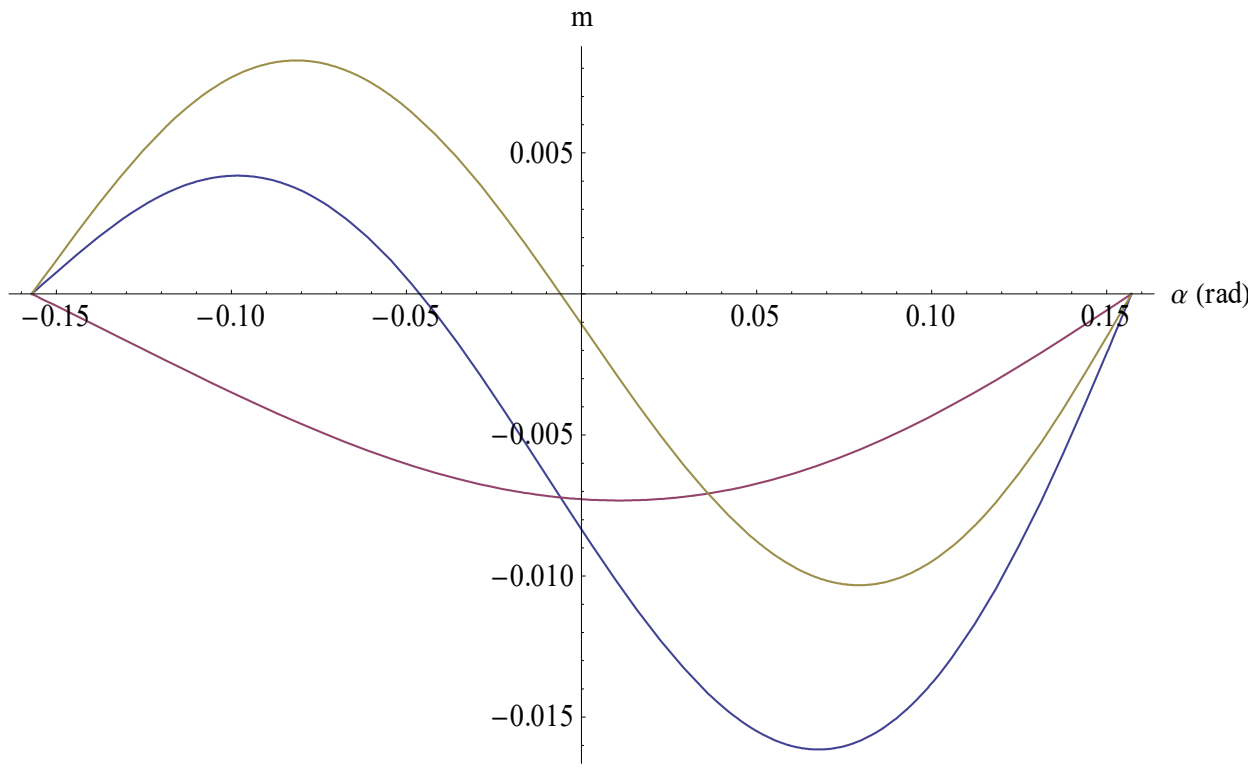

- $\delta$ xtxtTOT

$-\delta \mathrm{xtxtNx}$

$-\delta \mathrm{xtxtMz}$ 
Deformación $(\mathrm{Lt}=280 \mathrm{~m})$

Sección: Tablero 7 (Peatonal)

$\alpha \mathrm{p}=0.5 \alpha \mathrm{t}$

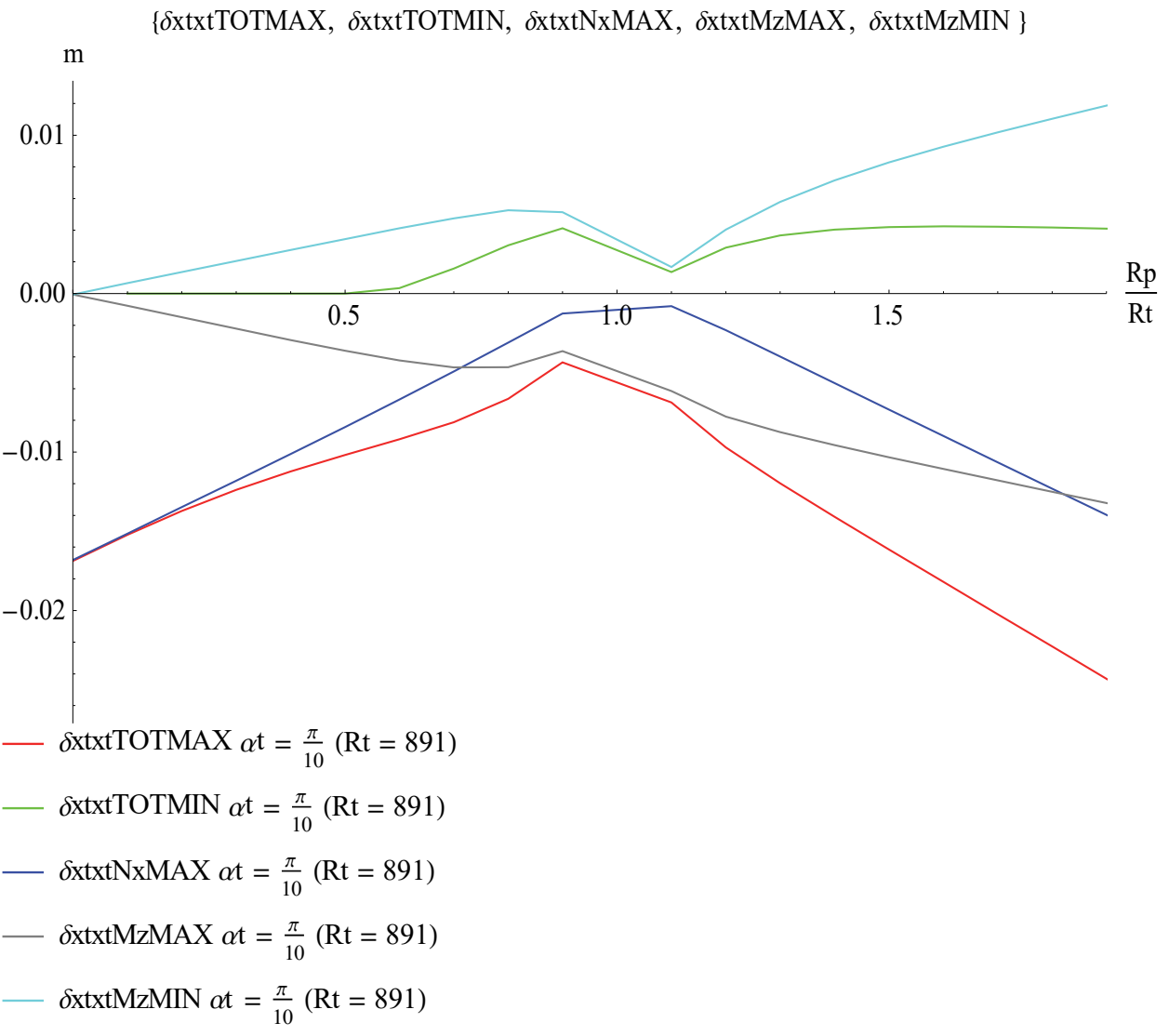

Deformación $(\mathrm{Lt}=280 \mathrm{~m})$

Sección: Tablero 7 (Peatonal)

$\mathrm{Rp} / \mathrm{Rt}=0.1 \alpha \mathrm{t}=\frac{\pi}{2} \alpha \mathrm{p}=0.5 \alpha \mathrm{t}$

$\{\delta x t x t T O T, \delta x t x t N x, \delta x t x t M z$ )

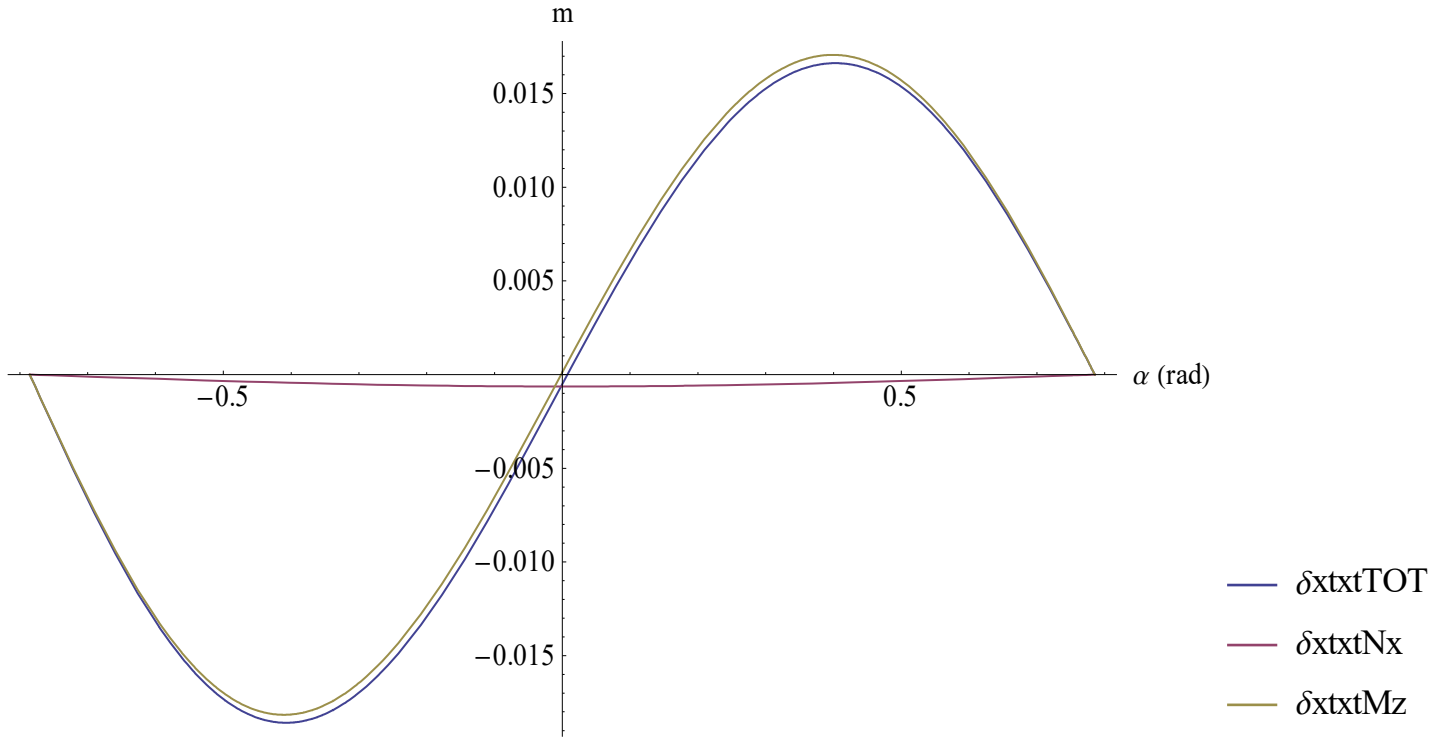


Deformación( $\mathrm{Lt}=280 \mathrm{~m})$

Sección: Tablero 7 (Peatonal)

$\mathrm{Rp} / \mathrm{Rt}=0.9 \alpha \mathrm{t}=\frac{\pi}{2} \quad \alpha \mathrm{p}=0.5 \alpha \mathrm{t}$

$\{\delta$ xtxtTOT, $\delta$ xtxtNx, $\delta$ xtxtMz)

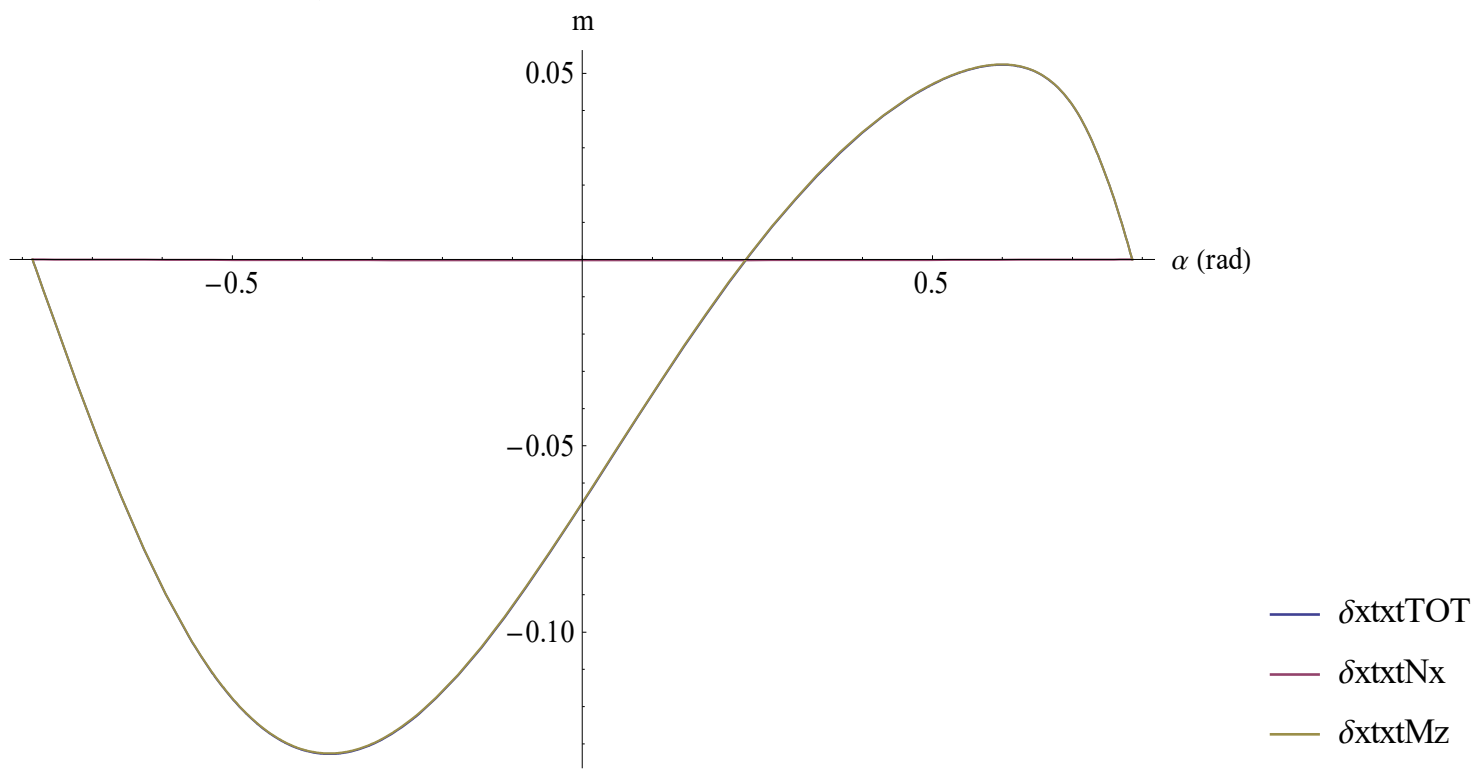

Deformación $(\mathrm{Lt}=280 \mathrm{~m})$

Sección: Tablero 7 (Peatonal)

$\mathrm{Rp} / \mathrm{Rt}=1.5 \alpha \mathrm{t}=\frac{\pi}{2} \alpha \mathrm{p}=0.5 \alpha \mathrm{t}$

$\{\delta x t x t T O T, \delta x t x t N x, \delta x t x t M z$ )

$\mathrm{m}$

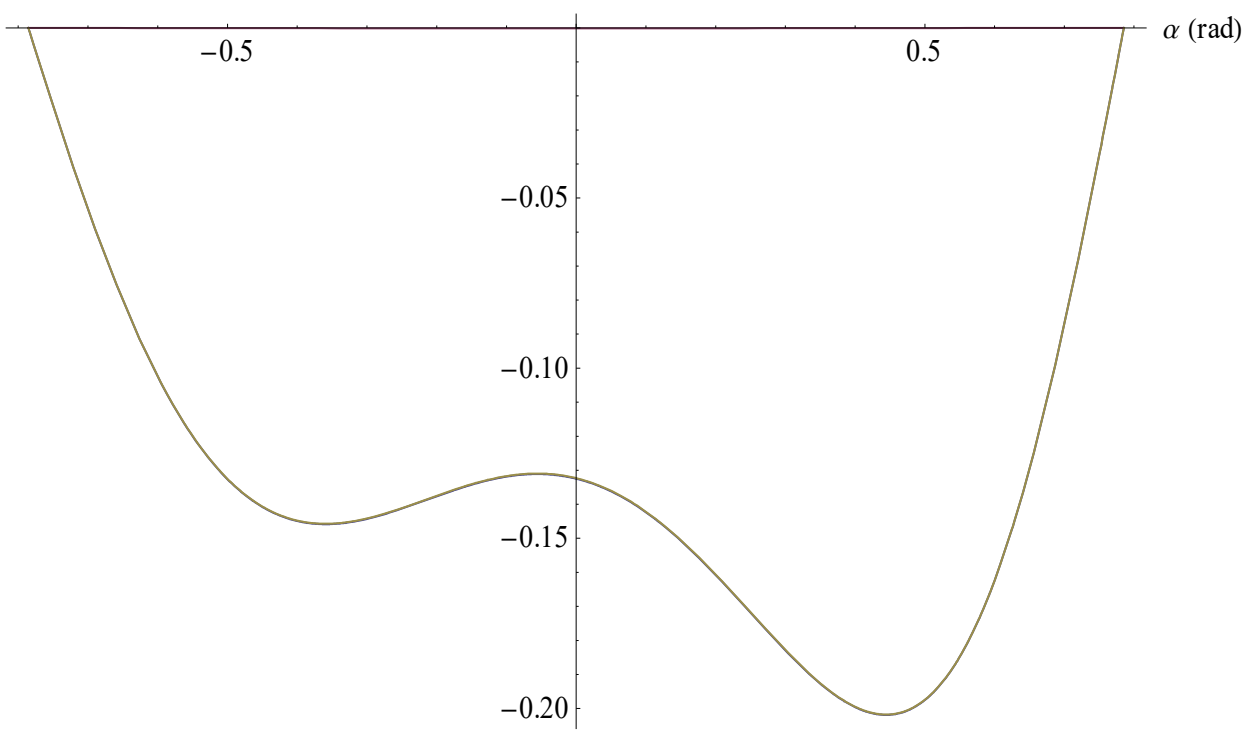

$\delta$ - - xtxtTOT

$-\delta \mathrm{xtxtNx}$

- $\mathrm{xtxtMz}$ 
Deformación $(\mathrm{Lt}=280 \mathrm{~m})$

Sección: Tablero 7 (Peatonal)

$\alpha \mathrm{p}=0.5 \alpha \mathrm{t}$

$\{\delta x t x t T O T M A X, \delta x t x t T O T M I N, \delta x t x t N x M A X, \delta x t x t M z M A X, \delta x t x t M z M I N\}$

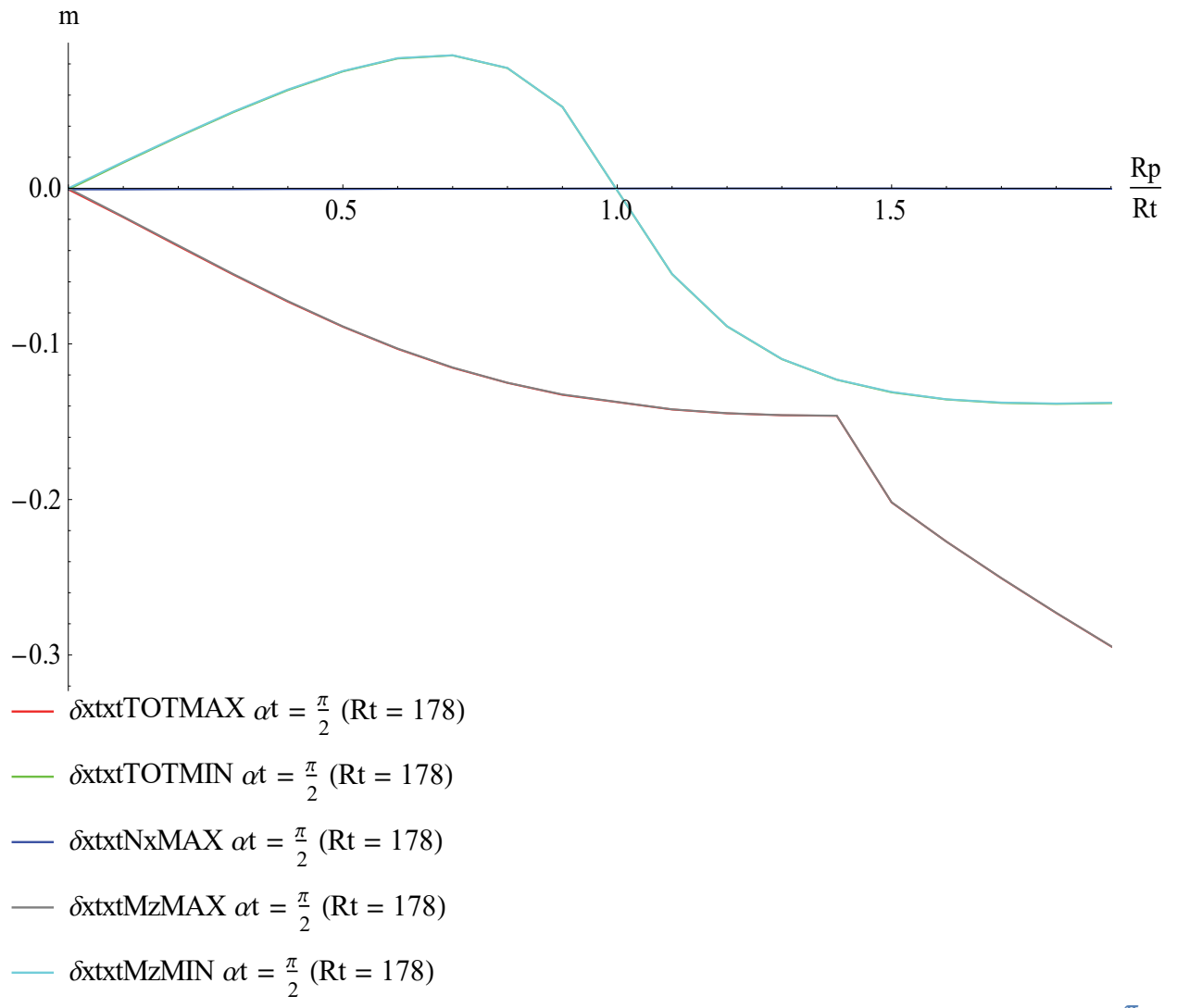

Diagrama 2.70. Deformaciones del tablero: Comportamiento "tipo viga" ( $L t=140 \mathrm{~m}, \alpha t=\frac{\pi}{10}, \alpha p=\alpha t / 4$,

Tablero 7 (Peatonal)). Comportamiento "mixto" ( $\boldsymbol{L t}=\mathbf{2 8 0} \boldsymbol{m}, \boldsymbol{\alpha t}=\frac{2 \pi}{10}, \alpha \boldsymbol{p}=\alpha \boldsymbol{t} / \mathbf{2}$, Tablero 7 (Peatonal)).

Comportamiento "tipo arco" ( $L t=280 m, \alpha t=\frac{\pi}{2}, \alpha p=\alpha t / 2$, Tablero 7 (Peatonal)).

Deformación $(\mathrm{Lt}=280 \mathrm{~m})$

Sección: Tablero 1 (Carretera)

$\mathrm{Rp} / \mathrm{Rt}=0.1 \alpha \mathrm{t}=\frac{\pi}{5} \alpha \mathrm{p}=0.5 \alpha \mathrm{t}$

$\{\delta x t x t T O T, \delta x \operatorname{xtNx}, \delta x$ txtMz)

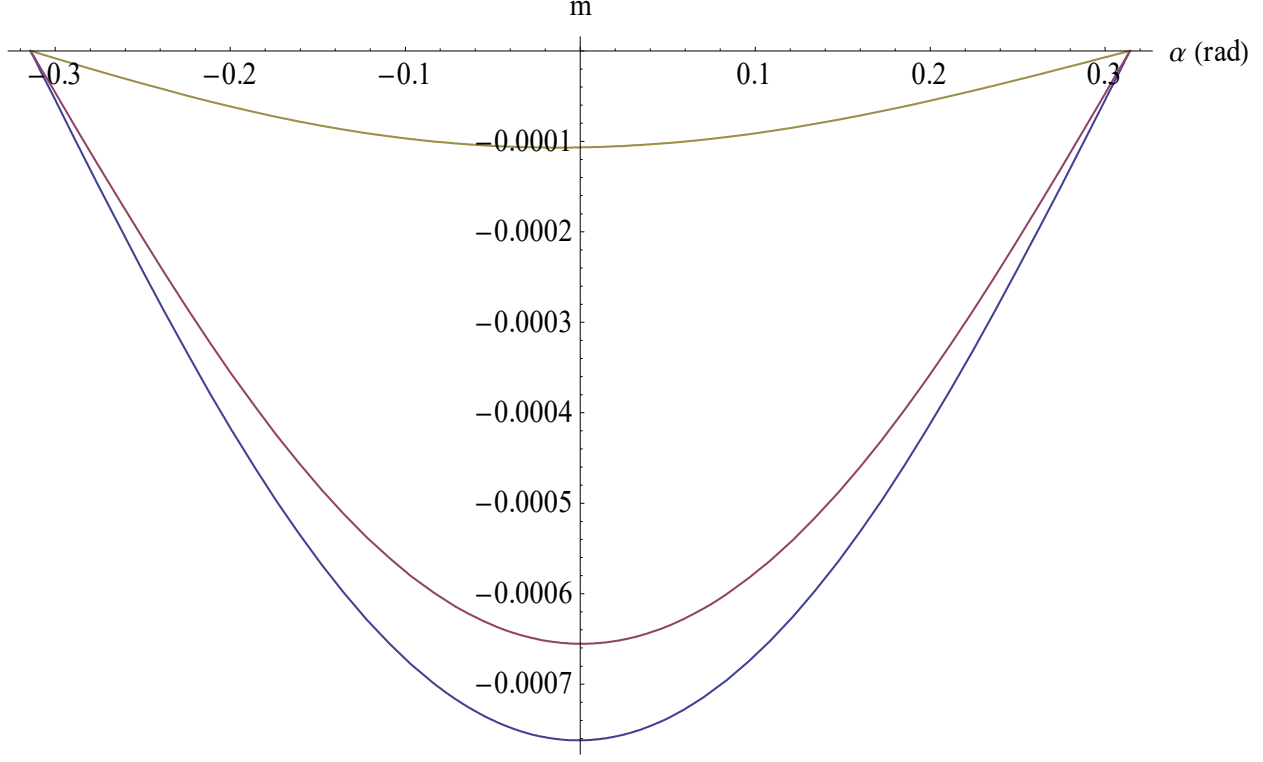

$-\delta$ xtxtTOT

$-\delta \mathrm{xtxtNx}$

- $\mathrm{xtxtMz}$ 
Deformación( $\mathrm{Lt}=280 \mathrm{~m})$

Sección: Tablero 1 (Carretera)

$\mathrm{Rp} / \mathrm{Rt}=0.9 \alpha \mathrm{t}=\frac{\pi}{5} \alpha \mathrm{p}=0.5 \alpha \mathrm{t}$

$\{\delta$ xtxtTOT, $\delta$ xtxtNx, $\delta$ xtxtMz $)$

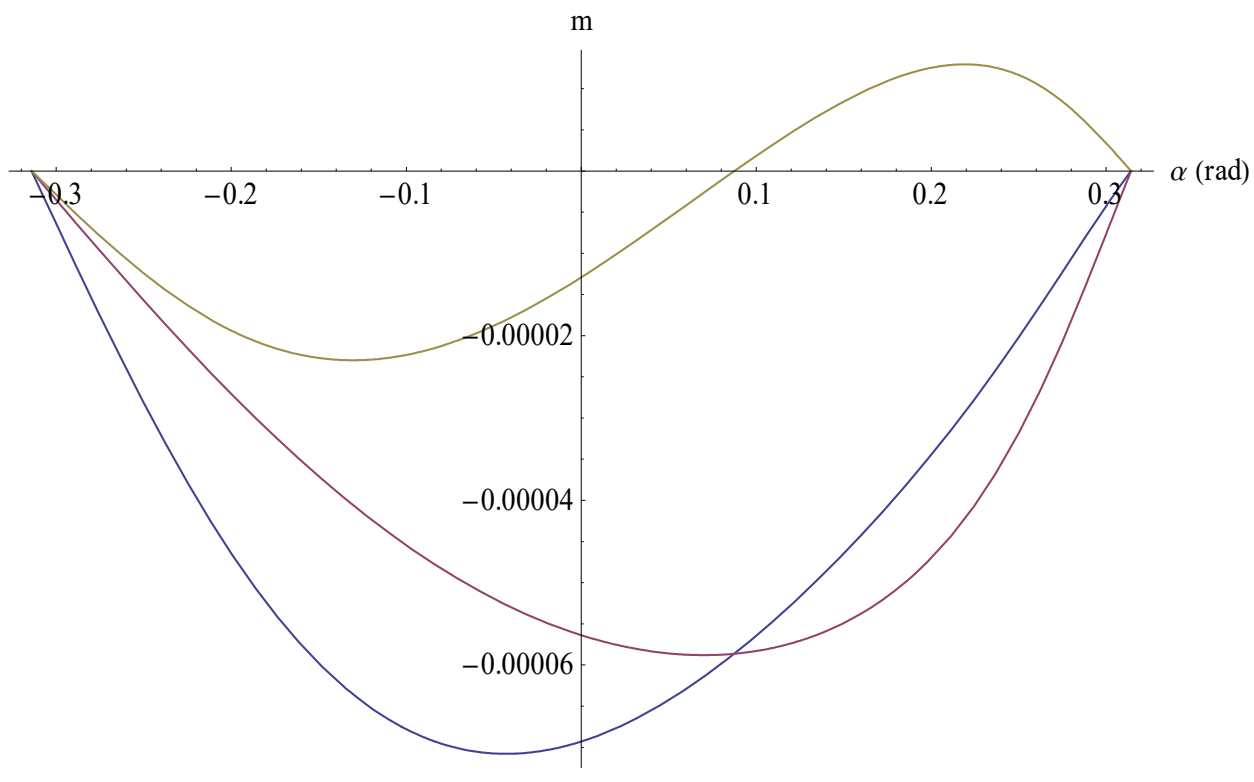

- $\delta \mathrm{xtxtTOT}$

- $\delta$ xtxtNx

Deformación $(\mathrm{Lt}=280 \mathrm{~m})$

Sección: Tablero 1 (Carretera)

$\mathrm{Rp} / \mathrm{Rt}=1.5 \alpha \mathrm{t}=\frac{\pi}{5} \alpha \mathrm{p}=0.5 \alpha \mathrm{t}$

$\{\delta \mathrm{xtxtTOT}, \delta \mathrm{xtxtNx}, \delta \mathrm{xtxtMz}\}$

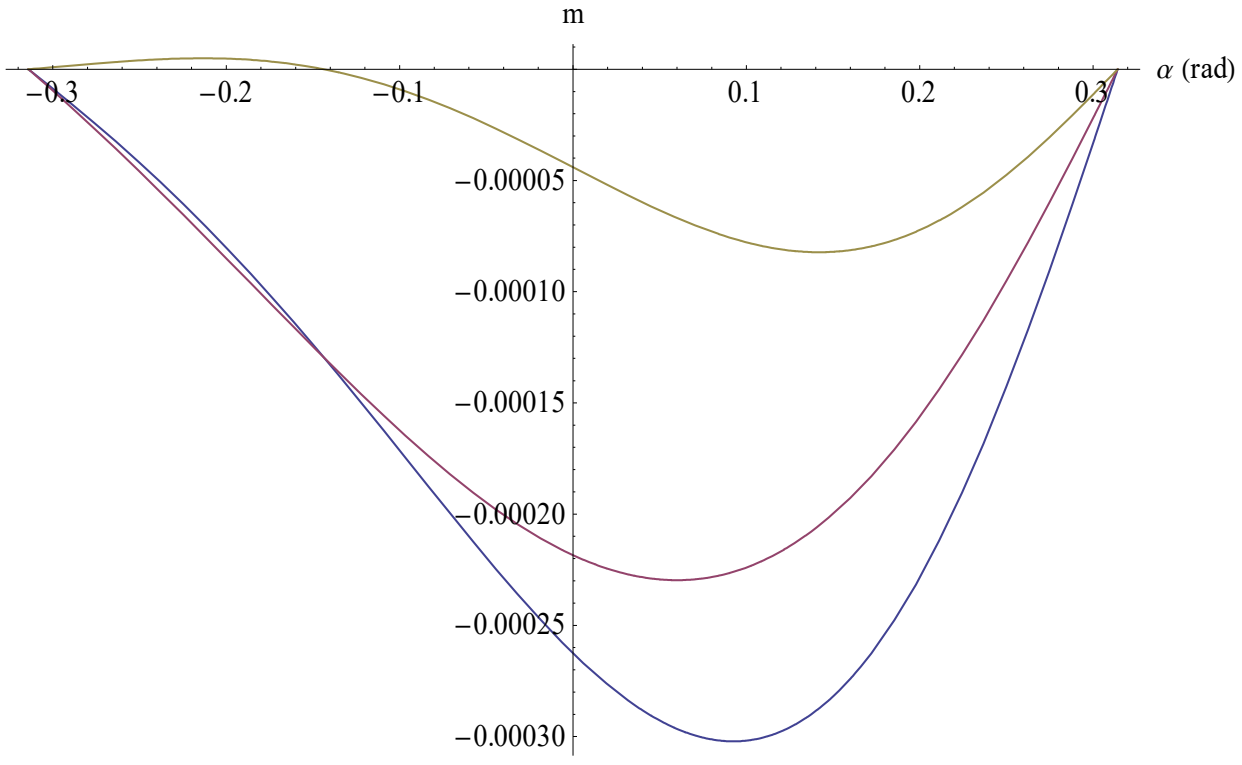

$-\delta$ xtxtTOT

$-\delta x t x t N x$

$-\delta$ xtxtMz 
Deformación $(\mathrm{Lt}=280 \mathrm{~m})$

Sección: Tablero 1 (Carretera)

$\alpha \mathrm{p}=0.5 \alpha \mathrm{t}$

$\{\delta$ xtxtTOTMAX, $\delta$ xtxtTOTMIN, $\delta x t x t N x M A X, \delta x t x t M z M A X, \delta x t x t M z M I N\}$

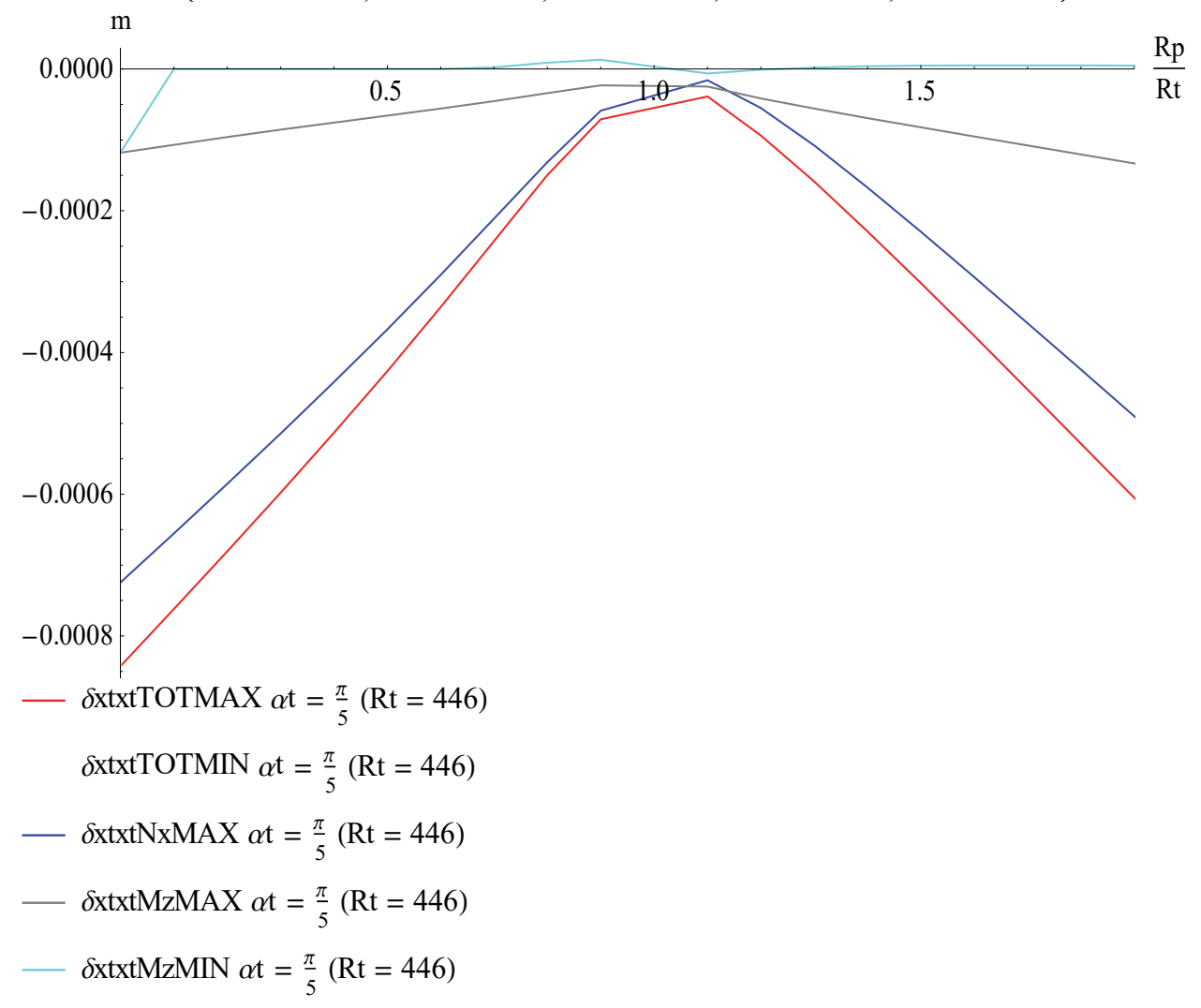

Deformación $(\mathrm{Lt}=280 \mathrm{~m})$

Sección: Tablero 1 (Carretera)

$\mathrm{Rp} / \mathrm{Rt}=0.1 \quad \alpha \mathrm{t}=\frac{3 \pi}{10} \alpha \mathrm{p}=0.5 \alpha \mathrm{t}$

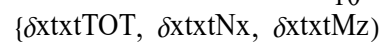

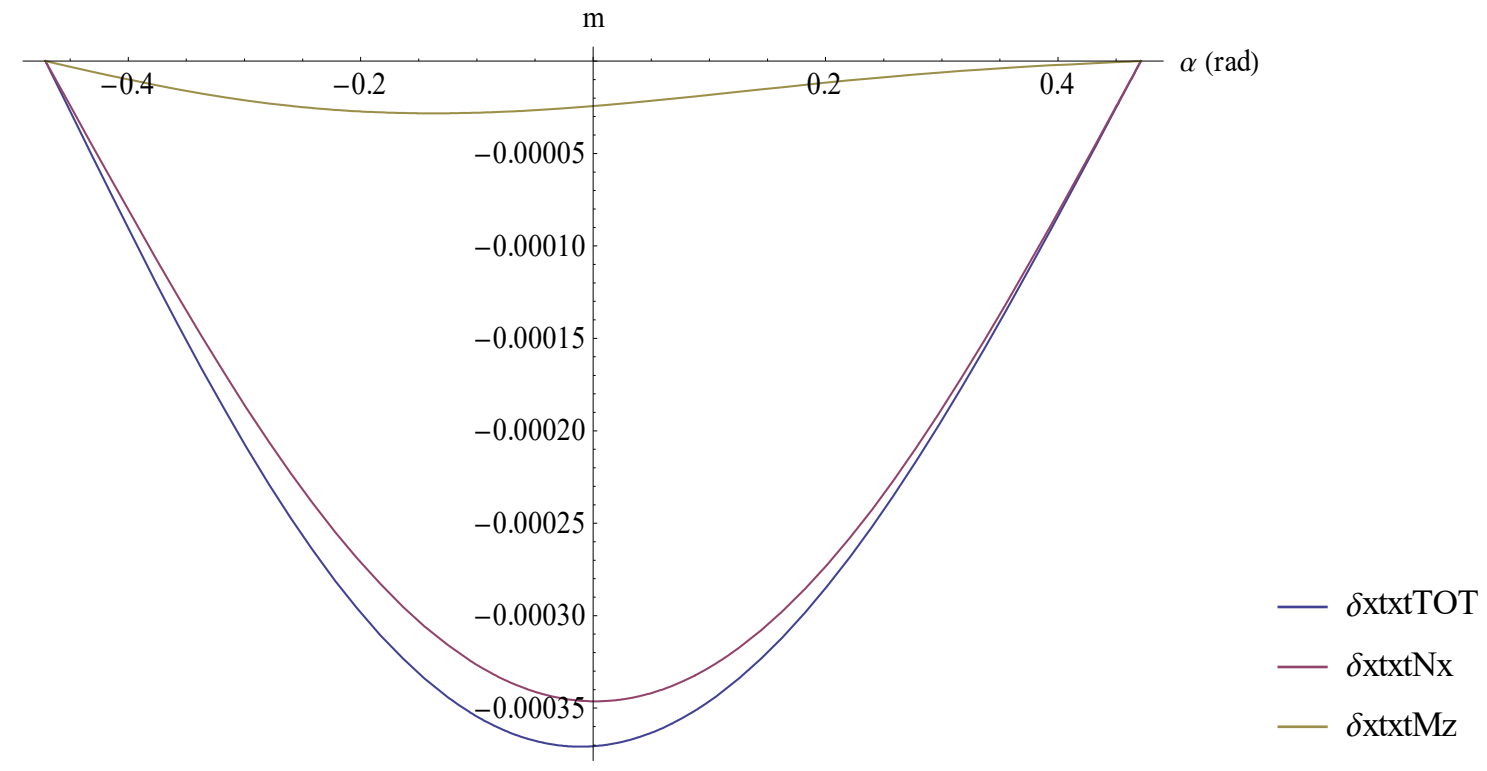


Deformación $(\mathrm{Lt}=280 \mathrm{~m})$

Sección: Tablero 1 (Carretera)

$\mathrm{Rp} / \mathrm{Rt}=0.9 \alpha \mathrm{t}=\frac{3 \pi}{10} \quad \alpha \mathrm{p}=0.5 \alpha \mathrm{t}$

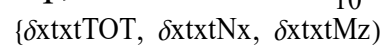

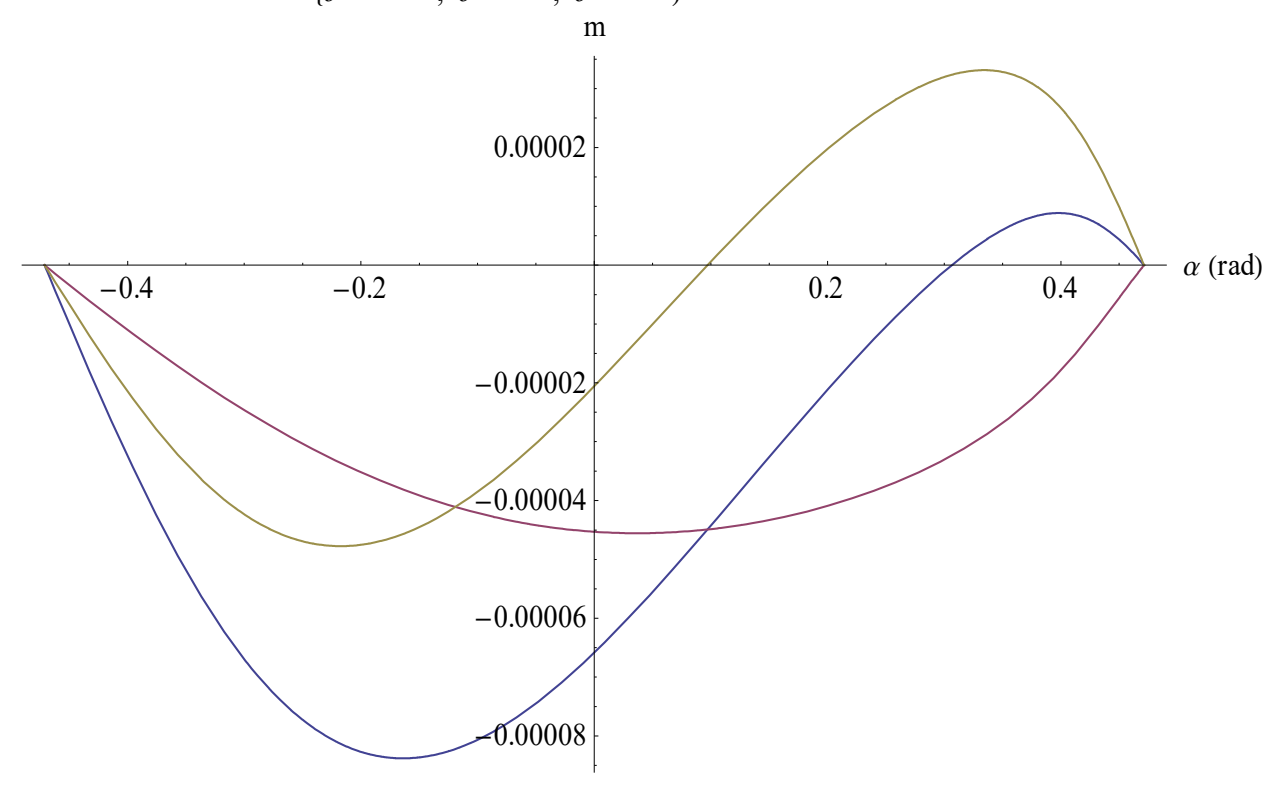

$-\delta \mathrm{xtxtTOT}$

Deformación $(\mathrm{Lt}=280 \mathrm{~m})$

Sección: Tablero 1 (Carretera)

$\mathrm{Rp} / \mathrm{Rt}=1.5 \alpha \mathrm{t}=\frac{3 \pi}{10} \alpha \mathrm{p}=0.5 \alpha \mathrm{t}$ $\{\delta x t x t T O T, \delta x t x t N x, \delta x t x t M z)$

$\mathrm{m}$

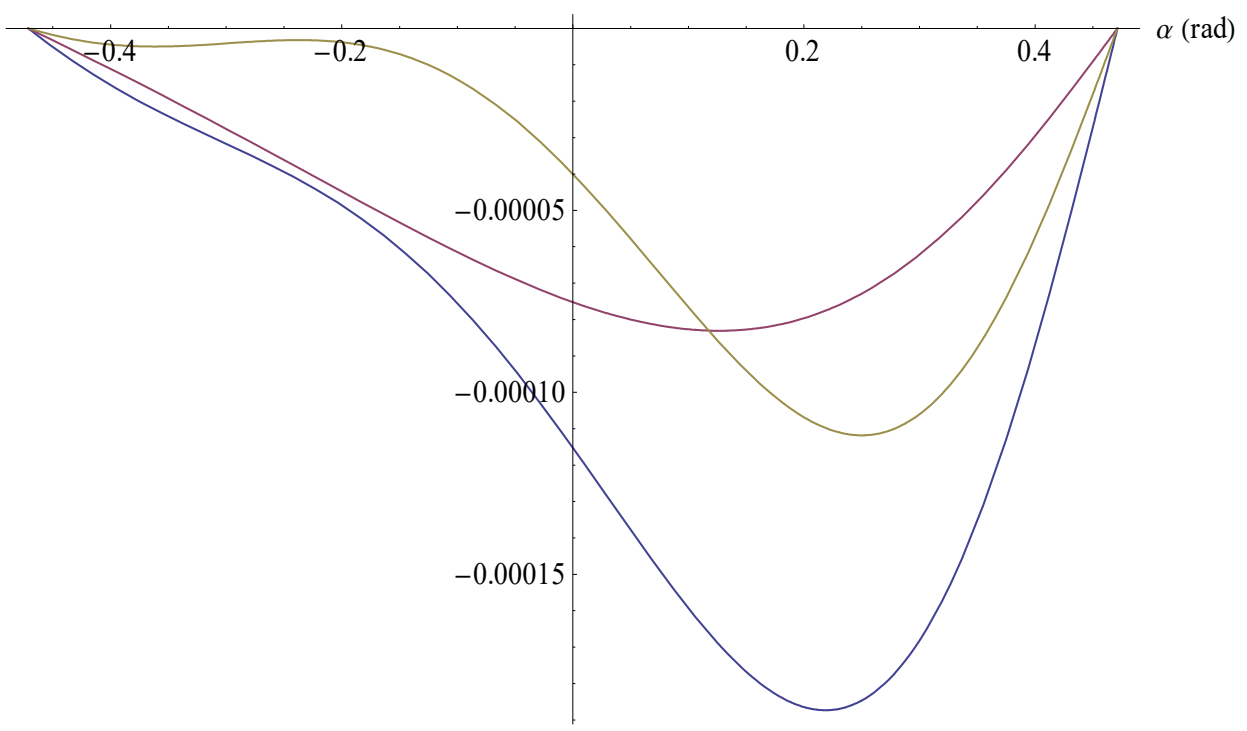

$-\delta$ xtxtTOT

$-\delta \mathrm{xtxtNx}$

$-\delta \mathrm{xtxtMz}$ 
Deformación $(\mathrm{Lt}=280 \mathrm{~m})$

Sección: Tablero 1 (Carretera)

$\alpha \mathrm{p}=0.5 \alpha \mathrm{t}$

$\{\delta x t x t T O T M A X, \delta x t x t T O T M I N, \delta x t x t N x M A X, \delta x t x t M z M A X, \delta x t x t M z M I N\}$

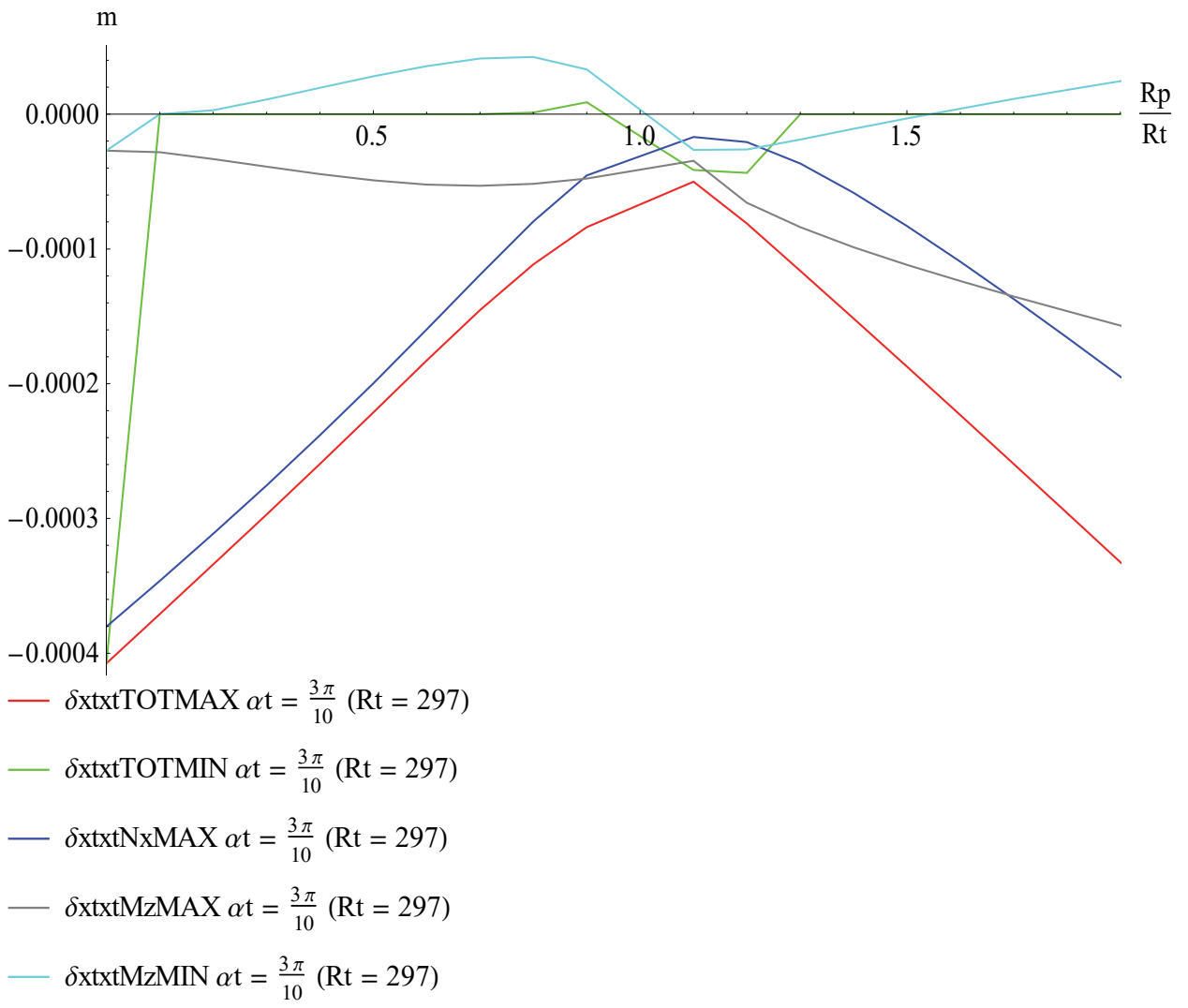

Deformación $(\mathrm{Lt}=280 \mathrm{~m})$

Sección: Tablero 1 (Carretera)

$\mathrm{Rp} / \mathrm{Rt}=0.1 \alpha \mathrm{t}=\frac{4 \pi}{5} \quad \alpha \mathrm{p}=0.5 \alpha \mathrm{t}$

$\{\delta \mathrm{xtxtTOT}, \delta \mathrm{xtxtNx}, \delta \mathrm{xtxtMz}$ )

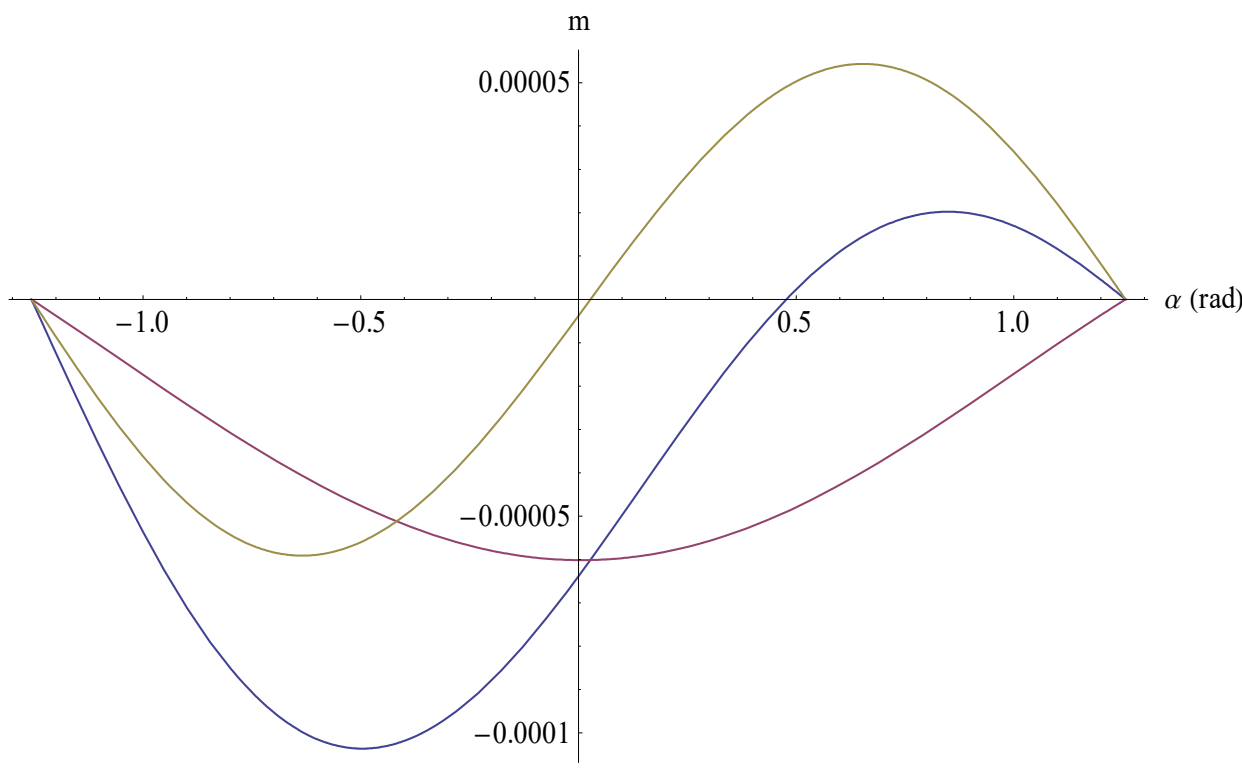

$-\delta$ xtxtTOT

$-\delta \mathrm{xtxtNx}$

$-\delta \mathrm{xtxtMz}$ 
Deformación $(\mathrm{Lt}=280 \mathrm{~m})$

Sección: Tablero 1 (Carretera)

$\mathrm{Rp} / \mathrm{Rt}=0.9 \alpha \mathrm{t}=\frac{4 \pi}{5} \quad \alpha \mathrm{p}=0.5 \alpha \mathrm{t}$

$\{\delta \mathrm{xtxtTOT}, \delta x \operatorname{xxtNx}, \delta x \operatorname{xtMz}\}$

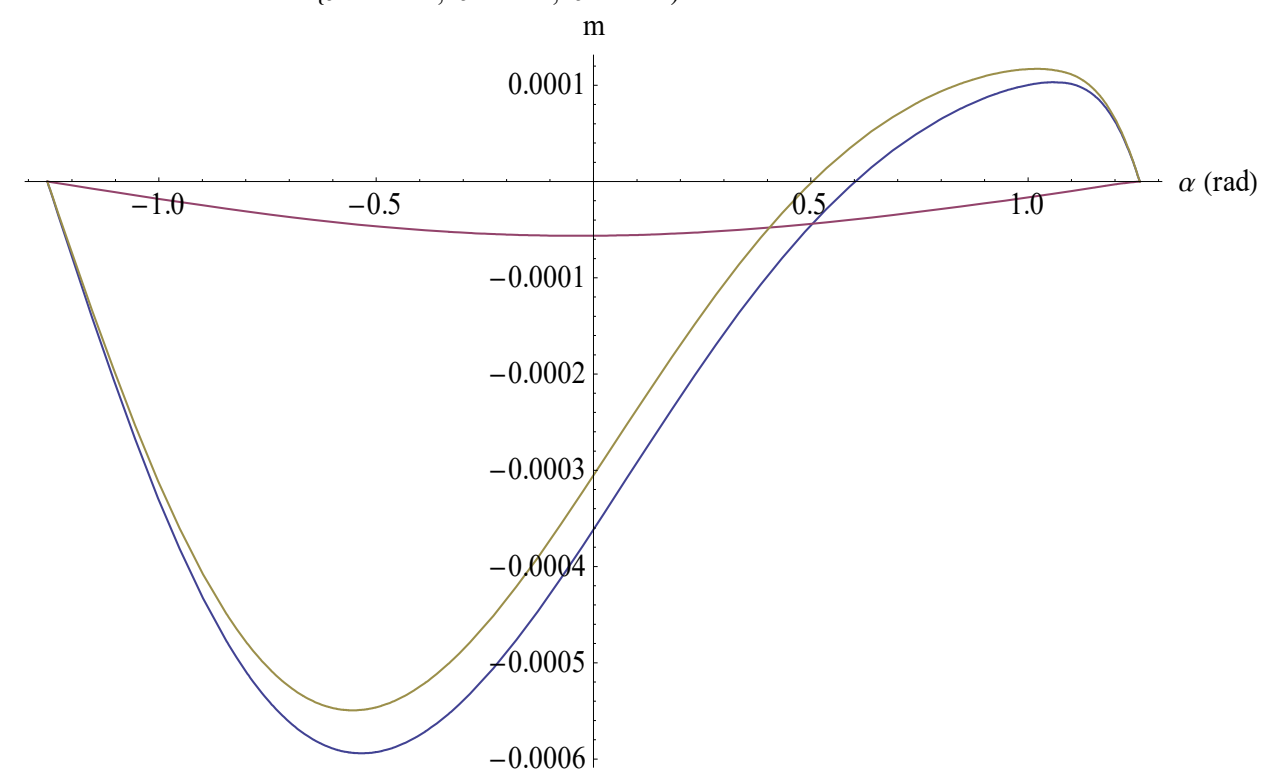

- $\delta$ xtxtTOT

- $\mathrm{xtxtNx}$

Deformación $(\mathrm{Lt}=280 \mathrm{~m})$

Sección: Tablero 1 (Carretera)

$\mathrm{Rp} / \mathrm{Rt}=1.5 \alpha \mathrm{t}=\frac{4 \pi}{5} \quad \alpha \mathrm{p}=0.5 \alpha \mathrm{t}$

$\{\delta \mathrm{xtxtTOT}, \delta \mathrm{xtxtNx}, \delta \mathrm{xtxtMz}$ )

- $\mathrm{xtxtMz}$

$\mathrm{m}$

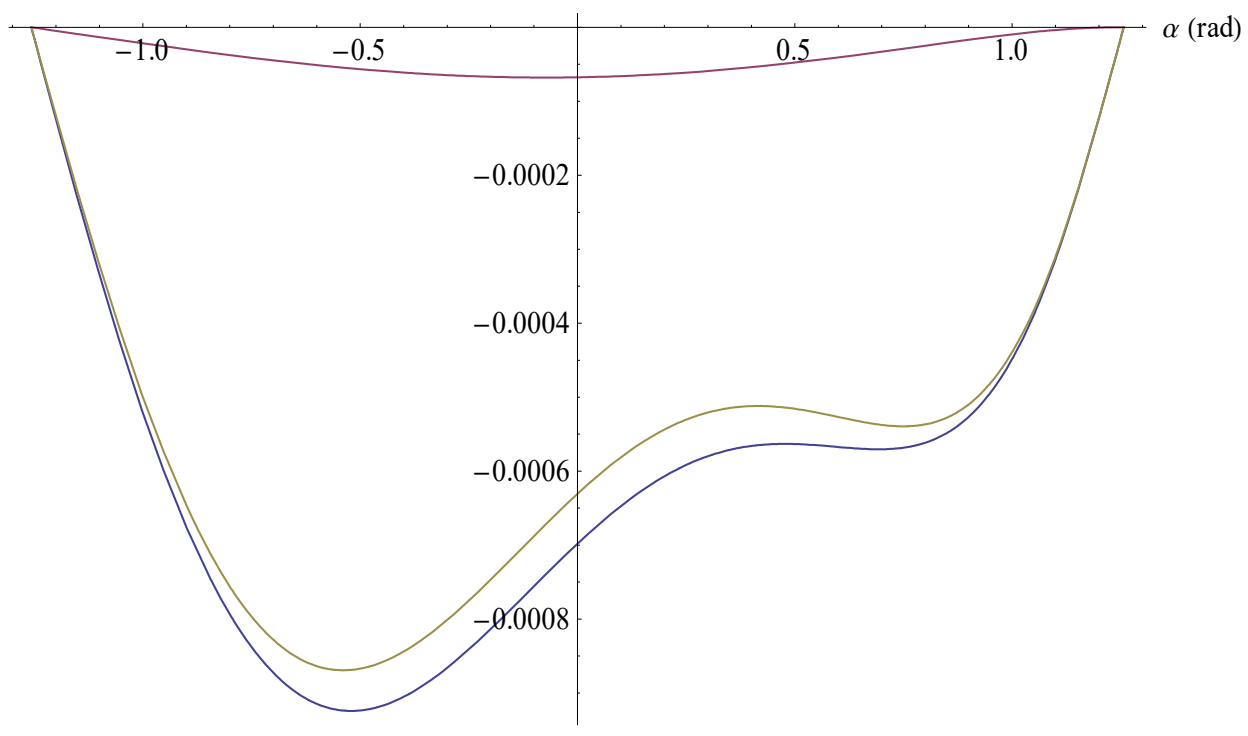

$-\delta$ xtxtTOT

$-\delta \mathrm{xtxtNx}$

- $\mathrm{xtxtMz}$ 
Deformación $(\mathrm{Lt}=280 \mathrm{~m})$

Sección: Tablero 1 (Carretera)

$\alpha \mathrm{p}=0.5 \alpha \mathrm{t}$

$\{\delta x t x t T O T M A X, \delta x t x t T O T M I N, \delta x t x t N x M A X, \delta x t x t M z M A X, \delta x t x t M z M I N\}$

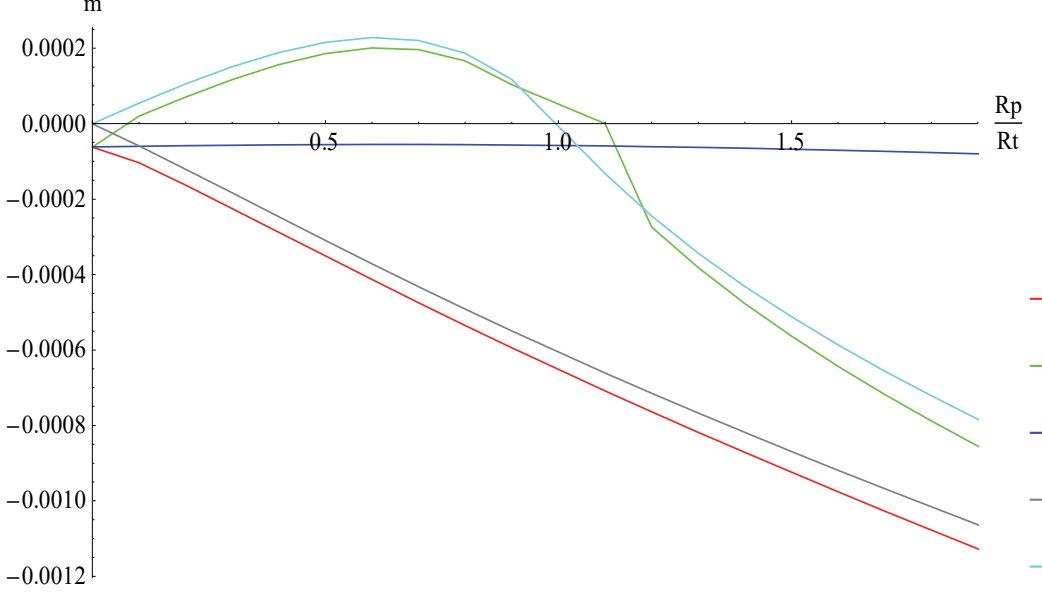

- $\delta \mathrm{xtxtTOTMAX} \alpha \mathrm{t}=\frac{4 \pi}{5}(\mathrm{Rt}=111)$

$-\delta \mathrm{xtxtTOTMIN} \alpha \mathrm{t}=\frac{4 \pi}{5}(\mathrm{Rt}=111)$

$-\delta \mathrm{xtxtNxMAX} \alpha \mathrm{t}=\frac{4 \pi}{5}(\mathrm{Rt}=111)$

$-\delta \mathrm{xtxtMzMAX} \alpha \mathrm{t}=\frac{4 \pi}{5}(\mathrm{Rt}=111)$

$\delta \mathrm{xtxtMzMIN} \alpha \mathrm{t}=\frac{4 \pi}{5}(\mathrm{Rt}=111)$

Diagrama 2.71. Deformaciones del tablero $(\alpha \boldsymbol{p}=\boldsymbol{\alpha t} / \mathbf{2})$ : Comportamiento "tipo viga" $\left(\boldsymbol{L t}=\mathbf{2 8 0} \boldsymbol{m}, \boldsymbol{\alpha t}=\frac{\pi}{\mathbf{5}}\right.$, Tablero 1 (Carretra)). Comportamiento "mixto" ( $\boldsymbol{L t}=\mathbf{2 8 0} \boldsymbol{m}, \boldsymbol{\alpha} \boldsymbol{t}=\frac{\mathbf{3 \pi}}{\mathbf{1 0}}$, Tablero 1 (Carretra)). Comportamiento "tipo $\operatorname{arco"}\left(\boldsymbol{L} \boldsymbol{t}=\mathbf{2 8 0} \boldsymbol{m}, \boldsymbol{\alpha} \boldsymbol{t}=\frac{4 \pi}{\mathbf{5}}\right.$, Tablero 1 (Carretra)).

El análisis realizado para el caso $\alpha p=0$, es completamente válido, como se puede apreciar en el Diagrama 2.70 y en el Diagrama 2.71. La diferencia fundamental, como ya se hizo patente en los diagramas de solicitaciones, es que el rango de las características, tanto mecánicas como de forma, que tienen un comportamiento "tipo viga" se reduce. Esto se hace patente en el Diagrama 2.70, donde se ha tenido que escoger un ejemplo con $\alpha p=\frac{\alpha t}{4}$, porque el funcionamiento del tablero 7 (Peatonal) con Lt $=140$ y $\alpha t=\frac{\pi}{10}$ resulta "mixto", quedando fuera del rango de funcionamiento "tipo viga". Se puede deducir la solicitación dominante en las deformaciones del tablero, solo con observar la deformada. También se aprecia como el factor $\varphi_{K N X M Z}$ ha perdido cierta importancia respecto del caso $\alpha p=0$, esto concuerda con el hecho de que los rangos de características que producen un comportamiento "tipo viga" se hayan reducido.

El comportamiento del tablero "tipo viga", sigue teniendo un comportamiento más homogéneo a medida que se acerca acercamos la pila al tablero, con el área como característica mecánica que marca la deformación del tablero. El tablero de comportamiento "tipo arco", pasa bruscamente de un comportamiento ("tipo arco") en el que la deformada está determinada por el área del tablero, a uno ("tipo esfera") en el que la deformación viene determinada por la inercia de eje vertical (Izz) del tablero. El comportamiento "tipo mixto", pasa de un comportamiento "tipo viga" a uno "tipo esfera" (con las deformaciones del "tipo viga", dominadas por el área del tablero, y las del "tipo esfera", por la inercia de eje vertical (Izz)). 
2.2.6.2.3 Sistema Hiperestático, restringiendo el desplazamiento en los 3 ejes de los estribos, carga en el plano del tablero, concéntrica. Configuraciones alternativas de atirantamiento a pila

\subsection{Introducción}

Como se describe en el capítulo 3 (35), existen tres tipos de configuraciones diferentes a la hora de conectar los tirantes a la pila en puentes atirantados: abanico, arpa y semiarpa. En el caso de los puentes curvos atirantados, la configuración tipo arpa resulta enormemente perjudicial para la pila, debido a la espacialidad del sistema, que incrementa la dificultad a la hora de compensar la pila. Las otras dos configuraciones restantes, junto con la tipología colgante (ampliamente utilizada por Schlaich (87), (88), 89), (101)), se reparten casi por completo los puentes curvos atirantados desarrollados hasta la fecha (con alguna excepción remarcable, como el puente South Quay de Londres, aunque debe remarcarse que se trata de un puente móvil), siendo la semiarpa la más utilizada (aunque en muchos casos los tirantes se anclan en un tramo tan pequeño de pila que su comportamiento se puede considerar tipo abanico), si bien existen remarcables ejemplos de soluciones tipo abanico, como la pasarela sobre el río Carrión en Palencia (44) o la pasarela de tablero de madera en Sao Paulo (22).

Hasta ahora, en el estudio de las cargas concéntricas que el subsistema Pila-Tirantes introduce sobre el tablero, se ha establecido el módulo de la carga $\operatorname{Ttir}[\alpha]$ a partir de la distancia entre la pila y el tablero. Esto supone implícitamente que el valor de la altura de la unión entre los tirantes y la pila es la misma para todos los tirantes. De cara al estudio del comportamiento del tablero, esta suposición resulta en general válida para el cálculo de sistemas tipo semiarpa, como se puede comprobar en el subapartado 2.2.6.2.3.4, permaneciendo válidas las conclusiones obtenidas. Esto se debe, fundamentalmente, a que el ángulo de los tirantes no va a variar demasiado, luego el módulo Ttir $[\alpha]$ tampoco (Diagrama 2.51 frente a Diagrama 2.84). Aun así, el estudio de los efectos que va a tener la variación de la altura de los tirantes sobre la carga concéntrica abre un interesante campo de investigación morfológica.

En este capítulo, en principio se va a analizar la función que defina la altura de los pilares $h p[\alpha]$ para un comportamiento óptimo del tablero. Esto se va a realizar a partir del estudio de la función del módulo de la carga concéntrica $(\operatorname{Ttir}[\alpha])$. Posteriormente, se va a analizar qué efectos tiene sobre el módulo de $\operatorname{Tt}$ tir $[\alpha]$ una configuración de anclaje de tirantes a pila tipo semiarpa, para poder compararlo con lo visto en los apartados anteriores de carga concéntrica.

\subsection{Optimización del comportamiento del tablero mediante la función del módulo de $\operatorname{Ttir}[\alpha], h p[\alpha]$}

Si se observa el comportamiento del tablero ante una carga concéntrica a la pila, cuando esta se sitúa en el centro del arco que forma el tablero (subapartado 2.2.6.1), se advierte cómo la carga concéntrica va "absorbiendo" el axil transversal a la directriz del puente a medida que este va girando. Este efecto impide al cortante transversal (Qy) alimentarse del axil mediante la curvatura, produciendo el sistema resistivo "tipo arco", que resulta tan ventajoso en lo que al comportamiento del tablero se refiere. 
El párrafo anterior se traduce matemáticamente mediante la ecuación diferencial que define la relación entre el cortante transversal (Qy), el axil ( $\mathrm{Nx}$ ) y la componente transversal al tablero de la carga concéntrica (py):

$$
\frac{d Q y[\alpha]}{d \alpha}=-N x[\alpha]+p y[\alpha] R t
$$

Si se observan los diferentes diagramas de la solicitación axil ( $\mathrm{Nx}$ ) y de la componente transversal de $\operatorname{Ttir}[\alpha]: p y[\alpha]$, desarrollados para los ejemplos con pila no situada en el centro del arco del tablero:

- $p y[\alpha]:$

o $\alpha p=0$ : Diagrama 2.52 .

o $\alpha p \neq 0$ : Diagrama 2.61 .

- Solicitaciones:

o $\alpha p=0$ : Diagrama 2.53 y Diagrama 2.54 (Tablero 1 (Carretera))

o $\alpha p \neq 0$ : Diagrama 2.62 y Diagrama 2.63 .

Se puede apreciar como los diagramas lejos de parecerse, resultan hasta cierto punto opuestos, coincidiendo mínimos de un diagrama con máximos del otro. Esto sin duda es una de las razones más importantes por las que en estas morfologías se impone el sistema resistivo "tipo viga" o "tipo esfera" sobre el sistema resistivo "tipo arco".

Si se parte de la premisa de que el sistema resistivo "tipo arco" resulta óptimo para el funcionamiento del tablero en el plano xy, se debe cumplir la siguiente igualdad:

$$
N x[\alpha]=p y[\alpha] R t
$$

A partir de la ecuación diferencial que define el diagrama de la solicitación axil (Nx), se puede obtener otra ecuación diferencial que defina la función del módulo de Ttir $[\alpha]$ que va a incitar al sistema resistivo "tipo arco" en el tablero.

$$
\begin{gathered}
N x^{\prime \prime}[\alpha]+N x[\alpha]=\left(p x^{\prime}[\alpha]+p y[\alpha]\right) R t \\
p y^{\prime \prime}[\alpha]=p x^{\prime}[\alpha]
\end{gathered}
$$

Donde:

$$
\begin{gathered}
p x[\alpha]=-\operatorname{Ttir}[\alpha] \operatorname{Sin}[\alpha l[\alpha]+\pi-\alpha] \\
p y[\alpha]=\operatorname{Ttir}[\alpha] \operatorname{Cos}[\alpha l[\alpha]+\pi-\alpha]
\end{gathered}
$$

Con:

$$
\begin{gathered}
x p p=R p \operatorname{Cos}[\alpha p] \\
y p p=R p \operatorname{Sin}[\alpha p] \\
x p t[\alpha]=R t \operatorname{Cos}[\alpha]
\end{gathered}
$$




$$
\begin{gathered}
y p t[\alpha]=R t \operatorname{Sin}[\alpha] \\
\alpha l[\alpha]=\operatorname{ArcTan}[x p t[\alpha]-x p p, y p t[\alpha]-y p p]
\end{gathered}
$$

Las condiciones de contorno para la resolución de las ecuaciones, pueden ser los valores del módulo de Ttir $[\alpha]$ en los extremos del tablero. Para esto se debe definir la altura de los puntos de anclaje en la pila de los tirantes que van a soportar los extremos del tablero (como se verá posteriormente y por otro lado resulta intuitivo, estos puntos se van a situar en lo más alto de la pila). Resulta obvio, que se debe de comenzar en algún punto para que se pueda definir la función.

La resolución de la ecuación diferencial se realiza numéricamente, por no existir una resolución exacta. Para cada conjunto de condiciones de contorno, la solución de la ecuación diferencial va a ser diferente. Si se estudia el ejemplo desarrollado en el subapartado 2.2.6.2.1.1, se obtiene la siguiente función para $\operatorname{Ttir}[\alpha]$ :

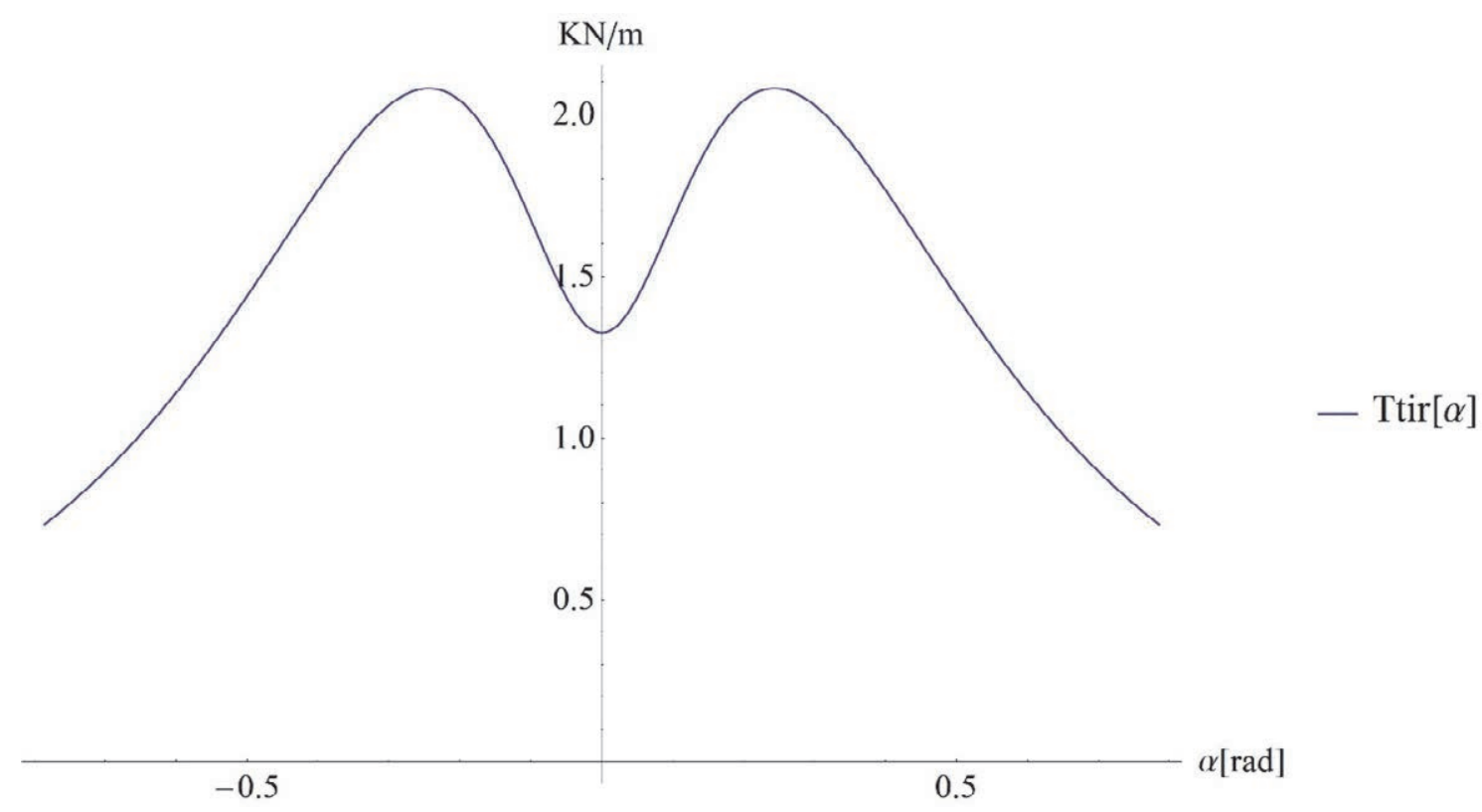

Diagrama 2.72. Valor de la carga Ttir $[\alpha]$ que minimiza las solicitaciones transversales del tablero. $R t=$ $280 m, R p=252.09 m, \alpha t=\frac{\pi}{2} y \alpha p=0$.

A la hora de analizar el Diagrama 2.72, se debe tener en cuenta una serie de cuestiones:

- En el planteamiento de las ecuaciones diferenciales desarrolladas para obtener la función Ttir $[\alpha]$, no se tiene en cuenta los grados de hiperestaticidad del tablero. Esto va a hacer que el correcto funcionamiento del sistema resistivo "tipo arco" va estar supeditado al ángulo desarrollado por el tablero $\alpha t$ y la relación de rigideces del tablero $\varphi_{K N X M Z}$, tal y como ocurría en el subapartado 2.2.6.1.

- El valor inicial de la función Ttir $[\alpha]$, correspondiente a los estribos, se ha relacionado con el radio del tablero Rt, tal y como se hizo en los subapartados: 2.2.6.2.1 y

2.2.6.2.2 (esta es la razón de que empiecen en el mismo punto el Diagrama 2.51 y el Diagrama 2.72). Esto permite comparar todos los diagramas de Ttir $[\alpha]$ a lo largo de 
los diferentes subapartados, relacionándolos con la distancia existente entre la pila y los diferentes puntos del tablero, dejando la altura de la pila constante.

Se puede observar cómo la función del módulo de Ttir $[\alpha]$ que optimiza las solicitaciones transversales resulta mucho mayor a lo largo del tablero (excepto en el valor del estribo, que se ha igualado) de lo que era cuando se posicionaba la pila en el centro del arco (Diagrama 2.51) y cuando se posicionaba en el centro de gravedad del tablero (Diagrama 2.60). Esto va a conllevar un claro inconveniente, sabiendo que Ttir $[\alpha]$ se muestra relativa a su valor cuando la pila se introduce en el centro del arco del tablero:

- Sin duda, una de las ventajas de acercar la pila al tablero es la disminución de las cargas en los tirantes y, por consiguiente, la disminución de las cargas horizontales en el sistema (esto se hace patente en el Diagrama 2.51). Esto resulta enormemente ventajoso para el subsistema Pila-Tirantes, que es el elemento transmisor de estas cargas. Del Diagrama 2.72 se extrae que optimizar las solicitaciones transversales en el tablero mediante $\operatorname{Tt} \operatorname{tir}[\alpha]$ conlleva un enorme incremento de carga, tanto sobre los tirantes de sujeción como para el sistema PilaTirCom (capítulo 3).

- Los valores de la función del módulo de Ttir $[\alpha]$ se disparan a medida que la pila se acerca al tablero, tendiendo a infinito, mientras que se moderan a medida que la acercamos al centro del arco.

- La ecuación diferencial se vuelve inestable si $R p>R t$, a menos que superemos la barrera de $R p>R t \operatorname{Tan}\left[\frac{\alpha t}{2}\right] \operatorname{Cos}\left[\frac{\alpha t}{2}\right]$, que en la práctica va a resultar excesiva.

A partir de la función que define $\operatorname{Ttir}[\alpha]$, se puede obtener la función $h p T[\alpha]$ que defina la altura a la que se debe conectar el tirante a la pila respecto de la altura del tablero $(h p T=0 \rightarrow h t)$.

$$
h p T[\alpha]=-\frac{\sqrt{\left((\operatorname{xpt}[\alpha]-\operatorname{xpp}[\alpha])^{2}+(\operatorname{ypt}[\alpha]-\operatorname{ypp}[\alpha])^{2}\right)}}{\operatorname{Ttir}[\alpha] R t}
$$

De cara a un análisis más claro, se va a mostrar la función $h p T[\alpha]$ relativa a su punto más alto, que va a corresponder a los extremos del tablero: 


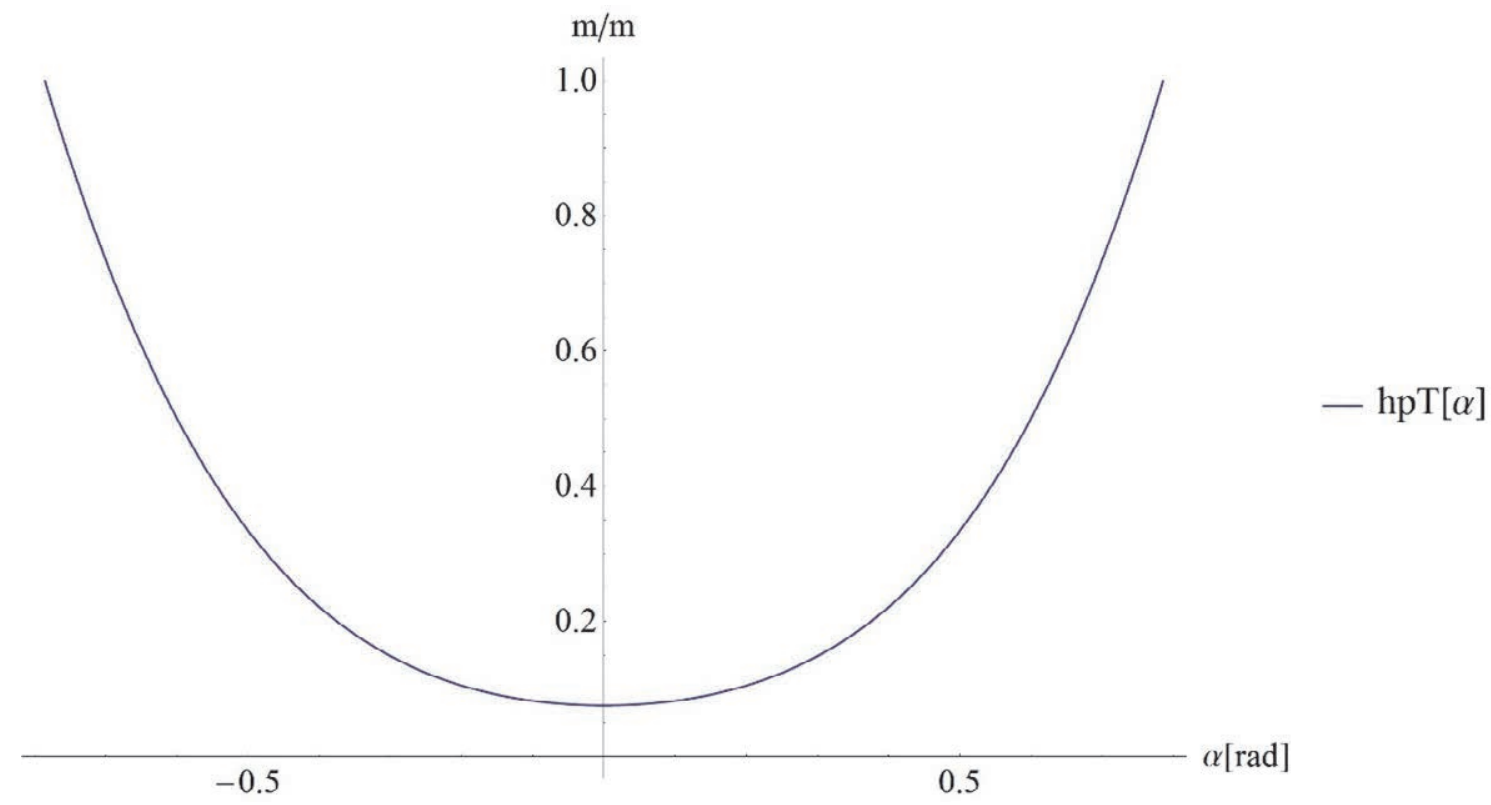

Diagrama 2.73. Función de $h p T[\alpha]$ que minimiza las solicitaciones transversales del tablero. $R t=280 \mathrm{~m}, R p=$ $252.09 m, \alpha t=\frac{\pi}{2}$ y $\alpha p=0$.

La primera conclusión que se obtiene del Diagrama 2.73 es que los tirantes se deben de anclar a lo largo de casi toda la longitud de la pila que sobresale respecto del tablero. Esto va a suponer unas enormes solicitaciones para la pila a lo largo de ese tramo, a menos que se lleve a cabo un sistema de compensación que resultará muy complejo. Se debe recordar que, a lo largo del tramo de pila conectado con tirantes, la resultante de los grupos de tirantes a compensar va a ir variando de dirección, como se expone en el capítulo 3 . A esto se le suma que, debido a la poca curvatura de la función $h p T[\alpha]$, en la zona próxima a $\alpha \approx 0$ pueden existir problemas de espacio para los anclajes, de forma parecida a lo que ocurre en las configuraciones de tirantes en abanico.

Se debe remarcar que tanto la función $\operatorname{Ttir}[\alpha]$ como $h p T[\alpha]$ son diferentes para cada grupo de condiciones de contorno. Como se ha comentado en el análisis de Ttir $[\alpha]$, sus valores se moderan a medida que se aleja la pila del puente. Esto significa una disminución en la longitud del tramo de conexión de la pila. Esto puede hacer más viable la solución en lo que a solicitaciones en la pila se refiere.

Si ahora obtenemos los diagramas para las componentes en los ejes locales del tablero de la carga $\operatorname{Ttir}[\alpha]$ y las solicitaciones para diferentes tipos de secciones de tablero: 


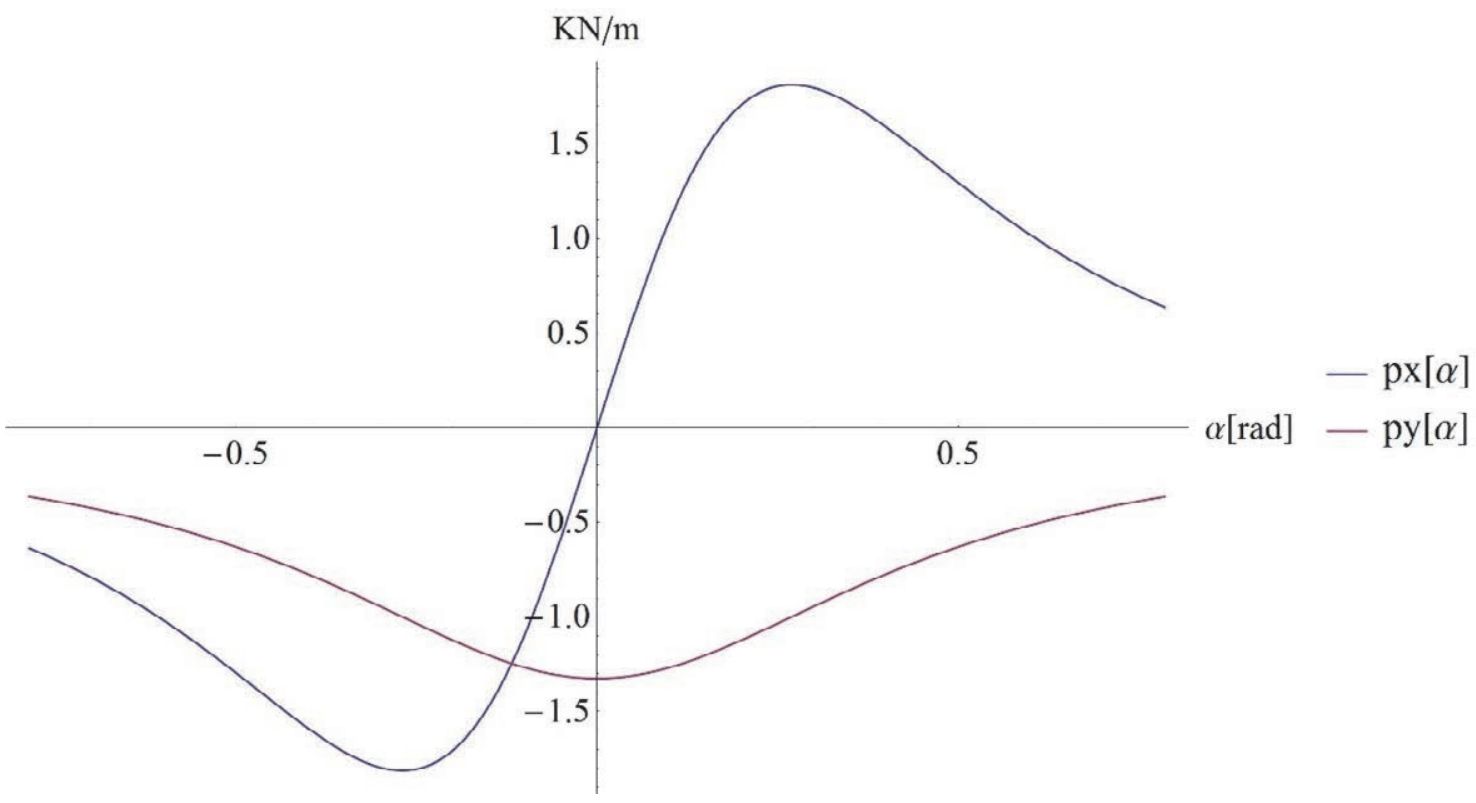

Diagrama 2.74. Valor de la carga según los ejes locales del tablero: $p x[\alpha]$ y $p y[\alpha]$ de la carga Ttir $[\alpha]$ que minimiza las solicitaciones transversales del tablero. $R t=280 \mathrm{~m}, R p=252.09 \mathrm{~m}, \alpha t=\frac{\pi}{2}$ y $\alpha p=0 \mathrm{~m}$.

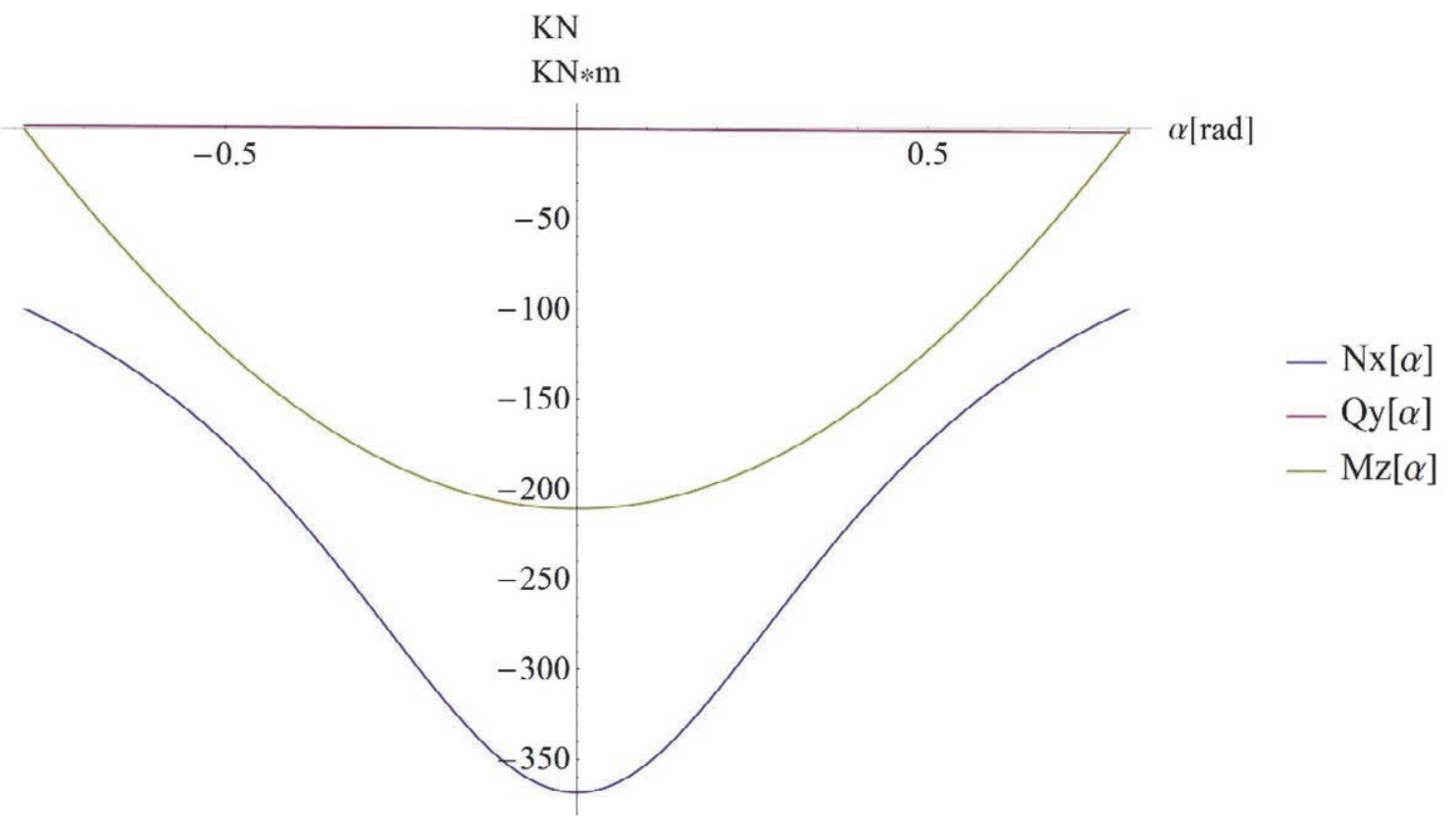

Diagrama 2.75. Solicitaciones sobre el tablero hiperestático bajo una carga concéntrica $\operatorname{Ttir}[\alpha]$ que minimiza las solicitaciones transversales del tablero. $\alpha t=\frac{\pi}{2}, R t=280 \mathrm{~m}$, Tablero 1 (Carretera). $\varphi_{K N x M z}=42,88$. 


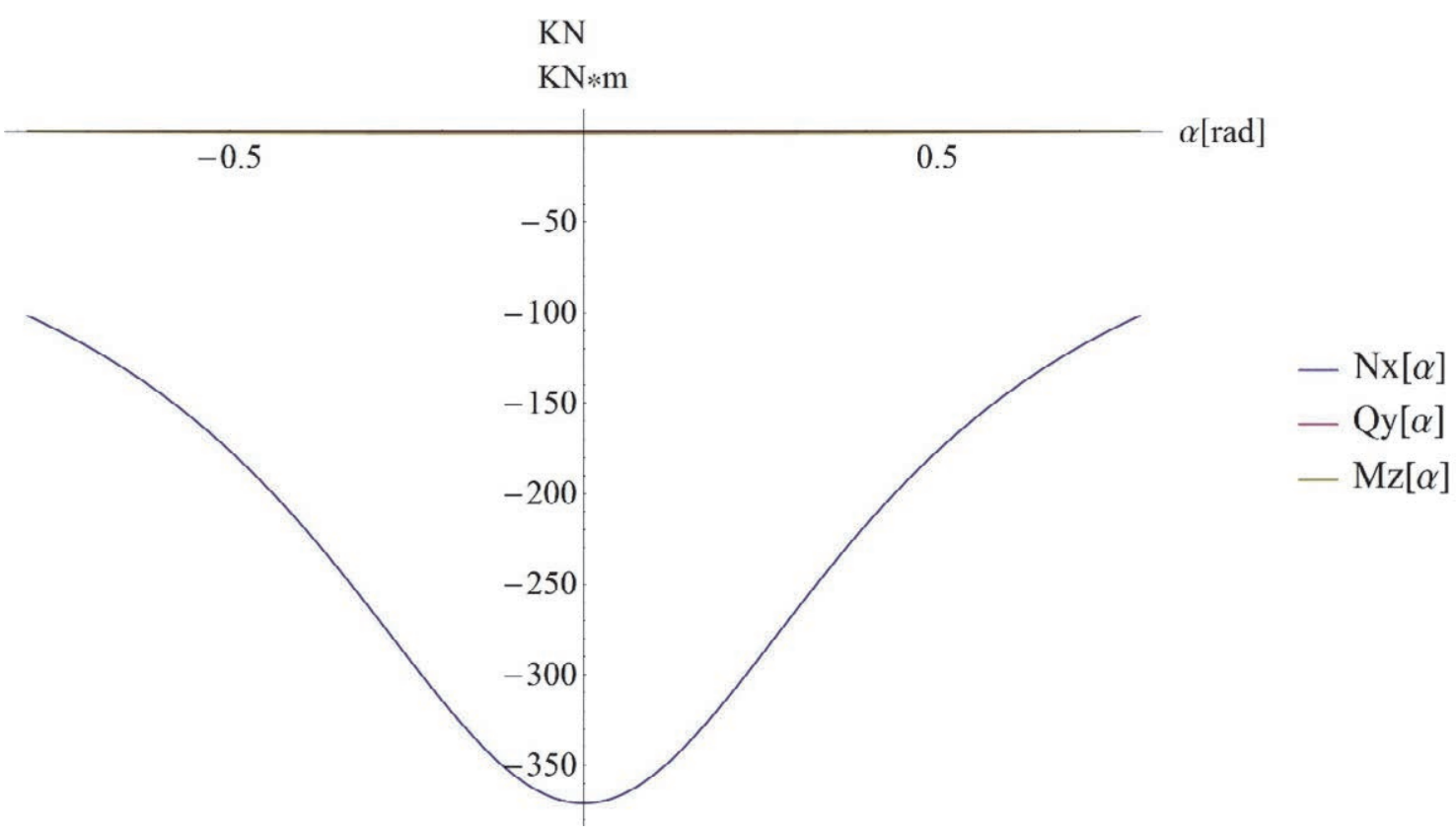

Diagrama 2.76. Solicitaciones sobre el tablero hiperestático bajo una carga concéntrica $T \operatorname{tir}[\alpha]$ que minimiza las solicitaciones transversales del tablero. $\alpha t=\frac{\pi}{2}, R t=280 \mathrm{~m}$, Tablero 7 (Peatonal). $\varphi_{K N x M z}=575,61$.

Las conclusiones que se pueden extraer de los diagramas presentados, tanto de cargas en ejes locales $(p x[\alpha]$ y $p y[x])$ como de las solicitaciones en el tablero son:

1. Se confirma, que asimilando el diagrama axil $(\mathrm{Nx})$ al de la componente transversal al tablero de $\operatorname{Ttir}[\alpha](p y[\alpha])$ por la curvatura $\left(\frac{1}{R t}\right)$, se estimula el sistema resistivo "tipo arco".

2. El comportamiento transversal del tablero resulta similar al visto en el subapartado 2.2.6.1, donde se situaba la pila en el centro del arco del tablero:

a. La hiperestaticidad de los apoyos de los estribos, estimula por su parte el funcionamiento del sistema resistivo "tipo viga".

b. Las solicitaciones son completamente dependientes del coeficiente $\varphi_{K N x M z}$ y de $\alpha t$. Tal y como ocurría en el caso de situar la pila en el centro del arco de la circunferencia.

3. El axil (Nx), va a tener un diagrama puntiagudo, fundamentalmente por las aportaciones de la componente longitudinal de la carga $\operatorname{Ttir}[\alpha](p x[\alpha])$.

4. Viendo los diagramas de solicitaciones, resulta evidente que las deformaciones van a quedar determinadas, principalmente, por la solicitación axil y la rigidez que ofrezca el tablero ante ellas $(E A)$. Esto resultará en un tablero con un comportamiento muy rígido que permitirá un funcionamiento correcto del sistema Pila-tirantes.

5. El procedimiento se puede realizar de forma similar para sistemas en los que la pila no se introduce en el eje de simetría del tablero $(\alpha p \neq 0)$, aunque cambiando las condiciones de contorno para la resolución de las ecuaciones diferenciales. Las diferencias básicas van a ser:

a. La hiperestaticidad del sistema modifica más los resultados. Sobre todo, en el estribo más cercano a la pila. Esto hace que se incrementen las solicitaciones transversales. 
b. El sistema va a requerir mayor altura de pila para un correcto funcionamiento. Esto resulta intuitivo, sabiendo que el vano de puente también resulta mayor.

\subsection{Configuración en arpa}

Como se ha concluido en el subapartado 2.2.6.2.3.2, cuanto más se aproxime el diagrama de axiles $(\mathrm{Nx})$ al de la componente transversal de la carga $p y[\alpha]$, menor van a ser los valores del diagrama de cortantes transversal (Qy). Viendo estos diagramas ( $p y[\alpha]$ y Nx) en lo referido al sistema de atirantamiento tipo abanico (subapartados 2.2.6.2.1 y 2.2.6.2.2), se aprecia cómo esta configuración fomenta el sistema de rigidez "tipo viga" cuando la pila no se introduce en el centro del arco.

Como se comentó en la introducción del apartado, la configuración de tirantes en arpa resulta muy perjudicial de cara a las solicitaciones sobre la pila, si bien su estudio resulta muy útil de cara a establecer un extremo para la configuración semiarpa (obviamente el otro extremo es el funcionamiento tipo abanico).

La configuración en arpa de los tirantes se debe redefinir para los puentes atirantados, ya que no resulta tan evidente como en el caso de los puentes rectos (esto se debe, de nuevo, a la espacialidad del subsistema Pila-Tirantes). Una forma de definir esta configuración, siguiendo en la línea de los anteriores apartados, es que en esta configuración el módulo de la carga Ttir $[\alpha]$ será constante. Esta definición resulta equivalente a definir la configuración como aquella que iguala los ángulos de inclinación de todos los tirantes de sujeción. Luego el diagrama del módulo de $\operatorname{Ttir}[\alpha]$ (de nuevo el valor inicial de la función Ttir $[\alpha]$, correspondiente a los estribos, se ha relacionado con el radio del tablero Rt, como en el Diagrama 2.72) queda:

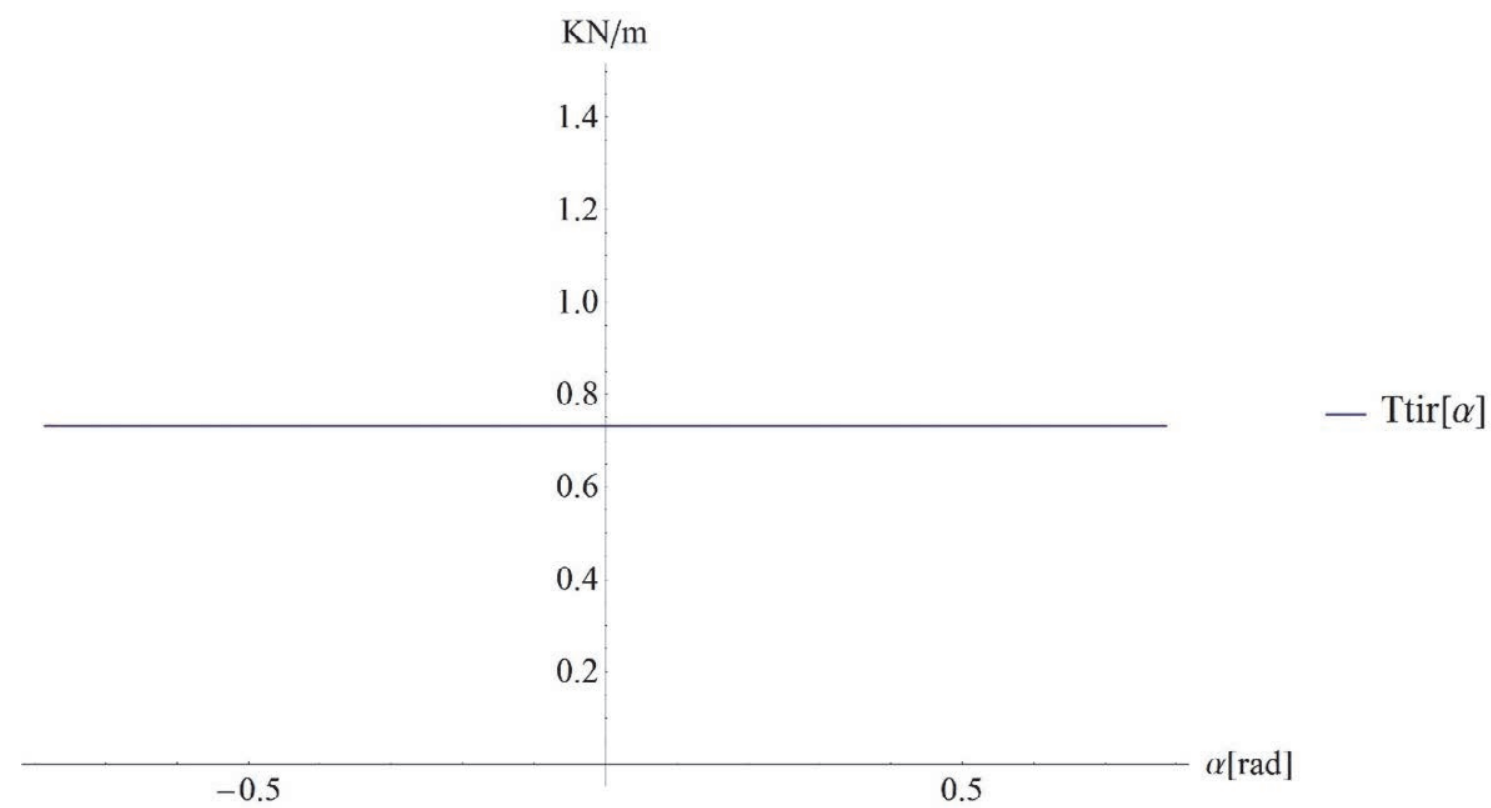

Diagrama 2.77. Valor de la carga Ttir $[\alpha]$, configuración de tirantes en arpa. $R t=280 \mathrm{~m}, R p=252.09 \mathrm{~m}, \alpha t=$ $\frac{\pi}{2} y \alpha p=0$. 
La configuración en arpa supone invertir la relación entre la carga Ttir $[\alpha]$ y la altura de anclaje de los tirantes $h p T[\alpha]$. En este caso, es la carga $\operatorname{Ttir}[\alpha]$ (o la inclinación de los tirantes) la que se mantiene constante y la altura de los tirantes la que debe adaptarse a esa premisa. El resultado es que se obtiene un diagrama para $h p T[\alpha]$ similar al que se obtuvo para $\operatorname{Ttir}[\alpha]$ con la configuración de tirantes tipo abanico.

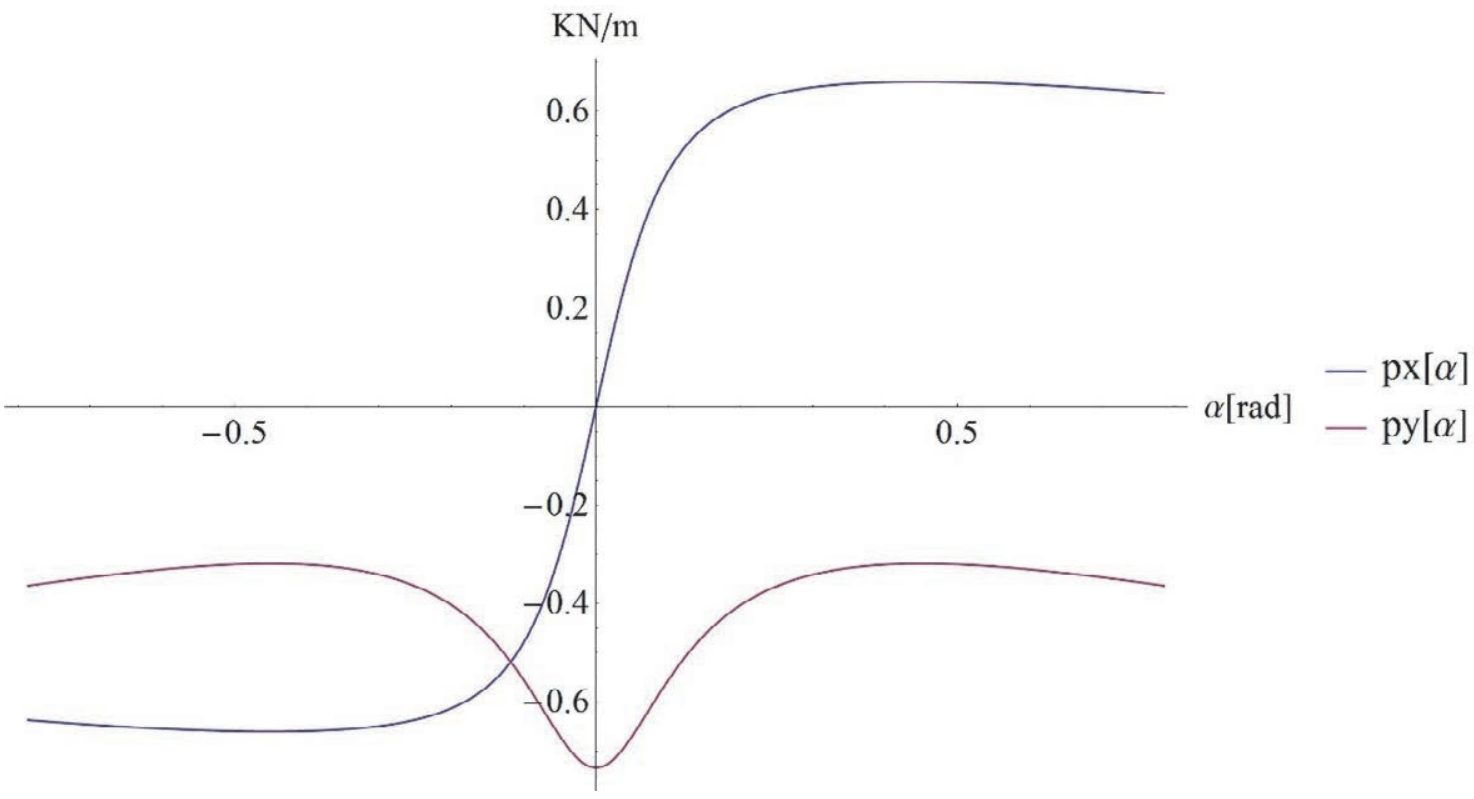

Diagrama 2.78. Valor de la carga según los ejes locales del tablero: $p x[\alpha]$ y $p y[\alpha]$ de la carga Ttir $[\alpha]$, configuración de tirantes en arpa. $R t=280 m, R p=252.09 m, \alpha t=\frac{\pi}{2} y \alpha p=0$.

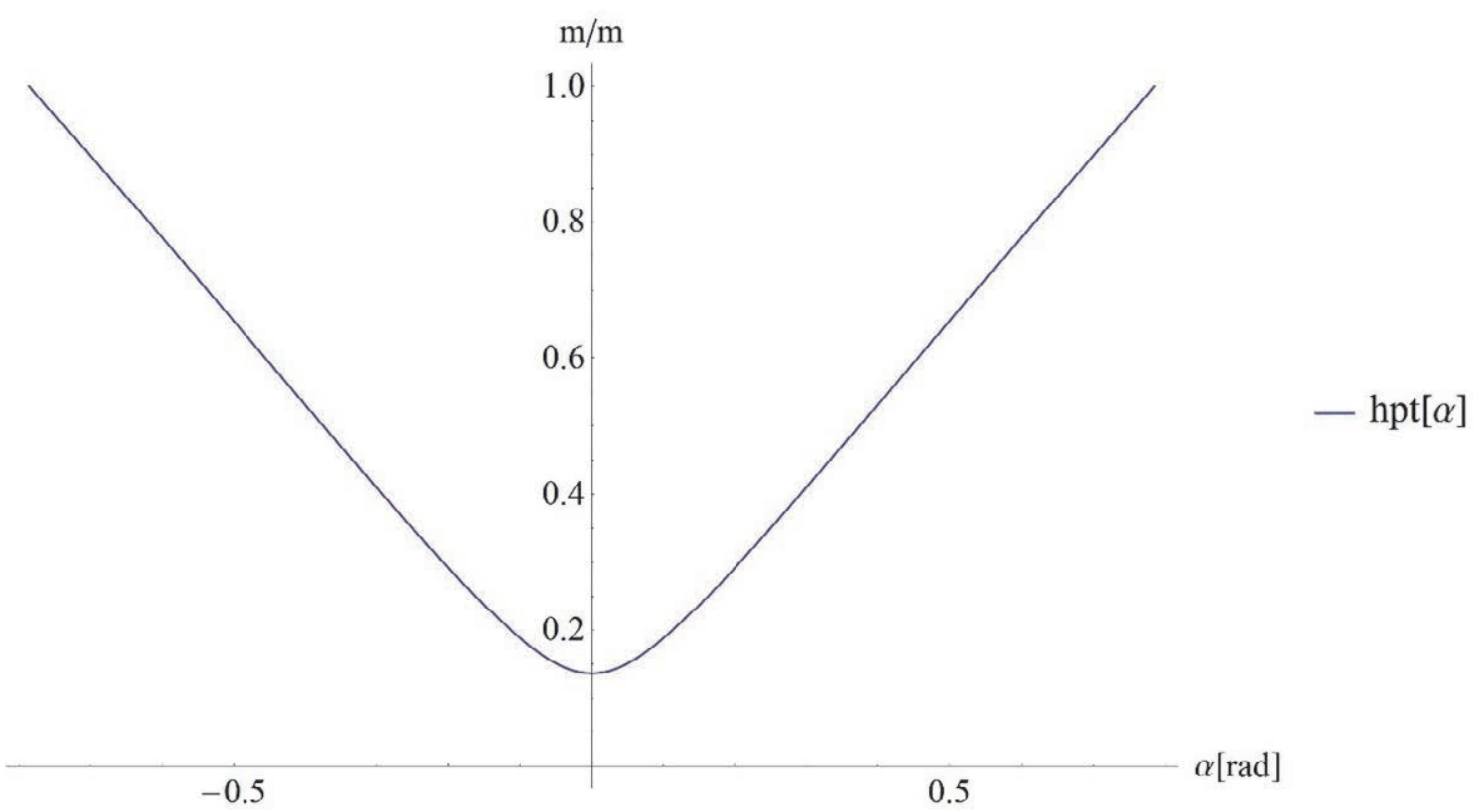

Diagrama 2.79. Función de $h p T[\alpha]$, configuración de tirantes en arpa. $R t=280 \mathrm{~m}, R p=252.09 \mathrm{~m}, \alpha t=\frac{\pi}{2} y \alpha p=$ 0 .

De nuevo, como en el Diagrama 2.73, se observa cómo queda repartida la carga a lo largo de casi toda la pila que queda sobre el tablero. Esto, como ya se comentó en el subapartado 2.2.6.2.3.2, da como resultado unas altas solicitaciones para la pila que pueden 
hacerla inviable. Aunque se tiene que tener en cuenta la disminución en el módulo de la carga, Diagrama 2.77. Si bien, en este caso también disminuye esta distancia de anclaje de tirantes en pila a medida que se acerca la pila al centro del arco del tablero.

En cuanto a las componentes en los ejes locales de la carga concéntrica $p x[\alpha]$ y $p y[\alpha]$, la disminución en el módulo de la carga se refleja en sus valores.

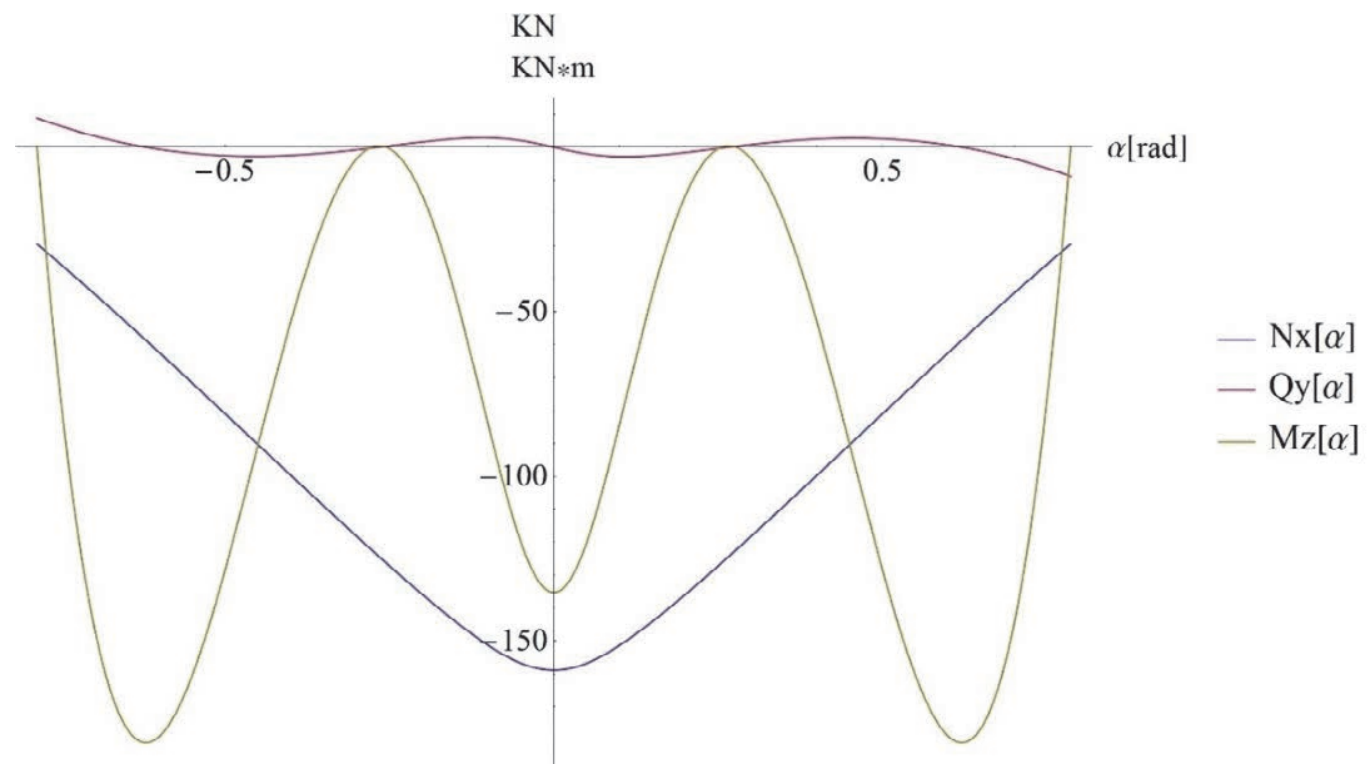

Diagrama 2.80. Solicitaciones sobre el tablero hiperestático bajo una carga concéntrica $\operatorname{Ttir}[\alpha]$, configuración de tirantes en arpa. $\alpha t=\frac{\pi}{2}, R t=280 \mathrm{~m}$, Tablero 1 (Carretera). $\varphi_{K N x M z}=42,88$.

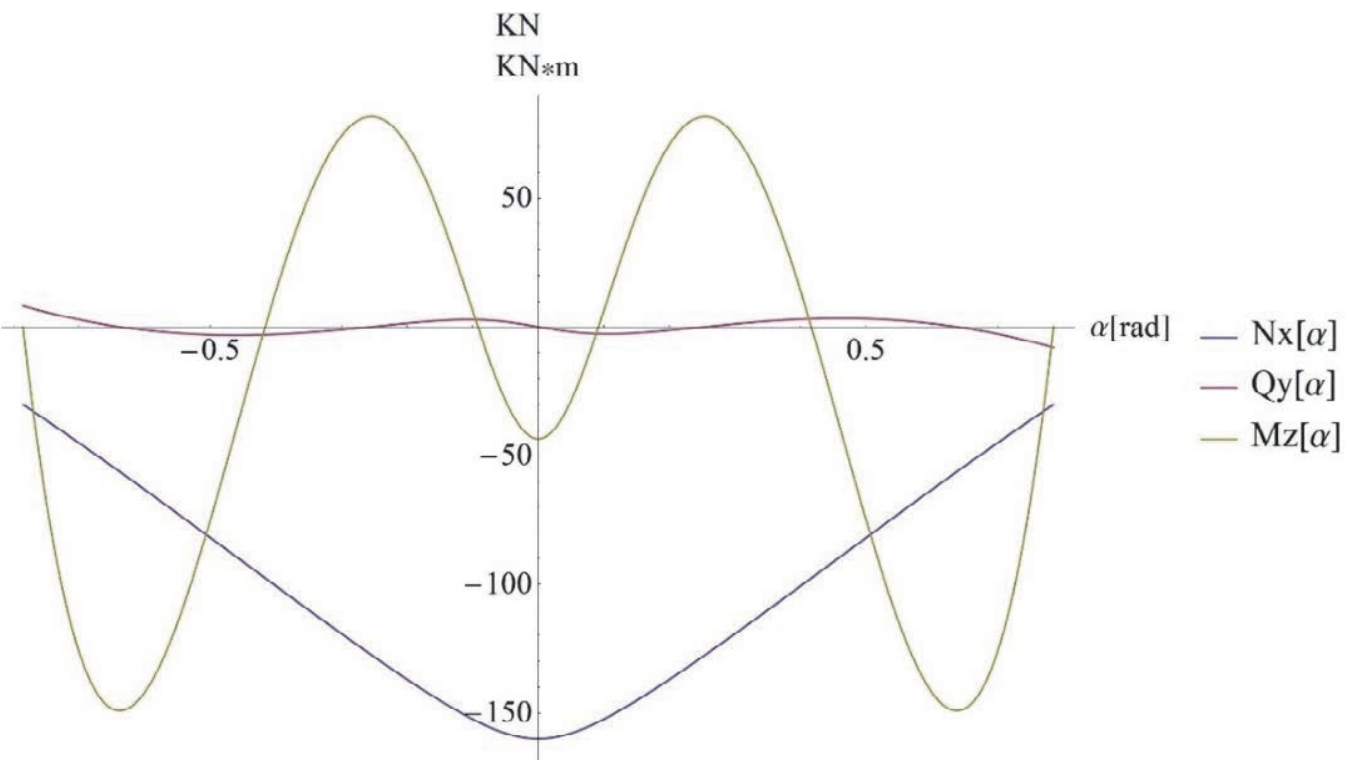

Diagrama 2.81. Solicitaciones sobre el tablero hiperestático bajo una carga concéntrica $T \operatorname{tir}[\alpha]$, configuración de tirantes en arpa. $\alpha t=\frac{\pi}{2}, R t=280 \mathrm{~m}$, Tablero 7 (Peatonal). $\varphi_{K N \times M z}=575,61$.

En los diagramas de solicitaciones se hace patente la diferencia existente entre el diagrama axil y la componente transversal de la carga concéntrica $p y[\alpha]$. Esto crea una similitud entre los diagramas de los diferentes tipos de secciones de tablero, aumentando el grado de independencia de las solicitaciones y el coeficiente de rigidez $\varphi_{K N X M z}$. Se puede 
apreciar cómo las solicitaciones transversales son significativamente menores que en la configuración tipo abanico.

La mejora en el comportamiento del tablero mediante la significativa reducción de las solicitaciones transversales se va diluyendo a medida que se acerca la pila al tablero $(R p \approx$ $R t$ ). Cuando se sitúa la pila sobre el tablero, las solicitaciones se vuelven sensiblemente mayores que para la configuración tipo abanico. Esto se debe a que en la zona central difieren mucho el diagrama de $p y[\alpha]$ y el diagrama de axiles $\mathrm{Nx}$. A medida que se aleja la pila del tablero, superando su radio $(R p>R t)$, la configuración en arpa de los tirantes se vuelve perjudicial para las solicitaciones transversales, produciendo un incremento significativo sobre ellas y, con ello, incrementando la participación del sistema resistivo "tipo viga". Resulta intuitivo que, a medida que el diagrama de axiles $(\mathrm{Nx})$ se invierte, porque la pila se sitúa con mayor radio que el tablero $(R p>R t)$, se debe hacer lo mismo con la configuración de los tirantes, invirtiendo el arpa (tirantes centrales más en la cabeza de la pila y extremos en la base), pero esta configuración se vuelve desastrosa de cara al comportamiento del subsistema Pila-Tirantes.

\subsection{1 Conclusiones}

Como conclusión, se puede decir que la configuración de tirantes tipo arpa queda entre la configuración tipo abanico y la configuración que minimiza las solicitaciones transversales del tablero cuando la pila se sitúa con radio inferior al del tablero $(R p<R t)$. Con la configuración tipo abanico, tiene en común:

- Cierta independencia entre las solicitaciones y las características mecánicas del tablero.

- El trabajo del sistema resistivo "tipo esfera" para el correcto comportamiento del tablero frente a la carga concéntrica.

- Cargas concéntricas significativamente menores a las del sistema con la pila en el centro del arco.

Mientras que con la configuración que minimiza las solicitaciones transversales del tablero, tiene en común:

- La amplia longitud de la pila donde se anclan los tirantes.

- La disminución de las solicitaciones transversales del tablero, debido a la mayor similitud entre el diagrama axil $(\mathrm{Nx})$ y el diagrama de la componente transversal de la carga concéntrica $p y[\alpha]$.

El comportamiento que muestra, ante cargas distribuidas, la configuración de tirantes en arpa en puentes con la pila fuera del eje de simetría, siempre y cuando (como ocurre con los sistemas con $\alpha p=0$ ) el radio de la pila sea inferior al radio del tablero $(R p<R t)$, resulta muy similar al visto para los casos en los que $\alpha p=0$. De nuevo se produce una mezcla entre el comportamiento del sistema con configuración de tirantes en abanico, con solicitaciones transversales, y la configuración óptima para las solicitaciones transversales, con una clara disminución de las solicitaciones transversales. En estos sistemas $(\alpha p \neq 0)$, como se comentó en las conclusiones del subapartado 2.2.6.2.3.2, el hiperestatismo del sistema produce 
mayores solicitaciones transversales, lo que se traduce en un mayor parecido al sistema con configuración en abanico. Como ejemplo, se muestra el comportamiento de un tablero similar al visto en el subapartado 2.2.6.2.2.1 (Diagrama 2.63), pero modificando su configuración de tirantes de abanico a arpa.

En este caso ( $\alpha p=\alpha t / 2)$, se van a anclar en la cabeza de la pila los tirantes del estribo más lejano a la pila, mientras que serán los del estribo más cercano los que se anclen en la base. Luego se va a igualar $\operatorname{Ttir}[\alpha]=\operatorname{Ttir}\left[-\frac{\alpha t}{2}\right]=1,22$ (de nuevo este valor inicial de la función Ttir $[\alpha]$ se ha relacionado con el radio del tablero Rt, como en el Diagrama 2.72).

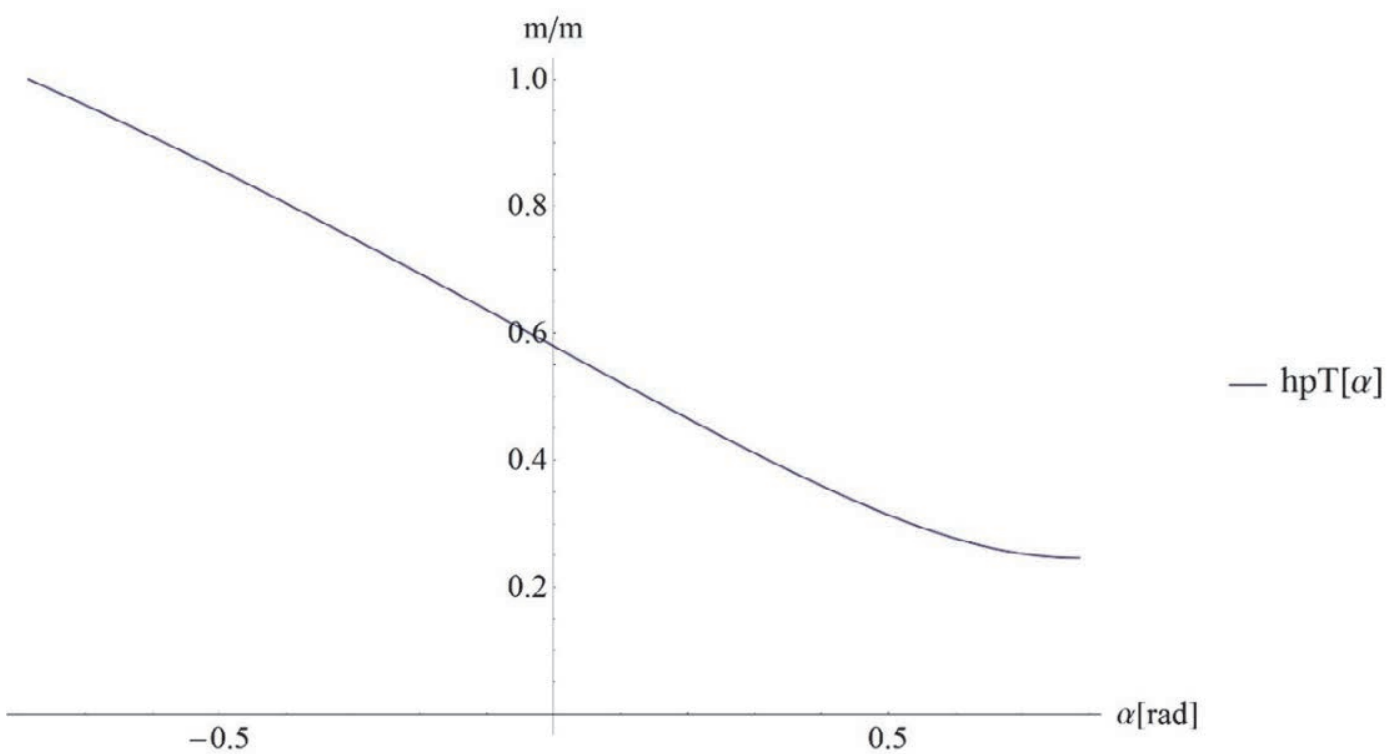

Diagrama 2.82. Función de $h p T[\alpha]$, configuración de tirantes en arpa. $R t=280 m, R p=252.09 m, \alpha t=\frac{\pi}{2}$ y $\alpha p=$ $\alpha t / 2$.

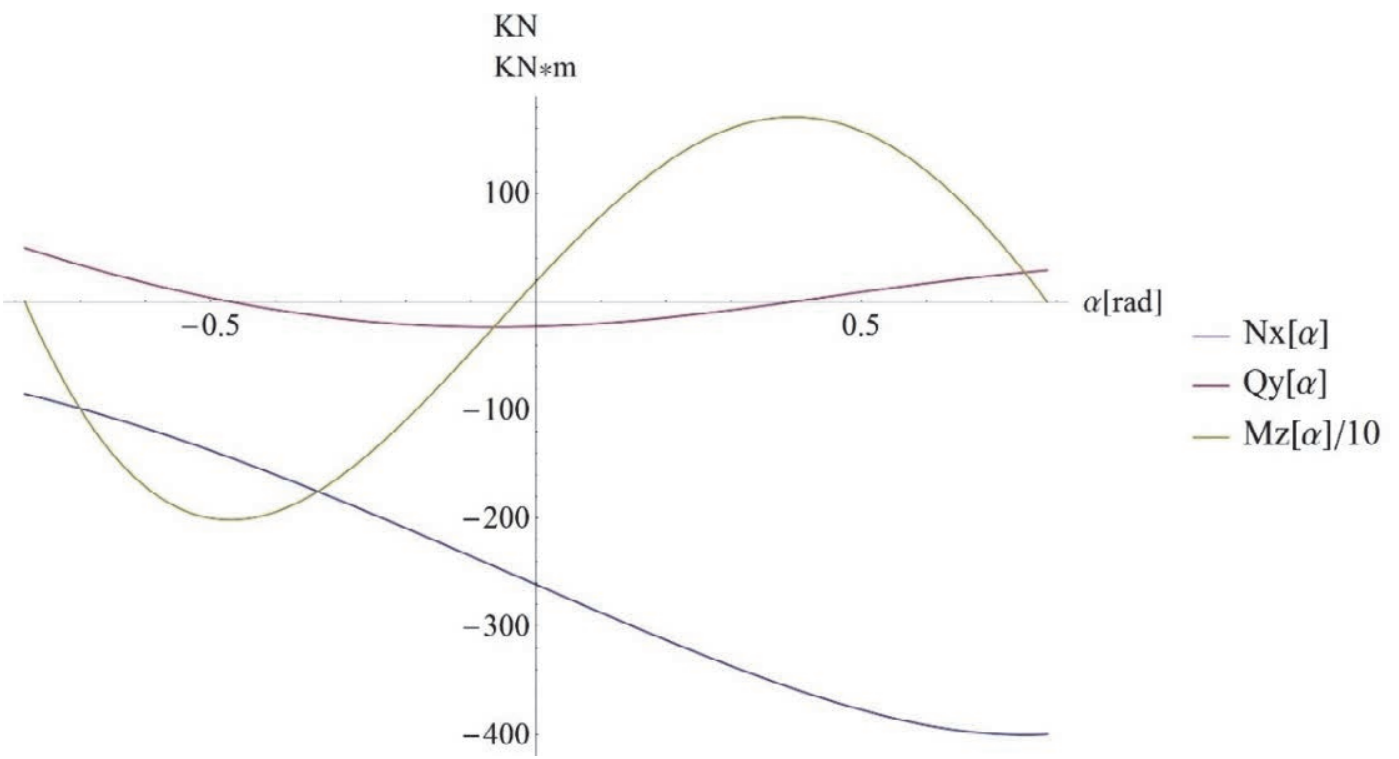

Diagrama 2.83. Solicitaciones sobre el tablero hiperestático bajo una carga concéntrica Ttir $[\alpha]$.

Tablero 7 (Peatonal). $\varphi_{K N x M z}=575,61 . R t=280 m, R p=0.7 R t, \alpha t=\frac{\pi}{2} y \alpha p=\alpha t / 2$. 


\subsection{Configuración en semiarpa}

Una vez presentados los comportamientos del tablero ante cargas concéntricas de configuraciones de tirantes en abanico y en arpa, se han establecido los comportamientos entre los que se va a mover la configuración semiarpa en la medida en la que los tirantes se dispongan más o menos próximos, acercándose a una configuración u otra.

Continuando con el ejemplo en que se disponía la pila en el centro de gravedad del tablero, se van a analizar dos tipologías de sección con dos configuraciones de tirantes: acumulándolos en la cabeza (en el $20 \%$ de la altura de la pila sobre el tablero), asimilándolos a una configuración en abanico, y distribuyéndolos de una forma más homogénea (en el $60 \%$ de la altura de la pila sobre el tablero).

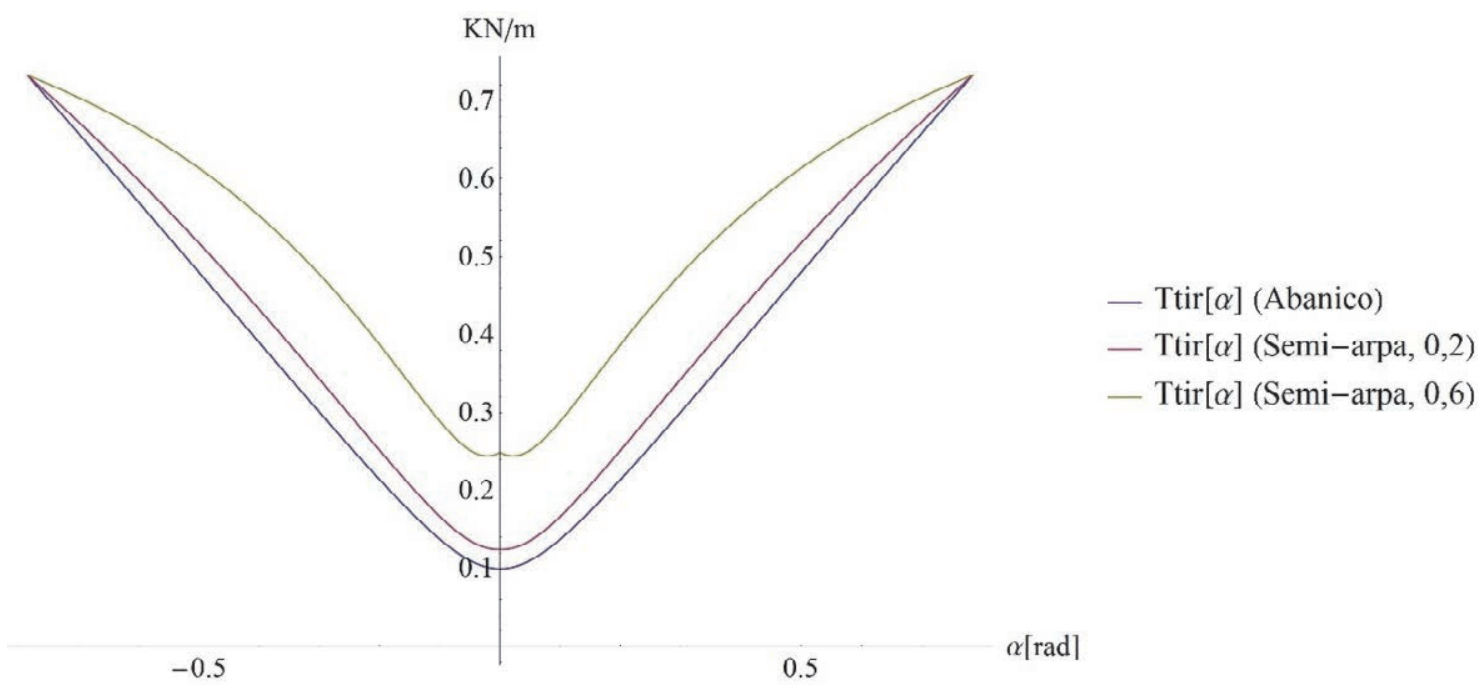

Diagrama 2.84. Valor de la carga $\operatorname{Ttir}[\alpha]$, comparativa diferentes configuraciones de tirantes a pila. $R t=$ $280 m, R p=252.09 m, \alpha t=\frac{\pi}{2}$ y $\alpha p=0$.

Como ya se adelantó en la introducción, en el Diagrama 2.84 se aprecia cómo el módulo de la carga concéntrica $(T \operatorname{tir}[\alpha]$ ) apenas varía entre la configuración de tirantes en abanico y en semiarpa, cuando este último se realiza concentrando los tirantes en la cabeza de la pila. A medida que los tirantes se distribuyen a lo largo de un mayor tramo de pila, el módulo de la carga concéntrica (Ttir $[\alpha]$ ) se va volviendo más homogéneo. Pero aun así, las diferencias entre los módulos para los diferentes sistemas siguen siendo bajas y su influencia sobre las solicitaciones del tablero aún menores (Diagrama $2.85 \rightarrow$ Diagrama 2.88).

Esta similitud de comportamientos se debe fundamentalmente a que la distancia entre la pila y el tablero $\left(\sqrt{\left((\operatorname{xpt}[\alpha]-\operatorname{xpp}[\alpha])^{2}+(\operatorname{ypt}[\alpha]-\operatorname{ypp}[\alpha])^{2}\right)}\right)$, varía mucho más bruscamente que la función $h p T[\alpha]$ a lo largo del tablero, para valores de Rp cercanos al del tablero (en nuestro caso $R p=252.09 \mathrm{~m}$ ). Luego es este valor el que domina el ángulo de los tirantes frente al de la altura $h p T[\alpha]$. En el caso de que la pila se encuentre más alejada del tablero, la influencia sobre la inclinación de los tirantes de sujeción de la altura de conexión de los tirantes con la pila será mayor, aunque si los tirantes se agrupan en la cabeza de la pila, la influencia siempre va a ser muy pequeña. 
Cuando se analizan los diagramas de solicitaciones (Diagrama $2.85 \rightarrow$ Diagrama 2.88), se concluye que la configuración de tirantes en semiarpa reduce las solicitaciones respecto de la configuración en abanico, siempre y cuando $R p<R t$. El incremento del axil ( $\mathrm{Nx}$ ) muestra como esa reducción se basa en una mayor implicación del sistema resistivo "tipo arco".

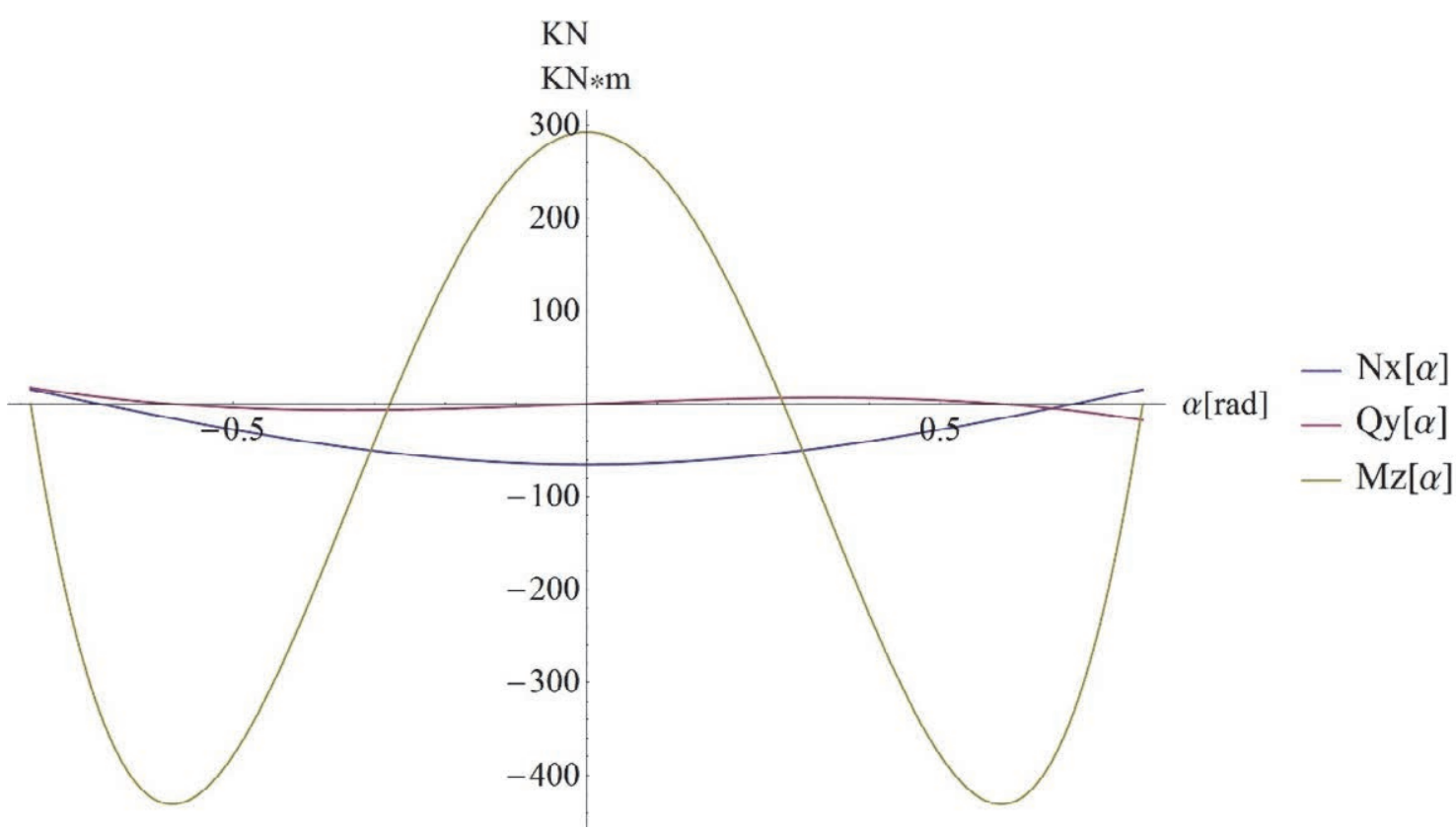

Diagrama 2.85. Solicitaciones sobre el tablero hiperestático bajo una carga concéntrica Ttir $[\alpha]$, configuración en semiarpa: 0,2. $\alpha t=\frac{\pi}{2}, R t=280 \mathrm{~m}$, Tablero 1 (Carretera). $\varphi_{K N x M z}=42,88$.

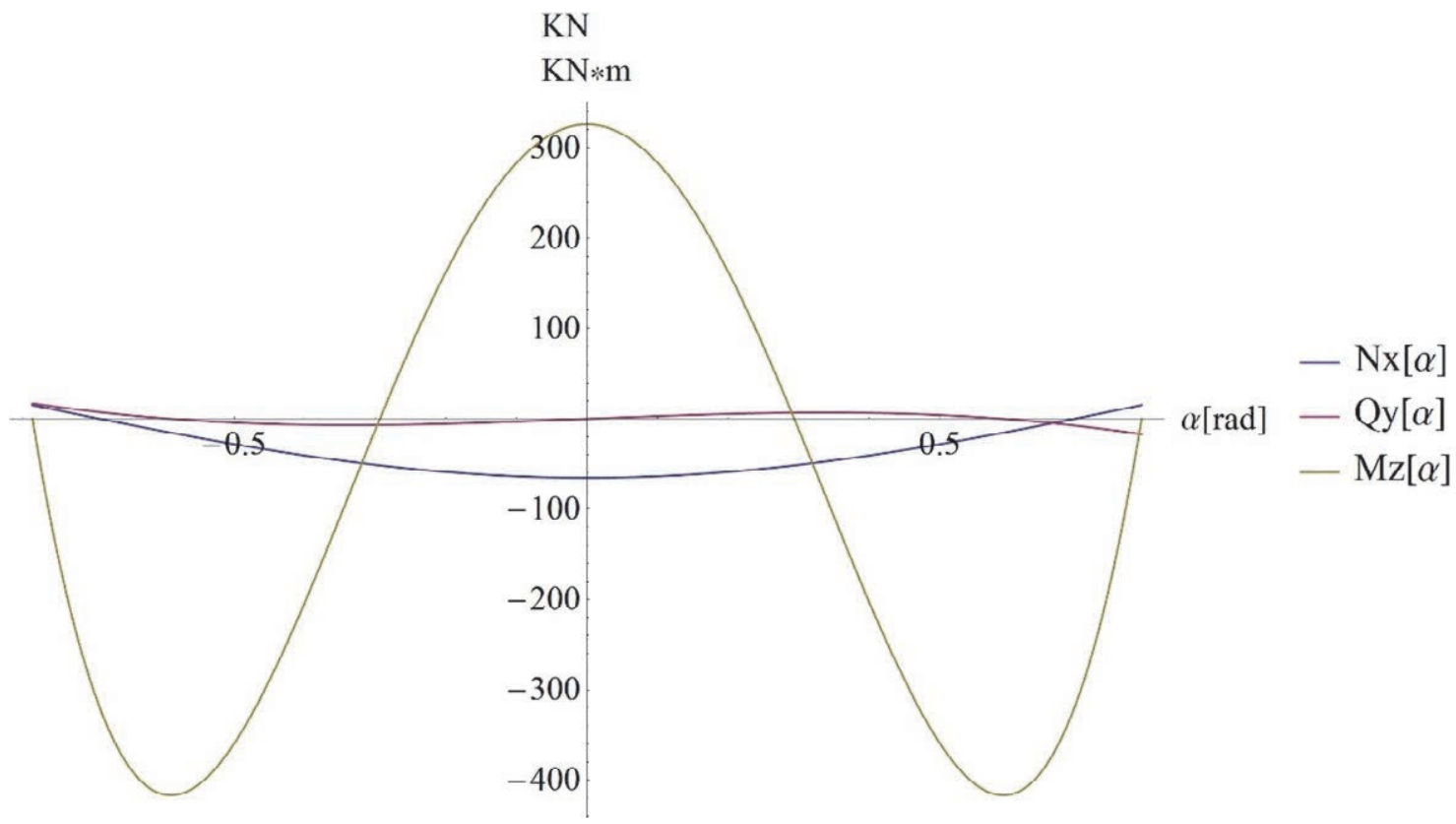

Diagrama 2.86. Solicitaciones sobre el tablero hiperestático bajo una carga concéntrica $T t i r[\alpha]$, configuración en semiarpa: 0,2. $\alpha t=\frac{\pi}{2}, R t=280 \mathrm{~m}$, Tablero 7 (Peatonal). $\varphi_{K N x M z}=575,61$. 


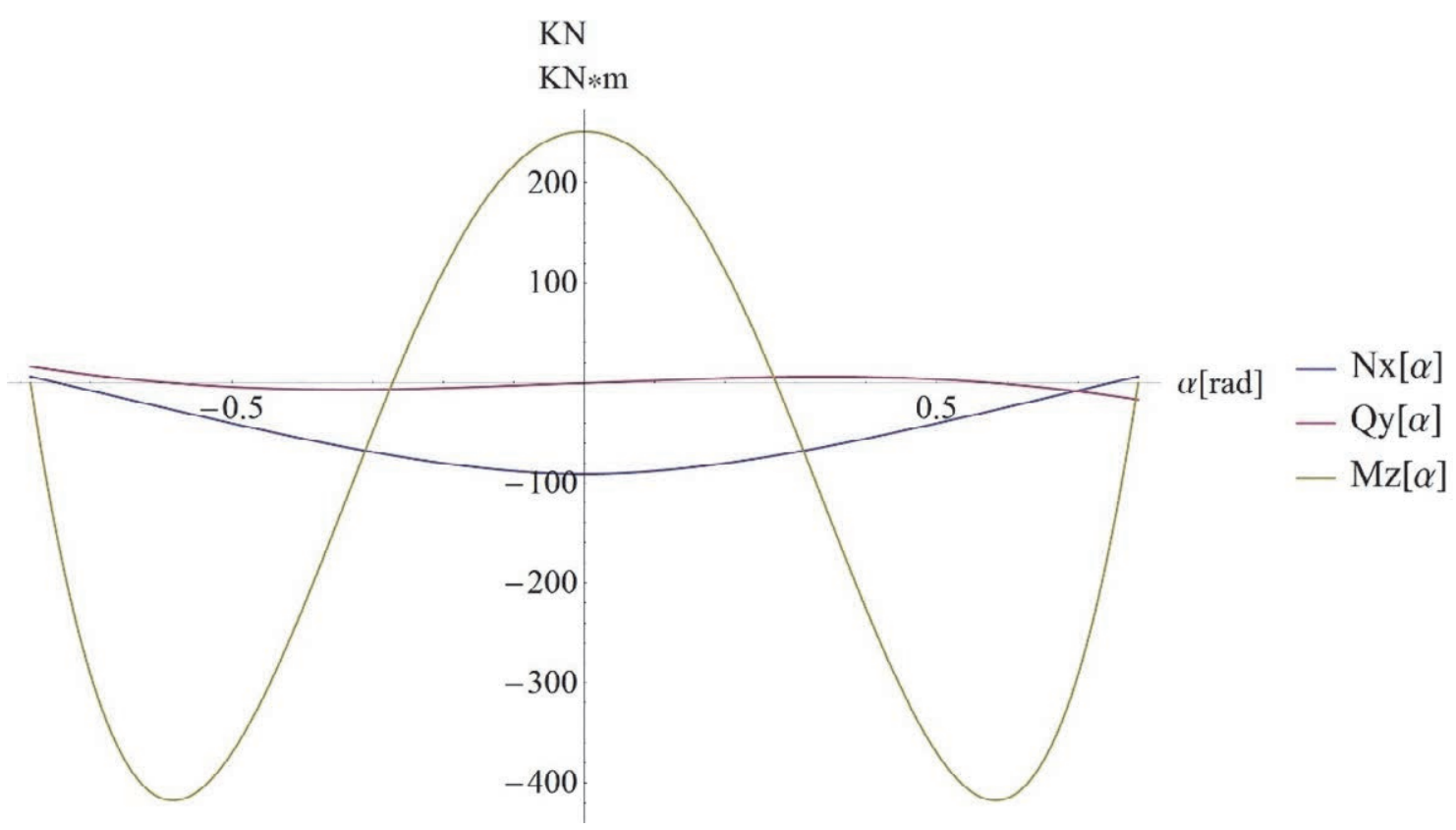

Diagrama 2.87. Solicitaciones sobre el tablero hiperestático bajo una carga concéntrica Ttir $[\alpha]$, configuración en semiarpa: 0,6. $\alpha t=\frac{\pi}{2}, R t=280 \mathrm{~m}$, Tablero 1 (Carretera). $\varphi_{K N x M z}=42,88$.

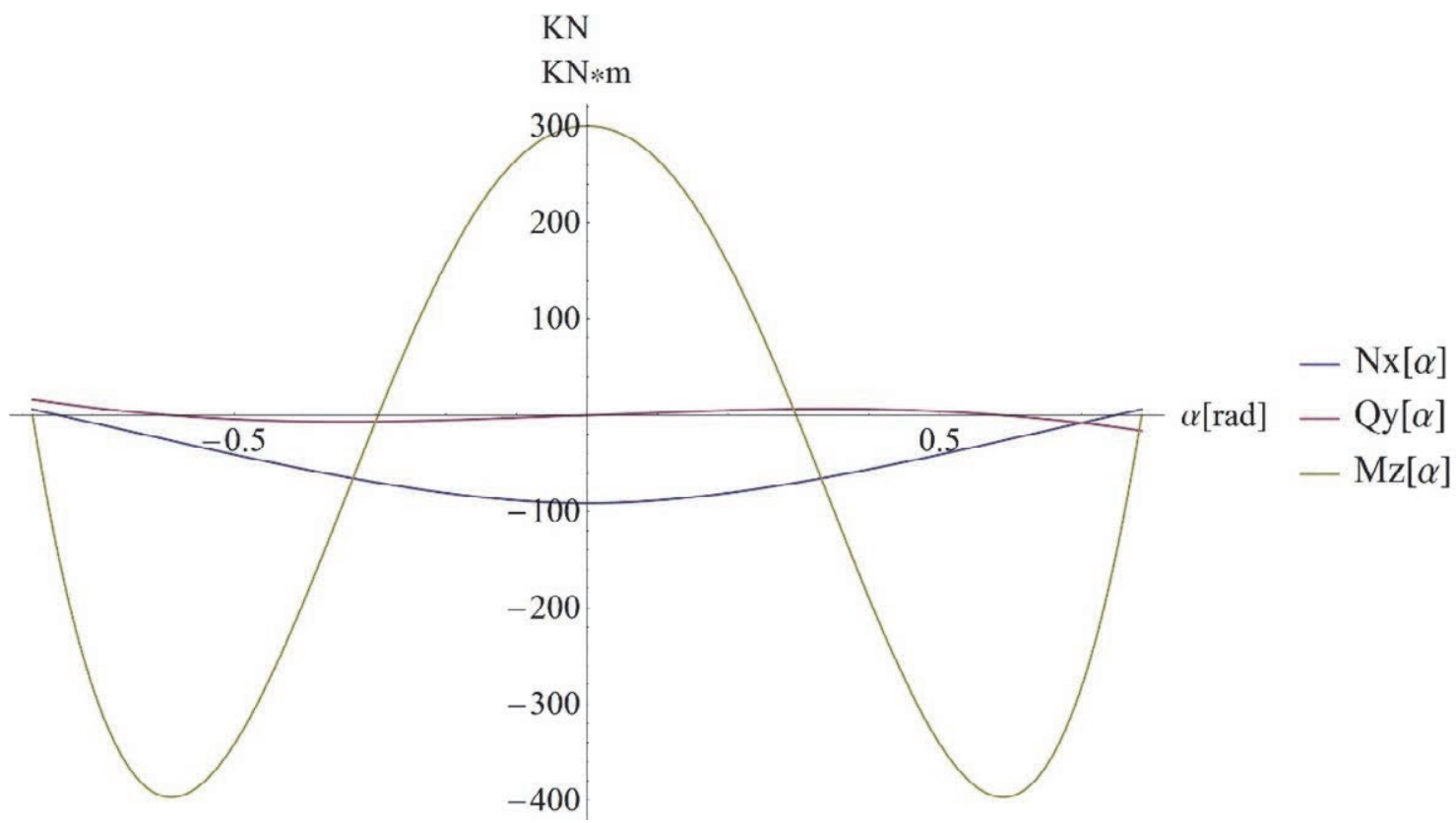

Diagrama 2.88. Solicitaciones sobre el tablero hiperestático bajo una carga concéntrica $T t i r[\alpha]$, configuración en semiarpa: 0,6. $\alpha t=\frac{\pi}{2}, R t=280 \mathrm{~m}$, Tablero 7 (Peatonal). $\varphi_{K N x M z}=575,61$. 


\subsection{Viga curva sobre apoyos puntuales, con carga perpendicular a su plano}

\subsubsection{Introducción y resumen}

Los puentes atirantados se comportan frente a las cargas perpendiculares a su plano de dos formas diferentes:

1. Como puente curvo sobre apoyos rígidos inclinados. Este es el comportamiento cuando se ponen en carga activamente los tirantes, tensándolos a medida que se introduce la carga, impidiendo el desplazamiento vertical del tablero. Normalmente, solo la carga de peso propio se contrarresta activamente con los tirantes (35) y (27).

2. Como puente curvo sobre apoyos elásticos. Este comportamiento puede llegar a ser muy complejo, según cómo se diseñe el sistema resistivo Pila-Tirantes. Este será el comportamiento del puente una vez se complete la estructura. Todas las cargas, salvo el peso propio, se resistirán mediante este sistema (35), (80), (29) y (73).

Las cargas horizontales introducidas por los tirantes, que se van a traducir en solicitaciones axil (Nx), cortante (Qy) y momento transversal (Mz), ya han sido analizadas en el apartado 2.2 .

En este punto se van a clasificar las solicitaciones en dos niveles según sus órdenes de magnitud en la sección del tablero. Por un lado, va a existir un nivel "local", cuyo orden de influencia va a corresponder con el de un vano entre dos tirantes y otro nivel "global", para aquellas solicitaciones de orden mayor.

Para los dos órdenes de magnitud descritos, es muy importante la disposición de los tirantes sobre el tablero:

- Si se disponen tirantes alineados sin capacidad de contrarrestar acciones torsoras (disposición habitual en este tipo de puentes, cuando son peatonales (40), (38) y (59)), en caso de que la carga produzca torsiones, estas se repartirán entre el empotramiento a torsión en el estribo, "eTxD" (en caso de que exista), y el empotramiento elástico, "ee", que se obtiene de la curvatura del tablero y los tirantes. Este último empotramiento provoca una importante transferencia de momento torsor $(\mathrm{Tx})$ a momento flector $(\mathrm{My})$ que puede resultar determinante para el dimensionamiento del tablero. Se puede diseñar una disposición de tirantes que permita contrarrestar la torsión del tablero (esta configuración está resultando muy habitual en puentes curvos atirantados de carretera: (104), (60), (15) y (18)), por ejemplo, mediante pares de tirantes en cada apoyo o desalineándolos. Esto introduciría un nuevo mecanismo de empotramiento para la solicitación torsora.

- La distancia entre tirantes va a ser determinante de cara a las solicitaciones, sobre todo a nivel "local".

Este apartado se va a centrar en el estudio y comprensión de estos mecanismos de empotramiento ("ee" y "eTxD") y en cómo se complementan a la hora de soportar las solicitaciones torsoras de las diferentes hipótesis de carga. También se analiza el posible 
empotramiento, tanto del momento torsor, eTx, como del flector, eMy, en los puntos de apoyo de los tirantes de sujeción. Esto se hace por dos motivos: para tener una referencia de la efectividad de los empotramientos "ee" y "eTxD" y para disponer de datos sobre la posibilidad de introducir un sistema de doble atirantamiento a los bordes del tablero.

Se plantean 3 escenarios de carga: carga distribuida centrada (subapartado 2.3.2), momento torsor distribuido a lo largo del tablero (subapartado 2.3.3), y la suma de las dos anteriores, como carga distribuida descentrada (subapartado 2.3.4).

Para cada hipótesis de carga y cada mecanismo de empotramiento, se modifican las condiciones geométricas y las propiedades mecánicas de la sección del tablero. Para cada una de las hipótesis de carga se analizan los diferentes tipos de empotramiento desde un punto de vista energético. El objetivo de este tipo de análisis es mostrar la efectividad de este tipo de mecanismos bajo diferentes condiciones de contorno.

Se concluye comparando estos mecanismos para remarcar la necesidad de su uso según las condiciones de contorno y la hipótesis de carga.

De la disposición alineada de los tirantes se puede desprender que va a existir una situación similar a la de la viga curva cargada perpendicularmente a su plano (apartado 2.1), donde se pudo ver cómo la relación entre las rigideces frente a la flexión y frente a la torsión $\left(\varphi_{K M y T}\right)$ resulta determinante en el comportamiento y en las solicitaciones de la viga.

En la siguiente ilustración se pueden identificar todas las variables que se van a utilizar en el análisis:

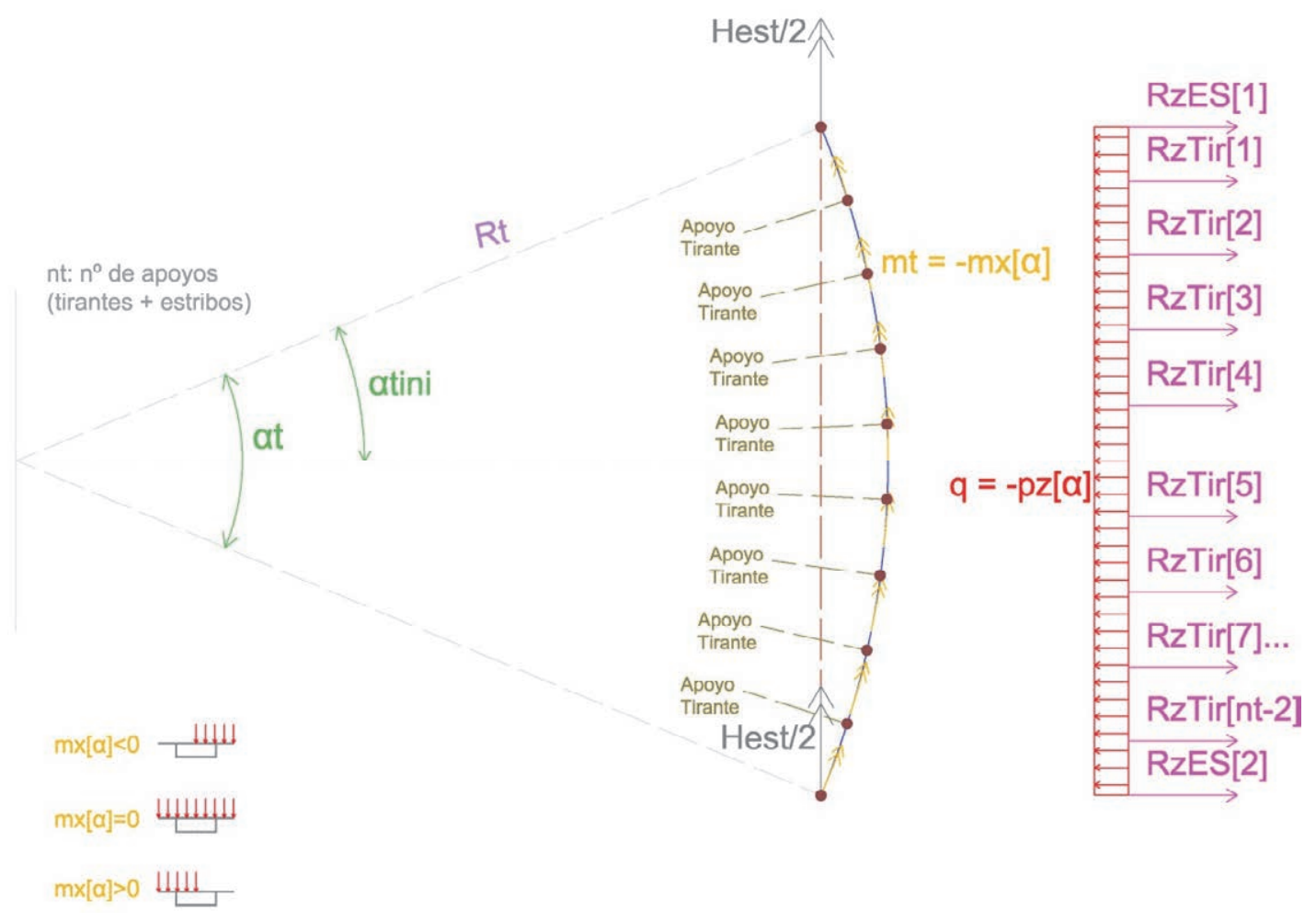

Ilustración 2.13. Modelo de cálculo para un tablero curvo sobre apoyos puntuales, con carga distribuida perpendicular a su plano. 


\subsubsection{Viga curva sobre apoyos puntuales inclinados, sometida a una carga distribuida perpendicular a su plano, sobre su centro de cortantes}

En este subapartado se van a estudiar aquellos tableros curvos sometidos a una carga exterior perpendicular a su plano sobre el centro de cortantes del tablero (se va a hacer coincidente con el de gravedad), sobre apoyos inclinados que impiden el desplazamiento vertical del tablero. Si bien no se van a analizar las solicitaciones en el plano del tablero que se introducen debido a la inclinación de estos apoyos (el comportamiento del tablero ante estas cargas se ha analizado en el apartado 2.2), sí que es conveniente puntualizar que los apoyos son inclinados y aunque no permitan los desplazamientos verticales, debido a la puesta en carga de los tirantes, se producen desplazamientos horizontales y, con ello, solicitaciones en el plano del tablero.

Como ya se ha comentado, en el comportamiento del tablero (y a partir de ahí, en las solicitaciones a nivel de sección) es determinante la relación entre rigideces al giro $\varphi_{K M y T}=$ $\frac{E I y y}{G J}$, que se analizó en el apartado 2.2. Pero en este caso, como se va a apreciar en los diferentes diagramas de solicitaciones y trabajos, cuando la carga queda centrada en el tablero, tanto el diagrama de momentos flectores (My) como el de torsores ( $\mathrm{T} x$ ) queda en un nivel "local" y la relación entre rigideces apenas va a cambiar el comportamiento resistente. Esto se debe a la hiperestaticidad creada por los apoyos puntuales y a la eficiencia de este tipo de empotramiento elástico (para una carga centrada). Solo en el caso de que la carga aplicada sobre el tablero esté descentrada, introduciendo torsiones, las solicitaciones de flexión (My) y torsión (Tx) pasan a un nivel "global", donde la influencia del factor $\varphi_{K M y T}$ se empieza a mostrar determinante.

Si se analiza en primer lugar el comportamiento de un Tablero 1 (Carretera) apoyado y empotrado a torsión en los estribos, con carga centrada q a lo largo de todo el tablero, se obtiene las solicitaciones del Diagrama 2.89. 


\section{Solicitaciones sobre el tablero}

\section{Axil (escala:0.) Cortante $Y^{\prime}-Y^{\prime}$ (escala:0.) Cortante $Z^{\prime}-Z^{\prime}$ (escala:1) \\ MOMENTO TORSOR X'-X' (escala:1) MOMENTO FLECTOR $Y^{\prime}-Y^{\prime}$ (escala:-1)}

MOMENTO FLECTOR Z'-Z' (escala:0.)

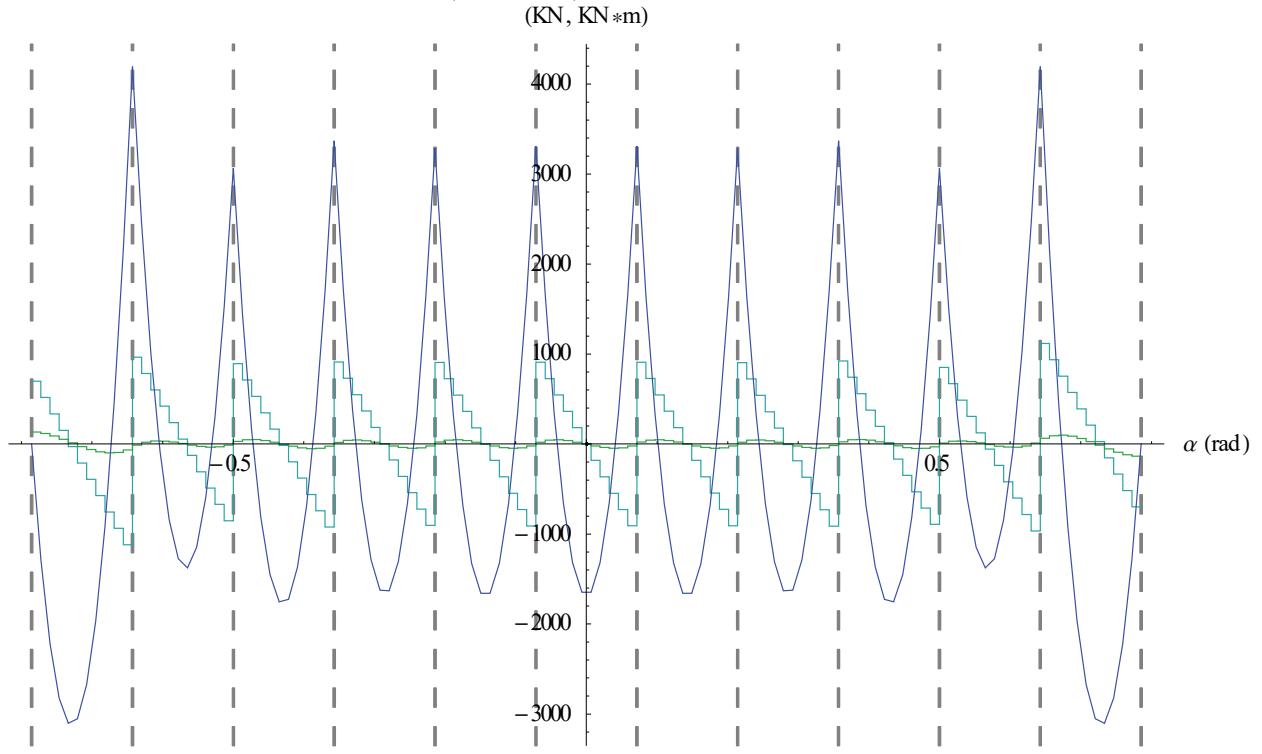

Diagrama 2.89. Diagrama de solicitaciones: $\boldsymbol{\alpha t}=\frac{\pi}{2} \mathrm{Rt}=140 \mathrm{~m}, \mathrm{Rp}=0 \mathrm{~m}, \mathrm{nt}=12, \mathrm{hp}=100 \mathrm{~m}, \mathrm{ht}=44 \mathrm{~m}$, Sección tipo: Tablero 1 (Carreta). pz= $-100 \mathrm{kN} / \mathrm{ml}$.

El comportamiento del tablero es muy parecido al de un tablero recto (Diagrama 2.89) recto solicitado por una carga vertical centrada. También se aprecia cómo las solicitaciones sobre el tablero están en un nivel "local", tanto el momento flector My como el torsor Mx. Este último apenas tiene relevancia con este tipo de cargas centradas.

\subsubsection{Sistemas resistivos}

Para entender mejor este fenómeno se va a analizar un vano entre apoyos, sometido a una carga centrada y con diferentes condiciones de soporte. Las condiciones de sustentación estudiadas van a producir siempre un sistema isostático (en realidad, es un sistema hiperestático, pero debido a su simetría, se supone que los dos grados de libertad coartados a partir de los apoyos del vano carga (definidos como "Avi"), equivalen a un solo grado de libertad coartado. En este vano se va a estudiar el trabajo desarrollado por la carga exterior para cada condición de contorno. Con esta información, y teniendo en cuenta el teorema de Menabrea, va a ser sencillo entender el sistema resistivo que va a utilizar el tablero para sostener la carga dispuesta sobre el tablero.

Los cálculos que se han desarrollado se basan en las ya nombradas ecuaciones diferenciales que dominan el comportamiento del tablero curvo fuera de su plano: 


$$
\begin{aligned}
& \operatorname{Tx}[s] \prime^{\prime}+\frac{\operatorname{Tx}[s]}{R t^{2}}=m x[s] '-\frac{Q z[s]}{R t} \\
& M y[s] \prime^{\prime}+\frac{M y[s]}{R t^{2}}==\frac{m x[s]}{R t}+Q z[s] ' \\
& Q z[s]^{\prime}==p z[s] \\
& \operatorname{Tx}[\alpha])^{\prime}+\operatorname{Tx}[\alpha]==\operatorname{Rt} \operatorname{mx}[\alpha]{ }^{\prime}-\operatorname{Rt} Q z[\alpha] \\
& \operatorname{My}[\alpha] \text { ' ' }+ \text { My }[\alpha]==\operatorname{Rt} \operatorname{mx}[\alpha]+\operatorname{Rt} Q z[\alpha] \text { ' } \\
& Q z[\alpha]^{\prime}==\operatorname{Rt} p z[\alpha]
\end{aligned}
$$

Con el siguiente momento desestabilizador en los apoyos del vano cargado, para el caso de carga distribuida y centrada en el tablero:

$$
\text { Hest }==q R t^{2} \alpha v i\left(\frac{2}{\alpha v i} \operatorname{Sin}[\alpha v i / 2]-\operatorname{Cos}[\alpha v i / 2]\right)
$$

Este momento desestabilizador es el que el sistema resistivo definido por las condiciones de contorno debe neutralizar. Según las diferentes condiciones de contorno propuestas en nuestro análisis, este momento desestabilizador se resiste de la siguiente manera (de nuevo el tablero con el que se va a realizar este estudio va a ser un Tablero 1 (Carretera)):

- eTx: empotramiento a torsión en los apoyos de los extremos del vano cargado (denominado Avi).

Este caso ya se ha estudiado en el apartado 2.1, pero se vuelve a introducir en este análisis, como posible restricción en los apoyos del vano cargado. Para resistir el momento desestabilizador, como ya vimos en el apartado 2.1, surge un momento de empotramiento a torsión (según la llustración 2.1):

Txemp -1 = = Txemp -2 == Txemp

$\operatorname{Txemp}==\frac{1}{2}$ Hest $/(\operatorname{Cos}[\alpha v i / 2])==\frac{1}{2} q \operatorname{Rt}^{2} \alpha v i\left(\frac{2}{\alpha v i} \operatorname{Sin}[\alpha v i / 2]-\operatorname{Cos}[\alpha v i / 2]\right) /(\operatorname{Cos}[\alpha v i / 2])$

- eMy: empotramiento a flexión en los apoyos de los extremos del vano cargado.

De nuevo, este caso ya se ha estudiado en apartado 2.1 , y en este momento solo se vuelve a introducir como punto de referencia para los empotramientos elásticos "ee". Para resistir el momento desestabilizador, como ya vimos en el apartado 2.1, surge un momento de empotramiento a torsión (según la llustración 2.1).

Myemp $-1==$ Myemp $-2==$ Myemp

Myemp $==\frac{1}{2} \operatorname{Hest} /(\operatorname{Sin}[\alpha v i / 2])==\frac{1}{2} q \operatorname{Rt}^{2} \alpha v i\left(\frac{2}{\alpha v i} \operatorname{Sin}[\alpha v i / 2]-\operatorname{Cos}[\alpha v i / 2]\right) /(\operatorname{Sin}[\alpha v i / 2])$ 
- ee: empotramiento elástico. Se le da continuidad al tablero en sus dos extremos, hasta 1 apoyo situado a $\frac{n-1}{2}$ vanos de Avi (quedando 4 apoyos en total, Ilustración 2.14). Estos vanos tienen las mismas propiedades geométricas que el vano cargado (Lvi, Rt, $\alpha v i)$.

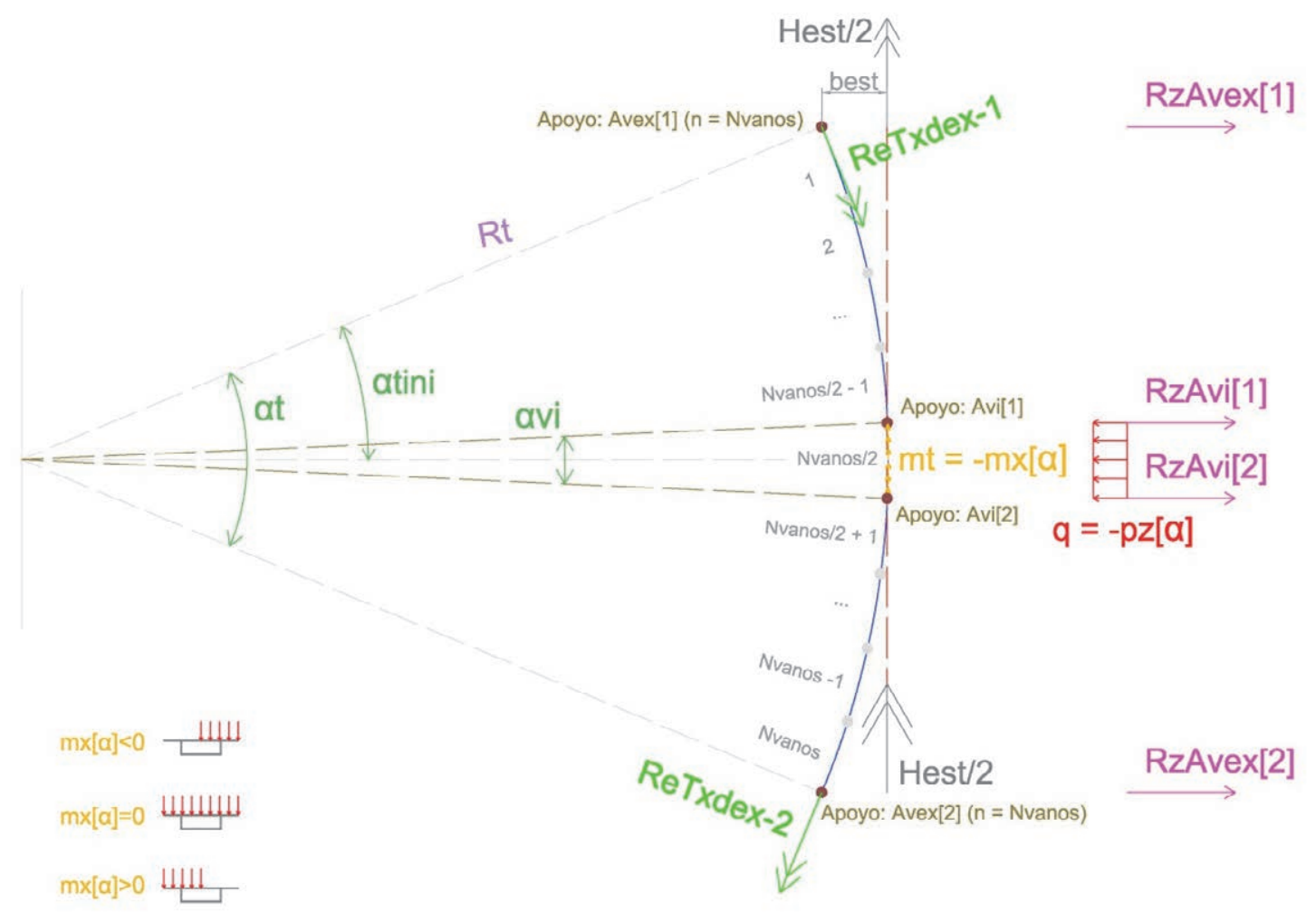

Ilustración 2.14. Modelo de cálculo simplificado para un tablero curvo sobre apoyos puntuales. Vano central cargado.

Este es un sistema resistivo inherente al puente multiapoyado. Para el modelo simplificado (Ilustración 2.14) de este empotramiento, se restringen los movimientos de los apoyos Avex y los Avi, permitiendo los giros. Este empotramiento funciona neutralizando el momento desestabilizador Hest, mediante un par estabilizador (Pest) entre los apoyos del vano cargado (Avi) y los que quedan a $\frac{n-1}{2}$ vanos de estos (Avex). El valor de la reacción estabilizadora RzAvex, según la llustración 2.14, va a ser:

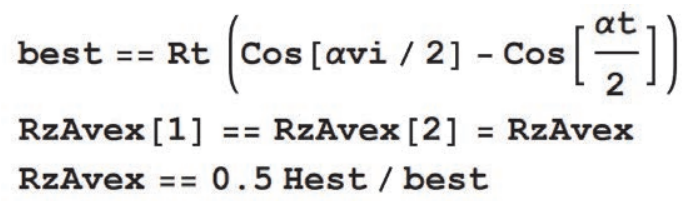

Se va a estudiar un ejemplo del comportamiento de este modelo simplificado, con las siguientes condiciones de contorno: 


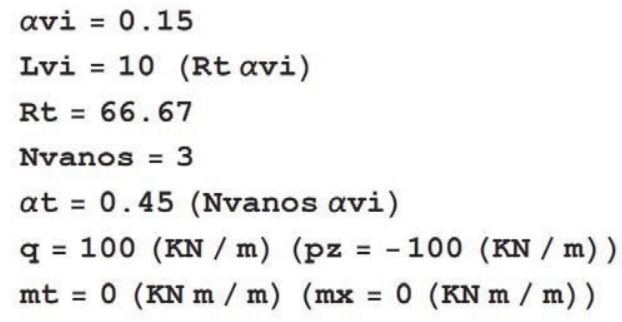

\section{Solicitaciones}

$(\alpha \mathrm{v}: 0.15$, Nvanos: 3, Rt: 66.6667)

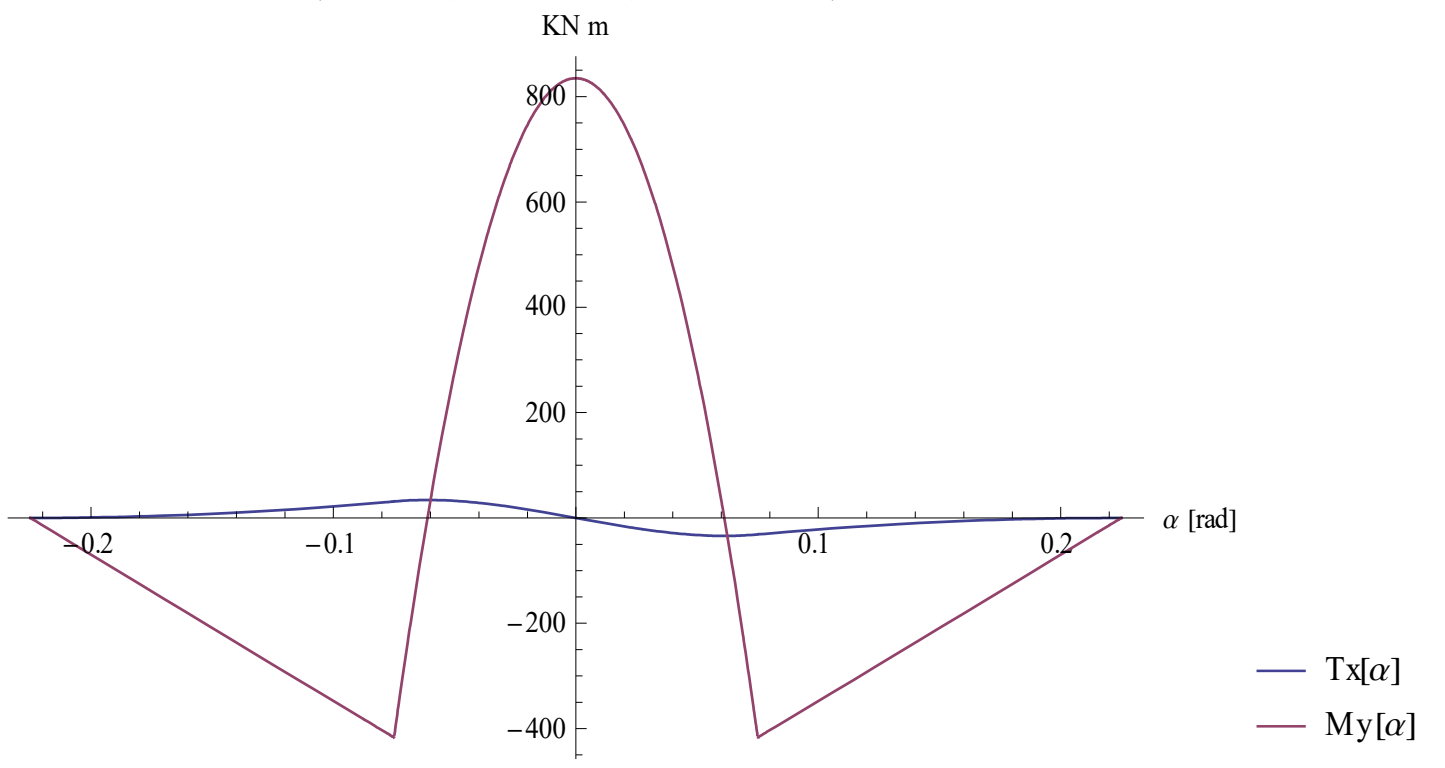

Diagrama 2.90. Diagrama de solicitaciones modelo simplificado. Sistema de empotramiento "ee". $\alpha v i=0.15$ Rt= $66.67 \mathrm{~m}, \alpha t=0.45$, Nvanos = 3, Lvi= $10 \mathrm{~m}$, Sección tipo: Tablero 1 (Carreta). Carga centrada distribuida en 1 vano $q=100 \mathrm{kN} / \mathrm{m}(\mathrm{pz}=-100 \mathrm{kN} / \mathrm{m})$.

Si se compara con un modelo completo (Diagrama 2.91 y Diagrama 2.93) de 11 vanos, se puede apreciar la gran similitud en el comportamiento. Esta es la razón de que la carga centrada se quede esencialmente en un nivel local. Es fácil proyectar los resultados obtenidos a una situación con varios vanos entre tirantes cargados, para entender que apenas afecta, en lo que a solicitaciones se refiere (en movimientos desplazamientos y giros, la influencia es mayor, aunque queda lejos de ser remarcable), lo que se realice en un vano con lo que se realice con los demás, menos al siguiente y al anterior al cargado, donde la influencia sí resulta más Ilamativa. Su comportamiento ante esta carga resulta similar al de un tablero recto sobre apoyos puntuales. 


\section{Solicitaciones sobre el tablero}

Axil (escala:0.) Cortante $Y^{\prime}-Y^{\prime}$ (escala:0.) Cortante $Z^{\prime}-Z^{\prime}$ (escala:0.)

MOMENTO TORSOR X'-X' (escala:1) MOMENTO FLECTOR Y'-Y' (escala:1)

MOMENTO FLECTOR Z'-Z' (escala:0.)

$(\mathrm{KN}, \mathrm{KN} * \mathrm{~m})$

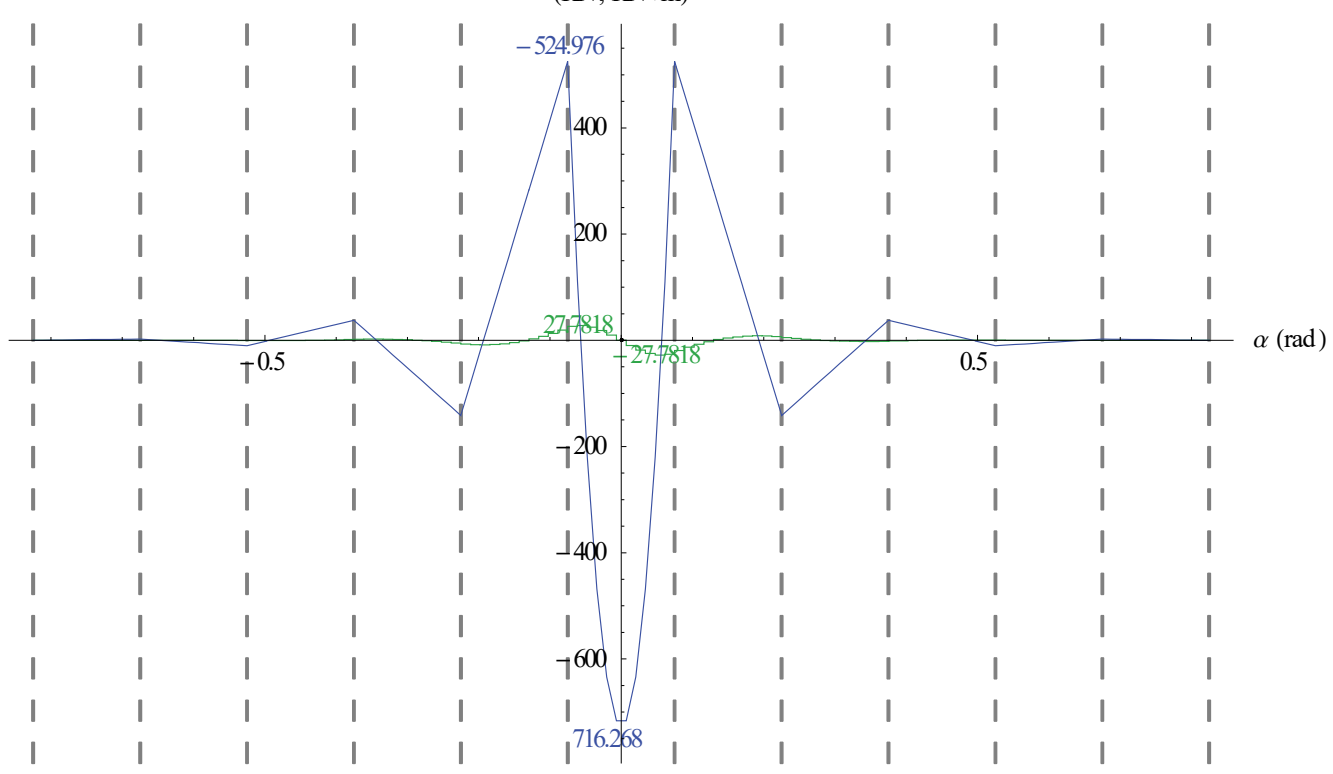

Diagrama 2.91. Diagrama de solicitaciones modelo completo. Rt $=66.67 \mathrm{~m}, \alpha t=0.45, \mathrm{nt}=12, \mathrm{Lvi}=10 \mathrm{~m}, \mathrm{Sección}$ tipo: Tablero 1 (Carretra). Carga centrada distribuida en 1 vano $q=100 \mathrm{kN} / \mathrm{m}$ (pz = -100 kN/m). Estribos sin empotramiento a torsión (simplemente apoyado).

\section{Desplazamientos y Giros}

Desplazamiento Z ( $\alpha \mathrm{v}$ : 0.15, Nvanos: 3, Rt: 66.6667)

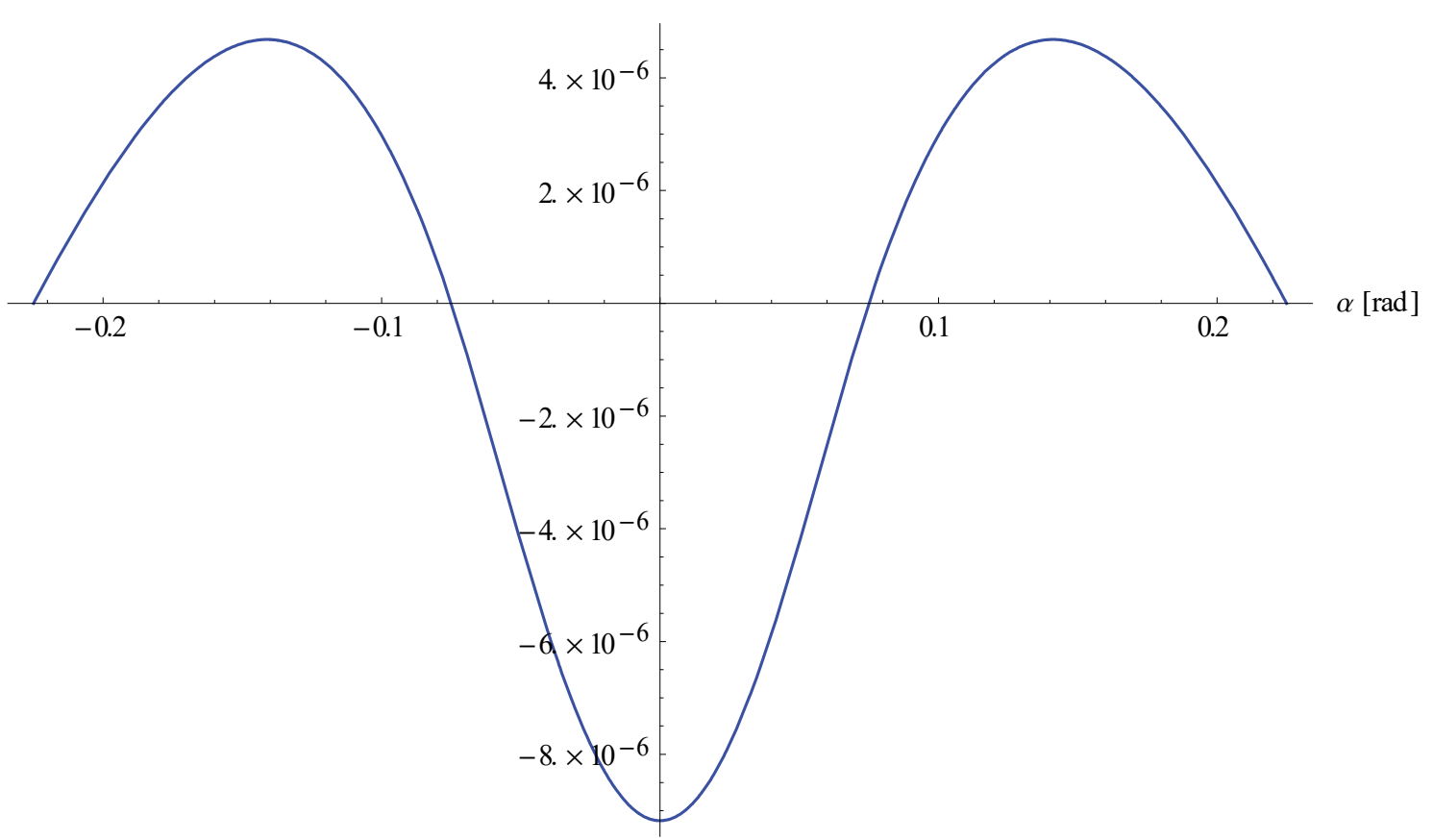

Diagrama 2.92. Diagrama de desplazamiento y giros, modelo simplificado. Sistema de empotramiento "ee". $\alpha v i=$ $0.15 \mathrm{Rt}=66.67 \mathrm{~m}, \alpha t=0.45, \mathrm{Nvanos}=3, \mathrm{Lvi}=10 \mathrm{~m}$, Sección tipo: Tablero 1 (Carretra). Carga centrada distribuida en 1 vano $q=100 \mathrm{kN} / \mathrm{m}(\mathrm{pz}=-100 \mathrm{kN} / \mathrm{m})$. 


\section{Desplazamientos y Giros}

\section{Desplazamiento TANGENCIAL (escala:0)}

Desplazamiento RADIAL (escala:0) Desplazamiento Z (escala:1)

Giro X'-X' (escala:0) Giro Y'-Y' (escala:0) Giro Z'-Z' (escala:0)

\begin{tabular}{|c|c|c|c|c|c|c|c|c|c|c|c|}
\hline & & & & & $\begin{array}{r}(\mathrm{m}, \\
4 \times 10^{-6}\end{array}$ & $\mathrm{rad}$ ) & & & & & \\
\hline I & I & I & I & I & 4. $\times 10^{-0}$ & 3.39803 & & I & I & I & I \\
\hline I & I & I & I & I & 1 & $1 /$ & I & I & I & I & I \\
\hline I & I & I & I & I & 2. $\times 10^{-6}$ & 1 & I & I & I & I & I \\
\hline I & I & I & I & I & I & I) & I & I & I & I & I \\
\hline I & I & I & I & $1 /$ & I & 1 & 1 & I & I & I & I \\
\hline H & 1 & & & $j$ & & 1 & 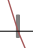 & & -1 & + & $\perp \alpha(\mathrm{rad})$ \\
\hline I & I & $T^{-}$ & | & 1 & & 1 & & & 0.5 & I & I \\
\hline I & I & I & I & I & I & I & I & I & I & I & I \\
\hline I & I & I & I & I & $-2 \times 10^{-6}$ & I & I & I & I & I & I \\
\hline I & I & I & I & I & I & I & I & I & I & I & I \\
\hline I & I & I & I & I & I & I & I & I & I & I & I \\
\hline I & I & I & I & I & $-4 . \times 10^{-6}$ & I & I & I & I & I & I \\
\hline I & I & I & I & I & I & I & I & I & I & I & I \\
\hline I & I & I & I & I & 1 & I & I & I & I & I & I \\
\hline I & I & I & I & I & $-6 . \times 10^{-6}$ & I & I & I & I & I & 1 \\
\hline I & I & I & I & I & I & I & I & I & I & I & I \\
\hline I & I & I & I & I & I & I & I & I & I & I & I \\
\hline I & I & I & I & I & $-8 . \times 10^{-0}$ & I-6 & I & I & I & I & I \\
\hline I & I & I & I & I & -8.33005 & $\times 10^{-6}$ & I & I & I & I & I \\
\hline
\end{tabular}

Diagrama 2.93. Diagrama de desplazamiento y giros modelo completo. $\mathrm{Rt}=66.67 \mathrm{~m}, \alpha t=0.45, \mathrm{nt}=12$, $\mathrm{Lvi}=10 \mathrm{~m}$, Sección tipo: Tablero 1 (Carretra). Carga centrada distribuida en 1 vano $q=100 \mathrm{kN} / \mathrm{m}$ (pz = -100 kN/m). Estribos sin empotramiento a torsión (simplemente apoyado).

El trabajo realizado por las cargas exteriores es igualmente similar.

Modelo simplificado:

Wext $_{\text {simp }}=\int_{-\alpha v i / 2}^{\alpha v i / 2} p[s] \delta z z[s] d s=0.0057 \mathrm{kN} \mathrm{m}$

Modelo completo:

$$
W e x t_{c o m p}=\int_{-\alpha v i / 2}^{\alpha v i / 2} p[s] \delta z z[s] d s=0.0052 \mathrm{kN} \mathrm{m}
$$

- eTxD: empotramiento de torsión a distancia. Se le da continuidad al tablero en sus dos extremos, hasta un empotramiento a torsión situado a $\frac{n-1}{2}$ vanos de Avi (donde se dispone un empotramiento a torsión, normalmente el estribo). Estos vanos tienen las mismas propiedades geométricas que el vano cargado (Lvi, Rt, $\alpha v i)$.

Este es un sistema resistivo opcional (un puente curvo multiapoyado puede funcionar sin la necesidad de introducir ningún empotramiento a torsión), siempre que sea posible, en un tablero multiapoyado. Para el modelo simplificado, se han coartado los giros según el eje de la directriz del tablero en Avex, pero se han liberado sus movimientos (Ilustración 2.14). Se ha separado este empotramiento del "ee" para poder ver por separado su capacidad de resistir 
los dos tipos de carga a los que se va a someter al tablero, carga vertical centrada y momento torsor. Al desplazar el empotramiento a torsor, se busca analizar las consecuencias de tener el empotramiento a torsión más o menos alejado de los apoyos del vano cargado, Avi [1] y Avi [2].

Con carga vertical centrada, el momento desestabilizador se resiste mediante un empotramiento a torsión ReTsdex en el apoyo Avex.

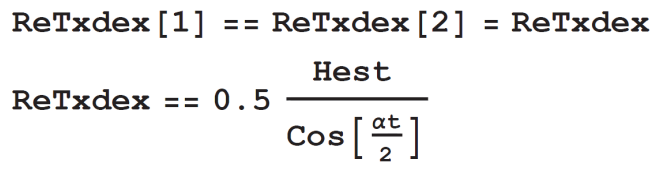

\subsubsection{Trabajo desarrollado por la carga exterior en cada sistema resistivo}

Si se analizan los trabajos realizados por la carga exterior, en el modelo simplificado, con una sección tipo Tablero 1 (Carretera), para cada uno de los sistemas propuestos, cambiando las características geométricas del problema, obtenemos:

Leyenda:

- $\operatorname{WeTx}(\mathrm{n}=1)$

-.- WeMy $(\mathrm{n}=1)$

_- Wee $(\mathrm{n}=3)$

- Wee $(\mathrm{n}=5)$

W Wee $(n=7)$

— Wee $(\mathrm{n}=9)$

... $\operatorname{WeTxD}(\mathrm{n}=3)$

-. $\operatorname{WeTxD}(\mathrm{n}=5)$

-.. WeTxD $(\mathrm{n}=7)$

... WeTxD $(n=9)$ 


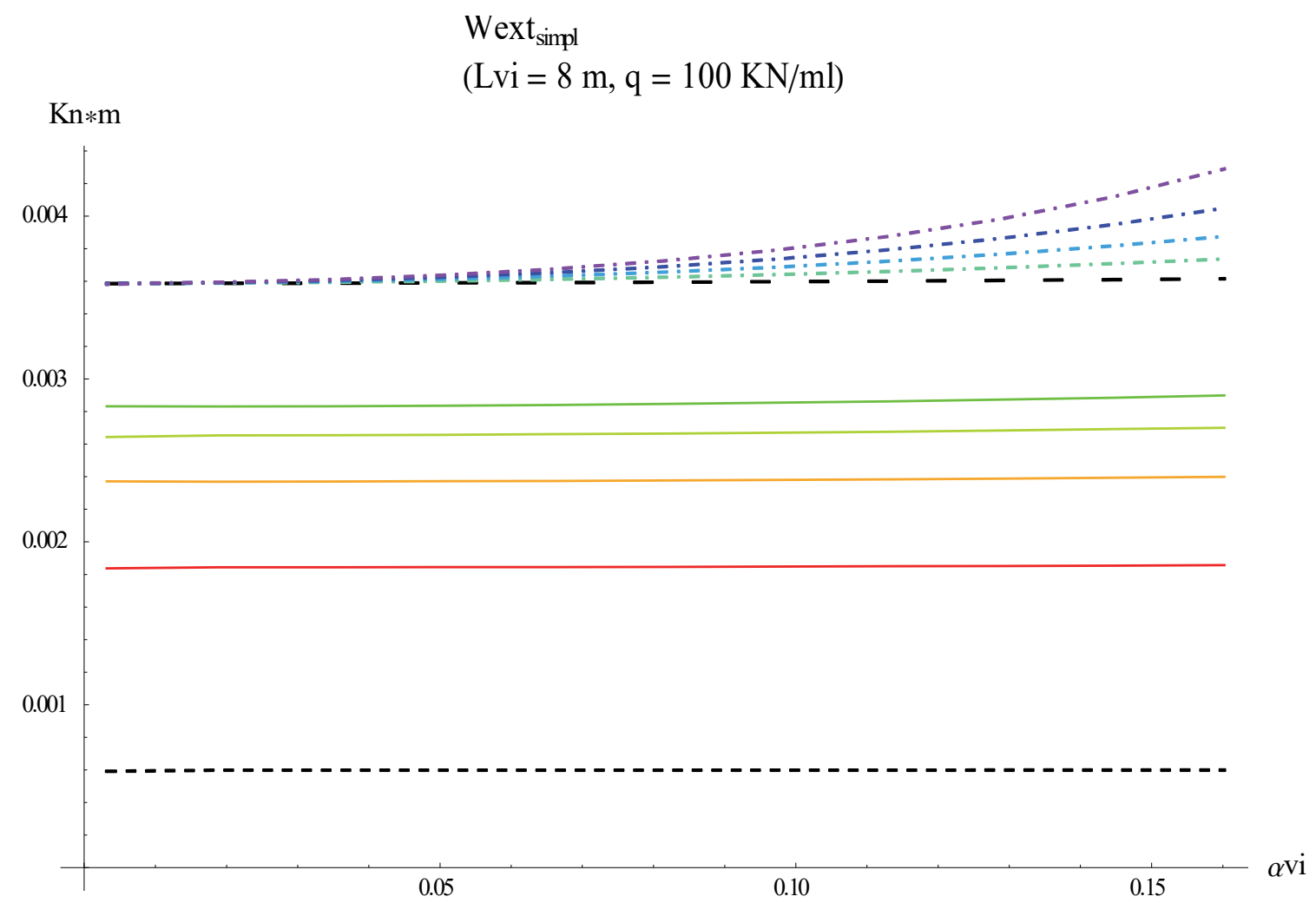

Diagrama 2.94. Trabajo realizado por la carga exterior. Modelo simplificado con diferente número de vanos $(n=$ $1,3,5,7,9) \cdot p z=-100, L v i=8 m$.

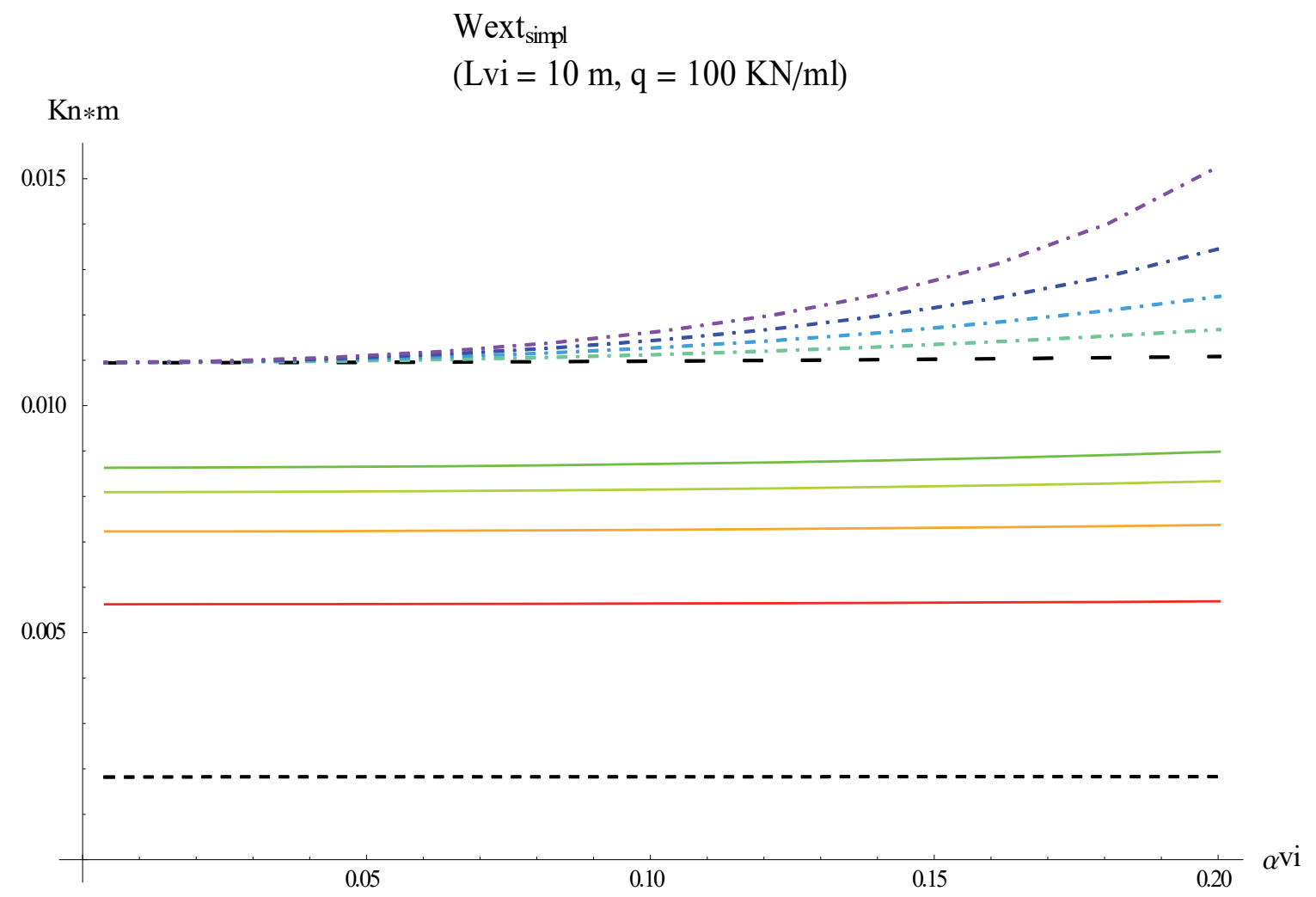

Diagrama 2.95. Trabajo realizado por la carga exterior. Modelo simplificado con diferente número de vanos $(n=$ $1,3,5,7,9) \cdot p z=-100, L v i=10 m$. 


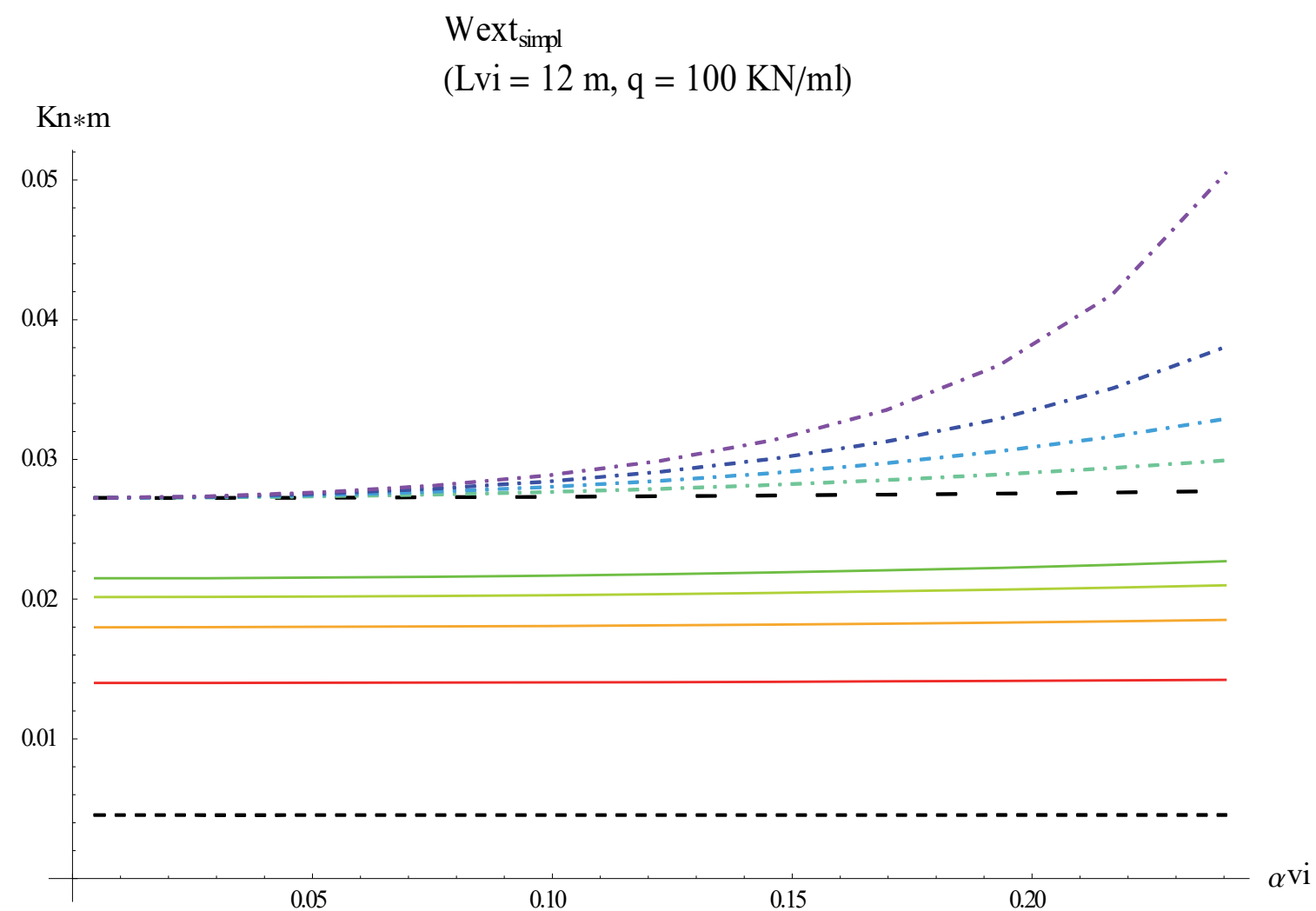

Diagrama 2.96. Trabajo realizado por la carga exterior. Modelo simplificado con diferente número de vanos $(n=$ $1,3,5,7,9) \cdot p z=-100$, Lvi $=12 m$..

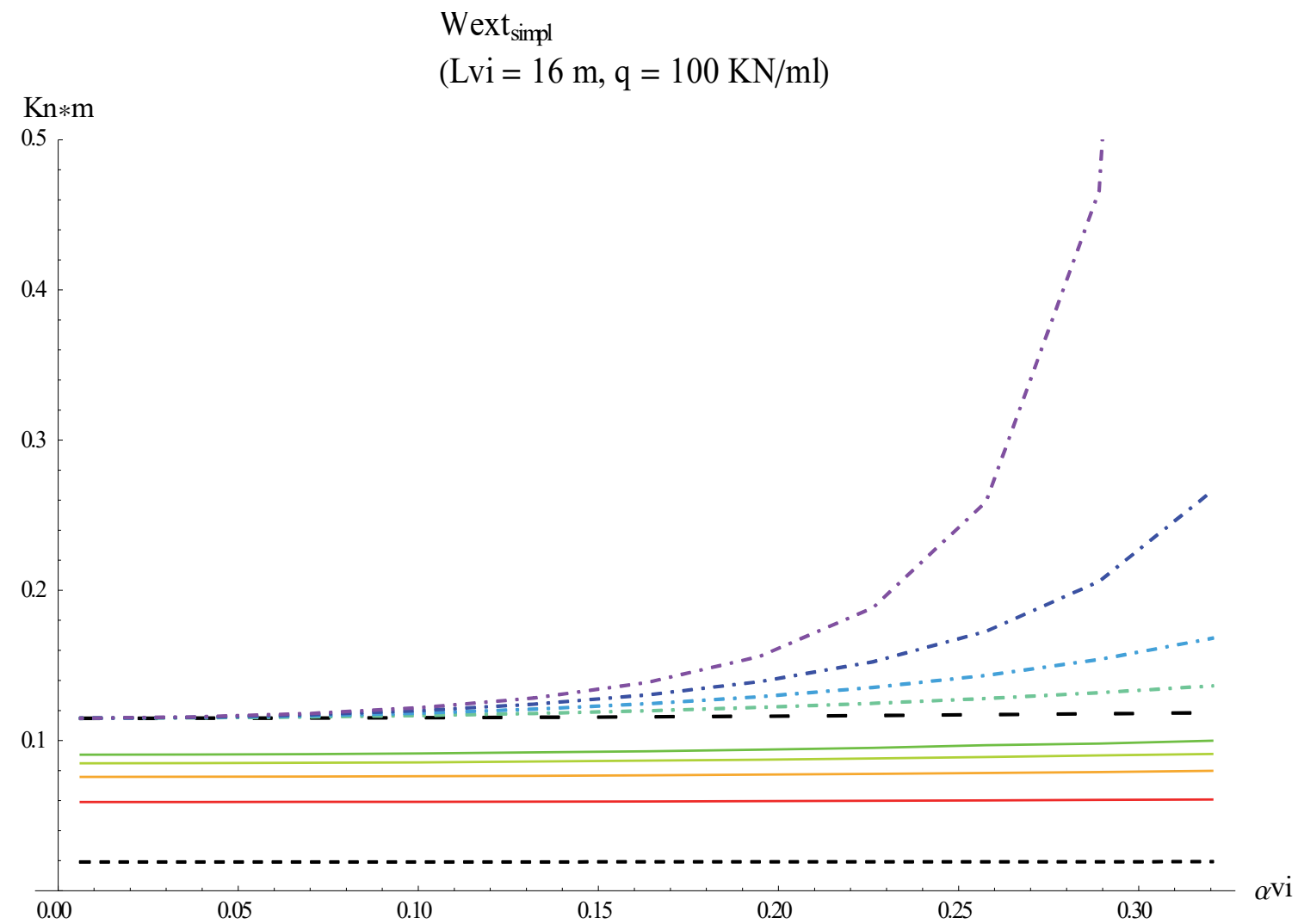

Diagrama 2.97. Trabajo realizado por la carga exterior. Modelo simplificado con diferente número de vanos $(n=$ $1,3,5,7,9) \cdot p z=-100, L v i=16 m$. 


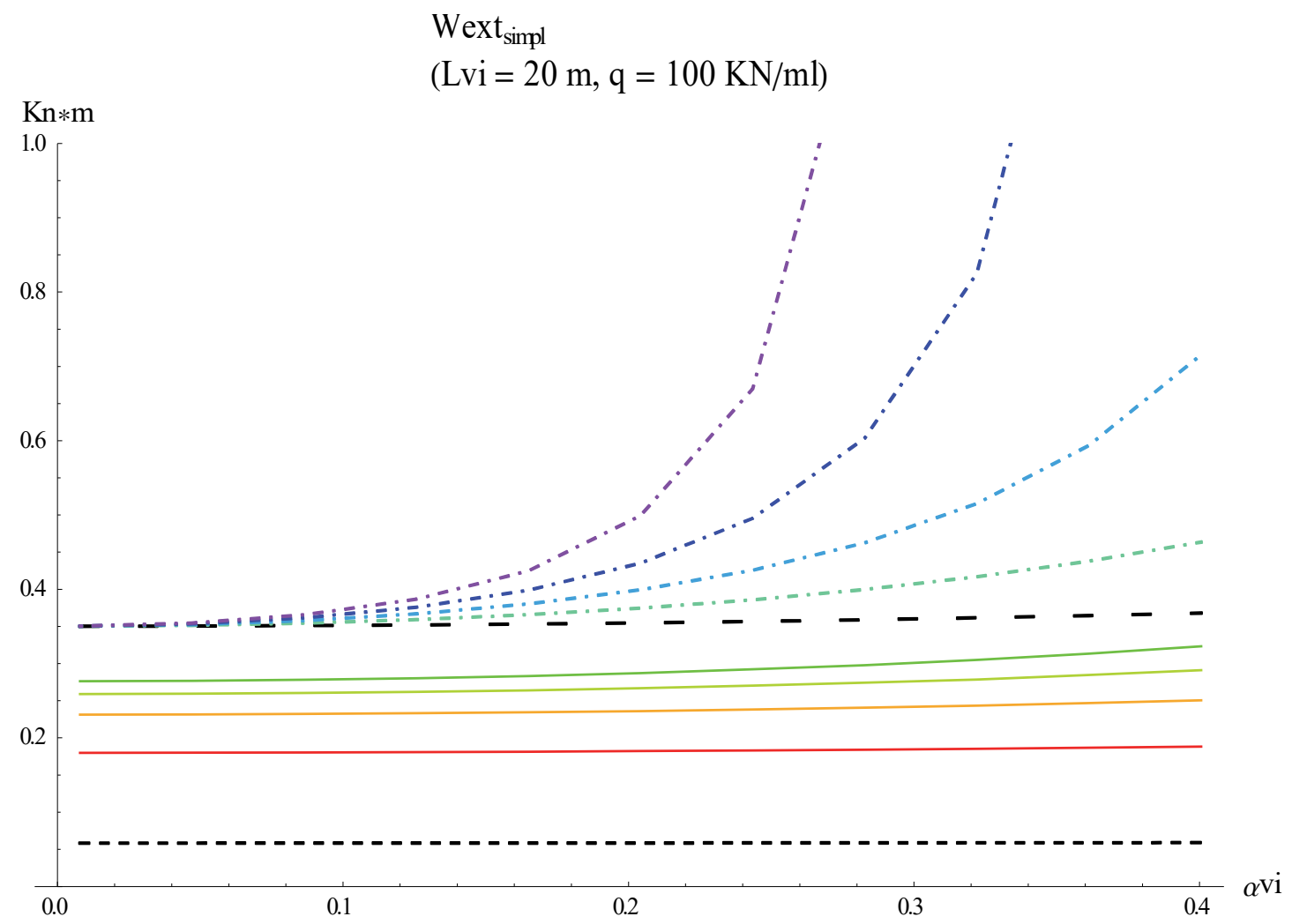

Diagrama 2.98. Trabajo realizado por la carga exterior. Modelo simplificado con diferente número de vanos $(n=$ $1,3,5,7,9) \cdot p z=-100, L v i=20 m$.

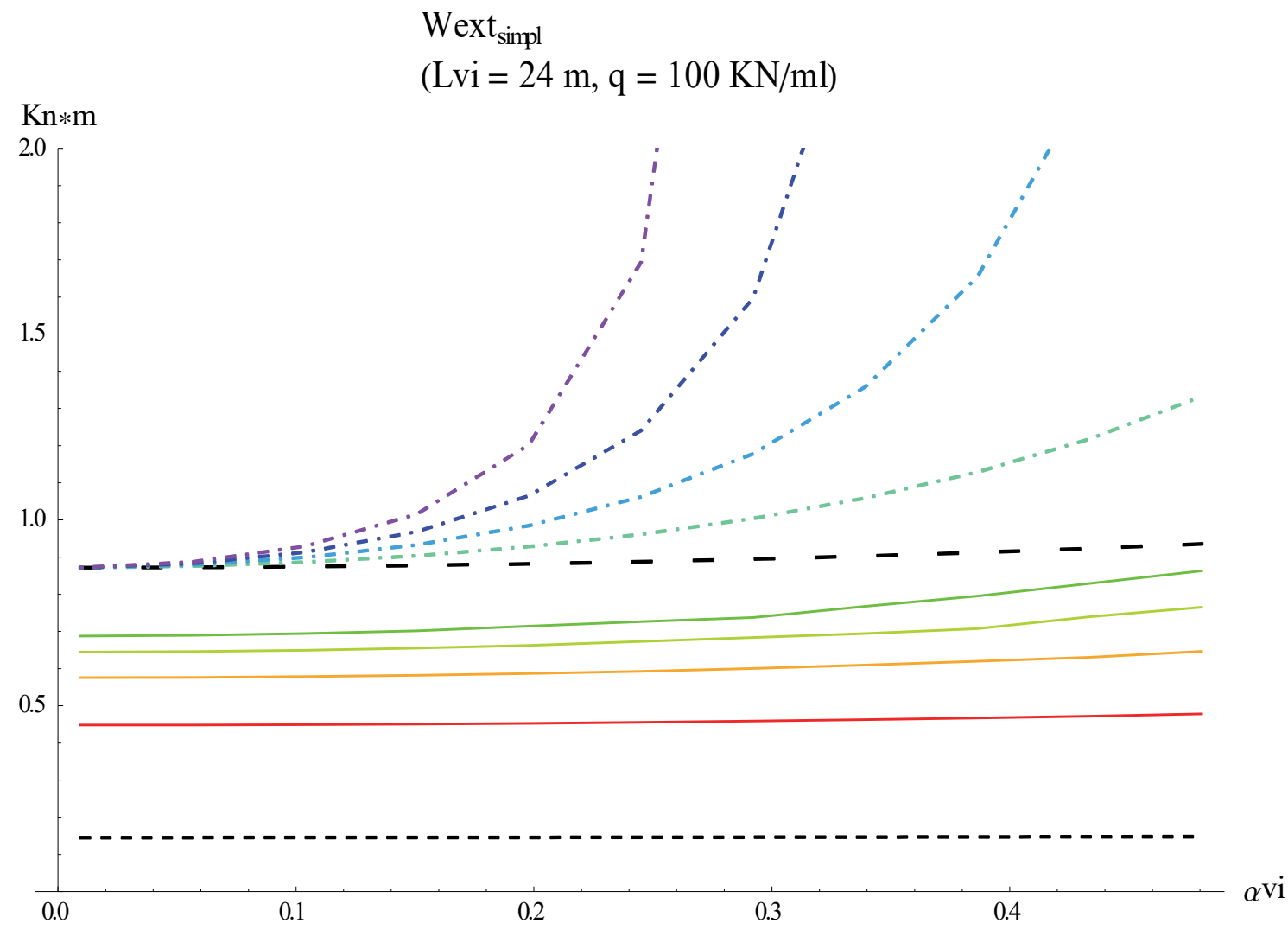

Diagrama 2.99. Trabajo realizado por la carga exterior. Modelo simplificado con diferente número de vanos $(n=$ $1,3,5,7,9) \cdot p z=-100, L v i=24 m$. 


\subsubsection{Conclusiones}

Los diagramas obtenidos corroboran lo descrito en el inicio del apartado (Diagrama 2.89, y la comparación entre modelo simplificado y completo, del Diagrama 2.90 al Diagrama 2.93), para diferentes longitudes de vano entre tirantes y diferentes radios de curvatura. El empotramiento elástico entre apoyos consecutivos es el sistema resistivo principal a la hora de resistir una carga distribuida centrada. También se puede observar cómo el empotramiento a torsión se hace menos eficiente a medida que se aleja el punto de empotramiento del vano cargado (Diagrama 2.100). Esto se debe a su pérdida de eficiencia a la hora de neutralizar Hest, provocando un gran momento torsor de empotramiento, que se acaba transformando, mediante la curvatura, en un momento flector positivo muy perjudicial en lo que a deformaciones en el vano cargado se refiere (Diagrama 2.100). Esto ya se analizó en el apartado 2.1 .

Todo el análisis se ha realizado con una sección Tablero 1 (Carreta), debido a que su relación $\varphi_{K M y T}=\frac{E I y y}{G J} \approx 1$ lo hace apropiado para que el sistema "eTxD" funcione correctamente (una sección abierta, no tiene la capacidad de hacer funcionar el sistema "eTxD" correctamente). Es evidente que, si queda demostrado que el sistema de empotramiento "ee" domina el funcionamiento del tablero con este tipo de sección (Tablero 1 (Carreta)), queda demostrado para el resto de secciones.

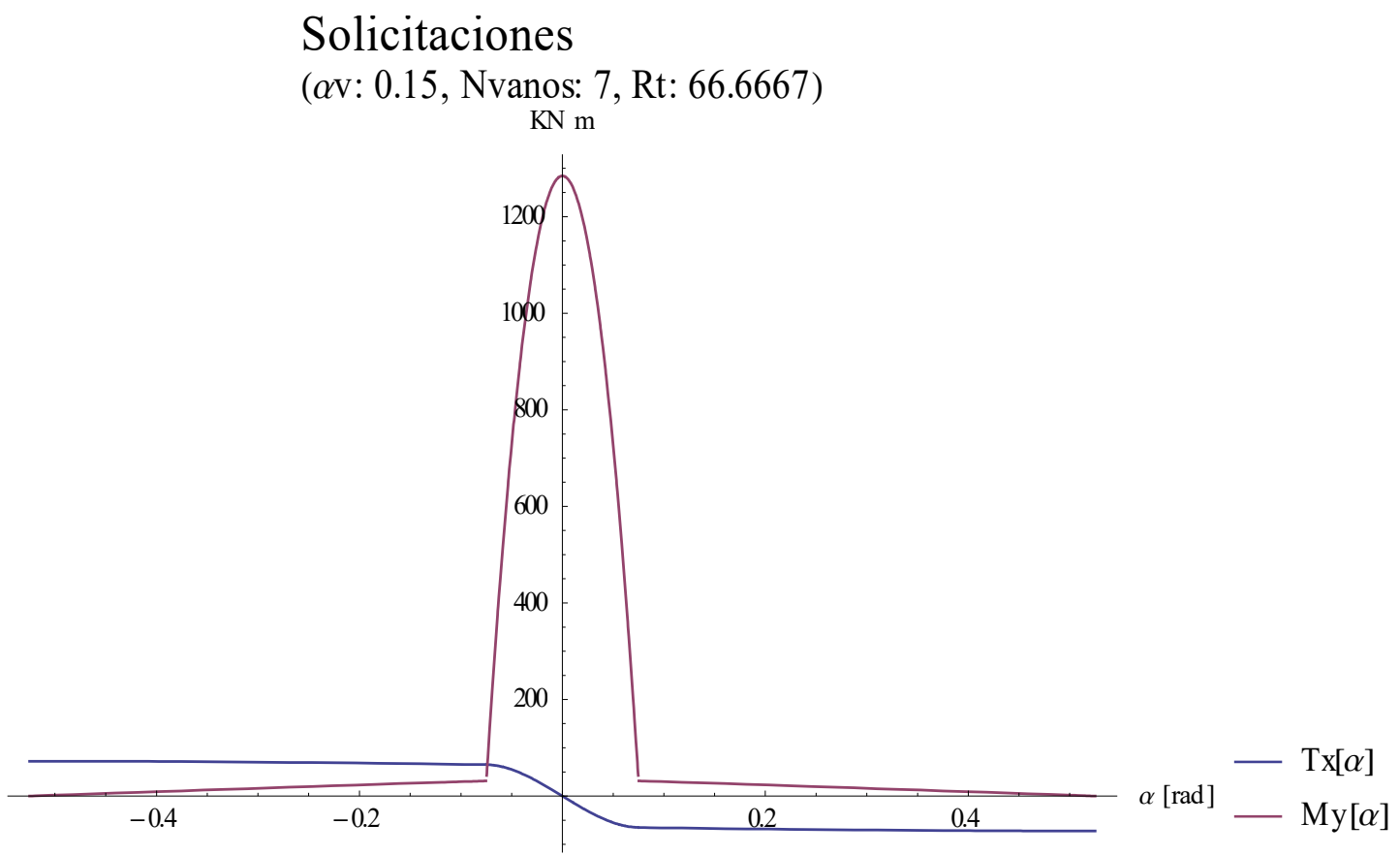

Diagrama 2.100. Diagrama de solicitaciones modelo simplificado. Sistema de empotramiento "eTxD". $\alpha v i=0.15$ $\mathrm{Rt}=66.67 \mathrm{~m}, \alpha t=1.05$, Nvanos $=7$, Lvi= $10 \mathrm{~m}$, Sección tipo: Tablero 1 (Carretra). Carga centrada distribuida en 1 vano $q=100 \mathrm{kN} / \mathrm{m}(\mathrm{pz}=-100 \mathrm{kN} / \mathrm{m})$.

\subsubsection{Viga curva sobre apoyos puntuales inclinados, sometida a un momento torsor distribuido}

En este subapartado se van a estudiar aquellos tableros curvos sometidos a un momento cuyo vector recorre la directriz del centro de cortantes del tablero, sobre apoyos inclinados, que impiden el desplazamiento vertical del tablero. De nuevo, no se van a analizar 
las solicitaciones en el plano del tablero que se introducen en el tablero debido a la inclinación de estos apoyos, como se explicó en el subapartado anterior.

Ante esta solicitación, a diferencia de lo que ocurría con la carga distribuida centrada en la directriz del centro de cortantes del tablero (que se ha considerado coincidente con el centro de gravedad de la sección), el tablero tiene un comportamiento muy marcado por la relación de rigideces $\varphi_{K M Y T}=\frac{E I y y}{G J}$ (con la carga centrada, quedó claro que siempre predomina el funcionamiento del sistema de empotramiento "ee") y un comportamiento con solicitaciones en un nivel "global" (Diagrama 2.101), a menos que se materialice un empotramiento a torsión en los apoyos, en cuyo caso las solicitaciones quedarán en un nivel "local". Existe un punto intermedio (como ocurría en el caso de carga centrada), que consiste en un empotramiento elástico a torsión mediante el contrapeado de la distancia radial de los puntos de apoyo del tablero (tirantes) al centro de cortantes de la sección. Este efecto, es muy beneficioso para las solicitaciones flectoras (My) sobre el tablero a la hora de soportar acciones que produzcan torsores, produciéndose una transformación de estos momentos flectores (My) en momentos torsores (Tx), aumentando estos últimos y disminuyendo los primeros. La contrapartida es que para cargas centradas (como el peso propio y la mayoría de las cargas muertas) aparecen momentos torsores, cuyo orden estará definido por el desplazamiento radial de los puntos de apoyo respecto de la directriz marcada por el centro de cortantes del tablero. Esta puede ser una opción de diseño para casos donde no se disponga de suficiente curvatura para hacer eficiente el sistema "ee" y la disposición de dobles tirantes en cada apoyo complique en exceso el subsistema Pila-Tirantes.

De cara a empezar a introducir carga de la magnitud que se va a dar en un puente de carretera, se ha introducido un puente de $25 \mathrm{~m}$ de plataforma, en el que existen $2.5 \mathrm{~m}$ de zona peatonal en los extremos, saliendo 3 carriles virtuales de 3 metros a cada lado del eje de simetría del tablero (el Tablero 1 (Carretera), el Tablero 2 (Carretera) y el Tablero 6 (Carretera) tienen eje de simetría y 25 metros de ancho), quedando $1 \mathrm{~m}$ de área remanente (que se deja en la zona central). Se ha introducido el momento torsor correspondiente a cargar solo una mitad del puente (según la que se ha cargado, el torsor se ha obtenido positivo o negativo) y la numeración de los carriles virtuales se ha realizado de la forma más desfavorable (todo según la normativa IAP (69)), empezando a numerar desde el exterior hasta el eje de simetría del tablero. No se han introducido las cargas puntuales.

$$
\begin{gathered}
\mathrm{q}=57 \mathrm{kN}\left(\mathrm{pz}=-57\left(\frac{\mathrm{kN}}{\mathrm{ml}}\right)\right) \\
\mathrm{mt}=-430 \mathrm{kN} \frac{\mathrm{m}}{\mathrm{ml}}\left(\mathrm{mx}=430 \mathrm{kN} \frac{\mathrm{m}}{\mathrm{ml}}\right)
\end{gathered}
$$

En este subapartado se va a analizar el comportamiento ante la carga torsora (mt, Ilustración 2.14). Se va a analizar el comportamiento de un Tablero 1 (Carretera), viendo que sistemas de empotramiento resultan más efectivos frente a esta carga mediante diferentes condiciones de apoyo en los estribos. Posteriormente se va a cambiar el tipo de sección, para apreciar los cambios de comportamiento a medida que cambia la relación de rigidez: $\varphi_{K M y T}=$ $\frac{E I y y}{G J}$. 
Solicitacionessobre el tablero

Axil (escala:0.) Cortante $Y^{\prime}-Y^{\prime}$ (escala:0.) Cortante $Z^{\prime}-Z^{\prime}$ (escala:1)

MOMENTO TORSOR X'-X' (escala:1) MOMENTO FLECTOR Y'-Y' (escala:-1)

MOMENTO FLECTOR Z'-Z' (escala:0)

BIMOMENTO W-W (escala:0.)

$(\mathrm{KN}, \mathrm{KN} * \mathrm{~m})$

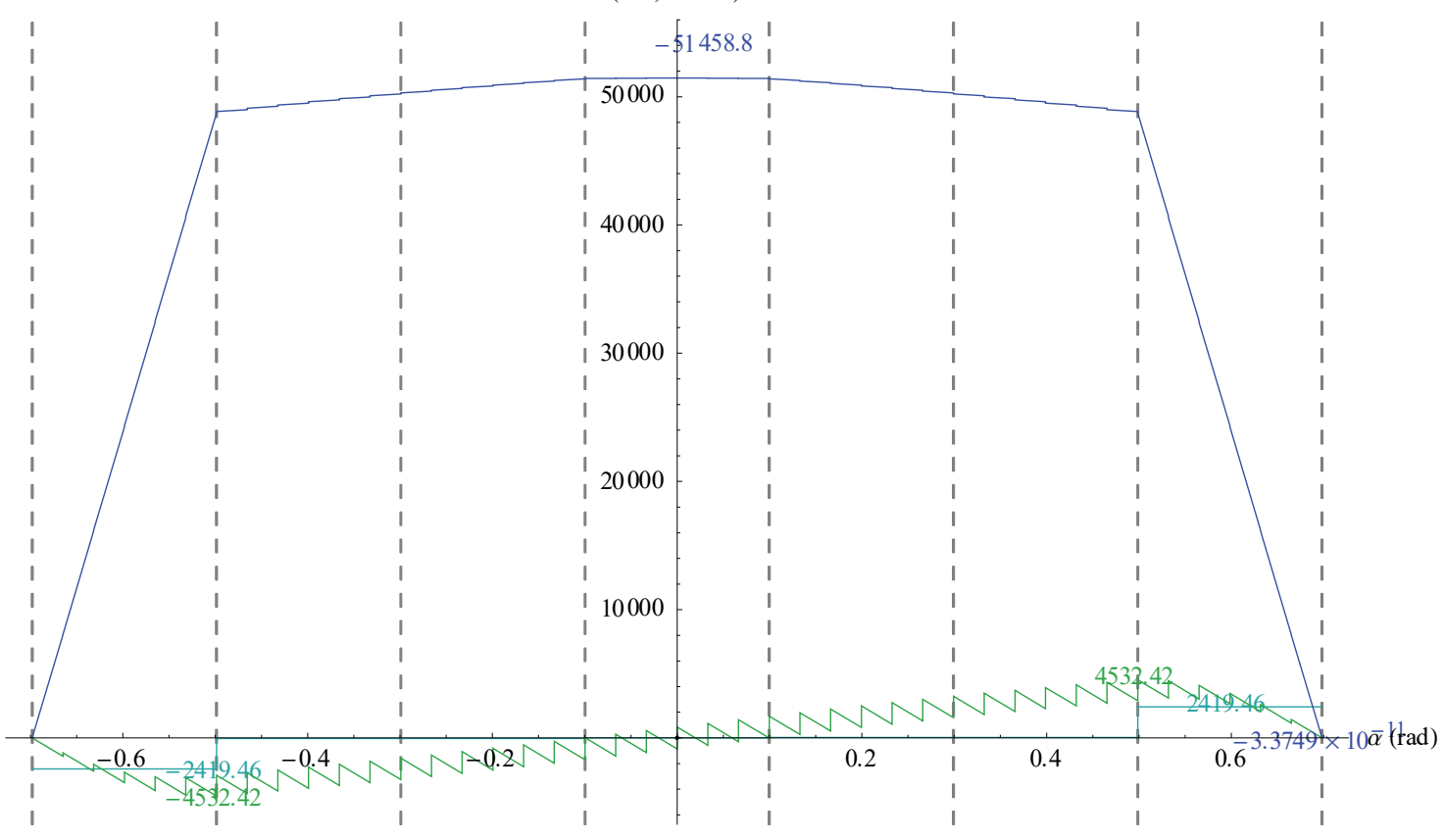

Diagrama 2.101. Solicitaciones en un puente con apoyos puntuales múltiples, modelo completo. $\mathrm{Rt}=100 \mathrm{~m}, \alpha t=$ $\frac{8}{18} \pi$, Nvanos $=7, \alpha v i=0.2 \mathrm{rad}$. Sometido a un momento torsor $\mathrm{mx}=-430 \mathrm{kN} \mathrm{m} / \mathrm{m}$, distribuido a lo largo de todo el tablero. Tablero 1 (Carretera). Estribos sin empotramiento a torsión (simplemente apoyado).

Analizando el diagrama, se pueden sacar algunas conclusiones tempranas. La primera es que toda la solicitación torsora se puede transformar en solicitación flectora mediante la curvatura. Se puede ver cómo para este empotramiento elástico, el tablero utiliza el último apoyo (esto se va a ver con más claridad cuando apliquemos el torsor sobre un solo vano), el estribo, como punto de compensación para resistir el torsor (Diagrama 2.101).

Si se empotra la torsión en los estribos (Diagrama 2.102), manteniendo invariables el resto de condiciones de contorno, se aprecia cómo el empotramiento elástico "ee" y el empotramiento a torsión en los estribos "eTxD", se reparten la solicitación torsora. Esta repartición se va a realizar según las flexibilidades de cada sistema de empotramiento. En esta repartición es donde la relación de rigideces $\varphi_{K M y T}=\frac{E I y y}{G J}$ se vuelve determinante (pudiendo llegar a hacer inoperante el empotramiento a torsión, Diagrama 2.103), aparte de la curvatura, obviamente. 


\section{Solicitacionessobre el tablero}

Axil (escala:0.) Cortante $Y^{\prime}-Y^{\prime}$ (escala:0.) Cortante $Z^{\prime}-Z^{\prime}$ (escala:1)

MOMENTO TORSOR X'-X' (escala:1) MOMENTO FLECTOR Y'-Y' (escala:-1)

MOMENTO FLECTOR Z'-Z' (escala:1)

BIMOMENTO W-W (escala:0.)

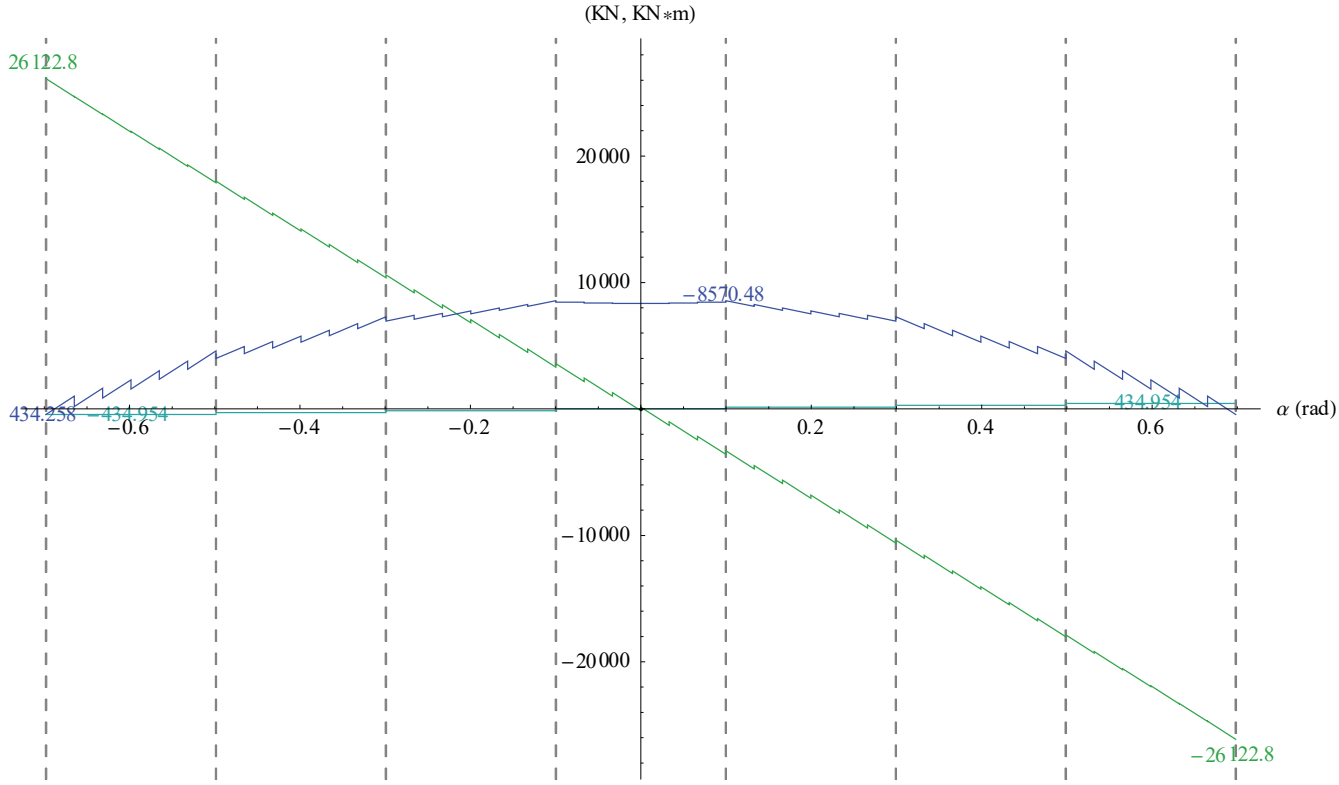

Diagrama 2.102. Solicitaciones en un puente con apoyos puntuales múltiples, modelo completo. $\mathrm{Rt}=100 \mathrm{~m}, \alpha t=$ $\frac{8}{18} \pi$, Nvanos $=7, \alpha v i=0.2$ rad. Sometido a un momento torsor $m x=-430 \mathrm{kN} \mathrm{m} / \mathrm{m}$, distribuido a lo largo de todo el tablero. Tablero 1 (Carretera) $\left(\varphi_{K M y T}=\frac{E I y y}{G J} \approx 1\right)$. Estribos con empotramiento a torsión.

\section{Solicitacionessobre el tablero}

Axil (escala:0.) Cortante $Y^{\prime}-Y^{\prime}$ (escala:0.) Cortante $Z^{\prime}-Z^{\prime}$ (escala:1)

MOMENTO TORSOR X'-X' (escala:1) MOMENTO FLECTOR Y'-Y' (escala:-1)

MOMENTO FLECTOR Z'-Z' (escala:1)

BIMOMENTO W-W (escala:0.)

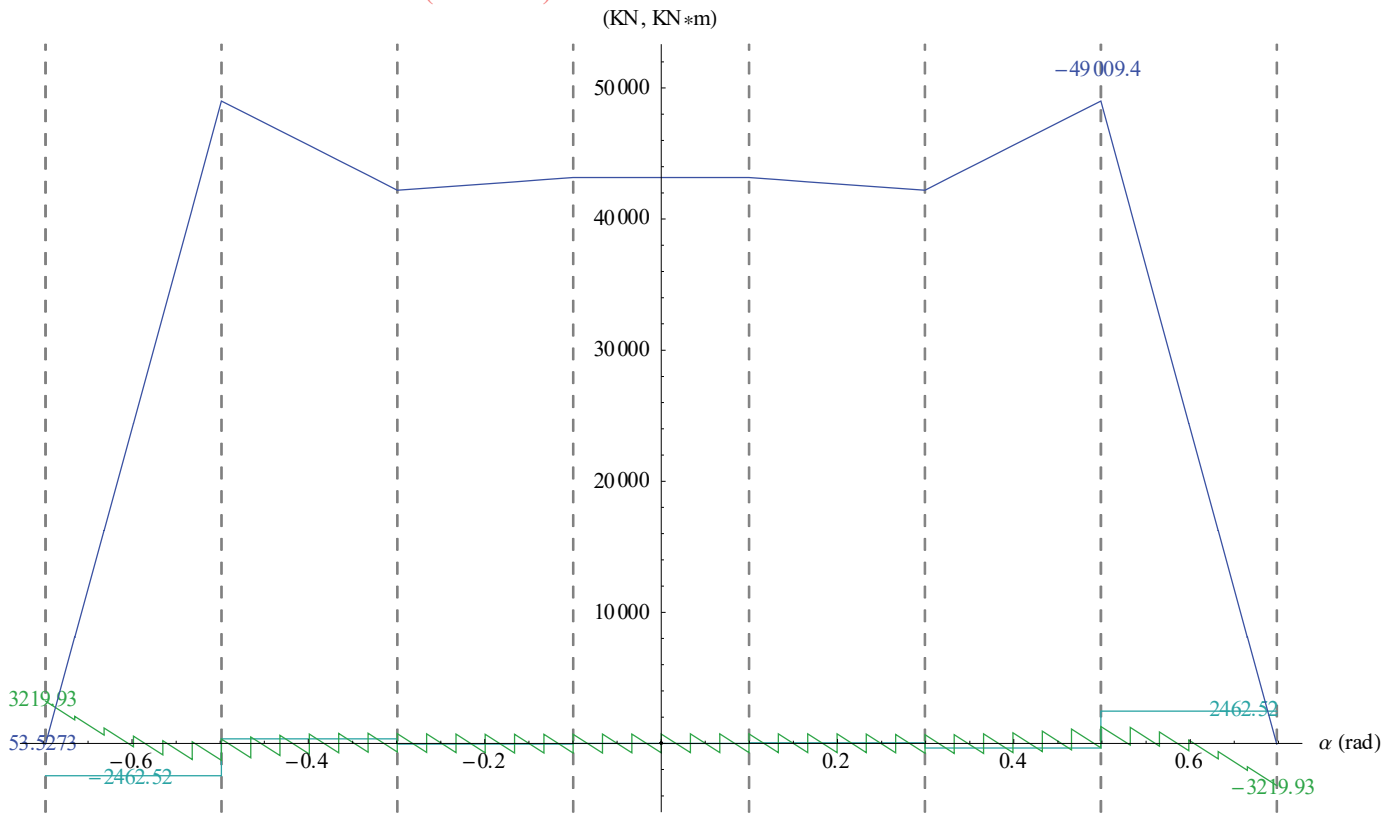

Diagrama 2.103. Solicitaciones en un puente con apoyos puntuales múltiples, modelo completo. $\mathrm{Rt}=100 \mathrm{~m}, \alpha t=$ $\frac{8}{18} \pi$, Nvanos $=7, \alpha v i=0.2 \mathrm{rad}$. Sometido a un momento torsor $\mathrm{mx}=-430 \mathrm{kN} \mathrm{m} / \mathrm{m}$, distribuido a lo largo de todo el tablero. Tablero 2 (Carretera) $\left(\varphi_{K M y T}=\frac{E I y y}{G J} \approx 490\right)$. Estribos con empotramiento a torsión. 


\subsubsection{Sistemas resistivos}

Para entender mejor este fenómeno, se va a realizar el mismo análisis que se hizo para carga centrada, pero sustituyendo la carga distribuida por un momento torsor distribuido.

De nuevo, el modelo simplificado de cálculo se va a basar en las ya nombradas ecuaciones diferenciales que dominan el comportamiento del tablero curvo fuera de su plano.

$$
\begin{aligned}
& T x[s] \prime^{\prime}+\frac{T x[s]}{R t^{2}}==m x[s] '-\frac{Q z[s]}{R t} \\
& M y[s] '{ }^{\prime}+\frac{M y[s]}{R t^{2}}==\frac{m x[s]}{R t}+Q z[s] ' \\
& \mathrm{Qz}[\mathrm{s}] \mathrm{I}^{\prime}==\mathrm{pz}[\mathrm{s}] \\
& \operatorname{Tx}[\alpha] \text { ' }^{\prime}+\operatorname{Tx}[\alpha]==\operatorname{Rt} \mathrm{mx}[\alpha] \text { ' }-\operatorname{Rt} Q \mathbf{z}[\alpha] \\
& \operatorname{My}[\alpha] \text { ' ' }^{\prime} \operatorname{My}[\alpha]==\operatorname{Rt} \operatorname{mx}[\alpha]+\operatorname{Rt} Q z[\alpha] \text { ' } \\
& Q z[\alpha] '==\operatorname{Rt} p z[\alpha]
\end{aligned}
$$

El momento desestabilizador en los apoyos del vano cargado, provocado por la carga torsora distribuida en el tablero:

$$
\text { Hest }=2 \mathrm{mt} \text { Rt } \operatorname{Sin}[\alpha \mathrm{vi} / 2]
$$

El momento desestabilizador se resiste de la siguiente manera según el tipo de empotramiento:

- eTx: empotramiento a torsión en los apoyos de los extremos del vano cargado (llamados Avi).

Este caso ya se ha estudiado en el apartado 2.1 (según la llustración 2.1, cambiando $\alpha_{t}$ $\left.\operatorname{por} \alpha_{v i}\right):$

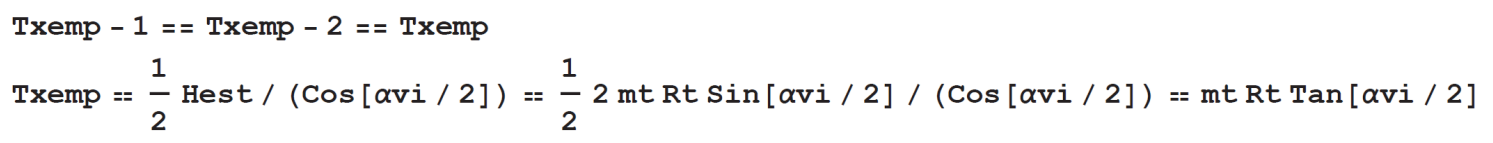

- eMy: empotramiento a flexión en los apoyos de los extremos del vano cargado.

Este caso ya se ha estudiado en el apartado 2.1 (según la llustración 2.1, cambiando $\alpha_{t}$ $\left.\operatorname{por} \alpha_{v i}\right)$ :

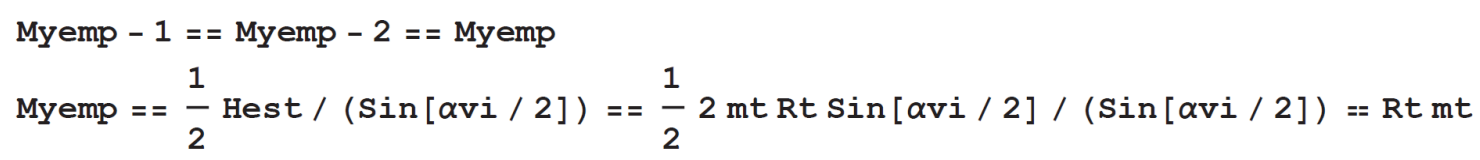

- ee: empotramiento elástico. Se le da continuidad al tablero en sus dos extremos, hasta 1 apoyo situado a $\frac{n-1}{2}$ vanos de Avi. Estos vanos tienen las 
mismas propiedades geométricas que el vano cargado (Lvi, Rt, $\alpha v i$ ), como se puede observar en Ilustración 2.14.

Como ya se ha comentado en el punto anterior, este sistema es inherente al puente multiapoyado. Para soportar la carga torsora, el empotramiento que proporciona el siguiente apoyo a Avi (Ilustración 2.14), resulta ineficiente. Esto es consecuencia de la poca distancia, según el eje global X, que hay al apoyo Avi para desarrollar el par estabilizador que neutralice Hest. En cambio, a medida que se separa el apoyo Avex (Ilustración 2.14), el empotramiento se vuelve cada vez más efectivo gracias a la curvatura. En el caso de la carga centrada, Hest resulta casi despreciable y son la solicitación My y el giro según el eje local "y" los dominantes, por eso el empotramiento elástico "ee" se produce entre Avi y el apoyo consecutivo. El valor de la reacción estabilizadora RzAvex, según la llustración 2.14 va a ser:

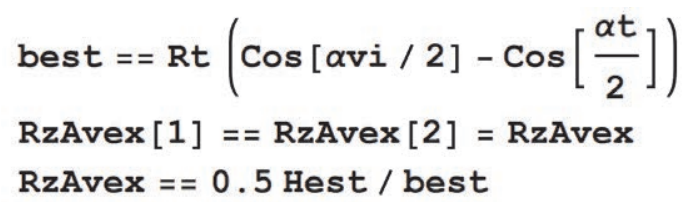

Si se analiza un ejemplo del comportamiento mediante un modelo simplificado similar al propuesto en el subapartado 2.3.2, con las siguientes condiciones de contorno (donde la carga de momento torsor se obtiene de un vehículo pesado, $600 \mathrm{kN}$, aplicado a una distancia de aproximadamente 8,5 metros respecto del eje de simetría del tablero, dividido por la longitud del vano):

\section{Solicitaciones}

( $\alpha$ vi: 0.15, Nvanos: 7, Rt: 66.6667)

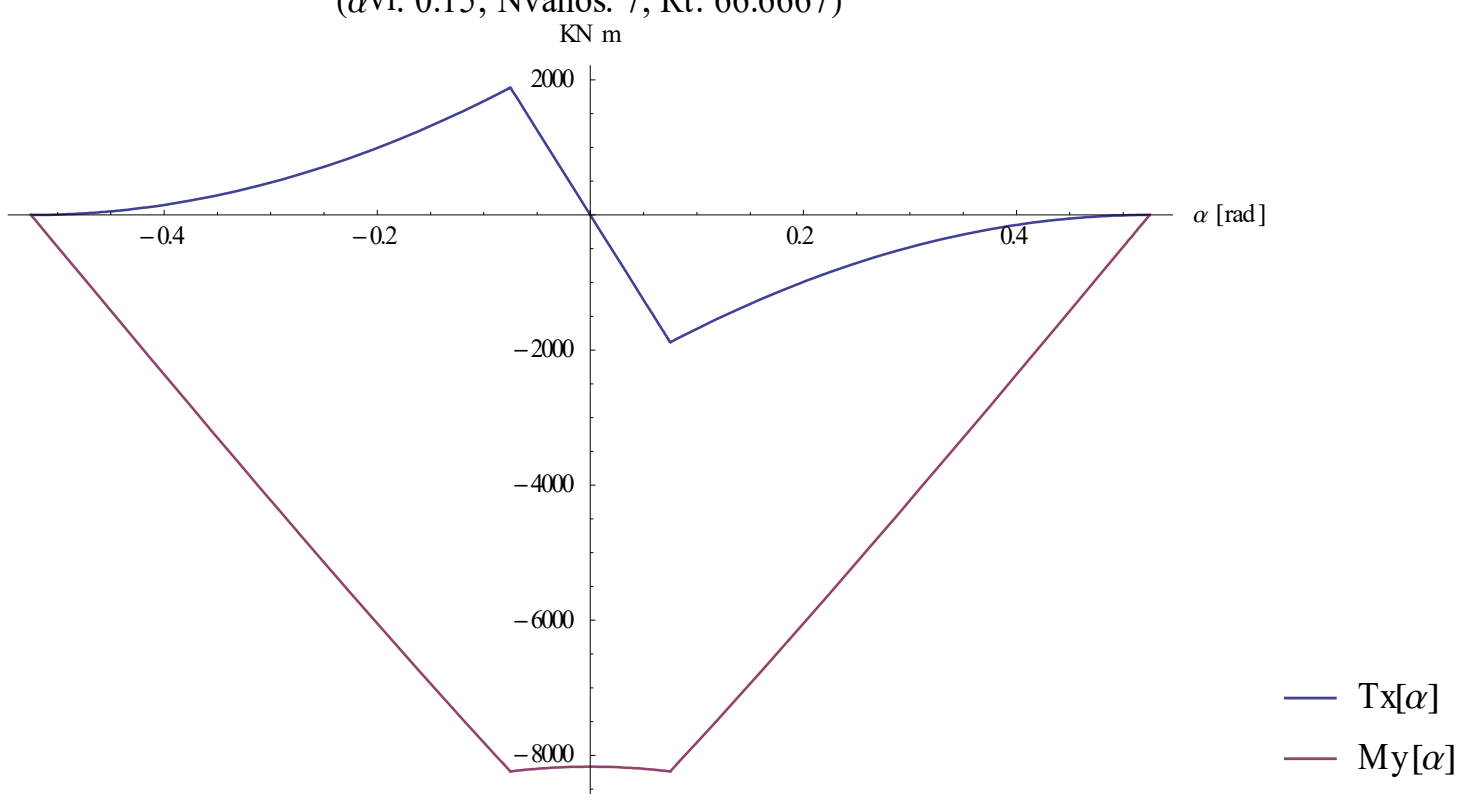

Diagrama 2.104. Diagrama de solicitaciones modelo simplificado. Sistema de empotramiento "ee". $\alpha v i=0.15 \mathrm{Rt}=$ $66.67 \mathrm{~m}, \alpha t=1.05$, Nvanos = 7, Lvi= $10 \mathrm{~m}$, Sección tipo: Tablero 1 (Carretra). Carga torsora distribuida en 1 vano $\mathrm{mx}=500 \mathrm{kN} / \mathrm{m}$. 


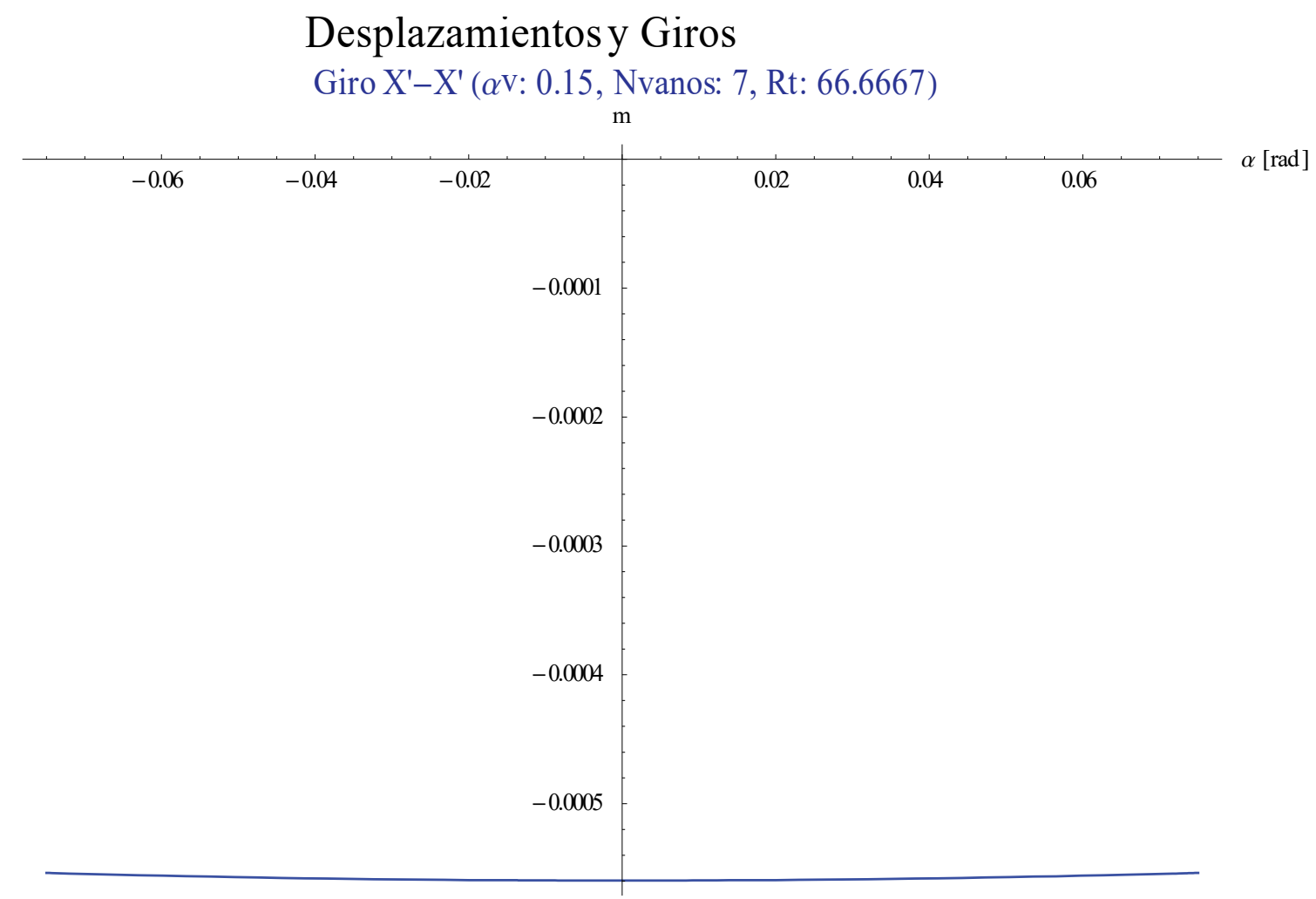

Diagrama 2.105. Diagrama de desplazamiento y giros, modelo simplificado. Sistema de empotramiento "ee". $\alpha v i=$ $0.15 \mathrm{Rt}=66.67 \mathrm{~m}, \alpha t=1.05$, Nvanos $=7$, Lvi= $10 \mathrm{~m}$, Sección tipo: Tablero 1 (Carretra). Carga torsora distribuida en 1 vano $m x=500 \mathrm{kN} / \mathrm{m}$.

Al comparar el modelo simplificado (Diagrama 2.104 y Diagrama 2.105) con el modelo completo (Diagrama 2.106 y Diagrama 2.107), con 7 vanos y sus estribos apoyados (sin empotramiento a torsión), se puede apreciar cómo en los dos modelos, efectivamente, el par estabilizador lo materializa el apoyo más alejado angularmente. Este par se completa en el modelo simplificado con los apoyos que delimitan el vano cargado (Avi en llustración 2.14), mientras que, en el caso del modelo completo, por compatibilidad de deformaciones y mayor rigidez, se completa con el apoyo siguiente al del estribo. Esta situación del par de estabilización en el modelo completo se produce porque los apoyos que se han introducido son infinitamente rígidos, en el momento en el que estos apoyos tengan cierta flexibilidad, el par compensador se materializa con el apoyo Avi, como en el modelo simplificado, Diagrama 2.108. Que el par estabilizador se produzca entre los apoyos extremos produce reacciones mayores en el modelo completo (el par estabilizador dispone de menor brazo), que se traducen en mayores cortantes en el vano extremo, anulándose el cortante en el resto del tablero. Esto provoca que el momento se distribuya más uniformemente a lo largo del tablero, con menores momentos flectores en el vano cargado, pero mayores en los vanos cercanos al estribo. El comportamiento del momento torsor es parecido, si bien, al contar con mayor momento flector del que alimentarse desde el estribo (se debe tener en cuenta que el torsor, hasta el vano cargado, se alimenta exclusivamente de su vinculación con el flector debido a la falta de empotramiento a torsor de los estribos) en el modelo completo, el momento desestabilizador Hest, se neutraliza con menor momento flector y mayor momento torsor. En cualquier caso, queda patente que cuando se aplica un momento torsor sobre un tablero curvo, si no queda empotrado en los apoyos intermedios, se producen solicitaciones de "nivel global". 


\section{Solicitaciones sobre el tablero}

Axil (escala:0.) Cortante $Y^{\prime}-Y^{\prime}$ (escala:1) Cortante $Z^{\prime}-Z^{\prime}$ (escala:1)

MOMENTO TORSOR X'-X' (escala:1) MOMENTO FLECTOR Y'-Y' (escala:-1)

MOMENTO FLECTOR Z'-Z' (escala:0.)

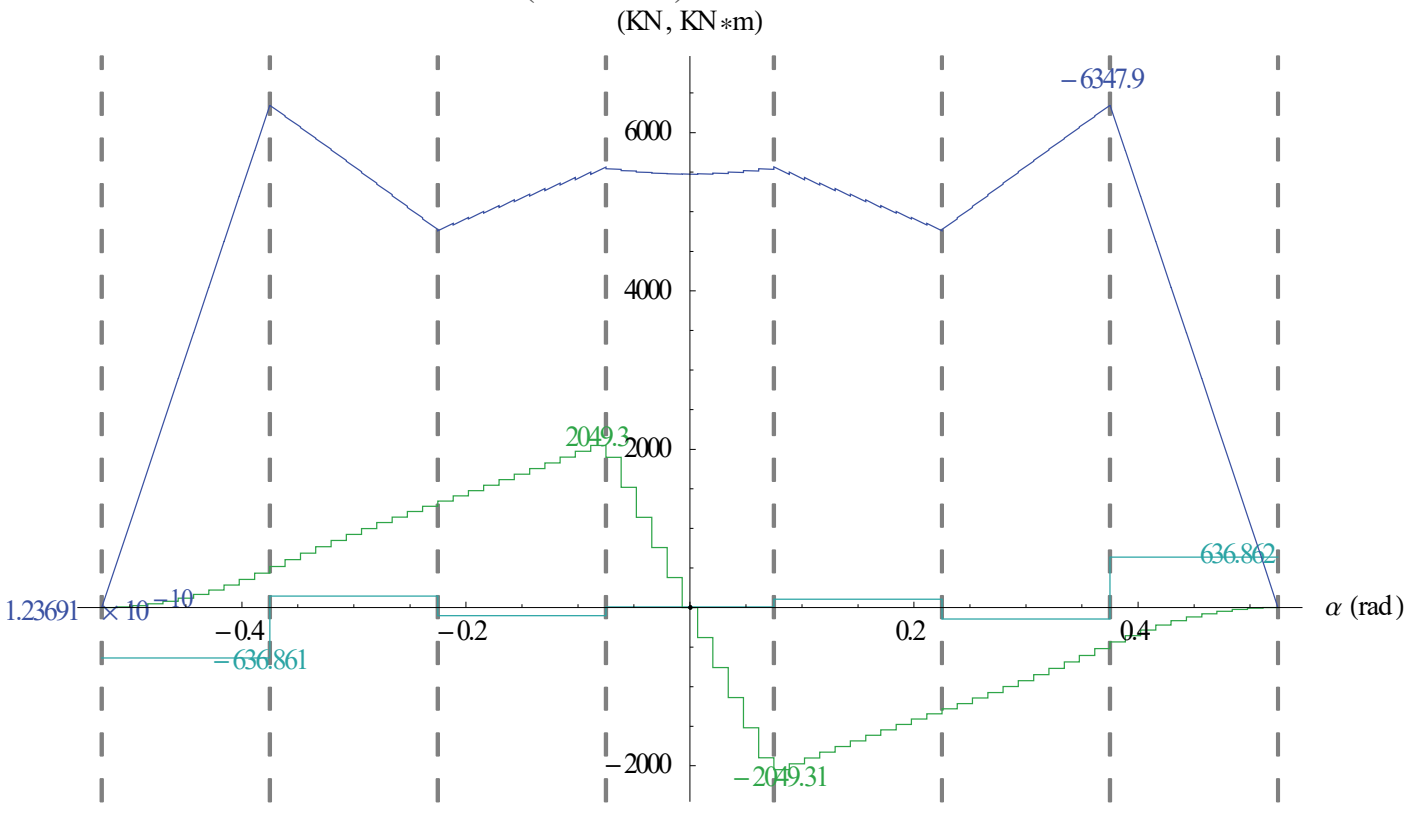

Diagrama 2.106. Solicitaciones en un puente con apoyos puntuales múltiples, modelo completo. $\mathrm{Rt}=66.67 \mathrm{~m}, \alpha t=$ 1.05, Nvanos = 7, Lvi= $10 \mathrm{~m}$, Sección tipo: Tablero 1 (Carretra). Carga torsora distribuida en 1 vano mx= $500 \mathrm{kN} / \mathrm{m}$. Estribos sin empotramiento a torsión (simplemente apoyado).

\section{Desplazamientos y Giros}

Desplazamiento TANGENCIAL (escala:0)

Desplazamiento RADIAL (escala:0) Desplazamiento Z (escala:1)

Giro X'-X' (escala:1) Giro Y'-Y' (escala:0) Giro Z'-Z' (escala:0) $(\mathrm{m}, \mathrm{rad})$

\begin{tabular}{|c|c|c|c|c|c|c|}
\hline 8.6 & $66423 \times 10^{-6}$ & 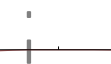 & " & ' & " & \\
\hline-0.00003212810 .4 & $\left.\right|^{-0.2}$ & I & I & 2 & 0 & $\gamma_{1}$ \\
\hline 1 & I & I & I & I & I & I \\
\hline I & 1 & -0.0001 & I & I & I & I \\
\hline I & 1 & 1 & I & I & I & I \\
\hline I & I & I & I & I & I & I \\
\hline I & I & -0.0002 & I & I & I & I \\
\hline I & I & I & I & I & I & I \\
\hline I & 1 & 1 & I & I & 1 & 1 \\
\hline I & I & -0.0003 & I & I & I & I \\
\hline I & I & I & I & I & I & I \\
\hline I & I & I & I & 1 & I & 1 \\
\hline I & I & -0.0004 & I & I & I & I \\
\hline I & I & I & I & I & I & 1 \\
\hline I & 1 & I & I & 1 & 1 & -0.000437599 \\
\hline I & I & -00005 & $T$ & I & I & I \\
\hline I & 1 & -0.00 .90 & I & I & I & 1 \\
\hline
\end{tabular}

Diagrama 2.107. Diagrama de desplazamiento y giros, puente con apoyos puntuales múltiples, modelo completo. $\mathrm{Rt}=66.67 \mathrm{~m}, \alpha t=1.05$, Nvanos $=7$, Lvi= $10 \mathrm{~m}$, Sección tipo: Tablero 1 (Carretra). Carga torsora distribuida en 1 vano $m x=500 \mathrm{kN} / \mathrm{m}$. Estribos sin empotramiento a torsión (simplemente apoyado). 
Aunque las solicitaciones tienen menos similitud, se aprecia cómo tanto los giros como como el trabajo desarrollado por el momento torsor en el vano cargado son muy próximos:

Modelo simplificado:

$W$ ext $_{\text {simp }}=\int_{-\alpha v i / 2}^{\alpha v i / 2} m t[s] \phi x x[s] d s=2.79 \mathrm{kN} \mathrm{m}$

Modelo completo:

$W \operatorname{ext}_{\text {comp }}=\int_{-\alpha v i / 2}^{\alpha v i / 2} m t[s] \phi x x[s] d s=2.4 \mathrm{kN} \mathrm{m}$

Si se introduce la flexibilidad, exclusivamente de los tirantes (contando con la pila como infinitamente rígida), las solicitaciones se asimilan mucho, aportando mayor credibilidad al modelo simplificado:

\section{Solicitaciones sobre el tablero}

Axil (escala:0.) Cortante $Y^{\prime}-Y^{\prime}$ (escala:0.) Cortante $Z^{\prime}-Z^{\prime}$ (escala:1)

MOMENTO TORSOR X'-X' (escala:1) MOMENTO FLECTOR Y'-Y' (escala:-1)

MOMENTO FLECTOR Z'-Z' (escala:0.)

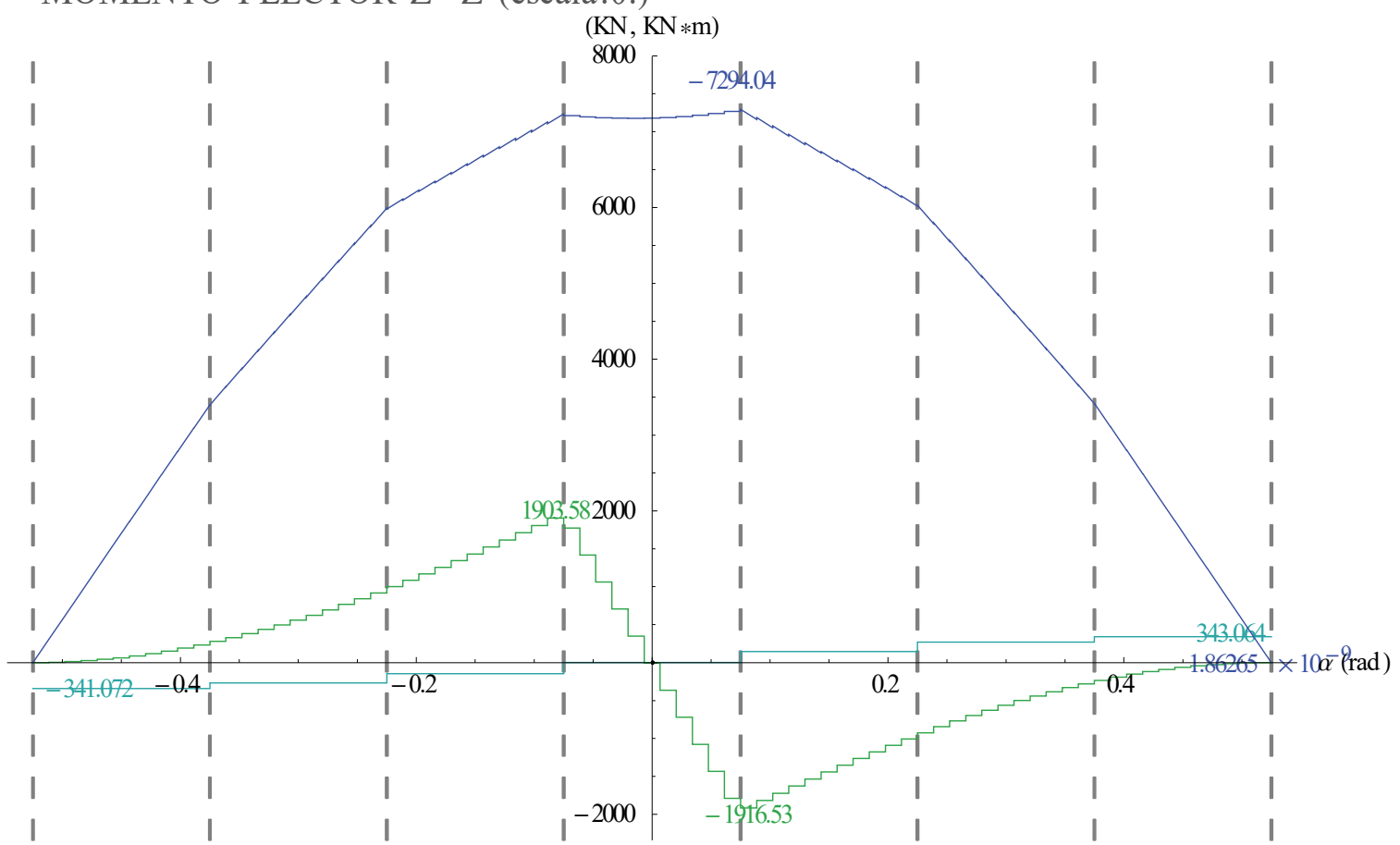

Diagrama 2.108. Solicitaciones en un puente con apoyos puntuales múltiples (apoyos elásticos, tirantes), modelo completo. Rt $=66.67 \mathrm{~m}, \alpha t=1.05$, Nvanos $=7$, Lvi= $10 \mathrm{~m}$, Sección tipo: Tablero 1 (Carretra). Carga torsora distribuida en 1 vano $\mathrm{mx}=500 \mathrm{kN} / \mathrm{m}$. Estribos sin empotramiento a torsión (simplemente apoyado).

- eTxD: empotramiento a torsión a distancia. Se le da continuidad al tablero en sus dos extremos, hasta un empotramiento a torsión situado a $\frac{n-1}{2}$ vanos de Avi. Estos vanos tienen las mismas propiedades geométricas que el vano cargado (Lvi, Rt, $\alpha v i$ ), como se puede observar en Ilustración 2.14. 
A diferencia del caso en el que se introducía una carga distribuida ( $\mathrm{pz}$ ) centrada a lo largo del centro de cortantes del tablero, en el caso de introducir una carga torsora igualmente distribuida, el empotramiento a torsión resulta muy efectivo, incluso obligado en el caso de que los ángulos desarrollados por el tablero no sean suficientes (por debajo de $\alpha_{t}=\pi / 4$ ). Este empotramiento va a quedar vinculado a relación de rigideces, $\varphi_{K M y T}=\frac{E I y y}{G J}$, que como ya se ha comentado es determinante a la hora de repartir la solicitación entre los dos sistemas de empotramiento cuando se neutraliza una acción torsora. En todo caso, como se va a analizar en los diagramas de trabajo externo, el empotramiento en el estribo va ser muy efectivo incluso con ángulos $\alpha_{t}$ grandes, si se cuenta con una sección cerrada con suficiente rigidez torsora.

El empotramiento a torsión va a ser:

$$
\begin{aligned}
& \text { ReTxdex }[1]==\operatorname{ReTxdex}[2]=\operatorname{ReTxdex} \\
& \operatorname{ReTxdex}==0.5 \frac{\text { Hest }}{\operatorname{Cos}\left[\frac{\alpha t}{2}\right]}
\end{aligned}
$$

Para esta solicitación, el modelo simplificado para el empotramiento "eTXD" se asemeja con bastante precisión al verdadero comportamiento del modelo completo, como se puede apreciar en los diagramas (Diagrama $2.109 \rightarrow$ Diagrama 2.111).

\section{Solicitaciones}

(ov: 0.15, Nvanos: 7, Rt: 66.6667)

$\mathrm{KN} \mathrm{m}$

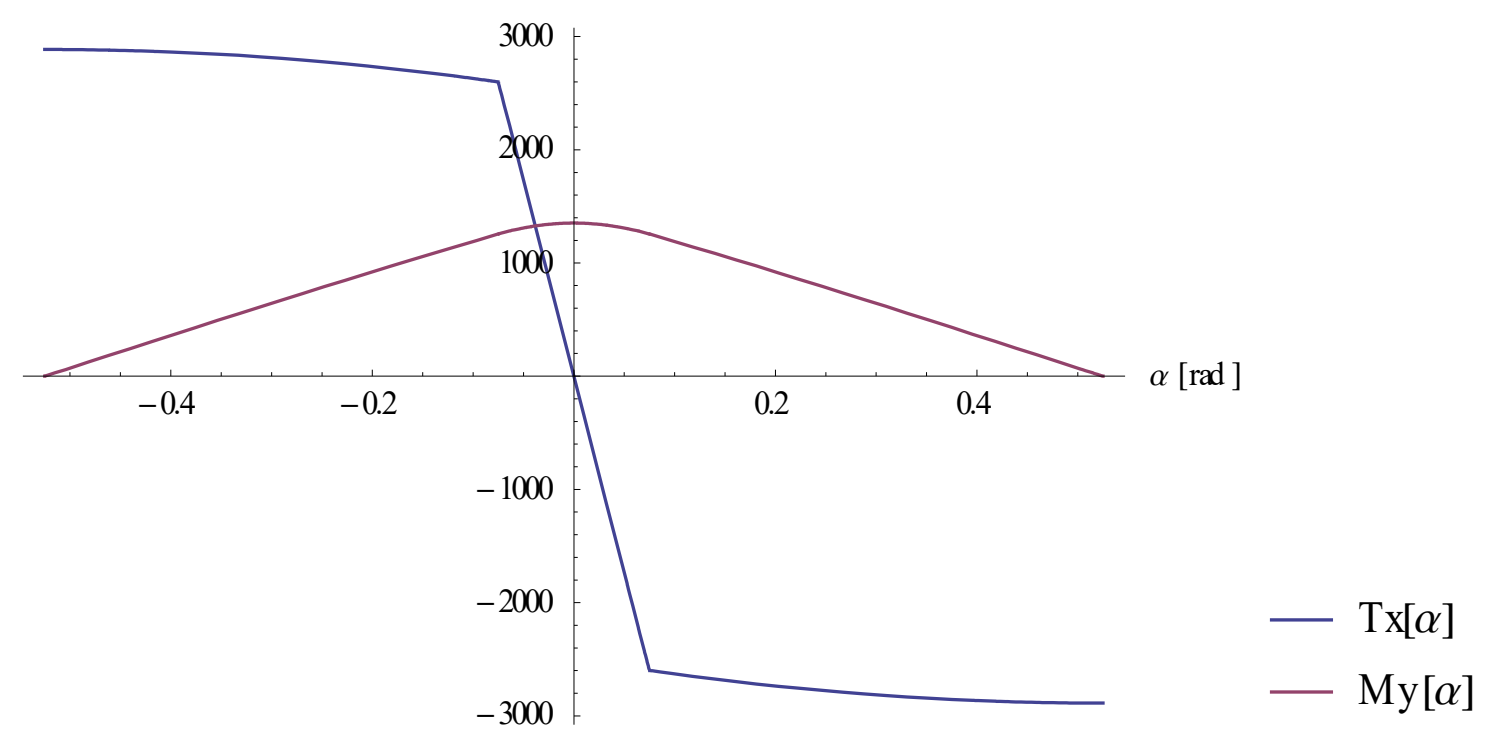

Diagrama 2.109. Diagrama de solicitaciones modelo simplificado. Sistema de empotramiento "eTxD". $\alpha v i=0.15$ $\mathrm{Rt}=66.67 \mathrm{~m}, \alpha t=1.05$, Nvanos = 7, Lvi= $10 \mathrm{~m}$, Sección tipo: Tablero 1 (Carretra). Carga torsora distribuida en 1 vano $m x=500 \mathrm{kN} / \mathrm{m}$. 


\section{Solicitaciones sobre el tablero}

Axil (escala:0.) Cortante $Y^{\prime}-Y^{\prime}$ (escala:0.) Cortante $Z^{\prime}-Z^{\prime}$ (escala:1)

MOMENTO TORSOR X'-X' (escala:1) MOMENTO FLECTOR Y'-Y' (escala:-1)

MOMENTO FLECTOR Z'-Z' (escala:0.)

$(\mathrm{KN}, \mathrm{KN} * \mathrm{~m})$

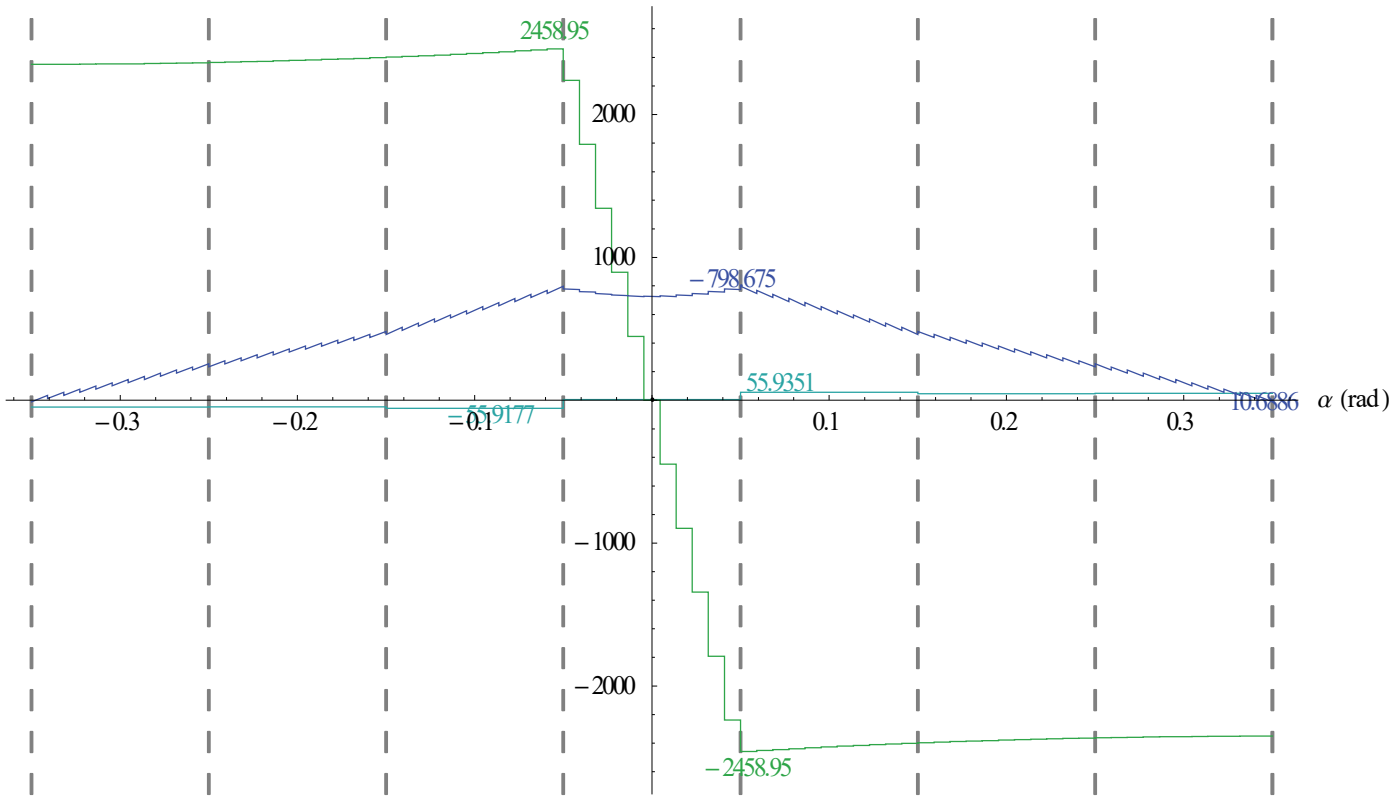

Diagrama 2.110. Solicitaciones en un puente con apoyos puntuales múltiples, modelo completo. Rt= $66.67 \mathrm{~m}, \alpha t=$ 1.05, Nvanos = 7, Lvi= $10 \mathrm{~m}$, Sección tipo: Tablero 1 (Carretra). Carga torsora distribuida en 1 vano mx=500 kN/m. Estribos con empotramiento a torsión.

\section{Desplazamientos y Giros}

Desplazamiento TANGENCIAL (escala:0)

Desplazamiento RADIAL (escala:0) Desplazamiento Z (escala:1)

Giro X'-X' (escala:1) Giro Y'-Y' (escala:0) Giro Z'-Z' (escala:0) $(\mathrm{m}, \mathrm{rad})$

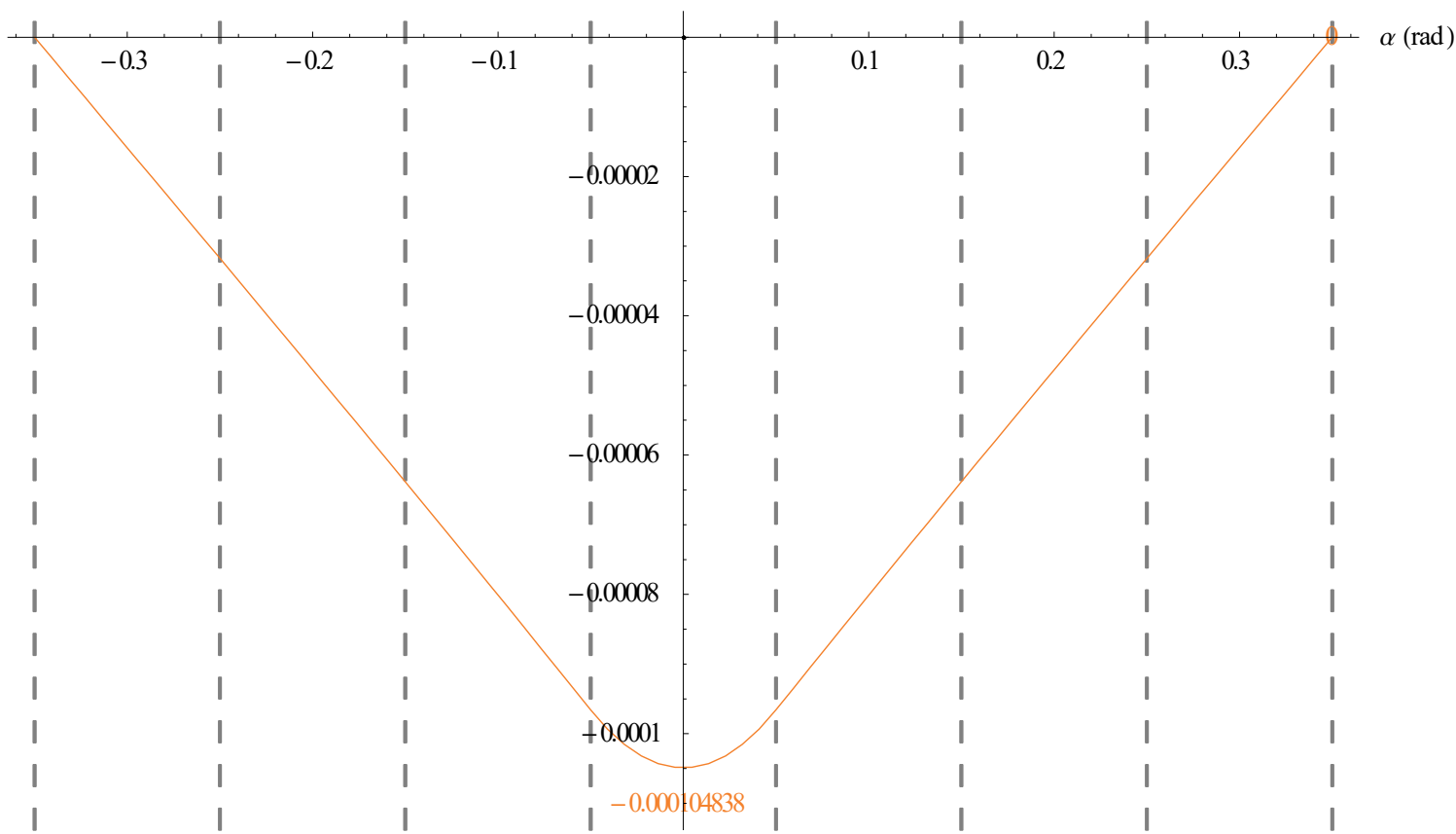

Diagrama 2.111. Diagrama de desplazamiento y giros, puente con apoyos puntuales múltiples, modelo completo. $\mathrm{Rt}=66.67 \mathrm{~m}, \alpha t=1.05$, Nvanos $=7$, Lvi= $10 \mathrm{~m}$, Sección tipo: Tablero 1 (Carretra). Carga torsora distribuida en 1 vano $m x=500 \mathrm{kN} / \mathrm{m}$. Estribos con empotramiento a torsión. 


\subsubsection{Trabajo desarrollado por la carga exterior en cada sistema resistivo}

Si se analizan los trabajos realizados por la carga exterior en el modelo simplificado para cada uno de los casos propuestos (ver leyenda de diagramas de trabajo), cambiando las características geométricas del problema, se obtiene que el trabajo que realiza la fuerza exterior es función de:

$$
W_{\operatorname{ext}} t_{\text {simp }}=m x H[n] G[L v i] F[\alpha v i]
$$

Siendo:

$$
G[L v i]=K L v i^{3}
$$

Luego si todas las curvas que se han desarrollado para los diferentes Lvi se dividen por el cubo de la longitud del vano cargado, se convierten en la misma curva. Si a esto se le añade que la relación de rigideces $\varphi_{K M y T}=\frac{E I y y}{G J}$, al contrario que en el caso de carga centrada, resulta determinante, se van a plantear curvas para diferentes tipologías de tableros. En las abscisas va a estar el ángulo desarrollado entre apoyos, $\alpha v i$, mientras que en las ordenadas va a estar el cociente del trabajo realizado por el torsor y el cubo de la longitud del vano cargado $L v i^{3}$.

Los Tableros elegidos, son los siguientes:

-Tablero (Carretera 1): $\varphi_{K M y T}=\frac{E I y y}{G J} \approx 1$

-Tablero (Carretera 6): $\varphi_{K M y T}=\frac{E I y y}{G J} \approx 3$

-Tablero (Carretera 7): $\varphi_{K M y T}=\frac{E I y y}{G J} \approx 200$

-Tablero (Carretera 2): $\varphi_{K M y T}=\frac{E I y y}{G J} \approx 490$ 
Leyenda:

- $\quad \frac{\mathrm{WeTx}}{\mathrm{Lvi}^{3}}(\mathrm{n}=1)$

- - $\frac{\mathrm{WeMy}^{3}}{\mathrm{Lvi}^{3}}(\mathrm{n}=1)$

- $\frac{\mathrm{Wee}}{\mathrm{Lvi}^{3}}(\mathrm{n}=3)$

- $\frac{\mathrm{Wee}}{\mathrm{Lvi}^{3}}(\mathrm{n}=5)$

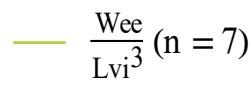

$-\frac{\mathrm{Wee}}{\mathrm{Lvi}^{3}}(\mathrm{n}=9)$

.. $\frac{\mathrm{WeTxD}}{\mathrm{Lvi}^{3}}(\mathrm{n}=3)$

-. $\frac{\mathrm{WeTxD}}{\mathrm{Lvi}^{3}}(\mathrm{n}=5)$

... $\frac{\text { WeTxD }}{\operatorname{Lvi}^{3}}(n=7)$

... $\frac{\text { WeTxD }}{\text { Lvi }^{3}}(n=9)$

\section{Wext $_{\text {simpl }}$ (Tablero 1 (Carretera))}

0.020

$(\mathrm{Lvi}=$ Cualquiera, $\mathrm{mt}=500 \mathrm{KN} / \mathrm{ml})$
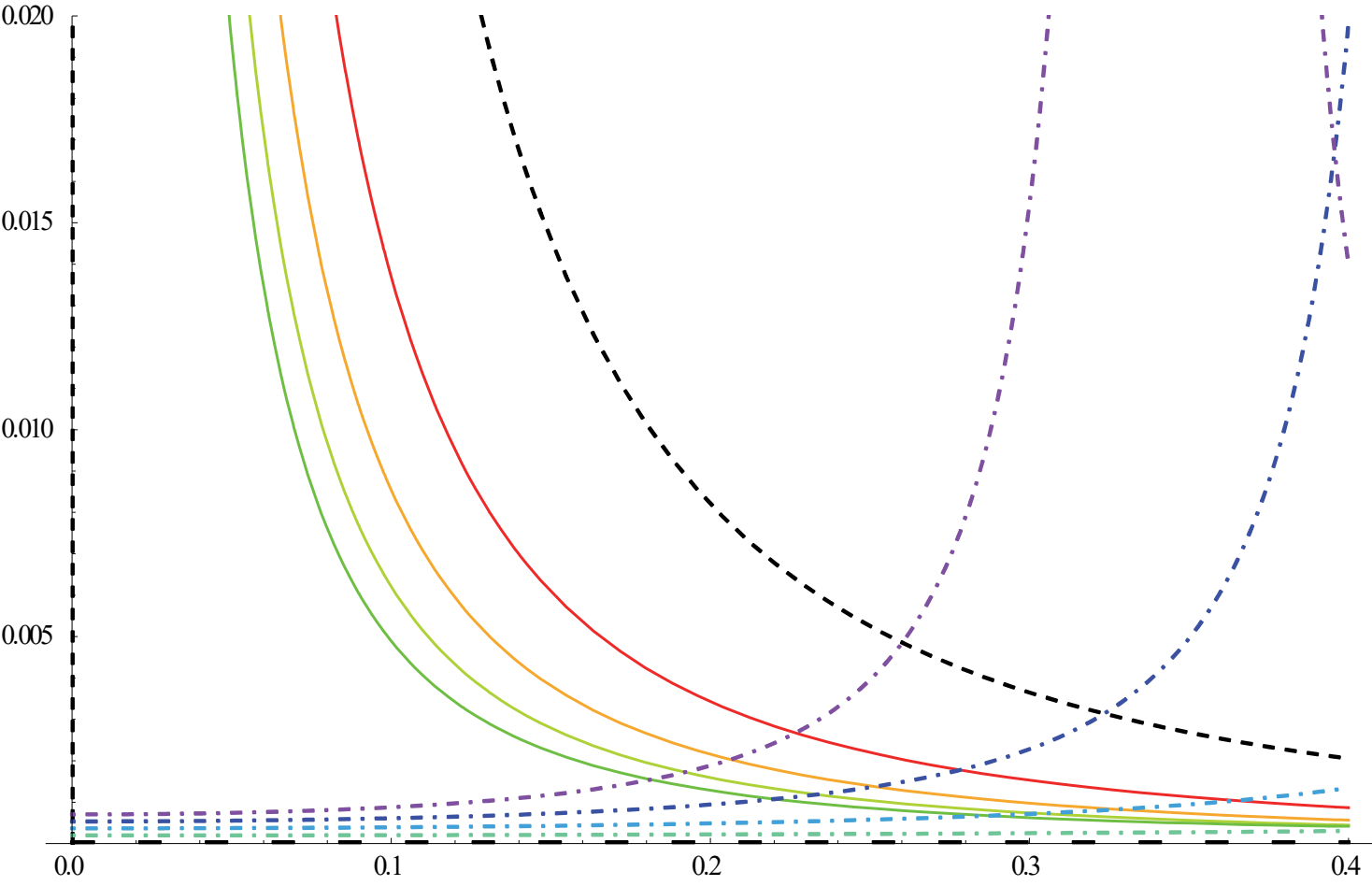

Diagrama 2.112. Cociente del trabajo realizado por la carga exterior y el cubo de la longitud del vano cargado $\left(\frac{W e x t_{s i m p l}}{L v i^{3}}\right)$ frente a $\alpha v i$ (ángulo de vano). Modelo simplificado. 


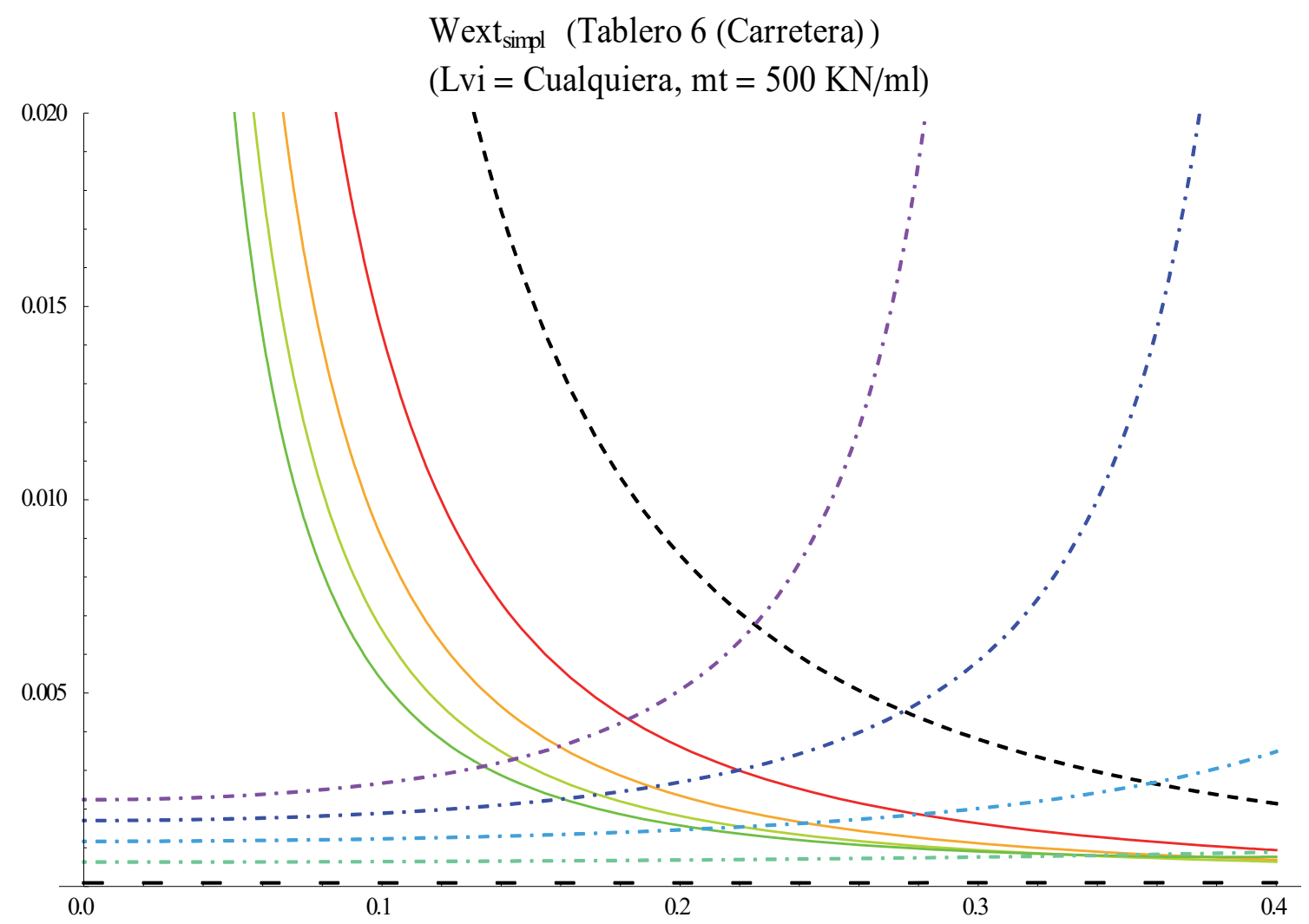

Diagrama 2.113. Cociente del trabajo realizado por la carga exterior y el cubo de la longitud del vano cargado $\left(\frac{W e x t_{s i m p l}}{L v i^{3}}\right)$ frente a $\alpha v i$ (ángulo de vano). Modelo simplificado.

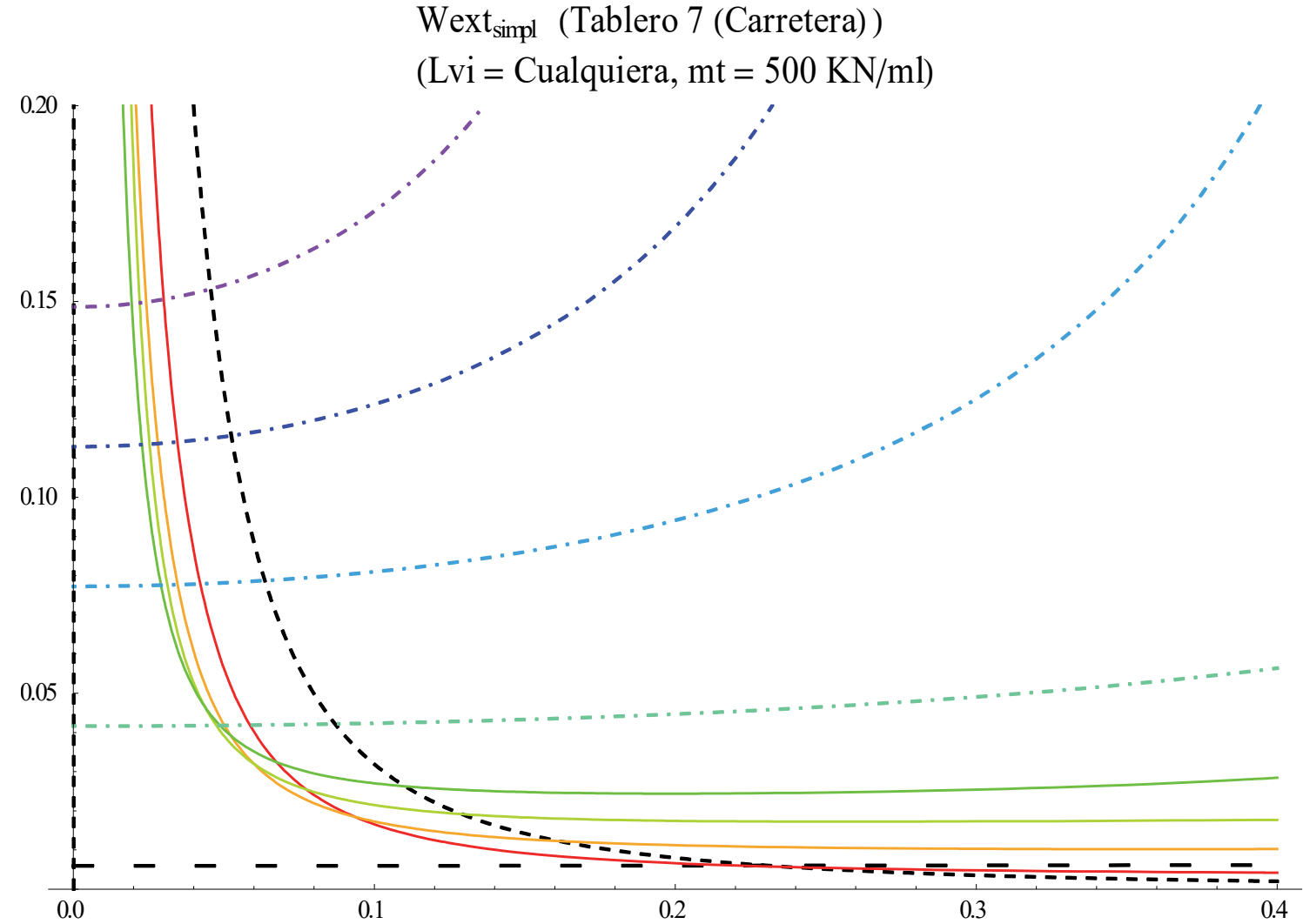

Diagrama 2.114. Cociente del trabajo realizado por la carga exterior y el cubo de la longitud del vano cargado $\left(\frac{W^{2 x t} t_{\text {simpl }}}{L v i^{3}}\right)$ frente a $\alpha v i$ (ángulo de vano). Modelo simplificado. 


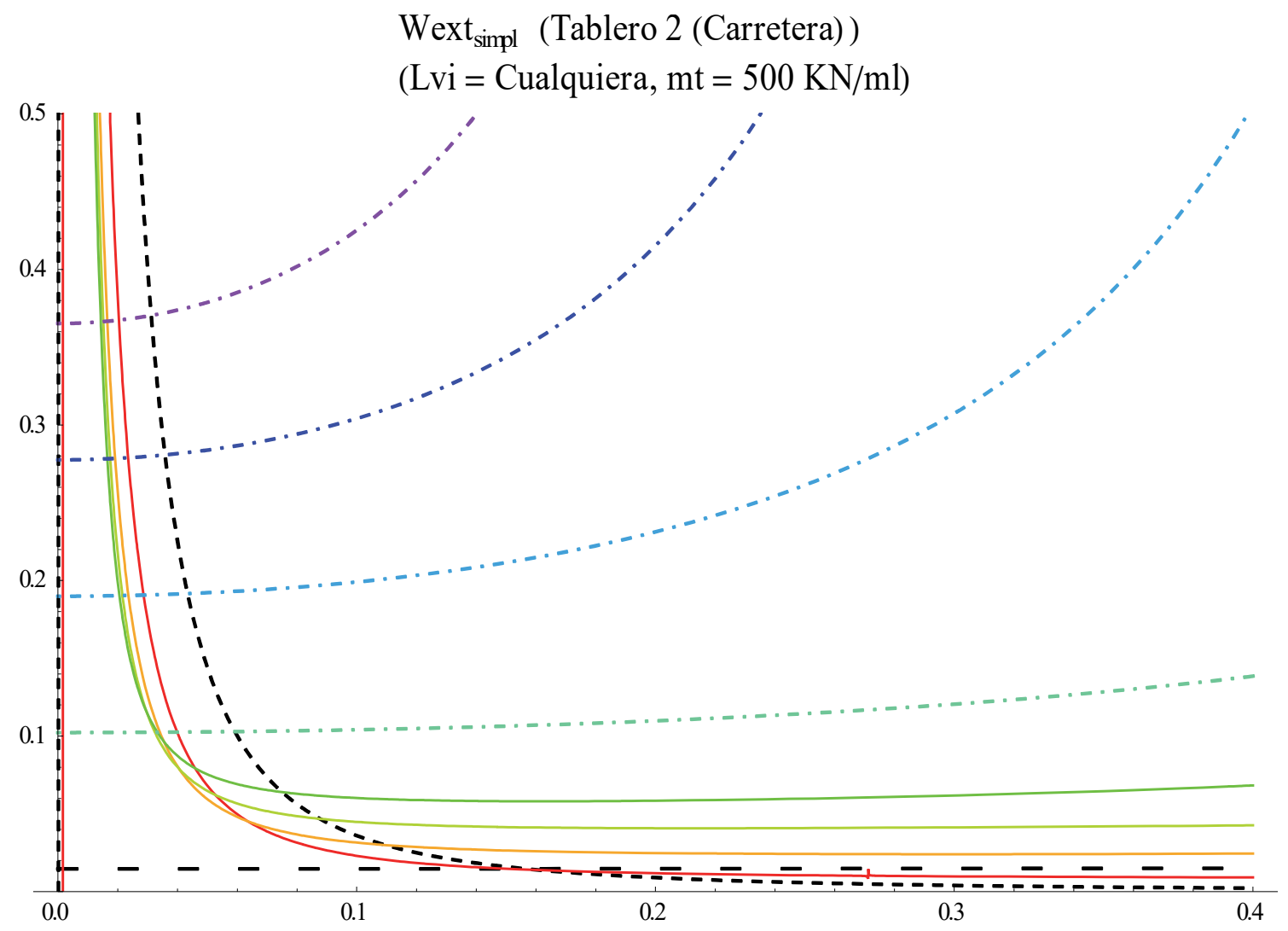

Diagrama 2.115 Cociente del trabajo realizado por la carga exterior y el cubo de la longitud del vano cargado $\left(\frac{\text { Wext }_{\text {simpl }}}{L v i^{3}}\right)$ frente a $\alpha v i$ (ángulo de vano). Modelo simplificado. 


\subsubsection{Análisis e inclusiones}

Con la acción torsora, los diagramas de trabajo exterior muestran un comportamiento resistivo más dispar a lo largo de los diferentes ángulos que se estudian, siempre vinculado a la relación de rigideces $\varphi_{K M y T}=\frac{E I y y}{G J}$, de lo que lo hacían con la carga centrada. Como se puede observar, el punto en el que el sistema resistivo "ee" se vuelve igual de eficiente que el sistema resistivo "eTXD", es cuando $\varphi_{K M y T}=\frac{E I y y}{G J} \approx 1$ coincide con un ángulo desarrollado por el tablero cercano a $\alpha_{t}=\frac{\pi}{2}$ (esto guarda una lógica, cuando $\varphi_{K M y T}=\frac{E I y y}{G J}$ no ayuda a ninguno de los sistemas de empotramientos, todo pasa a depender de las características geométricas).

También se confirma que si la relación de rigideces $\varphi_{K M y T}=\frac{E I y y}{G J}$ se mantiene en valores reducidos (tableros en cajón), el empotramiento a torsión en el estribo resulta muy positivo. La efectividad del empotramiento "eTxD" frente al empotramiento "ee" es función del ángulo desarrollado por el tablero $\left(\alpha_{t}\right)$ y solo en el caso de grandes ángulos $\alpha_{t}$ se pierde su efectividad frente al sistema "ee" para los vanos centrales. En el caso de vanos extremos, la efectividad de "eTxD" sigue siendo muy importante, aun con valores elevados de $\alpha_{t}$ (Diagrama 2.116).

Debido a la relación que la curvatura establece entre el momento torsor y el momento flector, se puede ver (por ejemplo, en los escalones que se aprecian en el Diagrama 2.104, el Diagrama 2.106 y el Diagrama 2.108, que corresponden con los nudos de los modelos completos, donde las barras cambian de dirección y se acumulan las transferencias entre momento flector (My) y momento torsor (Tx)) cómo en el caso del empotramiento "ee", el momento flector negativo se convierte en momento torsor estabilizador frente a Hest con la ayuda de la curvatura.

En el caso de $\varphi_{K M y T}=\frac{E I y y}{G J}$ más altos (secciones abiertas), el empotramiento "ee" es determinante, como se muestra en el Diagrama 2.114 y en el Diagrama 2.115. Ante grandes ángulos desarrollados $\alpha t$, este empotramiento "ee" pierde su efectividad al perder su orden global, debido a la incapacidad de la sección (por su falta de rigidez a torsión) de convertir el par estabilizador que proporciona el apoyo extremo (Avex) en un torsor estabilizador para el vano cargado. Esta falta de rigidez a torsión y el alto ángulo desarrollado $\alpha_{t}$, provoca que el empotramiento "ee" para la estabilización de Hest se produzca entre el apoyo Avi y el apoyo siguiente (como ocurría en el caso de la carga centrada pz), provocando un enorme momento flector que hace perder mucha efectividad al sistema "ee". De esta manera, se muestra la necesidad, a menos que la carga a resistir sea muy baja, de una cierta capacidad a torsión, aunque se pretenda que el sistema "ee" sea el principal ante las solicitaciones torsoras. En el caso de $\varphi_{K M y T}=\frac{E I y y}{G J}$ más bajos (secciones en cajón), puede existir una transferencia del empotramiento del sistema resistivo "ee" a apoyos más cercanos a Avi, pero se produce con $\alpha t$ mucho mayor y resulta un efecto directamente relacionado con la eficiencia que la geometría del tablero otorga al par estabilizador de cada apoyo (Diagrama 2.116). 


\section{Solicitaciones sobre el tablero}

Axil (escala:0.) Cortante $Y^{\prime}-Y^{\prime}$ (escala:0.) Cortante $Z^{\prime}-Z^{\prime}$ (escala:1)

MOMENTO TORSOR X'-X' (escala:1) MOMENTO FLECTOR Y'-Y' (escala:-1)

MOMENTO FLECTOR Z'-Z' (escala:0.)

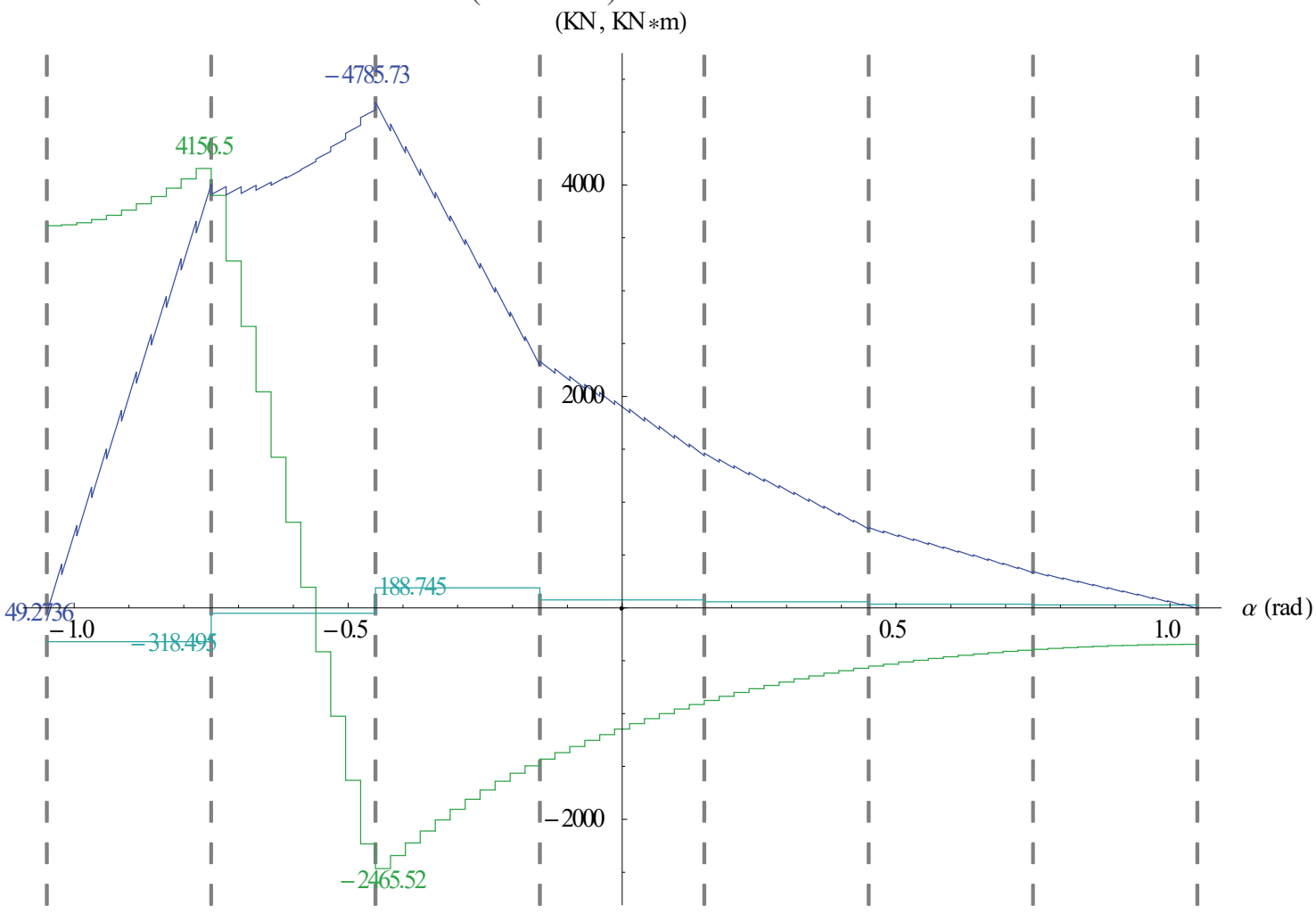

Diagrama 2.116. Solicitaciones en un puente con apoyos puntuales múltiples, modelo completo. $\mathrm{Rt}=53.33 \mathrm{~m}, \alpha t=$ 2.1, Nvanos = 7, Lvi= $16 \mathrm{~m}$, Sección tipo: Tablero 6 (Carretra). Carga torsora distribuida en 1 vano $\mathrm{mx}=500 \mathrm{kN} \mathrm{m} / \mathrm{m}$. Estribos con empotramiento a torsión. Cargando un vano cercano a uno de los estribos

El razonamiento de los párrafos anteriores abre una vía de estudio a la par interesante y necesaria para aquellos tableros con $\varphi_{K M Y T}=\frac{E I y y}{G J}$ muy altos (tableros de sección abierta). En los tableros de sección abierta, sobre todo si están formados por perfiles metálicos, la solicitación de torsión va a ser resistida casi íntegramente por la flexión de losas, jácenas y chapas alrededor del centro de cortantes (alabeo torsional). Para un correcto análisis de esta tipología de tableros, se hace imprescindible el estudio del alabeo torsional y su integración en los modelos de cálculo. También es importante remarcar, en este punto el hecho, de que se puede variar el centro de giro de una sección en los apoyos. En el caso de puentes colgantes, esto se materializa modificando el punto de conexión entre tablero y tirante. Que la sección gire en los apoyos, cuando resista solicitaciones torsoras, respecto de un punto diferente a su centro de cortantes, puede resultar beneficioso. 

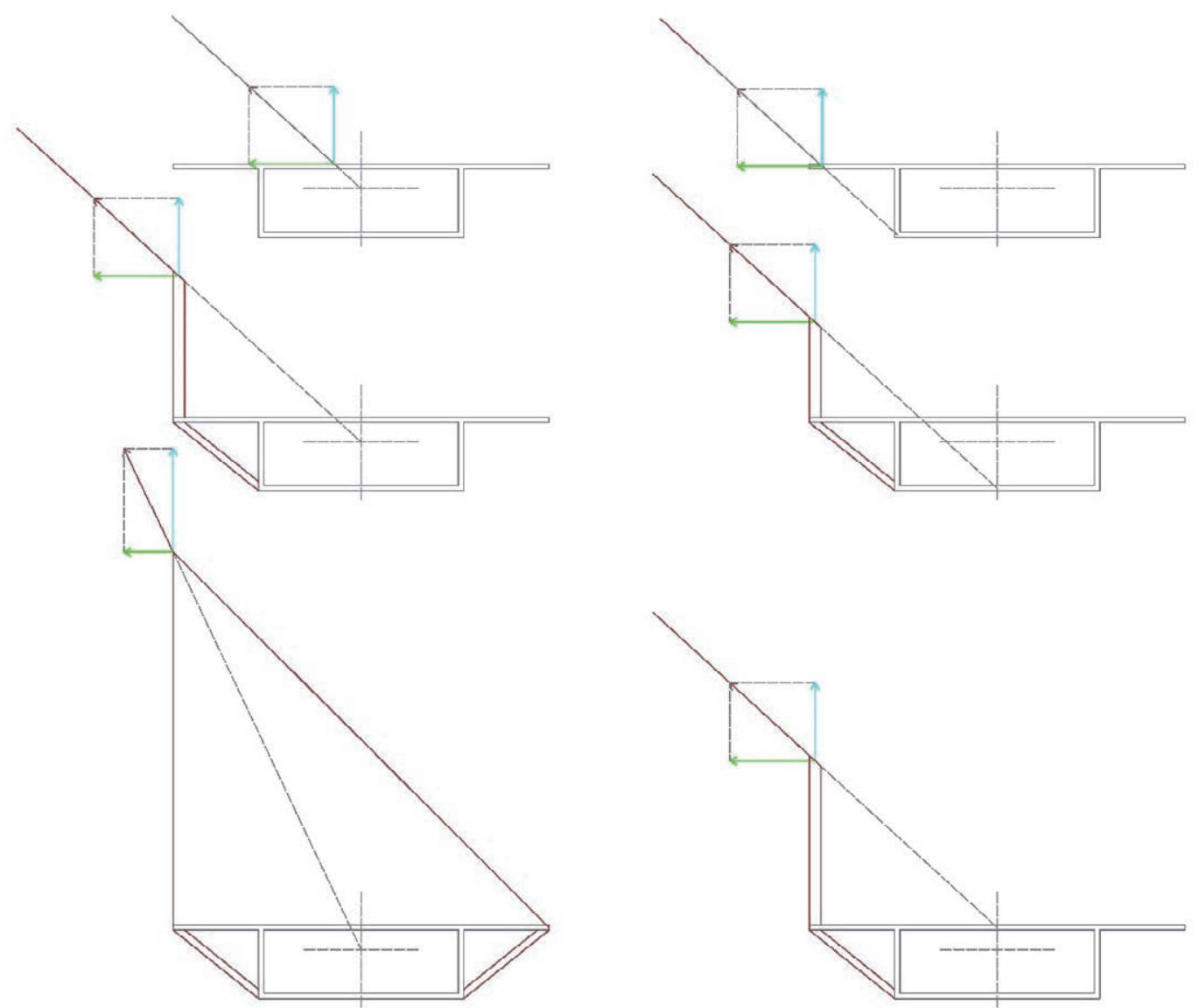

Ilustración 2.15. Posibilidades de conexión entre tirantes y tablero.

En el caso de que se cargue el vano central con un momento torsor ( $\mathrm{mx}$ ) positivo, se produce un cambio de signo en todas las solicitaciones. Luego todos los razonamientos esbozados son igualmente válidos.

\subsubsection{Viga curva sobre apoyos puntuales inclinados, sometida a una carga distribuida perpendicular a su plano, desplazada radialmente respecto de su centro de cortantes}

En el caso de que el tablero se someta a una carga vertical distribuida excéntrica respecto del centro de cortantes, si suponemos la sección transversal indeformable, se puede obtener sumando los efectos mostrados en los subapartados 2.3.2 y 2.3.3. Luego la hipótesis de carga descentrada se puede dividir (como ya se hizo en el apartado 2.1) en dos cargas: una carga vertical centrada y un momento torsor. Debido a la asimetría entre los momentos flectores (My) negativos y positivos, provocados por la carga vertical, cuando se combinan la hipótesis de la carga centrada con la torsora cobra cierta importancia el signo del momento torsor aplicado, en el caso de que el empotramiento "ee" sea dominante.

Si se cargan todos los vanos, las solicitaciones estudiadas en los subapartados anteriores (2.3.2 y 2.3.3) para un vano, se suman a lo largo de todo el tablero. La hipótesis de carga torsora domina por completo, tanto el diagrama del momento flector (My) como el diagrama de momento torsor (Tx). El tablero se ve obligando a soportar solicitaciones de orden "global", por la hipótesis de carga torsora, y solicitaciones de orden "local", por hipótesis de carga 
vertical centrada. Por otro lado, al descentrar la carga vertical distribuida, los giros con eje longitudinal y los desplazamientos verticales incrementan notablemente y los primeros se extienden a lo largo de todo el tablero.

Como se ha descrito en el subapartado 2.3.3, se pretende introducir cargas de la magnitud que se va a dar en un puente de carretera. Luego se va a utilizar las que se obtuvieron en ese subapartado para puentes de carretera:

$$
\begin{gathered}
\mathrm{q}=57 \mathrm{kN}\left(\mathrm{pz}=-57\left(\frac{\mathrm{kN}}{\mathrm{ml}}\right)\right) \\
\mathrm{mt}=-430 \mathrm{kN} \frac{\mathrm{m}}{\mathrm{ml}}\left(\mathrm{mx}=430 \mathrm{kN} \frac{\mathrm{m}}{\mathrm{ml}}\right)
\end{gathered}
$$

Solicitaciones sobre el tablero

Axil (escala:0.) Cortante $Y^{\prime}-Y^{\prime}$ (escala:0.) Cortante $Z^{\prime}-Z^{\prime}$ (escala:1)

MOMENTO TORSOR X'-X' (escala:1) MOMENTO FLECTOR Y'-Y' (escala:-1)

MOMENTO FLECTOR Z'-Z' (escala:1)

BIMOMENTO W-W (escala:0.)

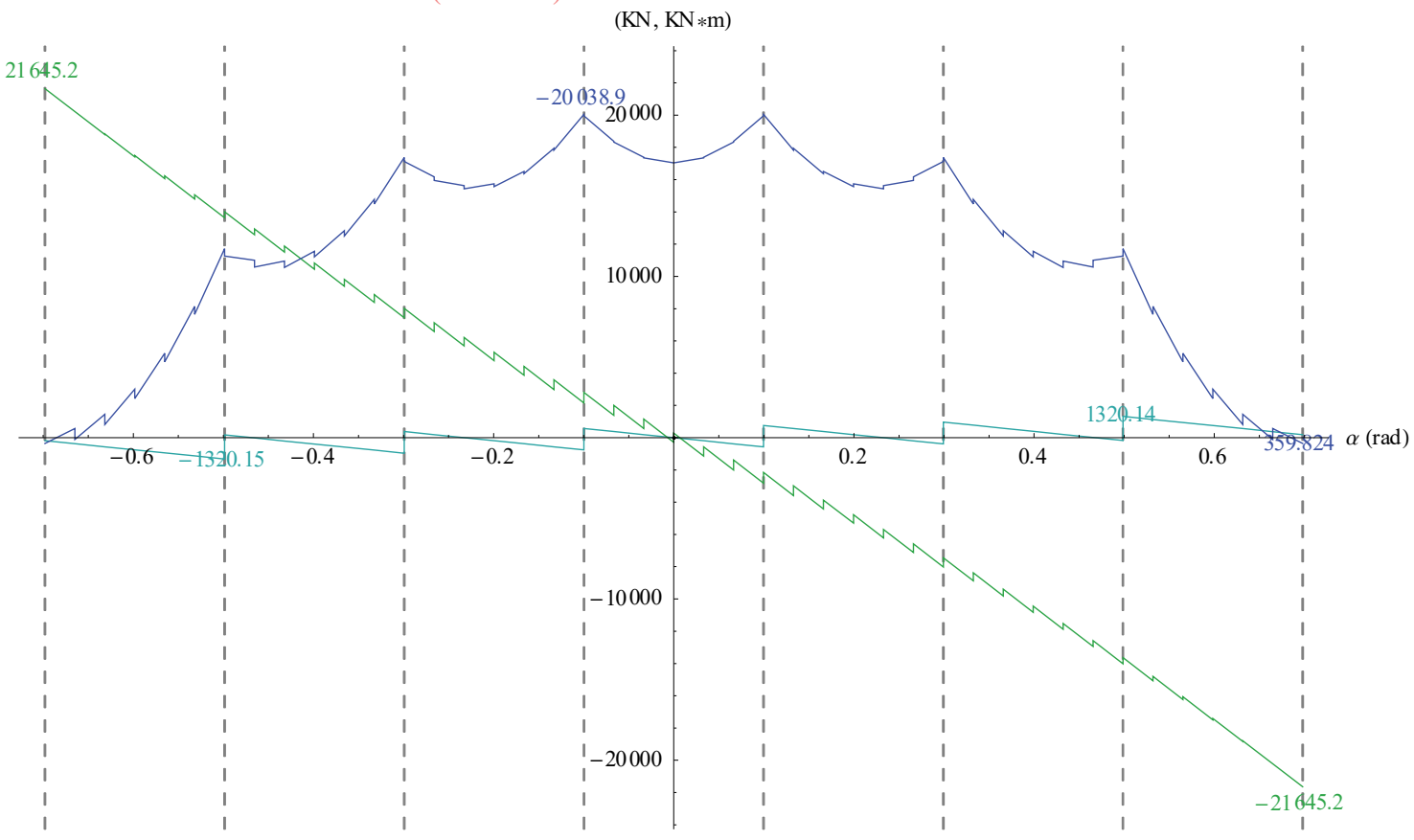

Diagrama 2.117. Solicitaciones modelo completo. Tablero 6 (Carretera) $m x=-430 \mathrm{kN} \mathrm{m} / \mathrm{m}, \mathrm{pz}=-57 \mathrm{kN} / \mathrm{m}$. $\alpha v i=$ $0.2 \mathrm{rad}, \mathrm{Lvi}=15 \mathrm{~m}(R t * \alpha v i), R t=100 \mathrm{~m}$, nvanos $=7, \alpha t=8 \pi / 18$. 


\section{Solicitacionessobre el tablero}

Axil (escala:0.) Cortante $Y^{\prime}-Y^{\prime}$ (escala:0.) Cortante $Z^{\prime}-Z^{\prime}$ (escala:1)

MOMENTO TORSOR X'-X' (escala:1) MOMENTO FLECTOR Y'-Y' (escala:-1)

MOMENTO FLECTOR Z'-Z' (escala:1)

BIMOMENTO W-W (escala:0.)

$(\mathrm{KN}, \mathrm{KN} * \mathrm{~m})$

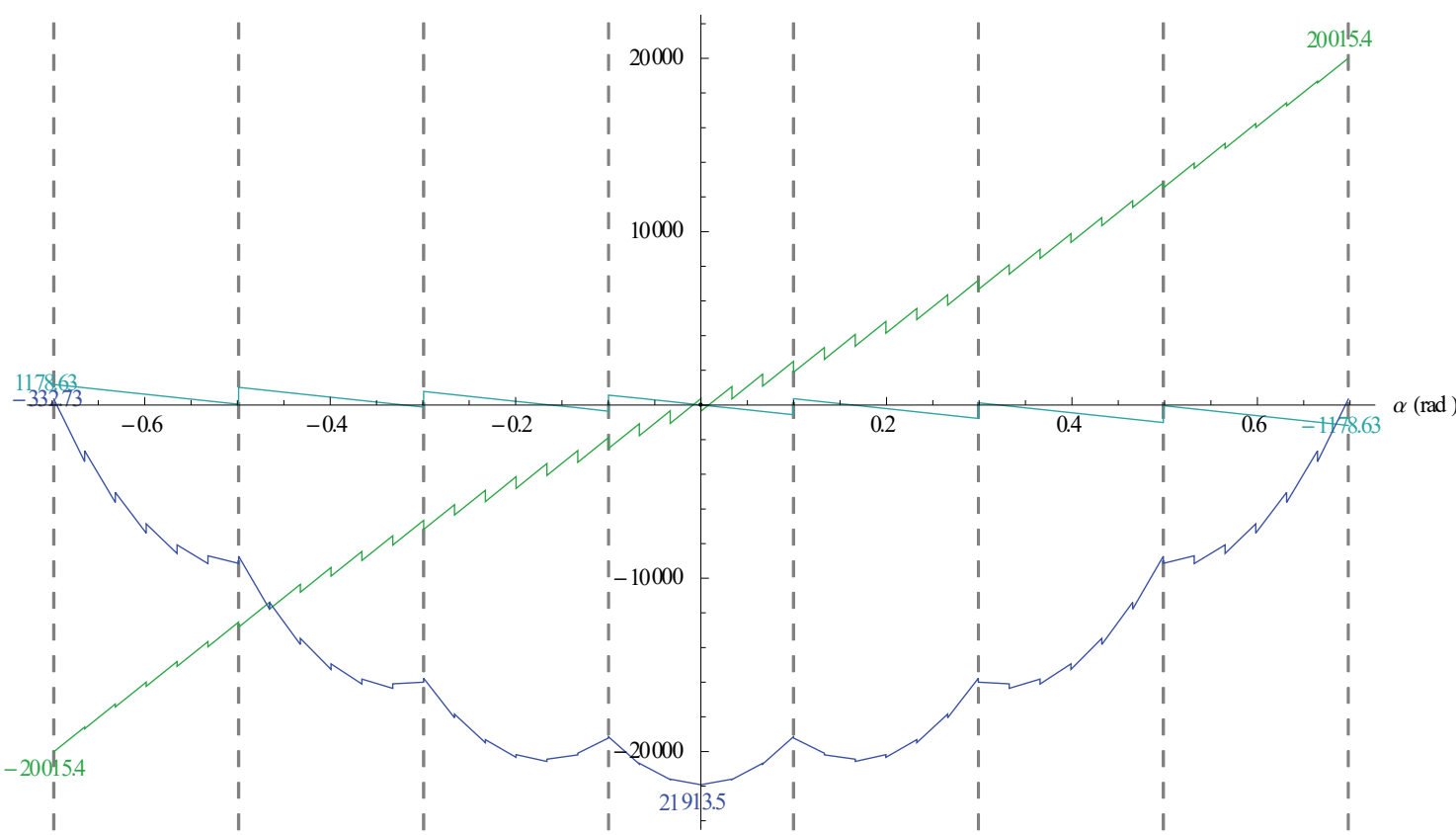

Diagrama 2.118. Solicitaciones modelo completo. Tablero 6 (Carretera). $\mathrm{mx}=430 \mathrm{kN} \mathrm{m} / \mathrm{m}, \mathrm{pz}=-57 \mathrm{kN} / \mathrm{m} . \alpha v i=$ $0.2 \mathrm{rad}, \mathrm{Lvi}=15 \mathrm{~m}(\mathrm{Rt} * \alpha v i), R t=100 \mathrm{~m}$, nvanos $=7, \alpha t=8 \pi / 18$.

\section{Desplazamientosy Giros}

Desplazamiento TANGENCIAL (escala:0)

Desplazamiento RADIAL(escala:1) Desplazamiento Z (escala:1)

Giro X'-X' (escala:1) Giro Y'-Y' (escala:0) Giro Z'-Z' (escala:0) Giro W-W (escala:0)

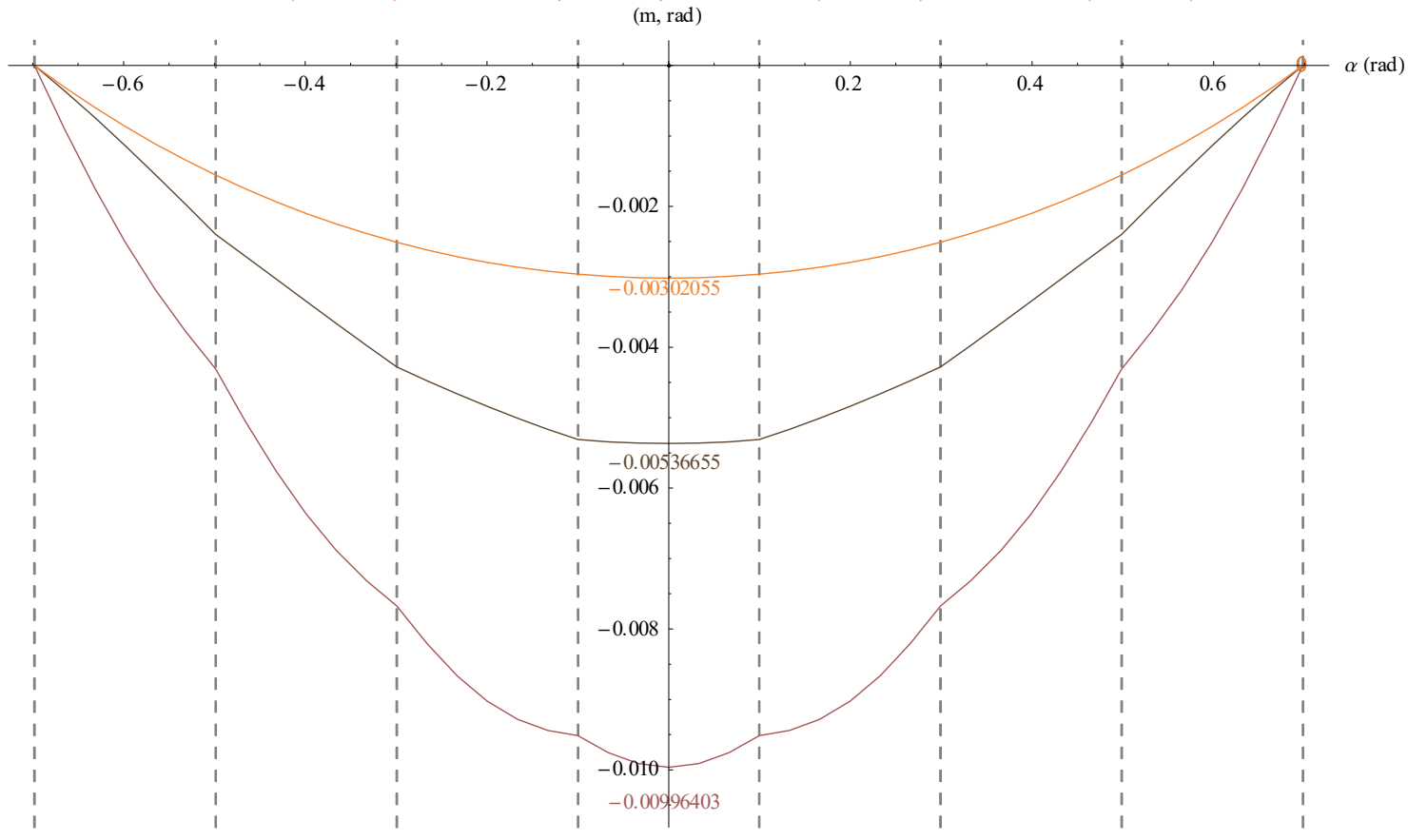

Diagrama 2.119. Deformaciones modelo completo. Tablero 6 (Carretera). $\mathrm{mx}=-430 \mathrm{kN} \mathrm{m} / \mathrm{m}, \mathrm{pz}=-57 \mathrm{kN} / \mathrm{m} . \alpha v i=$ $0.2 \mathrm{rad}, \mathrm{Lvi}=15 \mathrm{~m}(\mathrm{Rt} * \alpha v i), R t=100 \mathrm{~m}$, nvanos $=7, \alpha t=8 \pi / 18$. 


\section{Solicitaciones sobre el tablero}

Axil (escala:0.) Cortante $Y^{\prime}-Y^{\prime}$ (escala:0.) Cortante Z'-Z' (escala:1)

MOMENTO TORSOR X'-X' (escala:1) MOMENTO FLECTOR Y'-Y' (escala:-1)

MOMENTO FLECTOR Z'-Z' (escala:1)

BIMOMENTO W-W (escala:0.)

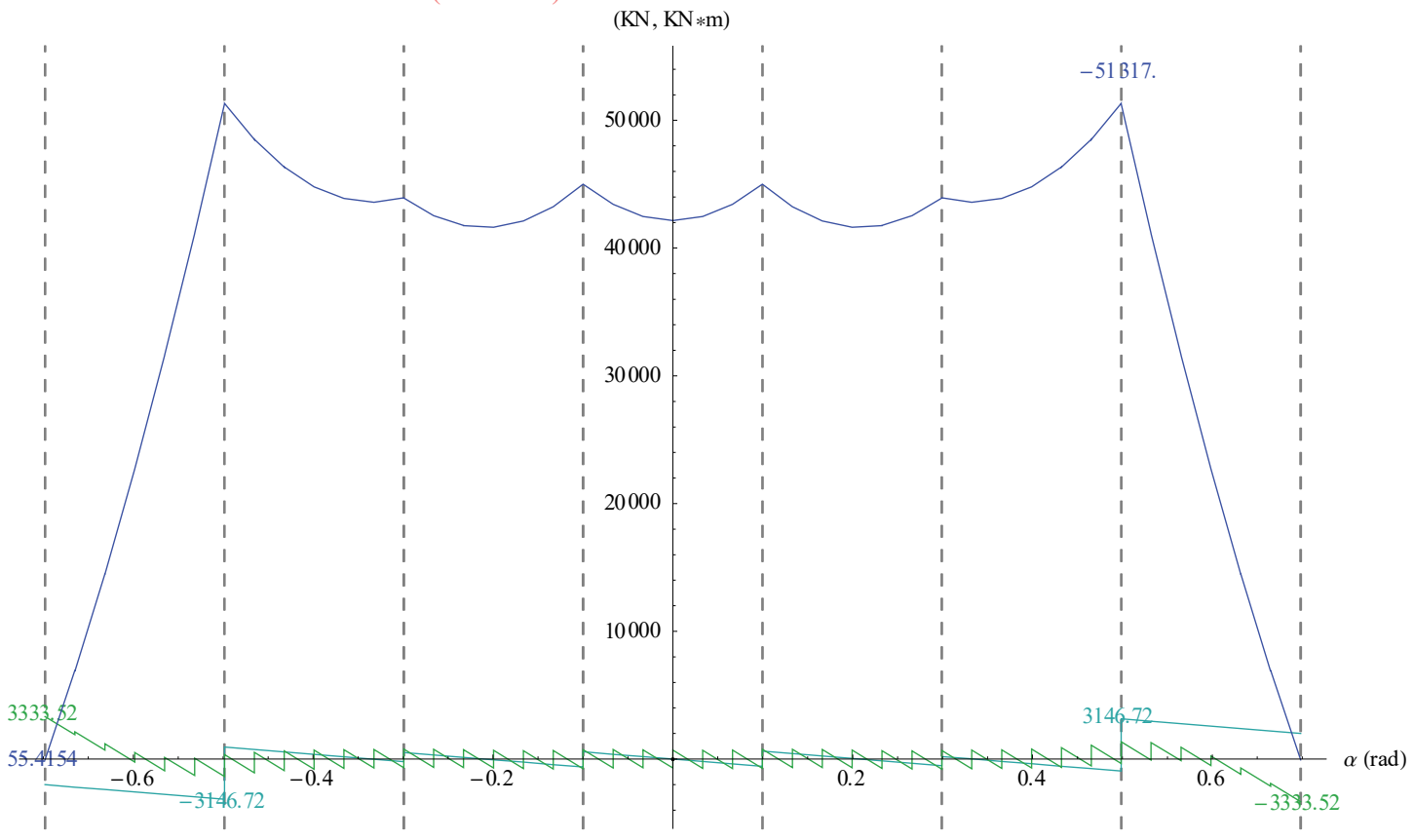

Diagrama 2.120. Solicitaciones modelo completo. Tablero 2 (Carretera). $\mathrm{mx}=-430 \mathrm{kN} \mathrm{m} / \mathrm{m}, \mathrm{pz}=-57 \mathrm{kN} / \mathrm{m} . \alpha v i=$ $0.2 \mathrm{rad}, \mathrm{Lvi}=15 \mathrm{~m}(\mathrm{Rt} * \alpha v i), R t=100 \mathrm{~m}$, nvanos $=7, \alpha t=8 \pi / 18$.

Solicitacionessobre el tablero

Axil (escala:0.) Cortante $Y^{\prime}-Y^{\prime}$ (escala:0.) Cortante $Z^{\prime}-Z^{\prime}$ (escala:1)

MOMENTO TORSOR X'-X' (escala:1) MOMENTO FLECTOR Y'-Y' (escala:-1)

MOMENTO FLECTOR Z'-Z' (escala:1)

BIMOMENTO W-W (escala:0.)

$(\mathrm{KN}, \mathrm{KN} * \mathrm{~m})$

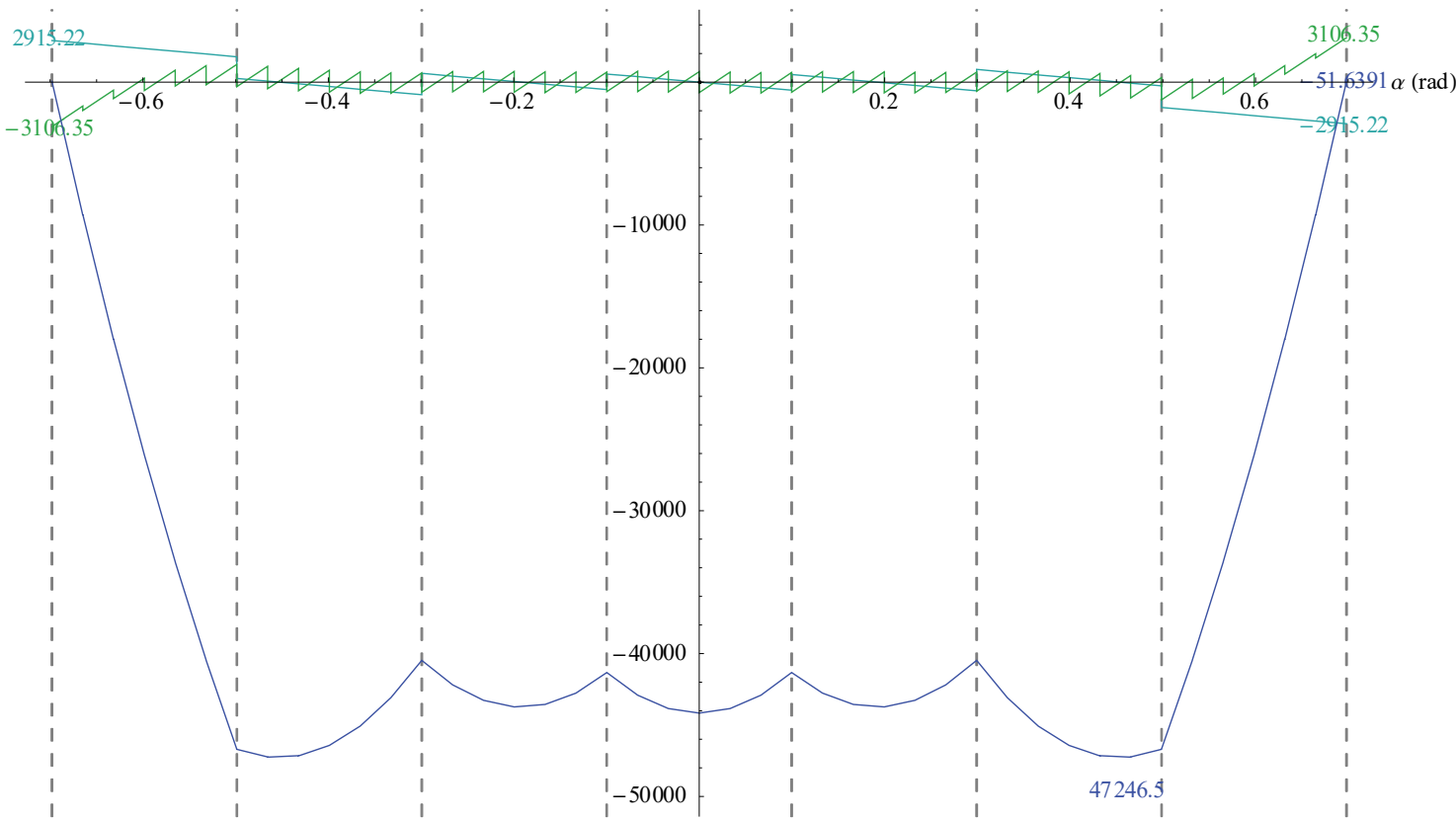

Diagrama 2.121. Solicitaciones modelo completo. Tablero 2 (Carretera). $\mathrm{mx}=430 \mathrm{kN} \mathrm{m} / \mathrm{m}, \mathrm{pz}=-57 \mathrm{kN} / \mathrm{m} . \alpha v i=$ $0.2 \mathrm{rad}, \mathrm{Lvi}=15 \mathrm{~m}(\mathrm{Rt} * \alpha v i), R t=100 \mathrm{~m}$, nvanos $=7, \alpha t=8 \pi / 18$. 


\section{Desplazamientosy Giros}

Desplazamiento TANGENCIAL (escala:0)

Desplazamiento RADIAL (escala:1) Desplazamiento Z (escala:1)

Giro $X^{\prime}-X^{\prime}$ (escala:1) Giro Y'-Y' (escala:0) Giro Z'-Z' (escala:0) Giro W-W (escala:0)

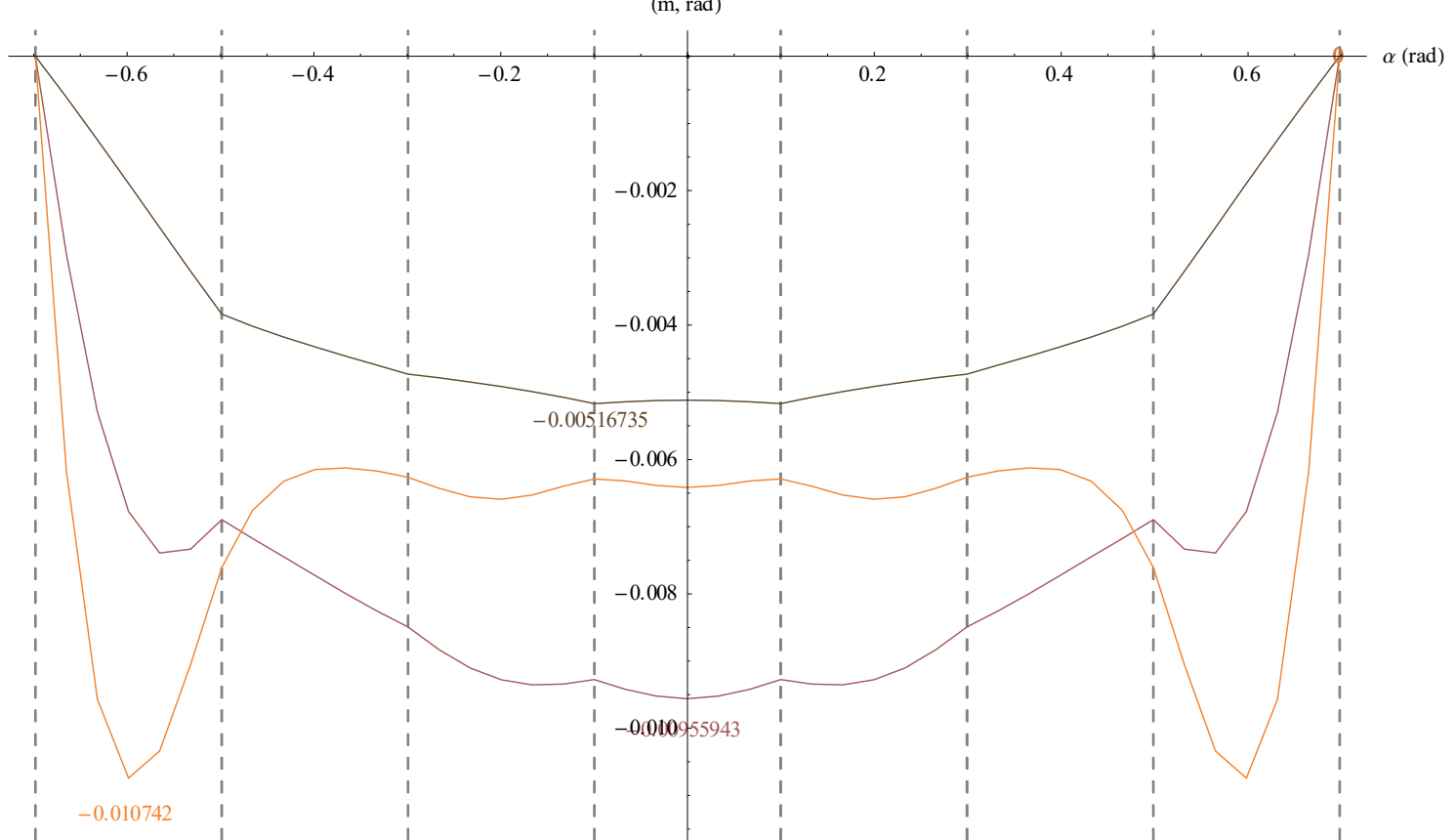

Diagrama 2.122. Deformaciones modelo completo. Tablero 2 (Carretera). $m x=-430 \mathrm{kN} \mathrm{m} / \mathrm{m}, \mathrm{pz}=-57 \mathrm{kN} / \mathrm{m}$. $\alpha v i=$ $0.2 \mathrm{rad}, L v i=15 \mathrm{~m}(R t * \alpha v i), R t=100 \mathrm{~m}$, nvanos $=7, \alpha t=8 \pi / 18$. 
